\title{
Proceedings ICIL'2010
}

International Conference on Industrial Logistics

"Logistics and Sustainability"

March $08^{\text {th }}$ to $11^{\text {th }}, 2010$

IME - Military Institute of Engineering, Rio de Janeiro - Brazil

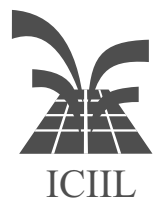

Editors:

Maria Cristina Fogliatti de Sinay, Military Institute of Engineering Maria Inês Faé, Federal University of Espíito Santo

Alberto G. Canen, COPPE/ Federal University of Rio de Janeiro 



\section{Editors Words}

The ICIL 2010 is being hosted by the Military Institute of Engineering - IME in Rio de Janeiro, Brazil with the formal endorsement of Governmental Institutions that financially support researches and studies in Science and Technology.

Submissions for this Conference came from 19 countries and its proceedings contains 46 articles motivated by the main theme, namely, Logistics and Sustainability. These articles were distributed in 10 technical sessions in the 4 conference days. Three general conferences complete the final program. These conferences establish the link with operations research and they are entitled: "Trends in using artificial intelligence in logistics", "Dynamics problems in logistics" and "Operations research in the public sector and nonprofit organizations".

The proceedings of the ICIL 2010 includes a qualify sample of the research carried out on Industrial Logistics and it reflects the concern to rationalize supply, production and distribution in a sustainable way.

Certainly this meeting will propitiate discussions as well as exchange of experiences in an internationally context on Industrial Logistics.

The editors are looking forward to receive you in Rio and wish you a successful conference!!!

Maria Cristina Fogliatti de Sinay

Maria Inês Fae

Antonio G. Canen 



\section{Committees}

\section{General Chairwoman}

Prof. Maria Cristina Fogliatti de Sinay, PhD.

Military Institute of Engineering

Department of Construction and Fortification

Master Program in Transportation Engineering

\section{Local Organizing Committees}

Prof. Maria Cristina Fogliatti de Sinay, PhD.

Military Institute of Engineering

Department of Construction and Fortification

Master Program in Transportation Engineering

Prof. Maria Inês Faé, PhD.

Federal University of Espírito Santo

Department of Production Engineering

Master Program in Geography

Prof. Alberto G. Canen, DSc

COPPE/ Federal University of Rio de Janeiro

Program of Production Engineering 



\section{Scientific Committee}

Adiel Teixeira de Almeida, PhD

Federal University of Pernambuco, Recife, Brazil

Alberto G. Canen, DSc

COPPE/ Federal University of Rio de

Janeiro, Rio de Janeiro, Brazil

\section{Algirdas Bargelis, Professor}

Dr habil, Kaunas University of Technology, Kaunas, Lithuania

Altair dos Santos Ferreira Filho, DSc, Brazilian Institute of Capital Markets, Ibmec, Rio de Janeiro, Brazil

Antonio G. N. Novaes, D.Eng.

Federal University of Santa Catarina,

Florianopolis, Brazil

Bernardo Zimberg, chem. Eng. ANCAP Refinery, Montevideo, Uruguay

Carlos Alberto dos S. Passos, PhD

CENPRA, Campinas, Brazil

Claudio Barbieri da Cunha, PhD

Escola Politécnica, University of São Paulo, São Paulo, Brazil

David J. Newlands, PhD

IESEG School of Management, Lille, France.

Eduardo Betanzo Quezada, Dr. Faculty of Engineering, Queretaro Autonomous University, Queretaro, Mexico.

Ehud Menipaz, Professor

Ben Gurion University, Beer Sheva, Israel.

Goran Dukic, PhD Assist. Prof. University of Zagreb, Faculty of Mechanical Engineering and Naval Architecture, Industrial Engineering Department, Zagreb, Croatia.

Hector Cancela, $\mathbf{P h D}$

Universidad de la Republica, Montevideo, Uruguay.

\section{Irad Ben-Gal, Professor}

Faculty of Engineering, Tel Aviv

University, Tel Aviv, Israel.

\section{Isabel Fernández, PhD}

High Polytechnic Faculty of Industrial

Engineering, EPSIG,

Gijon - Asturias, Spain.

José G. Hernández R, MSc.

Operations Research, Universidad

Metropolitana, Caracas, Venezuela.
Jose Holguin-Veras, Ph.D.

Rensselaer Polytechnic Institute, NY, USA

Luiz Antônio Silveira Lopes, DSc, Military Insitute of Engineering, IME, Rio de Janeiro, Brazil.

Marcio de Almeida D'Agosto, DSc, Federal University of Rio de Janeiro, Rio de Janeiro, Brazil.

Maria Cristina Fogliatti de Sinay, $\mathrm{PhD}$, Military Institute of Engineering, IME, Rio de Janeiro, Brazil.

Maria E. Urquhart, MSc,

Operation Research, Computer Science Institute, Engeneering Faculty, UDELAR, Uruguay.

Maria Inês Fae, PhD,

Federal University of Espirito Santo, Espirito Santo, Brazil.

Orlando Fontes Lima Jr, Dr,

LALT-UNICAMP, Campinas, Brazil.

Petri Helo, PhD,

University of Vaasa, Logistics Systems Research Group, Vaasa, Finland.

Ralph Coolidge Huntsinger, Ph.D., [SCS] Fellow (Society for Modeling and Simulation International) Founder, Emeritus Director, and International Ambassador of the McLeod Institute of Simulation Sciences (MISS)

Raymond MARIE, Professor,

University of Rennes 1, UEB, Rennes, France.

Reinaldo Morabito Neto, DSc, Federal University of São Carlos, São Paulo, Brazil

Rui Carlos Botter, Dr.,

Escola Politecnica of University of São Paulo, USP, São Paulo, Brazil.

Tauno Kekäle, Professor

University of Vaasa, Dept. of Production, Vaasa, Finland.

Vania Barcellos Gouvea Campos, DSc. Military Institute of Engineering, IME, Rio de Janeiro, Brazil.

Zilla Sinuany-Stern, Ph.D., Dept. of Ind. Eng.\& Mgmt. Ben Gurion University, Beer. Sheva, Israel and Dept. of Ind. Eng. Ariel University Center of Samaria, Ariel, Israel. 



\section{Table of contents}

Outsourcing Logistics Decision Support System for Product Design and Manufacturing.

\section{A. Bargelis}

Dynamic Investment Planning for Container Port Ventures

A. G. N. Novaes - E. M. Frazzon - V. M.D. Silva - H. Rosa

The Application of Innovations in Trade

A. Burinskiene

Clustering and Routing Model for Transport Logistics Using Software Agents

G. Singh - A. Timm-Giel - C. Gorg

Time-Based Competition Related to Logistics: an International Study of Furniture Companies

I. Tammela - A. G. Canen

Inkjet-Printed RFID's on Paper: a Quantum Leap in Industrial Logistics?

M.M.Tentzeri

Computer-Aided Tools Impact on Equipment Effectiveness

V. Senkus - I. Senkuviene

Modern Approaches of the Defense Acquisition Management within the Romanian Army

A. Olaru, O. Ungureanu - A. Capatina

Innovative Process Development Applying Intelligent Computer Aided Process

Planning

R. Mankute - A.Bargelis

Classification and Inventory Management of Retail Products: a Case Study

A.M.T. Thomé - A.F.C. Vieira

Logistic Concept as a Modern Form of the Total Logistic Integration of Regional Areas

Z. Ivanovic - L. Ivanovic

Application of Logistics Methods in Print Production

D. Milcic - D. Banic - D. Donevski

Supply Chain Integration and Adaptability - The Key To Be Fit for Turbulence?

M. Gerschberger - C. Söser - F. Staberhofer 
A Decomposition Strategy for Large-Scale Scheduling Problems in Multi-Stage Multi-Product Batch Plants

G.M. Kopanos - L. Puigjaner - C.A. Méndez

The Logistical Model Based in Indicators of Positions Through the Order Processing Manager

J. G. Hernández - M. J. García

Supply Chain Integration and Performance - American, European and Asian

Companies

C. Söser - M. Gerschberger - F. Roithmayr

"Standard-Hour" As Logistics Performance Evaluation Basis - a Case Study at Aracruz Celulose

M. M. Aragão - T. B. Brito - R. C. Botter

A MIP for the Integrated Production and Transportation Scheduling of an OEM

T. Makuschewitz - E. M. Frazzon - B. Scholz-Reiter, A. G.N. Novaes ..............

The Roles and Approaches of Supply Chain Optimizers

Y. Kristianto - P. Helo

Understanding the Human Factor: The Key to Process Improvement in Service Operations

T. Kekale - K. Spens - K. Phusavat

Use of Open Innovation as Posible Marketing Strategy in Logistic

S. Mihić - S. Raletic

A Hybrid Algorithm, Based on Iterated Local Search and Genius, for the Vehicle Routing Problem with Simultaneous Pickup and Delivery

M. T. Mine - M. S. A. Silva - A. Subramanian - L. S. Ochi - M. J. F. Souza ......

The Importance of Reverse Logistics in the Production Process: the Case of a Wine Bottling Company

R. M. Melo - M. M. Silva - A. C. B. R. F. Pinto

Multimodality and Container Filling in 3D

D. de La Fuente - I. Fernandez - R. Pino - N. García

European South-West Logistic Platform: a New Approach to the Integral Energy Management

M. Monterrey - D. de la Fuente - I. Fernandez - J. Parreño

Risk on Spares for Life-Time Maintenance Purposes Due to Uncertainties on the Mean Up Time

R. Marie 
Implementation of Data-Warehouses in Customer Relationship Management Systems

An Efficient Ant Colony System for Vehicle Routing Problems with Time Windows

The Need for Internet-Based, Light-Weight Tracking and ERP Systems for SCM in

SME - Intensive Multi - Company Networks - The Case of the Finnish Furniture

Industry

M. Ehrs - M. Suorsa

Strategic Intermodal Decision Making in Brazil

B. Gonçalves - M. B. Costa - M. D’Agosto

Greener Warehouses Through Increased Efficiency

G. Dukic - T. Opetuk - V. Cesnik

Back to Basics - Is Logistics Again About Cutting Costs?

K.Spens - G.Kovács

Inventory Location Problem with Stochastic Capacity Constraints under Periodic

Review (R, s, $S$ )

P. A. Miranda - G. Cabrera G.

A Comparison of Mathematical Modelling Approaches for Stability Analysis of

Supply Chains

B. Scholz-Reiter - M. Schönlein - M. Kosmykov - T. Makuschewitz

Sustainable Logistics - Case Study of an Automobile Manufacturer

S. Schmidt

The Effect of High Brazilian Interest Rates on a Logistical Optimization Strategy

A. R. A.Vallim Filho

Some Aspects of Process Planning Improvement

P. Cosic - N. Volarevic

Stochastic Modeling of Fuel Procurement for Electricity Generation

C. Testuri - B. Zimberg

How Radio Frequency Signals Can Assist in Providing Security to Industrial

Logistics

G. R. DeJean - D. Kirovski

Management of Loading Semi-Trailers with Virtual Balance Software

C. A. M. Souza - J. I. M. Vieira - C. A. Faria

Evaluating the Impact of Accidents Risk on Hydrogen Road Transportation Cost

A.C. Caputo - P. M. Pelagagge - P. Salini 
An Exact Method to Evaluate the Source-to-Terminal Diameter Constrained Reliability of a Communication Network

Effect of a Bridge Infrastructure in the Economic Growth of an Industrial Region K. O Ferreira - M. I. Faé

The Industry of Standardization Process: a Comparison Between two International Organizations

L. B. Aguiar

Steel Supply Chain Management by Simulation Modelling

M. Sandhu - P. Helo - J. Kristianto

Identification of Estrategic Logistics Nodes in the Central Region of Mexico

J.P. Antún, A. Lozano, R. Alarcón, F. Granados y L. Guarneros 


\title{
OUTSOURCING LOGISTICS DECISION SUPPORT SYSTEM FOR PRODUCT DESIGN AND MANUFACTURING
}

\author{
A. Bargelis \\ Kestucio 27, Kaunas LT-44312 \\ Department of Manufacturing Technologies \\ Kaunas University of Technology
}

\begin{abstract}
This paper deals with outsourcing logistics decision support system for integrated product design and manufacturing (OLDSS) in global business environment. The system has been developed on the activity analysis of a Lithuanian industry and theoretical assumptions by knowledge economy. Creation consists of the three type's knowledge base: marketing, products and processes development and products manufacturing. Interacting among developed system parts by appropriate interfaces is carried out. The OLDSS has been tested and adopted in Lithuanian chamber of trade and commerce.
\end{abstract}

\section{INTRODUCTION}

A new obvious reality started in 1990s: the impact of industrial vast competition. In high tech countries, the cost of workforce and manufacturing resources have increased and the struggle to survive had became as an integral part of each company's way of life Chen et al [1]. Customers are more and more demanding to products variety, properties, quality and costs. These new challenges, however, in new manufacturing environment of some organizations have not changed their work manner to meet these new requirements, because manufacturing management is still subordinate in strategy making to the marketing and finance functions. Seeking to survive, most Western companies began to look to developing countries in East Europe, South Asia and Latin America for partnership and co-operation producing products. On the other hand, the managers in developing countries are ready for such common activity as an additional way getting new orders. Logistics element in a new manufacturing environment has been taken the greatest operational challenges. The responsibility and accountability have been driven down to a lower level within the 
organization, a different set of rules applied and some new techniques will need to be utilized. A new way of doing business involves the modern work of organization forms applying informational flows through Internet, starting from the customers search, products development and manufacturing to finished products delivery. It includes in-bound and outbound logistics aspects of manufacturing company activity based on negotiations with new and traditional partners and suppliers.

Outsourcing in manufacturing field has many attractive features and potential sources in additional value creation procedure. Western high-developed countries have two main reasons for outsourcing: 1) economical, i.e. decrease the cost by shifting production to low-cost sites, and 2) technical, i.e. realizing better products and processes in shorter time. During first outsourcing steps, 20-30 years ago, the economical approach dominated because easier implementation. This approach has many advantages for both sides and suits very well for mass production products. When production is going to the batch size many organizational and logistics problems arise, and outsourcing becomes not so effective. In this case, technical approach looks more attractive and can decrease new product development and delivery time to customers.

This research is devoted on the latter strategy development. It addresses to the small and medium-sized enterprises (SMEs) distributed in different countries and even continents. Considered strategy creation focuses on an integrated approach of product and process development applying innovative intelligent models, methods and tools. Applied Internet technologies, in particular, play significant role to provide new ways of innovative products and processes development employing Virtual reality Egan et al [2], Concurrent engineering Ullman [3] and Agile manufacturing methods Anuziene and Bargelis [4].

\section{OUTSOURCING OF LOGISTICS DECISIONS}

The outsourcing of logistics decisions based on the mutual benefit of both customers and producers. Customers can be the final product producers or solicits. The final product producer looks for standard parts and original components suppliers or even for replacing all manufacturing divisions and becoming hollow company and getting maximal benefit. Appropriate models and techniques for outsourcing estimation and decision-making are necessary. The outsourcing logistics decision support system (OLDSS) as one of mentioned tool is developed in this research. Main objective of such development is to acquire and share 


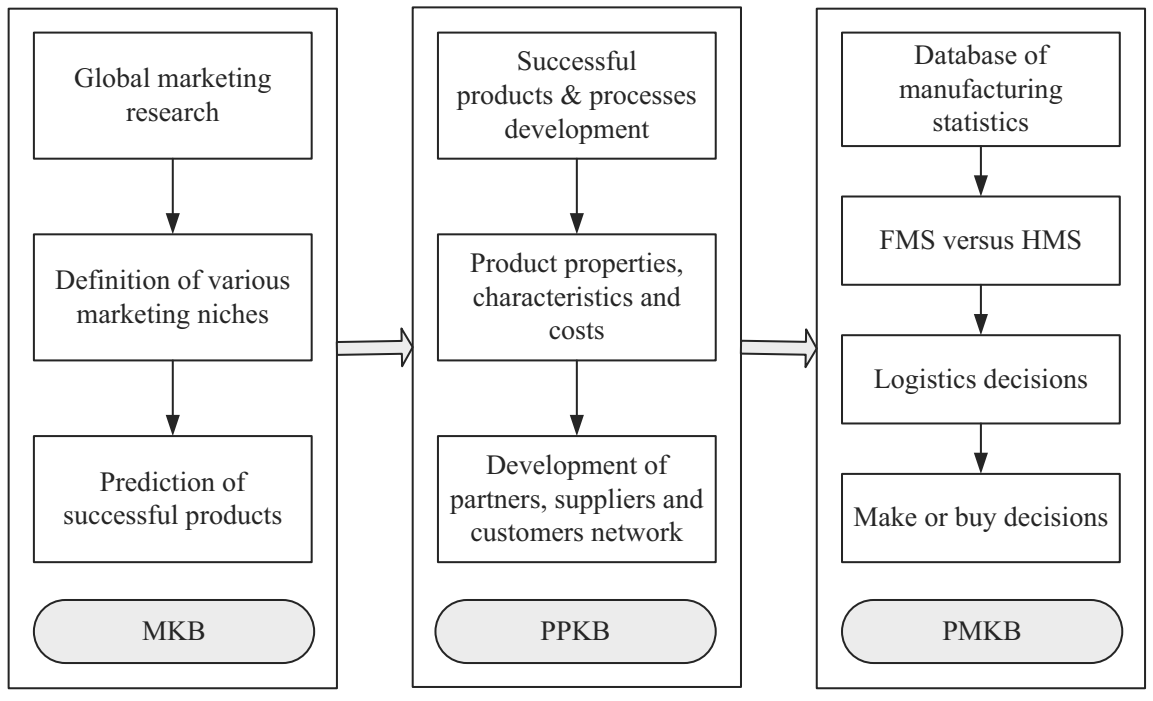

Fig. 1. The framework of OLDSS

of outsourcing knowledge and data helping to manufacturers and customers in decisionmaking procedure and seeking greatest available interest. The development grounded on knowledge base fundamentals and mathematical functions for forecasting and decision making procedures. These functions estimate available alternatives and help finding a best decision. Fig. 1 presents the developed OLDSS framework. It consists of the three parts: 1) Marketing knowledge base (MKB), 2) Products and processes development knowledge base (PPKB) and 3) Products manufacturing knowledge base (PMKB). Interacting among developed framework parts by appropriate interfaces is carried out. The main consideration in this paper falls on the two latter parts of an OLDSS system.

\subsection{Marketing knowledge base}

The development of marketing knowledge base (MKB) predicated on order-handled manufacturing approach. The initiative in this case is on the customers' proposals side. Database (DB) created of potential customers and their products on statistical information are a main resource of manufacturers. DB contains products' characteristics and customers, manufacturing costs, delivery deadlines and other specific information being in the past. Created DB can be upgraded into marketing knowledge base that increasing both the marketing knowledge of potential customers and innovative products requirements. The 
definition of peculiarities in various marketing niches and prediction of successful innovative products is a main objective of a developed MKB. It has rules, also accumulated experience knowing the customers requirements and tendencies of innovative products and processes to the different marketplace niches. Such information successfully applied in new product and process development employing the multicultural experience of different nations and countries Canen and Canen [5].

\subsection{Products and processes development knowledge base}

Integration of scientific principles and good practice for optimal new product and process development at an early business implementation stage is becoming very urgent and necessary getting advantages in distributed Global manufacturing (GM) environment. A role of winning orders and receiving high competitiveness in GM environment belongs to cheapest and motivated manufacturers. The manufacturing computational systems and virtual reality modeling Lim et al [6] of the innovative product and process employing concurrent engineering Prasad [7] are the main factors acquiring producers' motivation and advantage. The customer target cost of a product is often tendering close to materials cost. For this reason, order winners have to develop an optimal product and process structure with minimum cost and appropriate tooling, facilities, material suppliers and logistics functions. When managing an above-mentioned problem of product development, company needs to cooperate with or compete with its strategic partners in a Global business network if it wants to survive in modern manufacturing environment Yan et al [8].

The methodology applied in this research is modeling of the information-based system definition. Majority investigations of mechanical products and processes produced from smart materials, composite plastics and electronical components applying various manufacturing operations, delivery time, quality and manufacturing costs have been motivated by the interactions among these elements. As it was above-mentioned, in factories of the future will dominate a big variety of product types and low production volume, therefore, the adequate model structure in this research for a single run, small batch and medium batch manufacturing system is developed (Fig. 2). The model based on a man-machine computing approach and it concurrently examines the early stage of new product and process development. A first step of its development is classification of huge products variety into separate class level according to the product destination and quantitative-qualitative parameters [9]. Next steps 


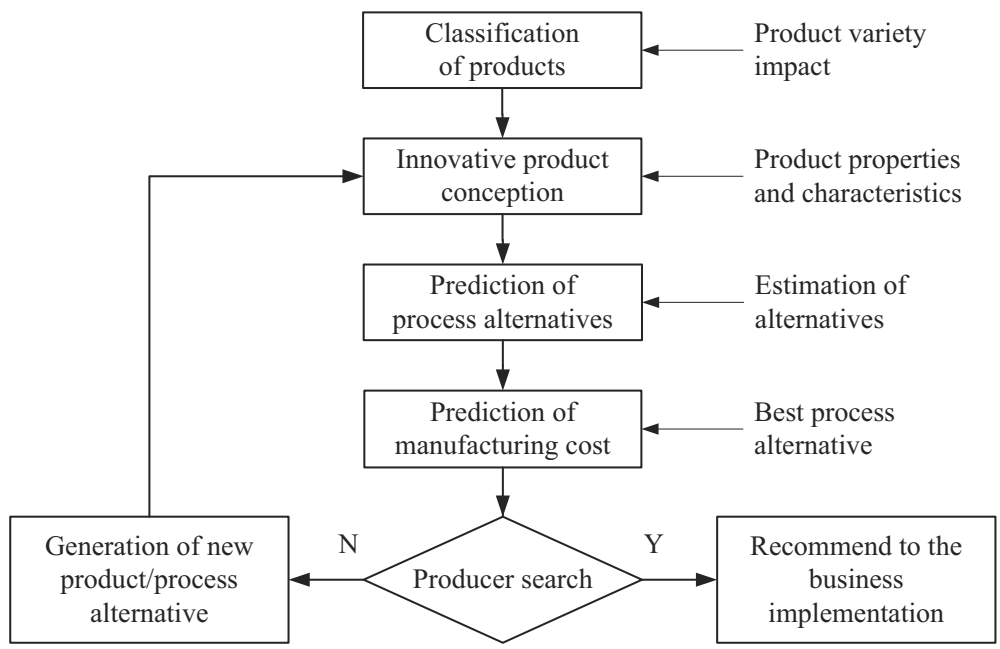

Fig. 2. Model structure of a single run manufacturing system

are development of innovative product conception, prediction of process alternatives and manufacturing costs. The forecasting of manufacturing cost for each process alternative is arranged and checked with the market requirements. If an alternative does not satisfy market requirements, then product or process is to be re-designed. The manufacturing cost is decisive to producer searching and order winning.

A knowledge-based approach of innovative product and process creation has a task to involve more developers in manufacturers' countries with different cultural-traditional mode of life. Such experience helps to define the customer requirements and configuration of innovative products and customer orders in various marketplace niches.

\subsection{Products manufacturing knowledge base}

The database (DB) of company manufacturing statistics is a principal part of products production knowledge base, as customers' orders, partners, suppliers, facts and rules. Rules and facts relate processes and operations, their sequence, machine tools, tooling, definition of operation manufacturing time and cost. Facts contain of labor productivity and quality capability in various companies and their experience producing products and parts, delivery reliability and innovative level. DB contains also definition methodology of Flexible machine stations (FMS) advantages and shortcomings versus to Hybrid manufacturing systems (HMS). Finding of logistics decisions in the information and material flows applying appropriate tools 
is grounded. Information flows keep virtual modeling data and techniques of possible decision variants while material flows - simulation data of real products development and manufacturing activity. There are two types of PMKB developments: customers and manufacturers. Customers' development to innovative product and process creation and appropriate logistics decision is concentrated, while the second type of technique on products production with minimum cost and highest quality and reliability is oriented.

Customers applying virtual reality (VR) and concurrent engineering technologies look to create products for mass production or for order handled manufacturing exploiting their in various countries and continents as possible longer time. They apply various tools and techniques that could help them achieving optimal product and process structure and finding innovative ideas and solutions. The OLDSS system is one of possible above-mentioned alternatives seeking advantages in manufacturing business. In the next paper chapter a sequence of developed system work and gotten main results are shown.

\section{RESULTS AND DISCUSSIONS}

The developed OLDSS system on the application of innovative products and processes that have attractive functionality and characteristics and use less hand work force in manufacturing is oriented. Development strategy of mentioned products and processes has two streams: 1) suitable for mass production and 2) suited for batch production. First stream products have design that is more constant and are very attractive to customer and manufacturer because they conditionally have bigger potency dominate in global market delivering less cost products. Second stream products dominate in today business environment because customers urgently look to higher variety of products. There is shown a sequence and results of developed system work for both stream products.

The two mass production products $A$ and $B$ made from sheet metal and divided to the house or living flat arrangements have been considered. Both products' types divided to a global market. Product $A$ is customized to the seven types with different size while product $B$ has only one size. Applying the experience of famous Europe Company $\mathrm{X}$ developing products $A$ and $B$, the OLDSS system marketing and products and processes development knowledge base $(\mathrm{KB})$ structure have been created. It consists of a $\mathrm{KB}$ framework, guidelines and main rules of product and process development applying mass production principles. The specialized machine tools dominate in this case. 
The creation principles of OLDSS system to the second stream products, the experience of some Lithuanian and European companies that work as order-handled manufacturing system were used. The key problem is application of innovative virtual reality and manufacturing processes with $\mathrm{CNC}$ machines, robotics, laser, information and other high technologies for the second stream products. It is grounded on process planning and production outsourcing rules that are logical expressions of various products manufacturing and looking for minimal cost. These rules are collected in developed KB structure with the associated database (DB). It contains the essential information related to the production peculiarities in each country, company and product group. The set of promises IF and the set of conclusions THEN have been used for selection of a suitable decision by appropriate rules meaning both the product process plan and outsourced company. Approximately 150 process-planning rules have been created for the products manufacturing $\mathrm{KB}$ in an order-handled manufacturing system. The rules contain available processes, machine tools, work pieces and outsourcing methods.

The developed outsourcing logistics support system has been tested in both laboratory and industry. The system is able to support a generation of process plan alternatives for various mechanical products. The verification and validation tests of a developed system have been conducted in laboratory. Some Lithuanian companies took a part conducting the acceptance tests of that system.

\section{CONCLUSIONS}

The research in this paper presents an intelligent decision support system for product design and manufacturing in global competitive business environment. The new product and process design is the essential task of the manufacturing organization that defines other areas of company activity. It is showed that developed framework of outsourcing logistics decision support system is able to help engineers and managers making advanced decisions in manufacturing business. It has been stated also that decision support system is a time consuming and new ideas generating helping tool in a daily company work. The method described in this research accomplishes the objectives of presented paper. However, this is not the only method currently available. Researchers and industrialists in many countries and companies have another developed tools and techniques but they are related with narrow tasks while this development involves cases that are more general. The testing and validation results of a created OLDSS showed its relevance for application. 


\section{ACKNOWLEDGMENT}

This research was partially supported by the European Commission (EC) Leonardo da Vinci project No 2006-EE/06/B/F/PP - 169004 "Interstudy - Advanced E-curricula and mobile tools for interdisciplinary modular study."

\section{References}

1. H.H. Chen, H-Y. Kang, X. Xing, A.H.I. Lee and Y. Tong, Developing New Products with Knowledge Management methods and Process Development Management in a Network, Computers in Industry, 59, pp. 242-253, 2008.

2. I. Egan, J.M. Ritchie, P.D. Gardiner, Measuring Performance Change in the Mechanical Design Process Arena, Proceedings of the Institution of Mechanical Engineers Part BJournal of Engineering Manufacture, 219, pp. 851-863, 2005.

3. D.G. Ullman, Robust Decision Making for Engineering Design, Journal of Engineering Design, 12, pp. 616-628, 2001.

4. L. Anuziene, A. Bargelis, Decision Support System for Agile Manufacturing of Mechanical Products, Mechanika, 3 (65), pp. 51-56, 2007.

5. A.G. Canen, A. Canen, Cultural Auditing: Some Ways Ahead for Multicultural Organizations and Logistics Management, Proceedings of Int. Conference on Industrial Logistics ICIL'2008, March 9-15, Tel Aviv, Israel, pp. 101-109, 2008.

6. T. Lim, H. Medellin, J.R. Corney, J.M. Ritchie and J.B.C. Davies, Decomposition of Complex Models for Manufacturing, Proceedings of the Int. Conference on Shape Modeling and Applications, Genoa, Italy, Jun 07-09, pp. 337-341, 2004.

7. B. Prasad, Concurrent Engineering Fundamentals: Integrated Product and Process Organization, Prentice Hall PTR, New Jersey, 1996.

8. W. Yan, M.C. Pritchard, C.H. Chen and L.P. Khoo, A strategy for Integrating Product Conceptualization and Bid Preparation, Int. Journal of Advanced Manufacturing Technology, 29, pp. 616-628, 2006.

9. A. Bargelis, Cost Forecasting Model of Product and Process Development at the Business Conception Stage, Proceedings of the Sixth Int. DAAAM Baltic Conference on Industrial Engineering, April 24-26, Tallinn, Estonia, pp. 303-308, 2008. 


\title{
DYNAMIC INVESTMENT PLANNING FOR CONTAINER PORT VENTURES
}

\author{
Antonio G. N. Novaes $^{1}$, Enzo M. Frazzon ${ }^{2}$,Vanina M.D. Silva ${ }^{1}$ and Hobed Rosa ${ }^{1}$ \\ ${ }^{1}$ Department of Production and Systems Engineering \\ Federal University of Santa Catarina \\ P.O.Box 476, Florianópolis, SC \\ 88040-900, Brazil \\ ${ }^{2}$ BIBA - Bremer Institut für Produktion und Logistik GmbH, \\ Universität Bremen, Hochschulring 20 D-28359 \\ Bremen, Germany
}

\begin{abstract}
A number of authors have studied the problem of optimally meeting a growing demand for capacity, considering deterministic or stochastic demand patterns and different forecasting formulations. The resulting cash flow, including investments, operating expenditures and revenues, are analyzed with a predefined interest rate and a given time horizon. Due to demand volatility, the venture is sometimes rejected as a result of negative economic outcomes. The real options approach introduces the possibility of incorporating other decision alternatives in the economic analysis, such as the option of waiting or postponing, abandoning, switching, etc. In this paper we discuss a case of a container port investment with an abandoning option and assuming a dynamic reviewing process.
\end{abstract}

\section{INTRODUCTION}

This paper deals with two important topics in the area of finance and economics applied to logistics endeavours, namely the capacity expansion problem and the real options concepts and methods. Since the classical models of capacity expansion assume a continuous, everincreasing demand curve and irreversible investments, they do not include all the practical variables usually encountered in present-day, dynamic investment problems. In a volatile global economy, decisions such as to postpone investments, to shutdown and later restart 
operations, to abandon the project, etc., are usually taken in practice by investors. The real options approach opens a way to evaluate the economic and financial impacts of such actions.

Capacity expansion is the process of adding facilities over time in order to satisfy rising demand (Manne [1]; Higle and Corrado [2]; Novaes and Souza [3]). Capacity expansion decisions in the business sector generally add up to a massive commitment of capital. The efficient investment of capital depends on making appropriate decisions in expansion undertakings, in such a way as the project remains profitable over an extended time period.

In general terms, an option is the right, but not an obligation, to take an economic or financial action in the future (Trigeorgis [4]). Options are valuable when there is uncertainty. When the transaction involves the right to buy an underlying asset at a fixed price on a future date, one has a call option. Conversely, a put option occurs when it involves the right to sell the underlying asset at a fixed price in a future horizon.

\section{CAPACITY EXPANSION MODELING}

The literature shows, along the last forty years, an evolving sequence of capacity expansion models (Manne [1]; Freidenfelds [5]; Higle and Corrado [2]; Bean et al. [6]; Novaes and Souza, [3]).

\subsection{The Classical Model}

In basic terms, the discounted cash flow $(D C F)$ approach assumes that the enterprise will follow a predetermined plan when investing, regardless of how events unfold in the future. By computing the net present value of a project $(N P V)$, the enterprise will increase its own value by making the investment when the $N P V$ is positive. The $N P V$ calculation presupposes that unknown-risk future cash flows be summarized by their expected values, discounted to the present at a specific rate. The net present value is given by

$$
N P V=-I_{0}+\sum_{t=1}^{T} \frac{R_{t}-E_{t}-I_{t}}{(1+r)^{t}}+\frac{S V_{T}}{(1+r)^{T}},
$$

where $I_{t}$ is the investment at time $t, r$ is the annual interest rate, $T$ is the duration of the project, $R_{t}$ is the sum of all revenues at year $t, E_{t}$ is the sum of all expenditures at year $t$, and $S V_{T}$ is the salvage value of the project at time $T$. The project is economically feasible if $N P V>0$ 


\subsection{Incorporating the Volatility Impact}

Manne [1], considering a linear demand function, showed that when demand is a Bachelier-Wiener diffusion process in continuous time, the effect of randomness can be equivalently represented by a reduction in the discounting interest rate. Later, Srinivasan [7] showed that this property is also valid for geometric rate of demand growth. Bean et al.[6] generalized the demand process under which the "equivalent interest rate" approach applies. Such models are based on Brownian motion theory, specifically the Wiener diffusion process in continuous time. Higle and Corrado [2] showed that the equivalent interest rate formulation is seen to be unaffected by the stochastic nature of the demand process, and thus, can be considered to be robust. Assume that $D(t)$, the demand level at time $t$, is a continuous stochastic process. Bean et al. [6] demonstrated that if $\{D(t), t \geq 0\}$ is a transformed Brownian motion with drift $\mu>0$ and variance $\sigma^{2}>0$, the modified continuous interest rate $r_{C}^{*}$ to be used in the basic discounted deterministic problem with interest rate $r_{C}$ is given by

$$
r_{C}^{*}=\left(\frac{\mu}{\sigma}\right)^{2}\left(\sqrt{1+2 r_{C}\left(\frac{\sigma}{\mu}\right)^{2}}-1\right)
$$

The equivalent interest rate formulation is, in fact, an elegant and robust way of incorporating the volatility component of demand in the capacity expansion model.

\section{ECONOMIC EVALUATION WITH THE REAL OPTIONS APPROACH}

Basically, there are three general methods to solve real options problems: the partial differential equation approach, the dynamic programming approach, and the simulation approach (Mun [9]). The method employed in this paper, the Black and Scholes equation, belongs to the first group and is based on the Wiener-Ito process. Black and Scholes (Trigeorgis [4]; Schwartz and Trigeorgis [8]; Mun [9]; Smit and Trigeorgis [10]) derived a partial differential equation based on a continuous application of a dynamic portfolio replication strategy under the assumption that the asset value follows a stochastic diffusion Wiener process of the form

$$
\frac{d S}{S}=\alpha d t+\sigma d z
$$


where $\alpha$ is the instantaneous expected return on the asset $S, \sigma$ is the instantaneous standard deviation of asset returns, and $d z$ is the differential of a standard Wiener process, with mean zero and variance $d t$. The Black and Scholes equation (Novaes and Souza [3]) is

$$
\frac{\partial f}{\partial t}+r S \frac{\partial f}{\partial S}+\frac{1}{2} \sigma^{2} S^{2} \frac{\partial^{2} f}{\partial S^{2}}=r_{f} f
$$

where $S$ is the the present value of the asset, $f$ is the price of the derivative, which is a function of $S, t, r$, and $\sigma$, and $r_{f}$ is the risk-free interest rate. For a European put option (Trigeorgis [4]), the boundary condition to solve (4), assuming $t=T$, is

$$
f=\max \{X-S, 0\} \text { for } t=T,
$$

where $X$ is the exercise price and $T$ is the time to expiration. The integration of (4), subject to (5), yields

$$
f=X \exp \left(-r_{f} T\right) N\left\{-d_{2}\right\}-S N\left\{-d_{1}\right\},
$$

where $N\{w\}$ is the integral of the standard normal distribution at point $w$, with

$$
d_{1}=\left[\ln \left(\frac{S}{X}\right)+\left(r_{f}+0.5 \sigma^{2}\right) T\right]\left[\frac{1}{\sigma \sqrt{T}}\right],
$$

and

$$
d_{2}=d_{1}-\sigma \sqrt{T} .
$$

The value of a European call option is similarly determined assuming the appropriate boundary conditions (Trigeorgis [4]). The Black-Scholes equation (4) gives a way of computing the economic impact on the project under study of real options as, for example, the exiting or abandonment option. In particular, Margrabe [11] developed a special model to evaluate an abandonment option. Suppose a firm is evaluating an investment proposal at time zero. At time $T_{A}$, the firm has the option to abandon or retain the project. If the project is abandoned, the discounted cash flow realized by the firm is $X_{0}$. On the other hand, if the project is retained, the value realized by the firm at that time is $S_{0}$. Admitting that both $X_{0}$ and $S_{0}$ are lognormally distributed, Margrabe's exchange option pricing model is (Margrabe [11])

$$
f=X_{0} \quad N\left(d_{1}\right)-S_{0} N\left(d_{2}\right)
$$

where

$$
d_{1}=\left[\ln \left(\frac{X_{0}}{S_{0}}\right)+0.5 \sigma^{2} T\right]\left[\frac{1}{\sigma \sqrt{T}}\right] \text { and } \quad d_{2}=d_{1}-\sigma \sqrt{T} \text {. }
$$


Margrabe (1978) decomposes $\sigma^{2}$ into two components, $\sigma_{X}^{2}$ and $\sigma_{S}^{2}$, according to the formula

$$
\sigma^{2}=\sigma_{X}^{2}-2 \sigma_{X} \sigma_{S} \rho_{X S}+\sigma_{S}^{2},
$$

where $\sigma_{X}$ is the coefficient of variation associated with the abandonment value of the project, $\sigma_{S}$ is the coefficient of variation associated with the value-in-use of the project, and $\rho_{X S}$ is the correlation between $X_{0}$ and $S_{0}$.

\section{APPLICATION TO A CONTAINER PORT INVESTMENT PLANNING}

Most of the data for this application was taken from the container terminal of the port of Rio Grande, in southern Brazil. But due to space limitations, the application had to be simplified, and part of the data was estimated from indirect sources. Thus, the application is solely a methodological example, intended to help in similar real-world analysis.

The terminal has been operated by a state agency, but the conceding authority intends to contract a private company to operate the facility for $T=20$ years. Suppose also that the conceding authority has accepted an agreement with the prospective operator under which the latter may abandon the project after $T_{A}=12$ years. If this situation occurs, the state will take over the project, and reimburse the operator for the non-depreciated part of the investments. All the investments are supposed to be linearly depreciated in $T_{B}=15$ years. At time zero the terminal has two berths. The operator has to built new berths (one or more, if necessary) whenever the average ship waiting time during a certain year is greater than 2 hours. Each berth, including the water front, the loading/unloading cranes and the necessary backyard area and equipments, will cost 130 million US dollars. All the port operating charges are 140 US dollars per TEU, and the associated costs are 95 dollars per TEU. In order to get the right to run the terminal, the operator agrees to pay 115 million dollars cash to the state agency at time zero. The interest rate assumed by the operator to analyze the corresponding cash-flow is computed according to the CAPM - Capital Asset Pricing Model relation (Campbell et al. [12])

$$
r=r_{f}+\left(r_{M}-r_{f}\right) \beta,
$$

where $r_{f}=5,75 \%$ is the annual risk-free interest rate, $r_{M}=10 \%$ is the portfolio's average rate of return per year, and $\beta=1.2$, yielding $r=0.1775$ per year to be used in the application. The continuous-time discount rate $r_{C}$ is given by $r_{C}=\ln (1+r)=0.1634$.

A time series of 10 years was analyzed in order to estimate the average growth rate of the demand and its volatility. The resulting equation was adjusted via regression analysis 


$$
D(t)=D_{0}(1+\theta)^{t},
$$

where $D_{0}$ is the demand at time $t$ ( $t$ in years), expressed in TEU per year, and $\theta$ is the annual expansion rate. One has $D_{0}=373,252 T E U$ and $\theta=0.09$. The annual volatility is $\sigma_{S}=\sigma / \mu=0.49$ (Novaes and Souza [2005]). Applying (2) one gets $r_{C}^{*}=0.1603$, leading to $r^{*}=0.1739$, which is the modified interest rate to take into account the volatility effect.

The ship waiting time is estimated assuming a $G / G / c$ queue, specifically a $M / E_{k} / c$ type (Novaes et al. [13]), where arrivals are Poisson distributed, service time follows an Erlang distribution of order $k=5$ (Novaes et al. [13]), and the terminal is served by $c$ berths (Morrison and Martin [14]; Novaes et al. [13] ). Knowing the demand at year $t$, expressed in $T E U$ containers, the queuing model defines the necessary number of berths to keep the average ship waiting time not greater than 2 hours.

\section{RESULTS AND CONCLUSIONS}

First, the number of berths that must be available at the terminal to keep container ships waiting, in average, no more than two hours is computed for each year within the time horizon of the project. The resulting berth supply program is indicated in Table 1. Apart from the two berths available at time zero, a total of 8 berths will have to be added during the project lifespan.

Table 1 - Berth addition plan

\begin{tabular}{|ccc|ccc|}
\hline Year & $\begin{array}{c}\text { Berth } \\
\text { addition }\end{array}$ & $\begin{array}{c}\text { Available } \\
\text { berths }\end{array}$ & Year & $\begin{array}{c}\text { Berth } \\
\text { addition }\end{array}$ & $\begin{array}{c}\text { Available } \\
\text { berths }\end{array}$ \\
\hline 1 & 1 & 3 & 19 & 1 & 7 \\
8 & 1 & 4 & 22 & 1 & 8 \\
13 & 1 & 5 & 24 & 1 & 9 \\
17 & 1 & 6 & 25 & 1 & 10 \\
\hline
\end{tabular}

The salvage value $S V_{T}$ represents the sum of non-depreciated part of all investments at time $T$. Its value is 520.00 million dollars, and its discounted value at time zero, with $r^{*}=0.1739$, is 9.44 million. Substituting all other elements in equation (1), one gets NPV $=$ -12.98 million, meaning the project is not economically feasible under the traditional discounted cash flow $(D C F)$ approach. 
Now, Margrabe's formulation [11] is applied to evaluate an abandonment put option at time $T_{A}=12$ years. If the project is abandoned at time $T_{A}$, the discounted cash flow realized by the firm in the period $1 \leq t \leq T_{A}$ is

$$
X_{0}=-I_{0}+\sum_{i=1}^{T_{A}} \frac{\left(R_{t}-C_{t}\right)-I_{t}}{\left(1+r^{*}\right)^{t}}+\frac{S V_{T A}}{\left(1+r^{*}\right)^{T A}}=227.15 \text { million. }
$$

On the other hand, if the project is retained at time $T_{A}$, the net present value of the project for the period $T_{A}+1 \leq t \leq T$ is

$$
S_{0}=\sum_{t=T_{A}+1}^{T} \frac{\left(R_{t}-C_{t}\right)-I_{t}}{\left(1+r^{*}\right)^{t}}=36.52 \text { million. }
$$

Since the abandonment value of the project, in this case, is an accounting figure with minor possible divergence between the state organization and the operator, a low value for $\sigma_{X}$ was assumed, namely $\sigma_{X}=0.15$. On the other hand, the correlation between $X_{0}$ and $S_{0}$ is practically nil in this case, i.e., $\rho_{X S} \square 0$. Thus, putting $\sigma_{X}=0.15, \sigma_{S}=0.49$, and $\rho_{X S} \square 0$ in equation (11), one has $\sigma=0.51$. Applying equation (9) with $T=12$ years, one gets $f=$ 200.43 million dollars, which is the value of the put-call option (Margrabe [11]) to be added to the project cash flow, given by $N P V^{\prime}=N P V+f=-12.98+200.43=187.45>0$. Thus, with the abandonment option at time $T_{A}=12$ years, the project becomes economically feasible.

Although the method described here is theoretically sound, the container market in the globalized world has been changing dramatically in the past years. Container ship sizes are increasing steadily, and the requirements to build berths, cranes, and incorporate other technologies tend to vary substantially in the next decades. On the operational side, a number of container terminals in the world are being transformed into hub ports, and at least one East Coast South American port will probably follow this trend in the future, dramatically changing its technical and operating characteristics. With all this in mind, the use of economic analysis as the one described here, in which one assumes operating characteristics for a long period of time, seems to be not completely satisfactory for investment purposes. But the investor could adopt a piece-wise way to do the analysis, periodically reviewing the assumptions and introducing new factors as they appear along time. Another possibility is to make use of strategic scenario analysis methods, based on technology forecasts.

\section{REFERENCES}

1. A.S. Manne, Capacity Expansion and Probabilistic Growth, Econometrica, 29, pp. 632$649,1961$. 
2. J.L. Higle and C.J. Corrado, Economic investment times for capacity expansion problems, European Journal of Operational Research, 59, 288-293, 1992.

3. A.G. Novaes and J.C. Souza, A Real Options Approach to a Classical Capacity Expan-sion Problem, Pesquisa Operacional, 25, (2), pp. 159-181, 2005.

4. L. Trigeorgis, Real Options, The MIT Press, Cambridge, MA., 1996

5. J. Freidenfelds, Capacity Expansion: Analysis of Simple Models with Applications, North-Holland, New York, 1981.

6. J.C. Bean, J.L. Higle and R.L. Smith, Capacity expansion under stochastic demand, Operations Research, 40, pp. S210-S216, 1992.

7. T.N. Srinivasan, Geometric rate of growth of demand, In: A.S.Manne (ed.) Investments for Capacity Expansion, Allen \& Unwin, USA, 1967.

8. E.S. Schwartz and L. Trigeorgis, Real Options and Investment under Uncertainty, The MIT Press, Cambridge, MA, 2001.

9. J. Mun, Real Options Analysis, John Wiley \& Sons, Hoboken, NJ, 2002.

10. H.T. Smit and L. Trigeorgis, Strategic Investment: Real Options and Games, Princeton University Press, Princeton, NJ, 2004.

11. W. Margrabe, The Value of an Option to Exchange One Asset for Another, The Journal of Finance, XXXIII, (1), pp. 177-186, 1978.

12. J.H. Campbell, A.W. Lo and A.C. MacKinlay, The Econometrics of Financial Markets, Princeton University Press, Princeton, NJ, 1997.

13. A.G. Novaes, V.D. da Silva and H. Rosa, Using Queueing Models and Simulation in the Planning of Container Port Terminals (in Portuguese), XXIII Anpet Conference, Vitória, ES, Brazil, November 2009.

14. J.R.Morrison and D. P. Martin, Practical extensions to cycle time approximations for G/G/m-queue with applications. IEEE Transactions on Automation Science and Engineering, 4, pp. 523-532, 2007.

\section{ACKNOWLEDGMENTS}

This research has been supported by the Brazilian CNPq/Fapesc Project $n^{\circ} 1.0810-$ 00684 (Pronex) and by Capes/DFG Bragecrim Project $n^{\circ} 2$. 


\title{
THE APPLICATION OF INNOVATIONS IN TRADE
}

\author{
A. Burinskiene \\ Department of International Economics and Management \\ Vilnius Gediminas Technical University \\ Sauletekio 11, Vilnius LT-10223
}

\begin{abstract}
The article disclose the perspectives of applying innovations in trade enterprises. In the article is indentified, that wholesale ant retail enterprises are implementing innovations according similar standards. It is defined, that the distinguishing line between wholesale and retail trade is gradually disappearing.

In the article a new approach towards the concepts of distribution channels is formed, traditional typology of distribution channels was expanded.
\end{abstract}

\section{INTRODUCTION}

The world has been changing: traditional economies are replaced by digital economies placing greater focus on knowledge and technologies.

Innovations are given exclusive significance under such conditions. Enterprises introduce innovations with an aim to improve their methods of trade and supply. The turnover of enterprises, which apply innovations, grows by $18 \%$. Enterprises allocate $1.5 \%$ of their revenues for implementation of innovations.

The application of innovations is significant for enterprises dealing in trade. The revenues of trading companies constitute $66 \%$ of the gross domestic product (GDP) in the European Union (EU). Within the enterprise structure, there are $31.8 \%$ of enterprises engaged in trading activities and employing over 30.9 million employees of 280.8 million EU workers.

The application of innovations determines the necessity to identify following key issues:

- the application of innovations in trade have not been widely discussed;

- the existing theoretical knowledge is not adequate to changes taking place in trade

The goal of this article is to disclose the perspectives of applying innovations in trade, and to put forward a new attitude towards the concepts of distribution channels. 
The article is based on statistical analysis, comparative analysis, and empirical analysis.

\section{THE CONCEPT OF TRADE}

Trade is an activity for selling goods and services. The word "trade" means to buy, sell or to exchange in goods. Trade is a branch of economy, dealing with goods are transfer from the sphere of production to consumption.

Trade is a type of activity covering (based on the NACE classifier):

- wholesale trade. The core activities of wholesale trade consist in the resale of goods to professional consumers and enterprises. Prior to selling, goods, without changing the essential form of goods, may be sorted out, packed, mixed or repacked;

- retail trade. In a number of cases retail trade is conducted in stores; however there are also such trading forms as the sale of goods over the internet, warehouse sale, etc.

\section{THE CONCEPT OF INNOVATIONS UNDER THE TECHNOLOGICAL PROGRESS CONDITIONS}

"Innovation" is an economic or most often technical term. Organisation for Economic Cooperation and Development (OECD) [1] suggests the following definition: "innovation is a successful commercial application of new methods, introduction of new and improved already existing business solutions into the market". M. E. Porter defines innovation as the main factor of enterprise competitiveness [2]. Broadly speaking, innovation is the introduction into the market of business solutions creating new business perspectives, value to consumers and shareholders, and affecting the growth of the GDP.

In scientific literature, technology is suggested to be assessed as innovation since any innovation has to start with an idea and to end with particular results. Technology is the totality of knowledge covering the proprietary law and scientific knowledge, as well as the results of investigations. Technology may be materialized and non-materialized. Nonmaterialized technology implies constructive solutions, methods. Materialized technology encompasses machinery, equipment, etc. [3].

Given fast technological progress in modern economies, an opinion prevails that a strong economic entity that applies an old technology frequently looses to the economic subject that applies a more progressive technology [4], since by applying a new technology it is possible to achieve a relatively higher productivity and operation efficiency. 
New technologies are developed and applied in different spheres of activities. Owing to the application of technologies, old production, trade and supply methods are changed into technologically new and considerably improved methods that have been created by using new knowledge. These methods foster the production of new or technologically improved goods that may not be manufactured, realized and delivered using the traditional methods, or induce the enhancement of efficiency in production, trade or supply.

\subsection{Assimilation of innovations}

The assimilation of innovations is unique. Some innovations are assimilated faster, others - slower. By analysing the assimilation of innovations in enterprises, the following types of enterprises may be distinguished (Fig. 1):

- enterprises - superinnovators. They are among the first ones to introduce innovations, and may share common experiences with other enterprises;

- enterprises - innovators. They face especially high costs of technology introduction;

- $\quad$ early majority enterprises. The early majority enterprises devote more attention to the analysis of advantages and opportunities offered by innovations;

- late majority enterprises. This group encompasses small enterprises that install innovations late;

- conservative enterprises. These enterprises deploy innovations the latest.

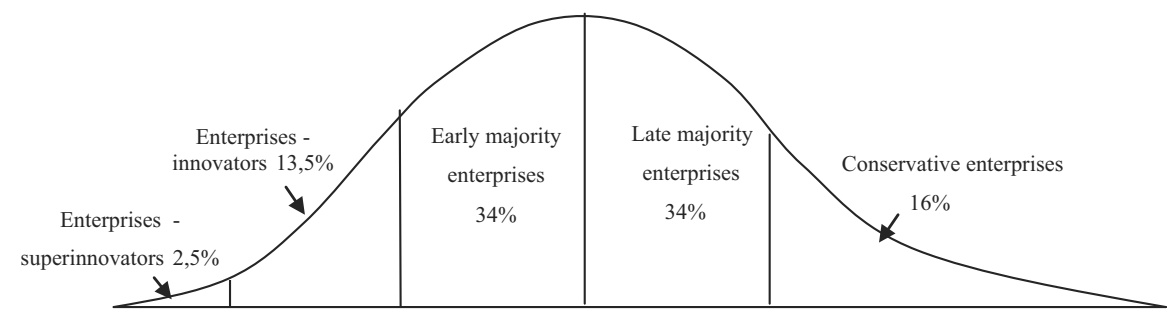

Fig. 1: Curve of the recognition of innovations according to Roger's (1962) model [5]

In terms of percentage, there are quite few enterprises - innovators; meanwhile the number of early majority companies is much more plentiful. 
The processes of the assimilation of innovations must be consistent. In order to achieve that innovation were recognized by the late majority, technologies are to be sometimes modified to facilitate their application to a major extent.

\subsection{Application of innovations}

Among trading companies innovations are most actively applied by wholesalers, and most passively - by retailers. Wholesale companies apply innovations for the following goals: $17 \%$ - increased capacities of the company, $12 \%$ - reduced operating costs per sale unit, $15 \%$ improved the flexibility of supply by the company. [6]

Based on Planet Retail database (www.planetretail.net) [7] covering 2,910 retail trade companies (in 140 countries of the world), an assessment is made how enterprises apply the ecommerce technologies. Studies revealed that $12.9 \%$ of retail trading companies (377 from 2910 companies) apply e-commerce technologies. By assessing the application of ecommerce as an innovation (based on the curve of the recognition, presented in Fig. 1), the conclusion is made that e-commerce technologies are applied by enterprises - innovators (mentioned technologies are applied by less than $16 \%$ of enterprises).

By analysing information about the application of e-commerce technologies compiled in the Best eEuropean Practice (BEEP) [8] database it is evident that both, wholesale and retail companies sell goods to enterprises and final consumers.

Apart from the innovations mentioned above, retail and wholesale companies also apply automation and robotics based technologies (abbr. ABT and RBT). 49\% of ABT sales consist ABT intended for transportation; 40\% - ABT intended for warehousing; $11 \%$ - ABT for collecting orders [9]. ABT have been implemented by Coca-Cola Bottling Co Ltd (Japan), Rynkeby Foods A/S (Denmark), Walkers Snack Foods (G. Britain), Mamut Sports Group (Switzerland), DM (Germany), Woolworths (Australia) and Albert Heijn (Holland) [10].

Among RBT, the most popular are the technologies intended for packing, formation of a cargo unit, or technologies performing the operations of collecting orders [11].

RBT have been installed by the following retail companies:

- Switzerland retail company COOP (in the packaging centre servicing stores and catering companies);

- IKEA retail company. The company uses the RBT for the manufacture of plastic parts; 
- ICA retail company applies the RBT for packaging. This RBT is intended for packaging meat products and their placement into plastic boxes. The company supplies these products to stores, restaurants and other catering companies [12].

\section{THE CONCEPT OF DISTRIBUTION CHANNELS}

Based on data of the Lithuanian Department of Statistics [13] it was determined that $65 \%$ of income of wholesale enterprises consists of the sales to other wholesale companies or professional consumers, and $30 \%$ - of the sales to retail companies.

It has been noticed that the application of innovations triggers the following changes:

- investments into the e-commerce technologies make wholesale companies to adjust internet trading to final consumers, i.e. apart from their core activities, they also pursue retail trade activities (e.g. such activities are conducted in Lithuania by Sanitex, Acme, GNT Lietuva, Ratanas);

- the implemetation of the RBT induce retail companies to manufacture a part of goods by themselves. Retail companies set up manufacturing - packaging units, and apart from their core activities, they engage in manufacturing and wholesaling;

- business changes associated with the investment of retail companies into ecommerce, $\mathrm{ABT}$ and $\mathrm{RBT}$ urge retail companies to engage in wholesaling too, i.e. to apply trade to professional users (offices, catering companies). Based on Planet Retail database, 201 retail companies are engaged in wholesale activities, of which 45 aforementioned enterprises also apply e-commerce technologies.

It is obvious that the distinguishing line between wholesale and retail trade is gradually disappearing: wholesale companies engage in retail trade and sell their goods to the final users; retail companies pursue wholesaling - they pack goods themselves and sell them to other companies.

Based on these changes the concepts of traditional distribution channels are suggested to be supplemented.

Until now the concepts of distribution channels have been differentiated into such groups:

- expanded distribution channel [14], when a manufacturer entrusts his goods to a wholesale company for their supply to retailer which sell them to the final consumer;

- limited distribution channel - the second alternative for the manufacturer; a wholesale enterprise is eliminated in this distribution channel $[15,16,17]$; 
- direct distribution channel - the third alternative for the manufacturer; here wholesale and retail trade companies are eliminated. Manufacturers look for buyers via TV, printed media or electronic mail [18].

Tab. 1: Traditional concepts of distribution channels and their supplements

\begin{tabular}{|c|c|c|c|c|c|}
\hline Channel type & $\begin{array}{l}\text { Traditional } \\
\text { concept of } \\
\text { expanded } \\
\text { channel }\end{array}$ & $\begin{array}{l}\text { Traditional } \\
\text { concept of } \\
\text { limited } \\
\text { channel }\end{array}$ & $\begin{array}{l}\text { Suggested } \\
\text { supplement } \\
\text { of limited } \\
\text { channel }\end{array}$ & $\begin{array}{l}\text { Traditional } \\
\text { concept of } \\
\text { direct } \\
\text { channel }\end{array}$ & $\begin{array}{l}\text { Suggested } \\
\text { supplement } \\
\text { to direct } \\
\text { channel }\end{array}$ \\
\hline Manufacturer & $\mathrm{X}$ & $\mathrm{X}$ & $\mathrm{X}$ & $\mathrm{X}$ & \\
\hline $\begin{array}{l}\text { Wholesale } \\
\text { company } \\
\text { professional } \\
\text { consumer }\end{array}$ & $x+$ & & $x \frac{1}{y}$ & & $\mathrm{X}$ \\
\hline Retail company & $X$ & $\mathrm{X}$ & & & $\mathrm{X}$ \\
\hline Final consumer & $x^{\downarrow}$ & $\mathrm{X}$ & $x^{\downarrow}$ & $\mathrm{X}$ & $x^{\downarrow} x$ \\
\hline
\end{tabular}

Considering changes, the concepts discussed above are suggested to be improved as follows (Tab. 1):

- the concept of limited distribution channel should cover the elimination of any one wholesaler or retailer, and may be formulated as follows: the manufacturer entrusts its goods to a trade company which sell these goods to the final consumer;

- the concept of direct channel should be adapted to the trading company which pursues manufacturing (as additional activities of the company). Therefore the concept of direct distribution channel should also cover direct sales to the final consumer.

According to Smaros and Holmstrom [19], by using internet final consumer has the possibility to choose a buyer easier and make a transaction with manufacturer directly. Capgemini's study [20] shows that $79 \%$ consumers in China and $65 \%$ in other countries would buy a car directly from manufacturer. It is obvious that manufacturers and consumers are inclined to make transactions without any intermediaries who don't create an added value.

Based on data of the Lithuanian Department of Statistics [13], an assessment is made which distribution channels are applied by Lithuanian trading companies. It has been 
established that Lithuanian retail companies have applied the traditional distribution channels so far (among which the expanded distribution channel dominates; $60 \%$ of purchases are made this way); meanwhile wholesale companies use both, the traditional distribution channels, and the ones put forward by the author (their direct sales to final consumers account for $5 \%$ of income).

\section{CONCLUSIONS}

It is noticeable that the application of technologies in trading companies is focused on the changes of processes; owing to their application, business processes are more actively developed and applied in trading companies. The application of innovations fosters a dynamic development of trading companies.

Trade may be characterized by the prevalence of the following trends:

- among trading companies in the EU, the most innovative are wholesale companies;

- sub-spaces have been established in retail and wholesale trading companies, which function according to the similar standards of the application of innovations.

It has been noticed that the application of innovations triggers the following changes:

- investments into the e-commerce technologies make wholesale companies to adjust internet trading to final consumers;

- the implementation of the RBT induce retail companies to manufacture a part of goods by themselves;

- business changes associated with the investment of retail companies into ecommerce, $\mathrm{ABT}$ and RBT urge retail companies to engage in wholesaling.

Based on these changes the author suggests supplementing the traditional concept of distribution channels, and also makes the conclusion that the application of innovations reduces the distinguishing line between wholesale and retail trade.

\section{REFERENCES}

1. OECD, Glossary online, Available at http://stats.oecd.org/glossary.

2. V. Ostasevicius, M. Kriaucioniene and V. Kauneliene, Innovation Management from "Development of entrepreneurship in the fields of social and engineering sciences at Kaunas University of Technology, and Vilnius Gediminas Technical University”, project materials, pp. 5-29, 2007. 
3. A.B. Knasas, Innovation strategies under the market internationalization conditions [manuscript], Vilnius, pp. 18-56, 2002.

4. V. Jakstas, Designing of technological development in an industrial enterprise, Technika, Vilnius, pp. 4-18, 2001.

5. E.F. Sanchez, Estrategia de innovacion, Thomson, Spain, 2005.

6. Eurostat, Database online, Available at http://ec.europa.eu/eurostat.

7. Planet Retail, Database online, Available at: www.planetretail.net.

8. BEEP, Database online, Available at http://www.beepknowledgesystem.org.

9. UNECE and IFR, World Robotics 2007, Available at www.ifrstat.org.

10. KOM International Inc., Centralized distribution center for slow movers lowers inventory levels, allows more frequent store deliveries, Holland, 1991.

11. K. Young, I. Tuersley and A. Vaidya, UK robotic installations statistics for 2004, Industrial Robot 32, pp. 444-448, 2005.

12. ABB, A magazine from ABB, 2006, Available at www.abb.com/robotics.

13. Lithuanian Department of Statistics, Database online, Available at http://www.stat.gov.lt.

14. H. Min, Distribution channels in Japan, challenges and opportunities for Japanese market entry, International Journal of Physical Distribution \& Logistics Management 10, pp. 2235, 1996.

15. B. Doherty and S. Tranchell, „Radical mainstreaming“ of fairtrade: the case of The Day Chocolate Company, Equal Opportunities International 7, pp. 693-711, 2007.

16. A.M. Doherty, The internationalization of retailing, International Journal of Service Industry Management 2, pp. 184-205, 2007.

17. C. Das and R. Tyagi, Wholesaler: a decision support system for wholesale procurement and distribution, International Journal of Physical Distribution and Logistics Management 10, pp. 4-12, 1994.

18. L. Dale, M., Wayne, M. Lewison and D. Wayne, Retailing, 1998.

19. J. Smaros and J. Holmstrom, Reaching the consumer through e-grocery VMI, International Journal of Retail \& Distribution Management 2, pp. 22-37, 2000.

20. Capgemini, Cars online 05/06 findings, Available at www.capgemini.com. 


\title{
CLUSTERING AND ROUTING MODEL FOR TRANSPORT LOGISTICS USING SOFTWARE AGENTS
}

\author{
Gulshanara Singh, A. Timm-Giel, Carmelita Görg \\ AG Communication Networks, \\ University Bremen, Germany \\ \{guls|atg|cg\}@comnets.uni-bremen.de
}

\begin{abstract}
Autonomous cooperation is an evolving trend in transport domain of logistics network. Integration of technologies like multi-agent systems and communication network strategies aid in bringing about autonomy and increased flexibility to handle complexity and dynamics in the network. A cluster based DLRP ${ }^{1}$ approach is presented using the software agent based simluation framework. DLRP involves the route discovery process both by the packages as well as the vehicles simultaneously. The route discovery process by the vehicle and packages can result in enormous communication. A performance evaluation of this approach was presented in [3]. However, this paper presents an enhancement of the analytical formulation and the analytical results are then compared with the simulation results.
\end{abstract}

\section{INTRODUCTION}

A lot of research is involved in the University of Bremen to bring about more autonomous control [1] in the logistics network. The concept of autonomous control is the research area of the German Collaborative Research Centre (CRC) 637 'Autonomous Cooperating Logistics Processes - A Paradigm Shift and its Limitations' [2]. The CRC is involved in developing new concepts for the dynamic and complex transport networks. This includes integration of technologies like RFID, communication networks and software agent technologies. Software agent technology has much to offer in terms of dynamics involved in the logistical network. As a software agent is autonomous, reactive and adaptable it acts as an autonomous entity providing autonomous control to handle dynamics and complexity. However, integrating these technologies also bring about additional complexities in terms of communications. For 
example, if each entity is independent to make decisions this results in complexity and message flooding in the network.

For example, one of the routing techniques adapted in CRC is based on the distributed routing algorithm from communication networks. Here the routing is done both by the packages and the vehicles. The new routing concept developed in CRC is termed Distributed Routing Logistics Protocol (DLRP).The DLRP is designed to match the routes of vehicles and goods in a dynamic network environment. In contrast to traditional algorithms for Vehicle Routing Problem (VRP), which handle static optimization, this approach tries to control an ongoing dynamic transport process [4].

In section 2, more detailed description of DLRP on which this work is based is presented. A software agent based clustering and routing approach is presented in section 3. An analytical formulation of the routing based clustering approach is presented. Section 4 and 5 presents the comparison of simulation and analytical results along with conclusion and future outlook in this direction of research.

\subsection{DLRP}

The real life scenarios of logistics processes require a kind of continuous control of objects. Example, in transport process, objects like packages and vehicles are dynamic which appear and disappear continuously. The autonomous concept, DLRP, was developed inspired by the internet routing protocols. DLRP was designed with the view of able to find routes through permanently changing and unknown network scenarios. In addition it is said to be able to deal with very large network scenarios without the centralized perspective.

The whole DLRP concept as essayed in [Scholz06] offers outstanding advantages for real life applications such as: self-adaptation, manual intervention, estimation of future net conditions, implicit uncertain knowledge, arbitrary decision processes and arbitrary kind and quantity of information. The approach taken for the DLRP to the transportation problem is basically different to the approach taken in the traditional VRP. The developed protocol is not an optimization algorithm for a static scenario, but an autonomous control algorithm designed for a continuous changing process [Rek08]. 


\section{ROUTING \& CLUSTERING}

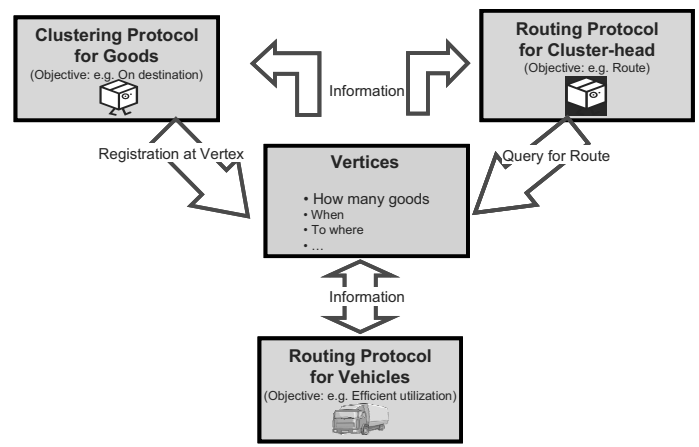

Figure 1: Cluster-based Distributed Logistics Routing Approach

In a logistics network, certain logistic entities may have common aims, e.g., several goods that are at the same location can have the same destination. In such a case, it can be reasonable to form communities of those entities and determine a leader with certain capabilities more than the other members like higher lifetime, later delivery date etc. The cluster-head acts as the information pool for its cluster members and can initiate as well as handle the negotiations within the cluster members and take decision on behalf of them depending on the responsibility or capability transferred to it.

As depicted in Figure, the approach of clustering is modelled and implemented in the agent-based framework PlaSMA along with the concept of DLRP. The idea behind this approach is, instead of individual goods starting the routing process, a cluster of goods is formed with respect to a common destination and the cluster-head initiates routing on behalf of all the other packages within the cluster. More of this work is presented in [5].

\section{ANALYTICAL FORMULATION}

\subsection{Routing Communication Overhead}

The total message count from one routing process is given by the following [3]:

$$
N_{\text {routing }}=4+\sum_{i=0}^{l} b^{i}+m+(2 n-1)(l+1)
$$

The routing starts with two queries to the associated vertex and the corresponding responses (i.e. 4 messages). These queries inform the package about some initial parameters 
that it needs for the routing. Then, the package sends a route request (RREQ, exactly one) to its associated vertex, which in turn adds some data to the request (available transport capacity, estimated handling times etc., depending on which parameters are used for route decisions) and forwards it to all neighbour vertices. Thus, it is multiplied by the vertex's branching factor, which states how many neighbours are available as recipients of the forwarded route request. This is continued until the request reaches the destination or its hop limit, $l . m$ route replies (RREP) are then sent back for each request that reaches the destination. On reception of the RREP, the package sends $n$ route announcements. Once, a final route has been selected, other $n-1$ routes are dis-announced.

So far, the average branching factor with a fixed value integer value was assumed. This may not be the case for all the scenarios. In this section we extend the formula to calculate the average branching factor depending on the scenario. After $i$ hop propagation of RREQ, the total number of route requests propagated is given by,

$$
R_{i}=b_{i}+b_{i}^{*} n_{i}
$$

where, $n_{i}=b_{i-1}+b_{i-1} * n_{i-1}$.

The variable $n$ represents the number of neighbours that have re-broadcasted the RREQ and $b_{i}$ represents the branching factor including all the $i$ hops over which the RREQ has propagated i.e., the number of branches coming out of the source over $i$ hops /number of nodes that are the source of the outgoing branches.

For example, for the case $i=1$,

$$
R_{1}=b_{1}+b_{1}^{*} n_{1}=b_{1} \quad a s, n_{1}=0
$$

For the case $i=2$,

For $i=n$,

$$
R_{2}=b_{2}+b_{2} * n_{2}=b_{2}+b_{2} * b_{1} \quad a s, n_{2}=b_{1}+b_{1} * n_{1}=b_{1}
$$

$$
\begin{aligned}
& R_{n}=b_{n}+b_{n} * n_{n}=b_{n}+b_{n} b_{n-1}+b_{n} b_{n-1} b_{n-2}+b_{n} b_{n-1} b_{n-2} b_{n-3}+\ldots \ldots .+b_{n} b_{n-1} \ldots b_{2} b_{1} \\
& \text { as } \quad n_{n}=b_{n-1}+b_{n-1} * n_{n-1} ; \quad n_{n-1}=b_{n-2}+b_{n-2} * n_{n-2} ; \ldots
\end{aligned}
$$

If all branching factors are the same i.e., $b_{n}=b_{n-1}=\ldots=b_{2}=b_{1}=b$ then,

$$
R_{n}=\sum_{i=1}^{n} b^{i}
$$




\subsection{Clustering Communication Overhead}

The clustering process starts by exchanging the registration request (RegReq) and Acknowledgement (RegAck) messages between the package and the associated vertex. These messages inform the associated vertex with the initial parameters it needs to start the clustering process such as the destination of the package etc. Once the package gets registered with the vertex, the associated vertex looks if there is already a cluster formed with the presently registered package destination and sends the cluster-head information (CHInfo) message of that cluster to the package. Then, the package registers with that cluster-head with the Cluster register request (CRegReq) message, and the cluster-head acknowledges with the cluster register acknowledge (CRegAck) message. In case that there is no cluster available for that destination the package itself becomes the cluster-head and the associated vertex sends a new cluster-head announcement message (CHAnn).

The total number of RegReq and the RegAck equals the number of packages $\left(N_{\text {packs }}\right)$. The total number of CHAnn equals the number of destinations $\left(N_{\text {dests }}\right)$ or number of clusters ( $N_{\text {clusters }}$ ). The total number of cluster-head information messages is $N_{\text {packs }}-N_{\text {clusters }}$. Thus, the total clustering traffic is given by

$$
\begin{aligned}
& \text { Total Clustering Volume }=5 N_{\text {packs }}-2 N_{\text {clusters }} \\
& \text { where } N_{\text {clusters }}=N_{\text {dests }} *\left\lceil\frac{N_{\text {packs }}}{N_{\text {dests }} * \text { clustersize }}\right\rceil .
\end{aligned}
$$

\subsection{Simulation Scenario}

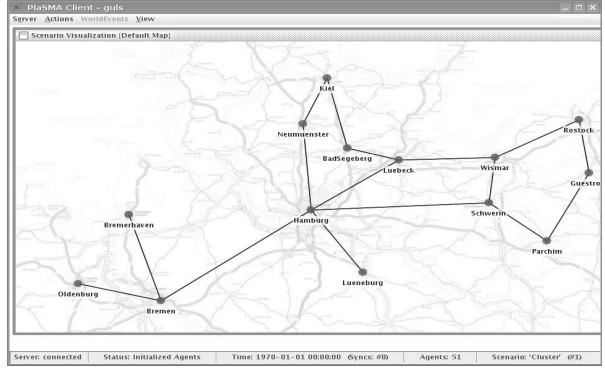

Figure 1a: Simulation Scenario - North Germany

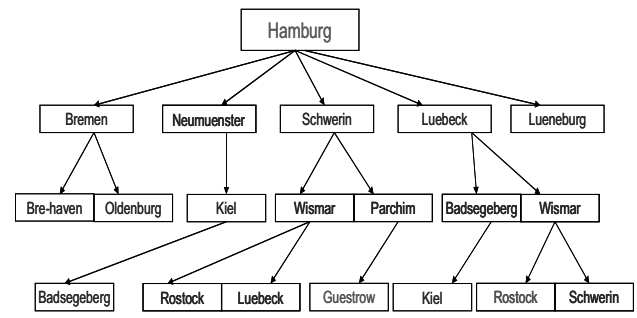

Figure 2b: Source-Hamburg and Destination-

Guestrow and Rostock 
The formulation can be validated with a realistic simulation scenario as seen in Figure 2a. In the simulation scenario considered, it is assumed having 3 different sources as Hamburg, Bremen and Guestrow with various destinations for each source. Various scenarios are analyzed with respect to different sources. For example, source Hamburg has two destinations Guestrow \& Rostock (refer Figure 2b), source Bremen has 5 destinations as Bremerhaven, Hamburg, Lueneburg, Kiel \& Badsegeberg and source Guestrow has a destination Luebeck.

Let us start with the case from the source Hamburg (Figure 2b), the number of route requests generated in this case will be $R_{1}=b_{1}+b_{1} * n_{1}=5$ where $n_{1}=0, b_{1}=5$. Coming to the second level of the scenario (from vertices: Bremen, Neumuenster, Schwerin, etc) the number of route request generated in this case is given by $R_{2}=b_{2}+b_{2} * n_{2}=12$ where, $n_{2}=5$ and $b_{2}=(5+2+1+2+2+0) /(1+5)=2$. Similarly, for third level of scenario (from vertices: Bremerhaven, Oldenburg, Kiel, Wismar, etc) the number of route requests $R_{3}=b_{3}+b_{3} * n_{3}=19$ where, $n_{3}=12$ (5 from the source node and 7 from the intermediate nodes) the average number of branching factor $b_{3}=.1 .4615$.

For the case with source Bremen, $R_{1}=b_{1}=3 ; R_{2}=7, b_{2}=1.75 ; R_{3}=12, b_{3}=1.5$ and for the case with source Guestrow, $R_{1}=b_{1}=2 ; R_{2}=4, b_{2}=1.33 ; \quad R_{3}=8, b_{3}=1.6$ respectively.

\subsection{Weighted Branching Factor}

In general, the weighted average of the branching factor is given by

$$
\mathrm{b}_{\mathrm{i}}^{\mathrm{w}}=\frac{\sum_{k} w^{k} b_{i}^{k}}{\sum_{k} w^{k}}
$$

For example, in case of the simulation scenario presented in the Figure 1, the total average branching factor is given as,

$$
\mathrm{b}_{3}^{\mathrm{w}}=\frac{w^{h} \mathrm{~b}_{3}^{\mathrm{h}}+w^{b} \mathrm{~b}_{3}^{\mathrm{b}}+w^{g} \mathrm{~b}_{3}^{\mathrm{g}}}{w^{h}+w^{b}+w^{g}}=\frac{2 * 1.4615+5 * 1.5+1 * 1,6}{2+5+1}=1.5208
$$

Where, $w$ represents the weight associated with each vertex (here assumed to be the number of destinations with respect to each source i.e. example, for source; Hamburg $-w^{h}=2$, Bremen $-w^{b}=5$, and Guestrow $-w^{g}=1$ ) and $b$ is the average branching factor for each source as calculated in the previous section. 
The weighted average of the neighbours' $n$ is given by,

$$
\mathrm{n}_{3}^{\mathrm{w}}=\frac{w^{h} \mathrm{n}_{3}^{\mathrm{h}}+w^{b} \mathrm{n}_{3}^{\mathrm{b}}+w^{g} \mathrm{n}_{3}^{\mathrm{g}}}{w^{h}+w^{b}+w^{g}}=\frac{2 * 12+5 * 7+1 * 4}{2+5+1}=7.875
$$

Therefore, the total or average number of route requests $R R E Q$ is given by,

$$
\mathrm{R}_{3}^{\mathrm{w}}=\left(\mathrm{b}_{3}^{\mathrm{w}}+\mathrm{b}_{3}^{\mathrm{w}} \mathrm{n}_{3}^{\mathrm{w}}\right) *\left(w^{h}+w^{b}+w^{g}\right)=106.7
$$

\section{RESULT}

For the simulation scenario of North Germany considered in Figure 2a, the corresponding curves for communication vs the number of packages is presented in Figure 3 and 4 respectively.

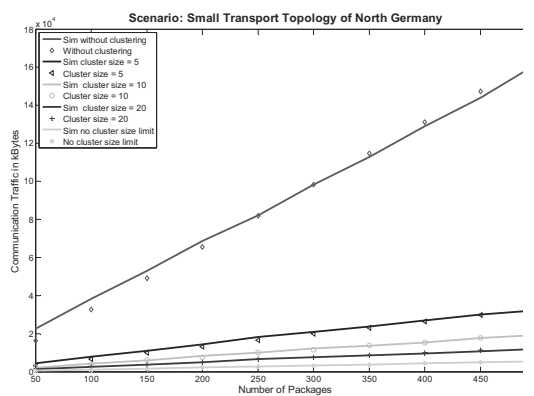

Figure 3: No. of packages vs Comm. traffic

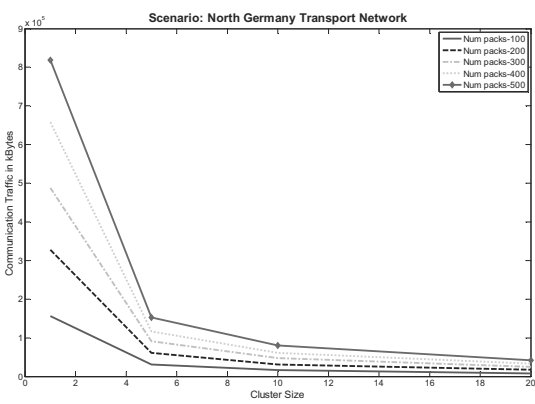

Figure 4: Cluster-size vs Comm. Traffic

As seen in the Figures 3 and 4 as the number of packages generated increases in the network the communication traffic also increases linearly with decrease in the cluster size. Similarly, with the increase in the cluster size, the communication traffic decreases as only the cluster-head does the communication on behalf of all other members in the cluster.

\section{CONCLUSION \& OUTLOOK}

This paper presents a analytical model for cluster-based routing appraoch in autonomous intelligent transportation network. In this approach as every entity is autonomous to act and react, the amount of communication is enormous. Thus, clustering can be seen as the effective 
technique to reduce the communication costs. The simulation results which were obtained in the software agent based simulation platform, PlaSMA, match with the analytical results. The future work would be dealing on the advantages of clustering approach in the negotiation aspects of the transportation domain. Eventually, what advantage and role can a cluster-head play in the negotiation process and how does the performance of the network increase with the clustering aspect integrated in the network would be studied.

\section{REFERENCES}

1. B. Scholz-Reiter, K. Windt, M. Freitag, Autonomous Logistic Processes - New Demands and First Approaches, $37^{\text {th }}$ CIRP Int. Sem. on Manufacturing Systems - CIRP ISMS '04, Budapest, pp. 357-362, 19 -21 May 2004.

2. M. Hülsmann, Prologue to Autonomous Cooperation- the Idea of Self-Organisation as its Basic Concepts, In Proc. Understanding Autonomous Cooperation and Control in Logistics, Springer-Verlag Berlin/Heidelberg pp 23-28

3. Singh.G, Wenning, B.-L. and Görg, C. : Efficient communication in autonomous logistic processes by application of cluster-based routing methods, In summer computer simulation conference (SCSC08), ADS track. Edinburgh, UK, 16-19 June: pp. 15-22

4. Reketsbrink, H., Makuschewitz, T., Scholz-Reiter, B. (2008). A distributed routing concept for vehicle routing problems, In Logistics Research Journal '08 Springer Verlag Berlin /Heidelberg pp. 45-52

5. Singh, G., Wenning, B. L., Singh, A., Görg, C.: Clustering in Autonomous Cooperating Logistic Processes, in: Research Report 2007/08, International Graduate School for Dynamics in Logistics, LogDynamics Research Report Vol 1/2008, page 48-51. 


\title{
TIME-BASED COMPETITION RELATED TO LOGISTICS: AN INTERNATIONAL STUDY OF FURNITURE COMPANIES
}

\author{
I. Tammela ${ }^{1}$ and A. G. Canen ${ }^{2}$ \\ ${ }^{1}$ Department of Science and Technology - Production Engineering \\ PURO/Fluminense Federal University \\ Recife St., Jardim Bela Vista, CEP:28890-000, Rio das Ostras, RJ, Brazil \\ ${ }^{2}$ Department of Production Engineering \\ COPPE/Federal University of Rio de Janeiro \\ P.O. Box 68507, CEP:21941-972, Rio de Janeiro, RJ, Brazil
}

\begin{abstract}
This paper presents research findings of a study that has involved furniture companies located in Brazil and Scandinavia. It analysed the time-based competition (TBC) relationships between logistics and multiculturalism and their impacts in the success of competitive strategies in culturally diverse markets and demands. It also discussed those issues as related to supply chain partners, analysing data from the study and their implications for the improvement of competitive market advantages.
\end{abstract}

\section{INTRODUCTION}

In a globalised world, organisations need to develop competitive strategies so as to ensure that products and services achieve the highest possible number of markets and countries. For the furniture companies, products and services must meet different demands in terms of design, innovation and technology.

In order for a company to sustain a competitive advantage, it must decide how to differentiate itself from competitors so as to add value to its products and services. According to Wilding and Newton [13], value is based on customers' perceptions. It is a mixture of tangible and intangible benefits, specific product features and also its image, reputation and responsiveness. For the mentioned authors, time is becoming increasingly important in the customers' perceptions of values. The agile competition demands that the processes that support creation, production and distribution of goods and services are centred on the 
customers' perceived value of products and time compression. Thus, organisations need to react faster to the constant market change, by introducing innovative products and services with quality and lower costs, according to customer's needs.

The primary goal of TBC, according to Willis and Jurkus [14]: "is to be able to reduce the time between the moment the customer expresses a need for a product and the moment the order is delivered to the customer's location or is put to use by the customer". Time reduction is successful inasmuch as the total cycle time in engineering, design, production, manufacturing, information, innovation, product, marketing and logistics is compressed in a manner to answer to the customers' needs and expectations, ensuring better products and services in a shorter time than that accomplished by the competitors.

Rich and Hines [8] point that time-based competitive strategies involve the development of a holistic approach to managing the internal and external supply chain for high performance in order to gain competitive advantage in the consumer market. Furniture companies are inserted in this competitive domain, forcing manufacturers to develop products and services compatible with their customer' demands. On the other hand, as presented by Vickery et al. [15], furniture industry holds a long delivery time and unreliable schedules.

Notwithstanding the above, in a globalised world, organisations deal with suppliers, partners and customers from different countries and cultures. In this sense, how can the furniture companies deliver their products and services in a shorter time with lower costs and better quality according to the customer' needs in a culturally diverse context of clients and partners? Cultural values, understandings, meanings and beliefs arguably influence decision making and competitive strategies of companies and managers (Canen and Tammela [4]) as well as play an important role on people's decision on products and services (Tammela et al. [10]). Different cultures have different assumptions about time and decision-making and organisational time-based strategies differ according to the perception of the companies' actors. Those perceptions also refer to the way they view their markets needs and their logistics strategies (Tammela et al. [10]).

This paper presents research findings on aspects of time-based competition, logistics and cultural diversity. It highlights the peculiarities of implementing TBC strategies by managers and organisations in culturally diverse contexts, in which furniture is geared towards different markets. Methodologically it can be considered a comparative case study, in which questionnaires to managers were applied to a sample of companies from Brazil and 
Scandinavian countries. European Union is the world leading in furniture commerce and Brazil is responsible for two thirds of the furniture production in Latin America (Brasil Moveis [2]). Brazil, Sweden and Denmark are the 20 world largest furniture producers (TMF [11]). The research presented here is part of a larger study that focuses on TBC strategies and multiculturalism in the furniture industry.

\section{TIME-BASED COMPETITION AND MULTICULTURALISM}

Time-based competition can be defined as a: "a strategy of customer responsiveness to a rapid new product introduction, together with competitive quality and cost. The essence of time-based competition involves compressing time in every phase of the product creation and delivery cycle" (Hum and Sim [7]).

Time reduction in every business aspects makes companies reduce the costs, improve the quality of their products and turn them closer to the market, therefore enhancing their profits, market shares and competitiveness. Time-based competitors have more conditions to respond to customers' demands because time compression in each phase (from the creation up to the product delivery) turns companies more integrated to market needs.

Time-based competition companies have several common factors such as: less total cycle time; less market response time; less time for new products development and introduction; less time between an order and product delivery; real time response to customer's needs (Stalk and Weber [9]); integration, suppliers partnership and customers proximity relation (Dröge et al. [5]); and efficient logistics (Hise [6], Zacharia and Mentzer [16]).

Globalization, international business, industrial location and mainly logistics play an important role in TBC competitive strategies as well multiculturalism as argued by Canen and Tammela [4]. Towill [12] showed that compressing time through supply chain greatly reduces the negative effect of uncertain demands, by increasing confidence in market forecasts, as provided by TBC competitive strategies.

On the other hand, multiculturalism has become a relevant issue for enterprise competitiveness strategies. For furniture companies, it is important to understand markets' cultural diversity in order to deliver products and services according to customers' needs in terms of design, quality, costs and delivery time.

According to Canen and Tammela [4], the competitive advantage is acquired insofar as a real integration among the parts exist. In many cases, the parts that have take place in business 
dealings are culturally distinct. The mentioned authors therefore stress the importance of multicultural sensitiveness in order for integration and trust to be fostered among the various partners within the business chain.

Tammela et al. [10] showed that Brazilian and Scandinavian furniture companies tend to establish strategies according to the needs of their markets and this reflects in the way they focus on time. The countries and companies involved in the previous research have different business strategies according to their different markets and customers. The factor of time also is perceived either as important or not, depending on their cultural views on the issue. Canen and Tammela [4] noticed that cultural dimensions are important to the comprehension of problems during business negotiation.

As mentioned before, logistics concepts lead to many implications for logistical management, such as the challenges to integrate and coordinate materials flow from a variety of suppliers, in general foreigners, located in many parts of the globe. Time-based companies can be considered as multicultural organizations since they deal with partners, customers and people from different countries and cultures (Canen and Canen [3]). Cultural factors may interfere on decision making and companies' strategies for competitiveness and market leadership. Developing a multicultural awareness turns companies more capable to predict and solve problems concerning peoples' integration and cultural misunderstandings. The relations between TBC strategies, logistics and cultural factors is the main purpose of this study which is based on a research involving furniture companies of different and culturally diverse countries.

\section{METHODOLOGY}

In this research only furniture manufacturing companies located in Brazil, Denmark, Finland, Norway and Sweden have been considered. The companies were named by furniture associations of each country. Brazilian companies were named by SEBRAE - a Brazilian Government body; Danish companies were suggested by the Institut for Afsætningsøkonomi; in the case of Finland, by the Association of Finnish Furniture and Joinery Industries; Norwegian's companies by the Norwegian Furniture Industry; and the Swedish by the Swedish Furniture Industry (TMF). The final sample consisted of 43 companies whose managers or CEOs agreed to answer to the interviews and to the questionnaire. 
The questionnaire was divided into four parts. The first was related to general information about the companies, such as size, number of employees, turnover, territory operation area, sales and factory units. The second was about time-based competition and a number of questions concerned the companies' strategies and vision of time. The third one referred to the companies' degree of understanding and awareness of multicultural aspects and cultural diversity and its importance to business competitiveness. The last part was composed of a list of open questions that were treated in the format of a semi-structured interview, focusing on strategy, planning, organisational success factors and their relations to TBC and multiculturalism.

Most of the companies' respondents were directors (30.2\%) and managers (27.9\%). The majority was classified as medium or large sized companies. However, concerning the employees number, most of them had from 10 to 49 employees (30.2\%) and from 100 to 499 employees (25.6\%). Concerning turnover, the companies declared more than US\$ 20 million $(32,6 \%)$ and from US\$ 0.5 million to US\$ 2.5 million (20.9\%).

More than $30 \%$ of companies have been in business for more than 50 years. Almost $50 \%$ of the companies sell furniture worldwide, $20 \%$ to Scandinavia and the rest only to Brazilian market. Those data seem to evidence that the majority of the companies presented in this research deal with diverse markets with different characteristics and cultures.

\subsection{Main Findings}

Descriptive statistics such as frequency and percentage as well statistic multivariate techniques such correlation and cluster analysis have been employed to analyze the collected data.

Correlation results indicated that there are significant correlations between TBC and cultural factors. Most of the time factors variables related to cultural variables are seen as related to local partnerships. In this analysis the TBC factors that were most interrelated were time and previous identification of clients' needs, as well expectations and planning clients' needs according to time $(0,877)$. Total cycle time reduction and a fast market introduction of products and services in the market were considered an essential point as well the need of integrated supply chain to ensure those strategies. Time to distribution and time to manufacturing were also strongly related (0.748). This implies that a lean, flexible and quality manufacturing is effective if products distribution logistics and supply chain management are 
integrated as well supply chain management, particularly in time sensitive markets, such as highlighted by Beesley [1] and Zacharia and Mentzer [16].

Among the cultural variables the most significant ones that were related were seeking for local partnerships as a way to improve the capacity of adaptation of different cultures and the use of customer's cultural aspects in communicating with them (0.827); and seeking for local partnerships as a way to improve the capacity of adaptation of different cultures and considering the customer's cultural context as the origin of meanings to products/services $(0.822)$.

Descriptive analysis revealed similarity to the companies' answers in grade of importance for the following variables: time to the orders transmission; time in tracing the executed service; considering customers from different countries cultural aspects to adapt or develop product/service; and considering regional/local sub-cultures in products/services development. In some aspects Danish companies had different answers according to time and cultural aspects to the others countries as pointed out by Tammela et al [10]. Despite of Scandinavians do not perceive cultural differences among them, Danish companies were the ones which most distanced themselves from the other Scandinavian companies. Also some of Brazilian companies present different answers concerning those issues, ranking from "not important" to "very important". Actually it was not possible to establish a pattern of answer among the countries, even among Scandinavians. The same can be noticed concerning their size, annual turnover and territory occupation area. It was not possible to establish a pattern of importance of time and cultural aspects among companies and countries.

Cluster analysis indicates that groups' formation were not uniform among companies. Companies from diverse sizes and countries determined different importance weight concerned to time and cultural factors. Large exporting companies considered time to the company and customer from very to less important. The same was noticed for cultural factors. For logistics and TBC strategies this shows the importance of understanding different cultures and demands as well their perception of time to establish real competitive strategies according various demands and suppliers. 


\section{CONCLUSIONS}

The main purpose of this paper was to show TBC strategies and their relation to cultural aspects and logistics according to different demands and time perceptions, as gauged from research involving furniture companies in Brazil and Scandinavia.

In research data analysis a correlation was observed between TBC and cultural aspects variables. This indicates a relation between companies' perceptions concerning strategies to reach different markets and the management of production, innovation, flexibility, agility and supply chain management according culturally to diverse markets values.

In Cluster analysis it was noticed that companies that perceived time as important to their strategies towards the customers tend to focus on manufacturing, raw material acquisition, stock control, innovation and supply chain management. However, for the companies that perceived time as very important, strategies tend to consider all the activities, mainly logistics as relevant to $\mathrm{TBC}$ strategies.

This implies that in the companies' decision making and in their establishment of competitive strategies, cultural diversity must be considered as a central factor for time-based companies. TBC allied to logistics and supply chain strategies may turn into a successful strategy if companies become increasingly aware of market real needs and expectations as well as the weight of cultural contexts in shaping those.

Also it was noticed that, seeking local partnerships had a strong correlation to TBC factors, which evidences the relevance of logistics partners and third parties (such as companies and institutes) to improve furniture companies' competitiveness and market share. This is valid not only concerning furniture companies, but also for all in the context of a globalised commerce.

\section{REFERENCES}

1. A. Beesley, Time Compression in the Supply Chain, Logistics Information Management, Vol. 10, No. 6, pp. 300-305, 1997.

2. Brasil Móveis, Relatório Setorial da Indústria de Móveis no Brasil. IN: Instituto de Estudos e Marketing Industrial - IEMI, São Paulo, SP, 2006.

3. A. G. Canen, A. Canen, Organizações Multiculturais: a Logística na Corporação Globalizada. 1 ed. Rio de Janeiro: Editora Ciência Moderna Ltda, 2005. 
4. A. G. Canen, I. Tammela, Competitiveness and the Cases of Brazil and Scandinavian Countries: Some Multicultural Concerns, Proceedings of the $8^{\text {th }}$ International Conference on Industrial Logistics, Kaunas, Lithuania, 26-29 June, pp. 37-46, 2006.

5. C. L. M. Dröge, J. Jayamaram, S. K. Vickery, The effects of internal versus external integration practices on time-based performance and overall firm performance, Journal of Operations Management, Vol. 22, pp. 557-573, 2004.

6. R. T. Hise, The Implications of Time-Based Competition on International Logistics Strategies, Business Horizons, September-October, pp. 39-45, 1995.

7. S. H. HUM, H. H. SIM, Time-Based Competition: Literature Review and Implications for Modeling, International Journal of Operations and Production Management, Vol. 16, No. 1, pp. 75-90, 1996.

8. N. Rich, P. Hines, Supply chain management and time-based competition: the role of supplier association, International Journal of Physical Distribution \& Logistics Management, Vol. 27 No. 3/4, pp 210-225, 1997.

9. G. Stalk Jr, A. M. Webber, Japan's Dark Side of Time, Harvard Business Review, JulyAugust, pp. 93-102, 1993.

10. I. Tammela, A. G. Canen, P. Helo, Time-Based Competition and Multiculturalism: A comparative approach to the Brazilian, Danish and Finnish furniture industries, Management Decision, Vol. 46, No 3, pp 349-364, 2008.

11. TMF - Swedish Federation of Wood and Furniture Industry, 2005, The World Furniture Production Industry - $\quad$ Trade - Market, disponível em: http://www.tmf.se/LitiumDokument20/GetDocument.asp?archive=1\&directory=672\&docum ent $=3124$, (accessed 30 January 2006).

12. D. R. Towill, Time compression and supply chain management - a guided tour, Supply chain Management, Vol 1, No.1, pp 15-27, 1996.

13. R.D. Wilding, J. M. Newton, Enabling time-based strategies through logistics - using time to competitive advantage, Logistics Information Management, Vol. 9 No. 1, pp 32-38, 1996.

14. T. H. Willis, A. F. Jurkus, Product Development: An Essential Ingredient of Time-Based Competition, Review of Business, Spring 2001, pp. 22-27, 2001.

15. S. K. Vickery, C. L. M. Dröge, J. M. Yeomans, Time-Based Competition in the Furniture Industry, Production and Inventory Management Journal, Fourth Quarter, Vol. 36, No. 4, pp. 14-21, 1995. 
Tammela \& Canen

16. Z. G. Zacharia, J. T. Mentzer, Logistics Salience in a Changing Environment, Journal of Business Logistics, Vol. 25, No. 1, pp. 187-194, 2004. 


\title{
INKJET-PRINTED RFID'S ON PAPER: A QUANTUM LEAP IN INDUSTRIAL LOGISTICS?
}

\author{
M.M.Tentzeris \\ School of ECE \\ Georgia Tech \\ Atlanta, GA 30332-250, U.S.A.
}

\begin{abstract}
This paper introduces for the first time all different components required to form a complete wireless RFID-enabled sensor network infrastructure. The presented material is a review of ATHENA group's major reported milestones in this area. First, we highlight the benefits of using paper as a suitable low-cost platform for "green” RFID's and wireless sensing applications, while giving details about the inkjet printing technology used. Next, we discuss the first integration of ICs and sensors on paper in a 2-D RFID-enabled wireless sensor module configuration providing guidelines for an extension to potential 3-D multilayer modules. Finally, the paper concludes by discussing the details for establishing for the first time an asynchronous wireless link between the aforementioned RFID tag and a widely used commercial wireless sensor network (WSN) mote using a simplified protocol, a step that could potentially be used to truly "ubiquitous" sensor networks minimizing the cost of required reader infrastructure and linking RFIDs to the mature level of wireless sensor networks. This approach could potentially revolutionize industrial logistics in the future.
\end{abstract}

\section{INTRODUCTION}

RFID is an emerging and disruptive compact wireless technology for the identification of objects, and is considered as an eminent candidate for the realization of completely ubiquitous ad-hoc wireless networks. This technology has several benefits over the conventional ways of identification, such as faster data transfer, higher read range, the ability of RFID tags to be embedded within objects, the ability to read large amount of tags simultaneously and no requirements of line of sight [1]. Already, a large list of applications is currently utilizing 
RFIDs including supply chain and logistics, pharmaceutical e-pedigree, access control, parcel and document tracking, real-time location systems, automatic payment, vehicle identification and livestock tracking.

Compared with the lower-frequency (LF/HF) tags already suffering from limited read range (1-2 feet), UHF RFID tags see the widest use due to their higher read range (over 20 feet) and higher data transfer rate [2]. The major challenges that currently hinder RFID practical implementation are: (1) cost, that has to be extremely low, especially for the RFID tags, in order to allow for mass-production amounts, (2) reliability, especially concerning tags/reader hardware and middleware, (3) regulatory situation, meaning that tags have to abide to a certain global regulatory set of requirements, such as Gen2 protocols defined by the EPC Global regulatory unit [3] and (4) environmentally-friendly conformal materials, that could allow for the implementation of "green" and "rugged" RFID solutions. Recently, there have been research efforts reporting deployment of RFIDs and sensors on glass, flexible and polymer substrates [4]-[7], mostly utilizing screen-printing metallization mechanisms, but still the cost and the complexity of these modules is far from that required for a large-scale implementation of this technology, especially for sensing and cognitive intelligence applications.

\section{PAPER: The cheapest substrate + INKJET PRINTING: The cheapest fabrication}

This first "green" ultra-low-cost organic substrate examined, on which the RFID tag circuitry and antenna were printed, is paper. There are many aspects of paper that make it an excellent candidate for an extremely low-cost substrate for RFID and other RF applications. First of all, the high demand and the mass production of paper make it the cheapest and most available material ever made. From a manufacturing point of view, paper is well suited for reel-to-reel processing thus mass fabricating RFID inlays on paper becomes more feasible. Furthermore, paper has low surface profile and, with appropriate coating, is suitable for fast printing processes such as direct write methodologies instead of the traditional metal etching techniques. As described in section III, a fast process, like inkjet printing, can be used efficiently to print electronics on/in paper substrates. In addition, paper can be made hydrophobic, and/or fire-retardant by adding certain textiles to it, which easily resolve any moisture absorbing issues that fiber-based materials suffer from. Last, but not least, paper is one of the most environmentally-friendly materials. Its high biodegradability, with respect to other ceramic substrates such as FR-4, allows it to turn into organic matter in land-fills in only 
a few months.

However, due to the wide availability of different types of paper varying in density, coating, thickness, texture, and implicitly, dielectric properties, dielectric RF characterization of paper substrates becomes an essential step before any RF “on-paper" designs. The knowledge of the dielectric properties such as dielectric constant $\left(\varepsilon_{\mathrm{r}}\right)$ and loss tangent $\left(\tan _{\delta}\right)$ become necessary for the design of any high frequency structure such as RFID antennas on the paper substrate and more importantly if it is to be embedded inside the substrate. Precise methods for highfrequency dielectric characterization include microstrip ring resonators, parallel plate resonators, and cavity resonators. The electrical characterization of paper has already been performed in [2] and results have shown the feasibility of the use of paper in the UHF and RF frequencies.

Unlike etching which is a subtractive method by removing unwanted metal from the substrate surface, inkjet printing jets the single ink droplet from the nozzle to the desired position, therefore, no waste is created, resulting in an economical fabrication solution. After the silver nano-particle droplet is driven through the nozzle, it is necessary to follow by the sintering process in order to remove excess solvent and to remove material impurities from the depositions. Another benefit provided by the sintering process is the increase in the bond of the deposition with the paper substrate. The conductivity of the conductive ink varies from $0.4 \sim 2.5 \times 10^{7}$ Siemens $/ \mathrm{m}$ depending on the curing temperature and duration time. At lower temperature, larger gaps exist between the particles, resulting in a poor connection. When the temperature is increased, the particles begin to expand and gaps start to diminish. That guarantees a virtually continuous metal conductor, providing a good percolation channel for the conduction electrons to flow.

The presented RFID-enabled wireless sensor module prototype using a dipole antenna was printed on a 2-D (single layer) photo-paper module. The overall dimensions of the structure are: $9.5 \times 6 \mathrm{~cm}$ and is shown in Fig. 1. The fabrication and assembly process is outlined in this section. In particular, the antenna and the circuit layout were printed and cured on paper using silver ink and the complete wireless sensor system comprising the TSSOP packaged integrated circuit (IC), including the MCU and the transmitter, its discrete passive components including a crystal oscillator, the TC1047 temperature sensor, and a Li-ion cell for "stand-alone" autonomous operation were assembled on it. The cost is below $\$ 1$, the range is above $300 \mathrm{~m}$ and the temperature accuracy is better than $0.2 \mathrm{C}$. 


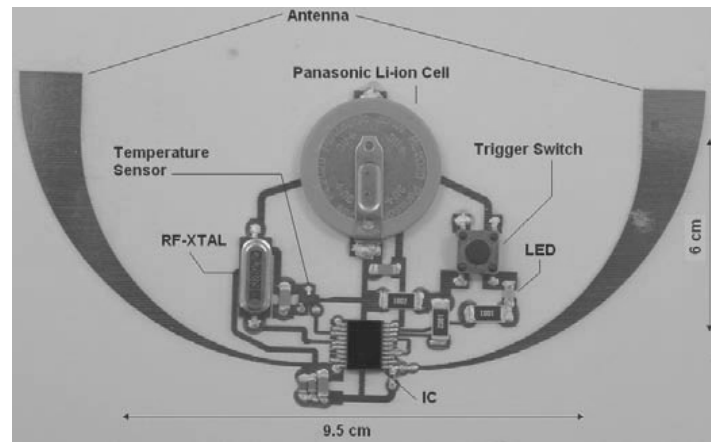

Fig.1 RFID-enabled wireless sensor transmitter using inkjet-printing on paper

\section{IMPACT ON LOGISTICS}

The use of flexible manufacturing stations undeniably requires the unique identification of the respective workpiece: after all, the machine must perform a program that is individualized for every workpiece. The theoretical possibility of using a computer to predict each good's movement is hardly practically realizable: the risk of possible deviations is too high, and the data technical effort too complex. Various identification systems are being applied in practice. In the simplest of cases, the product is given a process slip to take along, which contains a record of the manufacturing program. The employees will then set the machinery to the respective product. Obviously this method is not particularly mature. Apart from time consuming processing, a further problem is the high error risk. Incorrect input or wrong machine settings can lead to considerable costs and delays. Automatic identification systems should, therefore, be preferred. Although a process slip can also be used in this case, the product will only be identified via the barcode. The relevant data are called up from a database based on the read identification number. The advantage is in the prevention of input errors. A production order is created in the database at the production start. The identification number is printed on the process slip, which takes the product through production. The identification number is read out at every station and the machine set according to the specifications in the IT systems. However, this organization is also not efficient as the process slips are recorded manually, although this does seem completely sufficient for some goods that still require a large number of manual process steps, for example the assembly of personal computers, which cannot be fully automated. 
If the automated processing of the product is feasible, its identification should also take place automatically. 2D codes and the respective camera systems should be selected. In contrast to barcodes, the 2D codes can also be attached to the workpiece itself, for example with a laser. This not only permits identification in production but also during the entire life cycle - an important element for product tracking. This is realized by connecting the code readers directly to the programmable logic controllers, which monitor the production flow. If a workpiece is routed via suitable transport technology, the reader will initially recognize the coding and provides the PLC with the read number. This in turn sends the number of the IT system in the background and receives the information on the manufacturing program of this workpiece. Then, it sends a response to the database to note the changed workpiece status.

RFID systems could replace $2 \mathrm{D}$ codes as an alternative. The radio technology is insensitive to dirt of any kind. This makes it interesting for applications for which rough environmental conditions are unavoidable. One example would be paint robots and dips as they are applied in automobile manufacture. If the chassis is treated with atomized spray or color dipped, visual codes can no longer be recognized. An RFID transponder on the other hand will also function if they are covered in paint. The respective casing can provide heat resistant packaging for the transponders, which also allows their use in baking ovens after painting. In this way the transponder can accompany the chassis nearly through the entire production process.

Apart from insensitivity to environmental influence, a second advantage of RFID as opposed to visual codes is the possibility of rewriting the data carriers: once printed, a $2 \mathrm{D}$ code cannot be changed. Together with the high memory capacity of RFID transponders (up to 32 Kbytes), remote automation architectures can be realized, which clearly reduce the effort for local data maintenance. The concept (Fig. 2): An RFID transponder with a large memory is attached to each workpiece (or at the workpiece carrier) and stores all the required production data such as material list, production instructions, testing specifications, etc. These data are queried from the production control system at the start of a production line and programmed on the transponder. PLC controllers at the individual manufacturing stations read these data directly from RFID readers and use them to control the production step. Ideally the background systems need not be queried. After the production step is completed, the PLC can store the status and quality data on the RFID transponder before it is transported to the next station with the workpiece. Such a concept provides considerable advantages: the individual 
stations can perform their manufacturing step autonomously. Central planning and control is only required at the start of the manufacturing line, when the transponders are initialized. The complexity in the automation systems and in the engineering of such factors, therefore, decreases. Reducing complexity is equivalent to decreasing the susceptibility to failure for the entire plant. Small production modules are created instead of a monolithically organized block, and can be easily operated, maintained, optimized, or exchanged. In addition, a ubiquitous network of RFID-enabled sensors would provide a very accurate tracking/item positioning means even in rugged industrial environments, while providing real-time information on critical (temperature, pressure) industrial parameters.

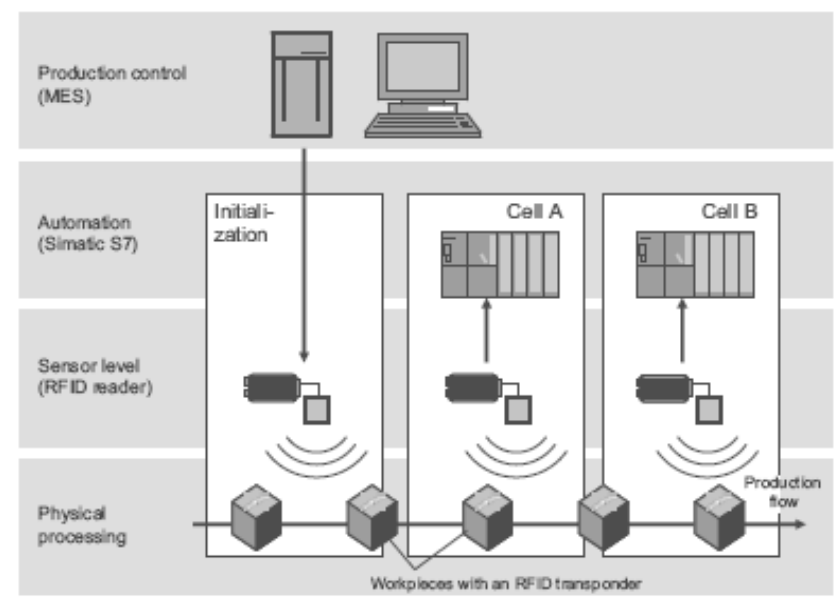

Fig.2 Remote production control with RFID's

The physical material flow of raw materials, components, partial systems, or finished products in production logistics is always offset by a respective information flow. The current information on the order, as well as the condition and quality of the individual object must be as promptly available as much as possible. Efficient material flow control, therefore, requires the extensive transparency of the working process in the production related logistics of material and data. RFID technology enables moved objects to be supplied with information and to link the material flow directly to the information flow. The use of RFID transponders on transport aids such as boxes, pallets, and pallet cages or on the material itself enables the real-time recording of information during transport, whereby the RFID transponders assume the identification of the objects as well as the remote and mobile data storage of further 
information such as order data, process, and quality data. The expected area-wide application of RFID in the cross-corporate information and material flows and supply chains will also lead to optimum and efficient production logistics.

The RFID supported logistics processes would go beyond the internal production plant and involve suppliers and customers. Together with the transport, the goods equipped with RFID transponders are automatically recorded during unloading from the truck. The information is reconciled with the orders and the supplier's delivery note. Erroneous or incomplete deliveries are recognized immediately. The internal transport information is then stored in the RFID transponders. The inward stock movement is automatically read at the storage points. The parts are rerecorded at stock removal and specified with transport information. The associated booking of goods takes place automatically.

It has to be noted that the automatic or manual identification of industrial assets and containers serves for the simplification of stocktaking processes. If the process chain is structured consistently, so that all the movements of the asset/container can be captured, continuous stocktaking can be performed. This means that a current image with all the information about the asset/containers can be retrieved within the process chain. In addition, the task of continuous tracking can be accomplished. The re-writable property of the RFID transponder is used in active container controlling to save the target address and other cyclespecific data on a per container basis. Quick and effective control of material flows can be achieved with the data directly on the container.

It is not only necessary to know the contents for the sequence-exact supply of containers. Moreover, there are applications where more detailed information regarding the load must be available at any time. For instance, in the foodstuff industry, information regarding expiration dates or production batches can be saved directly on the container. Here too - based on information regarding the product - focused steps and measures for further processing are initiated (e.g. application of the FIFO principle for products with a limited shelf life). Further central databases can be used via cross references in order to provide a comprehensive data record for the container or product. The container/asset management system promises high benefit especially in case of maintenance-intensive RTIs. For instance, it must be possible for all participants within the supply chain to have an overview of whether the relevant container is available for further utilization, or whether it must be repaired. Through the use of low-cost 
inkjet-printed RFID's, distributed validity and availability of container condition information enables the perfect planning and controlling of service-related actions.

\section{CONCLUSIONS}

In this paper, the first ever paper-based sensor-enabled RFID tag that can communicate with Wireless Sensor Networks for ultra-enhanced ranges is presented. The complete process, including the system and antenna design, circuit layout, printing methodology and assembly techniques, for the fabrication of this tag was outlined. This RFID could, therefore, set the foundation of ubiquitous ultra-low-cost RFID networks offering truly cognitive intelligence with an additional emphasis on "green" approaches, as well as easy "on-the-fly" deployment in "rugged" environments of the industrial logistics's future generations.

\section{References}

[1] K. Finkenzeller, RFID Handbook, 2nd ed., Wiley, 2004.

[2] L. Yang, A. Rida, R. Vyas, M. M. Tentzeris, "RFID Tag and RF Structures on a Paper Substrate Using Inkjet-Printing Technology," Microwave Theory and Techniques, IEEE Transactions on Volume 55, Issue 12, Part 2, Dec. 2007 Page(s):2894 - 2901

[3] A. Rida, L. Yang, and M. M. Tentzeris, "Design and characterization of novel paper-based inkjet-printed UHF antennas for RFID and sensing applications" Procs. of the 2007 IEEEAPS Symposium, pp2749-2752, Honolulu, HI, July 2007

[4] L. Yang, A. Rida, T. Wu, S. Basat, and M.M. Tentzeris, "Integration of sensors and inkjet-printed RFID tags on paper-based substrates for UHF "Cognitive Intelligence" applications" IEEE Antennas and Propagation International Symposium, 9-15 June 2007 Page(s): $1193-1196$

[5] A. Rida, R. Vyas, T. Wu; R.L. Li, and M.M. Tentzeris, "Development and Implementation of Novel UHF Paper-Based RFID Designs for Anticounterfeiting and Security Applications" IEEE International Workshop on Anti-counterfeiting, Security, Identification, 16-18 April 2007 Page(s):52 - 56

[6] L. Yang, A. Rida, J. Li, and M.M. Tentzeris, "Antenna Advancement Techniques and Integration of RFID Electronics on Organic Substrates for UHF RFID Applications in Automotive Sensing and Vehicle Security" IEEE Vehicular Technology Conference, Sept. 30 2007-Oct. 32007 Page(s):2040 - 2041

[7] R. Vyas, A. Rida, L. Yang, M.M Tentzeris, "Design, Integration and Characterization of a Novel Paper Based Wireless Sensor Module", IEEE International Microwave Symposium, June, 2008. 


\title{
COMPUTER-AIDED TOOLS IMPACT ON EQUIPMENT EFFECTIVENESS
}

\author{
V. Senkus ${ }^{1}$ and I. Senkuviene ${ }^{2}$ \\ ${ }^{1}$ Stevila UAB, Mokolai, LT-68460 Marijampole, Lithuania \\ ${ }^{2}$ Kaunas University of Technology, \\ Faculty of Mechanical Engineering and Mechatronics, \\ Kestucio 27-318, LT-44312 Kaunas, Lithuania
}

\begin{abstract}
The article analyses technological and organizational factors affecting the effectiveness of equipment. It brings into focus organizational factors, such as reporting on factual production figures and machinery downtime, and the speed of downtime elimination. The article presents a conceptual operation scheme of a computer-aided module for reporting visual factual production data. It analyses the impact of such module on the effectiveness of equipment at a mechanical tooling company.
\end{abstract}

\section{INTRODUCTION}

A modern mechanical tooling company usually employs CNC equipment for a variety of applications. Rocketing technological capabilities and advancing qualitative parameters enable to satisfy the growing requirements of the customers, to reduce the production time, the cost price, and to strengthen the position of the business in a competitive environment. However equipment requires sizable investments. Thus their efficient use is currently becoming increasingly important.

The effectiveness of equipment is greatly affected by organizational factors, including reporting on factual equipment workloads and direct information to each employee on the scheduled and completed work. Since idle time has a negative impact on the effectiveness of equipment, overt and timely information on downtime is also an integral part of an optimal production process.

The key objective of the research aimed at developing an efficient computer-aided tool for visual reporting of factual production data and analyzing the impact of such tool on the effectiveness of equipment at a mechanical tooling company. 


\section{COMPUTER-AIDED TOOLS IMPACT ON EQUIPMENT EFFECTIVENESS}

\subsection{Analysis of factors affecting the effectiveness of equipment}

The effectiveness of equipment can be defined as the ratio of the estimated result to the actual result, expressed in percentage (Oakland, [1]). The equipment effectiveness index reveals whether the company/division has worked the planned number of hours.

Typically, both estimated effectiveness and actual effectiveness are affected by technological and organizational factors:

$$
\mathrm{EE}=\mathrm{f}(\mathrm{Ft}, \mathrm{Fo})
$$

EE - equipment effectiveness;

$\mathrm{Ft}$ - technological factors;

Fo - organizational factors.

Technological and organizational factors affecting the effectiveness usually include:

Ft: equipment type, production technology, types of instruments, cutting modes, processed material, technological downtime, and speed of downtime elimination;

Fo: planning, types of tooled parts, workload volumes (numbers of orders, numbers of ordered parts, preparation and tooling time), production lot sizes, planning of production equipment, staff qualifications, organizational downtime, speed of eliminating organizational downtime, and data visualization.

The dependency of the effectiveness on those factors can be described using mathematical functions as well as computer-aided mathematical methods of optimization, statistics or artificial intellect (Jacobs and Holger, [2]). Still over and above those scientific effectiveness optimization methods, methods based on the insight and practical experience of engineers, foremen, and workers are also taken into consideration.

The analysis of the equipment effectiveness at a mechanical tooling company looked into the impact of overt reporting on the actual equipment workloads and idle time on the effectiveness index. The analyzed equipment groups included: small CNC machines (1 unit), medium $\mathrm{CNC}$ machines (4 units), large CNC machines (2 units), $\mathrm{C}$-axis CNC machines (2 units), $\mathrm{C}$-axis and $\mathrm{Y}$-axis $\mathrm{CNC}$ machines (1 unit), and $\mathrm{C}$-axis $\mathrm{CNC}$ robot system.

Figure 1 provides a comparison of the workload estimated for 2008 in accordance with the then orders and the actual workloads of the analyzed equipment. The estimated workloads do 
not guarantee an equivalent result of the factual equipment workloads: the actual order processing time may be longer or shorter than estimated. In its operation, an industrial company is always seeking the actual order processing time to be in the region of the scheduled timeframe. That is highly important due to several reasons, e.g. when the labor cost price of a product is calculated, the estimated working time is always taken into account and included into the product price. If the actual production time exceeds the estimated time, the actual cost price of the item increases, whereas a shorter production time results in a lower cost price. Significant fluctuations of the actual equipment workloads show that either the estimated values should be revised or the actual workloads should be reduced. An increase in the actual cost price brings about losses to the enterprise, while a decrease causes imbalance in the production planning processes whereas in the future they may lead to a fall in customer trust and numbers resulting from a too high estimated price (Wall, [3]).

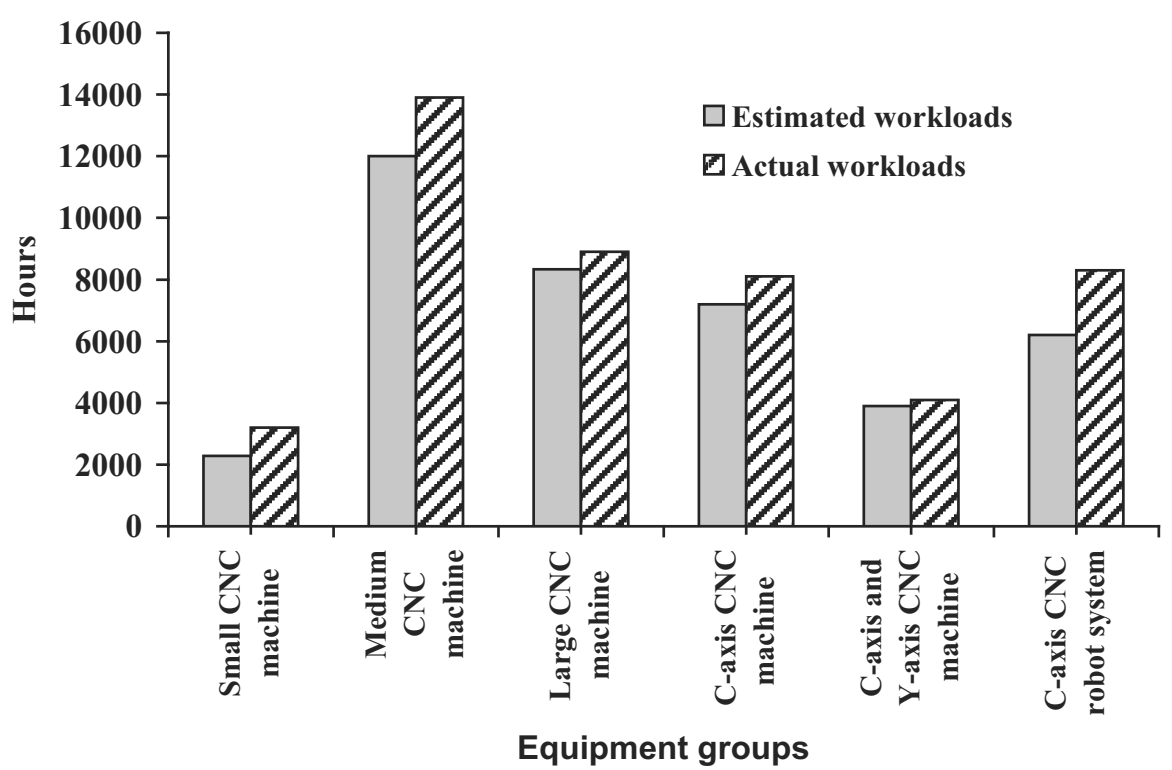

Fig. 1: Comparison of the equipment workload estimated for 2008 in accordance with the then orders and the actual workloads of the analyzed equipment (Source: Stevila UAB internal data) 
The equipment effectiveness is seriously affected by idle time. In production companies idle time is mainly caused by equipment breakdowns. However the work of equipment can also encounter other types of disruption, e.g. a failure to gear the equipment to process the order (lacking tool, material, documentation, and control program), inadequate qualification of the operator, rework of faulty products, etc. Figure 2 shows the aforementioned types of equipment downtimes and their average duration per month.

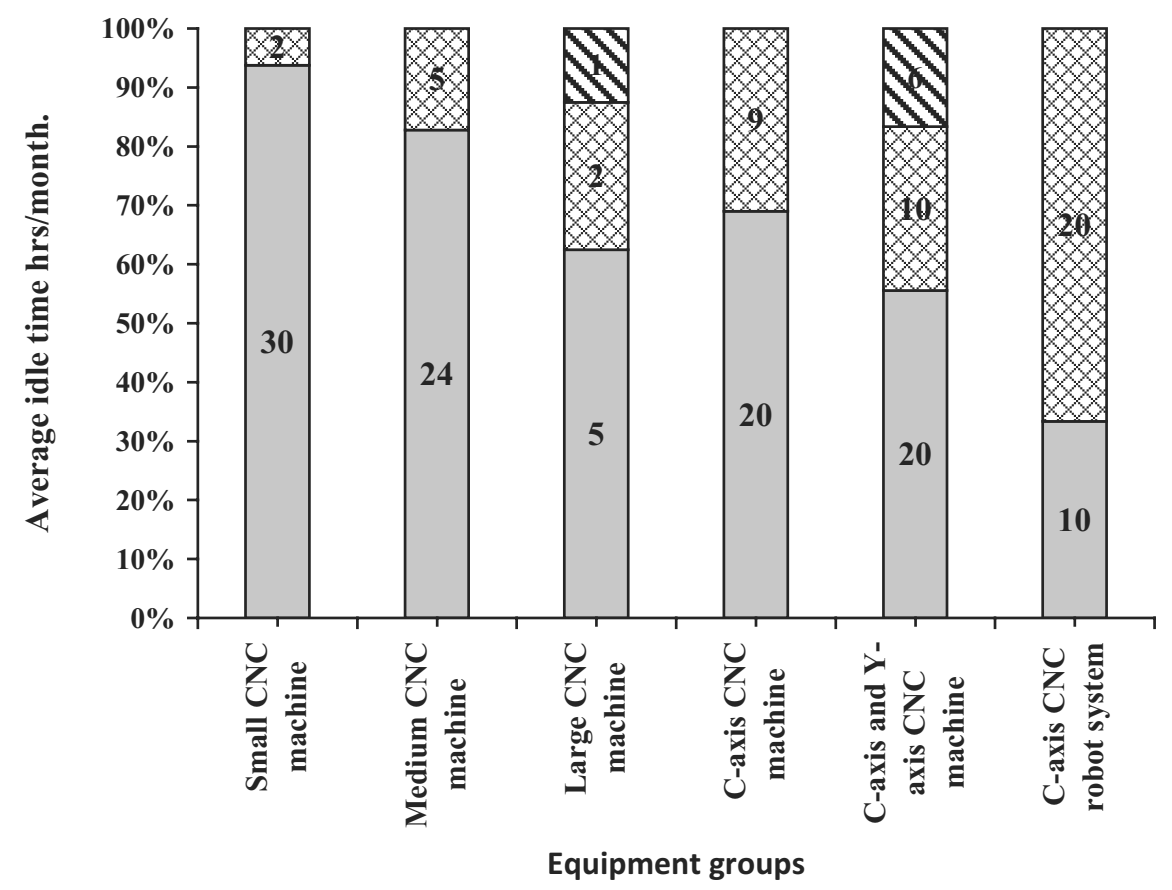

$\square$ Breakdowns $\otimes$ Lacking techn.documentation $\triangle$ Other reasons

Fig. 2: Equipment downtime types and their average duration hours/month. (Source:

Stevila UAB internal data for the last 6 months of 2008).

The most common cause of the idle time of the equipment covered by the research was found to be technological breakdowns ( $60 \%$ of total down time). The second most prevalent reason (35\%) is lacking technological documentation (flowcharts, CNC software). Lacking tools, materials, and rework of faulty items were attributed to other types of idle time (5\%). 
The speediness of fixing breakdowns is affected by technological and organizational capacities: early reporting on breakdown, type of the defective parts of the equipment and their delivery term, early arrival of technical staff and their qualification. At the analyzed enterprise, the occurrence of the second most common type of idle time, i.e. lacking flowcharts and CNC software, was caused exclusively by organizational reasons: staff negligence, faulty business planning, bigger numbers of orders, and shorter terms.

To reduce idle time, it was elected to visualize downtime types, since industrial practice shows that visual information on idle time, manufacturing processes, and equipment efficiency facilitate speedy control of the processes and enable to achieve better effectiveness rates. To ensure speedy elimination of breakdowns and technological documentation, material or tool deficiency, the research suggested to visualize the downtime types as well as to develop a computer-aided tool of SMS messaging to the executives.

Visual information can be valuable only when it is provided there and then. Therefore, in order to implement production process and downtime visualization, the research focused on computer-aided methods and tools.

\subsection{ERP system solutions: impact on the equipment effectiveness index}

The research aimed at developing a computer-aided informative model for providing visibility of actual production process data. The main objectives of the computer-aided tool included:

1. To provide a list of equipment at each company unit;

2. To specify the actual condition of each equipment;

3. To display equipment effectiveness indexes from the beginning of the current month;

4. To specify the conformance of the estimated process completion time to the actual time (shortfall/ remainder);

5. To ensure express communication of information on the downtown reasons to the managing staff.

The conceptual scheme of the module is presented in Fig. 3. 


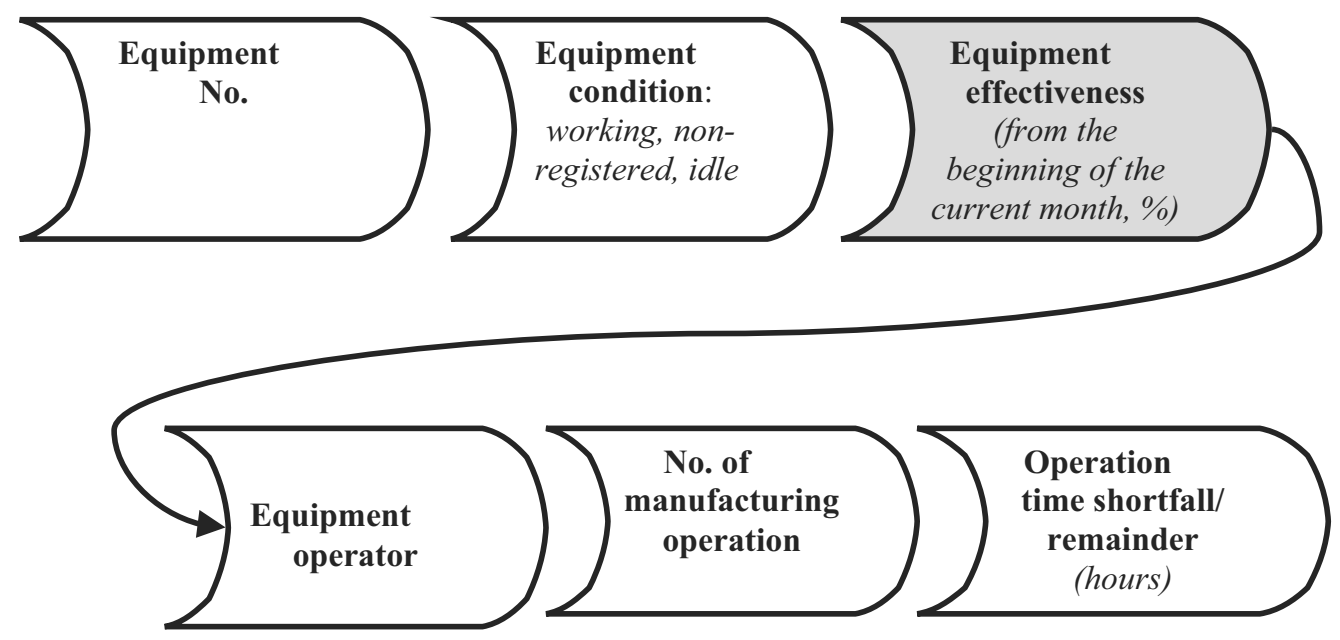

Fig. 3: Conceptual scheme of the visual computer-aided presentation of the equipment effectiveness and actual data

Based on the mechanism of the module, the key data on the equipment completed manufacturing operations, and quantities of produced quality and defective parts shall be registered by the equipment operators using hardware and bar codes provided in the documentation. The screens installed in the shops of each unit display some of the data generated at the time of the registration and further calculations, namely: equipment No, condition (working, idle, registered downtime, downtime duration), equipment performance, equipment operator, No of manufacturing operation, difference between the estimated and actual time of the operation (shortfall/ remainder). Once the downtime is registered, the causes are automatically communicated to the management staff by SMS. The module took half a year to develop, test, and adapt, January through June 2007. Fig. 4 shows documentation and hardware used during the research.

The comparison of the data for the first half 2008 and the data for the same period 2007 conducted by the research revealed an increase in plant and equipment performance at the mechanical tooling company. The analysis embraced two machines with similar estimated workloads, operator qualifications, and other factors, which are likely to affect the equipment performance, over the analyzed periods. In the first half of 2008, the performance of the 
machine group with $\mathrm{C}$-axis showed an increase of $30 \%$ as compared to the performance during the same period in 2007, while the performance of machines with $\mathrm{C}$-axis and Y-axis rose by $35 \%$.

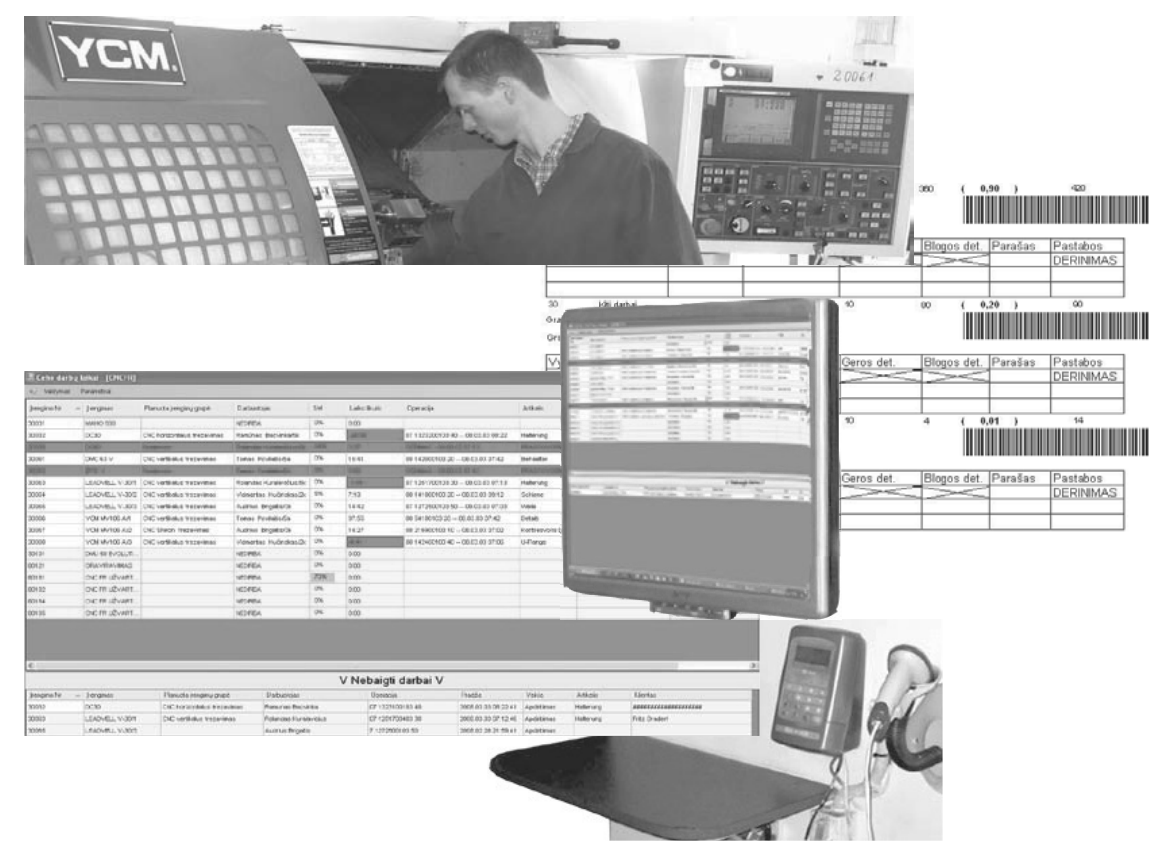

Fig. 4: Documentation and hardware used during the research

\section{CONCLUSIONS}

1. The effectiveness of equipment is affected by technological and organizational factors. Technological factors include types of equipment, production technology, types of tools, cutting modes, processed material, and technological downtime; organizational factors cover types of tooled parts, workload volumes (numbers of orders, numbers of ordered parts, preparation and tooling time), workload planning, production lot sizes, time schedules, staff qualification, organizational downtime, speed of eliminating downtime, and data visualization.

2. Information disclosure, speedy computer-aided communication and data visualization facilitate the effectiveness of equipment. At the mechanical tooling company, the research 
showed that once the computer-aided module was introduced the increase in effectiveness of the studied equipment ranged from $30 \%$ to $35 \%$.

3. At the analyzed company, the most common cause of the equipment idle time was found to be technological breakdowns. They accounted for $60 \%$ of the total downtime causes. The second most prevalent reason (35\%) was lacking technological documentation (flowcharts, CNC software). Other reasons accounted for 5\% of the total downtime. After the computer-aided production data visualization module was introduced, the total number of downtime decreased by $14 \%$, while the speed of idle time elimination increased by $8 \%$. The visualization of the downtime causes resulted in significant decrease in lacking technological documentation (by $22 \%$ ) and increase in the speed of eliminating this type of downtime.

\section{REFERENCES}

1. John S. Oaklang, Oakland on Quality Management, Butterworth Heinemann, p. 176$178,2004$.

2. Hans J. Jacobs and Holger Dürr, Entwicklung und Gestaltung von Fertigungsprozessen, Carl Hanser Verlag, München Wien, p. 31-34, 2002.

3. Friederiche Wall, Planungs- und Kontrollsysteme, Verlag Dr. Th. Gabler GmbH, Wiesbaden, p. 84-95, 1999. 


\title{
MODERN APPROACHES OF THE DEFENSE ACQUISITION MANAGEMENT WITHIN THE ROMANIAN ARMY
}

\author{
Adriana Olaru $^{1}$, Olga Ungureanu ${ }^{1}$ and Alexandru Capatina ${ }^{1}$ \\ ${ }^{1}$ 59-61, str. N. Balcescu, Department of Management \\ University "Dunarea de Jos" of Galati, Romania
}

\begin{abstract}
In this paper, we focused our attention on the peculiarities of the acquisition management within the Romanian Army.

The first two sections of the paper, which present the main components of the defense acquisition management integrated system and the planning process associated to of the armament endowment programs of the Romanian Army, provide the theoretical and methodological support for the third section which emphasizes the application of the global utility method in view to select the most efficient project concerning the endowment with armoured vehicles, based on four alternative scenarios and a set of specific indicators.

We consider that method can be successfully applied to other Romanian Army endowment projects, according to the regulations imposed by OTAN.
\end{abstract}

\section{CONSIDERATIONS REGARDING THE DECISION MAKING PROCESS WITHIN THE INTEGRATED MANAGEMENT SYSTEM OF THE DEFENSE ACQUISITION}

Within the integrated management of the acquisitions three major systems have been defined, three councils being founded which participate, interact and ensure the efficiency in making decisions: (Badalan [1])

1. The Requests Expression System, coordinated by the Requests Control Council which ensures the validation and approval of the Document with the mission's needs and the Document with the operational requests.

The Requests Control Council is responsible for the following actions: 
- the analysis of the possible threats and scenarios;

- the validation and approval of the Document with the mission's needs and the Document with the operational requests and the setting of the endowment priorities with new arms systems according to the forces projected;

- the supervision of the requests and basic performances' carrying out of the programs.

2. The Acquisition Management System, coordinated by the Acquisitions Council, is the one which ensures the making of decisions regarding the development of the acquisitions programs and has the following main tasks:

- the setting and publishing of the policies and procedures in the acquisitions domain;

- the coordination of financing the concept studies and the research - development projects in order to support the acquisitions programs;

- the programs' management and the execution of the acquisitions contracts;

- the information of all the decision factors concerning the development stage of the approved programs;

- the staff training in the acquisitions domain.

3. The Planning, Programming and Budgeting System, coordinated by the Defense Planning Council which ensures the setting of priorities concerning the planning and resources assignment for acquisitions.

This system is responsible for:

- the setting of priorities concerning the planning and resources assignment for the acquisitions programs by means of the Defense Planning Directive;

- the programming in multi - annual budgets of the resources necessary for the development of the programs in progress by multi- annual contracts;

- the planning, programming and budgeting coordination of all the army's programs.

The acquisitions management process is structured on acquisition categories, stages and decision sequences that cover the entire duration of a program, which starts from the planning before its official start and the examination of the stages of research, development, production, installing, logistic support, exploitation and behavior control in exploitation, up to going out of use and revaluation.

The resources assignment process for the acquisitions programs includes all the activities afferent to the resources evaluation (funds, materials, human resources, providers and equipments). It represents a cyclic process that involves four stages in which the defense 
budget project is prepared, with a systematic structure for making decisions in what concerns the development policy and strategy of the armed forces and the necessary capabilities to carry out the anticipated missions. (Table 1)

Table 1 - The main stages associated to the defense acquisitions programs

\begin{tabular}{|c|c|c|c|c|}
\hline Stage & $\begin{array}{c}\text { Stage 1 } \\
\text { The design of } \\
\text { the project }\end{array}$ & $\begin{array}{c}\text { Stage 2 } \\
\text { Technological } \\
\text { development }\end{array}$ & $\begin{array}{c}\text { Stage 3 } \\
\text { Armament } \\
\text { production }\end{array}$ & $\begin{array}{c}\text { Stage 4 } \\
\text { Support for } \\
\text { the simulated } \\
\text { military } \\
\text { operations }\end{array}$ \\
\hline Stage goal & $\begin{array}{c}\text { Setting of the } \\
\text { acquisition } \\
\text { program }\end{array}$ & $\begin{array}{c}\text { Testing the } \\
\text { military } \\
\text { capabilities' } \\
\text { system }\end{array}$ & $\begin{array}{c}\text { Setting the } \\
\text { efficient } \\
\text { production, based } \\
\text { on the military } \\
\text { requirements }\end{array}$ & $\begin{array}{c}\text { Insurance a } \\
\text { real support for } \\
\text { the military } \\
\text { operations }\end{array}$ \\
\hline
\end{tabular}

The aspects referring to financing are extremely important in the modernization process of the army's endowment. For example, in the period 2006 - 2008, the funds designed to the acquisitions of military technique in Romania have increased, thus, insuring a stable and coherent process of modernization of the military capabilities according to the contract obligations and the ones assumed at a national level.

\section{THE PLANNING OF THE ARMAMENT ENDOWMENT PROGRAMS OF THE ROMANIAN ARMY}

The planning process of the armament endowment programs of the Romanian Army implies four stages: the identification of the operational needs, the definition of the acquisitions needs, the elaboration of the scenario and the actors' coordination. (Sandu [2])

The first stage of an armament endowment program consists in the identification of the operational needs. The office for the conception of the forces systems in the Major State of the Terrestrial Forces is the main actor in the choice of the future capacities and the elaboration stage of the programs. One of its missions is to draw up the Major State Objective which initiates the elaboration stage. This document presents the military needs that must be satisfied according to the threat evolution, the mission's terms, the conceived means of action, 
the existent parks and the information provided by the General Direction for Munitions in what concerns the technical development and the new concepts. Starting from the Major State Objective, the architect of the forces system, the officer responsible with the operational coherence and the correspondent officers from the major states, reunited within the architecture team are in the position to begin the technical, operational and technical operational studies, as well as the functional and value analyses.

The management of an armament acquisition program is carried out by a team made up of a program manager, designed by the General Direction for Munitions and a program officer, designed by the major state. Each of these two deciders must select the experts and specialists they consider necessary for the mission's accomplishment.

The second stage is represented by the definition of the acquisitions needs; the card with military characteristics is drawn up based on the Major State Objective, which develops in three versions: exploration, temporary and referential. The purpose of this card is to provide, towards the structures of the General Direction for Munitions, the necessary elements for the technical and industrial actions which co-operate to carry out the military systems.

The third stage consists in the elaboration of the scenario. The training stage ends with the drawing up of the official form of the Card with Exploration Military Characteristics and a feasibility file. The approval of this file, by the Defense Minister, marks the beginning of the conception stage and the proper launching of the acquisitions programs.

Once launched, the development of the program includes three phases: the conception phase, the carrying out phase and the use phase. Each phase is subdivided in stages whose 'directors' are the synthesis offices on specific domains, respectively the 'Armament Systems' office and the 'Information and Communication Systems' office.

The fourth stage is represented by the actors' coordination. The team that attend the acquisitions program guide the Technical Department of the Terrestrial Forces in the management of the programs they took as a responsibility. Thus, the needs related to the involvement in fight are insured by the groups concerning the fighting forces and artillery. The end of the training phase and launching of the program in progress marks the introduction of the main actor: the team integrated by the program. The development of the acquisitions program, in the best conditions, depends on its efficiency and readiness. 


\section{THE APPLICATION OF THE GLOBAL UTILITY METHOD IN THE SELECTION OF AN ARMY ENDOWMENT PROJECT}

The deciders in the armed forces domain can use in the present a large series of methods to solve a problem of multi-criteria decision correctly.

The multi-criteria analysis represents an instrument that is useful to the decider considering the existence of a large number of decisional variants. In order to approach a problem of multi - criteria analysis, it is necessary to establish the following: the objective condition states in which the problem integrates in specific algorithms, the decisional variants, the judgment criteria and the application consequences of each variant for every criterion.

In the army endowment domain, this method can be used to compare some products of military technique and to decide for the most performing one, under the aspect of more criteria of technical - tactical and economic nature, these being included in the endowment programs in order to be bought by the army. (Cohrane and Hagan [3])

We considered appropriate the application of a project concerning the Romanian Army's endowment by means of the global utility method. We consider that a military unit, subordinated to the Romanian Defense Ministry wants to initiate an armoured vehicles acquisition program. The specialists within the unit propose four patterns of projects $\mathrm{P}_{1}, \mathrm{P}_{2}$, $\mathrm{P}_{3}$ and $\mathrm{P}_{4}$. The main characteristics had in view within each project are: the average speed on the field, the fuel consumption, the average time of a repair and the capacity to transport the military staff.

The unit commander, who intends to buy armoured vehicles, as a decider, gives the following importance coefficients to the four criteria:

- the average speed on the field - 0,3;

- the fuel consumption - 0,3;

- the average time of a repair $-0,2$;

- the capacity to transport the military staff $-0,2$.

The values of the analyzed characteristics, correlated to each type of project are expressed in table 2: 
Table 2 - The indicators associated to armoured vehicles endowment project of a military unit

\begin{tabular}{|c|c|c|c|c|}
\hline PROJECT & $\mathbf{P}_{1}$ & $\mathbf{P}_{2}$ & $\mathbf{P}_{3}$ & $\mathbf{P}_{4}$ \\
\hline The average speed on the field $(\mathrm{km} / \mathrm{h})$ & 52 & 48 & 50 & 53 \\
\hline The fuel consumption $(1 / 100 \mathrm{~km})$ & 95 & 97 & 102 & 104 \\
\hline The average time of a repair (days) & 7 & 5 & 9 & 6 \\
\hline $\begin{array}{c}\text { The capacity to transport military staff } \\
\text { (number of persons) }\end{array}$ & 6 & 8 & 7 & 6 \\
\hline
\end{tabular}

The method of the global utility presupposes the setting of the minimum and maximum criteria for the four characteristics submitted to the analysis. Thus, we will apply the minimum criterion for the fuel consumption and the average time of a repair and the maximum criterion for the average speed on the field and the capacity to transport military staff.

The determination formula of the partial utilities differs according to these two criteria:

$$
\begin{aligned}
& \text { MIN CRITERION: } \mathrm{u}_{i j}=\frac{u_{i_{\text {max }}}-u_{i}}{u_{i \max }-u_{i \min }} \\
& \text { MAX CRITERION: } \mathrm{u}_{i j}=\frac{u_{i}-u_{i \min }}{u_{i \max }-u_{i \min }}
\end{aligned}
$$

The determination of the partial utilities associated to the characteristics of the four projects implies the application of the two formulae:

$$
\begin{array}{llll}
\mathrm{u}_{11}=\frac{52-48}{53-48}=0,8 & \mathrm{u}_{21}=\frac{104-95}{104-95}=1 & \mathrm{u}_{31}=\frac{9-7}{9-5}=0,5 & \mathrm{u}_{41}=\frac{6-6}{8-6}=0 \\
\mathrm{u}_{12}=\frac{48-48}{53-48}=0 & \mathrm{u}_{22}=\frac{104-97}{104-95}=0,77 & \mathrm{u}_{32}=\frac{9-5}{9-5}=1 & \mathrm{u}_{42}=\frac{8-6}{8-6}=1 \\
\mathrm{u}_{13}=\frac{50-48}{53-48}=0,4 & \mathrm{u}_{23}=\frac{104-102}{104-95}=0,22 & \mathrm{u}_{33}=\frac{9-9}{9-5}=0 & \mathrm{u}_{43}=\frac{7-6}{8-6}=0,5 \\
\mathrm{u}_{14}=\frac{53-48}{53-48}=1 & \mathrm{u}_{24}=\frac{104-104}{104-95}=0 & \mathrm{u}_{34}=\frac{9-6}{9-5}=0,75 & \mathrm{u}_{44}=\frac{6-6}{8-6}=0
\end{array}
$$

The partial utilities, thus being calculated, are included in the utilities' matrixes: 


$$
\mathrm{U}_{i j}=\left[\begin{array}{cccc}
0,8 & 0 & 0,4 & 1 \\
1 & 0,77 & 0,22 & 0 \\
0,5 & 1 & 0 & 0,75 \\
0 & 1 & 0,5 & 0
\end{array}\right]
$$

The matrix thus obtained, multiplies by the line vector formed of the importance coefficients established by the decider, resulting a line vector that that reflects the utility of each project.

$$
\begin{gathered}
\mathrm{U}_{P}=\left(\begin{array}{llll}
0,3 & 0,3 & 0,2 & 0,2
\end{array}\right) \quad \mathrm{x}\left[\begin{array}{cccc}
0,8 & 0 & 0,4 & 1 \\
1 & 0,77 & 0,22 & 0 \\
0,5 & 1 & 0 & 0,75 \\
0 & 1 & 0,5 & 0
\end{array}\right] \\
\mathrm{U}_{P}=\left(\begin{array}{llll}
0,334 & 0,422 & 0,078 & 0,35
\end{array}\right)
\end{gathered}
$$

As a result of these calculations, the $\mathrm{P}_{2}$ project presents maximum global utility, being characterized by the next set of indicators: (table 3)

Table 3 - The selection of the project that presents maximum global utility

\begin{tabular}{|c|c|}
\hline PROJECT & P $_{2}$ \\
\hline The average speed on the field $(\mathrm{km} / \mathrm{h})$ & 48 \\
\hline The fuel consumption $(1 / 100 \mathrm{~km})$ & 97 \\
\hline The average time of a repair (days) & 5 \\
\hline $\begin{array}{c}\text { The capacity to transport military staff } \\
\text { (number of persons) }\end{array}$ & 8 \\
\hline
\end{tabular}

\section{CONCLUSIONS}

In Romania, there is a well structured system of defense acquisition management that disposes of specialized and experienced staff. The army endowment process in our country benefits of specialized structures and qualified staff in the international cooperation programs management in the munitions domain. (Zamfir [4])

The work procedures in the acquisition programs management are inter- operable and in agreement with the practices used in OTAN and EU and the army endowment is the basic element which will impose, in perspective, the level of the fight capacity of a professional 
army and will support the our country's contribution to the development of the OTAN and Europe's military capabilities.

The present level of the army forces endowment may be considered acceptable, in accordance with the funds assigned, disposing of a great development potential. (Tomescu [5])

The critical areas of the acquisitions process that influence unfavorably the Romanian Army endowment are represented by:

- the superficial planning of the acquisitions needs;

- the insufficient financing of the army endowment which discourages the multi - annual contraction;

- the reduced level of the investments in the research - development domain.

Referring to the national industry, the redimension of this sector represents a vital necessity, taking into consideration a series of criteria regarding the insurance of the technology transfer in the same time with the possibility of its use in other domains as well, based on some economic, political criteria and other elements of strategic order and the insurance of feasible alternatives for the acquisitions of foreign equipments, which are efficient from the point of view of the cost and requests' satisfaction of the army forces categories.

\section{REFERENCES:}

1. E. Badalan, The Management Art in the Military Actions, Ed. Militara, Bucharest, 2005

2. I. Sandu, The Management Integrated System of the Defense Acquisitions, Ed. Militara, 2005

3. C. Cohrane, and G. Hagan, Introduction to Defense Acquisition Management, Defense Acquisition University Press, Fort Belvin, 2005

4. O. Zamfir, The Integrated Management in the Fusion and Acquisition Processes, Ed. Tehnica, Bucharest, 2006

5. V. Tomescu, The Resources Assignment in the Acquisitions Integrated Management, article published in the review 'Military Dialogue', no. 3, 2008 


\title{
INNOVATIVE PROCESS DEVELOPMENT APPLYING INTELLIGENT COMPUTER AIDED PROCESS PLANNING
}

\author{
R. Mankute ${ }^{1}$ and A.Bargelis ${ }^{2}$ \\ ${ }^{1,2}$ Department of Manufacturing Technologies \\ Kaunas University of Technology, Kestucio str. 27, 44312 Kaunas, Lithuania,
}

\begin{abstract}
This paper describes the necessity of development the integrated paperless system of manufacturing engineering process. The aims and requirements of modern integrated system are presents in this research. The main part of development is Integrated Computer Aided Manufacturing Engineering system "SAT". The system structure, main functions, data base and area of application is given in this paper.
\end{abstract}

\section{INTRODUCTION}

Exchange of information between all departments and people, application of document less production technologies and simultaneous engineering methods are essential in modern manufacturing environment (Bargelis, Mankute et al. [1-3], Peng and Chung [4]). Design, planning and manufacturing control functions must be fully integrated. This can be achieved only in conditions of Computer Integrated Manufacturing (CIM). The philosophy of the CIM system allows joining separate automated activity "islands" of manufacturing system into one integrated system.

One of the most important work stages implementing the new products is manufacturing engineering (processes and manufacturing resources planning). It is constituent part of computer integrated manufacturing. For computerization of manufacturing engineering different computerized systems can be used. It is very important, especially in modern manufacturing environment, to integrate the whole manufacturing engineering process and to develop integrated Computer Aided Manufacturing Engineering System (CAME), as universal as possible. Integrated approach is mentioned also in researches of Draghici and Bondrea [5], Wang et al. [6].

The objective of this paper is to present main requirements for integrated CAME system introducing developed integrated Computer Aided Manufacturing Engineering system "SAT" 
for innovative process development, and to describe the structure, main functions and area of application.

\section{DEVELOPMENT OF INTEGRATED COMPUTER AIDED MANUFACTURING ENGINEERING SYSTEM}

\subsection{The aims and requirements of integrated CAME system}

Integrated system of Computer Aided Manufacturing Engineering (CAME), as one of most important CIM parts (Fig. 1), has to computerize and join the following main works:

1. Technological processes planning (CAPP system);

2. Material resources planning (MRP system);

3. Manufacturing resources planning (MRP II system).

Basic integration objective is to develop the manufacturing technology process guaranteeing the lowest production costs.

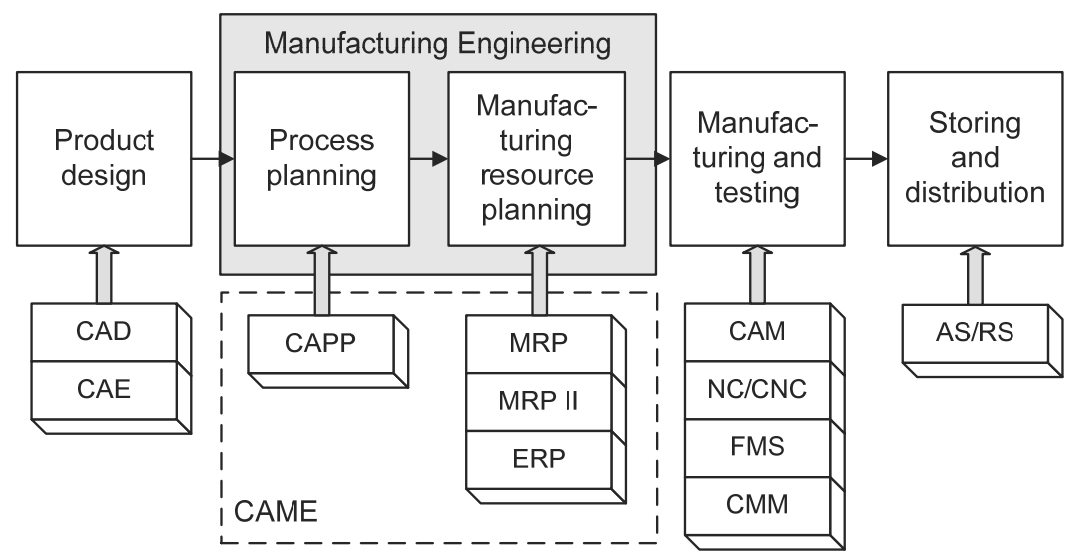

Fig.1 Manufacturing Engineering in CIM environment

(CAD - Computer Aided Design, CAE - Computer Aided Engineering,

CAPP - Computer Aided Process Planning, MRP - Material Resources Planning,

MRP II - Manufacturing Resources Planning, ERP - Enterprise Resources Planning,

$\mathrm{CAM}$ - Computer Aided Manufacturing, NC/CNC - Numerical Control/ Computer

Numerical Control, FMS - Flexible Manufacturing System, CMM - Coordinate Measurement Machine, AS/RS - Automatic Storage and Retrieval System) 
The analysis of various CAPP, MRP, MRP II, ERP systems (Tang et al [7], Xie and Xu [8], Bargelis and Mankute [9]), their data and functions, discussions with mechanical engineers in Lithuanian small end medium enterprises allows to compose the main requirements for integrated CAME system. The structure, data and functions of such integrated system have to meet the requirements as follows:

1. To suit to all mechanical components.

2. To design the main technological processes of all manufacturing types (machining, assembling, coating).

3. To form technological processes (TP) by means of all design methods (individual, analogue, unified TP).

4. To calculate material and work costs and general manufacturing resources of each TP variant.

5. To function under the interactive mode.

6. To be open for integration in CIM.

The main benefits of Integrated Computer Aided Manufacturing Engineering are as follows: optimization of manufacturing engineering, minimization of manufacturing resources, and minimization of product cost. Finally - the competitive products can be manufactured economically.

Feedbacks not only between separate sub-systems and CIM systems but also adjacent procedures have great influence to quality and performance speed of the work. In integrated manufacturing system it is very important to have constant links between separate data and sub-systems and to dispose general information during entire manufacturing engineering process. Very important information about manufacturability of designed technology processes, their application and necessary changes can quickly be obtained only through feedbacks in such integrated system.

\subsection{Integrated Computer Aided Manufacturing Engineering system "SAT"}

Integrated Computer Aided Manufacturing Engineering system "SAT" is developed in Kaunas University of Technology, department of Manufacturing Technologies for automated technology route design and manufacturing resources definition of mechanical components' 
(work pieces, assembly units, parts). It works as a man-machine system. User - engineer technologist.

Integrated system of Computer Aided Manufacturing Engineering allows information exchange with expedition in all stages of process design among various departments, react to changes of product structure and market needs. Different information is used and processed, and different data required for each stage of those works (Fig. 2).

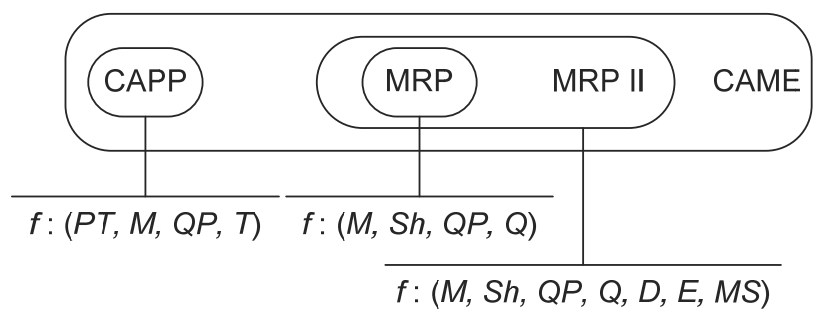

Fig. 2 Data functions structure of integrated CAME system

( $P T$ - product type, $M$ - materials, $Q P$ - quantitative and qualitative parameters of the product, $T$ - manufacturing traditions, $S h$ - shape of the part, $Q$ - quantity of parts, $D$ - machine-tools and devices, $E$ - technology equipment, $M S$ - parameters of manufacturing system)

Main advantage of this system - integrated CAME system can be effectively used for all types of mechanical components, all shapes of parts, all types of manufacturing, all methods of process planning. Main stages of innovative process development are presented in Fig. 3.

In data base of integrated system all necessary information about materials, work pieces, operations, technology steps and equipment is kept. Finished technological solutions can also be stored in data files. Integrated CAME system "SAT" can be affectively used for various machines and devices producing companies for computerization of manufacturing engineering processes; main users - engineers technologists. The system is developed on Visual Basic, Access data base, Windows environment.

Main functions of the system "SAT":

1. Data control: variable data (project data) and conditionally constant data (catalogues, classificators, archives) input ant control; selection of information: fast find, grouping, filter, etc.; data exchange between joining blocks and subsystems. 


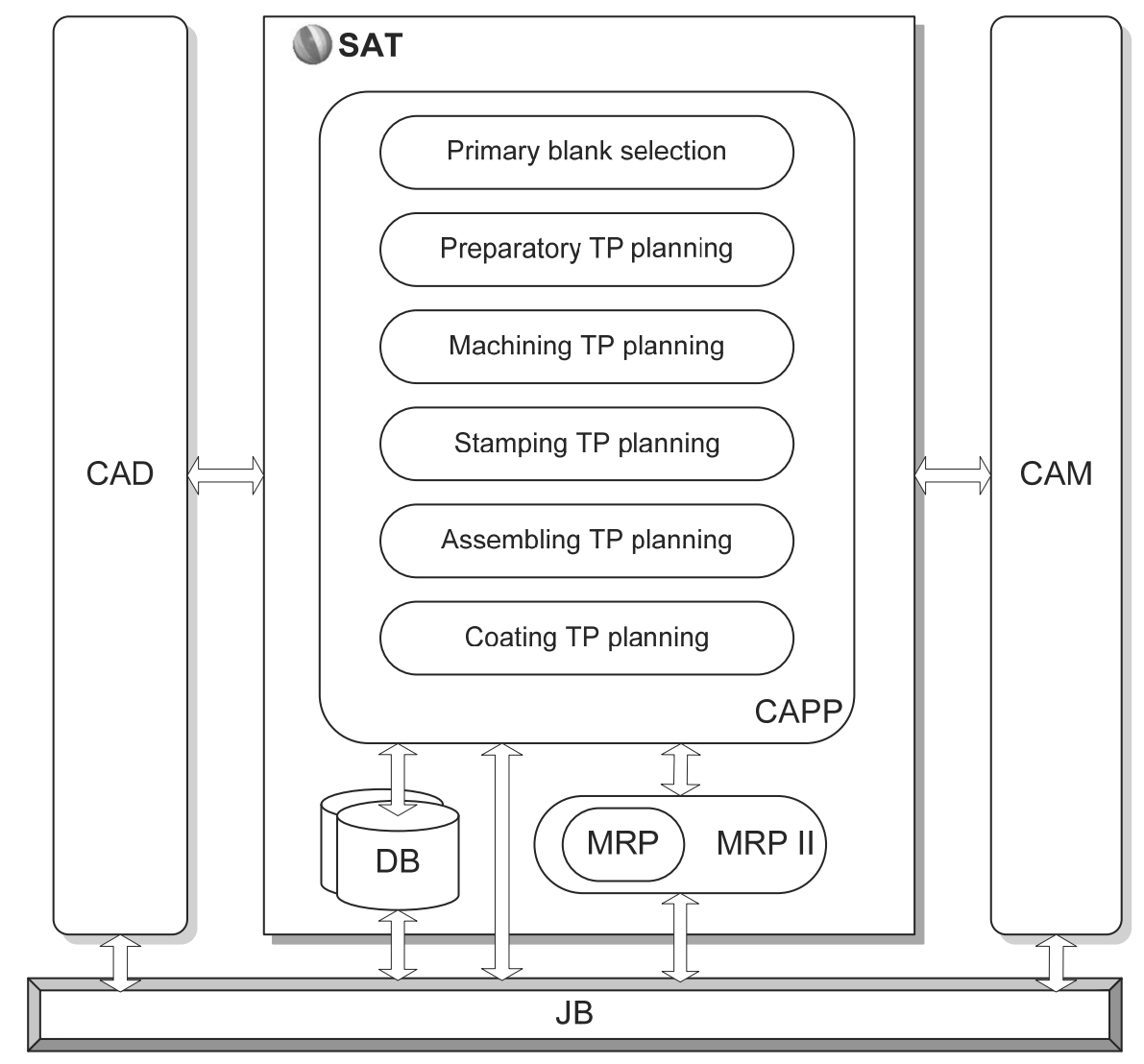

Fig. 3. Main stages of Computer Aided Manufacturing Engineering in CAME system "SAT"

2. Technological process planning: machining and coating process planning (typical and working processes, concentrate and differentiate structure).

3. Manufacturing resources planning: operation time ration (mechanical and coating, etc.); calculation of the main material consumptions (precise and approximate); calculation of the auxiliary material consumptions; calculation of the evolvent parameters for bended parts; calculation of the work piece material consumptions; design of the layout schemes on the primary blank; selection of the optimal primary blank and layout scheme; calculation of summary material consumptions and waste parameters.

4. Technological documentation formation: documents of material consumptions norms (main and auxiliary materials, primary blank layout schemes, etc.); documents of 
machining processes (process sheet, operation card, operation time sheet); documents of coating processes (coating typical technological process, sheet of coating parts, coating materials consumptions norms, etc.); documents of manufacturing system (equipment for virtual enterprise, etc.).

In the CAME system "SAT" the interactive integrated technological process planning method is used (Mankute and Raudeliunaite [10]). It is imposed for skilled engineers that have more knowledge and experience in the process planning. For engineer are left the intellectual processing fields and verification of the main technology processes, and for the system are left: calculation of all technological and manufacturing parameters (material resources, operation set up times, quantity of machinery, etc.); search of information in the data base, its selection and application; description of the created technology processes (documentation, printing etc.); integrated usage and transfer of planned data and results to other CIM systems and subsystems.

Interactive regime of the process development in this system keeps an interactive regime between engineer and system that allows the rational usage of computers and engineers time. By changes of construction or manufacturing conditions (machinery, used materials, technological equipment) of the product, the earlier developed technology process can be changed or corrected quickly and easily.

The main task for effective application of Computer Aided Manufacturing Engineering and Process Planning systems is to increase the intelligence level of developed products. Main methods, as mentioned also in researches of Bargelis, Mankute et al. [1, 2, 10-12] are as follows:

1. Formation of the additional subsystems, data files and comprehensive classificators or catalogues for the parts-analogues and complex parts that help to apply different TP planning methods effectively.

2. Formation of the archive for the finished technology processes or special technological solutions.

3. Formation of the data bases for the TP planning rules and knowledge and usage of the expert systems.

4. Formation of the automatic planning "islands" (subsystems).

5. Formation of the connecting blocks (interfaces) for the automatic transfer of data between different planning systems, Web-based solutions. 
These facilities allow making easier technologist's work and faster planning of the technological processes, to increase quality of the developed processes. It also helps to select the optimal process from several variants (using the archive of TP variants, etc.); to reduce the product lead time.

\section{CONCLUSIONS}

1. For manufacturing of competitive products and minimizing manufacturing costs, it is necessary to integrate the whole manufacturing engineering process as much as possible.

2. The structure, data and functions of CAME system "SAT" allows effectively integrate main tasks of manufacturing engineering of new product: technological process planning, manufacturing resources calculation, technological documentation formation, data transfer to other manufacturing and management departments.

3. Using main and common data structures, joining blocks, subsystem's functions and outcomes results of integrated CAME system "SAT", the optimal manufacturing engineering model can be developed.

4. For improvement of the technological process quality and accelerating the process development, it is necessary to increase the intelligence level in Computer Aided Manufacturing Engineering systems using Web-based solutions, Expert systems and so on.

\section{ACKNOWLEDGMENT}

This research was partially supported by the European Commission (EC) Leonardo da Vinci project No 2006-EE/06/B/F/PP - 169004 "Interstudy - Advanced E-curricula and mobile tools for interdisciplinary modular study".

\section{REFERENCES}

1. A. Bargelis, R. Mankute, Integration of process and manufacturing resources planning on an internet Web-based solution, Production System Design, Supply Chain Management and Logistics. Proceedings of the 9th International Multi-Conference Advanced Computer Systems ACS'2002, Part I, Miedzyzdroje, Poland, October 23-25, pp. 321-328, 2002.

2. A. Bargelis, R. Mankute, Internet Web-based integration of process and manufacturing resources planning, Supply Chain Optimization, Springer, USA, pp. 233-246, 2005. 
3. R. Mankute, I. Senkuviene, A. Bargelis, Developing and Modelling Interfaces of Computer Integrated Manufacturing of Mechanical Articles, Information Technology and Control, 1 (4), pp. 20-27, 1997.

4. O. Peng, Ch. Chung, The integration of manufacturing systems using visualised CAPP for agile manufacturing, International Journal of Manufacturing Technology \& Management, 11 (3/4), pp. 338-354, 2007.

5. G. Draghici, I. Bondrea, Integrated Approach in Computer Aided Process Planning, "Politehnica" University of Timisoara, http://www.mec.utt.ro/ draghici/draghisoce98.pdf.

6. X.H. Wang, X.G. Ming, J.Q. Yan, W.F. Lu, Q.J. Peng, Collaborative design and manufacturing process planning in tooling industry, International Journal of Computer Applications in Technology, 30 (3), pp. 221-234, 2007.

7. Y.S. Tang, J. Gao, G. Bennett, Computer-aided process planning for fabrication applications, Proceedings of the 12th Int. Conf. CAD/CAM, Robotics and Factories of the Future, London, pp. 1061-1066, 1996.

8. S.Q. Xie, X. Xu, STEP-compliant process planning system for compound sheet metal machining, International Journal of Production Research, 46 (1), pp.25-50, 2008.

9. A. Bargelis, R. Mankute, Computer aided process planning for manufacturing engineering automation, Mechanika, 4 (7), pp. 50-55, 1996.

10. R. Mankute, S. Raudeliunaite, Investigation of computer aided process planning methods in Lithuanian SME, Proceedings of 13th International Conference Mechanika-2008, April 3-4, Kaunas, Lithuania, pp. 325-331, 2008.

11. A. Bargelis, A. Cesnulevicius, A. Stasiskis, A. Sackus, Intelligent manufacturing engineering based on multi agent tools, Mechanika, 1(39), pp. 40-47, 2003.

12. R. Mankute, A. Stasiskis, A. Bargelis, Knowledge based expert system in forming the blanks for sheet metal design, Proceedings of the Baltic Sea Metal Forming and Cutting Seminar BAMFAC'98, Vilnius, Lithuania, pp. 120-126, 1998. 


\title{
CLASSIFICATION AND INVENTORY MANAGEMENT OF RETAIL PRODUCTS: A CASE STUDY
}

\author{
A.M.T. Thomé1 and A.F.C. Vieira2 \\ 1 BEMFAM, Av. Chile, 230. $17^{\circ}$ andar, Centro, Rio de Janeiro 20.031-170 \\ 2 Department of Industrial Engineering \\ Pontifical Catholic University of Rio de Janeiro
}

\begin{abstract}
Inventory management plays a central role in modern economy and businesses. The One Warehouse and $\mathrm{N}$ retailers' operations research problem of inventory management is applied to a case study. Actual inventory classification schemes and management policies for the case study are analyzed. Alternatives are proposed.
\end{abstract}

\section{INTRODUCTION}

The paper addresses techniques for inventory management of a distribution system of 570 coordinated stock keeping units (SKUs) of finished goods, scattered in a multi-echelon supply chain comprised of one central and seven regional warehouses serving 814 contracts and 2,030 service delivery points. The objective is to identify homogeneous classes of stock keeping units (SKUs) and related inventory policies in divergent distribution systems. Divergent systems are defined as having at most one predecessor and several successors. See Axsäter [1] and Nilsson [2].

The methodology consisted of a literature search described in the first section, followed by an application of classification methods and heuristics for inventory management. Conclusions and recommendations are outlined in the third section.

\section{LITERATURE REVIEW}

Inventory policies and models vary according to different methods of classification, groups of products, type of goods and industries. For classification purposes, SKUs are usually ranked in three classes based on their monetary value, referred as average dollar usage. Classes range from $\mathrm{A}$ to $\mathrm{C}$, in decreasing order of monetary importance. Classification 
schemes including more than one criterion to rank SKUs are referred to as ABC multi criteria $(\mathrm{ABCM})$. Criteria such as unit costs, lead time, commonality, criticality, substitutability and reparability are frequently added to the average dollar usage criteria in ABCM methods. Multiple criteria methods of inventory classification were first introduced by Flores and Whybark [3]. Their method consisted of a pair-wise comparison among criteria, not allowing for the inclusion of more than two factors at a time. Partovi and Hopton [4], Braglia et al. [5], among others, applied Analytical Hierarchical Process (AHP) to the ABCM problem. AHP allows simultaneous comparisons among several ranking criteria, use of verbal qualifiers to rank SKUs, among other advantages but it reintroduces management subjectivity into ABCM. Mathematical linear programming methods proposed by Ramanathan [6], Zhou and Fan [7], Wang Lung [8] are less prone to subjective judgments by managers and are easier to apply than AHP, according to the authors. The only subjective choice made by managers in linear programming methods is the ranking order of importance among criteria. Several other classification methods were proposed in recent decades and are briefly reviewed by Thome [9]. A review with application is found in Chen [10]. Chen et al. [11] emphasizes that different ABCM lead to different SKU's grouping and ranking. A framework to regroup ABC classes particularly suited to distributions with a large number of $\mathrm{C}$-items was proposed by Huiskonen et al. [12] and was applied to the case study. It is depicted in Figure 1.

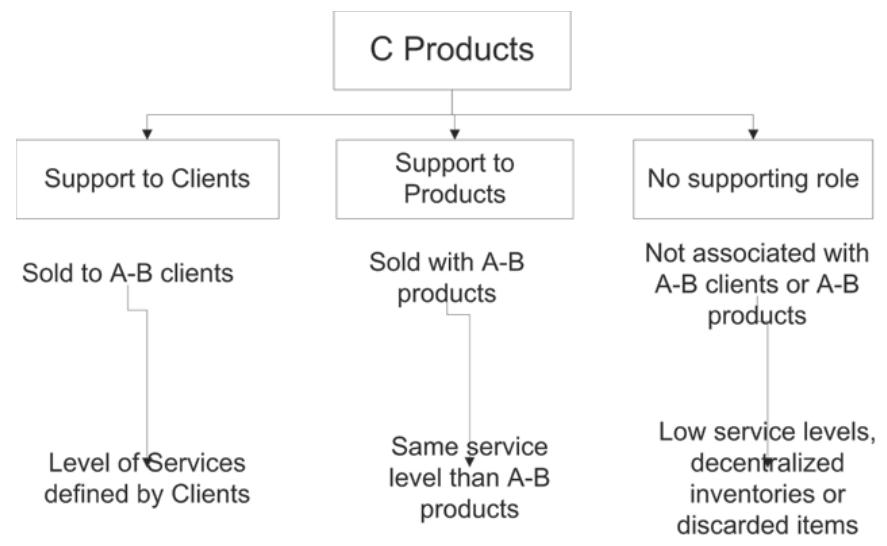

Figure 1 - The supporting role of C products. Adapted from Huiskonen et al. [12]

There are no generic rules to relate inventory management policies to $\mathrm{ABCM}$ classes in the literature reviewed. It rather varies according to the type of distribution or assembling 
system analyzed. A commonly-used policy in connection with coordinated replenishments in distribution systems is the periodic $(R, S)$ review, or order-up-to $S$ systems [13]. All items are jointly ordered every $R$ periods of time and inventories are replaced up to the maximum level $S$. Atkins and Iyogun [14] proposed two variants of this policy, for $R$ constant for all products and for $R$ varying by groups of products. They compared results with the continuous coordinated can-order inventory policies, denoted $(s, c, S)$ policies. In the later, when a product reach its reordering level $s$, all other products at the level $c$ are jointly reordered up to the maximum stock level $S(s>c<S)$. It was shown that can-order policies reduce inventory costs of up to $20 \%$ when compared with uncoordinated multi-item replenishment [15]. Atkins and Iyogun's heuristics can represent gains of up to 50\% when compared to the $(s, c, S)$-type policies [14]. Viswanathan expands the heuristic approach to joint periodic replenishment to what he calls the $P(s, S)$ policy: a periodic $(s, S)$ policy consisting of replacing inventories upto- $S$ for all items at the replacing level $s$ or bellow $s$ at the time of review, $P$. This policy results in lower costs for coordinated distribution systems than all other joint replenishment heuristics reviewed so far [16].

As for cycle time, it is common to use variations of power-of-two policies. In such policies, cycle time varies by a multiple of a constant; let's say a week, times a power of two: $2^{0}=1$ week, $2^{1}=$ two weeks, $2^{-1}=$ half week, $2^{2}=$ four weeks, etc. It was demonstrated by several authors that resulting costs when cycle times were changed by a multiple of a powerof-two policy exceeded optimal costs by at least $2 \%$ and at most $6 \%$ [17].

A number of heuristics were proposed in recent decades to improve centralized inventory control policies based on the original work of Clark and Scarf [18]. Two were selected as possible alternatives to the policy described for A-B items in the case study. They were the Axsäter, Marklund and Silver heuristic for centralized control of One warehouse and $N$ retailers distribution systems [19] and the so-called minimal service level guaranteed heuristic of Graves and Willems [20].

In the first heuristic, coordinated replenishments are effected in two-stages: (i) a virtual assignment is made to a central warehouse at the beginning of the replenishment cycle and; (ii) redistribution from the warehouse to retailers is made in two different times during the replenishment cycle. The first stage realizes gains of inventory risk pooling [21] [13]. In the second stage, an initial assignment of stock is made to all retailers based on their stock 
position at the beginning of the cycle time and subsequent stock assignments to retailers are delayed until the retailer's stock position is at or below replacement level. Stock unbalances among retailers due to uneven demand at each retailer site can thus be compensated with no need for the equal or so-called "balanced" stock assignment for all retailers. The balanced approach, also known as the classical approach proposed by Clark and Scarf [18] leads to costs of up to $50 \%$ superior to the ones obtained in numerical simulations of the heuristics performed by the authors [19].

A simpler and straightforward heuristic for two-echelon distribution systems was proposed by Graves [22] and Graves and Willems[21]. Following Axsäter[17], let

$\mu_{j}=$ average demand per unit of time at installation $j$,

$\sigma_{j}=$ standard deviation of demand per unit of time at installation $j$,

$S_{j}=$ order-up-to position at installation $j$,

$\mathrm{S}_{j}^{\text {out }}=$ service time at installation $j$ for all installations at lower levels in the supply chain,

$\mathrm{S}_{j}^{i n}=$ service time for installation $j$, provided by its immediate predecessors,

$L_{j}=$ time to process an order at installation $j$,

$k_{j}=$ security factor for installation $j$,

$p(j)=$ all installations that are immediate predecessors of installation $j$,

$I_{j}=$ stock on-hand at installation $j$.

Service time or delay to installation $j$ provided by its immediate predecessors equals the larger service time among all installations upstream: $s_{j}^{\text {in }}=\max _{i \in p(j)}\left\{s_{i}^{\text {out }}\right\}, i \in p(j)$. The lead time for replenishment is $L_{j}+s_{j}^{\text {in }}$. Average demand during the lead time is $\mu_{j}\left(L_{j}+s_{j}^{i n}\right)$ and the standard deviation during the lead time is provided by $\sigma_{j}\left(L_{j}+s_{j}^{i n}\right)^{1 / 2}$. Maximum stock level at installation $j, S_{j}$ is given by: $S_{j}=\sqrt{\mu_{j}\left(L_{j}+s_{j}^{\text {in }}-s_{j}^{\text {out }}\right)+k_{j} \sigma_{j}\left(L_{j}+s_{j}^{\text {in }}-s_{j}^{\text {out }}\right)}$. The expected inventory on hand at installation $j$ is therefore: $E\left(I_{j}\right)=\sqrt{k_{j} \sigma_{j}\left(L_{j}+s_{j}^{\text {in }}-s_{j}^{\text {out }}\right)}$.

\section{CASE STUDY}

Inventory classification and policies were applied to pharmaceuticals and educational materials distributed by BEMFAM - Family Welfare in Brazil, a Brazilian NonGovernmental Organization specialized in reproductive health and family planning services and products. Finished goods are highly concentrated in the A-B classes, with 17 products 
responding to $93 \%$ of dollar usage and 570 products classified as $\mathrm{C}$-items. The Wang Lung's $\mathrm{ABCM}$ technique resulted in the reclassification of an average of $25 \%$ of total SKUs. C-items were subdivided using the framework proposed by Huiskonen et al. [12]. The resulting classification scheme and related inventory policies are summarized in Table 1.

Table 1 - ABCM classes and Inventory Policies

\begin{tabular}{|c|l|l|c|}
\hline Classes & \multicolumn{1}{|c|}{ ABCM Methodology } & \multicolumn{1}{|c|}{ Type of Products } & $\begin{array}{c}\text { Inventory } \\
\text { Policies }\end{array}$ \\
\hline A -B & $\begin{array}{l}\text { ABC - dollar usage and ABCM - } \\
\text { dollar usage, unit costs, lead time }\end{array}$ & Pharmaceuticals & $(R, S)$ \\
\hline C1 & Support to A-B Clients or Services & Educational Materials & $(R, S, S)$ \\
\hline C2 & $\begin{array}{l}\text { None - candidates to centralized } \\
\text { distribution or to be discarded }\end{array}$ & Miscellaneous & $\begin{array}{c}(S, Q)-T w o \\
\text { bins }\end{array}$ \\
\hline C3 & $\begin{array}{l}\text { Support to A-B Products or Services } \\
\text { Sule of C-Products [12] }\end{array}$ & $\begin{array}{l}\text { Materials for clinics and } \\
\text { laboratory }\end{array}$ & $\begin{array}{c}\text { Wagner- } \\
\text { Within }\end{array}$ \\
\hline
\end{tabular}

A-B items were managed with a joint replenishment policy of the $(R, S)$ type, similar in design to the $P(s, S)$ policy prone by Wiswanathan [16]. The main difference is that all items are raised up to $S$ at the time of review, and not only those at or below replenishment level $s$. As calculations were performed independently for each warehouse, risk pooling effects were neglected. Also, safety stock levels are possibly higher than what could be obtained by virtually pooling all demands together. It also impacts cash flow by concentrating purchases in a single point in time. Computations and results for one product are summarized in Table 2.

All C items were managed with $(R, S, S)$-type policies: stocks are inspected every $R$ periods and those below or at the replenishment level $s$ are ordered up to $S$, or maximum stock. This class of inventory policy results in lower costs than all other joint replenishment policies for one echelon supply chains, although the exact mathematical values of parameters are difficult to optimize [15]. In practice, the $(R, s, S)$ policy was automated with $R$ equals 15 -day, $s$ equals lead time $(L T)$ and $S$ equals two months of stock. All parameters were empirically set by management based on observation, yielding acceptable but not optimal results. 
Table 2 - Application of $(R, S)$ policy to the replenishment of oral contraceptives

\begin{tabular}{|c|c|c|c|c|c|c|c|c|}
\hline Data / DCs & SC & BA & $A L$ & PE & PB & RN & MA & TOTAL \\
\hline Demand & 46.819 & 32.295 & 5.818 & 17.176 & 15.100 & 11.433 & 6.720 & 135.361 \\
\hline Standard Deviation & 8.690 & 3.571 & 1.488 & 1.689 & 4.092 & 1.761 & 2.770 & 10.994 \\
\hline CV & $18,56 \%$ & $11,06 \%$ & $25,58 \%$ & $9,83 \%$ & $27,10 \%$ & $15,40 \%$ & $41,22 \%$ & $8,12 \%$ \\
\hline Lead Time in days & 6,71 & 7,00 & 9,71 & 7,14 & 7,50 & 12,67 & 9,43 & 8,60 \\
\hline Standard Deviation - $L T$ & 1,89 & 1,41 & 3,90 & 4,22 & 3,66 & 3,72 & 6,08 & 3,56 \\
\hline$C V$ & $28,1 \%$ & $20,2 \%$ & $40,2 \%$ & $59,1 \%$ & $48,9 \%$ & $29,4 \%$ & $64,5 \%$ & $41,4 \%$ \\
\hline$I_{t}($ Stock Position in $t)$ & 6000 & 0 & 450 & 0 & 0 & 0 & 0 & 6.450 \\
\hline$R$ & 30 & 30 & 30 & 30 & 30 & 30 & 30 & 30 \\
\hline$L$ & 7 & 7 & 10 & 7 & 8 & 13 & 9 & 9 \\
\hline \multicolumn{9}{|l|}{ Parameters } \\
\hline$S=(R+L) \mu_{D}+k \sigma_{(R+L)}$ & 61.639 & 41.820 & 8.746 & 24.282 & 21.536 & 18.223 & 10.516 & 186.763 \\
\hline$(R+L) \mu_{D}$ & 57.743 & 39.831 & 7.757 & 21.184 & 19.127 & 16.387 & 8.736 & 170.765 \\
\hline $\begin{array}{l}E S=s=\sigma_{R+L}=k^{*} \sqrt{\sigma_{D}^{2} \mu_{D}(L+R)+\mu_{D}^{2} * \sigma_{L}^{2}} \\
\mathrm{k}=\text { inv.normp }(0,9)=1,28\end{array}$ & 3.895 & 1.990 & 989 & 3.099 & 2.409 & 1.836 & 1.780 & 15.998 \\
\hline$Q=S-I_{t}$ & 55.639 & 41.820 & 8.296 & 24.282 & 21.536 & 18.223 & 10.516 & 180.313 \\
\hline
\end{tabular}

After $\mathrm{ABCM}$ analysis, items $\mathrm{C}$ were subdivided into three classes (see Table 1): $\mathrm{C} 1$ regrouped educational material with supporting role to clients of the A-B group and will continue to be managed with $(R, S, S)$ policies; $\mathrm{C} 2$ had no supporting role and were candidates to be discarded or to be managed by simple two-bin inventory policies (for short, in two-bin inventory policies one bin holds cycle stock while the other bin holds $L T$ stock. When all cycle stock is used, replenishment is ordered to fill both bins and arrive when the LT-bin is close to its minimum). $\mathrm{C} 3$ items had a supporting role to A-B services in clinics and laboratory, regrouping low cost and highly critical items dependent upon the number of medical and laboratorial exams and procedures. A replenishment strategy minimizing stock acquisition and holding costs for deterministic variable demand is suggested for C3 items, through use of the Wagner-Within algorithm [23].

\section{CONCLUSIONS}

Methods and techniques for stock classification and coordinated inventory management in a centralized and divergent distribution system of finished retail products were reviewed. Main conclusions and further research directions were drawn. Management techniques used in the case study for coordinated replenishment of A-B class products can possibly be improved for both cost and service level performance. Instead of optimizing product 
coordination for a single warehouse, risk pooling gains could be obtained by optimizing echelon stock for the centralized supply chain. Both Axsäter et al. [19] and Graves and Willems [20] suggested heuristics of inventory management for the One Warehouse - $N$ Retailers problem that might result in lower costs at high service levels. Alternative inventory policies for $\mathrm{C}$-items were also drawn from the study. Research to fine-tune the selection among competing ABCM methods and to test the heuristics proposed in real situations would be of immediate practical interest. Development of new heuristics that could combine inventory risk pooling gains from transshipments among regional warehouses with risk pooling from the One Warehouse $-N$ Retailers framework would be beneficial from both an academic and a practitioners point of view.

\section{REFERENCES}

1. S. Axsäter, Supply Chain Operations: Serial and Distribution Inventory Systems. Handbooks in OR \& MS, Vol. 11. A. G. d. Kok and S. C. Graves. 11: pp. 525-559, 2003.

2. A. Nilsson, Essays on Joint Replenishment and Multi-Echelon Inventory Systems, Department of Business Administration and Social Sciences. Division of Industrial Logistics. Luleå, Luleå University of Technology. Licentiate Thesis: 93, 2006.

3. B.E. Flores and D.C. Whybark, Multiple criteria ABC analysis, International Journal of Operations and Production Management 6, pp. 38-46, 1986.

4. F.Y. Partovi and W.E. Hopton (1994). The analytic hierarchy process as applied to two types of inventory problems, Production and Inventory Management Journal 35(1): pp. 13-19, 1994.

5. M. Braglia, G. Andrea and R. Montanari, Multi-attribute classification method for spare parts inventory management, Journal of Quality in Maintenance Engineering, 10(1): pp. 55-65. 2004.

6. R. Ramanathan, $\mathrm{ABC}$ inventory classification with multiple-criteria using weight linear optimization, Computers and Operations Research 33: pp. 695-700, 2006.

7. P. Zhou, P. and L. Fan, A note on multi-criteria ABC inventory classification using weighted linear optimization. European Journal of Operational Research 182(2007): pp. 1488-1491, 2007

8. Ng Wang Lung, A simple classifier for multiple criteria ABC analysis, European Journal of Operational Research 177, pp. 344-353, 2007.

9. A.M.T. Thomé, Classificação e Gestão de Estoques de Varejo: um estudo de caso. Master of Sciences dissertation, Department of Industrial Engineering, Pontifical Catholic University of Rio de Janeiro, 2009. 
10. Y. Chen, Multiple Criteria Decision Analysis: Classification Problems and Solutions. Systems Design Engineering. Waterloo, Canada, University of Waterloo. Doctor of Philosophy:18, 2006.

11. Y. Chen, K. W. Lib and S. Liua (2008). A Comparative Study on Multicriteria ABC Analysis in Inventory Management, School of Economics and Management, Nanjing University of Aeronautics and Astronautics, Nanjing, 210016, China and Odette School of Business, University of Windsor, Windsor, ON, N9B 3P4, Canada: 5 pp. 2008 .

12. J. Huiskonen, P. Niemi and T. Pirttila, The role of C-products in providing customer service - refining the inventory policy according to customer-specific factors, Int. J. Production Economics 93-94: pp. 139-149, 2005.

13. D. Simchi-Levi, P. Kaminski and E. Simchi-Levi, Designing \& Managing the Supply Chain-Concepts, Strategies \& Case studies. New York, McGraw-Hill, 2004.

14. D. R. Atkins and P. O. Iyogun, Periodic versus 'Can-Order' Policies for Coordinated Multi-Item Inventory Systems, Management Science 34(6): pp. 791-796, 1988.

15. E. A. Silver and R. Peterson, Decision Systems for Inventory Management and Production Planning, John Willey \& Sons. 1985.

16. S. Viswanathan, Note. Periodic Review $(\mathrm{s}, \mathrm{S})$ Policies for Joint Replenishment Inventory Systems, Management Science 34(10): pp. 1447-1454, 1997.

17. S. Axsäter, Inventory Control, Springer, 2006.

18. A. J. Clark and H. Scarf, Optimal Policies for a Multi-Echelon Inventory Problem, Management Science 6(4): pp. 475-490, 1960.

19. Axsäter, S., J. Marklund and E.A. Silver, Heuristic Methods for Centralized Control of One-Warehouse, N-Retailer Inventory Systems, Manufacturing \& Service Operations Management 4(1): pp. 75-97, 2002.

20. S.C. Graves and S. P. Willems, Supply Chain Design: Safety Stock Placement and Supply Chain Configuration. Handbooks in $O R \& M S$, Chapter 3. A. G. d. Kok and S. C. Graves, Elsevier. 11, 2003.

21. G. Eppen, Effects of Centralization on Expected Costs in a Multi-Location Newsboy Problem, Management Sciences 25(19179): pp. 498-501, 1979.

22. S. C. Graves, A Multiechelon Inventory Model with Fixed Replenishment Intervals. Management Science 42(1): pp. 1-18, 1996.

23. H. M.Wagner and T. M. Whitin, Dynamic Version of the Economic Lot Size Model, Management Science 5(1): pp. 89-96, 1958. 


\title{
LOGISTIC CONCEPT AS A MODERN FORM OF THE TOTAL LOGISTIC INTEGRATION OF REGIONAL AREAS
}

\author{
Mr sci Zeljko Ivanovic ${ }^{1}$ and Ljubinka Ivanovic ${ }^{2}$ \\ Center for logistics and transportation "Z-Logistics", Ilino 69, 85000 Bar, Montenegro \\ e-mail: clt@t-com.me
}

\begin{abstract}
:
This paper describes one of the approaches in the development of logistic conceptual systematic solutions, as a modern form of modern connection of economic, transit and supply functions of urban and regional areas, into one multidimensional conceptual model aimed to make the basis for the implementation of total logistic integration process.
\end{abstract}

\section{INTRODUCTION}

In the process of redesigning conceptual system solutions, a unique, overall, systematic and multidisciplinary analysis of city and regional logistics processes and systems needs to be done. The motive is very clear, it needs to develop new conceptual systematic solutions which will enable total optimization of logistic processes realization process as well as creation of all necessary assumptions for better projection, organization, realization and control of all logistic processes and systems in one geographic area, in the forthcoming period. All this needs to be done on sustainable basis with the aim to reach greater economic, spatial, technical-technological and ecological effects. Newly developed conceptual systematic solutions have to be based upon the logistic principles and postulates. Furthermore, they have to be in accordance with: (i) clearly defined needs of logistic service users, (ii) modern scientific accomplishments, (iii) modern technological trends and demands, and (iv) practical experiences and results achieved so far. Such an approach in model development requires consolidation of three concepts: (i) concept of the realization of logistic flows, (ii) concept of the realization of information flows, and (iii) concept of the environmental protection. All three concepts have the aim to make the basis for: (i) spatial (physical) planning, (ii) transport planning, (iii) life quality, where main elements are space, money, time and life quality. 


\section{TERM AND IMPORTANCE OF THE DEVELOPMENT OF LOGISTIC CONCEPT}

\subsection{Logistic concept - term}

Logistic concept (LC) represents the form based on a set of principles, primarily logistic ones (Figure 1) for optimal connection of primary logistic elements (system structure, organization, logistic chains, logistic flows and telemathic technologies) and secondary logistic elements (public, private and public-private logistic measures) aiming at the development of new sustainable system and conceptual solution of city and regional logistics.

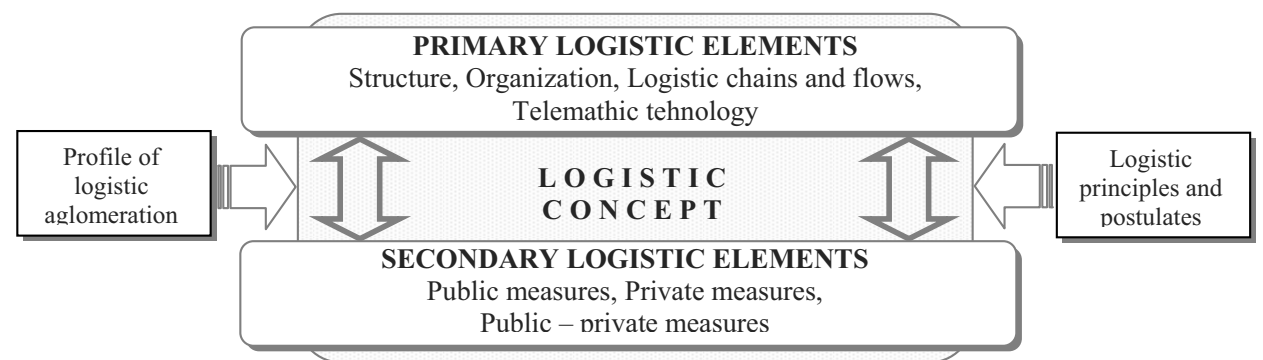

Figure 1: Logistic concept based on the connection of logistic schemes

\subsection{Importance of the development of sustainable logistic conceptual solutions}

In reference to sustainable conceptual solutions, we should depart from the fact that city and regional logistics represents one multilayer system mutually connected by correlative relations. Among layers there are market situations with the offer of and request for logistic services and all regulators which organize these markets on the principles of market economy and logistics [1]. In such relations, it is necessary to identify in a right way demands and causal relations among the subjects (Figure 2), observed on horizontal and vertial level.

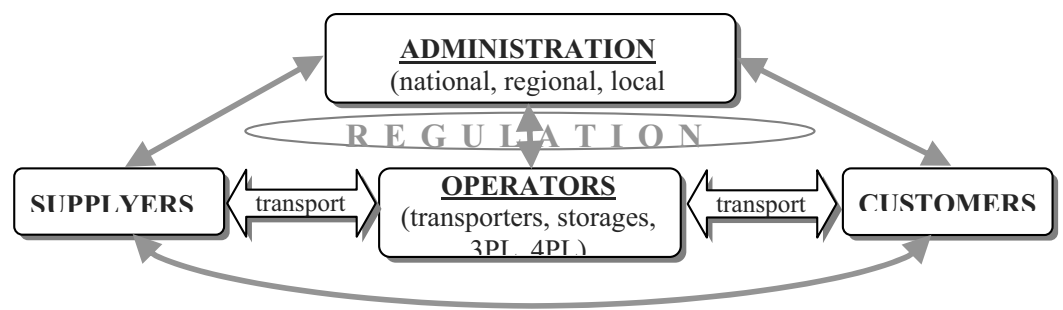

Figure 2: Key elements in city and regional logistic 
In conditions of business activities, each previously mentioned element has different demands, which are also very often conflicted. However, in the development process of new systematic solutions, three main demands have to be primarily satisfied [4]: (i) Mobility, (ii) Sustainability, (iii) Liveability. Above mentioned tasks demonstrate that for the development of sustainable logistic solutions it is necessary to have comprehensive strategic predicting and planning, which should enable connection of all subjects in logistics, making one system. Due to multidimensional influence onto economy, the development of modern logistic conceptual solutions has to be based upon the application of systematic approach using following relations: preparation $\Rightarrow$ analysis $\Rightarrow$ synthesis $\Rightarrow$ control. The development of new systematic solution should also be based upon: (i) multi-criteria analysis outputs, (ii) optimization model outputs where time and cost are main components, (iii) planning of activities regarding process model, (iv) using top-down or bottom-up approach, as well as both of them in decision making, (v) application of logistics controlling as a concept that enables integrated assistance to decision making, (vi) application of certain measures that will enable adjusting the gap between public and private sector, (vii) application of integrated logistics support (ILS), (viii) development of models for multi-criteria evaluating of possible solutions.

\section{MAIN CONDITIONS FOR THE DEVELOPMENT OF SUSTAINABLE LOGISTIC CONCEPTUAL SYSTEMATIC SOLUTIONS}

Condition 1: Modern tendencies for total optimization of logistic processes on some location basically are connected to the process of development of logistic centers (Figure 3) whose main function is to make the basis for concentration of all logistic activities in one location without duplicating capacities, and coordination and cooperation among certain links in the logistic chain.

Condition 2: New conceptual solutions require usage of new logistic strategies (LS). The aim of their application is to enable decrease of overall logistic costs, decrease of necessary financial resources, definition of optimal capacities of LC and rendering logistic service to the customer according to its demand with the tendency to continuously increase service quality.

Condition 3: Many obvious problems in logistic processes, especially in transport process cause demands for the application of modern logistic measures, which should (Figure 4) stimulate development of new sustainable conceptual solutions. 
Condition 4: Existence of logistic experts capable for and trained to realize and keep updated newly developed systematic solutions.

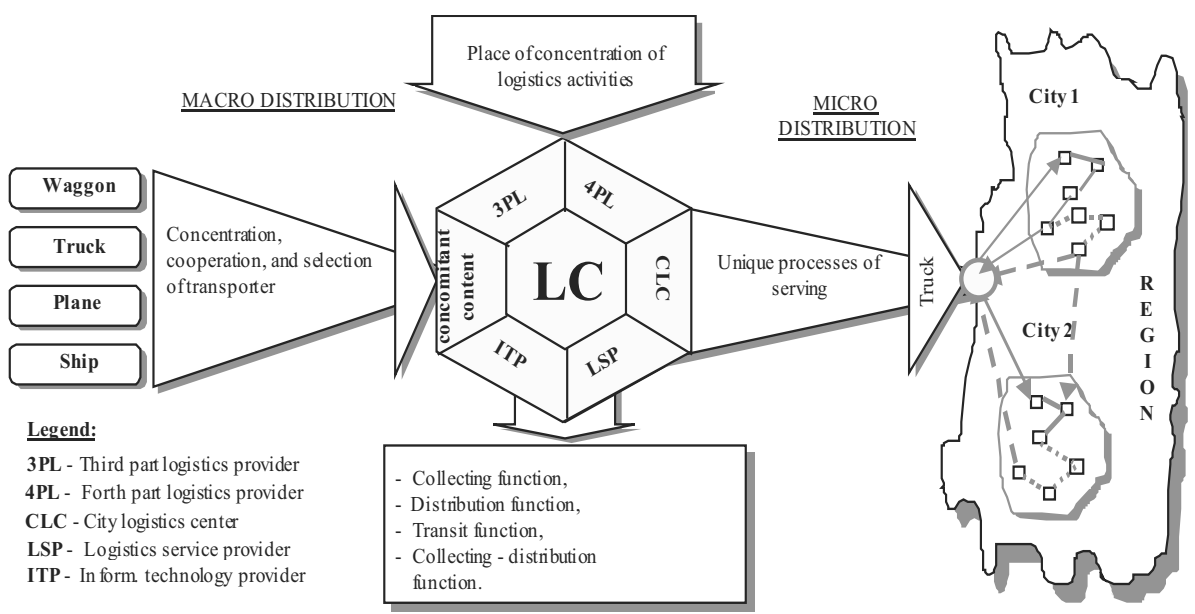

Figure 3: LC as a place of concentration of logistic activities [5]

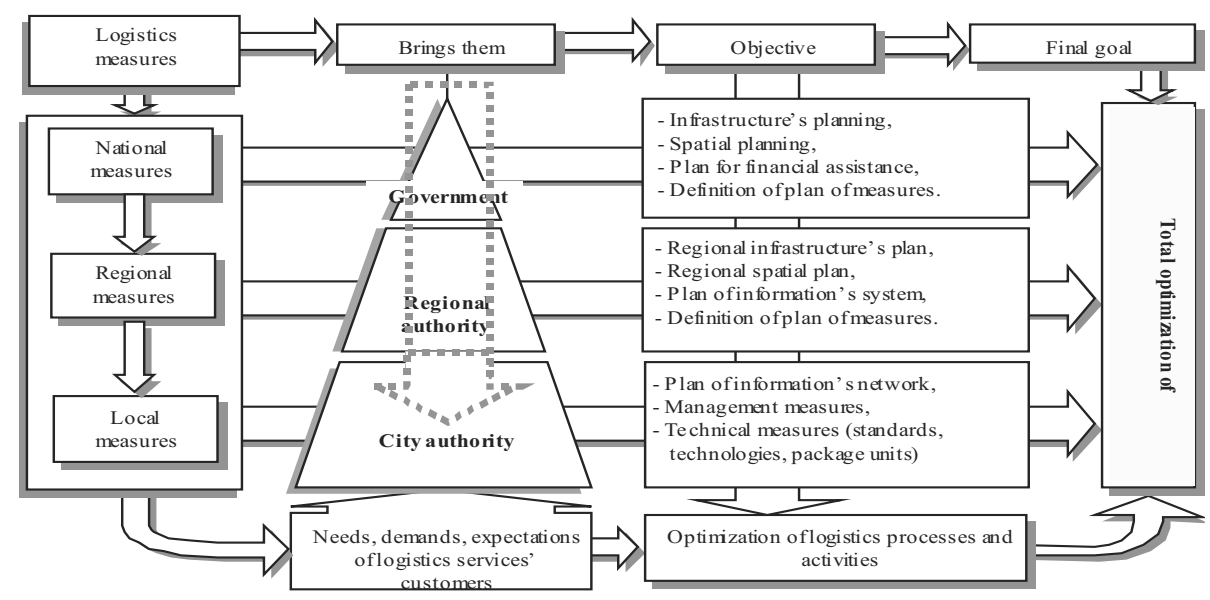

Figure 4: Presence of the measures in regional logistic [5]

\section{PROCEDURE OF THE DEVELOPMENT OF MODERN CONCEPTUAL SOLUTION}

Newly developed solution of logistic concept should incorporate three basic concepts: (i) concept of concentration, coordination, cooperation and rationalization of goods flows, (ii) concept 
of information flows, (iii) concept of environmental protection. Structure projection process of the new solution of logistic concept requires consideration of four questions: (i) how to plan the system of logistic flows realization, (ii) which organizational structure is optimal, (iii) how to manage logistic processes, (iv) how to realize the model of information connection. Methodology of development itself should have four phases: (i) phase 1: Preparation: basic theoretical postulates regarding the development of LC, (ii) phase 2: Analysis: multi-criteria analysis of logistics profile in the region, (iii) phase 3: Synthesis: new systematic solution is made, (iv) phase 4: Control: comparative overview of the existing and new solution.

\section{CONCRETE EXAMPLE OF THE DEVELOPMENT OF LOGISTIC CONCEPT}

Described procedure of the development of sustainable conceptual logistic solutions has been applied on the development of new conceptual solution for the regional area of Montenegrin coast, whose developing procedure is shown below, in the Figure 5 of this paper.

\subsection{Proposal for solution}

According to outputs obtained from case analysis, a new conceptual solution for regional logistics has been defined. The solution incorporates three concepts: (i) concept of rationalization of goods flows, (ii) concept of information flows integration, (iii) concept of environmental protection. Within the first concept, three possible solutions have been developed together with defined system structure and logistic chains. Solution structure of logistic concept for mentioned region is basically defined by: (i) structure and characteristics of technological demands of certain goods flows which show up and will show up in the forthcoming period, (ii) number, position and schedule of logistic services users, (iii) rule of incurrence of technological demands (determinism - stochasticism, stationarity nonstationarity, homogeneity - unhomogenity, continuity - discontinuity), (iv) number, spatial (physical) position and characteristics of basic technological elements and their connection to the existing transport modes in the region, (v) strategies and factors of further economic development, etc. The basic idea of the development of new logistic concept for the region of Montenegrin coast is that cargo center Bar should represent central element of its structure, where it will represent concentration, cooperation and transformation of all forms of goods flows. 


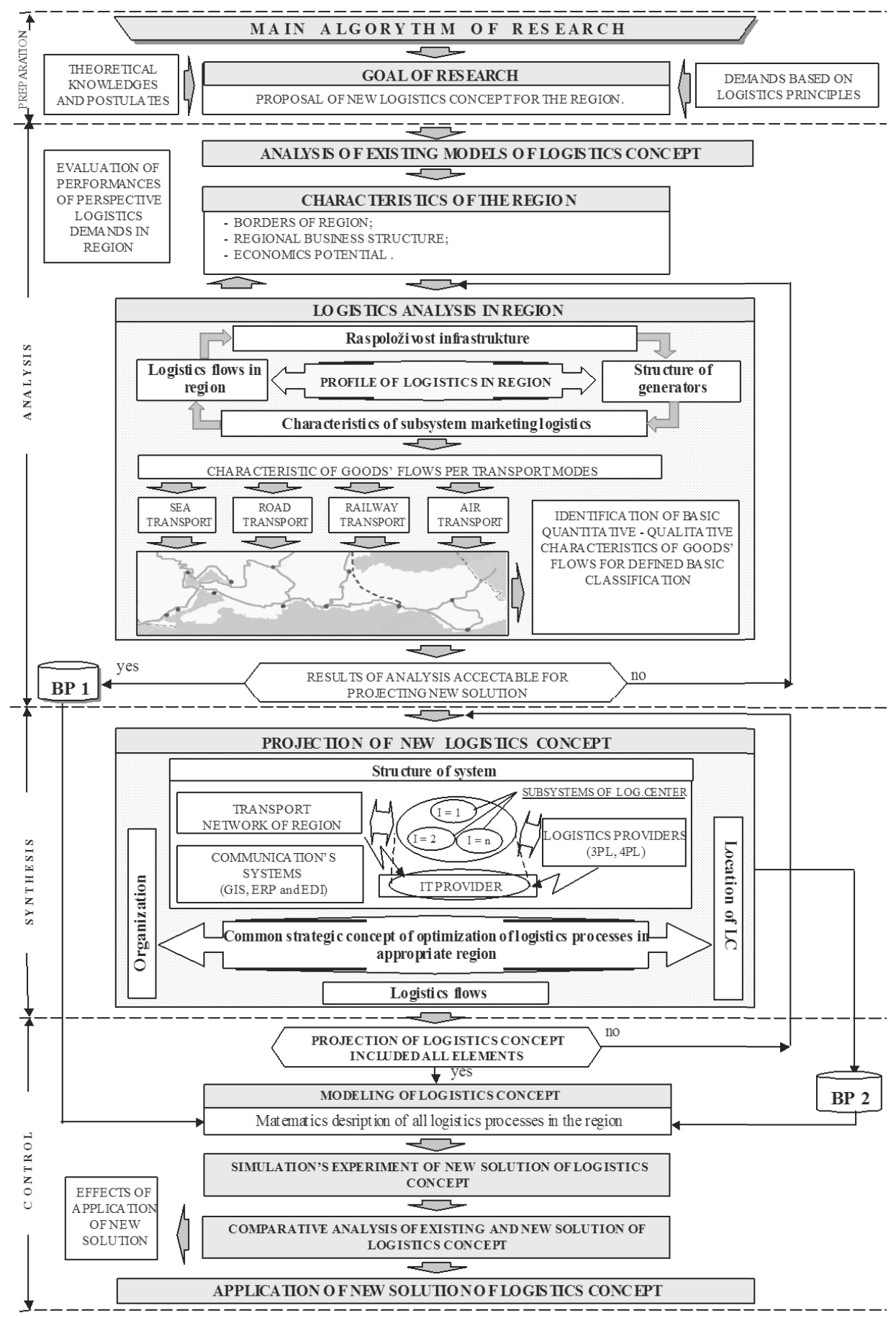

Figure 5: Contracted algorithm of the development of logistic concept 


\subsection{Development of simulation model for proposed solutions}

Overall problem of simulation modeling for newly developed solution of logistic concept in mentioned region, as per defined possible solutions, is divided in two levels, according to the functions of certain goods flows: (i) level 1 relates to the realization of macro flows during delivery, (ii) level 2 relates to the process of physical distribution.

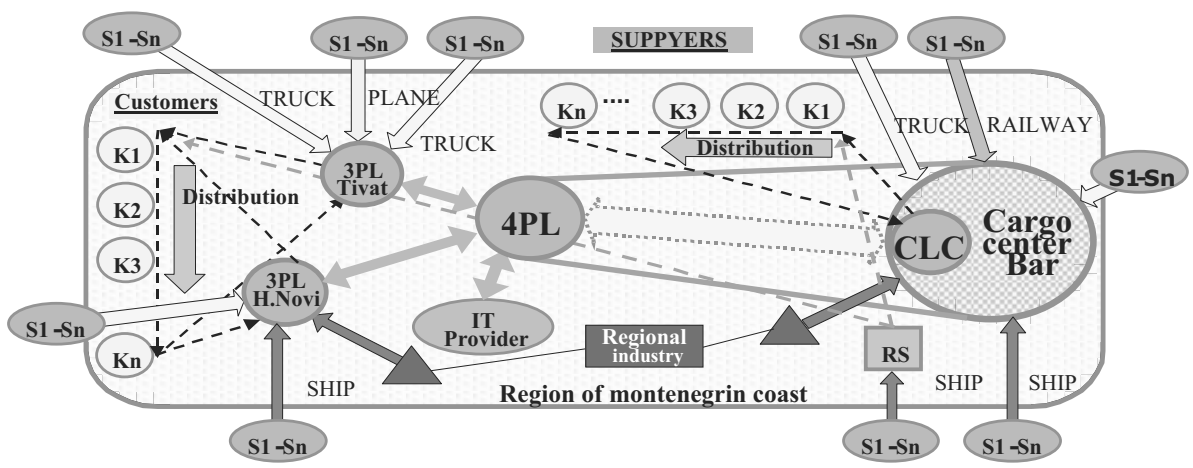

Figure 6: Overview of possible solution no.2

\subsection{Effects of the application of new logistic concept}

Simulation experiment on developed simulation model has been made using language ARENA 7.01 for three proposed solutions within the concept of the rationalization of goods flows. New conceptual solution changes the structure of participation of transport modes during delivery of goods in comparison to the existing solution reflected in decreasing participation from $56,72 \%$ for possible solution no. 1 and no. 2 and 52.62\% for possible solution no. 3. Newly developed solution contributes to disburdening of transport network in this region from heavy transport vehicles by increasing usage of railway and sea transport; that has particular importance during summer tourist season.

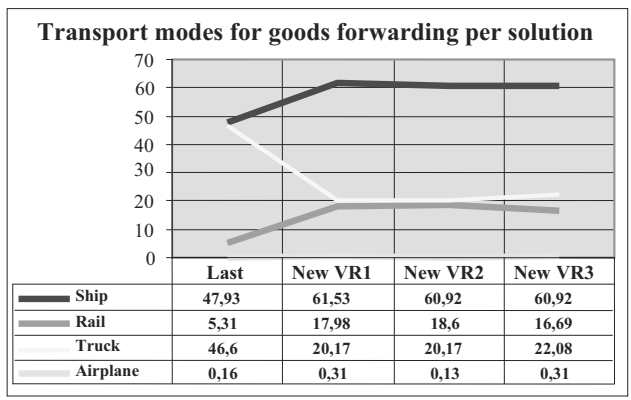

Figure 7: Modes of transport per solution

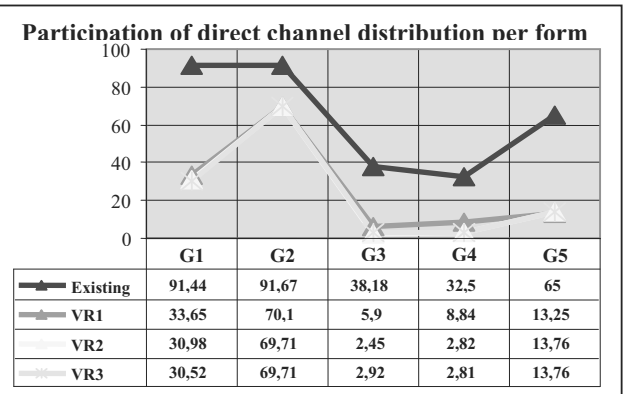

Figure 8: Direct channel of distribution/solution 


\section{CONCLUSION}

Development of logistic concept represents a set of rules and principles, which in base of systematic approach, must be connected among themselves making one modern form which will incorporate logistic principles and procedures. We can say that logistic concept represents modern generators of economic development of the region to which it is referred to. Their function is to connect economic, transit and supply functions of the agglomeration into one model, which should contribute to total optimization of logistic processes. That is why nowadays concepts have to be created in order to achieve greater economic, spatial, technical-technological and ecological effects within the region to which it is referred to. In this paper, special attention was paid to the methodology of model development for the creation of sustainable logistic conceptual systematic solutions as an approach for total optimization of logistic processes and unique connection of all logistic processes and logistic - transport systems in some special geographic areas. Proposed methodical approach also had its practical application on the region of Montenegrin coast. For proposed solution, simulation model has been developed using program language called Rockwell ARENA 7.01. On the basis of the experiment made by computer simulation on developed model, positive effects of the application of new solution for the region of Montenegrin coast have been detected.

\section{REFERENCES}

1. Bentzen Kent, Hoffmann Tobias, NeLoC, Service Concept Report for Logistics Centres, Association of Danish Transport Centres, Aalborg, 2004.

2. Binsbergen A., Visser J., New urban goods distribution systems, Delft University of Technology, Netherlands, 2000.

3. LEAN - Project, City Logistics Concepts, Puplic Report, 2000.

4. Taniguchi E., Thompson R. G., Yamada T. and Van Duin R., City Logistics - Network Modeling and Intelligent Transport Systems, London, 2001.

5. Ivanovic Z., Modern approach to the development of sustainable logistics conceptual system's solutions, Symposium of Operation research SYM-OP-IS, Banja Koviljaca, Serbia, 2006. 


\title{
APPLICATION OF LOGISTICS METHODS IN PRINT PRODUCTION
}

\author{
D. Milcic, D. Banic and D. Donevski \\ Faculty of Graphic Arts \\ University of Zagreb
}

Getaldiceva 2, 10000 Zagreb, Croatia

\begin{abstract}
The newsprint production process is by far the most dynamic print production process. It requires planning and time saving where that is possible. As the printing is usually done in three shifts, every delay in the printing of one publication jeopardizes the finishing of other publications within the contracted deadline. This paper describes the analysis of a print production process involving two printing presses with different capacities, and post-press (finishing) machines with three different capacities. Vogel and MODI optimization methods were used.
\end{abstract}

\section{INTRODUCTION}

During the research of the production processes and logistics in printing houses, it was noted that mathematical models and simulation of production processes are not used. The use of mathematical models and simulation yields much better results than the methods commonly used in practice. Various software tools which simplify the abovementioned analyses are available today. Software tools should only be used to simplify the analysis. If the user doesn't understand the method, and uses the software only to obtain results after entering the input parameters, then he is unable to intervene when intervention is required. For the purpose of this analysis, the production capacities were determined by monitoring the processes. The production process was divided on two parts, press and post-press. The printing house receives the digital copy prepared for production, and the capacity of the CTP (Computer to Plate) department is large enough not to cause delays during the plate production. 


\section{PROCESS OPTIMIZATION}

\subsection{Defining the Production Capacities}

$\mathrm{S}_{1}$ and $\mathrm{S}_{2}$ are used to denote two offset printing presses. The presses have the production capacities of 105 and 175 units of semi-product. The semi-products are temporarily put at three positions $\mathrm{O}_{1}, \mathrm{O}_{2}$ and $\mathrm{O}_{3}$, which have the capacities of storing 120, 90 and 160 units of such goods. From there, the semi-products are taken to the second (post-press) production phase. It consists of three working places, here denoted by $\mathrm{M}_{1}, \mathrm{M}_{2}$ and $\mathrm{M}_{3}$, which have the capacities of 50, 110 and 120 units. Those are the three binding machines used to bind magazines, each of which performs all of the finishing operations.

\subsection{Optimizing the Production Capacities}

The optimization problem is solved by finding the initial solution using the Vogel method, and the final solution using the MODI method, [1], Mirkovic. Table 1 displays the costs, e.g. x 1000 units of certain currency.

\section{Table 1, Costs}

\begin{tabular}{|c|c|c|c|c|c|c|c|}
\hline & $\mathrm{O}_{1}$ & $\mathrm{O}_{2}$ & $\mathrm{O}_{3}$ & $\mathrm{M}_{1}$ & $\mathrm{M}_{2}$ & $\mathrm{M}_{3}$ & \\
\hline $\mathrm{S}_{1}$ & 20 & 30 & 15 & $\bar{M}$ & $\mathrm{M}$ & $\mathrm{M}$ & 105 \\
\hline $\mathrm{S}_{2}$ & 7 & 10 & 3 & $\mathrm{M}$ & $\mathrm{M}$ & $\overline{\mathrm{M}}$ & 175 \\
\hline $\mathrm{O}_{1}$ & $\mathrm{M}$ & $\mathrm{M}$ & $\bar{M}$ & 21 & 37 & 40 & 120 \\
\hline $\mathrm{O}_{2}$ & $\mathrm{M}$ & $\mathrm{M}$ & M & 5 & 7 & 8 & 90 \\
\hline $\mathrm{O}_{3}$ & $\mathrm{M}$ & $\mathrm{M}$ & $\mathrm{M}$ & 9 & 10 & 11 & 160 \\
\hline
\end{tabular}

$\begin{array}{llllll}120 & 90 & 160 & 50 & 110 & 120\end{array}$

The Vogel Approximation method can be divided in six steps, [2]:

1. For each row and column, find the difference between the two lowest costs (opportunity cost)

2. Identify the row or column with the greatest opportunity cost

3. Assign as many units as possible to the lowest cost square in the row or column selected.

4. Eliminate any row or column that has just been completely satisfied by the assignment just made.

5. Recompute the cost differences for the transportation table, omitting rows or columns crossed out in the preceding step. 
6. Return to step 2 and repeat the steps until an initial feasible solution has been obtained.

This procedure is displayed in tables, from Table 2 to Table 10.

Fictive measures $S_{f}$ and $M_{f}$ are introduced to account for the greater capacity of storing positions $\mathrm{O}_{1}, \mathrm{O}_{2}$ and $\mathrm{O}_{3}$.

Table 2, Vogel Approximation method

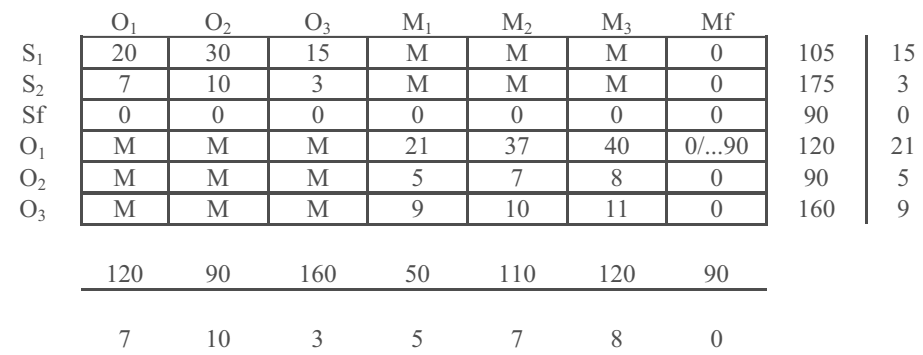

Table 3, Vogel Approximation Method

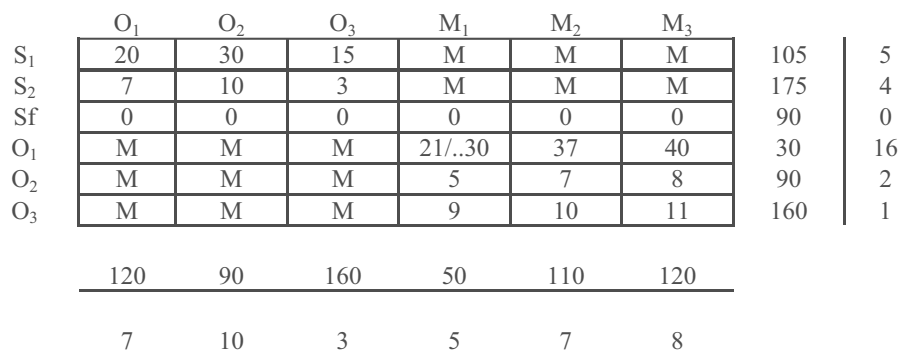

Table 4, Vogel Approximation Method

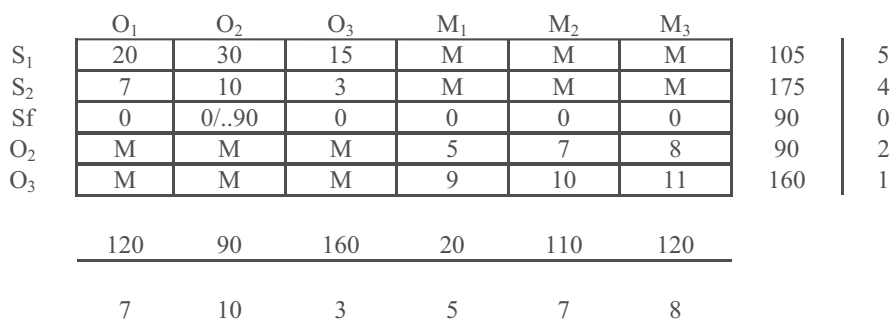


Table 5, Vogel Approximation Method

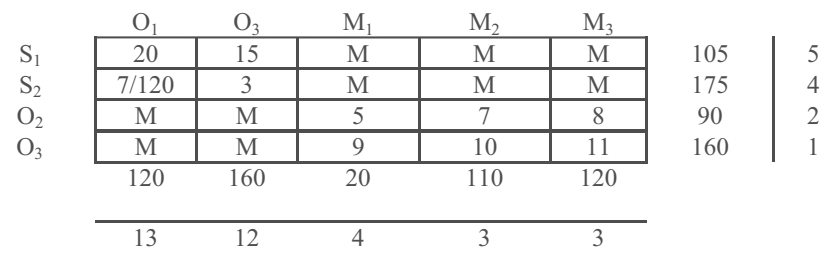

Table 6, Vogel Approximation Method

\begin{tabular}{|c|c|c|c|c|c|}
\hline $\mathrm{O}_{3}$ & $\mathrm{M}_{1}$ & $\mathrm{M}_{2}$ & $\mathrm{M}_{3}$ & \multirow{5}{*}{$\begin{array}{c}105 \\
55 \\
90 \\
160\end{array}$} & \multirow{5}{*}{$\begin{array}{c}\text { M-15 } \\
\text { M-3 } \\
2 \\
1\end{array}$} \\
\hline 15 & $\mathrm{M}$ & $\mathrm{M}$ & M & & \\
\hline $3 / 55$ & $\mathrm{M}$ & $\mathrm{M}$ & $\mathrm{M}$ & & \\
\hline $\mathrm{M}$ & 5 & 7 & 8 & & \\
\hline $\mathrm{O}_{3}$ & 9 & 10 & 11 & & \\
\hline 160 & 20 & 110 & 120 & & \\
\hline 12 & 4 & 3 & 3 & & \\
\hline
\end{tabular}

Table 7, Vogel Approximation Method

\begin{tabular}{|c|c|c|c|c|c|}
\hline $\mathrm{O}_{3}$ & $\mathrm{M}_{1}$ & $\mathrm{M}_{2}$ & $\mathrm{M}_{3}$ & \multirow{4}{*}{$\begin{array}{c}105 \\
90 \\
160\end{array}$} & \multirow{4}{*}{$\begin{array}{c}\text { M-15 } \\
2 \\
1\end{array}$} \\
\hline $15 / 105$ & $\mathrm{M}$ & $\mathrm{M}$ & $\mathrm{M}$ & & \\
\hline $\mathrm{O}_{2}$ & 5 & 7 & 8 & & \\
\hline $\mathrm{O}_{3}$ & 9 & 10 & 11 & & \\
\hline 105 & 20 & 110 & 120 & & \\
\hline M-15 & 4 & 3 & 3 & & \\
\hline
\end{tabular}

Table 8, Vogel Approximation Method

$\mathrm{O}_{2}$

\begin{tabular}{|c|c|c|c|c|}
\hline $\mathrm{M}_{1}$ & $\mathrm{M}_{2}$ & $\mathrm{M}_{3}$ & & \\
\hline $5 / 20$ & 7 & 8 & 90 & 2 \\
\hline 9 & 10 & 11 & 160 & 1 \\
\hline
\end{tabular}

\begin{tabular}{ccc}
20 & 110 & 120 \\
\hline 4 & 3 & 3
\end{tabular}


Table 9, Vogel Approximation Method

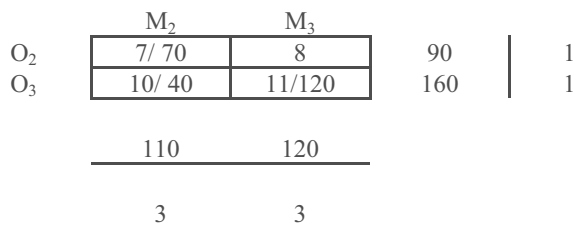

The product distribution is displayed in Table 10.

Table 10, Vogel Approximation Method - Product Distribution

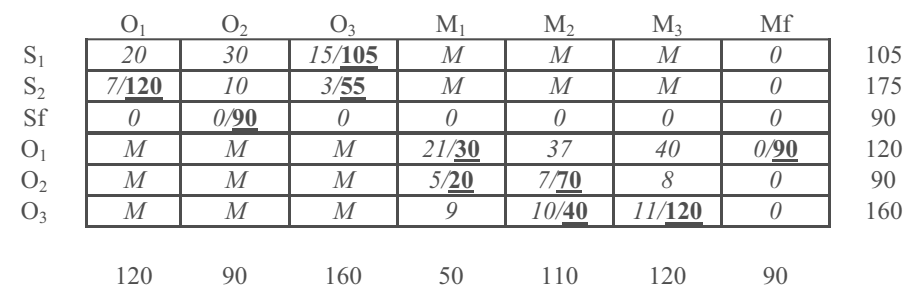

The optimality is checked using the MODI method

If $z_{i j}>0$, the solution is optimal, where $z_{i j}$ represents the improvement index.

$$
\mathrm{z}_{\mathrm{ij}}=\mathrm{c}_{\mathrm{ij}}-\left(\mathrm{u}_{\mathrm{i}}+\mathrm{v}_{\mathrm{j}}\right)
$$

$\mathrm{c}_{\mathrm{ij}}$ are costs, $\mathrm{u}_{\mathrm{i}} \mathrm{i} \mathrm{v}_{\mathrm{j}}$ are dual variables.

The values of dual variables are determined by the positions of products in such way that a given variable $\left(\mathrm{u}_{\mathrm{i}}\right.$ or $\left.\mathrm{v}_{\mathrm{i}}\right)$ is assigned a value of zero, and then their values are determined from that position. Equation 1 is used to determine the values of $z_{i j}$ for positions which do not contain any products. If the values are greater than or equal to zero, the solution is optimal. If some of the $z_{i j}$ values are negative, the greatest load is put on the position of the smallest negative $\mathrm{z}_{\mathrm{ij}}$ value, [3], Pasagic.

Determination of dual variables $\mathrm{u}_{\mathrm{i}}$ and $\mathrm{v}_{\mathrm{i}}$ is displayed in Table 11 . 
Table 11, Dual variables $u_{i}$ and $v_{i}$

\begin{tabular}{|c|c|c|c|c|c|c|c|}
\hline $\mathrm{O}_{1}$ & $\mathrm{O}_{2}$ & $\mathrm{O}_{3}$ & $\mathrm{M}_{1}$ & $\mathrm{M}_{2}$ & $\mathrm{M}_{3}$ & Mf & \\
\hline 20 & 30 & $15 / 105$ & $M$ & $M$ & $M$ & 0 & 105 \\
\hline $7 / 120$ & 10 & $3 / \mathbf{5 5}$ & $M$ & $M$ & $M$ & 0 & 175 \\
\hline $\mathrm{Sf}$ & $0 / 90$ & 0 & 0 & 0 & 0 & 0 & 90 \\
\hline $\mathrm{O}_{1}$ & $M$ & $M$ & $21 / \underline{\mathbf{3 0}}$ & 37 & 40 & $0 / \underline{\underline{0}}$ & 120 \\
\hline $\mathrm{O}_{2}$ & $M$ & $M$ & $5 / \overline{\mathbf{2 0}}$ & $7 / \underline{70}$ & 8 & 0 & 90 \\
\hline$M$ & $M$ & $M$ & 9 & $\overline{10 / \underline{\mathbf{4 0}}}$ & $11 / \mathbf{1 2 0}$ & 0 & 160 \\
\hline
\end{tabular}

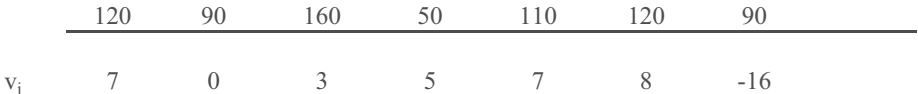

Values of $\mathrm{z}_{\mathrm{ij}}$ are displayed in Table 12.

Table 12, Improvement index $\mathrm{z}_{\mathrm{ij}}$

\begin{tabular}{|c|c|c|c|c|c|c|c|c|}
\hline & $\mathrm{O}_{1}$ & $\mathrm{O}_{2}$ & $\mathrm{O}_{3}$ & $\mathrm{M}_{1}$ & $\mathrm{M}_{2}$ & $\mathrm{M}_{3}$ & Mf & \\
\hline $\mathrm{S}_{1}$ & 1 & 18 & 0 & $M$ & $M$ & $M$ & 0 & 105 \\
\hline $\mathrm{S}_{2}$ & 0 & 10 & 0 & $\bar{M}$ & $\bar{M}$ & $\bar{M}$ & 0 & 175 \\
\hline $\mathrm{Sf}$ & & & & 0 & 0 & 0 & 0 & 90 \\
\hline $\mathrm{O}_{1}$ & $M$ & $M$ & $M$ & 0 & 14 & 16 & & 120 \\
\hline $\mathrm{O}_{2}$ & $M$ & $M$ & $M$ & 0 & 0 & 0 & & 90 \\
\hline $\mathrm{O}_{3}$ & $M$ & $M$ & $M$ & $\underline{1}$ & $\underline{\mathbf{0}}$ & $\underline{\mathbf{0}}$ & & 160 \\
\hline & 120 & 90 & 160 & 50 & 110 & 120 & 90 & \\
\hline $\mathrm{v}_{\mathrm{j}}$ & 7 & 0 & 3 & 5 & 7 & 8 & -16 & \\
\hline
\end{tabular}

All of the values are greater than or equal to zero, and the solution is therefore considered to be optimal. 


\section{CONCLUSION}

In a production process of any kind and especially in very dynamic processes such as daily press, logistics and process optimization are factors which in addition to quality help achieving best results. The time saved by process planning increases profit and assures that the goods are delivered to the customer within the agreed deadline. The models used in this paper are simple tools of process optimization. Understanding of this analysis process, and its use aided with computer software, would result in these methods becoming a more common practice in real-world production processes.

\section{REFERENCES}

1. Mirkovic D., Matematicke metode u istrazivanjima optimalnih rjesenja organizacijskih i ekonomskih problema, Sarajevo, 1973.

2. http://pages.intnet.mu/cueboy/education/notes/algebra/modivam.pdf

3. Pasagic H., Matematicko modeliranje i teorija grafova, Zagreb, 1998. 


\title{
SUPPLY CHAIN INTEGRATION AND ADAPTABILITY \\ - THE KEY TO BE FIT FOR TURBULENCE?
}

\author{
M. Gerschberger, C. Söser and F. Staberhofer \\ LOGISTIKUM - Competence Centre for Logistics and Enterprise Networks \\ University of Applied Sciences, Campus Steyr, \\ Wehrgrabengasse 1-3, 4400 Steyr, Austria
}

\begin{abstract}
In a world which has become ever more turbulent - due to environmental, political, technological, competitive events and disturbances - the ability to forecast and plan for the future is dramatically reduced. Instead, the ability to adapt flexibly and quickly to unexpected, unplanned events has become the major condition for survival of any organization. Under these circumstances an adequate degree of adaptability - while simultaneously establish integrated value networks - is advantageous for business performance as it keeps a company moveable.

This insight provided the stimulus for a major research effort by a consortium of academic and industrial partners based at the University of Applied Sciences - Campus Steyr. Fit for turbulence (FFT) intends to become the Austrian competence centre for value network solutions with a special focus on SC-adaptability. In this paper an explanatory model is developed based on an extensive literature review that higlights propositions whose investigation can improve the companies adaptability to be fit for turbulence.
\end{abstract}

\section{PAPER OBJECTIVE: DEVELOPMENT OF THE EXPLANATORY MODEL}

In today's dynamic and technology intensive environments, companies that operate in complex value networks are forced to satisfy changing individual needs economically. The term 'value network' is interpreted according to Angeli's [1] definition that a value network is a hybrid organizational form consisting of a fixed and a dynamic part enabling a flexible and demand-oriented expansion. This definition is valuable because of the definite indication of the adaptability of the relevant value network according to environmental turbulences (Gerschberger et al. [2]). The challenge lies more precisely in the identification of the relevant value network. Let's assume that the entire world is seen as network and all contacts of a company together constitute a companies network. Not all contacts create value within the 
company network and therefore the terms company network and value network have to be used differentiated. Those partners that contribute to the value creation within the company network are members of the value network. This consideration describes a traceable way to identify the value network. In situations of environmental turbulence the definition of the term relevance can be quite tricky. 'What criteria/what performance indicators decide about the relevance and furthermore what influence does a change of business goals (for example: asset instead of output orientation) have?' are questions that have to be answered to define the relevant value network. The relevant value network is the starting point for supply chain management - the highest stage of development in logistics. More recent literature suggests that in stable environmental conditions supply chain (SC) integration has been a key enabler to ensure company performance and in an environment affected by turbulences a diversified consideration is essential (Proposition (P) 8). [All propositions including authors supporting this proposition are summarized in table 2]

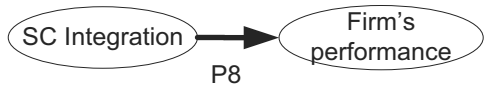

SC integration was the concept that coined the history of Supply Chain Management (SCM) (Frankel et al. [3], Haozhe Chen et al. [4]) and its positive influence on performance has been empirically investigated many times. Fabbe-Costes and Jahre [5] summarize the common feature of the definitions of 'integration' which is 'to operate as a seamless whole'. Further, they state that: "Integrating the supply chain activities is driven by the need to streamline operations to achieve quality service to customers". Integration is as a process of coordinating activities, resources and organisations in order to function in concert. The higher the integration the higher the propensity to act collectively in a uniform manner and adhere to common policies. Now environmental turbulences force companies to consistently and effectively reduce turbulences that affect the company directly and to develop the ability to be adaptable to cope with changed conditions (Barki and Pinsonneault [6], Braunscheidel and Suresh [7], Duclos et al. [8], Choi et al. [9]). Busquets et al. [10] defines 'adaptability' as 'the ability of an agent to consciously or unconsciously change to fit different circumstances for instance, changes in the environment. Likewise, we assume that agents can be both active and passive; they can accept the environment as is, or they can seek to influence or affect environmental change'. SC adaptability refers to the ability 'to reshape supply chains when necessary, without ties to legacy issues or the way the chain has been operated previously'. The main point is to be able to change in a radical way (Fabbe-Costes and Jahre [5]). This 
adaptability to a changed environment has to take place in a fast and efficient way to guarantee sustainable company performance (P1).

The inability of most companies to achieve the adequate fit of adaptability with respect to the changed environment results in an reduction of the company's performance. (P9)

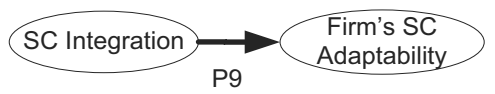

Unfortunately, SC integration and SC adaptability are not innately cross-fertilizing concepts. Hence, a high level of SC integration can reduce the firm's SC adaptability (P6) and an increase in the firm's SC adaptability can take place at the expense of reduced SC integration (P7) (Christopher [11], Towill and Christopher [12], White et al. [13]). A future core competence of companies will be to identify and to focus on the type of SC integration that is positively related to the firm's SC adaptability (P5).

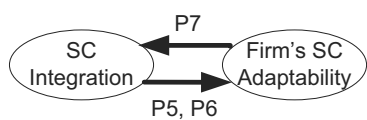

According to the extensive literature review [for further explanations see section on methodology] conducted, the key enabler of SC integration as well as SC adaptability is the use of information and communication technology (ICT) (P2.1, P3.1) (Söser et al. [14]). Especially those ICT's that enable both a higher level of SC integration and a higher level of the firm's SC adaptability (P4.1) need to be investigated in detail.

A global value network is a sociotechnical system. In such a system the question of changeable technology is not the only challenge that has to be met to identify the perfect fit between adaptability and integration within a system. Empirical evidence highlights that also employees along with operational and organizational structure are a key enabler (Nyhuis et al. [15]) as well and a significant issue for the adaptability/integration fit of a global value network. (P2.2, P3.2, P4.2)

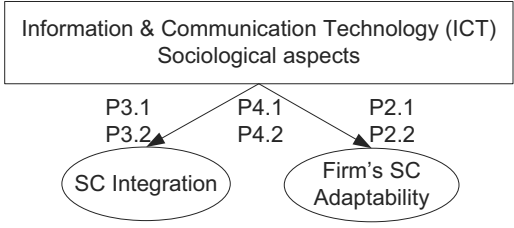

The educed propositions in the introductory chapter are consolidated into an explanatory model to identify the adequate fit between SC integration and SC adaptability with respect to 
a company's performance under the current environmental turbulences. Prior to the consolidation of the explanatory model in section 3 the methodology of this paper is described briefly in section 2. Finally, further steps and research activities are highlighted in the concluding section 4 .

\section{METHODOLOGY}

In this section, the extensive and structured literature review of business logistics, transportation and supply chain management articles as well as the selection of these articles is presented. For the purpose of selecting journals EBSCOHost, Emerald Insight and Science Direct were used. According to the analysis of Menachof et al. [16] the 12 top-ranked journals in economics have been reviewed from the year 2000 up to now. Menachof et al. [16] developed on the basis of a survey a ranking based on the quality of peer reviewed periodicals for faculty research use.

Table1: Propositions and authors identified in the literature review

\begin{tabular}{cl|c|} 
Ranking & \multicolumn{1}{|c|}{ Journal } & $\begin{array}{l}\text { Research usefulness } \\
\text { index }\end{array}$ \\
1 & Journal of Business Logistics & 41.921 \\
\hline 2 & International Journal of Physical Distribution and Logistics Management & 33.206 \\
3 & International Journal of Logistics Management & 29.071 \\
\hline 4 & Journal of Operations Management & 19.052 \\
\hline 5 & Supply Chain Management Review & 17.875 \\
6 & Transportation Journal & 17.525 \\
\hline 7 & Harvard Business Review & 15.108 \\
\hline 8 & Management Science & 14.249 \\
9 & Transportation Research: Part E, Logistics and Transportation Review & 13.899 \\
10 & Supply Chain Management: An International Journal & 12.309 \\
11 & International Journal of Operations and Production Management & 11.864 \\
\hline 12 & International Journal of Logistics: Research and Applications & 11.546 \\
\hline
\end{tabular}

In addition three academic journals focused especially on informations management: Information \& Management (I\&M), Information Systems (ISYS), Internal Journal of Information Management (IJIM) were selected as well. The developed explanatory model as well as the propositions are described in more detail in the subsequent section.

\section{RESULT: EXPLANATORY MODEL TO BE FIT FOR TURBULENCE}

The explanations made in the introductory chapter result consolidated in the proposition model displayed below. In the table in this section each proposition is mentioned and the 
authors identified in the literature review supporting or assuming this interrelation too are enumerated.

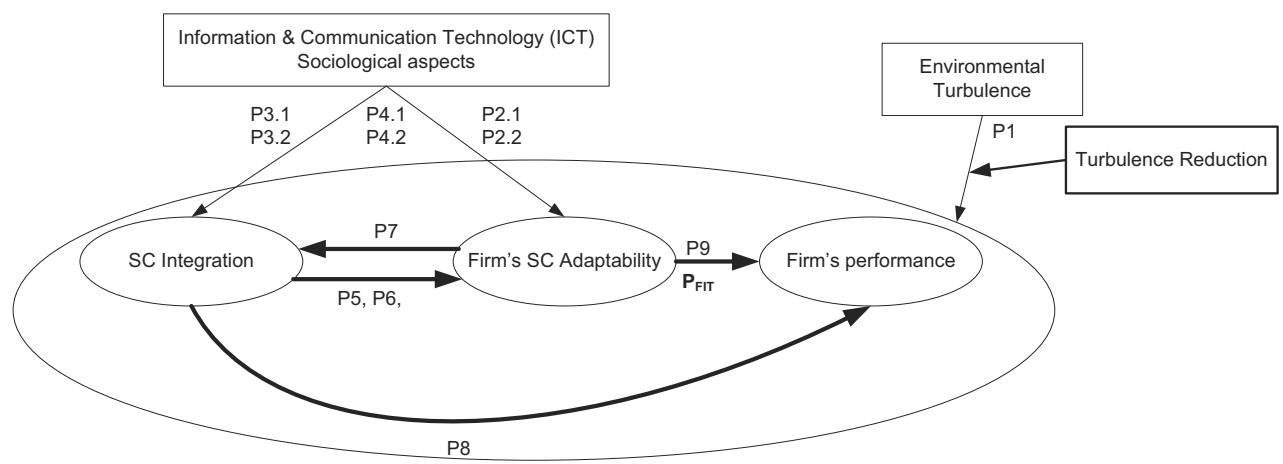

Figure1: Explanatory model of FFT

The identification of the adequate fit between the firm's SC adaptability and the level of SC integration (PFIT) dependent on the degree of environmental turbulence is the main challenge to be solved in FFT. All considerations are headed by the target function "maximization of company performance".

Prior to the identification of the ideal combination of integration and adaptability, a company has to aim to reduce environmental turbulence that affects the company's value network. Key enablers to reduce environmental turbulence are complexity reducing mechanisms (Barki and Pinsonneault [6], Siggelkow and Rivkin [17], Haleblian and Finkelstein [18], Ashmos et al. [19], Wade and Hulland [20], Gerschberger [21], Gerschberger et al. [2]). The use of these mechanisms may provide greater adaptability and allows the organization to overcome environmental turbulence (Barki and Pinsonneault [6]). 
Table2: Propositions and authors identified in the literature review

\begin{tabular}{|c|c|c|}
\hline & Proposition & Source \\
\hline P1 & $\begin{array}{l}\text { The use of turbulence reduction } \\
\text { mechanisms will attenuate the } \\
\text { effect of environmental turbulence } \\
\text { on organizations. }\end{array}$ & $\begin{array}{l}\text { Barki and Pinsonneault [6], Siggelkow and Rivkin [17], Haleblian } \\
\text { and Finkelstein [18], Ashmos et al. [19], Wade and Hulland [20] }\end{array}$ \\
\hline P2.1 & $\begin{array}{l}\text { Information \& Communication } \\
\text { Technology is a key enabler for the } \\
\text { firm's SC adaptability }\end{array}$ & $\begin{array}{l}\text { Barlow and Feng Li [22], Busquets et al. [10], Choi et al. [9], } \\
\text { Christopher [11], Dekkers and van Luttervelt [23], Duclos et al. [8], } \\
\text { Fabbe-Costes and Jahre [5], Großler et al. [24], Gunasekaran and } \\
\text { Ngai [25], Hagberg-Andersson [26], Hertz [27], Jain et al. [28], } \\
\text { Katayama and Bennett [29], Kisperska-Moron and Swierczek [30], } \\
\text { Mason-Jones et al. [31], Mohammed et al. [32], Naim and Barlow } \\
\text { [33], Pathak et al. [34], Reichhart and Holweg [35], Surana et al. } \\
\text { [36], Tang and Tomlin [37], Towill and Christopher [12], Vinod } \\
\text { Kumar et al. [38], Wang et al. [39], Wang and Wei [40], Wong et al. } \\
\text { [41], Yusuf et al. [42] }\end{array}$ \\
\hline P2.2 & $\begin{array}{l}\text { Sociological aspects are a key } \\
\text { enabler for the firm's SC } \\
\text { adaptability. }\end{array}$ & Nyhuis et al. [15], Söser et al. [43] \\
\hline P3.1 & $\begin{array}{l}\text { Information \& Communication } \\
\text { Technology is a key enabler for SC } \\
\text { integration }\end{array}$ & $\begin{array}{l}\text { Angeles [44], Cousins and Menguc [45], Devaraj et al. [46], Flynn et } \\
\text { al. [47], Frohlich and Westbrook [48], Frohlich and Westbrook [49], } \\
\text { Germain and Lyer [50], Germain et al. [51], Halley and Beaulieu } \\
\text { [52], Handfield et al. [53], Haozhe Chen et al. [54], Iyer et al. [55], } \\
\text { Kuk [56], Kulp et al. [57], Kyung Kyu Kim et al. [58], Lai et al. [59], } \\
\text { Lanier, JR. et al. [60], Lee et al. [61], Mitra and Singhal [62], } \\
\text { Narasimhan and Kim [63], Ordanini and Rubera [64], Rodrigues et } \\
\text { al. [65], Rosenzweig et al. [66], Sezen [67], Soonhong Min and } \\
\text { Mentzer [68], Stank et al. [69], Stank et al. [70], Stock et al. [71], } \\
\text { Swink et al. [72], Vachon and Klassen [73], Vickery et al. [74], } \\
\text { Wang et al. [75], Wisner [76] }\end{array}$ \\
\hline P3.2 & $\begin{array}{l}\text { Sociological aspects are a key } \\
\text { enabler for SC integration }\end{array}$ & $\begin{array}{l}\text { Angeles [44], Closs and Savitskie [77], Cousins and Menguc [45], } \\
\text { Flynn et al. [47], Germain and Lyer [50], Germain et al. [51], } \\
\text { Gimenez and Ventura [78], Gimenez and Ventura [79], Halley and } \\
\text { Beaulieu [52], Handfield et al. [53], Haozhe Chen et al. [54], Haozhe } \\
\text { Chen et al. [4], Iyer et al. [55], Kuk [56], Maloni and Benton [80], } \\
\text { Narasimhan and Soo Wook Kim [81], Narasimhan and Kim [63], } \\
\text { Ordanini and Rubera [64], Rodrigues et al. [65], Rosenzweig et al. } \\
\text { [66], Sezen [67], Soo Wook Kim [82], Soo Wook Kim [83], } \\
\text { Soonhong Min and Mentzer [68], Stank et al. [69], Stank et al. [70], } \\
\text { Stock et al. [71], Swink et al. [72], Vachon and Klassen [73], } \\
\text { Vickery et al. [74], Wang et al. [75], Wisner [76] }\end{array}$ \\
\hline P4.1 & $\begin{array}{l}\text { Information \& Communication } \\
\text { Technology is a key enabler for } \\
\text { achieving both: a higher level of } \\
\text { SC integration and a higher level of } \\
\text { the firm's SC adaptability }\end{array}$ & $\begin{array}{l}\text { Barlow and Feng Li [22], Busquets et al. [10], Choi et al. [9], } \\
\text { Christopher [11], Dekkers and van Luttervelt [23], Duclos et al. [8], } \\
\text { Fabbe-Costes and Jahre [5], Großler et al. [24], Gunasekaran and } \\
\text { Ngai [25], Hagberg-Andersson [26], Hertz [27], Jain et al. [28], } \\
\text { Katayama and Bennett [29], Kisperska-Moron and Swierczek [30], } \\
\text { Mason-Jones et al. [31], Mohammed et al. [32], Naim and Barlow } \\
\text { [33], Pathak et al. [34], Reichhart and Holweg [35], Surana et al. } \\
\text { [36], Tang and Tomlin [37], Towill and Christopher [12], Vinod } \\
\text { Kumar et al. [38], Wang et al. [39], Wang and Wei [40], Wong et al. } \\
\text { [41], Yusuf et al. [42] }\end{array}$ \\
\hline
\end{tabular}




\begin{tabular}{|c|c|c|}
\hline P4.2 & $\begin{array}{l}\text { Sciological aspects are a key } \\
\text { enabler for achieving both: a higher } \\
\text { level of SC integration and a higher } \\
\text { level of the firm's SC adaptability }\end{array}$ & $\begin{array}{l}\text { Barlow and Feng Li [22], Busquets et al. [10], Choi et al. [9], } \\
\text { Dekkers and van Luttervelt [23], Duclos et al. [8], Gates [84], } \\
\text { Goldsby et al. [85], Gosain et al. [86], Gunasekaran et al. [87], Hertz } \\
\text { [27], Jain et al. [28], Ketchen and Hult [88], Kisperska-Moron and } \\
\text { Swierczek [30], Mason-Jones et al. [31], Oloruntoba and Gray [89], } \\
\text { Pathak et al. [34], Quesada et al. [90], Surana et al. [36], Towill and } \\
\text { Christopher [12], Vinod Kumar et al. [38], Wadhwa and Saxena } \\
\text { [91], Wadhwa et al. [92], Wang and Wei [40], Wong et al. [41] }\end{array}$ \\
\hline P5 & $\begin{array}{l}\text { SC integration will be positively } \\
\text { related to the firm's SC } \\
\text { adaptability }\end{array}$ & $\begin{array}{l}\text { Bagchi et al. [93], Braunscheidel and Suresh [7], Elmuti et al. [94], } \\
\text { Gunasekaran et al. [87], Vinod Kumar et al. [38], Mohammed et al. } \\
\text { [32], Quesada et al. [90], Reichhart and Holweg [35], Rosenzweig et } \\
\text { al. [95], Sezen [96], Speier et al. [97], Swink et al. [98], Wadhwa et } \\
\text { al. [92], Wang and Wei [40], Wang et al. [39] }\end{array}$ \\
\hline P6 & $\begin{array}{l}\text { There is a trade-off between SC } \\
\text { integration and the firm's SC } \\
\text { adaptability. An increase in SC } \\
\text { integration reduces the firm's SC } \\
\text { adaptability. }\end{array}$ & $\begin{array}{l}\text { Christopher [11], Jahre and Fabbe-Costes [99], Towill and } \\
\text { Christopher [12], White et al. [13] }\end{array}$ \\
\hline P7 & $\begin{array}{l}\text { There is a trade-off between SC } \\
\text { integration and the firm's SC } \\
\text { adaptability. An increase in the } \\
\text { firm's SC adaptability reduces SC } \\
\text { integration. }\end{array}$ & Christopher [11], Jahre and Fabbe-Costes [99], White et al. [13] \\
\hline P8 & $\begin{array}{l}\text { Under conditions of low } \\
\text { environmental turbulence, a higher } \\
\text { degree of SC integration will be } \\
\text { positively related to the firm's } \\
\text { performance. }\end{array}$ & Iyer et al. [55] \\
\hline P9 & $\begin{array}{l}\text { Under conditions of high } \\
\text { environmental turbulence, a high } \\
\text { degree of SC adaptability will be } \\
\text { positively related to the firm's } \\
\text { performance. }\end{array}$ & Fabbe-Costes and Jahre [5], Iyer et al. [55] \\
\hline PFIT & $\begin{array}{l}\text { Under conditions of environmental } \\
\text { turbulence, a high degree of SC } \\
\text { adaptability in the entire network } \\
\text { will be positively related to the } \\
\text { firm's performance while } \\
\text { simultaneously keeping a high } \\
\text { degree of SC integration with the } \\
\text { permanent }\end{array}$ & Fabbe-Costes and Jahre [5], Iyer et al. [55] \\
\hline
\end{tabular}




\section{CONCLUDING REMARKS AND FURTHER RESEARCH ACTIVITIES}

The model propositions described above are the subject of consideration in the strategic projects executed in the research programme of FFT.

The investigation of the adequate fit between SC adaptability and SC integration is answered unsatisfactorily in the literature and therefore of central importance for this research programme. One reason is that even though adaptability is defined and mostly used in concensus, there are no common measures to determine the extent of adaptability in a company and its global value network (Fabbe-Costes and Jahre [5]). Currently, there is no unified approach to measure adaptability in a global value network.

In the research programme of FFT a decision model to measure adaptability and to identify the critical nodes within a value network will be built on the very promising graphmodel introduced by Müssigmann [100], Albani and Müssigmann [101], Albani et al. [102], Albani et al. [103], Müssigmann [104]. The expected result is the development of a dynamic segmentation filter that enables to consistently answer the question according to the most important adjusting levers within the relevant value network under consideration of changing business goals.

Prior to the development of a measurement model the proposition of the explanatory model have to be tested with a large sample quantitative survey. The focus of this survey is on Austrian companies as the literature review showed that only a few studies focused on European companies and no study focused on Austrian companies exists.

\section{REFERENCES}

1. R. Angeli, Aufbau und Koordination dynamischer Unternehmensnetzwerke, in Wissenschaftssymposium Logistik der BVL, BVL, Ed., 2002.

2. M. Gerschberger, C. Söser, and F. Staberhofer, Complexity in Global Value Networks: Introduction of a promising model to determine complexity, in Configuring manufacturing value chains: Responding to an uncertain world, University of Cambridge, Ed., 2009, pp. 142-150.

3. R. Frankel, Y.A. Bolumole, R.A. Eltantawy, A. Paulraj, and G.T. Gundlach, The domain and scope of SCM's foundational disciplines - insights and issues to advance research, Journal of Business Logistics, 29, 1, pp. 1-30, 2008.

4. Haozhe Chen, P.J. Daugherty, and A.S. Roath, Defining and operationalizing supply chain process integration, Journal of Business Logistics, 30, 1, pp. 63-84, 2009.

5. N. Fabbe-Costes, and M. Jahre, Flexible and Integrated Supply Chains - Towards an innovative Research Platform, Proceedings NOFOMA, pp. 191-207, 2009. 
6. H. Barki, and A. Pinsonneault, A Model of Organizational Integration, Implementation Effort, and Performance, Organization Science, 16, 2, pp. 165-179, 2005.

7. M.J. Braunscheidel, and N.C. Suresh, The organizational antecedents of a firm's supply chain agility for risk mitigation and response, Journal of Operations Management, 27, 2, pp. 119-140, 2009.

8. L.K. Duclos, R.J. Vokurka, and R.R. Lummus, A conceptual model of supply chain flexibility, Industrial Management \& Data Systems, 103, 6, p. 446, 2003.

9. T.Y. Choi, K.J. Dooley, and M. Rungtusanatham, Supply networks and complex adaptive systems: control versus emergence, Journal of Operations Management, 19, 3, pp. 351-366, 2001.

10. J. Busquets, J. Rodon, and J. Wareham, Adaptability in Smart Business Networks: An exploratory case in the insurance industry, Decision Support Systems, In Press, Corrected Proof.

11. M. Christopher, The Agile Supply Chain, Industrial Marketing Management, 29, 1, pp. 37-44, 2000.

12. D. Towill, and M. Christopher, The Supply Chain Strategy Conundrum: To be Lean Or Agile or To be Lean And Agile?, International Journal of Logistics: Research \& Applications, 5, 3, pp. 299-309, 2002.

13. A. White, E.M. Daniel, and M. Mohdzain, The role of emergent information technologies and systems in enabling supply chain agility, International Journal of Information Management, 25, 5, pp. 396-410, 2005.

14. C. Söser, M. Gerschberger, and C. Engelhardt-Nowitzki, Supply Chain Integration and Adaptability - Towards an innovative research platform, in The 1st International Conference on Logistics and Transport (ICLT) 2009: Innovative Management in Global Logistics and Transport, ICLT09, Ed., 2009.

15. P. Nyhuis, G. Reinhart, and E. Abele, Wandlungsfähige Produktionssysteme: Heute die Industrie von morgen gestalten. Garbsen: PZH Produktionstechnisches Zentrum, 2008.

16. D.A. Menachof, B.J. Gibson, J.B. Hanna, and A.E. Whiteing, An analysis of the value of supply chain management periodicals, International Journal of Physical Distribution \& Logistics Management, 39, 2, pp. 145-166, 2009.

17. N. Siggelkow, and J.W. Rivkin, Speed and Search: Designing Organizations for Turbulence and Complexity, Organization Science, Vol. 16, March-April, pp. 101-122, 2005.

18. J. Haleblian, and S. Finkelstein, Top Management Team Size, Ceo Dominance and Firm Performance: The moderating roles of environmental turbulence and discretion, Academy of Management Journal, 1993, 4, pp. 844-863, Vol. 36,

19. D.P. Ashmos, D. Duchon, and R.R. McDaniel, Organizational responses to complexity: The effect on organizational performance, Journal of Organizational Change Management, 13, 6, pp. 577-595, 2000.

20. M. Wade, and J. Hulland, The resource-based view and information systems research: Review, extension and suggestions for future research, MIS Quarterly, 28, 1, pp. 107142, 2004.

21. M. Gerschberger, Komplexität in Unternehmensnetzwerken: komplexitätsbasierte Identifikation der relevanten Partner im Unternehmensnetzwerk, in Produktion und Forschung, C. Engelhardt-Nowitzki, Ed., Maßßen: Shaker, 2009, pp. 1-13.

22. A. Barlow, and Feng Li, E-supply chains: understanding current and future opportunities and barriers, International Journal of Information Technology \& Management, 6, 2-4, pp. 1-1, 2007. 
23. R. Dekkers, and C.A. van Luttervelt, Industrial networks: capturing change ability?, International Journal of Networking \& Virtual Organisations, 3, 1, pp. 1-24, 2006.

24. A. Großler, A. Grubner, and P.M. Milling, Organisational adaptation processes to external complexity, International Journal of Operations \& Production Management, 26, 3, pp. 254-281, 2006.

25. A. Gunasekaran, and E.W.T. Ngai, Information systems in supply chain integration and management, European Journal of Operational Research, 159, 2, pp. 269-295, 2004.

26. A. Hagberg-Andersson, Does adaptation pay off?, Industrial Marketing Management, 35, 2, pp. 202-209, 2006.

27. S. Hertz, Dynamics of Alliances in Highly Integrated Supply Chain Networks, International Journal of Logistics: Research \& Applications, 4, 2, pp. 237-256, 2001.

28. V. Jain, L. Benyoucef, and S.G. Deshmukh, What's the buzz about moving from 'lean' to 'agile' integrated supply chains? A fuzzy intelligent agent-based approach, International Journal of Production Research, 46, 23, pp. 6649-6677, 2008.

29. H. Katayama, and D. Bennett, Agility, Adaptability and Leanness: A Comparison of Concepts and a Study of Practice, in Agile Manufacturing: The 21st Century Competitive Strategy, Oxford: Elsevier Science Ltd, 2001, pp. 483-496.

30. D. Kisperska-Moron, and A. Swierczek, The agile capabilities of Polish companies in the supply chain: An empirical study, International Journal of Production Economics, 118, 1, pp. 217-224, 2009.

31. R. Mason-Jones, B. Naylor, and D.R. Towill, Lean, agile or leagile? Matching your supply chain to the marketplace, International Journal of Production Research, 38, 17, pp. 4061-4070, 2000.

32. I.R. Mohammed, R. Shankar, and D.K. Banwet, Creating flex-lean-agile value chain by outsourcing: An ISM-based interventional roadmap, Business Process Management Journal, 14, 3, pp. 338-389, 2008.

33. M. Naim, and J. Barlow, An innovative supply chain strategy for customized housing, Construction Management \& Economics, 21, 6, pp. 593-602, 2003.

34. S.D. Pathak, J.M. Day, A. Nair, W.J. Sawaya, and M.M. Kristal, Complexity and Adaptivity in Supply Networks: Building Supply Network Theory Using a Complex Adaptive Systems Perspective, Decision Sciences, 38, 4, pp. 547-580, 2007.

35. A. Reichhart, and M. Holweg, Creating the customer-responsive supply chain: a reconciliation of concepts, International Journal of Operations \& Production Management, 27, 11, pp. 1144-1172, 2007.

36. A. Surana, S. Kumara, M. Greaves, and U.N. Raghavan, Supply-chain networks: a complex adaptive systems perspective, International Journal of Production Research, 43, 20, pp. 4235-4265, 2005.

37. C. Tang, and B. Tomlin, The power of flexibility for mitigating supply chain risks, International Journal of Production Economics, 116, 1, pp. 12-27, 2008.

38. Vinod Kumar, Kamel A.Fantazy, Uma Kumar, and Todd A.Boyle, Implementation and management framework for supply chain flexibility, Journal of Enterprise Information Management, 19, 3, pp. 303-319, 2006.

39. E.T.G. Wang, J.C.F. Tai, and H.-L. Wei, A Virtual Integration Theory of Improved Supply-Chain Performance, Journal of Management Information Systems, 23, 2, pp. 41-64, 2006.

40. E.T.G. Wang, and H.-L. Wei, Interorganizational Governance Value Creation: Coordinating for Information Visibility and Flexibility in Supply Chains, Decision Sciences, 38, 4, pp. 647-674, 2007. 
41. C.W.Y. Wong, K.-h. Lai, and E.W.T. Ngai, The role of supplier operational adaptation on the performance of IT-enabled transport logistics under environmental uncertainty, International Journal of Production Economics, In Press, Corrected Proof, 2009.

42. Y.Y. Yusuf, A. Gunasekaran, E.O. Adeleye, and K. Sivayoganathan, Agile supply chain capabilities: Determinants of competitive objectives, European Journal of Operational Research, 159, 2, pp. 379-392, 2004.

43. C. Söser, M. Gerschberger, and C. Engelhardt-Nowitzki, Supply Chain Integration and Adaptability - Towards an innovative research platform, in The 1st International Conference on Logistics and Transport (ICLT) 2009: Innovative Management in Global Logistics and Transport, ICLT09, Ed., 2009.

44. R. Angeles, Anticipated IT infrastructure and supply chain integration capabilities for RFID and their associated deployment outcomes, International Journal of Information Management, 29, 3, pp. 219-231, 2009.

45. P.D. Cousins, and B. Menguc, The implications of socialization and integration in supply chain management, Journal of Operations Management, 24, 5, pp. 604-620, 2006.

46. S. Devaraj, L. Krajewski, and J.C. Wei, Impact of eBusiness technologies on operational performance: The role of production information integration in the supply chain: Supply Chain Management in a Sustainable Environment; Special Issue on Frontiers of Empirical Supply Chain Research, Journal of Operations Management, 25, 6, pp. 1199-1216, 2007.

47. B.B. Flynn, B. Huo, and X. Zhao, The impact of supply chain integration on performance: A contingency and configuration approach, Journal of Operations Management, In Press, Corrected Proof, 2009.

48. M.T. Frohlich, and R. Westbrook, Arcs of integration: an international study of supply chain strategies, Journal of Operations Management, 19, 2, pp. 185-200, 2001.

49. M.T. Frohlich, and R. Westbrook, Demand chain management in manufacturing and services: web-based integration, drivers and performance, Journal of Operations Management, 20, 6, pp. 729-745, 2002.

50. R. Germain, and K.N.S. Lyer, The interaction of internal and downstream integration and its association with performance, Journal of Business Logistics, 27, 2, pp. 29-52, 2006.

51. R. Germain, C. Claycomb, and C. Dröge, Supply chain variability, organizational structure, and performance: The moderating effect of demand unpredictability, Journal of Operations Management, 26, 5, pp. 557-570, 2008.

52. A. Halley, and M. Beaulieu, Mastery of operational competencies in the context of supply chain management, Supply Chain Management: An International Journal, 14, 1, pp. 49-63, 2009.

53. R. Handfield, K. Petersen, P. Cousins, and B. Lawson, An organizational entrepreneurship model of supply management integration and performance outcomes, International Journal of Operations \& Production Management, 29, 1/2, pp. 100-126, 2009.

54. Haozhe Chen, D.D. Mattioda, and P.J. Daugherty, Firm-wide integration and firm performance, The International Journal of Logistics Management, 18, 1, pp. 5-21, 2007.

55. K.N.S. Iyer, R. Germain, and C. Claycomb, B2B e-commerce supply chain integration and performance: A contingency fit perspective on the role of environment, Information \& Management, 46, 6, pp. 313-322, 2009. 
56. G. Kuk, Effectiveness of vendor-managed inventory in the electronics industry: determinants and outcomes, Information \& Management, 41, 5, pp. 645-654, 2004.

57. S.C. Kulp, H.L. Lee, and E. Ofek, Manufacturer Benefits from Information Integration with Retail Customers, Management Science, 50, 4, pp. 431-444, 2004.

58. Kyung Kyu Kim, N.S. Umanath, and Bum Hun Kim, An Assessment of Electronic Information Transfer in B2B Supply-Channel Relationships, Journal of Management Information Systems, 22, 3, pp. 293-320, 2005.

59. K.-h. Lai, C.W.Y. Wong, and T.C.E. Cheng, A coordination-theoretic investigation of the impact of electronic integration on logistics performance, Information \& Management, 45, 1, pp. 10-20, 2008.

60. D. Lanier, JR., W.F. Wempe, and Z.G. Zacharia, Concentrated supply chain membership and financial performance: Chain- and firm-level perspectives, Journal of Operations Management, In Press, Corrected Proof, 2009.

61. C.W. Lee, I.-W.G. Kwon, and D. Severance, Relationship between supply chain performance and degree of linkage among supplier, internal integration, and customer, Supply Chain Management: An International Journal, 12, 6, pp. 444-452, 2007.

62. S. Mitra, and V. Singhal, Supply chain integration and shareholder value: Evidence from consortium based industry exchanges, Journal of Operations Management, 26, 1, pp. 96-114, 2008.

63. R. Narasimhan, and S.W. Kim, Effect of supply chain integration on the relationship between diversification and performance: evidence from Japanese and Korean firms, Journal of Operations Management, 20, 3, pp. 303-323, 2002.

64. A. Ordanini, and G. Rubera, Strategic capabilities and internet resources in procurement, International Journal of Operations \& Production Management, 28, 1, pp. 27-52, 2008.

65. A.M. Rodrigues, T.P. Stank, and D.F. Lynch, Linking Strategy, Structure, Process, and Performance in Integrated Logistics, Journal of Business Logistics, 25, 2, pp. 65-94, 2004.

66. E.D. Rosenzweig, A.V. Roth, and J.W. Dean, The influence of an integration strategy on competitive capabilities and business performance: An exploratory study of consumer products manufacturers, Journal of Operations Management, 21, 4, pp. 437456, 2003.

67. B. Sezen, Relative effects of design, integration and information sharing on supply chain performance, Supply Chain Management: An International Journal, 13, 3, pp. 233-240, 2008.

68. Soonhong Min, and J.T. Mentzer, Developing and Measuring Supply Chain Management Concepts, Journal of Business Logistics, 25, 1, pp. 63-99, 2004.

69. T.P. Stank, S.B. Keller, and D.J. Closs, Performance Benefits of Supply Chain Logistical Integration, Transportation Journal, 41, 2/3, pp. 32-46, 2001.

70. T.P. Stank, S.B. Keller, and P.J. Daugherty, Supply Chain Collaboration and Logistical Service Performance, Journal of Business Logistics, 22, 1, pp. 29-48, 2001.

71. G.N. Stock, N.P. Greis, and J.D. Kasarda, Enterprise logistics and supply chain structure: the role of fit, Journal of Operations Management, 18, 5, pp. 531-547, 2000.

72. M. Swink, R. Narasimhan, and C. Wang, Managing beyond the factory walls: Effects of four types of strategic integration on manufacturing plant performance, Journal of Operations Management, 25, 1, pp. 148-164, 2007. 
73. S. Vachon, and R.D. Klassen, Extending green practices across the supply chain, International Journal of Operations \& Production Management, 26, 7, pp. 795-821, 2006.

74. S.K. Vickery, J. Jayaram, C. Droge, and R. Calantone, The effects of an integrative supply chain strategy on customer service and financial performance: an analysis of direct versus indirect relationships, Journal of Operations Management, 21, 5, pp. 523539, 2003.

75. E.T.G. Wang, J.C.F. Tai, and H.-L. Wei, A Virtual Integration Theory of Improved Supply-Chain Performance, Journal of Management Information Systems, 23, 2, pp. 41-64, 2006.

76. J.D. Wisner, A Structural Equation Model of Supply Chain Management Strategies and Firm Performance, Journal of Business Logistics, 24, 1, pp. 1-26, 2003.

77. D.J. Closs, and K. Savitskie, Internal and External Logistics Information Technology Integration, The International Journal of Logistics Management, 14, 1, pp. 63-76, 2003.

78. C. Gimenez, and E. Ventura, Supply Chain Management as a Competitive Advantage in the Spanish Grocery Sector, The International Journal of Logistics Management, 14, 1, pp. 77-88, 2003.

79. C. Gimenez, and E. Ventura, Logistics-production, logistics-marketing and external integration: Their impact on performance, International Journal of Operations \& Production Management, 25, 1, pp. 20-38, 2005.

80. M. Maloni, and W.C. Benton, Power influences in the Supply Chain, Journal of Business Logistics, 21, 1, pp. 49-73, 2000.

81. R. Narasimhan, and Soo Wook Kim, Information System Utilization Strategy for Supply Chain Integration, Journal of Business Logistics, 22, 2, pp. 51-75, 2001.

82. Soo Wook Kim, Effects of supply chain management practices, integration and competition capability on performance, Supply Chain Management: An International Journal, 11, 3, pp. 241-248, 2006.

83. Soo Wook Kim, The effect of supply chain integration on the alignment between corporate competitive capability and supply chain operational capability, International Journal of Operations \& Production Management, 26, 10, pp. 1084-1107, 2006.

84. E. Gates, The defence firm of the future, Defence \& Peace Economics, 15, 6, pp. 509517, 2004.

85. T.J. Goldsby, S.E. Griffis, and A.S. Roath, Modeling lean, agile, and leagile supply chain strategies, Journal of Business Logistics, 27, 1, pp. 57-80, 2006.

86. S. Gosain, A. Malhotra, and O.A. El Sawy, Coordinating for Flexibility in e-Business Supply Chains, Journal of Management Information Systems, 21, 3, pp. 7-45, 2004.

87. A. Gunasekaran, K.-h. Lai, and T.C. Edwin Cheng, Responsive supply chain: A competitive strategy in a networked economy, Omega, 36, 4, pp. 549-564, 2008.

88. D.J. Ketchen, and G.T.M. Hult, Bridging organization theory and supply chain management: The case of best value supply chains, Journal of Operations Management, 25, 2, pp. 573-580, 2007.

89. R. Oloruntoba, and R. Gray, Humanitarian aid: an agile supply chain?, Supply Chain Management, 11, 2, pp. 115-120, 2006.

90. G. Quesada, R. Rachamadugu, M. Gonzalez, and J.L. Martinez, Linking order winning and external supply chain integration strategies, Supply Chain Management, 13, 4, pp. 296-303, 2008.

91. S. Wadhwa, and A. Saxena, Decision knowledge sharing: flexible supply chains in KM context, Production Planning \& Control, 18, 5, pp. 436-452, 2007. 
92. S. Wadhwa, A. Saxena, and F.T.S. Chan, Framework for flexibility in dynamic supply chain management, International Journal of Production Research, 46, 6, pp. 13731404, 2008.

93. P.K. Bagchi, B.C. Ha, T. Skjoett-Larsen, and L.B. Soerensen, Supply chain integration: a European survey, The International Journal of Logistics Management, 16, 2, pp. 275 294, 2005.

94. D. Elmuti, W. Minnis, and M. Abebe, Longitudinal assessment of an integrated industrial supply chain, Supply Chain Management: An International Journal, 13, 2, pp. 151-159, 2008.

95. E.D. Rosenzweig, A.V. Roth, and J.W. Dean, The influence of an integration strategy on competitive capabilities and business performance: An exploratory study of consumer products manufacturers, Journal of Operations Management, 21, 4, pp. 437456, 2003.

96. B. Sezen, Relative effects of design, integration and information sharing on supply chain performance, Supply Chain Management: An International Journal, 13, 3, pp. 233-240, 2008.

97. C. Speier, D. Mollenkopf, and T.P. Stank, The Role of Information Integration in Facilitating 21st Century Supply Chains: A Theory-Based Perspective, Transportation Journal, 47, 2, pp. 21-38, 2008.

98. M. Swink, R. Narasimhan, and C. Wang, Managing beyond the factory walls: Effects of four types of strategic integration on manufacturing plant performance, Journal of Operations Management, 25, 1, pp. 148-164, 2007.

99. M. Jahre, and N. Fabbe-Costes, Adaptation and adaptability in logistics networks, International Journal of Logistics: Research \& Applications, 8, 2, pp. 143-157, 2005.

100. N. Müssigmann, Strategische Liefernetze: Evaluierung, Auswahl, kritische Knoten, Univ., Diss.--Augsburg, 2006. 1st ed. Wiesbaden: Dt. Univ.-Verl., 2007.

101. A. Albani, and N. Müssigmann, Evaluation of Strategic Supply Networks, Meersmann, R.; Tari, Z.; Herrero, P. (Hrsg.): On the Move to Meaningful Internet Systems 2005: OTM 2005 Workshops. Agia Napa, Cyprus, October 31 - November 4, 2005. Springer Lecture Notes in Computer Science (LNCS) 3762., pp. 582-591, 2005.

102. A. Albani, N. Müssigmann, and K. Turowski, Extended ERP: Dynamic Strategic Supply Network Development, Stefanou, C. J. (Hrsg.): 2nd ICESAcc 2005 - Second International Conference on Enterprise Systems and Accounting. 11 -, pp. 463-476, 2005.

103. A. Albani, N. Müssigmann, and J.M. Zaha, A Reference Model for Strategic Supply Network Development, in Reference Modeling for Business Systems Analysis, P. Loos, and P. Fettke, Eds., Hershey, USA: Idea Group Inc., 2006, pp. 217-240.

104. N. Müssigmann, Mitigating Risk during Strategic Supply Network Modeling, in Managing risks in supply chains: How to build reliable collaboration in logistics, W. Kersten, B. Bemeleit, and Kersten-Blecker, Eds., Berlin: Schmidt, 2006, pp. 213-226. 


\title{
A DECOMPOSITION STRATEGY FOR LARGE-SCALE SCHEDULING PROBLEMS IN MULTI-STAGE MULTI-PRODUCT BATCH PLANTS
}

\author{
G.M. Kopanos ${ }^{1}$, L. Puigjaner ${ }^{1}$ and C.A. Méndez ${ }^{2}$ \\ ${ }^{1}$ Department of Chemical Engineering, Universitat Politècnica de Catalunya, \\ ETSEIB, Av. Diagonal 647, Barcelona 08028, Spain \\ ${ }^{2}$ INTEC (UNL-CONICET), Güemes 3450, Santa Fe 3000, Argentina
}

\begin{abstract}
An efficient two-stage decomposition solution strategy for solving real-world scheduling problems in multi-product multi-stage batch plants is presented. The proposed method has as a core a mathematical model. The MILP-based solution strategy consists of a constructive step, wherein a feasible and good solution is rapidly generated by following some criteria, and an improvement step, wherein the initial solution is systematically enhanced by adopting several rescheduling techniques. The proposed strategy perfomance is tested on a number of problem instances of a realworld multi-product multi-stage pharmaceuticals scheduling problem. High quality solutions are reported with low computational effort.
\end{abstract}

\section{INTRODUCTION}

Nowadays, it is widely recognized that the gap between scheduling practice and theory is still evident. New academic developments are mostly tested on relatively small problems whereas current real-world industrial applications consist of hundreds of batches, numerous multiple units available for each task and long sequence of processing stages. Additionally, there also exist a wide range of operational constraints which should be taken into account in order to guarantee the feasibility of the proposed solution. Most industrial problems are very hard-constrained, thus optimization solvers have to find the optimal or near-optimal solutions in a huge search space with a relatively small feasible region.

Since most industrial scheduling problems are large-scale combinatorial and complex optimization problems, they rarely can be solved to optimality within a reasonable amount of computational time. In industrial environments, computational time tends to be thus as 
important as the scheduling problem itself; since industry demands solutions that are both optimal, or at least close-optimal, and quick to be reached. As a result, heuristic or metaheuristic techniques have been developed in order to reduce the computational burden of the addressed problem. For instance, genetic algorithms, simulation annealing, tabu search, particle swarm and ant colony optimization methods have been used in a variety of scheduling problems. Despite the fact that the aforementioned methods generate fast solutions, they usually neither guarantee optimality, or near-optimality, nor provide reliable solutions. Moreover, these techniques are strongly problem-specific and they cannot be considered as standard (general) solution strategies.

In order to make the use of exact methods more attractive in real-world applications, increasing effort has been oriented towards the development of systematic techniques that allow maintaining the number of decisions at a reasonable level, even for large-scale problems. A reduced search space usually results in manageable model sizes that often guarantee a more stable and predictable optimization model behavior. Furthermore, once the best possible feasible solution has been generated in the short time, optimization-based methods could be employed to gradually enhance a non-optimal solution in low computational effort. An apparent drawback of these techniques is that optimality can no longer be assured. Nevertheless, bear in mind that requiring optimality may not be relevant in many industrial scenarios mainly due to the following: (i) a very short time is usually available to generate a solution and send it to the plant floor, (ii) optimality is easily lost because of the dynamic nature of industrial environments, (iii) implementing the schedule as such is limited by the real process, and (iv) only a part of the real scheduling goals are taken into account since not all scheduling objectives can be quantified. Refer to Méndez et al. [1] for a detailed review of the main methods used to deal with large-scale scheduling problems.

\section{MATHEMATICAL FORMULATION}

The Mixed-Integer Linear Programming (MILP) model used is based on the global precedence sequencing concept, introduced by Röslof et al. [2]. The mathematical model formulation can be found in Méndez \& Cerdá [3]. Note that global precedence formulations result in models with small model size and they are computationally faster on average.

However, a drawback of these models is that they cannot optimize objectives containing sequence-dependent changeover issues (such as costs, etc.). For this reason, a new unit- 
specific general precedence framework, for scheduling multi-product multi-stage batch plants, has been recently developed by Kopanos et al. [4], as a general mathematical formulation, which is able to cope with any objective function.

\section{MILP-BASED SOLUTION STRATEGY}

The proposed MILP-based solution strategy has as a core a MILP scheduling framework and it consists of two procedure steps: (i) the constructive step, and (ii) the improvement step. The generation of a feasible schedule in short time is the objective in the constructive step. Afterwards, this schedule is gradually improved by implementing some rescheduling techniques, in the improvement step. Thus, a feasible and good schedule can be finally obtained. It follows the description of the proposed solution strategy steps (see Figure 1).
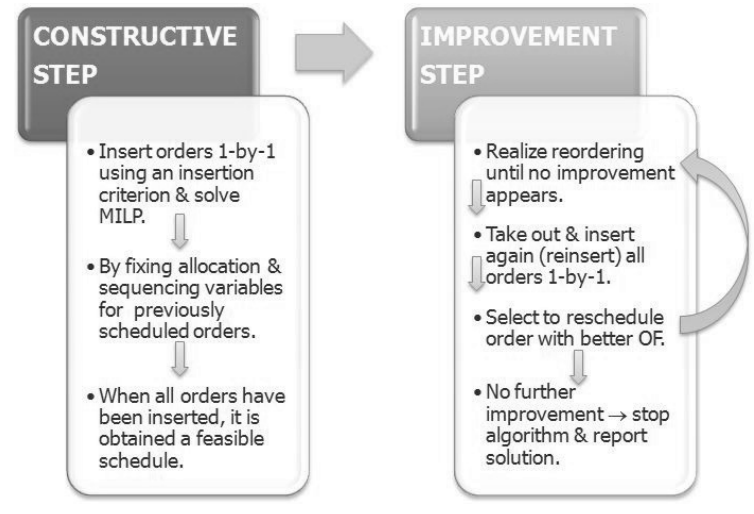

Figure 1. MILP-based solution strategy scheme.

\subsection{Constructive step}

The constructive step is performed in an iterative mode. A predefined number of product orders are scheduled at each iteration, with lower degrees of freedom; until all product orders are finally scheduled. The number of orders used in each iteration should be small enough to ensure the quick resolution of each iteration, and thus generating a feasible schedule in short time. In this study, it is proposed to insert (schedule) product orders one-by-one, since it has been observed, after a series of experiments, that insertion of a higher number of products per iteration: (i) do not guarantee a better constructive step schedule, and (ii) it is more computationally expensive. 
After each iteration, allocation and global sequencing binary variables for the previously scheduled product orders are fixed in order to reduce the computational effort. In other words, unit allocation decisions and relative sequencing relations of the already scheduled product orders cannot be modified in the following iterations. However, timing decisions may change thus permitting the insertion of new inserted product orders among the previously scheduled product orders. When all product orders have been inserted, a feasible schedule can be finally obtained in relatively short time. Figure 2 delineates an illustrative example (single-stage products and single-unit) of the allowed sequences when a product $D$ is inserted to a current schedule containing products $A, B$, and $C$. Note that just 4 sequences are permitted, instead of the 24 possible sequences, thus reducing significantly the computational cost.

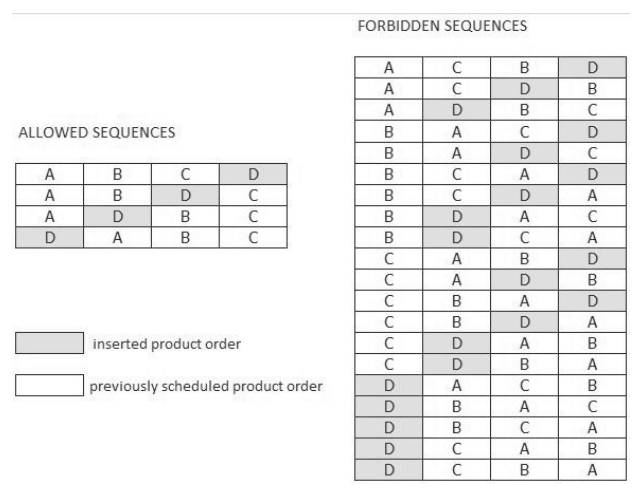

Figure 2. Illustrative example for allowed sequences in constructive step.

\subsubsection{Insertion criterion}

In order to decrease the possibility of obtaining a bad constructive step schedule, an insertion criterion could be adopted regarding the product orders' insertion sequence. It is proposed to insert first the products will less unit-stage allocation flexibility. In other words, products with a lower number of alternative units should be scheduled first. By doing so, unit allocation decisions are first made for the less unit-stage-flexible products.

Lets consider a single-stage two-product $(A \& B)$ batch plant with two parallel processing units $(J 1 \& J 2)$. The product's $A$ processing time on unit $J 1$ is $3 \mathrm{hrs}$ and on unit $J 2$ equals to 2 hrs. Product $B$ can be only processed on unit $J 2$ in $3 \mathrm{hrs}$. The minimization of makespan is the optimization goal. Lets consider the following insertion sequences: the case I that first is inserted product $A$ and afterwards product $B$; which opposes our proposed insertion criterion, and the case II that first is inserted product $B$ and then product $A$; in accordance with our 
insertion criterion. Observe that the first insertion strategy (case I) results in a makespan equals to 5 hrs. Both products are allocated to unit $J 1$. Following our insertion criterion (case II) a makespan of $3 \mathrm{hrs}$ is obtained. Figure 3 illustrates the schedules for both cases.

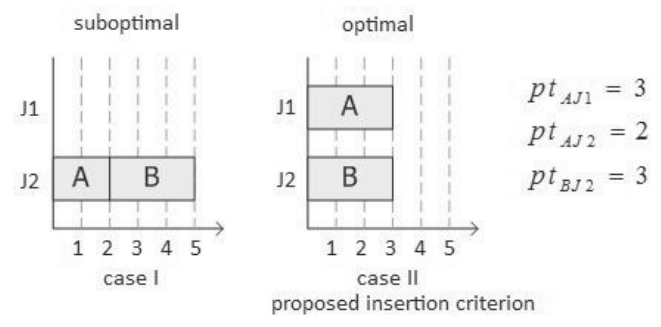

Figure 3: Illustrative example for insertion criterion.

\subsection{Improvement step}

The initial feasible schedule provided by the constructive step can be improved through reordering and/or reassignment operations; in accordance with the main rescheduling concepts of the work presented by Mendez \& Cerdá [3]. The improvement step is a two-stage closed loop procedure. It consists of the reordering stage and the reinsertion stage, which are performed sequentially until no improvement is observed. It follows the description of the improvement step's stages.

\subsubsection{Reordering stage}

In this stage, unit allocation decisions maintain fixed and reordering actions are iteratively applied on the initial schedule until no further improvement is observed. A full unit reordering tactic results impractical due to the large number of batches and processing units in real-world industrial scheduling problems. Instead, the alternative of limited reordering operations could improve the current schedule with relatively low computational effort.

It is a common sense that there exists a strong trade-off between the degrees of freedom and the resolution time. In an industrial environment, the scheduler should appropriately define the reordering tactic/limitations, followed in this step, depending on the scheduling problem's complexity. In this study, a local reordering tactic is adopted. Concretely, reordering of batches with just their direct predecessor or successor are only allowed in order to preserve a low computational cost. An illustrative example is included here to highlight the local reordering computationally benefits. Lets consider the reordering scheduling problem of 4 single-stage products $(A, B, C$, and $D)$ on a single-unit. As Figure 4 shows, a local 
reordering policy will only examine 4 potential sequences instead of the 23 total possible sequences. On the one hand, solution quality is probably decreased since one of the 19 unexplored sequences may yield to a better solution. On the other hand, the research space is significantly reduced and thus the quick resolution of the rescheduling problem is favored. Have in mind that considering the whole set of possible sequences impacts drastically the computational performance of the reordering step. Other less-limited reordering tactics could be also easily applied. The interested reader is referred to the work of Méndez \& Cerdá [3].
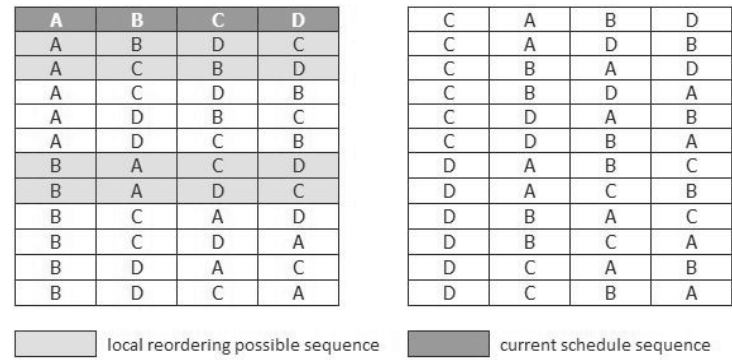

Figure 4. Illustrative example for local reordering.

\subsubsection{Reinsertion stage}

The reordering step's schedule constitutes the initial schedule in the reallocation stage. Unit allocation and sequencing decisions for a small number of product orders are left free. Let refer to these product orders as reinserted orders. The remaining product orders' unit assignment decisions as well as sequencing decisions, among them but reinserted orders, are fixed. In other words, some products orders may be extracted from the current scheduled and they are reinserted aiming at improving the initial schedule.

In this study, since our scope is to proposed a general standard algorithm for large-scale industrial scheduling problems, we adopt the lowest number of reinsertion orders, that is one at a time, in order to favor low resolution times. The scheduler could set the number and the set of reinserted orders depending on the scheduling problem under question. In the standard reinsertion stage, all product orders are reinserted one-by-one. Therefore, the number of iterations in this stage equals the number of product orders. Afterwards, the solutions of all reinserted orders (iterations) are compared and it is finally selected the best one. If the best solution of this stage is better that the one of the reordering stage, then the algorithm goes to the reordering stage again. In the contrary, the solution algorithm stops and reports the best solution found. 


\section{PHARMACEUTICALS CASE STUDY}

A real-world multi-product multi-stage pharmaceuticals batch plant is considered. The scheduling problem of a considerable high number of product orders (30 and 60$)$ in the 17 plant's processing units is addressed. Product orders should pass from 5 to 6 processing stages as Figure 5 depicts. It is noted that some products do not pass from the third processing stage. The pharmaceuticals plant operates in Unlimited Intermediate Storage (UIS) policy.

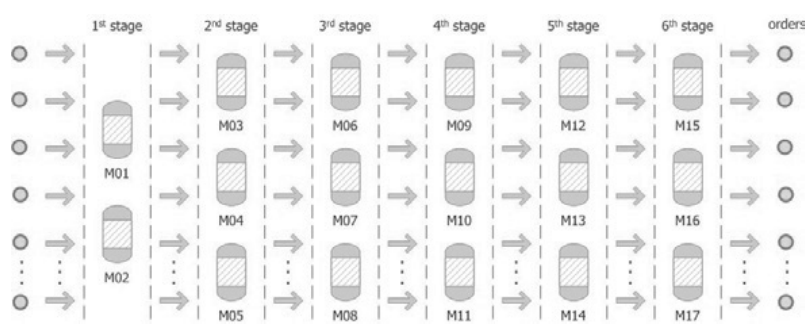

Figure 5. Pharmaceuticals multi-stage batch process.

Two different problem instances have been addressed, regarding the total number of products: (i) 30 product orders (168 batches), and (ii) 60 products (336 batches); minimizing makespan. The problems were solved in GAMS 22.8 (CPLEX 11.0), in a Dell Inspiron 1520 ( $2 \mathrm{GHz}, 2 \mathrm{~GB}$ RAM). Note that a pure MILP model cannot solve even a case with 8 products.

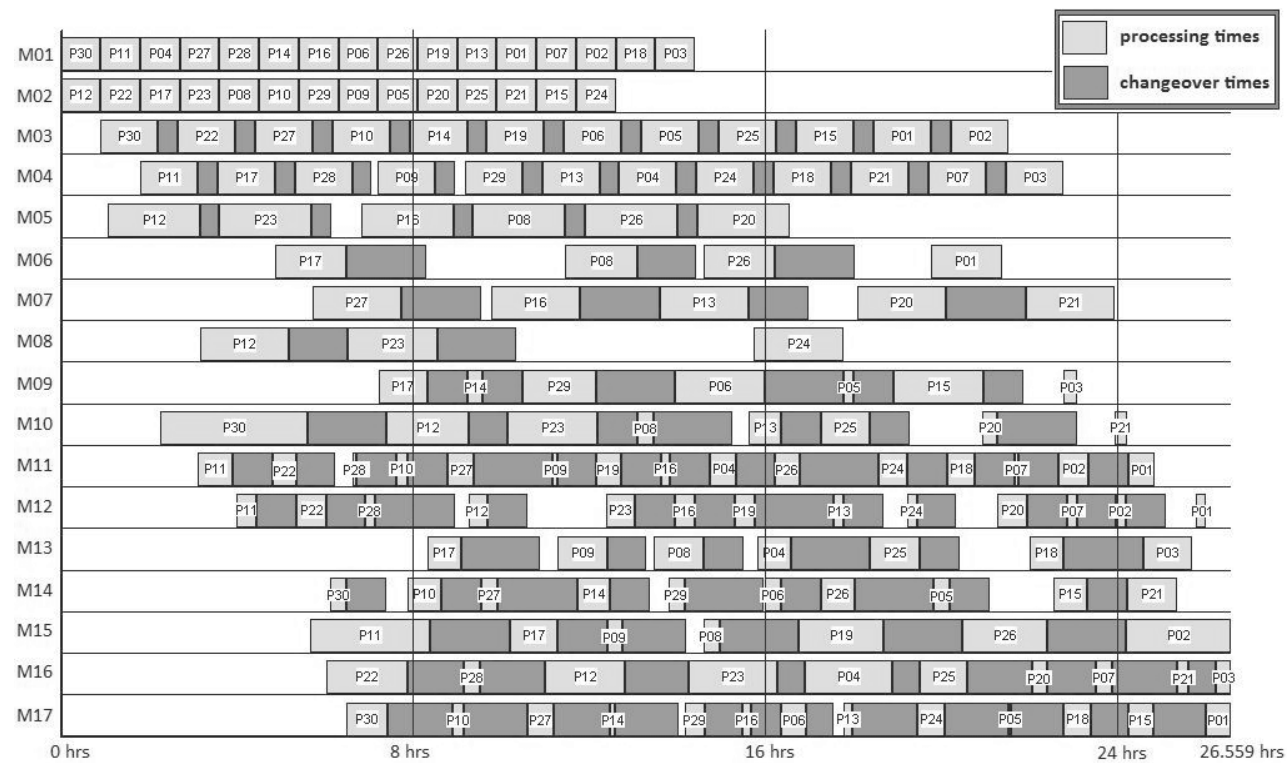

Figure 6. Best schedule for nominal 30-product case (makespan minimization). 
Both cases have been solved by using as a core mathematical model the one of Méndez \& Cerdá [3], since there is no need of minimization of sequence-dependent times and/or costs. The 30-product case was solved in 230 CPU seconds. Figure 6 shows the best schedule found, which results to a $26.559 \mathrm{hrs}$ of makespan. The highly complicated 60-product case was solved in just $780 \mathrm{CPU}$ seconds, reporting a makespan equals to $48.547 \mathrm{hrs}$.

\section{DISCUSSION}

The proposed solution technique is able to generate feasible and good solutions in short time, as the several problem instances of the pharma scheduling problem reveal. It is pointed out that the user can define appropriately the decisions degrees of freedom by balancing the trade-off between computational time and optimality. Moreover, this work aims to be a step towards reducing the gap between scheduling theory and practice, since it has clearly shown that real-world industrial problems can be solved by the aim of exact methods. The obtained results are promising and the further enhancement of the proposed solution method seems a challenging future research task.

\section{REFERENCES}

1. C.A. Méndez, J. Cerdá, I.E. Grossmann, I. Harjunkoski and M. Fahl, Review: State-ofthe-art of Optimization Methods for Short-term Scheduling of Batch Processes, Computers \& Chemical Engineering 30, pp. 913-946, 2006.

2. J. Röslof, I. Harjunkoski, J. Björkqvist, S. Karlsson and T. Westerlund, An MILP-based Reordering Algorithm for Complex Industrial Scheduling and Rescheduling, Computers \& Chemical Engineering 25, pp. 821-828, 2001.

3. C.A. Méndez and J. Cerdá, Dynamic Scheduling in Multiproduct Batch Plants, Computers \& Chemical Engineering 27, pp. 1247-1259, 2003.

4. G.M. Kopanos, J.M. Laínez and L. Puigjaner, An Effcient Mixed-Integer Linear Programming Scheduling Framework for Addressing Sequence-dependent Setup Issues in Batch Plants, Industrial \& Engineering Chemistry Research 48, pp. 6346-6357, 2009.

\section{ACKNOWLEDGEMENTS}

Financial support received from the Spanish Ministry of Education (FPU grant) from project PCI - D/024726/09 and project DPI2006-05673 is fully appreciated. 


\title{
THE LOGISTICAL MODEL BASED IN INDICATORS OF POSITIONS THROUGH THE ORDER PROCESSING MANAGER.
}

\author{
J. G. Hernández ${ }^{1}$ and M. J. García ${ }^{2}$ \\ ${ }^{1}$ Dep. de Gestión de la tecnología, Universidad Metropolitana, Caracas, Venezuela \\ jhernandez@unimet.edu.ve \\ ${ }^{2}$ Gerencia de Investigación, Minimax Consultores, Caracas, Venezuela \\ Minimaxconsultores@yahoo.com
}

\begin{abstract}
In order to facilitate the learning of enterprise logistics several models of academic origin have been created, one of them is the Logistic Model Based on Positions (MoLoBaC), that explain logistic through the associated positions and between the forty three positions that conform it are included the Order Processing Manager. On the other hand MoLoBaC serves as platform to the Logistic Model Based on Indicators of Position (MoLoBaICa), that analyzes the logistics measuring the indicators of performance for the different positions related to logistics. From the conjunction of these two models, the objective of this work arises: To show through the Order Processing Manager, how it works and as which are the benefits of the MoLoBaICa.
\end{abstract}

\section{INTRODUCTION}

Given the complexity of teaching enterprise logistic, a series of qualitative-quantitative models has been created, with the intention of facilitating this process. These models have been based, mainly, in the most relevant aspects of logistic and their integration to the supplying chain management (SCM): Supplying, integrated or not integrated to the SCM (Alex [1]; Das et al. [2]; Hult et al. [3]; Roth and Kaberger [4]; Stock et al. [5]), Production and productive process (Alex [1]; Das et al., [2]; Stock et al., [5]), Distribution, including transportation (Quak and Koster [6]; Roth and Kaberger [4]; Stock et al. [5]) and Inverse logistics (Pokharel and Mutha [7]; Xanthopoulos and Iakovou [8]). So far, there are four independent models: (Hernández and García [9]; [10]; Hernández et al., [11]): The Logistic Model Based on Positions (MoLoBaC), that explains logistics through the functions that carry out the different associated positions; the LAPDI model (Logistic of Supplying, Production, 
Inverse and Distribution), that explains logistics through the flows; the Logistic Model Based on Indicators of Positions (MoLoBaICa), that as its name indicates, measures the performance of the different positions from the MoLoBaC, through indicators and the Strategic, Tactical, Operative, Logistic Model, with Inverse logistics (MoLETOI), that study logistics from its beginnings, with a vision of the strategic, tactical and operative stages.

Using one of the forty three positions of MoLoBaC, the Order Processing Manager, and following the algorithmic approach, established in MoLoBaICa, the objective of this work arises: To show through the Order Processing Manager, how it works and as which are the benefits of the MoLoBaICa.

In order to achieve this objective, the traditional methodology for making decision will be used, which does not establish hypothesis, but follows a series of consecutive steps (Hernández et al. [11]), that goes from step a) To define the problem, in this case showing through the Order Processing Manager, how it works and as which are the benefits of the MoLoBaICa, until step g) To establish controls, or mechanisms that allows to recognize if the proposed model, with the passage of time, would continue being valid.

The limitations and reaches will be established by the objectives, resumed when presenting the MoLoBaICa, through the Order Processing Manager.

\section{THE ORDER PROCESSING MANAGER, MoLoBaC AND MoLoBaICa}

The basic representation of $\mathrm{MoLoBaC}$, is the organizational chart presented in figure 1 , where the Order Processing Manager is highlighted, in this figure it is shown that the positions of $\mathrm{MoLoBaC}$ are grouped in areas and these in stages, simultaneously being able to visualize six stages and twelve areas: a) Supplying, with an area, Procure, which is pure, while being conformed by positions that belongs to a single stage; b) Production, conformed by two pure areas, Maintenance and Inventories; c) Distribution, with four areas, Order Processing, that is the area in which this work is centered and is considered a mixed area, since integrates positions of different stages, Physical Distribution, a pure area, Transportation, which it is a mixed area and the area that is the reason of being of the MoLoBaC, Costumer Service, which is pure; d) Inverse, formed an unique pure area, Inverse Logistic; e) General to the company, with three areas, all pure, Intrinsic to logistics, Supported by logistic and Supporting logistics and f) Information (General to Information), formed by a mixed area, Information. 


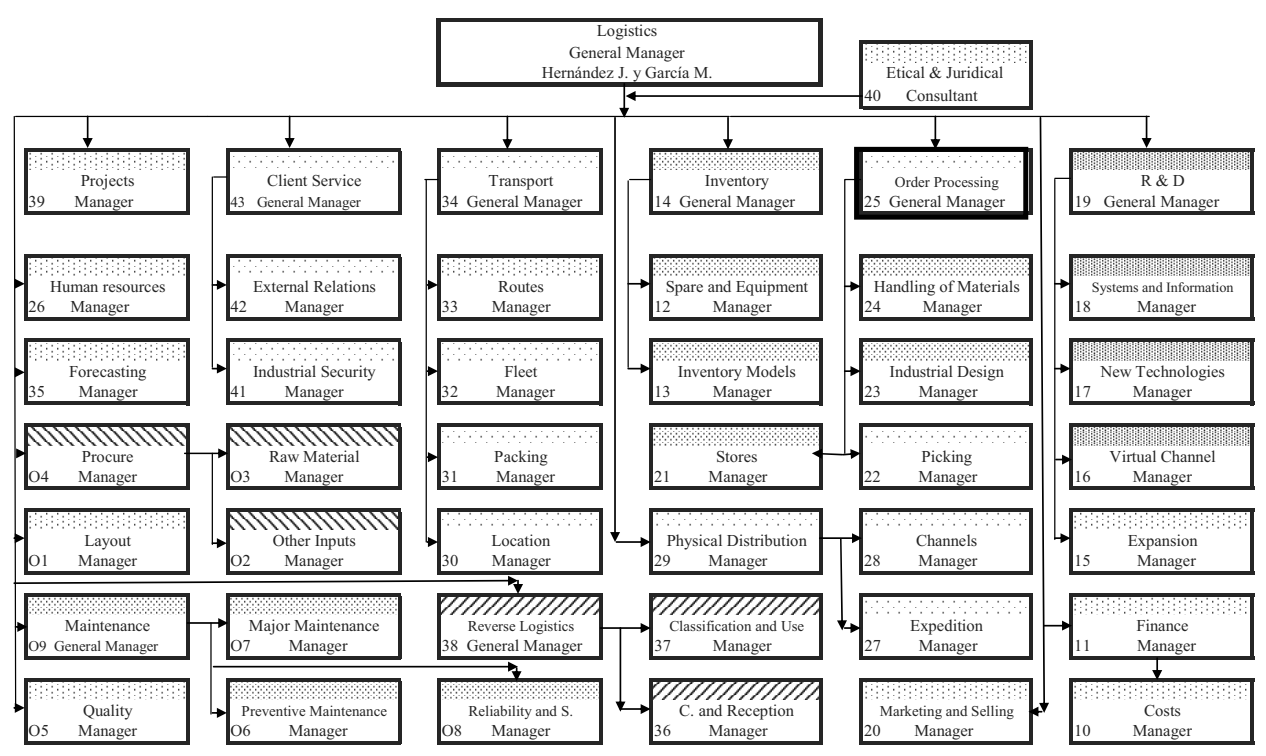

O2 Other Supply and Services

19 Research and Development

28 Distribution channels: Major and Retail

41 Industrial Security and Internal Relations

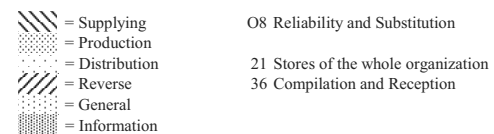

1) = Information
21 Stores of the whole organization

36 Compilation and Reception

\section{Figure 1: Logistic Model Based in Positions (MoLoBaC).}

Table 1: Calculation of the indicators for MoLoBaICa.

\begin{tabular}{|l|l|l|}
\hline 0 & To have MoLoBaC. \\
\hline 1 & To determine the position of MoLoBaC for which they are wanted to define their indicators. \\
\hline 1.1 & $\begin{array}{l}\text { For the respective charge to determine and to define each one of their functions clearly, although } \\
\text { each position can be characterized for up to forty two functions it is recommended to only choose the } \\
\text { twelve more outstanding to establish the indicators. }\end{array}$ \\
\hline 1.2 & $\begin{array}{l}\text { At this time it settles down for each function the weight that it represents in the measure of the } \\
\text { respective position. It is recommended to assign to each function a grade of importance between zero } \\
\text { and a hundred and then to normalize when knowing the pesos of all the functions of the position. }\end{array}$ \\
1.2 .1 & $\begin{array}{l}\text { Chosen the function to which their indicators will determine, to settle down: } \\
\text { a) the relationship to measure, that is to say the application field, at the same time that they } \\
\text { are expressed the or the elements of the numerator and the or the denominator elements and } \\
\text { the proportional relationship of the quotient clearly; } \\
\text { b) the application range, corresponding to the minimum, maximum and media prospective } \\
\text { value for the indicator; } \\
\text { c) the revision conditions, which can come settled down by a period of time, or the number } \\
\text { of times that the inferior or superiors limits are violated. }\end{array}$ \\
1.2.1.1 & $\begin{array}{l}\text { With these steps it is established the indicative one and at once it notices their } \\
\text { weight inside the indicators of the function. } \\
\text { A recommendation is to give it a value between zero and a hundred to each } \\
\text { indicator one and then to obtain its definitive weight for normalization among } \\
\text { the different indicators of the respective function. }\end{array}$ \\
\hline
\end{tabular}


As it is possible to observe in figure 1, the Order Processing Manager, identified with number 25, is the main position (for this reason it is identified as Order Processing General Manager) of the area Order Processing, that is the first area of the stage Distribution.

As far as MoLoBaICa, its algorithmic approach can be summarized in three phases, one where the indicators are established (Table 1), a second where the indicators for each position are measured (steps 0 to 7 of table 2) and the report of results (steps 8 and 9 of table 2).

As would be seen in the next session, where MoLoBaICa is illustrated, through the Order Processing Manager, the displayed algorithmic approach show in table 1, is recurrently being called to value each one of the indicators.

\section{ILUSTRATION OF MoLoBaICa}

For space reasons, all the details of the application of the model will not be discussed, but through tables $3,4,5,6,7$ and 8 it will be shown how it can be applied, having like protagonist the Order Processing Manager.

Although, without a doubt the study is much more complex, since it is meant to work for all the positions of the company, with the simplified illustration in tables 3 to 8 , there will be enough elements to see the functionality of MoLoBaICa. From table 3 to 8 , the obtained fields product of the interview or the observation are highlighted in italics.

In particular in table 3 , it is indicated the beginning of the study and the initially obtained information, gathering information of the contracting company, emphasizing that here it is defined, how many positions will be analyzed, where it must be observed that these positions, do not have to coincide with existing positions in MoLoBaC, but instead, one of first tasks to make, through interview and observation, is the position with which each employee will be associated, as table 4 reflects, in which information about specific employees is obtained, which will allow to be determine their functions, their dedication to each one of them and with the aide of the observation knowing which positions of MoLoBaC are to be associated.

Whereas table 5 consolidates this information and the weights of each function and the number of indicators are established that are going to measure each one of these functions.

In table 6, the indicators of each function are established, for each position in study, in fact, just as in table 7, that displays the summary of the valuation of each indicator, they are a set of tables, but for space reasons, it will only appear one of each one, the one of smaller number of indicators. 
Table 2: Valuation of positions and presentation of results in MoLoBaICa.

\begin{tabular}{|c|c|c|}
\hline 0 & \multicolumn{2}{|c|}{$\begin{array}{l}\text { To have all the indicators of the different functions of the different charges of MoLoBaC expressed in a } \\
\text { scale of one (1) at the a hundred (100). They come from the chart } 1 \text {. }\end{array}$} \\
\hline 1 & \multicolumn{2}{|c|}{$\begin{array}{l}\text { To define, the period in study and people that will be evaluated; in general, each individual is associated } \\
\text { to a position that not necessarily coincides with those of MoLoBaC. }\end{array}$} \\
\hline 2 & \multicolumn{2}{|c|}{$\begin{array}{l}\text { To determine for each person, the position in MoLoBaC to which will associate. This is made through } \\
\text { their dedication, for the period in study; it is determined how many hours it dedicates to each one of the } \\
\text { functions that carries out and it associates to the position for which dedicates mayor number of hours. } \\
\text { This verification is necessary, because mainly in small and medium companies, it usually happens that a } \\
\text { person carries out functions characteristic of different charges. }\end{array}$} \\
\hline 3 & \multicolumn{2}{|c|}{$\begin{array}{l}\text { To measure for the carried out charge each one of the indicators of the different functions of the same } \\
\text { one. This is made through interviews and observation, following the steps of the chart } 1 \text {. }\end{array}$} \\
\hline 4 & \multicolumn{2}{|c|}{$\begin{array}{l}\text { To return to the step three (3) until draining all the sub-positions carried out by the individual. If the } \\
\text { person carries out functions of different positions, it yield will be determined in each one of the positions } \\
\text { for separate. }\end{array}$} \\
\hline 5 & \multicolumn{2}{|c|}{ To return to the step two (2), until they are not individuals to be interviewed. } \\
\hline 6 & \multicolumn{2}{|c|}{$\begin{array}{l}\text { To determine for each individual the yield in each one of their indicators. Based on the definitions, values } \\
\text { and scales settled down in the step zero }(0) \text { and valuing each one of the parameters of the different } \\
\text { indicators. }\end{array}$} \\
\hline 7 & \multicolumn{2}{|c|}{ To repeat the step six (6) until completing all the individuals. } \\
\hline 8 & \multicolumn{2}{|c|}{ To consolidate the yields: } \\
\hline & \multicolumn{2}{|c|}{ For each individual. } \\
\hline & 8.1 .1 & $\begin{array}{l}\text { For each charge that the individual carries out. According to the valuations obtained in the } \\
\text { different indicators, and to the weights settled down in each indicator and in each } \\
\text { function. Only the functions that apply in each position. }\end{array}$ \\
\hline & 8.1 .2 & $\begin{array}{l}\text { For the individual in general. As the pondered sum, according to their dedication, of the } \\
\text { yields of their different positions. }\end{array}$ \\
\hline & \multicolumn{2}{|r|}{$\begin{array}{l}\text { For each function of each one of the positions. As the sum pondered according to the hours of } \\
\text { dedication of each one of the individuals that they carry out that function. }\end{array}$} \\
\hline & \multicolumn{2}{|r|}{$\begin{array}{l}\text { For each position. As the sum pondered according to the hours of dedication of each one of the } \\
\text { individuals that they carry out that position. }\end{array}$} \\
\hline & \multicolumn{2}{|c|}{ For each area. As the sum of the yields of the positions of the area. } \\
\hline & \multicolumn{2}{|c|}{ For each stage. As the sum of the yields of the areas of the stage. } \\
\hline & \multicolumn{2}{|c|}{ For the organization in general. As the sum of the yields of the stages. } \\
\hline 9 & \multicolumn{2}{|c|}{ To give consolidated report of the study, to the contracting organization. } \\
\hline
\end{tabular}

Table 3. Beginnings of the search of information in MoLoBaICa.

\begin{tabular}{|l|l|}
\hline Company: $A B X Y Z$ \\
\hline Person responsible for the study in the enterprise: $G . G$. & Position: President \\
\hline Responsible consultant: $M . G$. & Responsible for carrying out the survey: $J . H$. \\
\hline Study begins: $09 / 2009$ & Study ends: $12 / 2009$ \\
\hline Base period for the study: Week_X_Fortnight & Month_ Other_ (to Indicate) \\
\hline Lists of employees to be interviewed & Charge that Carrie out \\
\hline$B . Y$. & In charge of warehouse. \\
\hline C. $W$. & Customer attention responsible. \\
\hline
\end{tabular}

Finally in table 8 , the valuations of the positions, the areas, the stages and general of the company appears, only that here for reasons of space and according to the objectives of the work, it will only be shown the Order Processing Manager position. 
Table 4. Information of an employee and its charge in MoLoBaC.

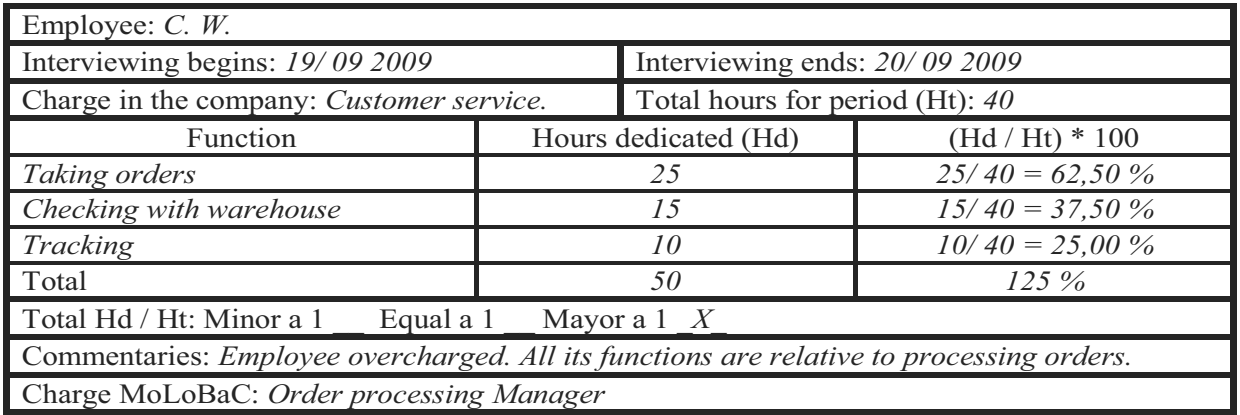

Table 5. Weights and indicator numbers for each function in MoLoBaICa.

\begin{tabular}{|l|c|c|}
\hline Employee: $C . W$. & \multicolumn{2}{c|}{ Charge MoLoBaC: Order processing Manager } \\
\hline Function & It weigh of the function & Number of indicators \\
\hline Taking orders & $60 \%$ & Four (4) \\
\hline Checking with warehouse & $15 \%$ & Three (3) \\
\hline Tracking & $25 \%$ & Two (2) \\
\hline
\end{tabular}

Table 6. Creation of the indicators for each function of a position in MoLoBaICa.

\begin{tabular}{|c|c|c|c|c|c|c|c|}
\hline \multicolumn{8}{|c|}{\begin{tabular}{|l|l|l} 
Employee: $C . W$. & Charge MoLoBaC: Order processing Manager \\
Function: Tracking
\end{tabular}} \\
\hline \multicolumn{8}{|c|}{ It weigh of the function in the evaluation of the position ( 1 to 100): 25} \\
\hline \multirow[b]{2}{*}{ Indicator } & \multirow[b]{2}{*}{$\begin{array}{l}\text { Indicator } \\
\text { description }\end{array}$} & \multirow[b]{2}{*}{$\begin{array}{l}\text { Mathematical } \\
\text { expression } \\
\text { (Quotient) }\end{array}$} & \multicolumn{3}{|c|}{ Value } & \multirow[b]{2}{*}{$\begin{array}{l}\text { Revision } \\
\text { Condition }\end{array}$} & \multirow{2}{*}{$\begin{array}{l}\text { Value of } \\
\text { the } \\
\text { indicator } \\
\text { for the } \\
\text { function } \\
(1 \text { to } 100)\end{array}$} \\
\hline & & & Low & Medium & High & & \\
\hline No Answer & $\begin{array}{c}\text { Clients } \\
\text { without } \\
\text { answer for } \\
\text { lack of } \\
\text { knowledge } \\
\text { of the } \\
\text { situation }\end{array}$ & $\begin{array}{c}\text { (Uncertain } \\
\text { answers) } \\
\text { (Attended } \\
\text { orders) }\end{array}$ & 0,05 & 0,10 & 0,12 & $\begin{array}{c}\text { Five } \\
\text { consecutive } \\
\text { occasions } \\
\text { outside of } \\
\text { range }\end{array}$ & 90 \\
\hline $\begin{array}{l}\text { Quality } \\
\text { Tracking }\end{array}$ & $\begin{array}{c}\text { Returned } \\
\text { orders for } \\
\text { poor } \\
\text { delivering }\end{array}$ & $\begin{array}{l}\text { (Returned } \\
\text { orders) } \\
\text { (Attended } \\
\text { orders) }\end{array}$ & $O, O O$ & 0.01 & 0,03 & $\begin{array}{c}\text { Two } \\
\text { consecutive } \\
\text { occasions } \\
\text { outside of } \\
\text { range }\end{array}$ & 100 \\
\hline
\end{tabular}

Table 7. Valuation of indicators for each employee function.

\begin{tabular}{|c|c|c|c|}
\hline Employee: $C . W$. & \multicolumn{4}{l|}{ Charge MoLoBaC: Order processing Manager } \\
\hline Function: Tracking & $\begin{array}{c}\text { Value of the } \\
\text { denominator }\end{array}$ & Value of the indicator & Value (1 to 100) \\
\hline $\begin{array}{c}\text { Value in the } \\
\text { numerator }\end{array}$ & \multicolumn{3}{|c|}{ Indicator: No answer } \\
\hline \multicolumn{4}{|c|}{0,0800} \\
\hline 16 & 200 & Indicator: Quality Tracking & 92,00 \\
\hline 26 & 200 & 0,1300 & 87,00 \\
\hline
\end{tabular}


Table 8. Final Valuation trough MoLoBaICa.

\begin{tabular}{|c|c|c|c|}
\hline Employee: $C . W$. & \multicolumn{3}{|c|}{ Charge MoLoBaC to measure: Order processing Manager } \\
\hline $\begin{array}{l}\text { Function: Taking } \\
\text { orders }\end{array}$ & $\begin{array}{l}\text { Weigh of the function } \\
\text { (Pf): } 60\end{array}$ & \multicolumn{2}{|c|}{ Hours dedicated to the function $(\mathrm{Hd}): 25$} \\
\hline Indicator & $\begin{array}{l}\text { Obtained value in the } \\
\text { indicator (Vi) }\end{array}$ & Indicator Weight $(\mathrm{Pi})$ & $\mathrm{Vi} * \mathrm{Pi}$ \\
\hline Volume & 87,50 & 80 & 7000,00 \\
\hline Income & 78,75 & 90 & 7087,50 \\
\hline Efficiency & 95,23 & 90 & 8570,70 \\
\hline Quality & 97,14 & 100 & 9714,00 \\
\hline Summation & 358,62 & 360 & 32372,20 \\
\hline $\begin{array}{l}\text { Value of the } \\
\text { function (Vf) }\end{array}$ & \multicolumn{2}{|c|}{$\begin{array}{l}\text { (Summation Vi } * \mathrm{Pi} / \text { Summation } \mathrm{Pi}) * \mathrm{Pf} * \mathrm{Hd}= \\
(32372,20 / 360) * 60 * 25=134884,17\end{array}$} & $\mathrm{Pf} * \mathrm{Hd}=1500$ \\
\hline $\begin{array}{l}\text { Function: } \\
\text { Checking with } \\
\text { warehouse }\end{array}$ & $\begin{array}{l}\text { Weigh of the function } \\
\text { (Pf): } 15\end{array}$ & \multicolumn{2}{|c|}{ Hours dedicated to the function (Hd): 15} \\
\hline Indicator & $\begin{array}{l}\text { Obtained value in the } \\
\text { indicator (Vi) }\end{array}$ & Indicator Weight $(\mathrm{Pi})$ & $\mathrm{Vi} * \mathrm{Pi}$ \\
\hline Available & 90,48 & 90 & 8143,20 \\
\hline Lost & 99,05 & 100 & 9905,00 \\
\hline $\begin{array}{l}\text { Quality } \\
\text { Warehouse }\end{array}$ & 97,00 & 100 & 9700,00 \\
\hline Summation & 286,53 & 290 & 27748,20 \\
\hline $\begin{array}{l}\text { Value of the } \\
\text { function (Vf) }\end{array}$ & \multicolumn{2}{|c|}{$\begin{array}{l}(\text { Summation } \mathrm{Vi} * \mathrm{Pi} / \mathrm{Summation} \mathrm{Pi}) * \mathrm{Pf} * \mathrm{Hd} \\
=(27748,20 / 290) * 15 * 15=21528,78\end{array}$} & $\begin{array}{l}\mathrm{Pf} * \mathrm{Hd}=225 \\
\text { Summation } \mathrm{Pf} * \mathrm{Hd}= \\
1725\end{array}$ \\
\hline $\begin{array}{l}\text { Function: } \\
\text { Tracking }\end{array}$ & \multicolumn{2}{|c|}{ Weigh of the function (Pf): 25} & $\begin{array}{l}\text { Hours dedicated to the } \\
\text { function }(\mathrm{Hd}): 10\end{array}$ \\
\hline Indicator & $\begin{array}{l}\text { Obtained value in the } \\
\text { indicator (Vi) }\end{array}$ & Indicator Weight $(\mathrm{Pi})$ & $\mathrm{Vi} * \mathrm{Pi}$ \\
\hline No answer & 92,00 & 90 & 8280,00 \\
\hline Quality Tracking & 87,00 & 100 & 8700,00 \\
\hline Summation & 179,00 & 190 & 16980,00 \\
\hline $\begin{array}{l}\text { Value of the } \\
\text { function (Vf) }\end{array}$ & \multicolumn{2}{|c|}{$\begin{array}{l}\text { (Summation } \mathrm{Vi} * \mathrm{Pi} / \text { Summation } \mathrm{Pi}) * \mathrm{Pf} * \mathrm{Hd} \\
\quad=(16980,00 / 190) * 25 * 10=22342,11\end{array}$} & $\begin{array}{l}\mathrm{Pf} * \mathrm{Hd}=250 \\
\text { Summation } \mathrm{Pf} * \mathrm{Hd}= \\
1975\end{array}$ \\
\hline $\begin{array}{l}\text { Value of the } \\
\text { charge }(\mathrm{Vc})\end{array}$ & \multicolumn{3}{|c|}{$\begin{array}{l}\text { Summation Vf / Summation } \mathrm{Pf} * \mathrm{Hd}=178755,06 / 1975=90,51 \\
\text { (All the functions of the position) }\end{array}$} \\
\hline $\begin{array}{l}\text { Value of the area } \\
\text { (Va) }\end{array}$ & \multicolumn{3}{|c|}{$\begin{array}{l}\text { Summation Vf / Summation Pf* Hd } \\
\text { (All the functions of the positions of the area) }\end{array}$} \\
\hline
\end{tabular}

Having presented the results of table 8 , Value of the charge equal 90,51\%, in spite of the limited space for the discussion of such, the evaluation of the company through MoLoBaICa can be seen, which allows to present conclusions.

\section{CONCLUSIONS}

The first conclusion is having achieved the general objective, to present the operation of the MoLoBaICa, through an example, where the analyzed position is the Order Processing 
Manager, which as well allows to conclude, on the importance of visualizing enterprise logistics through positions, as MoLoBaC does and the interesting that MoLoBaICa becomes, since it allows to measure individual performance, of the areas, stages and of the organization as a whole, through indicators, which can be of general use or established in particular for the company in study.

\section{REFERENCES}

1. R. Alex, Fuzzy point estimation and its application on fuzzy supply chain analysis, Fuzzy Sets and Systems 158, pp. 1571-1587, 2007.

2. A. Das, M. Pagell, M. Behm, A. Veltri, Toward a theory of the linkage between safety and quality, Journal of Operations Management, doi: 10.1016/j.jom.2007.06.005, 2007.

3. G. T. Hult, D. J. Ketchen, E. L. Nichols, Organizational learning as a strategic resource in supply management, Journal of Operations Managemen , 21, pp. 541-556, 2003.

4. A. Roth, T. Kaberger, Making transport systems sustainable, Journal of Cleaner Production 10, pp. 361-371, 2002.

5. G. N. Stock, N. P. Greis, J. D. Kasarda, Enterprise logistics and supply chain structure: the role of fit, Journal of Operations Management, 18, pp. 531-547, 2000.

6. H. J. Quak, M. B. M. de Koster, Exploring retailers' sensitivity to local sustainability policies, Journal of Operations Management, doi: 10.1016/j.jom.2007.01.020, 2007.

7. S. Pokharel, A. Mutha, Perspectives in reverse logistics: A review, Resources, Conservation \& Recycling, doi: 10.1016/j.resconrec.2008.11.006, 2009.

8. A. Xanthopoulos, E. Iakovou, On the optimal design of the disassembly and recovery processes, Waste Management, doi: 10.1016/j.wasman.2008.11.009, 2009.

9. J. G. Hernánde, M. J. García, The Importance of the Procurement Function in Logistics, Proceedings ICIL'2006, pp. 149-157, 2006.

10. J. G. Hernández, M. J. García, El Gerente de proyectos y la Logística, Notas Gerenciales 18, pp. 47-58, 2008.

11. J. G. Hernández, M. J. García, G. J. Hernández, Measurement of the enterprise logistics across Quality Management, GBATA Reading Book, pp. 492-499, 2009. 


\title{
SUPPLY CHAIN INTEGRATION AND PERFORMANCE - AMERICAN, EUROPEAN AND ASIAN COMPANIES
}

\author{
C. Söser ${ }^{1}$, M. Gerschberger ${ }^{1}$ and F. Roithmayr ${ }^{2}$ \\ ${ }^{1}$ LOGISTIKUM - Competence Centre for Logistics and Enterprise Networks \\ University of Applied Sciences, Campus Steyr, \\ Wehrgrabengasse 1-3, 4400 Steyr, Austria \\ ${ }^{2}$ Institute of Business Informatics - Information Engineering, \\ Johannes Kepler University Linz, \\ Altenbergerstraße 69, 4040 Linz, Austria
}

\begin{abstract}
The purpose of this paper is to analyze former empirical studies investigating the link between supply chain integration and performance as well as to discuss the reported evidence to this fundamental question for supply chain management by comparing American, European and Asian companies. Based on an extensive and systematic review of supply chain integration articles between 2000 and 2009 in scientific periodicals in logistics / supply chain management and information systems management, this paper presents and discusses the results of prior empirical studies. The review and analysis especially focuses on and compares research conducted in America, Europe and Asia. The results show that a differentiated view of integration within supply chain management is needed and further areas of research are suggested.
\end{abstract}

\section{INTRODUCTION AND PURPOSE}

In day-to-day business companies act in complex supply networks characterized by numerous supplier relationships, multiple global production sites and distribution centers as well as numerous customer relationships in different regions around the globe. The companies' need for the integration with supply network partners has risen in order to perform well in supply networks with an increasing level of technology in material- and information flows. Inter-organizational and intra-organizational integration has become a core topic in economics, especially in supply chain management and information systems management. The main enabler for flexible and integrated supply chains with supply network 
partners is mainly seen in information technology and information systems (Christopher [1], Hertz [2], Reichhart and Holweg [3], Wang et al. [4]). As a result, the question of whether more external integration with customers and/or suppliers or even if the integration with the customers' customer and the suppliers' supplier does lead to improved performance seems fundamental for managers who want to improve the performance of their companies. Both researchers and managers often assume and state that 'the more integration the better'. However, literature offers unclear and sometimes contradictory statements (Lanier, JR. et al. [5], Stank et al. [6], Stock et al. [7] versus Hertz [2], Closs and Savitskie [8], Gimenez and Ventura [9]). Additionally, recent research concludes that there are dissimilar empirical findings between companies of different global regions (Zailani and Rajagopal [10]).

Therefore, the purpose of this article is to analyse previous research regarding the following points: the type of relationships found between SCI and performance, the scope of integration that leads to improved performance, and the differences in American, European and Asian companies regarding supply chain integration (SCI) and performance.

The research questions guiding this study were:

i. What types of relationships are found between SCI and performance?

ii. What type of impact has had the scope of SCI on the supply chain?

iii. What results have been found in American, European and Asian companies regarding SCI and performance?

The paper is structured in the following way. The methodology is described first of all and is followed by the subsequent section summarizing the findings from the literature review and analysis. This latter section discusses the results concerning the relationship of supply chain integration and dependent performance variables are discussed. Finally, the conclusions are presented and an outlook for further research is given. 


\section{METHODOLOGY}

Based on the purpose and research questions, the research approach was structured in three phases. In the first phase, an extensive literature review with a total number of 5333 papers in the fourteen journals from 2000 to mid2009 on supply chain integration and performance indicators was conducted. A number of supply chain management and information system management related journals were searched through in order to select 288 research articles related to supply chain integration concepts and practices. In the second phase, investigation efforts were narrowed down to research on supply chain integration and performance research conducted in Asia, Europe and America. 48 research papers remained. In the third phase, comparisons were made between Asian, European and American companies.

\subsection{Selection of the papers}

For the purpose of selecting journals EBSCOHost, Emerald Insight and Science Direct were used. The following fourteen journals were selected: Information \& Management (I\&M), Information Systems (ISYS), International Journal of Information Management (IJIM), International Journal of Logistics Management (IJLM), International Journal of Logistics: Research \& Applications (IJL-RA), International Journal of Operations \& Production Management (IJOPM), International Journal of Physical Distribution \& Logistics Management (IJPDLM), Journal of Business Logistics (JBL), Journal of Management Information Systems (JMIS), Journal of Operation Management (JOM), Supply Chain Management: An International Journal (SCM-IJ), The Journal of Strategic Information Systems (JSIS), Transportation Journal (TJ), Transportation Research - Part E (TR-E). The selection of the journals was supported by journal rankings (Menachof et al. [11], WI Wirtschaftsinformatik [12], Peffers and Ya [13]).

\subsection{Classification of the papers}

For the purpose of analysis and discussion, papers were systematically classified. The term 'integration' refers to different but complementary and interrelated dimensions of integration. Within this research we follow the definition of integration with the multidimensional framework of Fabbe-Costes and Jahre [14]. Thereby, different scopes of integration (i.e. nature and number of organizations or participants included in the integrated 
supply chain) are distinguished. In this research, the scope of supply chain integration is coded as follows: limited dyadic downstream, limited dyadic upstream, limited dyadic with both customers and suppliers, limited triadic and extended. These five possible codes are used for classification of the papers depending on the scope of the SCI measures used in former empirical investigations. Limited dyadic downstream refers to the external integration with customers; limited dyadic upstream to the external integration with suppliers. The external integration with both suppliers and customers is coded with limited dyadic with both suppliers and customers. Limited triadic is used when the measures focus on a triadic relationship which relates to the integration from the suppliers over the company to the customers. When the SCI measures focus on the integration from the suppliers' supplier to the customers' customer, the code extended is used.

The dependent variable performance is classified like in Söser et al. [15]. Therefore, we distinguish between operational performance/supply chain performance/logistics performance, financial performance, and mixed performance. Operational performance/supply chain performance/logistics performance summarizes performance measures such as lead time, productivity growth, quality, delivery and flexibility. Financial performance refers to firm performance measures such as EBIT, EVA or cost measures. Mixed performance subsumes performance measures with more than one performance focus e.g. operational \& market performance OR financial \& operational performance (including logistics/supply chain performance and operational performance).

\subsection{Hypotheses}

The hypotheses defined in this research are shown in Table 1.

Table 1: Hypotheses regarding SCI and performance

\begin{tabular}{|l|l|}
\hline Code & Hypotheses \\
\hline H1. & $\begin{array}{l}\text { Increased external integration with customers improves performance of the firm (and/or the supply } \\
\text { chain). Improving company's integration with customers improves performance in terms of (a) } \\
\text { operational performance / supply chain performance / logistics performance. (b) financial } \\
\text { performance. (c) Mixed performance. }\end{array}$ \\
\hline
\end{tabular}




\begin{tabular}{|l|l|}
\hline H2. & $\begin{array}{l}\text { Increased external integration with suppliers improves performance of the firm (and/or the supply } \\
\text { chain). Improving company's integration with suppliers improves performance in terms of (a) } \\
\text { operational performance / supply chain performance / logistics performance. (b) financial } \\
\text { performance. (c) Mixed performance. }\end{array}$ \\
\hline H3. & $\begin{array}{l}\text { Increased external integration with both suppliers and customers improves performance of the } \\
\text { firm (and/or the supply chain). Improving company's integration with both suppliers and customers } \\
\text { improves performance in terms of (a) operational performance / supply chain performance / logistics } \\
\text { performance. (b) financial performance. (c) Mixed performance. }\end{array}$ \\
\hline H4. & $\begin{array}{l}\text { Increased integration from the suppliers over the company to the customers improves } \\
\text { performance of the firm (and/or the supply chain). Improving company's integration from suppliers to } \\
\text { customers improves performance in terms of (a) operational performance / supply chain performance / } \\
\text { logistics performance. (b) financial performance. (c) Mixed performance. }\end{array}$ \\
\hline H5. & $\begin{array}{l}\text { Increased integration from the suppliers' supplier to the customers' customer improves } \\
\text { performance of the firm (and/or the supply chain). Improving company's integration from suppliers to } \\
\text { customers improves performance in terms of (a) operational performance / supply chain performance / } \\
\text { logistics performance. (b) financial performance. (c) Mixed performance. }\end{array}$ \\
\hline
\end{tabular}

\section{RESULTS}

In total, 48 papers were found reporting findings from America, Europe and Asia. Three (Chang [16], White et al. [17], Zailani and Rajagopal [10]) of the 48 papers focus on countries of two continents. There are 20 papers that report findings regarding the relationship between SCI and performance in America. Thereby, two papers contain data from other continents as well - White et al. [17] focuses on USA and UK and Zailani and Rajagopal [10] compares the USA and East Asia. Most American papers (14) focus solely on the USA, five papers (Jacobs et al. [18], Stank et al. [6], Swink et al. [19], Vachon and Klassen [20], Vickery et al. [21]) state that they build on data from North America. Only Halley and Beaulieu [22] focus on Canada. Surprisingly, there were no reports found from investigations in South America.

15 papers focus on Europe, whereby White et al. [17] focus on both - the USA and the UK and Chang [16] on Taiwan and the UK. Chang [16], Childerhouse and Towill [23], Cousins and Menguc [24], Frohlich and Westbrook [25], Handfield et al. [26], White et al. [17] focus on the UK, Forza et al. [27], Ordanini and Rubera [28], Persona et al. [29] on Italy, Gimenez and Ventura [9], Gimenez and Ventura [30], Mejias-Sacaluga and Prado-Prado [31] on Spain, 
Trkman et al. [32] on Slovenia, and Hertz [2] on Sweden. There is only one (Bagchi et al. [33]) paper that considers more than one European country (8) and therefore names itself "the first empirical work measuring the state of supply chain integration in European firms".

Table 2: Comparison of SCI in America, Europe and Asia

\begin{tabular}{|c|c|c|c|c|c|c|c|c|c|}
\hline \multirow{2}{*}{ Hypothesis } & \multicolumn{4}{|c|}{ The more is the better. } & \multicolumn{4}{|c|}{ The more is not always better. } & \multirow[t]{2}{*}{$\#$} \\
\hline & America & Europe & Asia & \# & America & Europe & Asia & \# & \\
\hline $\begin{array}{l}\text { H1 } \\
\text { (Limited dyadic } \\
\text { downstream) }\end{array}$ & $\begin{array}{l}\text { Maloni and } \\
\text { Benton } \\
\text { [34], Sahin } \\
\text { and } \\
\text { Robinson, } \\
\text { JR. [35] }\end{array}$ & $\begin{array}{l}\text { Gimenez } \\
\text { and Ventura } \\
\text { [30], } \\
\text { Trkman et } \\
\text { al. [32] }\end{array}$ & $\begin{array}{l}\text { Chen et al. } \\
{[36]}\end{array}$ & 5 & $\begin{array}{l}\text { Closs and } \\
\text { Savitskie } \\
{[8]}\end{array}$ & $\begin{array}{l}\text { Gimenez } \\
\text { and Ventura } \\
{[9]}\end{array}$ & - & 2 & 7 \\
\hline $\begin{array}{l}\mathbf{H 2} \\
\text { (Limited dyadic } \\
\text { upstream) }\end{array}$ & $\begin{array}{l}\text { Jacobs et al. } \\
{[18]}\end{array}$ & $\begin{array}{l}\text { Cousins and } \\
\text { Menguc } \\
\text { [24], } \\
\text { Handfield et } \\
\text { al. [26], } \\
\text { Ordanini and } \\
\text { Rubera [28] }\end{array}$ & - & 4 & $\begin{array}{l}\text { Elmuti et al. } \\
\text { [37] }\end{array}$ & & $\begin{array}{l}\text { Kyung Kyu } \\
\text { Kim et al. } \\
\text { [38], Wang } \\
\text { et al. [4] }\end{array}$ & 3 & 7 \\
\hline $\begin{array}{l}\text { H3 } \\
\text { (Limited dyadic } \\
\text { - with both } \\
\text { suppliers and } \\
\text { customers) }\end{array}$ & $\begin{array}{l}\text { Stank et al. } \\
{[39] \text {, }} \\
\text { Vachon and } \\
\text { Klassen } \\
{[20]} \\
\text { Zailani and } \\
\text { Rajagopal } \\
{[10]}\end{array}$ & - & $\begin{array}{l}\text { Soo Wook } \\
\text { Kim [40], } \\
\text { Zailani } \\
\text { and } \\
\text { Rajagopal } \\
{[10]}\end{array}$ & 5 & $\begin{array}{l}\text { Halley and } \\
\text { Beaulieu } \\
\text { [22], Iyer et } \\
\text { al. [41] }\end{array}$ & $\begin{array}{l}\text { Bagchi et al. } \\
\text { [33] }\end{array}$ & $\begin{array}{l}\text { Haozhe } \\
\text { Chen et al. } \\
\text { [42], Flynn } \\
\text { et al. [43], } \\
\text { Sezen [44] }\end{array}$ & 6 & 11 \\
\hline $\begin{array}{l}\mathbf{H 4} \\
\text { (Limited triadic) }\end{array}$ & $\begin{array}{l}\text { Lanier, JR. } \\
\text { et al. [5], } \\
\text { Stank et al. } \\
\text { [6], Stock et } \\
\text { al. [7], } \\
\text { Vickery et } \\
\text { al. [21] }\end{array}$ & $\begin{array}{l}\text { Chang [16] } \\
\text { Frohlich } \\
\text { and } \\
\text { Westbrook } \\
{[25]}\end{array}$ & $\begin{array}{l}\text { Chang } \\
{[16],} \\
\text { Soo } \\
\text { Wook } \\
\text { Kim } \\
\text { [45], } \\
\text { Narasim } \\
\text { han and } \\
\text { Kim } \\
\text { [46] }\end{array}$ & 9 & $\begin{array}{l}\text { Swink et } \\
\text { al. [19] }\end{array}$ & - & $\begin{array}{l}\text { Lai et al. } \\
{[47]}\end{array}$ & 2 & 11 \\
\hline $\begin{array}{l}\text { H5 } \\
\text { (Extended) }\end{array}$ & $\begin{array}{l}\text { Rodrigues } \\
\text { et al. [48], } \\
\text { White et al. } \\
\text { [17] }\end{array}$ & $\begin{array}{l}\text { Childerhou } \\
\text { se and } \\
\text { Towill [23], } \\
\text { Forza et al. } \\
\text { [27], } \\
\text { Mejias- } \\
\text { Sacaluga } \\
\text { and Prado- } \\
\text { Prado [31], } \\
\text { White et al. } \\
\text { [17] }\end{array}$ & $\begin{array}{l}\text { Loi } \\
\text { Teck } \\
\text { Hui } \\
\text { [49], } \\
\text { Narasim } \\
\text { han and } \\
\text { Soo } \\
\text { Wook } \\
\text { Kim } \\
\text { [50], } \\
\text { Kannabi } \\
\text { ran and } \\
\text { Bhaumi } \\
\text { k [51] }\end{array}$ & 9 & $\begin{array}{l}\text { Devaraj et } \\
\text { al. [52], } \\
\text { Germain } \\
\text { et al. [53], } \\
\text { Mitra and } \\
\text { Singhal } \\
\text { [54] }\end{array}$ & $\begin{array}{l}\text { Hertz [2], } \\
\text { Persona et } \\
\text { al. [29] }\end{array}$ & $\begin{array}{l}\text { Sha et al. } \\
{[55]}\end{array}$ & 6 & 15 \\
\hline \# & 12 & 11 & 9 & 32 & 8 & 4 & 7 & 19 & 51 \\
\hline
\end{tabular}


16 papers report on SCI and performance in Asia. Thereby, Chang [16], Chen et al. [36], Sha et al. [55], Wang et al. [4] focus on Taiwan - Chang [16] focuses (besides Taiwan) on the UK as well. Soo Wook Kim [45], Soo Wook Kim [40], Narasimhan and Kim [46] focus on two countries - Korea and Japan. Kyung Kyu Kim et al. [38], Narasimhan and Soo Wook Kim [50] focus solely on Korea. Two papers (Haozhe Chen et al. [42], Flynn et al. [43]) state they have data from Chinese companies. Another one (Lai et al. [47]) focuses on Hongkong. Kannabiran and Bhaumik [51] reports findings from India. One paper (Loi Teck Hui [49]) uses data from Malaysia. And Sezen [44] focuses on Turkey. Zailani and Rajagopal [10] compare the US and East Asia.

Table 2 shows the comparison of the results from former investigations regarding SCI integration and performance in America, Europe and Asia. It shows that nearly $75 \%$ of former investigations in European companies conclude that increased external integration improves performance of the firm (and/or supply chain). On the contrary, in Asian companies only about $55 \%$ of the investigations fully support this statement. In America about $60 \%$ of the papers state "the more integration the better". Approximately $30 \%$ of the analysed papers on SCI and performance have an extended scope. About half of these papers use a case study methodology and therefore have a limited empirical base. Most papers have a dyadic or triadic scope. Interestingly, almost 70 percent of the papers claiming that a higher degree of integration is not always better, were published in recent years (past the year 2006).

Furthermore, it is noticeable that the performance measures used in the former investigations differ significantly. Most papers use operational performance/supply chain performance/logistics performance as the dependent variable, followed by mixed performance and financial performance. Some articles include - in addition to firm performance - others' performance (e.g. the whole supply chain or suppliers) as well.

\section{CONCLUSIONS}

The purpose of this article was threefold. Firstly, the type of relationships found between SCI and performance was analysed. Therefore an evaluation of recently published articles within the area of supply chain management and information systems management was conducted. Approximately 60 percent of former investigations report that increased external 
supply chain integration leads to performance improvements. More and more investigations show that increased integration does not always lead to improved performance. Secondly the scope of integration that leads to improved performance was analysed. This article shows that the term supply chain integration is measured on different scopes. Some articles do not explicitly mention the scope considered in their investigation.

Thirdly to identify the differences in American, European and Asian companies regarding SCI and performance, a comparison regarding the continents was carried out. The findings summarized in Table 2 show that a differentiated view of integration within supply chain management is needed. The research indicates that empirical evidence cannot clearly conclude that a higher degree of supply chain integration necessarily leads to a better performance. As another sample may have given other results, further research could include additional journals, such as Supply Chain Management Review, Organization Science, Management Information Systems Quarterly, and Journal of Supply Chain Management. Additionally, further research should include Oceania (Australia and New Zealand) Africa and worldwide studies. More empirical investigations with clear definitions and measures should be carried.

Moreover, further research should differentiate "the more the better" in number of external partners and the degree of linkage on certain layers. The findings indicate that integration decisions have to be made regarding the performance-critical external partners as well as regarding the layers of supply chain integration (flows, processes, systems, actors).

\section{REFERENCES}

1. M. Christopher, The Agile Supply Chain, Industrial Marketing Management, 29, 1, pp. 37-44, 2000.

2. S. Hertz, Dynamics of Alliances in Highly Integrated Supply Chain Networks, International Journal of Logistics: Research \& Applications, 4, 2, pp. 237-256, 2001.

3. A. Reichhart, and M. Holweg, Creating the customer-responsive supply chain: a reconciliation of concepts, International Journal of Operations \& Production Management, 27, 11, pp. 1144-1172, 2007.

4. E.T.G. Wang, J.C.F. Tai, and H.-L. Wei, A Virtual Integration Theory of Improved Supply-Chain Performance, Journal of Management Information Systems, 23, 2, pp. 41-64, 2006. 
5. D. Lanier, JR., W.F. Wempe, and Z.G. Zacharia, Concentrated supply chain membership and financial performance: Chain- and firm-level perspectives, Journal of Operations Management, In Press, Corrected Proof, 2009.

6. T.P. Stank, S.B. Keller, and P.J. Daugherty, Supply Chain Collaboration and Logistical Service Performance, Journal of Business Logistics, 22, 1, pp. 29-48, 2001.

7. G.N. Stock, N.P. Greis, and J.D. Kasarda, Enterprise logistics and supply chain structure: the role of fit, Journal of Operations Management, 18, 5, pp. 531-547, 2000.

8. D.J. Closs, and K. Savitskie, Internal and External Logistics Information Technology Integration, The International Journal of Logistics Management, 14, 1, pp. 63-76, 2003.

9. C. Gimenez, and E. Ventura, Supply Chain Management as a Competitive Advantage in the Spanish Grocery Sector, The International Journal of Logistics Management, 14, 1, pp. 77-88, 2003.

10. S. Zailani, and P. Rajagopal, Supply chain integration and performance: US versus East Asian companies, Supply Chain Management: An International Journal, 10, 5, pp. 379393, 2005.

11. D.A. Menachof, B.J. Gibson, J.B. Hanna, and A.E. Whiteing, An analysis of the value of supply chain management periodicals, International Journal of Physical Distribution \& Logistics Management, 39, 2, pp. 145-166, 2009.

12. WI - Wirtschaftsinformatik, WI-Journalliste 2008, [2009 Aug 25], Available at http://www.wirtschaftsinformatik.de/pdf/wi2008_2_155-163_mitteilg-wkwi.pdf.

13. K. Peffers, and T. Ya, Identifying and evaluating the universe of outlets for information systems research: Ranking the journals, Journal of Information Technology Theory and Application, 5, 1, pp. 63-84, 2003.

14. N. Fabbe-Costes, and M. Jahre, Logistics integration and disintegration - in search of a framework, ILS'06 Proceedings International Conference on Information Systems, Logistics and Supply Chain, FUCAM edition, Mons, Belgium, May 14-17, pp. 841-850, 2006.

15. C. Söser, M. Gerschberger, and C. Engelhardt-Nowitzki, Supply Chain Integration Improves Performance - A Review of Empirical Evidence, in Proceedings 14th Asia Pacific Management Conference, Indonesia, November 18-20, APMC14, Ed., 2009.

16. H.H. Chang, A model of computerization of manufacturing systems: an international study, Information \& Management, 39, 7, pp. 605-624, 2002.

17. A. White, E.M. Daniel, and M. Mohdzain, The role of emergent information technologies and systems in enabling supply chain agility, International Journal of Information Management, 25, 5, pp. 396-410, 2005.

18. M. Jacobs, S.K. Vickery, and C. Droge, The effects of product modularity on competitive performance: Do integration strategies mediate the relationship?, International Journal of Operations \& Production Management, 27, 10, pp. 1046-1068, 2007.

19. M. Swink, R. Narasimhan, and C. Wang, Managing beyond the factory walls: Effects of four types of strategic integration on manufacturing plant performance, Journal of Operations Management, 25, 1, pp. 148-164, 2007. 
20. S. Vachon, and R.D. Klassen, Extending green practices across the supply chain, International Journal of Operations \& Production Management, 26, 7, pp. 795-821, 2006.

21. S.K. Vickery, J. Jayaram, C. Droge, and R. Calantone, The effects of an integrative supply chain strategy on customer service and financial performance: an analysis of direct versus indirect relationships, Journal of Operations Management, 21, 5, pp. 523$539,2003$.

22. A. Halley, and M. Beaulieu, Mastery of operational competencies in the context of supply chain management, Supply Chain Management: An International Journal, 14, 1, pp. 49-63, 2009.

23. P. Childerhouse, and D.R. Towill, Engineering the Seamless Supply Chain, The International Journal of Logistics Management, 14, 1, pp. 109-120, 2003.

24. P.D. Cousins, and B. Menguc, The implications of socialization and integration in supply chain management, Journal of Operations Management, 24, 5, pp. 604-620, 2006.

25. M.T. Frohlich, and R. Westbrook, Demand chain management in manufacturing and services: web-based integration, drivers and performance, Journal of Operations Management, 20, 6, pp. 729-745, 2002.

26. R. Handfield, K. Petersen, P. Cousins, and B. Lawson, An organizational entrepreneurship model of supply management integration and performance outcomes, International Journal of Operations \& Production Management, 29, 1/2, pp. 100-126, 2009.

27. C. Forza, P. Romano, and A. Vinelli, Information Technology for Managing the Textile Apparel Chain: Current Use, Shortcomings and Development Directions, International Journal of Logistics: Research \& Applications, 3, 3, pp. 227-243, 2000.

28. A. Ordanini, and G. Rubera, Strategic capabilities and internet resources in procurement, International Journal of Operations \& Production Management, 28, 1, pp. 27-52, 2008.

29. A. Persona, A. Regattieri, H. Pham, and D. Battini, Remote control and maintenance outsourcing networks and its applications in supply chain management: Supply Chain Management in a Sustainable Environment; Special Issue on Frontiers of Empirical Supply Chain Research, Journal of Operations Management, 25, 6, pp. 1275-1291, 2007.

30. C. Gimenez, and E. Ventura, Logistics-production, logistics-marketing and external integration: Their impact on performance, International Journal of Operations \& Production Management, 25, 1, pp. 20-38, 2005.

31. A. Mejias-Sacaluga, and J.C. Prado-Prado, Integrated Logistics Management in the Grocery Supply Chain, The International Journal of Logistics Management, 13, 2, pp. 67-78, 2002.

32. P. Trkman, M.I. Stemberger, J. Jaklic, and A. Groznik, Process approach to supply chain integration, Supply Chain Management: An International Journal, 12, 2, pp. 116 $128,2007$. 
33. P.K. Bagchi, B.C. Ha, T. Skjoett-Larsen, and L.B. Soerensen, Supply chain integration: a European survey, The International Journal of Logistics Management, 16, 2, pp. 275294, 2005.

34. M. Maloni, and W.C. Benton, Power influences in the Supply Chain, Journal of Business Logistics, 21, 1, pp. 49-73, 2000.

35. F. Sahin, and E.P. Robinson, JR., Information sharing and coordination in make-toorder supply chains, Journal of Operations Management, 23, 6, pp. 579-598, 2005.

36. M.-C. Chen, T. Yang, and H.-C. Li, Evaluating the supply chain performance of ITbased inter-enterprise collaboration, Information \& Management, 44, 6, pp. 524-534, 2007.

37. D. Elmuti, W. Minnis, and M. Abebe, Longitudinal assessment of an integrated industrial supply chain, Supply Chain Management: An International Journal, 13, 2, pp. $151-159,2008$.

38. Kyung Kyu Kim, N.S. Umanath, and Bum Hun Kim, An Assessment of Electronic Information Transfer in B2B Supply-Channel Relationships, Journal of Management Information Systems, 22, 3, pp. 293-320, 2005.

39. T.P. Stank, S.B. Keller, and D.J. Closs, Performance Benefits of Supply Chain Logistical Integration, Transportation Journal, 41, 2/3, pp. 32-46, 2001.

40. Soo Wook Kim, Effects of supply chain management practices, integration and competition capability on performance, Supply Chain Management: An International Journal, 11, 3, pp. 241-248, 2006.

41. K.N.S. Iyer, R. Germain, and C. Claycomb, B2B e-commerce supply chain integration and performance: A contingency fit perspective on the role of environment, Information \& Management, 46, 6, pp. 313-322, 2009.

42. Haozhe Chen, P.J. Daugherty, and A.S. Roath, Defining and operationalizing supply chain process integration, Journal of Business Logistics, 30, 1, pp. 63-84, 2009.

43. B.B. Flynn, B. Huo, and X. Zhao, The impact of supply chain integration on performance: A contingency and configuration approach, Journal of Operations Management, In Press, Corrected Proof, 2009.

44. B. Sezen, Relative effects of design, integration and information sharing on supply chain performance, Supply Chain Management: An International Journal, 13, 3, pp. 233-240, 2008.

45. Soo Wook Kim, The effect of supply chain integration on the alignment between corporate competitive capability and supply chain operational capability, International Journal of Operations \& Production Management, 26, 10, pp. 1084-1107, 2006.

46. R. Narasimhan, and S.W. Kim, Effect of supply chain integration on the relationship between diversification and performance: evidence from Japanese and Korean firms, Journal of Operations Management, 20, 3, pp. 303-323, 2002.

47. K.-H. Lai, C.W.Y. Wong, and T.C.E. Cheng, A coordination-theoretic investigation of the impact of electronic integration on logistics performance, Information \& Management, 45, 1, pp. 10-20, 2008. 
48. A.M. Rodrigues, T.P. Stank, and D.F. Lynch, Linking Strategy, Structure, Process, and Performance in Integrated Logistics, Journal of Business Logistics, 25, 2, pp. 65-94, 2004.

49. Loi Teck Hui, Business timeliness: the intersections of strategy an operations management, International Journal of Operations \& Production Management, 24, 6, pp. 605-624, 2004.

50. R. Narasimhan, and Soo Wook Kim, Information System Utilization Strategy for Supply Chain Integration, Journal of Business Logistics, 22, 2, pp. 51-75, 2001.

51. G. Kannabiran, and S. Bhaumik, Corporate turnaround through effective supply chain management: the case of a leading jewellery manufacturer in India, Supply Chain Management: An International Journal, 10, 5, pp. 340-348, 2005.

52. S. Devaraj, L. Krajewski, and J.C. Wei, Impact of eBusiness technologies on operational performance: The role of production information integration in the supply chain: Supply Chain Management in a Sustainable Environment; Special Issue on Frontiers of Empirical Supply Chain Research, Journal of Operations Management, 25, 6, pp. 1199-1216, 2007.

53. R. Germain, C. Claycomb, and C. Dröge, Supply chain variability, organizational structure, and performance: The moderating effect of demand unpredictability, Journal of Operations Management, 26, 5, pp. 557-570, 2008.

54. S. Mitra, and V. Singhal, Supply chain integration and shareholder value: Evidence from consortium based industry exchanges, Journal of Operations Management, 26, 1, pp. 96-114, 2008.

55. D.Y. Sha, P.K. Chen, and Y.-H. Chen, The strategic fit of supply chain integration in the TFT-LCD industry, Supply Chain Management: An International Journal, 13, 5, pp. 339-342, 2008. 


\title{
"STANDARD-HOUR" AS LOGISTICS PERFORMANCE EVALUATION BASIS - A CASE STUDY AT ARACRUZ CELULOSE
}

\author{
Marcelo Mattos Aragão \\ Thiago Barros Brito \\ Rui Carlos Botter \\ Department of Logistics Systems Engineering \\ São Paulo University, São Paulo
}

\begin{abstract}
Performance management should be viewed as a key business process to any logistics operation success. A correctly structured performance management is the basis for logistics problems identification. The aim of this work is to develop an indicator to measure the productivity of a truck fleet (the main cost factor in medium-time horizon transportation planning). This indicator is supposed to allow the comparison of the productivity level of different trucks units (regarding capacity, routes and others), the data consolidation of freight companies, the treatment of uncertainties in transportation process (such as rain, strikes, etc.) and the comparison of the results with the performance goals. The following issues will be addressed: what to evaluate as performance in the transportation process and how to evaluate and apply the proposed methodology in a wood freight company. In addition, the performance indicator should incorporate the effects of changes in transportation scenarios, such as fleet composition, average route distance, transportation restrictions, product density, among others. Therefore, the methodology for performance evaluation used should allow the comparison of different time periods, taking into account different general characteristics and being able to evaluate the evolution of logistics performance.
\end{abstract}

\section{INTRODUCTION}

Logistics performance indicators are tools that allow a better understanding and evaluation of improvement of companies' processes, by ensuring that decision making is based on objective criteria, indicating where improvements should be made and revealing the problems that are naturally hidden because of any preconception, trend or habit. (ÑARI 1998). 
According to Nauri (1998), "the purpose of performance measurement in organizations is to establish the level of progress or stagnation of its' processes, as well as the level of suitability of its' goods and services utilization, providing appropriate information at the right time, allowing preventive and/or corrective actions to be taken and leading to goals achievement". Lebas (1995, p. 23) emphasizes the importance of performance measurement evaluation implementation and states that "management can hardly exist without measurement." However, the identification of relevant metrics for each process is a tricky task for any company. To Razzolini Filho (2000) the formulation of indicators depends on five basic questions: Why to evaluate performance? What to evaluate as performance? How to evaluate performance? When to evaluate performance? What to do with the evaluation's results?

Another difficulty in the indicators' implementation process is the need for reliable, relevant and frequent information to be provided. It is also necessary to have a minimum sensitivity when evaluating the performance indicators results, since in some cases the results interpretation is dependent on previous experience or subjectivity.

According to Razzolini (2000), the evaluation of the results should be clear enough and understandable to all staff involved in order to make possible changes in management, lead to revolutions in organizational culture and allow the formalization of logistics process.

The aim of this work is to develop an indicator to measure the productivity of a truck fleet (the main cost factor in medium-time horizon transportation planning). This indicator is supposed to allow the comparison of the productivity level of different trucks units (regarding capacity, routes and others), the data consolidation of freight companies, the treatment of uncertainties in transportation process (such as rain, strikes, etc.) and the comparison of the results with the performance goals.

\section{WHAT TO EVALUATE AS PERFORMANCE}

To SCHMITT (2002, p. 44) "there are many variables that can be measured and evaluated, so knowing to distinguish which are the most important ones depends not only on the perception and experience of managers, but mainly on the methodology or approach used". The first consideration about indicators' building is the analysis time horizon: short, medium or long. The short-time (one hour to one day period) indicators are assigned primarily 
to evaluate the demand fulfillment. They must allow fast calculations, easy analysis and provide immediate and dynamic information, contributing to correctives actions as equipment moving or routes re-planning. In a medium-time (one week to 6 months period) horizon, the fleet composition, average route length, the product density/value, among other things, may suffer significant changes. Because of that, the medium-time horizon indicators should allow the comparison of the transportation performance level on scenarios that change over time. The long-time (usually over 1 year period) indicators support strategic decisions such as the composition of the transportation matrix and warehouse localization. In the long-time horizon, the aggregated fleet is usually considered for transportation capacity calculations; fleet individual identification has little relevance, and average volume and distance data is analyzed.

So, to answer whether a truck is being used efficiently, the performance indicator should be positioned on the medium time horizon, being able to incorporate the effects of scenario changes and, at the same time, maintaining the detail level at the truck unit. It must allow: the identification of equipments with high or low performance level in order to find out problems associated to equipment and/or operators; the comparison of performance between different capacity trucks, data consolidation by different criteria (freight companies, routes and others); the treatment of uncertainties during transportation process (such as rain, strikes, etc.), once those factors affect resource availability; the comparison of the results with the performance goal and the comparison of changes in transportation scenarios such as fleet composition, average route distance, transportation restrictions, product density, among others.

Thus, to evaluate the transportation system of Aracruz Celulose (ARCEL), a new methodology, called "standard-hour", was developed. It's main concept is based on the evaluation of a "standard-route time" - obtained by the sum of the planned route times, rather than the accomplished route time.

\section{HOW TO EVALUATE PERFORMANCE}

\subsection{Efficiency of the truck utilization regarding its availability}

It would be easy to calculate the truck fleet productivity if the planned routes would start and finish at the same day, as shown in Figures 2 and 3. 


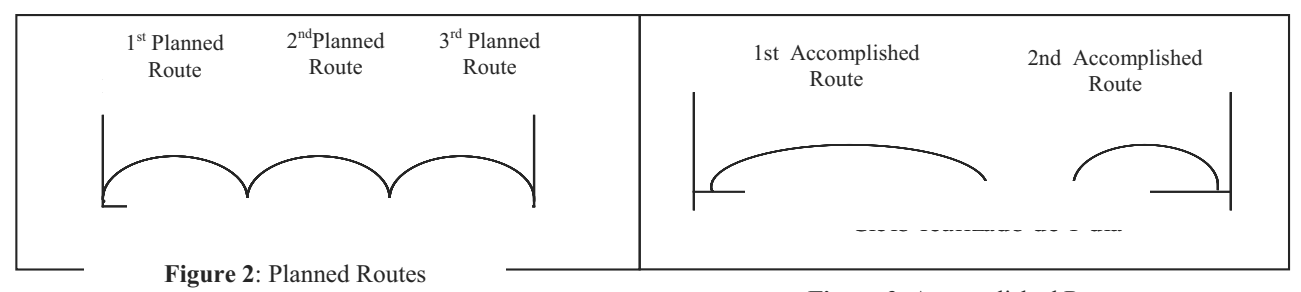

Figure 2: Planned Routes

Figure 3: Accomplished Routes

Thus, to calculate the indicator of the truck efficiency, it is enough to consider only the accomplished routes, convert them into "standard-route time" and add them up. The result should be divided by the route net time - which calculation consists in ignoring route idle time caused by external factors (rain, strikes and others), as demonstrated bellow:

$$
\text { Productivity Rate }=\frac{\text { ASH }}{\text { D }- \text { I }}
$$

$\mathrm{ASH}=$ Accomplished Standard-Hours

$\mathrm{D}=$ Truck daily operation time

$\mathrm{I}=$ Total idle time caused by external factors such as rain, and other strikes.

However, in the ARCEL operation, trucks work 24 hours continuously, causing routes to start in one day and finishing in the next one (Figure 4).

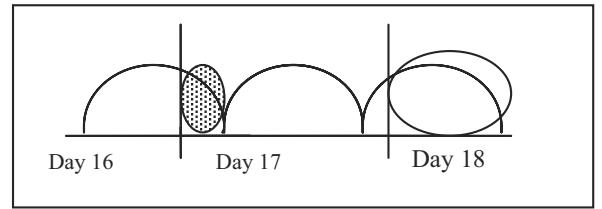

Figure 4: Over-one-day route

According to the proposed methodology, only routes starting on the analysis day should be considered. Thus, according to Figure 4, the calculation of day 17 standard-hours should exclude the route's gray fraction on Figure 4 (this route starts on day 16) and consider the fraction of the route highlighted on day 18 (this route starts on day 17). With this definition, it is possible to compare the daily productivity of trucks in different scenarios:

$$
\text { Productivity Rate }=\frac{\text { ASH }}{\mathrm{D}+\mathrm{FA}-\mathrm{FP}-\mathrm{I}}
$$

ASH $=$ Accomplished Standard-Hours

$\mathrm{D}=$ Truck daily operation time 
$\mathrm{FA}=$ Route fraction completed on the day after

$\mathrm{FP}=$ Route fraction to be completed on the previous day.

$\mathrm{I}=$ Total idle time caused by external factors such as rain, and other strikes.

The table below shows the planned routes for a truck leaving the central base of Aracruz.

Table 2: Truck accomplished routes, in a 2-day period

\begin{tabular}{|c|c|c|c|c|}
\hline Route Destiny & Start & End & Route Time & Standard Route Time \\
\hline São Mateus & $08 / 02 / 200511: 30$ & $08 / 03 / 200502: 55$ & $15: 25: 00$ & $11: 00: 00$ \\
\hline Aracruz & $08 / 03 / 200512: 06$ & $08 / 03 / 200517: 36$ & $05: 30: 00$ & $05: 00: 00$ \\
\hline Bahia & $08 / 03 / 200517: 45$ & $08 / 04 / 200507: 13$ & $13: 28: 00$ & $13: 00: 00$ \\
\hline
\end{tabular}

To calculate the productivity rate of day 3 , the 5 -hour and the 13 -hour standard route times of the first and second routes should be considered as ASH. The 24-hour truck daily operation time, added up to 7 hours and 13 minutes of the over one-day route (the third cycle starts on 08/03 and finishes on 08/04) should be considered at the denominator. The exceeding 2 hours and 55 minutes, already accounted on the day before, should not be considered.

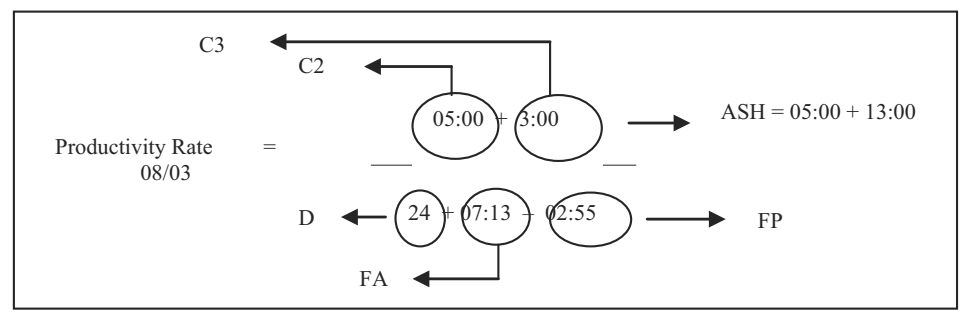

Figure 5: Productivity rate of day 03

\subsection{Effectiveness of trucks` route planning}

When calculating the effectiveness of the trucks routes planning there is a peculiarity not found at the calculation of the truck utilization efficiency methodology. Because it is a planning, there is the possibility of its non-execution, what can lead to overlap during routes re-planning. This problem is caused by the fact that the planning is generated usually with a one-day horizon in advance. So if an unexpected factor (such as a car break downs or, traffic delays, etc) happens, planning may not be fulfilled and new route may be scheduled. However, the rescheduled route may overlap an originally but non-performed planned route (Figure 6). In this situation, instead of considering the "standard route time" as the sum of the 
planned routes times, as already explained, it is considered only the planned route fraction not accomplished until the time the truck is declared available again.

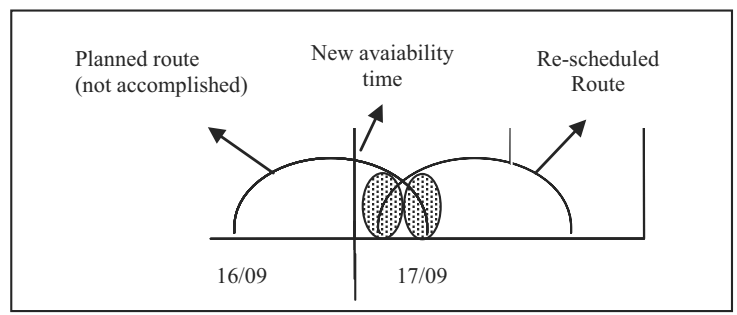

Figura 6: Overlapping

In that way, the planning productivity rate is obtained by the following formula:

$$
\underset{\substack{\text { Rate } \\ \text { Planning Productivity }}}{\mathrm{T}_{\mathrm{F}} \mathrm{FA}^{*}-\mathrm{D}-\mathrm{A}}
$$

PSH $=$ Planned standard-hour

$\mathrm{D}=$ Truck daily operation time

$\mathrm{FA}^{*}=$ Fraction of the route completed on the next day, adjusted by the new availability time of the truck on the next day

$A=$ New truck availability time on the analysis day.

Table 4 shows a truck's route planning on a 3-day horizon:

Table 4 - Truck's route planning on a 3-day horizon

\begin{tabular}{|c|c|c|c|c|c|}
\hline Destiny & Start & Finish & Route Time & $\begin{array}{c}\text { Standard Route } \\
\text { Time }\end{array}$ & $\begin{array}{c}\text { Adjusted } \\
\text { Route Time }\end{array}$ \\
\hline \multicolumn{7}{|c|}{ Truck available for new scheduling at $10: 30$ of $08 / 02$} \\
\hline São Mateus & $08 / 02 / 200511: 30$ & $08 / 02 / 200522: 34$ & $11: 04: 00$ & $11: 00: 00$ & $11: 00: 00$ \\
\hline São Mateus & $08 / 02 / 200522: 34$ & $08 / 03 / 200509: 35$ & $11: 01: 00$ & $11: 00: 00$ & $11: 00: 00$ \\
\hline \multicolumn{7}{|c|}{ Truck available for new scheduling at 12:00 of 08/03 } \\
\hline Aracruz & $08 / 03 / 200512: 06$ & $08 / 03 / 200517: 10$ & $05: 04: 00$ & $05: 00: 00$ & $05: 00: 00$ \\
\hline Bahia & $08 / 03 / 200521: 31$ & $08 / 04 / 200510: 53$ & $13: 22: 00$ & $13: 00: 00$ & $2: 39: 00$ \\
\hline \multicolumn{7}{|c|}{ Truck available for new scheduling at 00:10 of $08 / 04$} \\
\hline Aracruz & $08 / 04 / 200500: 15$ & $08 / 04 / 200505: 25$ & $05: 10: 00$ & $05: 00: 00$ & $05: 00: 00$ \\
\hline Aracruz & $08 / 04 / 200505: 35$ & $08 / 04 / 200510: 40$ & $05: 05: 00$ & $05: 00: 00$ & $05: 00: 00$ \\
\hline Bahia & $08 / 04 / 200510: 45$ & $08 / 04 / 200523: 55$ & $13: 10: 00$ & $13: 00: 00$ & $13: 00: 00$ \\
\hline
\end{tabular}

Based on the table, to calculate the productivity rate of day 2, the two 11-hour standard route times of the first and second routes should be considered as PSH, since there was no overlapping of the routes, so the standard route times are equal to the adjusted route times. The 24-hour truck daily operation time, added up to 9 hours and 35 minutes of the over one- 
day route (the second route starts on $08 / 02$ and finishes on $08 / 03$ ) should be considered at the denominator. However, 10 hours and 30 minutes related to the new truck availability time (on day 08/02), should also be taken into account.

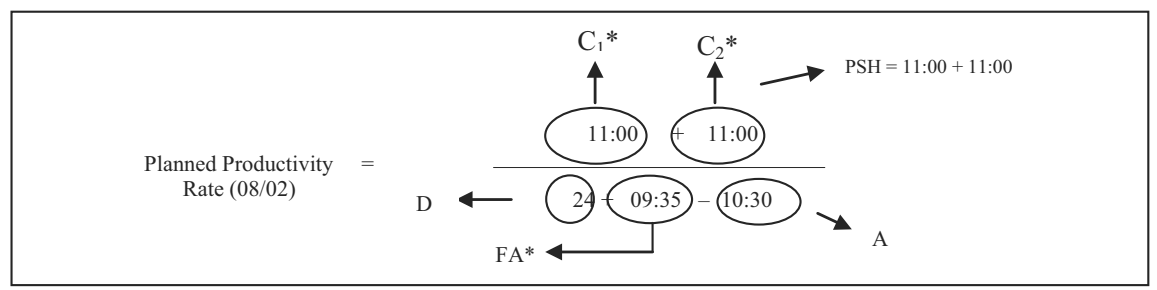

Figure 7: Calculation of the planning effectiveness - day 2

On the 2nd day of operation, there is an overlap on routes planning: there is a route planned to start at day 4 at 00:15, while the last route planned to start on day 3, should finish on day 04 at 10:53. In this situation, the "standard route time" should be adjusted taking into consideration the new availability time of the truck. Thus, on the calculation of the planned standard-hours of day 3, the 5- hour standard route time of the first route should be considered, together with 2 hours and 39 minutes regarding the adjusted route time of the second route of the day (instead of the 13-hours standard route time), as PSH. In the denominator, we must contemplate the 24-hour daily operation time and, the new truck availability time and the fraction of the route completed on the day after (FA*). However, because the standard route time has been adjusted, the FA* must also be modified. So instead of 10 hours and 53 minutes, only 10 minutes should be considered (00:10 - 00:00), regarding the fraction of the route started on day 3 until the new truck availability time on day 4 .

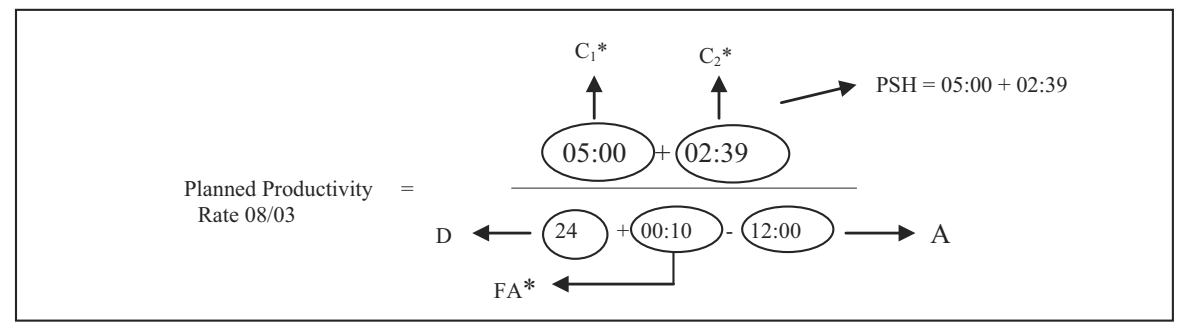

Figure 8: Calculation of the planning effectiveness - day 3

\section{RESULTS ANALYSIS}

The proposed methodology was applied on two real companies that provide transportation services for Aracruz (the data were slightly modified to keep the information confidentiality). The analysis was based on the May to July period and the result is shown in Table 5. 
Table 5: Standard-hours - Planned and Accomplished

\begin{tabular}{|c|c|c|c|c|}
\hline \multicolumn{2}{|c|}{ Company 1 } & \multicolumn{2}{c|}{ Company 2 } \\
\hline \multirow{2}{*}{ Month } & Planned standard-hours & Accomplished standard-hours & Planned standard-hours & Accomplished standard-hours \\
& & & & $20: 15$ \\
\hline May & $20: 25$ & $15: 14$ & $20: 05$ & $15: 30$ \\
\hline June & $20: 12$ & $14: 36$ & $21: 53$ & $17: 37$ \\
\hline July & $22: 02$ & $16: 38$ & 19 \\
\hline
\end{tabular}

Table 5 corresponds to the standard hours planned and accomplished in May, June and July. For example, to each Company 1 truck, it was planned to have 20 hours and 25 minutes standard-hours operation. However, each truck just accomplished 15 hours and 14 minutes standard-hours. According to the table, we conclude that:

- The comparison of companies 1 and 2 planned standard-hour (PSH) shows very close numbers. This is a requirement of ARCEL operation.

- The month of June presented the worst productivity rate. During this period, a drivers' strike caused the suspension of wood transportation. Also, factors such as rain and road conditions contributed negatively to the transportation scenario. Those factors justify a lower planned and accomplished standard-hours during the month of June. A better performance in July is associated with a shorter queuing time in shipments process and at the factory, and with a better utilization of idle trucks waiting for rescheduling.

- The difference between the ASH (accomplished standard-hours) and PSH (planned standard- hours) still quite significant, what demonstrates that during the study period, there was a huge influence of idle time, such as queuing, rain, road conditions, trucks` downtime and drivers shift changing, raising routes' total times. This difference calculation is an opportunity for process improvement, since this methodology allows identifying logistics bottlenecks.

\section{CONCLUSION}

The need to measure improvements in logistics management of Aracruz Celulose resulted in the building of a new logistics productivity indicator to its truck fleet. This indicator, the standard-hour, allows assessing performance, the efficiency of freight companies operating in different scenarios, the truck unit individual performance, and doing the benchmarking with other companies, at the medium-time horizon 
The standard-hour performance indicator considers the truck unit utilization, allowing the comparison to its maximum available hours. Once it does not considers the accomplished routes times but the originally planned route times, the proposed methodology permits the evaluation of the transport process regarding expected behaviors. The possibility of using particular characteristics varying during time and different transportation logistics scenario infers flexibility to the indicator.

A major challenge in implementation was the need of a reliable database of routes and operation times. This information obtainment required the creation of mechanisms to capture time and cleaning/correction procedures, able to generate credibility to the data.

After implementation, it was possible to follow the evolution the indicator, contributing to logistics problems identification. To face those problems, the company must promote changes in the logistics/transportation management that can be, once again, evaluated by this new productivity indicator.

\section{REFERENCES}

Lebas,MJ. Performance measurement and performance management. International Journal of Production Economics, n.41, p-23 -25, 1995.

LIMA JÚNIOR, Orlando F. Análise e Avaliação do Desempenho dos Serviços de Transporte de Cargas. In: Caixeta-Filho, José A.; Martins, Ricardo S. Gestão Logística do Transporte de Cargas. São Paulo: Atlas, 2001.p. 108-147.

ÑAURI, Miguel H. Caro. As medidas de desempenho como base para a melhoria contínua de processos: o caso da Fundação de Amparo à Pesquisa e Extensão Universitaria (FAPEU). 1998. 109 f. Dissertação (Mestrado em Engenharia de Produção) - Universidade Federal de Santa Catarina, Florianópolis. (http://www.eps.ufsc.br/disserta98/caro/index.html)

RAZZOLINI Fo, Edelvino. Avaliação do desempenho logístico de fornecedores de medicamentos: um estudo de caso nos hospitais paranaenses. 2000. 202 f. Masters in Industrial Engineering - Universidade Federal de Santa Catarina, Florianópolis.

SCHMITT, Bruno Henrique. Modelo de Avaliação de Desempenho de Operadores Logísticos Atuantes no Setor Agrícola de Cargas a Granel. 2002. 158f. Masters in Industrial Engineering - Universidade Federal de Santa Catarina, Florianópolis. 


\title{
A MIP FOR THE INTEGRATED PRODUCTION AND TRANSPORTATION SCHEDULING OF AN OEM
}

\author{
Thomas Makuschewitz ${ }^{1}$, Enzo M. Frazzon ${ }^{1}$, Bernd Scholz-Reiter ${ }^{1}$, Antônio G.N. Novaes ${ }^{2}$ \\ ${ }^{1}$ BIBA - Bremer Institut für Produktion und Logistik $\mathrm{GmbH}$ at the University of Bremen \\ ${ }^{2}$ Department of Industrial Engineering, UFSC - Federal University of Santa Catarina
}

\begin{abstract}
In this paper we address the integrated production and transportation scheduling problem (PTSP) for an original equipment manufacturer (OEM). The proposed mixed integer program (MIP) fosters a sustainable alignment between production and transportation systems by combining the open flow shop problem and vehicle routing problem of a manufacturing company. Current capabilities of transportation and production systems as well as a rolling time horizon are taken into account by the formulation. The computational analysis shows that the formulated program supports the aimed sustainable alignment and that heuristics are needed for suitably dealing with this kind of complex problem.
\end{abstract}

\section{INTRODUCTION}

In a manufacturing company, different departments usually execute the production scheduling and the transportation planning for the distribution of customer orders. On the operational level, different stakeholders perform the scheduling and planning tasks making locally bounded decisions. As a drawback the obtained results may be locally optimal but do not pay attention to the requirements of the linked systems. Furthermore perturbations events, e.g. breakdown of a resource, that affect the current capabilities of the involved systems have to be considered in order to ensure a sustainable and overall competitive performance of the manufacturing company. First studies show that a significant improvement can be achieved by an integrated scheduling of production and transportation systems compared to a sequential scheduling approach [1]. 
An optimal solution of the PTSP requires solving the production and transportation scheduling problems simultaneously. Since the underlying mathematical programs are NPhard, an excessive computational effort is required even for dealing with small problems. Furthermore, the classic production and transportation scheduling problem often assumes the transportation to be instantaneous and does not address the routing of the transportation vehicles [2-4]. Moreover, most of the existing concepts focus on the strategic or tactical planning and scheduling [5]. Research dealing with detailed schedules for the transportation can be classified according to the objectives of applied mathematical programs and heuristics. The first group focuses on the lead-time of orders' production and transportation [6]. The second group takes associated costs and lead times into account [1,7]. The challenge of integrating the vehicle routing has only been addressed by a few authors [3, 8]. So far no approach is able to deal with perturbations and a rolling time horizon.

This paper is structured as follows: section 2 introduces a MIP of the PTSP for a manufacturing company with deliveries to its customers. A test case is studied in section 3 . Section 4 presents some conclusions and suggests directions for future research.

\section{INTEGRATING PRODUCTION AND TRANSPORTATION SCHEDULING}

This section introduces a mathematical program for the operational level that combines the production scheduling of an OEM and the associated vehicle routing for the transportation of orders to the customers. The MIP considers delivery dates of the orders, current capabilities of production and transportation systems as well as the needs of a rolling time horizon.

The applied production scheduling is based on an open flow-shop with several consecutive production levels. Each production level can consist of several machines, which feature an order-type specific processing time and processing cost. All orders have to be processed at one machine at each production level. The orders can be stored before the first production level, between production levels and before the assigned tour departs.

An adapted vehicle routing formulation is employed for the transportation scheduling of orders. A new tour becomes available as soon as a tour from a preceding production facility arrives. All considered tours start and terminate at the OEM location and have a limited transportation capacity. If at least one order is assigned to a tour this tour is conducted. In this case fixed and variable costs occur. The variable costs depend on the duration of the tour. Only a minimal transportation time between two consecutive locations of a tour is enforced. 
By extending this time, orders can be stocked during their transportation. A late delivery of an order to the customer is penalised. Within a certain tour each location of the transportation network can be visited only once. However, a location can be visited by several tours, in order to deliver different orders. The program can cope with a rolling time horizon by initialising orders that are already in production and tours that are on their way to the customers. Perturbations can be considered by adjusting the related parameters between two consecutive planning runs.

\subsection{Nomenclature}

Sets

I Locations

$I^{D} \quad$ production location; $\left(I^{D} \subseteq I\right)$

$I_{v}^{S L} \quad$ Start location of tour $v ;\left(I_{v}^{S L} \subseteq I\right)$

$I_{i}^{s} \quad$ Connected locations to $i ;\left(I_{i}^{s} \subseteq I\right)$

$J \quad$ Customer orders

$T \quad$ Order types

$T_{j, t}^{j} \quad$ Assignment of $j$ and $t$

$N \quad$ Production levels

$N_{j, n}^{p} \quad$ Production levels of order $j$

$M \quad$ Machines

$M_{n}^{e} \quad$ Machines at production level $n$

$V \quad$ Tours to customers

$A_{j, v}^{\text {tour }} \quad$ Assignment of orders $j$ to tours $v$

$A_{j, j^{\prime}}^{\text {seq }} \quad$ Assignment of order sequence $j, j^{\prime}$

$A_{j, n, m}^{\text {mach }}$ Assignment $j$ to $m$ on $n$

Parameters

$c^{d} \quad$ Costs for delayed delivery

$c^{d v} \quad$ Variable costs of tour $v$

$c^{f v} \quad$ Fixed costs of tour $v$

$c^{h} \quad$ Storage costs of an order

$c_{j, t, n, m}^{p}$ Processing costs of $j$ at $n$ on $m$

$d_{i, i^{\prime}, v} \quad$ Travel time of $v$ between $i$ and $i^{\prime}$

$M \quad$ BigM; large scalar

$p t_{j, t, n, m}$ Processing time of $j$ at $n$ on $m$

$r_{j} \quad$ Required transportation capacity

$\bar{r}_{v} \quad$ Transportation capacity of $v$

$t_{j, n}^{a} \quad$ Supply date of order $j$
Variables (positive)

$T_{j, n}^{c} \quad$ Completion time of $j$ at $m$ on $n$

$T_{j}^{d} \quad$ Delivery delay of $j$ to the customer

$T_{j}^{h} \quad$ Storage time of $j$ befor $n=1$

$T_{j, n, n^{\prime}}^{h p} \quad$ Storage time of $j$ between $n, n^{\prime}$

$T_{j}^{h v} \quad$ Storage time $j$ before transportation

$T_{v}^{s} \quad$ Start time of tour $v$

$T_{v, i}^{a} \quad$ Arrival time of tour $v$ at location $i$

$T_{v}^{d v} \quad$ Duration of tour $v$

\section{Binary variables}

$X_{j, n, m} j$ is processed at $m$ on $n$

$Y_{j, j^{\prime}, n} \quad j$ is processed before $j^{\prime}$ on $n$

$Z_{v, i, i^{\prime}} \quad i^{\prime}$ is visited after $i$ by tour $v$

$A_{j, v} \quad j$ is assigned to tour $v$

$O_{v} \quad$ tour $v$ is conducted. 
$t_{v}^{a v} \quad$ Earliest departure date of tour $v$

$t_{i, j}^{d d} \quad$ Desired delivery date of $j$ at $i$

\subsection{Mathematical Model}

The production of an order is assigned in equation (1) to one machine at each production level that needs to be passed by this order. Since the model is designed for a rolling time horizon, the number of production levels decreases for a specific order between consecutive planning runs.

$$
\sum_{m \in M_{n}^{e}} X_{j, n, m}=1 \quad\left(j \in J ; n \in N_{j, n}^{p}\right)
$$

The completion time of an order at a given production level has to be greater than the sum of the completion time at the previous production level and the required processing time of the assigned machine. In the case that a planning is carried out while an order is processed on a machine the required production time is adapted to a remaining processing time. Furthermore the assignment of job, production level and machine is fixed.

$$
\begin{array}{ll}
T_{j, n-1}^{c}+t_{j, n}^{a}+\sum_{m \in M_{n}^{e}} p t_{j, t, n, m} X_{j, n, m} \leq T_{j, n}^{c} & \left(j \in J ; t \in T: j, t \in T_{j, t}^{j} ; n \in N_{j, n}^{p}\right) \\
X_{j, n, m}=1 & \left(j \in J ; n \in N_{j, n}^{p} ; m \in M_{n}^{e} \wedge A_{j, n, m}^{\text {mach }}\right)
\end{array}
$$

The processing of orders is scheduled by equations (4) to (6). Equation (4) and (5) ensure that at each point in time only one order is processed at a certain machine. Note that for one production level the sequence of all orders is the same at all machines. The results of a previous scheduling can be considered partly by enforcing the obtained sequence of orders at the production levels.

$$
\begin{aligned}
Y_{j, j^{\prime}, n}+Y_{j^{\prime}, j, n}=1 & \left(j, j^{\prime} \in J: j<j^{\prime} ; n \in N_{j, n}^{p} \wedge N_{j^{\prime}, n}^{p}\right) \\
T_{j, n}^{c}+p t_{j^{\prime}, t, n, m} \leq & T_{j^{\prime}, n}^{c} \\
& +M\left(2-X_{j, n, m}-X_{j^{\prime}, n, m}\right) \\
& +M\left(1-Y_{j, j^{\prime}, n}\right) \\
& \quad\left(j, j^{\prime} \in J: j \neq j^{\prime} ; t \in T: j, t \in T_{j, t}^{j} ; n \in N_{j, n}^{p} \wedge N_{j^{\prime}, n}^{p} ; m \in M_{n}^{e}\right) \\
& \quad\left(j, j^{\prime} \in J: j, j^{\prime} \in A_{j, j^{\prime}}^{\text {seq }} ; n \in N_{j, n}^{p} \wedge N_{j^{\prime}, n}^{p}\right)
\end{aligned}
$$

Since the production capacities are limited the orders can be stored before and between the production levels. The storage times are obtained by equations (7) and (8).

$$
\begin{array}{ll}
T_{j}^{h} \geq T_{j, n}^{c}-\sum_{m \in M_{n}^{e}} p t_{j, t, n, m} X_{j, n, m}-t_{j, n}^{a} \quad & \left(j \in J ; t \in T: j, t \in T_{j, t}^{j} ; n \in N_{j, n}^{p}: n=1\right) \\
T_{j, n-1, n}^{h p} \geq T_{j, n}^{c}-T_{j, n-1}^{c}-\sum_{m \in M_{n}^{e}} p t_{j, t, n, m} X_{j, n, m} & \left(j \in J ; t \in T: j, t \in T_{j, t}^{j} ; n \in N_{j, n}^{p}: n=2, \ldots, N\right)
\end{array}
$$


Each order is transported by a tour to the customers. Therefore orders are assigned to a tour. Before the assigned tour of an order starts the order can be stored.

$$
T_{j}^{h v} \geq T_{v}^{s}-T_{j, n}^{c}-M\left(1-A_{j, v}\right) \quad\left(j \in J ; n \in N_{j, n}^{p}: n=N ; v \in V\right)
$$

In the case that an order has been already passed the production at the execution time of the planning, the completion time at the last production level is assumed to be zero. Hence, it is immediately available for transportation.

$$
T_{j, n}^{c} \leq 0 \quad\left(j \in J ; n=N: N_{j, n}^{p}=\varnothing\right)
$$

Equations (11) to (13) define the route of a tour in the case that it is conducted. The tour starts at the considered production facility. In the event that a tour has already departed from the production facility at the time of planning, the previously passed location is considered as starting location. A tour is only considered by the program when at least two route segments remain and an order has to be delivered. Each tour terminates at the production facility.

$$
\begin{aligned}
& \sum_{i^{\prime} \in I_{i}^{S}} Z_{v, i, i^{\prime}}=O_{v} \quad\left(i \in I_{v}^{S L} ; v \in V\right) \\
& \sum_{i \in I_{:}} Z_{v, i, i^{\prime}}=O_{v} \quad\left(i^{\prime} \in I^{D} ; v \in V\right)
\end{aligned}
$$

The continuity of route segments of a tour is given by equation (13).

$$
\sum_{\substack{i \in I: \\ h \in I_{i}^{S}}} Z_{v, i, h}-\sum_{i^{\prime} \in L_{h}^{S}} Z_{v, h, i^{\prime}}=0 \quad(h \in I ; v \in V)
$$

Each order is assigned to one tour; partial deliveries are not allowed. The results of the previous planning are taken into account by fixing the assignment of orders and tours.

$$
\begin{array}{ll}
\sum_{v \in V} A_{j, v}=1 & (j \in J) \\
A_{j, v}=1 & \left(j \in J ; v \in V: j, v \in A_{j, v}^{\text {tour }}\right)
\end{array}
$$

A regular tour from the considered production facility to the customers can start as soon as all assigned orders are manufactured and the transportation device is available. In the case that a tour already departed the production facility at the execution time of the planning, the completion time of orders is assumed to be zero as well as the date of availability of the transportation devise. Hence, the tour can be resumed immediately. Furthermore, the departure time for a not conducted tour equals zero.

$$
\begin{array}{ll}
T_{v}^{s} \geq T_{j, n}^{c}-M\left(1-A_{j, v}\right) & (j \in J ; n=N ; v \in V) \\
T_{v}^{s} \geq t_{v}^{a v}-M\left(1-A_{j, v}\right) & (j \in J ; v \in V) \\
T_{v}^{s} \leq O_{v} M & (v \in V)
\end{array}
$$


A lower bound for the arrival time of a tour at the first location is given by the departure time from the starting location and the minimal required travel time between the locations. In the event that the tour already departed while the planning is carried out, the travel time is adjusted to a remaining travel time for this tour.

$$
T_{v}^{s}+d_{i, i^{\prime}, v}-M\left(1-Z_{v, i, i^{\prime}}\right) \leq T_{v, i^{\prime}}^{a} \quad\left(i \in I_{v}^{S L} ; i^{\prime} \in I: i^{\prime} \in I_{i}^{s} ; v \in V\right)
$$

Equations (20) and (21) ensure that the arrival time at a consecutive location of a tour is greater than the sum of preceding arrival time and the minimal required travel time. If the planning is carried out while a tour is between two locations the required travel time is adjusted to a remaining travel time for this tour.

$$
\begin{aligned}
& T_{v, i}^{a}+d_{i, i^{\prime}, v}-M\left(1-Z_{v, i, i^{\prime}}\right) \leq T_{v, i^{\prime}}^{a} \quad\left(i, i^{\prime} \in I \backslash I_{v}^{S L} \wedge I^{D}: i^{\prime} \in I_{i}^{s} ; v \in V\right) \\
& T_{v, i}^{a}+d_{i, i^{\prime}, v}-M\left(1-Z_{v, i, i^{\prime}}\right) \leq T_{v, i^{\prime}}^{a} \quad\left(i \in I: i^{\prime} \in I_{i}^{s} \wedge i^{\prime} \in I^{D} ; v \in V\right)
\end{aligned}
$$

In the case that a location is not part of the tour the arrival time equals zero.

$$
\sum_{i^{\prime} \in I: i \in I_{i^{s}}^{s}} Z_{v, i^{\prime}, i} M \geq T_{v, i}^{a} \quad(i \in I ; v \in V)
$$

Each tour has a limited transportation capacity. In the case that a tour has already departed while the planning is carried out the transportation capacity of this tour is adjusted to the required capacity of the assigned orders. Hence the tour cannot pickup any additional orders.

$$
\sum_{j} A_{j, v} r_{j} \leq \bar{r}_{v} \quad(v \in V)
$$

In the case that at least one order is assigned to a tour the tour is conducted.

$$
\sum_{j \in J} A_{j, v} \leq O_{v} M \quad(v \in V)
$$

The duration of a tour is greater than zero in the case that the tour is conducted.

$$
T_{v}^{d v} \geq T_{v, i}^{a}-T_{v}^{s}-M\left(1-O_{v}\right) \quad\left(i \in I^{D} ; v \in V\right)
$$

Each order has a desired delivery date. The delivery of an order cannot be early but late.

$$
\begin{array}{ll}
T_{v, i}^{a} \geq t_{i, j}^{d d}-M\left(2-A_{j, v}-O_{v}\right) & (i \in I ; j \in J ; v \in V) \\
T_{j}^{d} \geq T_{v, i}^{a}-t_{i, j}^{d d}-M\left(2-A_{j, v}-O_{v}\right) & (i \in I ; j \in J ; v \in V)
\end{array}
$$

The objective function minimises the costs for delayed deliveries, the processing and storage costs of orders and as well the fixed and variable costs of each conducted tour.

$$
\begin{aligned}
\text { Min. } & \sum_{j \in J} T_{j}^{d} c_{j}^{d}+\sum_{j \in J} \sum_{\substack{t \in T: \\
j, t \in T_{j, t}^{j}}} \sum_{n \in N_{m \in M_{n}^{e}}} X_{j, t, n, m} c_{j, t, n, m}^{p} \\
& +\sum_{j \in J}\left(T_{j}^{h}+T_{j}^{h v}+\sum_{n \in N} T_{j, n-1, n}^{h p}\right) c^{h}+\sum_{v \in V}\left(O_{v} c^{f v}+T_{v}^{d v} c^{d v}\right)
\end{aligned}
$$




\section{COMPUTATIONAL ANALYSIS OF THE ADAPTED PTSP}

Section 3 applies the formulated PTSP for an OEM to a test case in Germany and identifies the limitations of the mathematical program.

\subsection{Test case}

The test case consists of a OEM in Kassel who ships the customer orders all over Germany. The production is described by Scholz-Reiter et al. [9]. The transportation network equals the German highway network, weighted with the required travelling times [10].

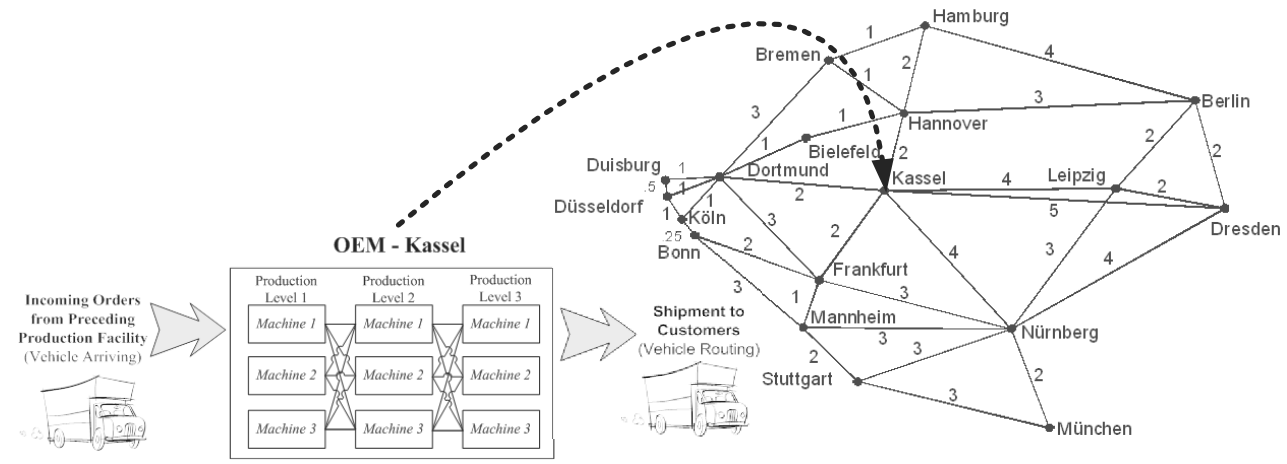

Fig. 1: Structure of test scenario

\subsection{Computational results}

For simplicity all costs, costs per time unit and required capacities are in general chosen to be 1 . The processing times of the production are given in [9]. Processing costs are assumed to be 1 per required time unit. Fixed costs for a conducted tour are 10. Each transportation device has a maximal transportation capacity of 5 units. The considered test instances comprise maximal five Table 1: Gap to the optimal solution after 600 seconds transportation devices that arrive at the following points in time: 2, 10, 18, 26 and 34. The proposed mathematical formulation has been implemented in GAMS 22.8 and was solved by CPLEX 11 in a deterministic mode with four

\begin{tabular}{c|c|c}
$\begin{array}{c}\text { Transportation } \\
\text { devices }\end{array}$ & Orders & $\begin{array}{c}\text { Gap to } \\
\text { optimal solution }\end{array}$ \\
\hline 1 & 3 & $0,00 \%$ \\
\hline 1 & 5 & $23,81 \%$ \\
\hline 2 & 7 & $32,35 \%$ \\
\hline 2 & 10 & $31,38 \%$ \\
\hline 3 & 13 & $42,62 \%$ \\
\hline 3 & 15 & $43,04 \%$ \\
\hline 4 & 17 & $50,48 \%$ \\
\hline 4 & 20 & $63,16 \%$
\end{tabular}
threads. The computation was carried out on a $2.67 \mathrm{GHz}$ quad-core computer with $4 \mathrm{~GB}$ of 
RAM. The results are given in table 1 . Table 1 shows the relative gap between the best integer solution and the best node remaining after 600 seconds. For very small instances the optimal solution can be obtained within this time. Hence, the programm can support a sustainable allignment of production and transportation systems by suggesting a schedule to the invoved stakeholders. For a number of 5 transportation devices and 23 orders no feasilbe solution could be found within 600 seconds. Hence, an increasing number of orders and transportation devices shows the need for a heuristic.

\section{CONCLUSIONS}

In this paper we introduced an mathematical formulation of the PTSP for an OEM that is part of a supply chain. This formulation can be applied on a rolling time horizon and takes dynamic changing capabilities of the transportation and production into account. The computational analysis has shown that a sustainable integration of production and transportation can be fostered with this approach and that a powerful heuristic is required.

\section{REFERENCES}

1. Chen, Z.-L.; Vairaktarakis, G.L. (2005): Integrated scheduling of production and distribution operations. Management Science, 51, pp. 614-628.

2. Sarmiento, A.; Nagi M.R. (1999): A review of integrated analysis of productiondistribution systems. IIE Transportation 31, pp. 1061-1074.

3. Chandra, P.; Fisher, M.L. (1994): Coordination of production and distribution planning. European Journal of Operational Research 72, pp. 503-517.

4. Fumero, F.; Vercellis, C. (1999): Synchronized development of production, inventory, and distribution schedules. Transportation Science 33, pp. 330-340.

5. Chen, Z.L. (2004): Integrated production and distribution operations: Taxonomy, models, and review. Handbook of Quantitative Supply Chain Analysis: Modelling in the EBusiness era. Simchi-Levi, D., Wu, S.D., Shen, Z.J. (eds.). Kluwer Academic Publishers, New York.

6. Geismar, H.N.; Laporte, G.; Lei, L.; Sriskandarajah, C. (2008): The Integrated Production and Transportation Scheduling Problem for a Product with Short Lifespan. INFORMS Journal on Computing, Vol. 20/1, pp. 21-33.

7. Pundoor, G.; Chen, Z.-L. (2005): Scheduling a production-distribution system to optimize the tradeoff between delivery tardiness and distribution cost. Navel Research Logistics, 52, pp. 571-589. 
8. Li, C.-L.; Vairaktarakis, G.; Lee, C.-Y. (2005): Machine scheduling with deliveries to multiple customer locations. European Journal of Operational Research, 164, pp. 39-51.

9. Scholz-Reiter, B.; Freitag, M.; de Beer, C.; Jagalski, T. (2005): Modelling Dynamics of Autonomous Logistic Processes: Discrete-event versus continuous approaches. Annals of the CIRP, 55, pp. 413-417.

10. Rekersbrink, H.; Makuschewitz, T.; Scholz-Reiter, B. (2009): A distributed routing concept for vehicle routing problems. Logistics Research, 1, pp. 45-52, Springer.

\section{ACKNOWLEDGMENTS}

This research was supported by the German Research Foundation (DFG) as part of the Brazilian-German Collaborative Research Initiative on Manufacturing Technology (BRAGECRIM). 


\title{
THE ROLES AND APPROACHES OF SUPPLY CHAIN OPTIMIZERS
}

\author{
Yohanes Kristianto and Petri Helo \\ Department of Production \\ University of Vaasa \\ P.O.Box 700, Vaasa 65101
}

\begin{abstract}
This article reviews some approaches on building such software packages. Software tools for strategic, tactical and operational decision making levels are analysed from their optimization objectives and methodology point of views. These approaches are compared to general theory. Optimization approaches are related to inventory allocation and cost savings. The key difference seems to be in problem setting: what are the key decisions vary between software tools. Many approaches are tied to specific industry problems and built on top of generic purpose optimization engines. In the near future, new problems can be solved by using optimization due to increased volume of real-time information from the supply chains. This paper contributes on analyzing optimization software approaches and suggests new areas for application development.
\end{abstract}

\section{INTRODUCTION}

The potential role of supply chain optimization in the domain of supply chain support system is still lack of discussion. Indeed, supply chain support system for instances information sharing and postponement give significant contribution to lead time and total costs minimization. Without intending to make trivial assumption on this deficiency then we have the following research question

In what extend supply chain optimization role, how it has been conducted and what is future opportunity to supply chain optimization?

In considering the above research question, this paper sequenced the discussion as follows: First there is a review of supply chain optimization (Section 2). The applied optimization model in some commercial software is reviewed in Section 3 that is divided into strategic level (Section 3.2.) and everyday operations (Section 3.2). All of those reviews are concluded in Section 4 by comparing some applications of supply chain optimization (Section 4.1) and finding future opportunities for further applications (Section 4.2). 


\section{SUPPLY CHAIN OPTIMIZATION LITERATURES}

Based on various optimization methods and problem formulation, many supply chain problems have been presented in the literature. Table 1 lists the key concepts of some selected supply chain optimization problem related papers. Due to large number of papers, it is impossible to review all. The tables listed below should give a good overview what type of problems and solutions have been applied and reported in the academic literature.

Table 1: Review of some optimization model in supply chain

\begin{tabular}{|c|c|c|c|c|c|c|c|c|c|c|c|c|c|c|c|c|}
\hline & \multicolumn{4}{|c|}{ Model type } & \multicolumn{4}{|c|}{$\begin{array}{c}\text { Performance } \\
\text { measures }\end{array}$} & \multicolumn{8}{|c|}{ Decision variables } \\
\hline & 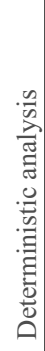 & 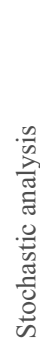 & 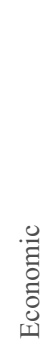 & 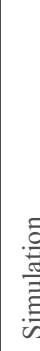 & in & 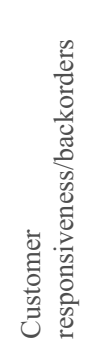 & 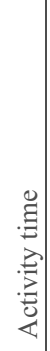 & 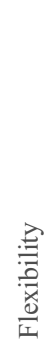 & 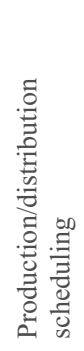 & 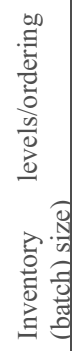 & 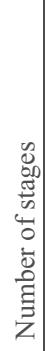 & 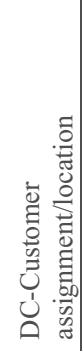 & 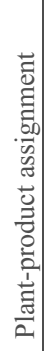 & 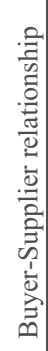 & 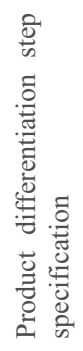 & 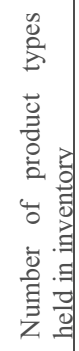 \\
\hline Disney and Towill [1] & & & & $\sqrt{ }$ & & $\sqrt{ }$ & & & & $\sqrt{ }$ & & & & $\sqrt{ }$ & & \\
\hline Fruchter et al [2] & & & & & & & & & & & & & & & & \\
\hline Gen M. and Lin. L [3] & & $\sqrt{ }$ & & & $\sqrt{ }$ & $\sqrt{ }$ & & $\sqrt{ }$ & & $\sqrt{ }$ & & & & & $\sqrt{ }$ & \\
\hline Graves and Willems [4] & & $\sqrt{ }$ & & & & & & & & & & & & & & \\
\hline Graves and Willems [5] & $\sqrt{ }$ & & & & $\sqrt{ }$ & $\sqrt{ }$ & & $\sqrt{ }$ & & $\sqrt{ }$ & & & & & $\sqrt{ }$ & \\
\hline Graves and Tomlin [6] & & $\sqrt{ }$ & & & $\sqrt{ }$ & $\sqrt{ }$ & & $\sqrt{ }$ & & $\sqrt{ }$ & & & & & $\sqrt{ }$ & \\
\hline Graves et al [7] & $\sqrt{ }$ & & & & $\sqrt{ }$ & $\sqrt{ }$ & & $\sqrt{ }$ & & $\sqrt{ }$ & & & & & $\sqrt{ }$ & \\
\hline $\begin{array}{l}\text { Han, C } \quad \text { and } \\
\text { Damrongwongsiri M [8] }\end{array}$ & & $\sqrt{ }$ & & & $\sqrt{ }$ & & & $\sqrt{ }$ & & $\sqrt{ }$ & & $\sqrt{ }$ & $\sqrt{ }$ & & & \\
\hline Helo et al [9] & & & & $\sqrt{ }$ & $\sqrt{ }$ & & $\sqrt{ }$ & & & $\sqrt{ }$ & & & $\sqrt{ }$ & & $\sqrt{ }$ & $\sqrt{ }$ \\
\hline Kristianto and Helo [10] & & $\sqrt{ }$ & $\sqrt{ }$ & & $\sqrt{ }$ & $\sqrt{ }$ & & $\sqrt{ }$ & & & & & & $\sqrt{ }$ & & \\
\hline Krikke et al [11] & $\sqrt{ }$ & & & & $\sqrt{ }$ & & & & & & & $\sqrt{ }$ & $\sqrt{ }$ & & & \\
\hline Lee et. al [12] & $\sqrt{ }$ & & & & $\sqrt{ }$ & & & & $\sqrt{ }$ & $\sqrt{ }$ & & $\sqrt{ }$ & & & & \\
\hline $\begin{array}{lll}\mathrm{Ma} & \text { and } & \text { Davidrajuh } \\
{[13]} & & \\
\end{array}$ & $\sqrt{ }$ & & & & $\sqrt{ }$ & $\sqrt{ }$ & & & & & $\sqrt{ }$ & $\sqrt{ }$ & & & & \\
\hline Ma and Suo $[14]$ & $\sqrt{ }$ & & & & $\sqrt{ }$ & & & $\sqrt{ }$ & & $\sqrt{ }$ & & & $\sqrt{ }$ & & & \\
\hline Santoso et al [15] & & $\sqrt{ }$ & & & $\sqrt{ }$ & & & & & & & $\sqrt{ }$ & & & $\sqrt{ }$ & \\
\hline Syariff et al [16] & & $\sqrt{ }$ & & & & & & & & & & & & & & \\
\hline Towill [17] & & & & $\sqrt{ }$ & & $\sqrt{ }$ & & & & & & & & $\sqrt{ }$ & & \\
\hline
\end{tabular}




\section{OPTIMIZATION IN SOME SOFTWARE APPLICATIONS}

Optimisation is used in many software packages. We have selected strategic network planning software packages and operational level optimization tools for analysis. The data has been collected from public downloads and reported sources. The aim of analysis is to show what type of problem setting the decision support systems have been developed for and highlight some key features from the software packages. For this review, we will examine the following strategic network planning tools: (1) LLamasoft Supply Chain Guru [18], (2) IBM Supply Chain Simulation, (3) ASDN, and tactical/operational category (4) I2 Rhythm, and (5) SAP APO.

\subsection{Strategic-level: optimizing the network structure}

High level decision making starts from optimization of the network structure, which may concern node locations, inventory levels and to ordering policies in multi-echelon systems. A good example of top-down hierarchy is provided in the Optiant [19] software structure. It starts from SLIM Networks Design to optimize inventory and distribution flows together with their cash flow, power chain inventory that consists of strategic multi-echelon inventory, strategic supply chain analysis and intelligence supply chain, power chain planner includes tactical policy management, supply chain intelligence, and enterprise integration connector and Power chain echelon includes all area of capacity optimization by concern to some constraints such as demand variability and capacity. Optiant combines their solution into multi echelon capacity and manufacturing capacity optimization.

A good example of strategic level simulation tool with financial optimization is Supply Chain Guru developed by Llamasoft [18]. Its application lies on sourcing, manufacturing, inventory, transportation and network design. Algorithms are not hard-coded in Supply Chain Guru to add some custom constraints besides the listed standard constraints. User could use Mosel Language that has already included in the package.

IBM Supply Chain Simulation (SCS) is a well-documented tool that offers combination of graphical process modeling, discrete event simulation, animation, activity based costing, and optimization. SCS deploys a mix of simulation and optimization functions to model and analyze supply chain issues such as site location, replenishment policies, manufacturing policies, transportation policies, stocking levels, lead times, and customer service [20]. SCS provides modeling functions for seven different supply chain processes: (1) customer, (2) 
manufacturing, (3) distribution, (4) transportation, (5) inventory planning, (6) forecasting, and (7) supply planning. Table 3 shows inputs and outputs from SCS.

Besides above outputs, there also an inventory optimizer that is separated from main simulation function. Usually, this tool is used before simulation conducted. It helps users in determining optimal inventory level. The results mentioned is their paper are optimal overall inventory cost, or serviceability, annual shipment, turnover, inventory units and cost by part number and by location, work-in-process unit and cost, and the base-stock level [20]. In addition to commercial tools, there are also some open source packages available in the field of SCM design. ASDN is an object oriented rapid modeling tool for supply chain development. This software is also applied to networks design, ranging from single structure to multi structure supply chain networks (multi suppliers and multi distributors). Mapping process has been fitted to problem coverage area by globe model networks. It is easier to user due to give realism view of supply chain networks design.

\subsection{Optimising everyday operations: tactical and operational software}

Second category of optimization tools is the decision support for tactical and operational problems. These software packages are connected to ERP's and in real-time data from suppliers and distribution centers. While internet now has to be a common communication media, E-collaboration will play a key role in optimization. Typically these applications are related to everyday scheduling, inventory level optimization in large networks and advanced planning and scheduling (APS).

Discrete event simulation has been combined with APS in order to achieve fast, realistic and high flexibility optimization [21]. I2 Rhythm is a software package that offers a range of SCM functions for close to real-time decision making. I2 Rhythm splits SCM into three modules of demand planning, supply planning and demand fulfillment. Furthermore, it will be combined with ERP/MRP system to enable production scheduling. Data from ERP/MRP systems will be used as input to model and user can solve analyze from the result quickly.

SAP APO enables applications from detailed planning, optimization and scheduling, allowing the supply chain to be accurately and globally monitored even beyond enterprise boundaries. The decision area includes collaboration with trading partners and customers. According to SAP Library, there are five optimization criteria: (1) total lead time, (2) setup times, (3) setup costs, (4) delay costs, (5) mode costs. Optimization is bounded into optimization range and resources allocation. Optimization range is defined either optimization horizon or resources 
that is transferred. Optimization horizon will optimize each activity in optimization range, however due to interrelation between activities in these two regions. These fixed activities would determine their action according to their flexibility.

\section{CONCLUSIONS}

Supply chain optimization direction, optimization tools progress and its applications will be an increasing area within business information systems. Real-time information from supply chains can be processed in simulation and optimization tools. These tools can give suggestions in short time and can be seen as improved decision making. Currently, the software packages are aimed for larger companies, which control larger parts of the chains.

\subsection{Comparison}

Each of software package analysed has its own characteristics and focus areas as Table 2 below

Table 2: Comparison among operational level Supply Chain Optimization software.

\begin{tabular}{|c|c|c|c|c|}
\hline & SAP APO $(*)$ & I2 RHYTIM (*) & $\begin{array}{l}\text { IBM Supply Chain } \\
\text { Simulator }(* *)\end{array}$ & $\begin{array}{l}\text { OPTIANT Slim Network } \\
\text { Design and Power Chain } \\
(* * *)\end{array}$ \\
\hline $\begin{array}{l}\text { Demand } \\
\text { Planning }\end{array}$ & $\begin{array}{l}\text { 1. } \begin{array}{l}\text { Promotional } \\
\text { planning, causal } \\
\text { analysis }\end{array} \\
\text { 2. life cycle concept } \\
\text { 3. } \begin{array}{l}\text { Collaborative } \\
\text { forecasting }\end{array}\end{array}$ & $\begin{array}{l}\text { Forecasting } \\
\text { process through } \\
\text { statistical } \\
\text { methods and } \\
\text { multiple inputs } \\
\text { from different } \\
\text { organization } \\
\text { units }\end{array}$ & $\begin{array}{l}\text { Forecasting and previous } \\
\text { aggregate demand data }\end{array}$ & $\begin{array}{l}\text { Forecasting based on } \\
\text { historical actual orders, } \\
\text { historical forecasts, or future } \\
\text { forecasts and enable gather } \\
\text { information from external } \\
\text { systems in varying levels of } \\
\text { granularity and product } \\
\text { family aggregation. }\end{array}$ \\
\hline $\begin{array}{l}\text { Available } \\
\text { to promise } \\
\text { (ATP) }\end{array}$ & $\begin{array}{l}\text { 1. Rule based ATP } \\
\text { 2. Multi level multi site } \\
\text { ATP. } \\
\text { 3. Capable to Promise } \\
\text { (CTP) function }\end{array}$ & $\begin{array}{lr}\text { User } & \text { friendly } \\
\text { product } & \text { catalog } \\
\text { and } & \text { product } \\
\text { configuration }\end{array}$ & $\begin{array}{l}\text { Available to product } \\
\text { material substitution and } \\
\text { location selection }\end{array}$ & $\begin{array}{l}\text { Integrated system to SAP } \\
\mathrm{APO} \text { and R3 }\end{array}$ \\
\hline $\begin{array}{l}\text { Advanced } \\
\text { Scheduling }\end{array}$ & $\begin{array}{l}\text { 1. Simultaneously } \\
\text { material and capacity } \\
\text { planning and } \\
\text { scheduling } \\
\text { 2. Costs } \\
\text { optimization based }\end{array}$ & $\begin{array}{l}\text { 1. Scheduling and } \\
\text { sequencing } \\
\text { based on GA } \\
\text { 2. Interactive } \\
\text { schedule editor }\end{array}$ & $\begin{array}{l}\text { Assembly line and its } \\
\text { production plan and } \\
\text { inventory control and also } \\
\text { enable to supplier } \\
\text { modeling. }\end{array}$ & $\begin{array}{l}\text { Multi echelon inventory and } \\
\text { manufacturing capacity } \\
\text { optimization combination }\end{array}$ \\
\hline
\end{tabular}

Table 2: Comparison among operational level Supply Chain Optimization software (Continued) 


\begin{tabular}{|c|c|c|c|c|}
\hline & SAP APO $(*)$ & I2 RHYTIM (*) & $\begin{array}{l}\text { IBM Supply Chain } \\
\text { Simulator }(* *)\end{array}$ & $\begin{array}{l}\text { OPTIANT Slim Network } \\
\text { Design and Power Chain }(* * *)\end{array}$ \\
\hline $\begin{array}{l}\text { Distribution } \\
\text { Planning }\end{array}$ & $\begin{array}{l}\text { 1. Transportation } \\
\text { planning and vehicle } \\
\text { scheduling to multi- } \\
\text { site optimization by } \\
\text { GA and additional } \\
\text { heuristic components } \\
\text { 2. VMI Support } \\
\text { 3. Demand Supply } \\
\text { synchronization }\end{array}$ & $\begin{array}{l}\text { Use transportation } \\
\text { modeler, optimizer } \\
\text { and manager order } \\
\text { by customer } \\
\text { servicer and } \\
\text { financial settlement }\end{array}$ & 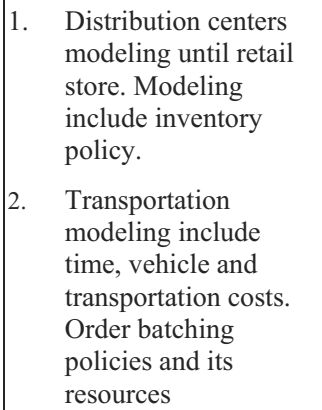 & $\begin{array}{l}\text { The ability to } \\
\text { optimize inventory } \\
\text { turns and distribution } \\
\text { flows for all products, } \\
\text { ranging from slow to } \\
\text { fast moving goods. } \\
\text { 2. Use linear / mixed } \\
\text { integer programming to } \\
\text { create supply networks }\end{array}$ \\
\hline
\end{tabular}

The key question seems to be how to develop collaborative planning in supply chain is missing. For instances purchasing should be aligned to ATP in order to give $100 \%$ guaranteed lead times and minimizing inventory [3], [6].

\subsection{Opportunity for Future Developments}

Today agile supply chain is focused to how to optimize supply chain networks as flexible as possible in order to anticipate custom order. In Table 1, costs, responsiveness and flexibility have been to be performance indicators. Optiant has done this task in their software package. We believe that there is a tendency to move optimization efforts to wider scope: strategic and tactical planning alignment, risk mitigation involvement and simulation and optimization combination are three issues.

This question has challenged us to take this advantage as future research consideration. Based on analysis from some selected software packages and literature review, we can outline following development areas:

(1) More detailed integration to real-time information on supply chain parameters.

(2) Mash up of data sources combining several data sources: consumer behavior data, real-time transportation data, and supplier's capacity data.

(3) Distributed decision-making - sharing information and decisions real-time in the supply chain or with project suppliers. Supply chain resilience analyses for both strategic and tactical/operational level decision making. 


\section{References}

[1] Disney, S.M. and Towill, D.R., The effect of vendor managed inventory (VMI) dynamics on the bullwhip effect in supply chains, International Journal of Production Economics, 85, pp.199 - 215, 2003.

[2] Fructher G.E., Fligler A. and Winer R.S, Optimal Product Line Design : Genetic Algorithm Approach to Mitigate Cannibalization, Journal of Optimization Theory and Applications, 131 (2), pp. 227 - 244, 2006.

[3] Gen, M and Lin L ,Multi-objective Hybrid Genetic Algorithm for Bicriteria Network Design Problem", Graduate School of Information, Production and System, Waseda University, Wakamatsu-ku, Kitakyushu, 808-0135, Japan, 73 - 82. http://www.complexity.org.au/conference/upload/gen01/gen01.pdf. Accessed: 3 August 2009

[4] Graves, S, C., and Willems, S, P., Optimizing strategic safety stock placement in supply chains, Manufacturing and Service Operations Management, 2 (1), pp.68-83, 2000

[5] Graves S.C and Willems S.P, Optimization the Supply Chain Configuration for New Product, Management Science, 49 (7), pp 1165 -1180. 2005.

[6] Graves, S, C., and Willems, S, P., Optimizing strategic safety stock placement in supply chains: non stationary demand, Manufacturing and Service Operations Management, 10 (2), pp. 278-287, 2008.

[7] Graves, S, C., Kletter, D.B., and Hetzel, W.B., A dynamic model for requirements planning with application to supply chain optimization, Operations Research, 46 (3), pp. S35-S49, 1998.

[8] Han. C. and Damrongwongsiri,M., Stochastic Modeling of a two Echelon Stochastic System with Genetic Algorithm, Journal of Manufacturing Technology Management. 16 (1), pp. $87-108.2005$.

[9] Helo, P., Xiao, Y., and Jiao, J.R., A web based logistics management system for agile supply demand network design, Journal of Manufacturing Technology Management, 17 (8), pp. 1058 - 1077. 2006

[10] Kristianto, Y. and Helo, P. Strategic thinking in supply and innovation in dual sourcing procurement, Int. J. Applied Management Science, 1 (4), pp.401-419. 2009.

[11] Krikke, H., Bloemhof-Ruwaardz, J., and Van Wassenhove, L.N., Concurrent product and closed-loop supply chain design with an application to refrigerators, International Journal of Production Research, 41 (16) , pp. 3689 - 3719. 2003. 
[12] Lee Y.H, Jeong,C.S., and Moon, C, Advanced Planning and Scheduling, Computer and Industrial Engineering, 43 , pp. 351 - 374.2002.

[13] Ma, H and Davidrajuh R., An Iterative Approach for Distribution Chain Design in Agile Virtual Environment, Industrial Management and Data Systems, 105 (6), pp 815 - 834. 2005.

[14] Ma, H. and Suo, C., A model for designing multiple products logistics networks, International Journal of Physical Distribution and Logistics Management, 36 (2), pp. $127-135,2006$.

[15] Santoso, S., Ahmed, S., Goetschalckx, M., and Shapiro, A., A stochastic programming approach for supply chain network design under uncertainty, European Journal of Operations Research, 167 , pp. $96-115,2005$.

[16] Syariff, A., Yun Y.S., and Gen, M., Study on multi-stage logistic chain network: a spanning tree-based genetic algorithm approach, Computers in Industry, 43 (1/2), pp. 299-314, 2002.

[17] Towill, D., Industrial dynamic modeling of supply chains, International Journal of Physical Distribution \& Logistics Management, 26 (2), pp. 23-42, 1996.

[18] Llamasoft 2009 ,'Supply Chain Guru, (http://www.llamasoft.com/downloads.html). Accessed: 3 August 2009

[19] OPTIANT, (2009), “The Executive Guide to Maximizing Working Capital without Crippling Your Supply Chain", OPTIANT white paper, http://www.optiant.com/solutions/network design . Accessed: 3 August 2009

[20] Bagchi, S, Buckley, S, Ettl, M and Lin, G.Y., Experience using IBM Supply Chain Simulator", Proceedings of the 1998 Winter Simulation Conference, (D.J. Medeiros, E.F. Watson, J.S. Carson and M.S. Manivannan, eds). pp.1387 - 1394,1998.

[21] Lendermann, P., Gan, B.P., and McGinnis, L.F., (2001) ,'Distributed simulation with incorporated APS procedures for high-fidelity supply chain optimization", Proceedings of the 2001 Winter Simulation Conference B. A. Peters, J. S. Smith, D. J. Medeiros, and M. W. Rohrer, eds, pp $1138-1145.2001$ 


\title{
UNDERSTANDING THE HUMAN FACTOR: THE KEY TO PROCESS IMPROVEMENT IN SERVICE OPERATIONS
}

\author{
Tauno Kekale ${ }^{1}$ Karen Spens ${ }^{2}$ and Kongkiti Phusavat ${ }^{3}$ \\ ${ }^{1}$ University of Vaasa, \\ Department of Production, P.O.Box 700 \\ 65101 Vaasa, Finland \\ ${ }^{2}$ Department of Marketing \\ Hanken School of Economics \\ P.O.Box 479, 00101, Helsinki, Finland \\ ${ }^{3}$ Department of Industrial Engineering \\ Kasetsart University \\ ,50 Paholyothin Road \\ Bangkok 10900, Thailand
}

\begin{abstract}
This paper is grounded in service science and the paper attempts to, by presenting an illustrative pharmacy case study, highlight the difficulties of introducing new technology whereby often the human dimension involved in the introduction is forgotten. The paper proposes, as does other academic literature in the field of operations management, that an early link between the technology introduced and those who will be introduced to the new technology be made. This link requires commitment not only from the parties involved in the use of the new technology but also all other types of actors involved in the process. The paper concludes by proposing a generic framework for process improvement in service operations.
\end{abstract}

\section{INTRODUCTION}

Drawing a distinct line between services and production is getting more and more difficult. Almost all service operations have some kind of back office where the tangible part of the service is being produced: kitchen for restaurants, laundry rooms for hotels, catering in airlines etc. As services are being systematized the importance of industry-like systems also 
grows and many service organizations (universities, hospitals etc) run SAP or other enterprise resource planning systems (ERP). At the same time, research indicates that many of the implementations are not succesful and that costly systems are underutilized, De Vries [1].

Already Zuboff [2] wrote about the problems of bringing electronic control to banks and paper mills; people felt alienated from their work and did not trust in the new systems. In a study of SMEs Kekäle et al. [3] similar issues were found to be true regarding the personnel of small companies in four countries. The issue at hand in this study was why SMEs are not using internet-based training courses for their personnel training. The biggest problems found were clearly not of technical nature. Unanimously expressed as the major impediments by all the respondent groups (trainers/consultants, entrepreneurs, software developers) were: lack of time and acceptance of IT-based training among the workforce. These results were surprising, because some of these impediments seen by the practitioners were the very benefits IT-based training was supposed to bring. The explanation provided by the 104 specialists that participted in the Delphi study was typically one of the the two general problems quoted in many change projects: lack of management commitment and/or difficulty to see the benefit the new methods would bring. More recently, a big number of IT development projects have been launched in public services, but (e.g. in Finland) the results seem often to be between miserable and unexpectedly weak. For example, VTV [4] reports to the Parliament of Finland on some of the biggest projects in making public services net-based that "the actors in these projects were not committed enough, which led to lowered goal levels, and the results of the projects were unfinished or unsatisfying compared to the original goals". This may be due to bad software providers, or bad project management, but also - as in the two previous examples explained briefly above - a lot of the services are still staffed with people from a non-ERP generation, and they feel very unsure and doubtful when encountering ERP systems.

One important issue that the forementioned examples have brought up is that we still do not understand the human factor well enough in our systems projects. Our claim is that whenever management systems are introduced, a similar pattern is repeated, starting from "hard" systems engineering and only later - with huge cost - attempting to understand the soft side of the process. This finding therefore leads to the proposal of a framework in which the organizational aspects and"soft" aspects are included. We now start by introducing one illustrative example underlining the issue of the importance of including the organizational embedding at en early stage of the process improvement project. Thereafter a discussion 
relating this finding to recent literature is provided and the paper is concluded by presenting the proposed framework.

\section{AN ILLUSTRATIVE CASE EXAMPLE}

The case presented is a study of a hospital pharmacy examining the problems in medicine production and delivery processes that were encountered when medicine delivery volumes grew rapidly. We used process, movement and layout analysis and staff interviews to describe and pinpoint the problems, then compared the results to another hospital pharmacy where similar problems did not surface. The paper hereby embraces the basic idea of "service science" where service is defined as the application of resources for the benefit of another Maglio et al. [5].

\subsection{Introducing the pharmacy}

We were recently asked to participate in an improvement project of a hospital pharmacy. The pharmacy was working reasonably well, but its external customers were increasing in numbers, the internal delivery volume to the various departments of the hospital was increasing, and the hospital could not guarantee an increasing resourcing for the pharmacy. It became quite soon clear for us that the problem was in internal logistics of the pharmacy. There was medicine on the floors, in the corridors, and on the shelves, and also small stockkeeping cards everywhere. The dtock-keeping cards are an old system for visual stock control, but what was interesting was that the pharmacy had a couple of years earlier invested in an ERP system complete with bar-code readers and a replenishment-order-suggestion system. However, the workers felt the barcode readers did not bring the correct information to the system, and thus they refused to use them. The barcode reader software was also quite prone for crashes. Thus, the system worked through the cards, and a back-office worker keyed in the orders and stock levels from the cards after some delay. When the back-office worker did not work on the weekends, the stock levels in the ERP system and the real stock levels could be off with up to 4 days (the medicine arrived and/or delivered on Friday morning could be keyed in the system on Monday afternoon), and thus also the order-suggestion system was off by the same amount of days - and was not used because its suggestions could not have been relied upon. 
The process of reception of incoming material requires a setup of the stock- cards; if these can be found, it is reasonably quick, but if not, the products still next day wait for being arranged to shelves. The variation of process times would have been bigger than in the benchmark hospital even without the card system due to the process flow complications, but the most notable inherent weakness of the system - loss of cards, possible in a myriad of different ways (wrong archiving in alphabetical order; card falls from the table, etc.) was what made the variation to expand from seconds to minutes.

We arranged to visit a benchmark hospital pharmacy nearby where we knew there was a somewhat similar ERP system implemented at about the same time, and where the volumes of medicine sales and the size of both staff and premises were within $10 \%$ of that of our case hospital pharmacy. We did some standard clocking of processes, studied and photographed the process flows, and interviewed people. In most of the processes the case pharmacy showecd a huge variation in throughput times compared to that of the benchmark pharmacy and in most of the processes the culprit was in the handling of the stock-keeping cards. The cards then caused additional problems such as either incoming or outgoing medicine waiting in carts for the cards in an already crowded area of the pharmacy floor.

The process flows of reception of incoming goods and packaging and sending outgoing goods were also quite different. In our case study pharmacy, the layout was in a "T" shape, but the flows were complex and messy, with most of the incoming and outgoing logistics as well as the storing, picking, and "overflow" concentrated on the "bar" area of the "T. In the benchmark pharmacy, the bigger (typically liquid-medicine and nutrition, could be easily characterized by "must be lifted with two hands") packages were not taken into the pharmacy premises at all, but taken care of by a warehouse worker in a separate, easy-to-access warehouse. Only when picking some of these for delivery, a pharmacist walked to this separate warehouse for checking the products and quantities to be delivered. For packages of medicine that typically were delivered in minute quantities (typically pills, creams) there were shelves in the pharmacy instead, but the medicine was shelved in their wholesale packages which made moving them on shelves much easier. The whole pharmacy floor flow was organized as a real product-specific through-flow: in from the base of the $\mathrm{T}$, out in either end of the "bar" portion of the T, depending on whether the delivery was intenally to the hospital or to one of the external customers. 
It is easy to see that our case pharmacy had their share of problems already in their process flow, that was due to historical reasons (it had always been like this, while the benchmark pharmacy was planned from scratch only some years previous to our visit). The personnel at "case" did not see this as a big problem though; what made them lose their nerves completely was the ERP system and the secondary phenomena that its bad actions caused - especially the cards. The main question we could present thus was: if everybody hates the cards, because they cause most of the process flow problems AND double work (keeping cards up to date, AND later keying the same data from the cards into the ERP system), and there is a relatively new ERP system in existence, why do then the workers and the management envisage keeping to the cards system? Like in the classic work of Zuboff, the problems were in the lack of trust of the workers on the ERP system. As the implementation and training were not conducted properly, and the workers felt that the system did not work, they stuck to the earlier manual system and then found ways to run both of these systems parallelly, which stressed them to tears daily. The latter problem might to a part be an effect of the lack of transparency and understanding of the products and services available. Trusting in the benefits of internet-based training would thus require, as in Zuboff's examples, a thorough training to be trained in a new way. As we know, the situation is the same in many services and due to the services' non-existence before their consumption: it is more difficult to trust something that one does not have yet and has never seen than to trust in something one already knows.

\section{BUILDING A FRAMEWORK}

Recent studies in the area of inventory management also indicate that little to no attention is paid to the organizational embedding of inventory systems. De Vries [1] introduces an inventory management model suggesting the inclusion of four dimensions which are considered as being of eminent importance when assessing and (re) shaping inventory systems in general and inventory systems in a health care setting in particular; the physical infrastructure; the planning and control system; the information system; the organizational embedding. The physical infrastructure encompasses the physical setting of the inventory system and consists of the main goods flows and stock points of products and items.Inventory planning and control relate e.g. to the models used, in practice often the Economic Order Quantity EOQ and/or the Economic Batch Quantity (EBQ). The information system, e.g ERP, 
is closely related to the structuring of the planning and control system as ERP software for instance is built around several modules, financial, inventory and production planning modules. De Vries [1]. In their study on inventory systems, Zomerdijk et al. [6] address four areas of importance with respect to the organizational context of inventory systems. The allocation of tasks, authorities and responsibilities to employees, the way decision-making processes are organized, the communication patterns as well as the behavior of the stakeholders involved in the decision making processes in practice are key-issues affecting the performance of inventory systems.

Once the overall contribution of the inventory system towards achieving the internal and external performance objectives has been assessed, the first step proposed by De Vries [1], the achievement of the objectives is further worked out. So starting from an overall blueprint of the inventory system and the objectives, the four main decision-areas as well as their interrelationships need to be addressed when defining an inventory management concept. The four dimensions should not only be addressed separately but have to be related to each other. Management practices in hospitals indicate that a misalignment between the four dimensions mentioned above, is often the reason for a lacking performance of the inventory system and it is therefore important to take the issue of alignment explicitly into account when defining an inventory concept. De Vries [1]. Our framework builds on the inventory management concept proposed by De Vries, however, emphasizing processes and improvement of processes in service operations.

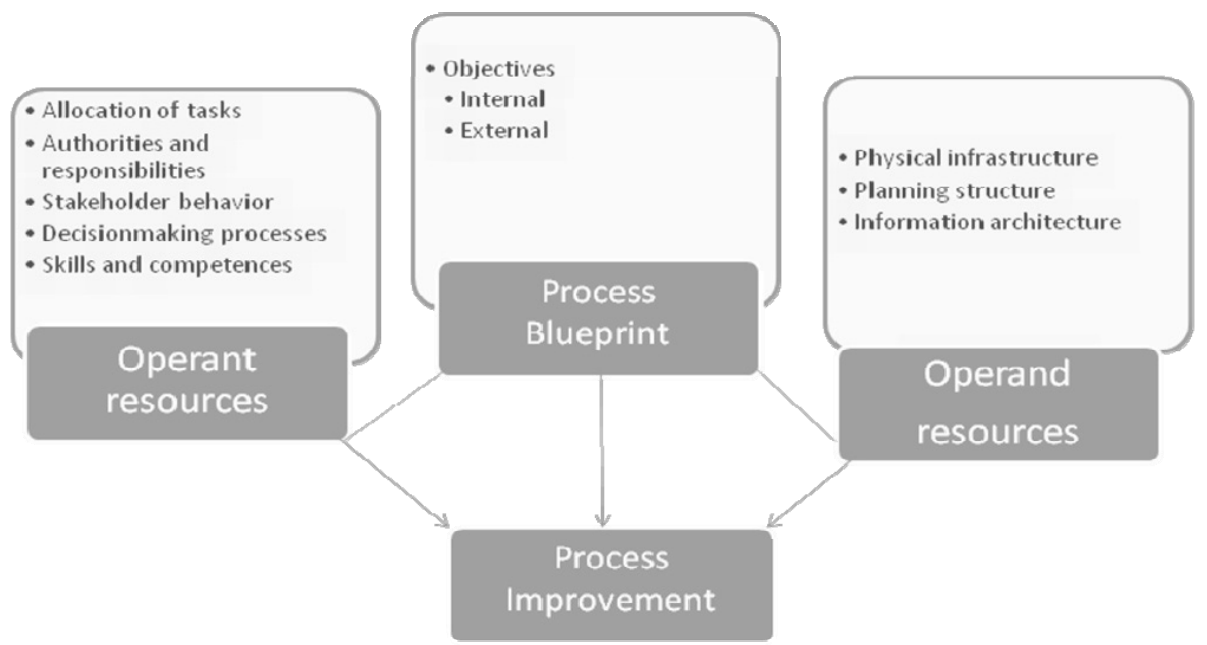

Figure 1 A service process improvement framework 
As stated earlier this paper builds on the basic idea of the "service science" movement: any process improvement must include, analyse, understand and improve all the major facets of the service process together. A service system is, above all, a socio-technical system. We must name, as areas to be included in the study, at least the process itself, the information system, and finally the culture and the skills of the staff. Studies on the role stakeholders paly during inventory projects also reveal that the outcomes of the projects are are frequently influenced by the interests of different stakeholders. De Vries [8]. Our framework proposes that the service process to be improved should be assessed, a clear blue-print of the service process includes also an examination of objectives, both internal and external. The earlier focus of de Vries on operand resources (physical infrastructure, planning structure and information architecture) in our view needs to be combined with an extended view on operant resources. Operand resources are tangible resources whereas operant resources are invisible intangible resources that at the firm level often include core competencies or dynamic capabilities. Maglio et al. [5]. Our framework thereby proposes that process improvement, in order to be effective, should not only focus on investigation and improvement of the operand resources, which is typically the focus in inventory management projects. In order to be effective, that is in order for the project to be successful, the operant resources, that is the resources that employ the operand resources, should be included in the investigation. Including e.g. skills and compentences in the investigation means that the gap between current skills and competences as well as those needed in the reshaped service process, should be assessed. Adequate training e.g. would consequently need to be included in order to succesfully implement the new improved service process.

\section{CONCLUSIONS}

This paper presents a study from a hospital pharmacy where the problems in the medicine production and delivery processes that were encountered when the medicine delivery volumes grew. In the "service science" spirit, we used process, movement and layout analysis and staff interviews to describe and pinpoint the problems, then compared the results to another hospital pharmacy where similar problems did not surface. Like in the classic work of Zuboff, the problems were found to be mostly in the lack of trust of the workers on the ERP system. The implementation and training to the ERP system were not conducted properly and the 
workers felt that the system did not work so they held on to the earlier manual system and then found ways to run both of these systems in paralell.

The results of the illustrative case study are similar to other case studies conducted as well as recent studies in the field of inventory management. The results show that there is heavy investement in technology but unfortunately no investment in the human factor, leading to non-use of expensive equpment and even worse service than before the initial process improvement project.

Our proposed framework builds on the inventory management concept proposed by De Vries [1]. As stated earlier this paper also builds on the basic idea of the "service science" movement: any process improvement must include, analyse, understand and improve all the major facets of the service process together. A service system is, above all, a socio-technical system. De Vries states that organizational embedding is an important dimension that has not received attention, we now broaden this view to include skills and competences, thereby moving the focus from the organization to operant resources. This focus, in our view, could enhance the understanding of the human factor in our systems projects.

For future work, one possible road could focus on integrating the ERP system to include other operations, including outpatient-related processes such as scheduled and unscheduled visits, registration, examination, payment, etc. Alternatively, it would be interesting to test with real-life figures how much less inventory a hospital has to carry after the ERP implementation? Or, for example, could better visualization of the situation by management then be realized? Only if the difference in such metrics would be substantial, then and only then it could be said that the use of ERP system (such as SAP and ORACLE) really has helped financial and productivity management.

\section{REFERENCES}

1. J. de Vries, Diagnosing Inventory Management Systems: An Empirical Evaluation of a conceptual approach, International Journal of Production Economics, 108, pp. 63-73. 2007.

2. S. Zuboff, In the Age of the Smart Machine. The Future of Work and Power, Basic Books, New York, 1988.

3. T. Kekäle, K. Pirolt and C. Falter, IT tools in Personnel Training in Small Enterprises: Results of Project 'APPLY'", Journal of Workplace Learning 14 (7), pp. 269-277, 2002.

4. VTV Valtiontalouden tarkastusvirasto, Alueellisten tietoyhteiskuntahankkeiden toteutus. ("Implementation of regional information society projects"), Valtiontalouden 
tarkastuskeskuksen toiminnantarkastuskertomus 158/2008, Dnro 309/54/06, VTV, Helsinki, FI, 2008.

5. Maglio, P.P., Vargo, S.L., Casweell, N. and J. Spohrer, 2009, The service system is the basic abstraction of service science, Information Systems and E-Business Mangaement, Vol. 7 No 4, pp. 395-406. Vries, J. de, 2009. Assessing inventory projects from a stakeholder perspective: Results of an empirical study, International Journal of Production Economics, 118, 136-145.

6. Zomerdijk, L.G. and de Vries J., 2003. An organizational perspective on inventory control: Theory and Practice, International Journal of Production Economics, Vol. 81$82,173-183$

7. Boonstra, A., 2006. Interpreting an ERP-implementation project from a stakeholder perspective, International Journal of Project Management, 24, 38-52.

8. Vries, J, de, 2009, Assessing inventory projects from a stakeholder perspective: Results of an empirical study, International Journal of Production Economics, Vol 118, pp. 136-145. 


\title{
USE OF OPEN INNOVATION AS POSSIBLE MARKETING STRATEGY IN LOGISTIC
}

\author{
Svetlana Mihić, \\ Faculty of Business and Law studies in Novi Sad \\ Grčkoškolska 221000 Novi Sad \\ drmihic@sbb.rs \\ Saša Raletić \\ Faculty of Entrepreneurial Management, University Alpha \\ Modene 5, 21000 Novi Sad \\ rsasaca@hotmail.com
}

\section{ABSTRACT}

Consumers are mutually different significantly by demographic characteristics, cultures, social diversity, level of education, experience, and numerous personal and psychologically features. Taking into account these facts is the basis for the successful development of the company, ie segmentation and positioning.

Many companies tend to be too much focus and organize according to their products and services, and too few of them focus on quality management own customers. Global competition, today, increasingly force manufacturing enterprises to direct their services towards individual needs and requirements, and to develop specific products by customer wish. Shift from market vendor in the market buyer has caused a drastic increase in the number of product variants, but the increase in the cost of such production. To remain competitive, companies have had to reduce the cost of internal units using new forms of logistics in which they fully support open innovation.

Many facts indicate that the main driver of innovation development, success and high profitability of the company. This means that many do not even question why they are important innovations. Instead the focus is on how innovation and innovative way of keeping the process. The new management model innovation, which is called the open, recently introduced and popularized, based on the need for companies to open their innovation processes, and to combine its internal and external technology development to create new 
value. The idea of open innovation, first presented Chesbrough 2003rd year. The author of this subject, moreover, the vision of open innovation, as well as appropriate marketing strategies to overcome problems in proper logistics, as well as overcoming barriers between producers and final consumers. Above all, modern themes, and try to explain through numerous examples of the application of new forms of logistics.

\section{INTRODUCTION}

All companies that the consumer is in the center of events, began to appreciate the opinions, attitudes and needs of customers. But, since no competition does not lose time, occurs the need to establish stronger and long-term cooperation with customers, for better informing their needs, even for friendly cooperation in order to raise customer relationships to the highest possible level, to the directions and the direction which now goes modern logistics. Building partnership with customers, are the relationships that are based primarily on trust, which will continue to be of great benefit to offer maximum adapt to the wishes of the target market, with the least possible cost. That is, trust and loyalty, as well as a new logistics base, through which customers can indicate a higher value for the company of quick sales of inadequate products. In this way, the unbreakable and build lasting relationships with customers, which means establishing long-term operations and reduce costs especially in the field of logistics. Customers today require more than just products to buy, they seek pleasure and satisfying their specific "needs emotional", Brian Squire, Jeff Readman, Steve Brown and John Bessant [1], which leads to increasing requests by designing their own experience and taste. Customization abandoned the traditional model of development produces and leads two part model, in which the first stage of area companies, and other areas of the buyer. Such a marketing approach leads to the need to turn these parts modeled, and it is possible to make use of open.

The new management model innovation, which is called the open, recently introduced and popularized, based on the need for companies to open their innovation processes, and to combine its internal and external technology development to create new value.

\section{SCOPE OF OPEN INNOVATION}

Many facts indicate that the main driver of innovation development, success and high profitability of the company. 
In the old model of closed innovation, the traditional way of business companies rely on the assumption that an innovative process to be controlled by company-based research on self-sufficiency. This model applied to logistics, and general functioning of the marketing strategy of the company produces high costs do not become acceptable in modern society. Several factors led to the deterioration of the closed innovation. First, mobility and availability of highly educated people has grown over the years, and their needs constantly growing, because they expand their knowledge and views according to their needs and interests. As a result, a large amount of knowledge exists outside the research laboratories of large companies. We must not forget that you and those people and consumers. Changes in society and industry, the advent of the Internet, which is closer to sources of information, led to new ways of marketing the goods.

The focus lies in the transformation of the solid boundaries previous company permeable half membranes, in order to allow innovation to move easily between the external environment and internal research and development (IR) process, that goal is the search for new ideas that have market potential.

Open Innovation, we can describe as combining internal and external ideas. The point is permeable half membranes that allow innovations to more easily flow between research and development sector enterprises and the environment. We recognize that the modern approach to consumer-customization needed in modern business.

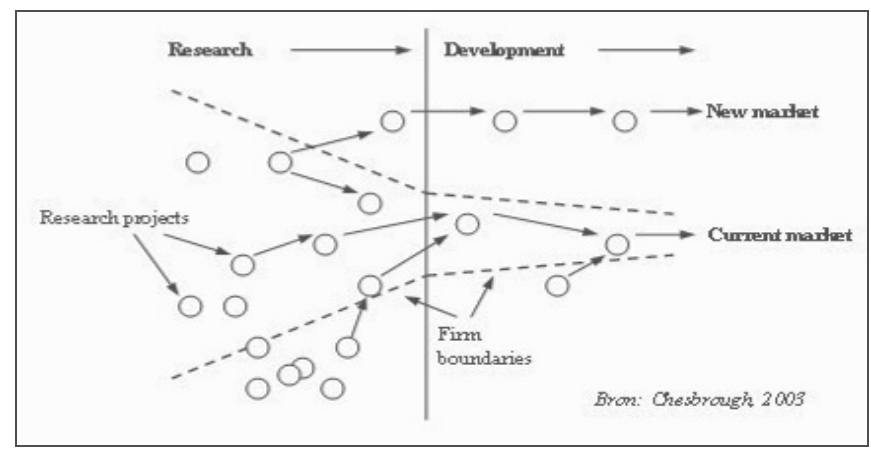

Image No.1.Open innovation

Open innovation Companies offer several important advantages over traditional methods. The most obvious benefit is the reduction and/or differentiation of risk. So we see that 
contemporary access to consumer-customization. If participate in the implementation of product and company, as the basis of potential products, and consumers, as well as codesigner, the risk is minimized and the cost of logistics is also minimal. And consumer satisfaction achieved their individual, specific needs based on potential module products / services offered by the company.

\section{OPEN INNOVATION FOR THE NEW IMPERATIVE CREATING AND PROFITING FROM LOGISTICS}

Most companies annually lose approximately $25 \%$ of their customers usually because the strong competition, the wrong strategy, or because of frequent changes in the same manner and the functioning of the logistics company. Five times more costs to win new customers than to retain an existing one. Just, 1:1 marketing strategy is directed towards creating loyal, profitable customers.

\subsection{The role of distribution in the marketing mix of products customiyation}

It is believed that mass production of standardized products and customization products should have an approximate price, or customization products can be a little more expensive because of the production process and the monetary cost. Also, it is considered that customization has certain cost efficiency, first inventory and distribution. Strategy mass customiyation partly involves the reduction of inventories of finished products, which decreases the total cost. That is, most of the raw material supplies and parts, based on which further creates an individualized product. Also, it is often abbreviated chain of distribution of products, and buyers go to the factory for its products. Consumer co-designer also spent their time and participate in the process of realization of products, which is an additional "investment" by the buyer, which also affects the level of prices customization product or service, Andreas M. Kaplan and Micheal Haenlen [2].

Longer delivery period explains the production process that is required for the realization of individual variants manufacture, and psychologically aspect. And identification of customers with only his custom product and a higher degree of satisfaction specific 'emotional needs. Deliverables are often implied and exactly where, when and how to deliver the goods, which is actually customization delivery. Creates a new trend, a distribution chain of demand and traditional distribution supply chain is replaced by a new distribution chain demand, 
Andreas M. Kaplan and Micheal Haenlen [3]. This way of creating a logistics chainn reduces costs and has positive impact on company profits.

\subsection{Marketing strategies 1-1 as part of open innovation}

1-1 marketing strategy encompasses four basic stages, or four processes, namely:

- Identification of consumer,

○ Differentiation of consumers,

○ Interactions with customers,

- Planning, customization, customize certain aspects of the product and business conduct to customer based on their needs and values.

Human beings are changing and dynamic "creations". Marketing one to one based on the idea of "treating different customers differently." The aim is to conduct business according to the individual consumer focus, based on knowledge of the consumer, and consumer information that provide. New understanding of trends and changing consumer demand the company, the company became a 1-1 company. Building a 1:1 relationship involves the interaction of companies with individual consumers through the information, knowledge, which further builds on the long-term loyalty. The company, regardless of which type of product or service is, every interaction becomes "smarter" and their products or services adapted to the specific needs of individual consumers. Communication time becomes deeper, and knowledge of consumers is all more, and if competitors offer the same product or service, customers will not waste time and energy to re-introduce a competitive company with their individual needs and preferences. The deeper and stronger relationship, the customer is loyal.

Dialogue is the heart interdependence relations. The dialogue is transformed into useful information, which is combined with its capabilities and become more self-knowledge. Knowledge still allows you to create a service / product that will satisfy customers, and satisfied customers are loyal customers.

Each individual consumer, based on their preferences and needs, creates its own rankings of certain aspects of the product or service you buy, from very attractive to neatraktivnog. On the basis of long-term relationship builde company learns to configure all aspects, to program the different sets of actions, communications and offers, in order to meet the individual needs of its customers, in order to put emphasis on those dimensions offers that are relevant to consumers. The consumer is always the final destination of products. Modern marketing 
research based on individual information on consumers as individuals. It is about recognizing what consumers want and what the consumer wants. That is not enough to know that the consumer is satisfied, but as satisfied. You must learn how customers see the company and its offer and not only that, but why is it so visible.

\section{MASS CUSTOMIZATION}

Mass customization derived from the model of open innovation, and today is a new trend in production and especially in the way of distribution of products. This approach today is gaining popularity due to the growing number of variants producing and increased opportunities for e-commerce. Competitiveness in the global marketplace requires companies to change the existing approaches in the production, which relied on "view seller, the approaches that will be facing the customer and his wishes. The result is the dramatically increase number of product variants. In order to maintain high competitiveness in the market, the company models their products, which include customers' individual wishes. This way of doing business is one of the most important industrial strategy today.

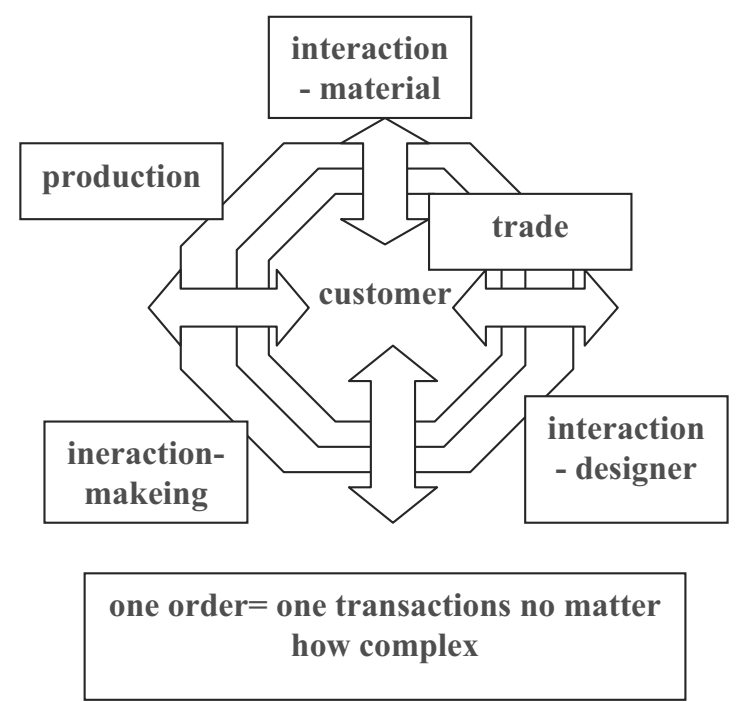

Image No.2.Principle mass organization, Chesbrough H.W[4].

Often the distinction between e-customization traditional mass customization. Traditional customization involves participation of consumers as co-designers in the process of creating 
products, not present new technologies. Tailor neck by the wishes of clients, or based on their individual physical measures, the desired material, model, etc.Development of IT sector has enabled the creation of such software, which support the process of creating products at the customer's wishes through the computer. With the module, customers can choose, these software composed the product the user intended. This form of mass customization called edustomiyation and implies that at least one of the three-dimension entities in the market, product and averages, is digital, Andreas M. Kaplan and Micheal Haenlen [5].

The company has formed a designer product, or area of possible solutions, while the buyer is a co-designer, and he decides on the final solution. The second level of the roots changes the role of the buyer to the buyer producing partner in the creation of new values. Customers today require more than just products to buy, they seek pleasure and satisfactions their specific "needs emotional" which leads to increasing requests by designing their own experience and taste. Mass customization does not always end consumers, such a strategy can be used on the business market. The reasons are usually high value orders and special customer needs that justify such marketing and sales efforts. With the help of open innovation - permeable membrane, in the new era, logistics begins to take other forms and meanings changed.

\section{CONCLUSION}

Business philosophy today as a result of the development of information technology faces two contradictory processes: globalization and individualization. Satisfaction of individual desires and needs of end customers is the key to success in a dynamic market struggles.

Mass customization means that consumers become partners of the company, and codesigners of the final product solution, given that the company with his opportunities limited area of base products. Mass customization is guided by the individual, the most emotional, requirements, creating new value for customers, or emotional connection between consumers and custom poizvoda and services. Such operations of the company reduces the risk of its business, and create satisfied customers, which is the source of competitiveness and profit.

In order to increase market efficiency companies trying to create a unique relationship with every customer, which is possible with the application of marketing 1:1. Marketing orientation to individual buyers $1: 1$ in the modern business is becoming increasingly important. Development of information technology, especially computers and the Internet, 
enables manufacturers available with various information about customers. Marketing approach, "one on one" instead of fighting for market share, going struggle for participation in the budget of each individual user and mass customization, as today a growing global trend, offers enormous market potential.

\section{REFERENCES}

[1]Brian Squire, Jeff Readman, Steve Brown and John Bessant, Mass customizatin: the key customer valie?, Taylor \& Francis; Production Planning \& Control, pp.431, No.4, June 2004. [2]Andreas M. Kaplan and Micheal Haenlen, Toward a Parsimoniouse Definition of Traditional and Eletronic Mass Customization, Product Innovation Managment, pp.178., 2006.

[3]Chesbrough H.W., The era of open innovation, MIT Sloan Management Review, Vol.44, No.3, pp.35-41.; 2003.

[4]Chesbrough H.W., Open innovation: Researching a new paradigm, In: Chesbrough, H. W., Vanhaverbeke, W. and West, J. (Eds.), Oxford University Press, Oxford, pp.15-33.; 2006.

[5]Jobber David, Fahy John, Basic of marketing, Data Status; Beograd; 2006.

[6]B.Joseph Pine II, Bart Victor and Andrew C. Boznton, Making Mass Customization Work, Hardvard Business Review; September- October, 1993.

[7]Vanhaverbeke, W. and Cloodt, M, Open innovation in value networks. In: Chesbrough, H. W., Vanhaverbeke, W. and West, J. (Eds.).Open innovation:researching a new paradigm, Oxford University Press, Oxford: pp.258-28, 2006.

[8]Philipp Herzog, Open and Closed Innovation Different Cultures for different Strategies, GWV Fachverlage GmbH, Wiesbaden; pp.19-21; 2008,

[9]www.openinnovation.eu 


\title{
A HYBRID ALGORITHM, BASED ON ITERATED LOCAL SEARCH AND GENIUS, FOR THE VEHICLE ROUTING PROBLEM WITH SIMULTANEOUS PICKUP AND DELIVERY
}

\author{
Marcio Tadayuki Mine ${ }^{1}$, Matheus de Souza Alves Silva ${ }^{1}$, Anand Subramanian ${ }^{1}$, \\ Luiz Satoru Ochi ${ }^{1}$ and Marcone Jamilson Freitas Souza ${ }^{2}$ \\ ${ }^{1}$ Instituto de Computação, Universidade Federal Fluminense \\ Rua Passo da Pátria, 156 E, $3^{\circ}$ andar, 24.210-240, Niterói, RJ, Brasil \\ ${ }^{2}$ Departamento de Computação, Universidade Federal de Ouro Preto \\ Campus Universitário, Morro do Cruzeiro, 35.400-000, Ouro Preto, MG, Brasil
}

\begin{abstract}
This work deals with the Vehicle Routing Problem with Simultaneous Pickup and Delivery (VRPSPD). The VRPSPD is a common problem in the area of reverse logistics, which aims to plan the transportation of products to customers, as well as the return of leavings or products used by them for recycling or to special depots. The VRPSPD is NP-hard, since it can be reduced to the classical Vehicle Routing Problem when no client needs the pickup service. To solve it, we propose a hybrid heuristic algorithm, called GENILS, based on Iterated Local Search, Variable Neighborhood Descent and GENIUS. The proposed algorithm was tested on three well-known sets of instances found in literature and it was competitive with the best existing approaches.
\end{abstract}

\section{INTRODUCTION}

The Vehicle Routing Problem (VRP) is a well-know problem in the field of Logistics and Operations Research and it can be defined as follows. Given a set of $N$ clients, each one with a demand $d_{i}$, and a homogeneous vehicle fleet with capacity $Q$, the objective is to design the vehicle routes in such a way that the clients' demands are completely attended in a single visit and the sum of the traveled costs are minimized.

In the late 80's, Min [1] proposed an important variant of the VRP: the Vehicle Routing Problem with Simultaneous Pickup and Delivery (VRPSPD), in which the pickup and delivery services must be performed simultaneously. This model is a basic problem in the Reverse Logistics field. Its main goal is to manage the transportation of products to 
customers, as well as the return of residues or products utilized by these clients for recycling or specialized depots. The Reverse Logistic can be observed, for instance, in the postal logistics or in the distribution planning of the drinks industry.

The VRPSPD is a NP-hard problem since it can be reduced to the classical VRP when no client need pickup services. Therefore, heuristic approaches have been frequently applied to solve the problem. Dethloff [2] developed an Cheapest Insertion based method in which the clients are added to the routes according to the following criteria: (1) distance; (ii) residual capacity; (iii) clients' distance to the depot. Röpke and Pisinger [3] developed a heuristic inspired on the Large Neighborhood Search (LNS) approach.

Montané and Galvão [4] utilized the Tabu Search (TS) metaheuristic considering four neighborhood structures: shift, swap, crossover and 2-opt. Chen and $\mathrm{Wu}$ [5] developed a methodology based on the record-to-record travel approach, which in turn is a variation of the Simulated Annealing. Wassan et al. [6] proposed a reactive version of the TS metaheuristic.

Subramanian et al. [7] developed an algorithm based on the Iterated Local Search (ILS), which uses the VND procedure in the local search. Zachariadis et al. [8] proposed a hybrid heuristic for the VRPSPD which combines the TS and Guided Local Search metaheuristics.

This work presents a new heuristic algorithm to solve the VRPSPD. The proposed algorithm, called GENILS, combines the ILS, VND and an adaptaton of the GENIUS heuristic. It differs from the one developed by Subramanian et al. [7] because the GENILS includes the GENIUS heuristic and the 3-opt and 4-opt procedures. The results obtained show that these strategies appeared to be efficient in the resolution of the problem.

The remainder of the paper is organized as follows. Section 2 presents the constructive heuristic. Section 3 deals with the algorithm GENILS. Sections 4 e 5 shows, respectively, the results obtainted by the proposed algorithm and the concluding remarks and future works.

\section{CONSTRUCTIVE HEURISTIC}

Three insertion based heuristics are employed to generate an initial solution. The first one, called CI-1R, is an adaptation of the Cheapest Insertion and the solution is build route by route. The second one, called CI-NR, was proposed by Subramanian et al. [7] and it is based on the insertion heuristic of Dethloff [2]. The last one, VRGENIUS, is an adaptation of the GENIUS heuristic (Gendreau et al., [9]) originally proposed for the Traveling Salesman Problem and it is divided into two steps: construction (VRGENI) and improvement (VRUS). 
The VRGENI is an generalized insertion based method whose main feature is that the insertion of a client $i$ is not necessarily limited to a position between two consecutive clients. The VRUS consists in removing one client from the solution and re-inserting it in another position with a view of improving the current solution. This procedure ends when there is no more possibility of improvements. It is important to mention that both removal and insertion of a client is performed by applying 3-opt and 4-opt moves. The efficiency of these procedures relies in the fact that the solution space to be explored is restricted to the number of neighbors of each client. This number is determined by a parameter $p$.

\section{NEIGHBORHOOD STRUCTURES}

In order to explore the solution space of the problem, the following seven neighborhood operators are applied: (a) Shift(1,0): one client $i$ is transferred from a route $r_{1}$ to a route $r_{2}$; (b) Shift(2,0): two consecutive clients $i$ and $j$ are transferred from a route $r_{1}$ to a route $r_{2}$; (c) Swap(1,1): one client $i$ from a route $r_{1}$ is permuted with a client $\mathrm{j}$ from a route $r_{2}$; (d) $\operatorname{Swap}(2,1)$ : two consecutive clients $\mathrm{i}$ and $\mathrm{j}$ from a route $r_{1}$ are permuted with a client $k$ from a route $r_{2}$; (e) Swap(2,2): two consecutive clients $i$ and $j$ from a route $r_{1}$ are permuted with another two consecutive clients $k$ and 1 from a route $r_{2}$; (f) M2-Opt: two non-adjacent arcs are removed and another two are inserted in such a way that a new route is formed; (g) kOr-Opt: $k$ consecutive clients are removed and re-inserted in another position of the route. It's important to emphasize that only feasible movements are considered.

\section{GENILS ALGORITHM}

A hybrid algorithm, called GENILS, is proposed to solve the VRPSPD. This algorithm uses the method to generate an initial solution described in Section 2 and combines the ILS (Stützle and Hoos [10]), VND (Hansen and Mladenović [11]) and an adaptation of the GENIUS heuristic (Gendreau et al. [9]). The GENILS pseudocode is presented in Figure 1.

The perturbations are performed by one of the three following mechanisms chosen at random: (a) Multiple Shifts: Consists in performing $k$ Shift movements (described in Section 3) successively. The value of $k$ is randomly defined between 1, 2 or 3; (b) Multiple Swaps: It follows the same idea of the previous perturbation, but Swap movements are applied; (c) Ejection Chain: First, a subset composed by $m$ routes $R=\left\{r_{1}, r_{2}, \ldots, r_{m}\right\}$ is arbitrarily chosen. Next, a client is transferred from the route $r_{1}$ to the route $r_{2}$, another is client is transferred 
from a route $r_{2}$ to the route $r_{3}$ and so on until a client is transferred from the route $r_{m}$ to the route $r_{1}$. In this perturbation, the clients are randomly selected.

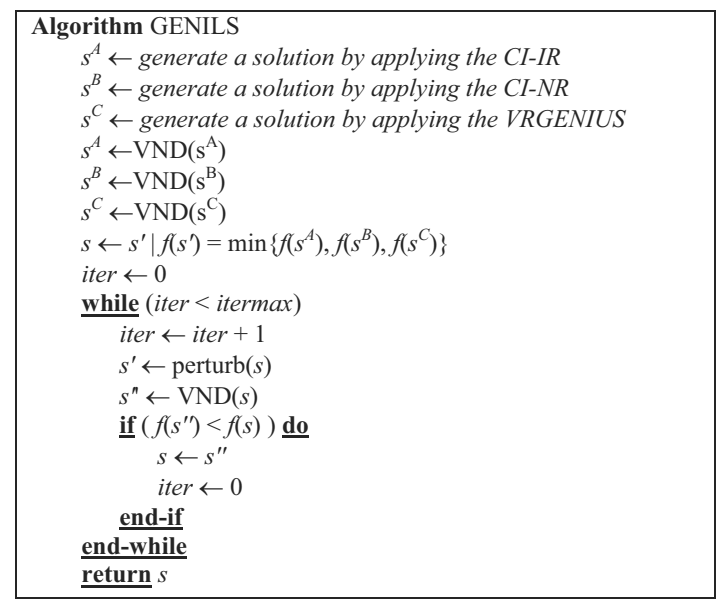

Figure 1 - Algorithm GENILS

The VND with random neighborhood ordering explores the solution space by means of the movements described in Section 3. An intensification phase is also embedded into to the VND procedure and it is performed using intra-route movements based on the following neighborhoods: Shift(1,0), Shift(2,0), Swap(1,1), M2-Opt, $\operatorname{Swap}(2,1), \operatorname{Swap}(2,2)$ and $k O r-o p t$ with $k=3,4,5$. In addition, this intensification phase also includes another two local search procedures, called G3-opt e G4-opt, which are based on the GENIUS heuristic. These movements are adaptations of the 3-opt and 4-opt neighborhoods. The adaptation consists in evaluating an arc insertion $\left(v_{i} ; v_{j}\right)$ only if the clients $v_{i}$ and $v_{j}$ are relatively closed. In view of this, define $N_{p}(v)$ as the set of $p$ neighborhoods closest to the client $v$ in a given route $r$ of the solution $s$, where $p$ is a parameter. Consider also the following definitions: $N^{r}$, set of all clients in route $r ; v_{i}$ : client $v_{i} \in N^{r} ; v_{h+1}$ and $v_{h-1}$ : clients in route $r$ which, respectively, succeeds and precedes the client $v_{h} \in N^{r} ; v_{j}$ : client $v_{j} \in N_{p}\left(v_{i}\right) ; v_{k}$ : client $v_{k} \in N_{p}\left(v_{i+1}\right)$ in the path between $v_{j}$ to $v_{i} ; v_{l}$ : client $v_{l} \in N_{p}\left(v_{j+1}\right)$ in the path between $v_{i}$ to $v_{j}$. The G3-opt works as follows: at each iteration, the $\operatorname{arcs}\left(v_{i} ; v_{i+1}\right),\left(v_{j} ; v_{j+1}\right)$ and $\left(v_{k} ; v_{k+1}\right)$ are removed and the $\operatorname{arcs}\left(v_{i} ; v_{j}\right),\left(v_{i+1}\right.$; $\left.v_{k}\right)$ and $\left(v_{j+1} ; v_{k+1}\right)$ are inserted in the route $r$, in such a way that the solution $s$ is improved and its cost is the least possible. It should be pointed out that both directions of the route $r$ are examined. This procedure is repeated until is no longer possible to improve the solution $s$. The G4-opt is similar to the G3-opt with the difference that, at each iteration, the $\operatorname{arcs}\left(v_{i}\right.$; 
$\left.v_{i+1}\right),\left(v_{l-1} ; v_{l}\right),\left(v_{j} ; v_{j+1}\right)$ and $\left(v_{k-1} ; v_{k}\right)$ are removed and the $\operatorname{arcs}\left(v_{i} ; v_{j}\right),\left(v_{l} ; v_{j+1}\right),\left(v_{k-1} ; v_{l-1}\right) \mathrm{e}$ $\left(v_{i+1} ; v_{k}\right)$ are inserted.

\section{COMPUTATIONAL RESULTS}

This section presents the computational results obtained by the hybrid heuristic algorithm proposed to solve the VRPSPD. The algorithm was coded in $\mathrm{C}++$ using the Microsoft Visual $\mathrm{C}++$, version 2005 and it was implemented in a Intel Core 2 Duo with $1.66 \mathrm{GHz}$ and $2 \mathrm{~GB}$ of RAM memory running Windows Vista 32 bits. In order to validate the algorithm, three set of instances were used, namely those of: Salhi and Nagy [12], Dethloff [2] and Montané and Galvão [4]. The maximum number of iterations of the GENILS adopted was 10,000. Tables 1, 2 and 3 compare the peformance of the GENILS with the different algorithms proposed in the literature. The Gap column shows the percentual deviation of the average solutions of the GENILS with respect to the best known solutions. The Gap is calculated by the expression Gap $=100 \times($ Average - Best $) /$ Best (Gap column $).$

Table 1 - Results obtained by the GENILS in the instances of Montané and Galvão [4]

\begin{tabular}{|c|c|c|c|c|c|c|c|c|c|}
\hline \multirow{2}{*}{ Problem } & \multicolumn{2}{|c|}{ Montané and Galvão } & \multicolumn{2}{|c|}{ Zachariadis et al. } & \multicolumn{2}{|c|}{ Subramanian et al. } & \multicolumn{3}{|c|}{ GENILS } \\
\hline & Best & $\operatorname{Time}^{(1)}(\mathrm{s})$ & Best & Time $^{(2)}(s)$ & Best & Time $^{(3)}(s)$ & Best & Time $^{(4)}(\mathrm{s})$ & Gap (\%) \\
\hline r101 & 1042.62 & 12.20 & 1019.48 & 10.50 & 1010.90 & 10.51 & 1009.95 & 35.65 & -0.09 \\
\hline r201 & 671.03 & 12.02 & 666.20 & 8.70 & 666.20 & 6.24 & 666.20 & 39.62 & 0.00 \\
\hline c101 & 1259.79 & 12.07 & 1220.99 & 10.20 & 1220.26 & 12.73 & 1220.18 & 18.34 & -0.01 \\
\hline c201 & 666.01 & 12.40 & 662.07 & 5.70 & 662.07 & 4.18 & 662.07 & 16.62 & 0.00 \\
\hline $\mathrm{rc} 101$ & 1094.15 & 12.30 & 1059.32 & 12.90 & 1059.32 & 9.48 & 1059.32 & 12.79 & 0.00 \\
\hline $\mathrm{rc} 201$ & 674.46 & 12.07 & 672.92 & 10.50 & 672.92 & 4.21 & 672.92 & 24.03 & 0.00 \\
\hline r1_2_1 & 3447.20 & 55.56 & 3393.31 & 61.80 & 3371.29 & 95.79 & 3357.64 & 175.81 & -0.40 \\
\hline r2_2_1 & 1690.67 & 50.95 & 1673.65 & 47.40 & 1665.58 & 24.13 & 1665.58 & 103.44 & 0.00 \\
\hline c1_2_1 & 3792.62 & 52.21 & 3652.76 & 66.30 & 3640.20 & 95.17 & 3636.74 & 117.62 & -0.10 \\
\hline$c 221$ & 1767.58 & 65.79 & 1753.68 & 60.90 & 1728.14 & 41.94 & 1726.59 & 127.81 & -0.09 \\
\hline rce $12-1$ & 3427.19 & 58.39 & 3341.25 & 45.30 & 3327.98 & 76.30 & 3312.92 & 299.30 & -0.45 \\
\hline $\mathrm{rc2} 22-1$ & 1645.94 & 52.93 & 1562.34 & 62.40 & 1560.00 & 34.28 & 1560.00 & 77.48 & 0.00 \\
\hline r1_4_1 & 10027.81 & 330.42 & 9758.77 & 315.30 & 9695.77 & 546.39 & 9627.43 & 2928.31 & -0.71 \\
\hline r2_4_1 & 3685.26 & 324.44 & 3606.72 & 273.60 & 3574.86 & 231.73 & 3582.08 & 768.60 & 0.20 \\
\hline c1_4_1 & 11676.27 & 287.12 & 11207.37 & 283.50 & 11124.30 & 524.35 & 11098.21 & 1510.44 & -0.23 \\
\hline c2_4_1 & 3732.00 & 330.20 & 3630.72 & 336.00 & 3575.63 & 293.18 & 3596.37 & 569.01 & 0.58 \\
\hline $\mathrm{rc}^{-} \overline{4} 1$ & 9883.31 & 286.66 & 9697.65 & 145.80 & 9602.53 & 550.90 & 9535.46 & 2244.18 & -0.70 \\
\hline $\mathrm{rc} 241$ & 3603.53 & 328.16 & 3498.30 & 345.00 & 3416.61 & 291.15 & 3422.11 & 3306.84 & 0.16 \\
\hline
\end{tabular}

In the instances of Dethloff [2], the GENILS obtained all the best known solutions. In the 14 instances of Salhi and Nagy [12], the proposed algorithm found 4 of the best known solutions, with a maximum gap of $3.16 \%$ in the remaining instances. It is important to remark that none of the algorithms has a clear superiority in the terms of solution quality in these set of instances. The best performance of the GENILS was in the instances of Montané and 
Galvão [4] in which it improved 9 of the best known solutions and equaled another 6, while in the 3 remaining instances the value of the maximum gap was $0.58 \%$. Comparing the GENILS with the other algorithms, it can be verified that it had a performance quite similar to the one developed by Subramanian et al. [7]. Indeed, in the instances of Dethloff [2] and Montané and Galvão [4] both the algorithms taken together produced all the best results. In this second set of instances, the GENILS was superior in 9 instances and inferior in 3. On the other hand, In Salhi and Nagy [12] instances, the GENILS was superior in 2 cases and inferior in another 5.

A comparision in terms of execution time was not performed because the results found by the other algorithms were obtained using different machines.

Table 2 - Results obtained by the GENILS in the instances of Dethloff [2]

\begin{tabular}{|c|c|c|c|c|c|c|c|c|c|}
\hline \multirow{2}{*}{ Problem } & \multicolumn{2}{|c|}{ Röpke e Pisinger } & \multicolumn{2}{|c|}{ Zachariadis et al. } & \multicolumn{2}{|c|}{ Subramanian et al. } & \multicolumn{3}{|c|}{ GENILS } \\
\hline & Best & $\operatorname{Time}^{(1)}(\mathrm{s})$ & Best & $\operatorname{Time}^{(2)}(\mathrm{s})$ & Best & $\operatorname{Time}^{(3)}(s)$ & Best & Time $^{(4)}(s)$ & Gap (\%) \\
\hline SCA3-0 & 636.10 & 232.00 & 636.06 & 2.83 & 635.62 & 0.90 & 635.62 & 6.77 & 0.00 \\
\hline SCA3-1 & 697.80 & 170.00 & 697.84 & 2.12 & 697.84 & 1.12 & 697.84 & 8.49 & 0.00 \\
\hline SCA3-2 & 659.30 & 160.00 & 659.34 & 2.58 & 659.34 & 1.19 & 659.34 & 8.13 & 0.00 \\
\hline SCA3-3 & 680.60 & 182.00 & 680.04 & 3.13 & 680.04 & 1.13 & 680.04 & 8.45 & 0.00 \\
\hline SCA3-4 & 690.50 & 160.00 & 690.50 & 2.68 & 690.50 & 1.32 & 690.50 & 8.09 & 0.00 \\
\hline SCA3-5 & 659.90 & 178.00 & 659.90 & 2.56 & 659.90 & 1.17 & 659.90 & 8.19 & 0.00 \\
\hline SCA3-6 & 651.10 & 171.00 & 651.09 & 4.40 & 651.09 & 1.23 & 651.09 & 8.21 & 0.00 \\
\hline SCA3-7 & 666.10 & 162.00 & 659.17 & 2.98 & 659.17 & 1.69 & 659.17 & 6.76 & 0.00 \\
\hline SCA3-8 & 719.50 & 157.00 & 719.47 & 3.98 & 719.47 & 1.08 & 719.48 & 8.85 & 0.00 \\
\hline SCA3-9 & 681.00 & 167.00 & 681.00 & 3.86 & 681.00 & 1.03 & 681.00 & 8.63 & 0.00 \\
\hline SCA8-0 & 975.10 & 98.00 & 961.50 & 3.21 & 961.50 & 2.52 & 961.50 & 5.65 & 0.00 \\
\hline SCA8-1 & 1052.40 & 95.00 & 1050.20 & 3.55 & 1049.65 & 2.98 & 1049.65 & 5.67 & 0.00 \\
\hline SCA8-2 & 1039.60 & 83.00 & 1039.64 & 4.67 & 1039.64 & 3.42 & 1039.64 & 5.92 & 0.00 \\
\hline SCA8-3 & 991.10 & 94.00 & 983.34 & 3.29 & 983.34 & 3.44 & 983.34 & 4.58 & 0.00 \\
\hline SCA8-4 & 1065.50 & 84.00 & 1065.49 & 2.68 & 1065.49 & 2.74 & 1065.49 & 5.98 & 0.00 \\
\hline SCA8-5 & 1027.10 & 96.00 & 1027.08 & 4.50 & 1027.08 & 3.44 & 1027.08 & 6.62 & 0.00 \\
\hline SCA8-6 & 972.50 & 93.00 & 971.82 & 2.67 & 971.82 & 2.48 & 971.82 & 6.57 & 0.00 \\
\hline SCA8-7 & 1061.00 & 92.00 & 1052.17 & 4.32 & 1051.28 & 5.39 & 1051.28 & 5.56 & 0.00 \\
\hline SCA8-8 & 1071.20 & 85.00 & 1071.18 & 3.43 & 1071.18 & 2.05 & 1071.18 & 5.57 & 0.00 \\
\hline SCA8-9 & 1060.50 & 86.00 & 1060.50 & 4.12 & 1060.50 & 3.10 & 1060.50 & 5.62 & 0.00 \\
\hline CON3-0 & 616.50 & 171.00 & 616.52 & 3.89 & 616.52 & 2.02 & 616.52 & 6.77 & 0.00 \\
\hline CON3-1 & 554.50 & 190.00 & 554.47 & 2.97 & 554.47 & 1.83 & 554.47 & 7.76 & 0.00 \\
\hline CON3-2 & 521.40 & 176.00 & 519.26 & 3.32 & 518.00 & 2.10 & 518.01 & 9.28 & 0.00 \\
\hline CON3-3 & 591.20 & 177.00 & 591.19 & 2.78 & 591.19 & 1.34 & 591.19 & 9.18 & 0.00 \\
\hline CON3-4 & 588.80 & 173.00 & 589.32 & 3.12 & 588.79 & 1.79 & 588.79 & 6.29 & 0.00 \\
\hline CON3-5 & 563.70 & 179.00 & 563.70 & 3.45 & 563.70 & 1.71 & 563.70 & 9.16 & 0.00 \\
\hline CON3-6 & 499.10 & 195.00 & 500.80 & 2.98 & 499.05 & 1.93 & 499.05 & 7.33 & 0.00 \\
\hline CON3-7 & $\mathbf{5 7 6 . 5 0}$ & 226.00 & 576.48 & 2.40 & 576.48 & 1.52 & 576.48 & 6.96 & 0.00 \\
\hline CON3-8 & 523.10 & 174.00 & 523.05 & 5.02 & 523.05 & 1.51 & 523.05 & 8.75 & 0.00 \\
\hline CON3-9 & 578.20 & 163.00 & 580.05 & 3.14 & 578.24 & 1.58 & 578.25 & 6.87 & 0.00 \\
\hline CON8-0 & 857.20 & 86.00 & 857.17 & 3.40 & 857.17 & 3.74 & 857.17 & 6.36 & 0.00 \\
\hline CON8-1 & 740.90 & 81.00 & 740.85 & 3.73 & 740.85 & 2.82 & 740.85 & 4.88 & 0.00 \\
\hline CON8-2 & 716.00 & 84.00 & 713.14 & 2.87 & 712.89 & 2.46 & 712.89 & 6.95 & 0.00 \\
\hline CON8-3 & 811.10 & 91.00 & 811.07 & 3.82 & 811.07 & 2.82 & 811.07 & 5.87 & 0.00 \\
\hline CON8-4 & 772.30 & 87.00 & 772.25 & 2.98 & 772.25 & 3.37 & 772.25 & 5.01 & 0.00 \\
\hline CON8-5 & 755.70 & 94.00 & 756.91 & 5.76 & 754.88 & 3.30 & 754.88 & 5.82 & 0.00 \\
\hline CON8-6 & 693.10 & 96.00 & 678.92 & 4.00 & 678.92 & 3.04 & 678.92 & 5.67 & 0.00 \\
\hline CON8-7 & 814.80 & 94.00 & 811.96 & 2.46 & 811.96 & 2.73 & 811.96 & 4.71 & 0.00 \\
\hline CON8-8 & 774.00 & 94.00 & 767.53 & 4.21 & 767.53 & 3.42 & 767.53 & 5.23 & 0.00 \\
\hline CON8-9 & 809.30 & 92.00 & 809.00 & 3.87 & 809.00 & 3.60 & 809.00 & 5.86 & 0.00 \\
\hline
\end{tabular}

(1) CPU time in a Pentium IV $1.5 \mathrm{GHz}$; (2) CPU time in a Pentium IV $2.4 \mathrm{GHz} . ;$ time in a Intel Core 2 Duo 1.6 GHz. 
Mine, Silva, Subramanian, Ochi \& Souza

Table 3 - Results obtained by the GENILS in the instances of Salhi and Nagy [12]

\begin{tabular}{|c|c|c|c|c|c|c|c|c|c|}
\hline \multirow{2}{*}{ Problem } & \multicolumn{2}{|c|}{ Wassan et al. } & \multicolumn{2}{|c|}{ Zachariadis et al. } & \multicolumn{2}{|c|}{ Subramanian et al. } & \multicolumn{3}{|c|}{ GENILS } \\
\hline & Best & $\operatorname{Time}^{(\mathrm{I})}(\mathrm{s})$ & Best & Time $^{(2)}(\mathrm{s})$ & Best & Time $^{(3)}(s)$ & Best & $\operatorname{Time}^{(4)}(s)$ & Gap $(\%)$ \\
\hline CMT1X & 468.30 & 48 & 469.80 & 2.89 & 466.77 & 1.10 & 466.77 & 7.82 & 0.00 \\
\hline CMT1Y & 458.96 & 69 & 469.80 & 3.85 & 466.77 & 1.08 & 466.77 & 7.61 & 1.68 \\
\hline CMT2X & 668.77 & 94 & 684.21 & 7.42 & 684.21 & 6.99 & 684.21 & 17.62 & 2.31 \\
\hline СМТ2Y & 663.25 & 102 & 684.21 & 8.02 & 684.21 & 5.84 & 684.21 & 20.10 & 3.16 \\
\hline CMX3X & 729.63 & 294 & 721.27 & 11.62 & 721.40 & 6.80 & 721.40 & 59.61 & 0.02 \\
\hline СMT3Y & 745.46 & 285 & 721.27 & 13.53 & 721.40 & 7.37 & 721.27 & 58.72 & 0.00 \\
\hline CMT12X & 644.70 & 242 & 662.22 & 11.80 & 662.22 & 8.02 & 662.22 & 22.89 & 2.72 \\
\hline CMT12Y & 659.52 & 254 & 662.22 & 7.59 & 662.22 & 7.32 & 663.50 & 22.33 & 0.60 \\
\hline CMT11X & 861.97 & 504 & 838.66 & 17.78 & 839.39 & 12.58 & 846.23 & 48.85 & 0.90 \\
\hline CMT11Y & 830.39 & 325 & 837.08 & 14.26 & 841.88 & 14.80 & 836.04 & 287.30 & 0.68 \\
\hline CMT4X & 876.50 & 558 & 852.46 & 27.75 & 852.46 & 50.72 & 852.46 & 134.26 & 0.00 \\
\hline CMT4Y & 870.44 & 405 & $852.46^{\mathrm{a}}$ & 31.20 & 852.46 & 46.06 & 862.28 & 266.76 & $1.17^{\mathrm{b}}$ \\
\hline CMT5X & 1044.51 & 483 & 1030.55 & 51.67 & 1030.55 & 53.51 & 1033.51 & 768.94 & 0.29 \\
\hline CMT5Y & 1054.46 & 533 & 1030.55 & 58.81 & 1031.17 & 58.74 & 1036.14 & 398.75 & 0.54 \\
\hline
\end{tabular}

\section{CONCLUSIONS AND FUTURE WORKS}

This work proposed a hybrid heuristic algorithm, called GENILS, to solve the VRPSPD. Adaptations of the Cheapest Insertion and the GENIUS heuristic were employed to generate an initial solution. To improve this solution, an ILS based procedure, that uses the VND method in the local search, was developed. The latter also includes an intesification strategy which uses: G3-opt, G4-opt (both based on the GENIUS) and Reverse movements.

From the results obtained, it can be observed that the GENILS is competitive with the best approaches in the literature. Indeed, in a set of well-known instances, the algorithm was able to produce all the best results reported in the literature; in another one, 9 new solutions were generated and another 3 were equaled; and in a third set, 3 best known solutions were equaled and the maximum gap in the remaining problems of this set was 3.16\%. In addition, the GENILS obtained solutions with variability smaller than $1 \%$ in 67 of the 72 instances. One interesting behavior of the algorithm is the fact of obtaining a better performance in most instances of Montané and Galvão [4], illustrating its potential in solving real-life applications, where it is common to deal with large-scale problems.

As for future work, one can improve the G3-opt e G4-opt procedures by considering the recombination of multiple routes. In addition, it is strategic to combine the GENILS with the Tabu Search (TS), where the latter can be triggered by replacing the VND, e.g. after a certain number of ILS iterations. This has to do with the fact that the TS is the base algorithm of those developed by Wassan et al. [6] and Zachariadis et al. [7], where both have obtained most of the best known results in the instances of Salhi and Nagy [12], and it was in this set that the GENILS had its worst performance. 


\section{REFERENCES}

1. Min, H. The multiple vehicle routing problems with simultaneous delivery and pick-up points. Transp. Res. A, 23(5):377-386, 1989.

2. Dethloff, J. Vehicle routing and reverse logistics: the vehicle routing problem with simultaneous delivery and pick-up. OR Spektrum, 23:79-96, 2001.

3. Röpke, S.; Pisinger, D. A unified heuristic for a large class of vehicle routing problems with backhauls. Tech. Rep. 2004/14, University of Copenhagen, 2006.

4. Montané, F.; Galvão, R. A tabu search algorithm for the vehicle routing problem with simultaneous pick-up and delivery service. Comp. and Oper. Res., 33(3):595-619, 2006.

5. Chen, J. F.; Wu, T. H. Vehicle routing problem with simultaneous deliveries and pickups. J. of the Oper. Res. Soc., 57(5):579-587, 2006.

6. Wassan, N.; Wassan, A.; Nagy, G. A reactive tabu search algorithm for the vehicle routing problem with simultaneous pickups and deliveries. J. of Combinatorial. Optimization, 15(4):368-386, 2008.

7. Subramanian, A.; Cabral, L. A. F.; Ochi, L. S. An efficient ILS heuristic for the vehicle routing problem with simultaneous pickup and delivery. Tech. Rep., Universidade Federal Fluminense, available at http://www.ic.uff.br/PosGraduacao/RelTecnicos/401.pdf, 2008.

8. Zachariadis, E. E.; Tarantilis, C. D.; Kiranoudis, C. T. A hybrid metaheuristic algorithm for the vehicle routing problem with simultaneous delivery and pick-up service. Expert Systems with Applications, 36(2):1070-1081, 2009.

9. Gendreau, M.; Hertz, A.; Laporte, G. New insertion and post optimization procedures or the traveling salesman problem. Oper. Res., 40:1086-1094, 1992.

10. Stützle, T.; Hoos, H. H. Analyzing the run-time behaviour of iterated local search for the tsp. In Proc. of the 3th Metaheuristics Inter. Conf., p 449-453, Angra dos Reis, RJ, 1999.

11. Hansen, P.; Mladenović, N. Variable neighborhood search: Principles and applications, European J. of Oper. Res., 130:449-467, 2003.

12. Salhi, S.; Nagy, G. A cluster insertion heuristic for single and multiple depot vehicle routing problems with backhauling. J. of the Oper. Res. Soc., 50:1034-1042, 1999.

\section{ACKNOWLEDGMENTS}

This research was partially supported by CAPES, CNPq and FAPERJ 


\title{
THE IMPORTANCE OF REVERSE LOGISTICS IN THE PRODUCTION PROCESS: THE CASE OF A WINE BOTTLING COMPANY
}

\author{
R. M. Melo ${ }^{1}$, M. M. Silva ${ }^{2}$ and A. C. B. R. F. Pinto ${ }^{3}$ \\ ${ }^{123}$ Department of Industrial Engineering \\ Federal University of Pernambuco
}

Av. Prof. Moraes Rego, 1235 - Cidade Universitária, Recife - PE - CEP: 50670-901

\begin{abstract}
This paper presents a study of reverse logistics in a wine bottling company in Brazil. The practice of reverse logistics in the company is undertaken with respect to the reuse of bottles. As highlighted in the article, due to the company employing continuous improvement techniques such as GMP (good manufacturing practices), 5S and MAC (Monthly Appraisal Carreteiro), the results achieved were: a reduction from $0.9 \%$ to $0.5 \%$ of losses in the recovery of bottles and success in meeting the service standards of service required by the competent agencies.
\end{abstract}

\section{INTRODUCTION}

The wine market is an industry that moves billions of gallons of wine a year. According to the Wine Business Monthly Journal [1] the main producing countries are France and Italy. Thereafter come Spain, the United States and Argentina, which has emerged as the largest producer in South America then Australia, South Africa, and finally Chile and Portugal both of whom produce approximately the same amount of wine. Germany appears in these statistics as the largest importer, but also as a major producer. Brazil is regarded as an expanding wine-producer country. These data underscore the importance of this market as well as justifying the need for studies in the area.

This work is based on a study in a bottling company, which owns a well-known wine local brand of wine - Carreteiro, in Pernambuco. The company currently has been doing an outstanding work in the area of logistics and reverse logistics in particular, in which it invests a significant amount of its resources and efforts. 
According to Ballou [2] "Logistics is a vital issue. It is an economic fact that both the resources and their customers are spread across a wide geographical area”. Companies, in most cases, face great difficulties in these processes due to distances between the producer and their clients, who want their products quickly and on favorable terms.

Currently there is a major concern with environmental issues, mainly by companies themselves and this is the reason why several guidelines for minimizing environmental risks of production have been created. One set of norms for companies to adhere to is set by ISO 14000 , which sets out standards to be followed in the selective collection, recycling, and on the life cycle of products and reverse logistics. Moreover, modern organizations which comply with such standards end up achieving a competitive advantage in the market.

The main objective of this paper is to identify the way that reverse logistics is conducted in this Brazilian company, which is part of the wine industry, and its relevance to the production process. This study provides a better understanding of the subject which may lead to its being applied in other industries.

\section{METHODOLOGY}

Data for the study were collected through visits and semi-structured interviews with the staff in charge of logistics in the company, in addition to which a review was made of the literature and information retrieved.

An interview is a meeting between two people, so that one obtains information about a particular subject, by means of conversing with a professional from the area under study [3].

According to Oliveira [4], specialist literature aims to identify the different forms of scientific contributions that have been made on a given subject or phenomenon. In order to make better use of the two instruments mentioned above, documentary research was also undertaken, which, according to Marconi and Lakatos [3], is the source of data collection which is limited to documents, written or otherwise, that are regarded as being primary sources. Therefore this study takes a qualitative research approach, which, according to Richardson [5], is characterized by the attempt to reach a detailed understanding of the meanings and situational characteristics presented by respondents, rather than by producing quantitative measures of characteristics or behaviors. 


\section{REVERSE LOGISTICS}

Reverse logistics process generates reused materials that return to the traditional process of supply, production and distribution. The concept of reverse logistics is also closely linked to the life cycle of the product because, from the logistical point of view, a product undergoes various stages of "life" which therefore do not end when the product is delivered to the customer, as it may be damaged or it may simply not work anymore. As a result, such products should be returned to their point of origin at which point the reverse flow is closed. Moreover, currently there is a clear trend that companies will be held responsible for the whole lifecycle of their products. This brings to the fore issues such as how companies show environmental concern and respond to the demands of environmentally conscious consumers.

In the reverse logistics process it becomes necessary to study and identify the types of material that return to their point of origin and why they were returned. Materials can be divided into two groups: products and packaging. For products, the flow of reverse logistics will be determined by the need for repair, recycling, or simply because the customers return them - for example, a duplicate present or the product does not fit into the space the client thought it would. As to packaging, flows of reverse logistics occur primarily due to their being suitable for reuse or due to legal restrictions e.g on other means of disposal.

Reverse logistics process is normally divided into two fully independent areas, which are differentiated by the stages the products reach and their life cycle, and are deemed as postsales and post-consumption reverse logistics.

\subsection{The Practice of Reverse Logistics in Different Sectors of Industry}

Currently, several companies have reverse logistics: some do so in order to reduce costs; some are thinking of other social and environmental responsibilities; and some even do so with the goal of customer loyalty with post-consumer. This is not to say that these are exclusive of each other. Some companies may conduct reverse logistics with two or even all three of these goals in mind.

The issue of social responsibility makes many managers concerned about what the fate of disposables, including toxic or hazardous materials. In this scenario, the practice of reverse logistics has gained strength and led companies around the world to assessing their ability to organize the return of materials through the supply chain. 
The following are examples of research into some companies using the practice of reverse logistics in their operational processes, and what impact this process has.

Martins and Silva [6] undertook a study in several companies from different economic sectors, primarily in Rio de Janeiro and Sao Paulo. The objective was to describe, to explain and to explore the real conditions and effective implementation of reverse logistics. Among these companies, $73 \%$ had pro-active business attitudes with respect to the environment, followed by $18 \%$ who did so for reasons of the value added, and finally, $9 \%$ of responses demonstrated the companies were taking a reactive approach to reverse logistics. Another issue noted is the lack of management time dedicated solely to issues related to reverse logistics, which was observed in $91 \%$ of the companies involved. Moreover, only $9 \%$ have managers who specialize in logistics. Therefore, the failure of business to engage in reverse logistics is evident.

Another example is the study conducted by Linhares et al [7] with a vocational education institution in Curitiba. This study defines the concern with materials that are used by the chemical and glassware industries in general, since the residues from these products, when disposed of into the environment without special measures, cause major impacts on it.

The final example is the study by Ferreira et al [8] on logging companies that used reverse logistics in their operations. For the production of timber, it is perceived that many different forms of waste are generated and it is estimated that by the end of the trunk cutting process, almost half of the original wood is lost, which implies there are unnecessary losses. The process of re-using residual material through reverse logistics was undertaken, which showed that, for various activities using wood, residues can be reused to make products with plywood, or even as material for gardening e.g compost, stakes to support plants, fencing, etc.

\section{THE LOGISTICS PROCESS}

\subsection{Company Description}

Currently, the company has an operational staff of 95 contract employees, working in two shifts. The company is not a wine producer itself. It receives pure dry wine from Rio Grande do Sul and from the vineyards of the São Francisco. After that, the wine is tested in the laboratory in order to ensure it meets the company's standards. Monthly production fully meets the needs of the market, offers various options, and always takes into account the characteristics of each sales point in the market. 
The company has used reverse logistics since its foundation, with respect to the $600 \mathrm{ml}$ bottle. The process starts with processing orders, when sales representatives issue the order, for subsequent approval by a credit analyst, who authorizes the delivery trucks to be loaded. According to the company, the reverse logistics process of that container is the company's most sensitive one. This is with respect to receiving in exchange for the full bottle, delivered by the company, an empty one, noting that the container returned can have any type of fault. The distribution of the company's products on the market is made by $100 \%$ outsourced companies. The control of containers is the responsibility of the delivery company, and it is charged an amount of $\$ 0.75$ per bottle that does not comply with the standard required by the company. This type of strategy designed and used by the company is necessary for the progress of its operations in order to reduce the unnecessary costs that would be incurred by constantly having to purchase new containers. The recycling process is not part of the culture of bottle makers, as this would require a physical structure and operational staff that would result in having to make specific investments for this purpose, which is regarded as being distant from a bottler's main focus of production.

The truck leaves to deliver the products with 500 crates, each with 24 bottles, totaling 12,000 (twelve thousand) bottles. Given the strategy mentioned above, there is a total recovery of $99.5 \%$ of bottles returned, without any kind of damage, which means there is a $0.5 \%$ loss. Previously the percentage loss was around $0.9 \%$ loss.

When the truck returns to the company, another logistics process starts: making the glass bottle re-usable. First, the containers pass through the unloading bay, where they are inspected and screened. In these operations, each and every container is evaluated and a distinction is made between those which are fit for reuse and those which are not. If a container is damaged, it is removed, and then discarded. Next, the process of cleaning the glass starts in a quasi-craft manner: the bottles are washed one by one, so that they become thoroughly clean, and soon thereafter, they are sterilized. Then they are placed on a conveyor belt for the filling and labeling processes of the bottles to be done by machines.

This whole process of bottling the $600 \mathrm{ml}$ containers is supervised by staff who are skilled in their specific functions. These features give order to the entire process, from packaging and sorting to the consumer and back again to the bottling plant for re-filling and labeling.

To better understand the logistics of the life cycle of the $600 \mathrm{ml}$ bottle, Figure 1 shows the flow diagram of the process. 


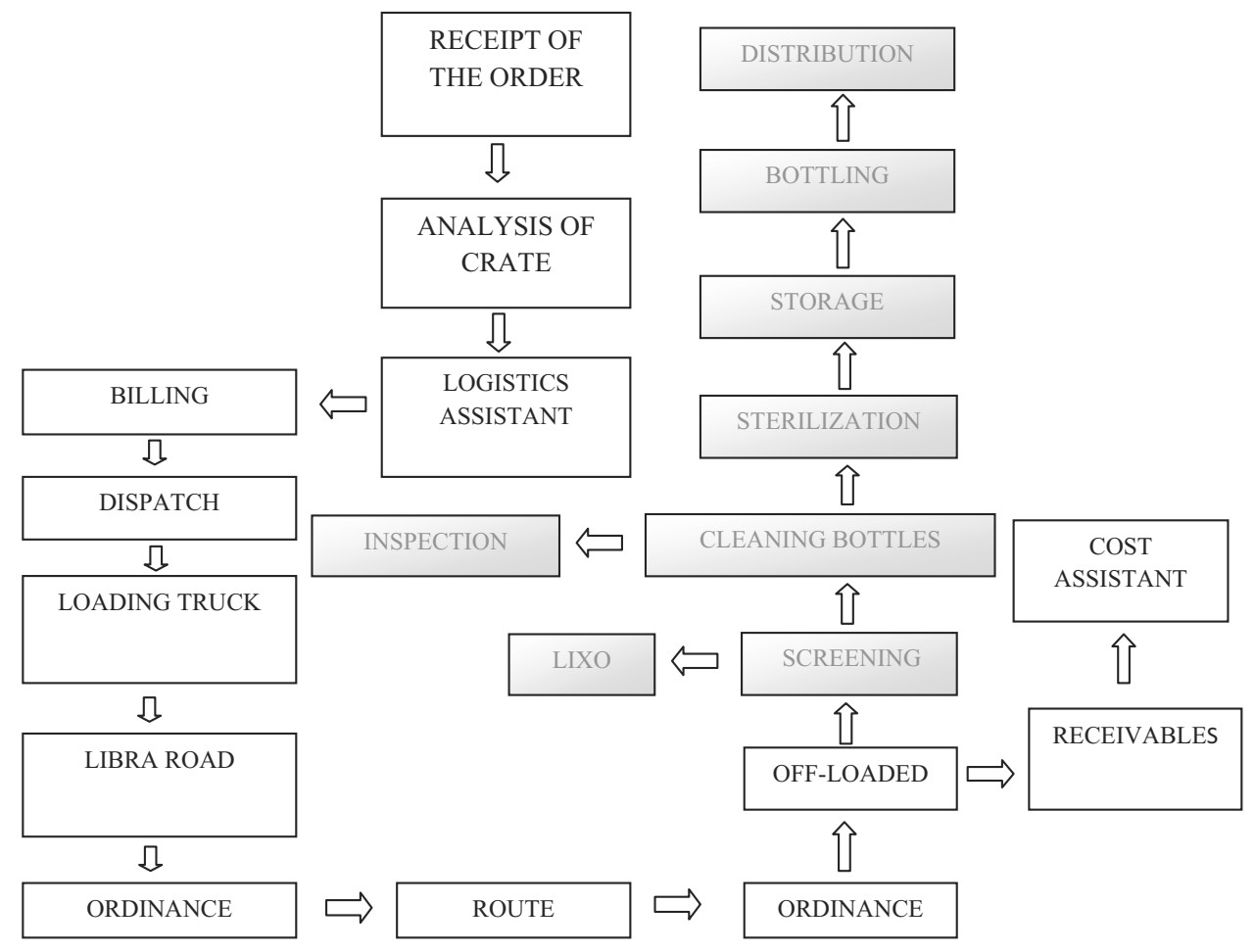

Fig 1: Process Flow

\subsection{Continuous Improvement}

It is worth emphasizing the importance of working with continuous improvement by using tools, programs and standards, and in this context, the logistics manager has an important role. The logistics manager's main function is to plan the activities of bottling, storage, distribution and transportation. Besides this, he is responsible for managing teams, managing the financial and material resources of the area and controling the operational process, and evaluating results.

The company, on seeking better efficiency in their internal processes, has three continuous improvement programs, namely: GMP, 5S and MAC.

GMP (Good Manufacturing Practices) was implemented by two industrial engineers in 2005 and includes the effective involvement of all sectors of the company in order to achieve results in all its departments. 
The $5 \mathrm{~S}$ is a program developed in Japan in 1950 that aims to transform the environment of organizations and the attitude of people so as to improve the life quality of employees, reduce waste, reduce costs and increase the productivity of organizations.

MAC (Monthly Evaluation Carreteiro) is a program that aims to achieve institutional goals in all sectors of the company. Every month there is a meeting where the targets are announced and the previous month's winning team is posted on the mural inside the company. It is hoped that certain goals are met, for example, less loss of bottles per driver, the target customer orders billed in sales, closing invoices billed paid by customers, closing the production goal of bottles filled and so forth. The achievement of these goals is encouraged by offering awards and prizes to employees who contribute most to the success of operations.

According to the company, after the continuous improvement programs were implemented, the company was able to meet some of the standards laid down by the competent bodies, such as: Ministry of Agriculture Norms [9]: LAW NUMBER 7678, OF 8 NOVEMBER, 1988, “article"(clause) 1º; Environmental Health [10]: ORDER MME/MS N 805, OF 06 JUNE 1978, Paragraph VII § 3, 4 and 5; CPRH - Water Resources Company of Pernambuco [11]: LAW NUMBER 11.132 OF 4 JULY 2005, Article (clause) 22.

\section{CONCLUSIONS}

Although reverse logistics is still given low importance in Brazilian businesses, some corporations have already seen it as an opportunity to achieve a competitive advantage by reducing costs and engaging with environmental issues.

The company of this study has been growing in its sector, not only because of its products, but also, thanks to an efficient reverse logistics, it has been able to reduce the percentage of lost containers to around $0.5 \%$. The company, by using best logistic practices, reached significant improved levels for the business, since the volume flow of goods reaches about 240,000 (two hundred and forty thousand) bottles of $600 \mathrm{ml}$ per day.

The continuous improvement processes, by modifying the company's organizational structure and production flow solidified its market and gained it recognition by other companies in the sector and also by its target clients. The results for the company show the benefits of good practice and of how an organization that has existed for over 40 years in the market, by using scientific concepts and improving its production processes may gain market share and become a reference model for many other companies in this sector. 


\section{REFERENCES}

1. Wine business monthly journal, Available in http://www.winebusiness.com/wbm/, Acessed in: 11 december, 2008

2. R. H. Ballou, Logística Empresarial: Transportes, administração de materiais e distribuição física, Atlas, São Paulo, 1993.

3. M. A. Marconi and E. Lakatos, Fundamentos de metodologia científica, Atlas, São Paulo, 2003.

4. S. L. Oliveira, Tratado de metodologia cientifica: Projeto de Pesquisa, IGI, TCC, monografia, dissertações e teses. Pioneira, São Paulo, 2004.

5. R. J. Richardson, Pesquisa social: Métodos e técnicas, Atlas, São Paulo, 2007.

6. V. M. A. Martins and G. C. C. Silva, Logística reversa no Brasil: Estado das Práticas, XXVI Encontro Nacional de Engenharia da Produção-ENEGEP, Ceará, 2006.

7. A. C. S. Linhares, et al., Logística reversa: O caso do destino de produtos químicos e vidrarias de uma instituição de ensino profissionalizante de Curitiba, XXVIII Encontro Nacional de Engenharia de Produção-ENEGEP, Rio de Janeiro, 2008.

8. A. R. Ferreira, et al., O uso da logística reversa para atender à responsabilidade sócioambiental: O caso do tratamento de resíduos sólidos em organizações madeireiras, XXVIII Encontro Nacional de Engenharia de Produção-ENEGEP, Rio de Janeiro, 2008.

9. Ministry of Agriculture Norms, available in http://extranet.agricultura.gov.br , Acessed in: 11 december, 2008.

10. Order MME/MS. Available in http://e-

legis.anvisa.gov.br/leisref/public/search.php?actName=Consolidada, Acessed in: 11 december, 2008.

11. CPRH, Artigo de regulamentação e conservação a natureza, Available in http://www.cprh.pe.gov.br/frme-index-secao.asp?idconteudo=123 , Acessed in: 11 december, 2008. 


\title{
MULTIMODALITY AND CONTAINER FILLING IN 3D
}

\author{
D. de La Fuente, I. Fernandez, R. Pino, N. García \\ Gijón Higher Polytechnic School of Engineering \\ University of Oviedo \\ Campus of Viesques s/n. 33204. Gijón. Asturias. Spain
}

\begin{abstract}
First of all, the present work pursues to describe the different necessities associated with the development of multimodal transport; subsequently, it deepens in one of those necessities: the filling of containers, identifying the necessary and standardized requirements to be taken into account for their optimization. Finally, it shows the achieved advances, both in the application of the artificial intelligence in heuristic techniques for the optimization of the three-dimensional filling and in the development of graphic simulator, which offers the visualization of those solutions.
\end{abstract}

\section{INTRODUCTION}

This paper is part of a more ambitious study aimed to:

a) study the application of AI-based heuristics and memory and learning algorithms to the optimization of container loading process in order to reduce the execution operation time. b) Gather requirements derived from each transport mode with influence on the optimization system: type and shape of containers, weight restrictions, common goods, loading/unloading sequence. c) Analyze the optimization algorithm and 3D Simulator on different container filling scenarios.

The work was carried out in collaboration with the real company CEVA, one of the world's leading logistics companies, providing end-to-end design, implementation and operational capabilities in freight forwarding, contract logistics, transportation management and distribution management. With presence in more than 100 countries and operating in different sectors, the company manages 614 warehouses and invoices 6,300 million euro per year. 
More specifically, this work tries to maximize the container volume capacity, since the achievement of this goal involves a reduction in the number of freight and thus a reduction in costs. To that aim we analyse a container-loading-focused algorithm to optimize the available space, so the whole volume offered by the container is used, reducing at minimum the empty space. Although an $100 \%$ use is impossible (in part, due to the back door frame of the truck), CEVA has an ambitious objective of completing $65 \mathrm{~m}^{3}$ in the High Cube containers, 40' $\left(76,34 \mathrm{~m}^{3}\right.$ total of volume), which means a use rate of the $85 \%$.

\section{DESCRIPTION OF THE PROBLEM.}

The sector focused in this paper is the automotive sector. The most used parts in the loads can be grouped according to the kind of package criteria in which they are transported, as shown in the Table 1.

\begin{tabular}{|c|c|c|c|c|}
\hline PIECE & FEATURES & $\begin{array}{c}\text { PACKAGE } \\
\text { DIMENSIONS }\end{array}$ & $\begin{array}{l}\text { PACKAGE } \\
\text { WEIGHT }\end{array}$ & PACKAGE TYPE \\
\hline Engines & Heavy piece & $2270 \times 1170 \times 1270$ & $1000 \mathrm{~kg}$. & Returnable metallic package \\
\hline Speed boxes & Heavy piece & $2270 \times 1170 \times 1090$ & $700 \mathrm{Kg}$. & Returnable metallic package \\
\hline Different parts & $\begin{array}{l}\text { Different } \\
\text { features }\end{array}$ & Standard package & Variable & Lost package \\
\hline Special parts & $\begin{array}{l}\text { Fragile or } \\
\text { special } \\
\text { geometry }\end{array}$ & Special dimensions & Variable & $\begin{array}{l}\text { Non-standard package and } \\
\text { non-returnable }\end{array}$ \\
\hline $\begin{array}{l}\text { Parts in } \\
\text { returnable } \\
\text { packages }\end{array}$ & $\begin{array}{l}\text { Different } \\
\text { features }\end{array}$ & $\begin{array}{c}\text { 2270x1170x1270 ó } \\
1090\end{array}$ & Variable & Returnable metallic package \\
\hline $\begin{array}{l}\text { Small-size parts, } \\
\text { regrouped }\end{array}$ & $\begin{array}{l}\text { Different } \\
\text { features }\end{array}$ & $\begin{array}{c}\text { Standard package or } \\
2270 \times 1170 \times 1270 \text { or } \\
1090\end{array}$ & Variable & $\begin{array}{c}\text { Returnable metallic package } \\
\text { or cardboard }\end{array}$ \\
\hline $\begin{array}{c}\text { Small box to } \\
\text { introduce in other } \\
\text { packages }\end{array}$ & $\begin{array}{l}\text { Different } \\
\text { features }\end{array}$ & Small size & Variable & $\begin{array}{l}\text { Inside a metallic package } \\
\text { already counted }\end{array}$ \\
\hline
\end{tabular}

Table 1. Description of the parts and their package

There are two general processes of container filling depending on the type of transport (collecting or distribution). Figure 1 shows the steps followed in the collecting case. 


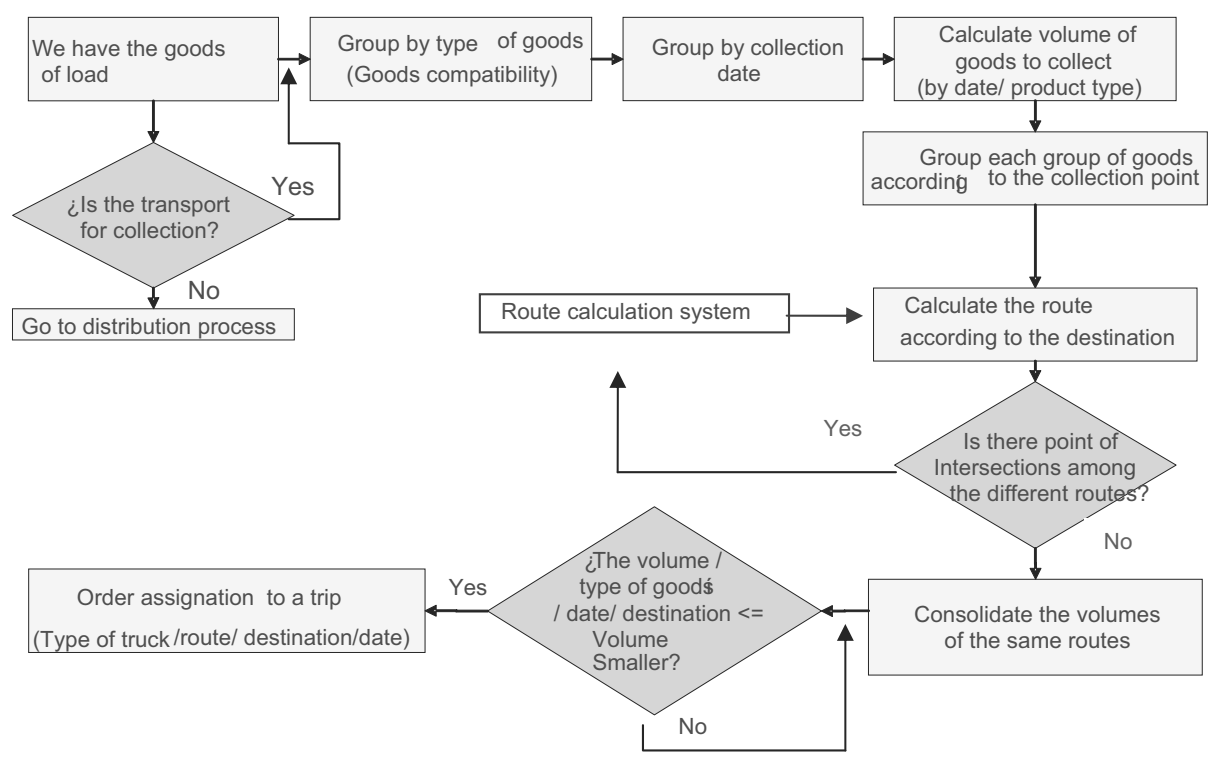

Figure 1. Collecting procedure.

Currently, the parts arrive to a warehouse already packed. When a shipment has to be prepared for dispatching, one operator draws on the ground a flat image of the container. On it he places the ordered parts in the most suitable way he is able to, according to his experience, trying to meet the greatest number of existing restrictions. Once this task is fulfilled, the parts are moved into the real container, reproducing the result obtained on the ground.

The computer program presented in this paper, aims to achieve an optimal part disposition in the container, offering thereby a valuable tool for the operator to avoid the previous mentioned handwork. That means not only to give him the distribution sequence, but also the possibility of generating a $3 \mathrm{D}$ solution.

\subsection{Previous considerations to package location within the container.}

When a customer asks for parts in small cardboard boxes, these boxes are grouped and introduced in a bigger cardboard package on top of a wooden pallet. If the number of demanded boxes is not enough to fill a bigger cardboard package, the possibility of using metallic packages is analysed. If this option is not feasible for some box, this one must be placed over a wooden pallet on the top of a package load.

The priority criteria for the package location are: 
1. Well-balanced load: Weight distribution in the container should be even, avoiding excessive weight in one part of it.

2. Piling up of packages should be made according to the container dimensions:

a. Maximum height of the container (load in 2, 3 or 4 levels).

b. Codification according to the package weight ( $\mathrm{L}$-low-, $\mathrm{M}$-medium-, $\mathrm{H}$-high-).

c. Prioritization within the same category (L, M, H).

d. Accumulated weight of the package: Maximum weight of the package $750 \mathrm{~kg}$.

e. Fragility of the parts: Placed in the top positions.

Following it is a table with examples of package:

\begin{tabular}{|c|c|c|c|c|c|c|c|c|c|c|}
\hline $\begin{array}{c}\text { Top } \\
\text { Position }\end{array}$ & $\mathrm{H}$ & $\mathrm{M}$ & $\mathrm{H}$ & $\mathrm{L}$ & $\mathrm{H}$ & $\mathrm{M}$ & $\mathrm{H}$ & $\mathrm{L}$ & $\mathrm{M}$ & $\mathrm{L}$ \\
\hline $\begin{array}{c}\text { Middle } \\
\text { position }\end{array}$ & $\mathrm{M}$ & $\mathrm{H}$ & $\mathrm{L}$ & $\mathrm{H}$ & $\mathrm{H}$ & $\mathrm{M}$ & $\mathrm{L}$ & $\mathrm{H}$ & $\mathrm{L}$ & $\mathrm{M}$ \\
\hline $\begin{array}{c}\text { Low } \\
\text { Position }\end{array}$ & $\mathrm{L}$ & $\mathrm{L}$ & $\mathrm{L}$ & $\mathrm{L}$ & $\mathrm{M}$ & $\mathrm{M}$ & $\mathrm{M}$ & $\mathrm{M}$ & $\mathrm{H}$ & $\mathrm{H}$ \\
\hline Allowed? & $\begin{array}{c}\text { Yes, desired } \\
\text { result }\end{array}$ & No & $\begin{array}{c}\text { Analyze } \\
\text { middle load }\end{array}$ & No & Yes & $\begin{array}{c}\text { Yes, analyze } \\
\text { middle and } \\
\text { top load }\end{array}$ & No & No & No & No \\
\hline
\end{tabular}

Table 2. Types of loads.

\subsection{Composition of the container image. Actual procedure.}

As mentioned above, the operator draws an "image" on the ground with the dimensions of the container plant before loading. In order to check the height of the load, he uses a bar with an impressed mark of this maximum height. The criteria taken into account for the location of the load will be: the destination port and the expedition date of the merchandise (containers with the same destination and that can be expedited in the same week will be placed in the same image). After that, depending on the volume to send, we will look for the possibility that there is only one customer for each container. In the case that the volume does not permit it (there is not enough number of packages to complete a container), we will put together different clients, only when the destination port and the expedition same are the same.

The location of packages in the image is carried out from the front part of the container, completing the image from the back to the front. 


\section{METHODOLOGY: ALGORITHM OF CONTAINER FILLING}

A literature review shows different approaches used to deal with the issue of filling container. See: H. Gehring and A. Bortfeldt.(1997), O. Faroe, et al. (2003), T.G. Grainic et al. (2009), A. Paul Davies, et al. (1999).

The algorithm proposed in this paper achieves the completion of the container filling in two steps: first, filling the bottom surface base of the container by means of a genetic algorithm, consequently, giving the sequence in which containers must complete and second, calculating of the coordinates where each box must be placed within the container.

\section{Genetic algorithm.}

It is based on the algorithm developed by Gómez \& De la Fuente (2000). This work, optimizes the placement of rectangular pieces of different sizes on an also rectangular surface. We have adapted the algorithm from two to three dimensions and we have included filling container restrictions previously commented. The outcome of the algorithm is twofold: first, it provides the sequence to be followed when introducing the boxes into containers, in order to optimize the bottom surface of the container. Afterwards, the algorithm produces a second list, concerning boxes generally smaller, to be used for filling the remaining volume in the container on top of the first layer boxes already disposed. From here, the second step of the process is to calculate the exact position of each box in the container.

\section{Calculation of coordinates.}

The approach used to accomplish this second step is a mixed approach of the proposed one by Martello (2000) combined with the one by Huang \& He (2008).

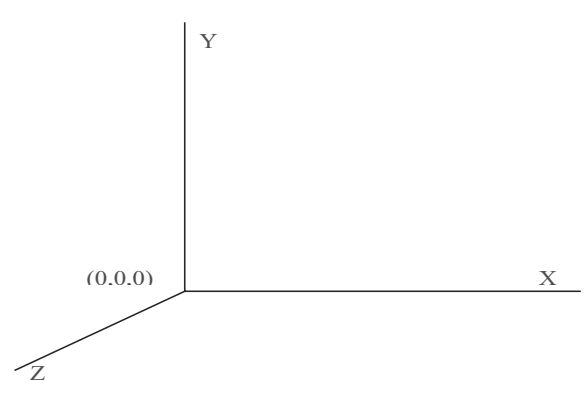

The algorithm is based on the placement of the boxes at the corners of the container. These positions will appear in a list of available positions that initially contains only one, which is precisely the located at the location $(0,0,0)$.

The first action consists of selecting the first box of the sequence provided by the genetic algorithm and places it in the single available position on the list, which is the corner $(0,0,0)$.

The fitness of the box to this position is checked. If the box does not fit the position, another one from the sequence is evaluated. Once the position is filled, it is removed from the list of available positions and in turn, the new feasible positions generated by the first box are 
added. For instance: if dimensions of the first box located in the container are: width 3, 2 and long 1 height, three new corners are generated, where the other boxes may be affixed to: $(3,0,0),(0,2,0)$, or $(0,0,1)$. Priority is given first to the position above, then the one aside and last in front of the previous one.

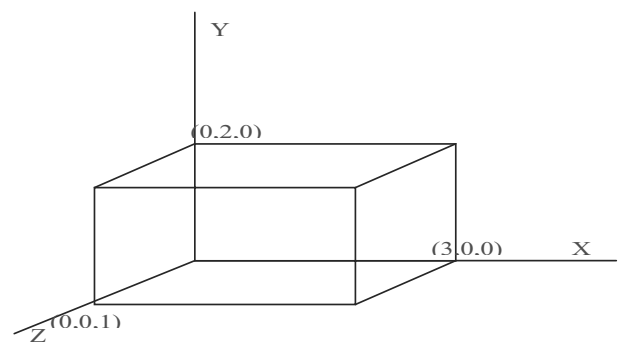

The corner $(0,2,0)$ on the list of available positions means that above the first box exist additional space to be filled. Therefore, previous to the location of a second box on the bottom of the container, the second list generated by the AG will be used to fill in the best possible way this space. Once this is done, the corner $(0,2,0)$ will be removed from the list of available positions.
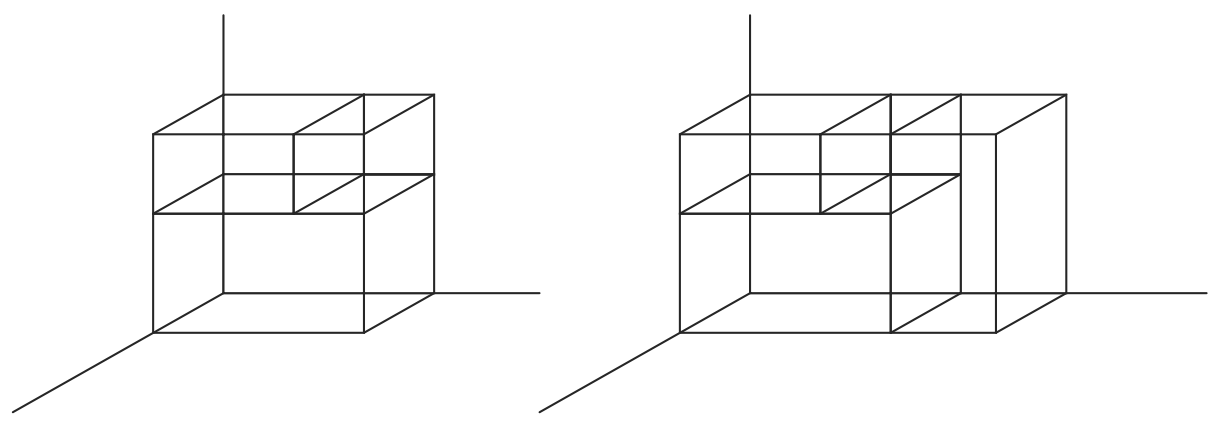

If a second box with dimensions $(1,2,1)$ is now to be placed, the corner $(3,0,0)$ will be checked. If the box does not fit in this position, the corner $(0,0,1)$ will be evaluated instead.

If the second box was placed at the $(3,0,0)$ corner, this position will be deleted from the list, and new corner will be added. In that case only the corner $(4,0,0)$ will became the first candidate of the list to prioritize the placement of the next box. The algorithm proceeds similarly till the container has been filled (not remaining corners available therein), and therefore a second container should be filled.

\section{Visual display unit of the solution.}

The visual display unit represents the boxes in three colours: red, green and blue, according to the assigned codes of the boxes (according to their fragility), so it will be easier 
to identify them. Each step, the added piece is represented in yellow to identify the added piece quickly in each situation.

The following image sequence shows an example of the visualisation process of the loading process. Step 1. Initially, both containers are empty (Figure 2).

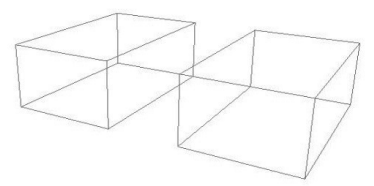

Figure 2

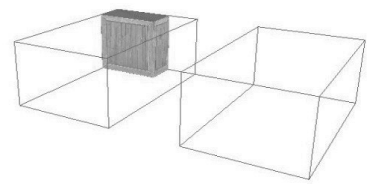

Figure 3

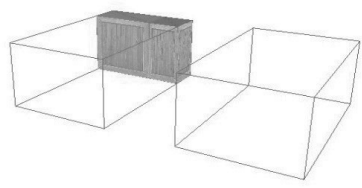

Figure 4

Step 2. When the first piece is added, it temporarily appears in yellow colour (Figure 3), adopting later its true colour (green in the Figure 4). This helps to immediately identify where the new piece is placed.

After placing the first 4 boxes (Figure 6), a space can be observed on top of the last placed box. This gap will be filled with other smaller boxes (figures 7 and 8 ) before placing a new box on the bottom of the container.

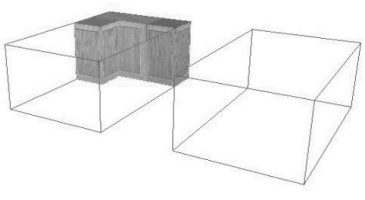

Figure 5

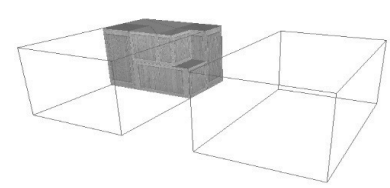

Figure 8 .

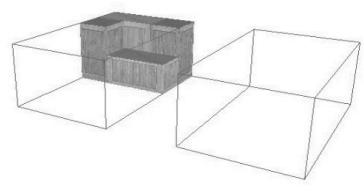

Figure 6.

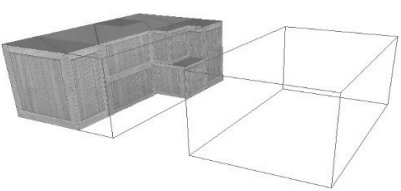

Figure 9.

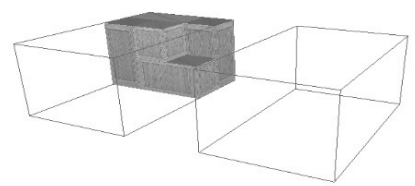

Figure 7

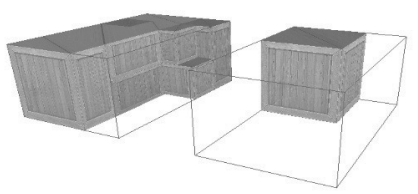

Figure 10 
The filling process continues until the situation depicted in Figure 9 is reached, that is, when the space left in the container is not enough for any additional box. The filling of a second container starts (Figure 10).

\section{CONCLUSIONS}

In this work we present a real study about multimodality and filling of containers in $3 \mathrm{D}$, where we describe a problem often present in multimodal transport context. We present a methodology for optimally loading of containers in 3D and a visual display unit of the filling.

The methodology consists of, on the one hand, a genetic algorithm responsible for providing the loading sequence leading to the optimization of the container bottom surface. On the other hand, the exact position where to place each box within the container is then calculates.

\section{REFERENCES}

Faroe, O.; Pisinger, D. \& Zachariasen, M. (2003). Guided local search for the threedimensional bin packing problem, Informs Journal on Computing, 15(3), pp. 267-283.

Gehring, H. \& Bortfeldt, A. (1997). A genetic algorithm for solving the container loading problema, International transactions in operational research, 4(5-6), pp.401-418.

Gómez, A. \& De la Fuente, D. (2000). Resolution of strip-packing problems with genetic algorithms. Journal of Operational Research, Vol. 51, No. 11, 1 pp. 1289-1295.

Grainic, T.G.; Perboli, G. \& Tadei, R. (2009). TS ${ }^{2}$ PACK: A two-level tabu search for the three-dimensional bin packing problem, European Journal of Operational Research, 195(3), pp. 744-760.

Huang, W. \& He, K. (2009). A caving degree approach for the single container loading problem. European Journal of Operational Research, Vol. 196, No. 1, pp. 93-101.

Martello, S.; Pisinger, D. \& Vigo. D. (2000). The Three-Dimensional Bin Packing Problem. Operations Research, Vol. 48 , No. 2, pp. $256-267$.

Paul Davies, A. \& Eberhard E. (1999). And Bischoff, Weight distribution considerations in container loading, European Journal of Operational Research, 114(3), pp. 509-527. 


\title{
EUROPEAN SOUTH-WEST LOGISTIC PLATFORM:
}

\section{A NEW APPROACH TO THE INTEGRAL ENERGY MANAGEMENT}

\author{
M. Monterrey, D. de la Fuente, I. Fernandez, J. Parreño \\ University of Oviedo. Higher Polytechnic School of Engineering, Gijón \\ Campus of Viesques, Energy Sector \\ 33203 Gijón, Asturias, España
}

\begin{abstract}
The industrial area design is undergoing an obvious evolving process that can be summarized in the terciarization of the real state offer. The industrial production spaces are often combined with logistics, commercial and even residential applications which lead to the generation of an advanced and added value service demand by their users. Among these services, we propose here the interior renewable energy production and distribution through the study of a pioneer case at an international level, not only from the financial point of view but also from its running.
\end{abstract}

\section{INTRODUCTION}

The concept of energy centralization is not new. There have been common heating nets for several buildings (the so-called District Heating) for over forty years, and it has been proved that its use gives way to a more efficient use of energy and, therefore, to economic saving. The new trends combine the heat and cooling distribution - comfort - with the simultaneous electricity production. This integral energy treatment is called trigeneration. It presents a much better use than the independent production of thermal and electrical energies, and an important reduction in the greenhouse gases emission to the atmosphere. These technologies are fully adaptable to the particular case of a logistic platform, where electricity necessities exist in warehouses, buildings and offices, cooling necessities in cold-store warehouses and comfort necessities in offices and the rest of inhabited places. 
For the management of this energy system, it is necessary the collaboration between a technologist and the logistics platform nominal partnership itself. Both of them form a partnership called Energy Systems Company (ESCO), which is responsible for the investment, operation and management of the energetic plant and the distribution net, as well as the consumed energy turnover, under the terms of heat, cooling and electricity, for the companies settled in the platform. The initial investment is recouped through the subsequent sale of the energy by the ESCOs to the eventual consumers, who are offered an important saving regarding the traditional system, without any cost. In this way, the Energy Systems Company can become a Platform Landlord, which charge at the same time the rent for space and the supply of several services, in this case, related to the electricity and comfort distribution.

\section{THE EUROPEAN SOUTH-WEST LOGISTIC PLATFORM}

Extremadura, thanks to its strategic position as a link between the south and north of Spain and the Iberian capital cities (Madrid and Lisboa), is presented as an absolutely favorable location for a logistic platform to be settled. According to its strategic planning (Monterrey, 2009), The European South-West Logistic Platform (PLSE) appears to give answer to the necessity of fomenting and improving the commercial exchanges between Spain and Portugal.

In general terms, the main aim of the PLSE is to contribute to the regional economical development, creating an area which:

- Constitutes a hub or new node in the distribution of certain products, mainly food and agriculture ones.

- In the same space brings companies related to distribution, logistics, and transport together with companies devoted to the realization of transformation tasks that put an end to the production process so that an added value can be generated. In this way, it is easier to get benefit from the synergies produced among the complementary activities.

- Brings together companies related to the renewable energies and energy efficiency. The PLSE will be the location for the Iberian Centre for Energy Efficiency and Renewable Energy (CIEREE). 
The PLSE occupies an area of 560 hectares between the Spanish city of Badajoz and the border with the Portuguese Alentejo. It consists of a multimodal space, with railway infrastructures of traditional gauge and AVE (high- speed train) Madrid- Lisboa, divided highway Madrid - Lisboa and a high capacity node in the Silver Road, from the North to the South of Spain. The social capital of the PLSE, S.A is 6 millions of Euros, being its ownership $100 \%$ public.

\section{A BRIEF REVIEW OF AVAILABLE TECHNOLOGIES}

Next, some of the technologies applied to this integral energy management model will be explained briefly. All of them are collected in the plentiful documentation edited by the Energy Savings and Identification Institute -IDAE (2003). We do not pretend this document to be exhaustive but explanatory of the installation typologies which are most suitable for this type of project.

\subsection{Trigeneration}

Trigeneration is known as the simultaneous production of power, heat and cooling. When electricity is produced, the inefficiency of the system lies on the need to include refrigeration systems that dissipate heat to the atmosphere (refrigeration towers, condensers, etc.). If instead of wasting this heat, it is used to feed an air-conditioning system or an industrial process, the global efficiency of the system increases considerably.

For each 100 fuel units, only $35-40 \%$ is mostly used in a traditional cycle in the electricity generation. If we add to this the fact that this generation is not usually local but far away from the consuming point, we will still have to subtract the losses for distribution and electrical energy transformation from this percentage, which decreases even more the percentage of fuel that is really used, making energy more expensive. By making a local generation, not only the transport losses are eliminated, but the residual heat can be used (about $61 \%$ of the energy) for the satisfaction of the comfort- heat and cooling needs. In this way, we move from an energy use less than $37 \%$ to percentages that can be between 75 and $90 \%$, depending on the percentage of this heat that is needed for the cooling production. 


\subsection{Gheotermics}

Far from what many people believe, there is no need to have a big heat source (thermal waters or magma) for a good use of earth energy. The Earth acts as a big accumulator of solar heat that is received during the day and thanks to its big amount of thermal inertia, it keeps a constant temperature during all the year, only few meters under the surface. This temperature - higher that the environmental one in winter and lower in summer - can be used so that an equipment, called heat bomb, works in optimal conditions to fulfill the need of hot water, heating in winter and air-conditioning in summer

The heat bomb is a peculiar thermal machine as, although it requires electricity supply, it is able to supply more energy in the form of heat than the one it receives from the net in the form of electricity. This does not go against the thermodynamics laws because this plus of energy is got from a constant temperature focus that can be air, water or earth. While in most of the machines the key parameter is the performance, always less than 1, to know the efficiency of a heat bomb, the COP (Coefficient Of Performance) is used, which in the case of geothermics, it varies between 3 and 6 or even more. This means that per each Kilowatt-hour that the thermal machine receives in form of electricity, it is able to supply between 3 and 6 kilowatts-hours in the form of thermal energy, that is, heat.

Although geothermics is not an alternative for this simultaneous generation of electricity and comfort, it can be an option when looking for a supporting system for the production of hot and cool water if the main system was not able to fulfill the needs for the air-conditioning of the complex.

\subsection{Biomass}

Biomass is a specific term to refer to the amount of living material produced by plants, animals, fungus or bacteria, in a specific area. It is usually used to refer to the energy fuel that is obtained directly or indirectly from these biological resources. A characteristic that makes biomass different from other energy resources is the fact that it is potentially renewable. Coal, gas, petrol and other fossil fuels, although their origin is organic, are not considered biomass 
as the time they need for their formation (millions of years) make them not be considered as renewable.

The original energy source which is in the biomass is the sun. Chloroplasts (small "factories" which are in plants) use solar energy (luminous energy or photons), $\mathrm{CO}_{2}$ which is in the air, and the water from the land to make carbohydrates (sugar, cellulose, etc,). The original energy from the sun is now stored in all these components. This energy can be released again and be used by the human being through combustion. Biomass, from its origin, far from being a new technology, has been used by human beings for thousands of years (they used wood as fuel). The biomass combustion produces $\mathrm{CO}_{2}$, greenhouse gas, in the same way that it is produced by fossil fuels (petrol, gas coal). The reason why biomass is considered non-polluting is that the own $\mathrm{CO}_{2}$ that is released during the combustion had been eliminated from the atmosphere during the growth of the plant. So, biomass is said to have a neutral $\mathrm{CO}_{2}$ cycle.

\section{ENERGY IN THE PLSE}

In the case of PLSE, given the great demand of heat and cool, the best thing has been to build a trigeneration plant that produces electricity, heat and cold. Moreover, given the importance of the agricultural and forest sector in Extremadura and the specialization in these activities by the Platform, they have turned to the use of biomass as fuel for the cogeneration. Nevertheless, that does not discard the installation of poly-fuel boilers that work, not only with biomass, but with other energy sources, such as gas oil or natural gas when there is a lack of the first fuel. On the other hand, the building of a cogeneration plant does not avoid from building an electrical substation. Moreover, it seems very interesting to have both installations, as the cogeneration plant will produce heat and cool used by the companies settled in the Platform, while their electricity consumption will come from the net.

The great advantage is that the electrical energy produced by cogeneration can either be given to the supplier at a regulated tariff (which will depend on the type of biomass we are talking about) or sold in the market. In this case, the benefit can be higher as the price is 
reckoned as market price plus a bonus, but there may be a risk in the final amount of money to be received, derived from the participation in the daily electricity market.

\section{MANAGEMENT MODEL}

\subsection{Introduction to the Energy Services Companies (ESCOs)}

The execution of energy efficiency projects are often held back by the need to make high economic investments. Although they can be profitable and appealing, the difficulty to find the right financing, even more at the present time of bank loan crisis, many times makes it impossible that a company can take a step ahead and bet on sustainability and efficiency. An alternative way to find this financing is with the Energy Services Companies (ESCOs). These companies, different from the eventual user, assume the risks of the necessary investment for the installation of a system that brings a less final electricity consumption, recouping the plant on the basis of a percentage of the savings got by itself with regard to the former situation under a transaction phase. This kind of companies assume the installation and the subsequent maintenance and charge the eventual user with the energy supplied, which can be power, heat or cool, in the same invoice.

The ESCOs take on the responsibility of all the phases in the investment intended for a more rational use of the energy, finance all the investment expenditures (studies, engineering, labor force, starting up, measures and results monitoring) and they also recoup the total cost of the investments, including their industrial profit through the savings produced and the public subsidies that are applied to them. It is necessary to state that the ESCOs do not lend money to make a project but they are the ones who really make the investment; therefore, we can not talk about interest rates but about profitability of a project, profitability of an investment.

The contractual relationship between the ESCOs and the eventual user is shown on the socalled supply contract, which establishes the technical and economic conditions about the supply of energy services to the user as well as other points such as the contract duration, the ownership of the installed equipments, economic compensation, guarantees, payment method etc. The eventual user gets an immediate reduction on the energy expenditures without 
making any investment. So, he can have all his financial resources for other projects, keeping his creditworthiness and therefore, his investment capacity. Besides, the user gets a renewal of his installations without any cost. Once the contract for the operation of the installations from the ESCOs has been finished, the eventual users will be the owners of a series of equipments without having made any previous investment and they will increase their savings eliminating the percentage that the ESCOs charged them.

\subsection{Corporation structure}

For the energy management in the PLSE, it has been determined to form a legal corporation owned by PLSE S.A. and a technologist specialized in the energy sector. This corporation created for this purpose is the one which makes the necessary investments for building energy infrastructures (cogeneration plants, geothermal infrastructures, etc,) while it will get the tariffs from the sale of electricity energy to the net and from supplying to the platform tenants with heat and cool . Because of being a corporation founded with public equity, PLSE S.A. has put he selection of a private partner out to tender, keeping a certain percentage of participation in the ESCOs created for the energy management. In this way, part of the investment necessary for the energy infrastructures are made by private companies while PLSE S.A gets a canon for the use of land and private benefits derived from the ESCOs activity.

\subsection{Economic and financial research}

In this section, a first economic research related to the building of a $20 \mathrm{MW}$ electrical energy trigeneration plant is made for the first stage of the PLSE development (138 hectares). The investment is about 52.000.000 €, and it means an inflation for the incomes of 2,5\%, and $3 \%$ for the expenditures. Concerning the incomes, the electrical energy is supplied to the net with a regulated tariff of $0,1077 € / \mathrm{Kwh}$. The plant is working 7.600 hours a year. As regards the expenditures, the fuel used is biomass (pellets), which costs $4.330 .000 €$ annually. The plant has been supposed to create 10 jobs, with a total cost of $200.000 € /$ year, as well as $1.800 .000 € /$ year on operations and maintenance. Finally, an annual canon of $5 \%$ of the incomes has been fixed. Public subsidies have not been considered. 
Once the hypotheses to start with have been established, annual cash flows have been estimated in Table 1:

\begin{tabular}{|l|c|c|c|c|c|c|c|c|c|c|}
\cline { 2 - 10 } \multicolumn{1}{c|}{} & Year 1 & Year 2 & Year 3 & Year 4 & Year 5 & Year 6 & Year 7 & Year 8 & Year 9 & Year 10 \\
\hline Incomes & 16370400 & 16779660 & 17199152 & 17629130 & 18069859 & 18521605 & 18984646 & 19459262 & 19945743 & 20444387 \\
\hline Expenditures & 7148520 & 7362976 & 7362976 & 7362976 & 7362976 & 7362976 & 7362976 & 7362976 & 7362976 & 7362976 \\
\hline Cash Flow & 9221880 & 9416684 & 9836176 & 10266155 & 10706883 & 11158629 & 11621670 & 12096286 & 12582767 & 13081411 \\
\hline
\end{tabular}

Table 1: Cash Flow evolution

According to the calculated cash-flow, the investment pays-back is in 5, 25 years' time.

\section{CONCLUSIONS}

The project described here has meant a singular implementation of the savings and energy efficiency policies promoted by the Government of Spain. Thus, a logistic platform has been used as a testing ground for the combination of the new Energy Services Companies (ESCOs), referring to investment and management, and the implementation of efficient technologies and energy savings generating technologies such as trigeneration. Besides, renewable energy sources have been used like biomass. The combined effect of all these factors makes a harmonious, balanced, profitable and environmentally responsible system be considered.

\section{REFERENCES}

1. M. Monterrey, Strategic Planning for the European South-west Logistic Platform, 2009.

2. IDEA, 2008-2012 Action Plan under Spain's Energy Saving and Efficiency Strategy. 2003 


\title{
RISK ON SPARES FOR LIFE-TIME MAINTENANCE PURPOSES DUE TO UNCERTAINTIES ON THE MEAN UP TIME
}

\author{
Raymond MARIE \\ IRISA / Université de Rennes 1 / INRIA \\ Université Européenne de Bretagne \\ Campus de Beaulieu, 35042 Rennes Cedex, France, \\ marie@irisa.fr
}

\begin{abstract}
We consider the case of a mono-production of a small quantity of complex (and expensive) systems, where we have to determine, at the moment when the global system is produced, the quantity of spares we want to produce for life-time maintenance purposes. The present difficulty comes from the fact that we assume that the steady state mean up time is not known precisely but is considered as uniformly distributed on a time interval $[a, b]$.
\end{abstract}

\section{INTRODUCTION}

In the case of a mono-production of a small quantity of complex (and expensive) systems, we often have to determine the quantity of spares we want to produce for life-time maintenance purposes at the moment when the global system is produced; simply because the idea of putting back a subsystem into production many years later is often a nightmarish idea.

In such a situation, a natural approach for fixing the quantity of spares to produce is to take the quantity $N_{S}$ such that the probability of running out of spares is lower than a given threshold $\epsilon_{0}$.

Assuming the steady state mean up time (MUT) is known for the new subsystem, the Poisson distribution is used for determining the value of the integer $N_{S}$; the man in charge of the task takes the minimal value satisfying the following inequality:

$$
\sum_{k=0}^{N_{S}} e^{-n T / \mathrm{MUT}} \frac{(n T / \mathrm{MUT})^{k}}{k !} \geq 1-\epsilon_{0}
$$


where $n$ is the number of copies of this subsystem used on the field and $T$ is the forecast operational life-times of the systems (eg, 25 years).

Assuming that this formula can be used means either that the relability of the subsystem is exponentialy distributed or that the population size $n$ is large enouth such that the point process corresponding to the occurences of spare requests is close to a Poisson process with a rate of $n /$ MUT.

But estimating a mean up time (MUT) for a new component generally relies on an extrapolation of information obtained on one or several matured components of the same family. In charge of such a task, who has not wondered : «why 5000 hours rather than 4000 hours? or 6000 hours?».

In case of an over-estimation of the MUT, the customer will not obtain the required availability for the new complex system on the field; while in case of an under-estimation of the MUT, very costly spares might be produced needlessly.

In order to take this risk into consideration, we propose to consider the steady state mean up time MUT as a random variable $(r v)$.

In this paper we consider the MUT as uniformly distributed on a time interval $[a, b]$. Note that when no additional information is available, it is meaningful to use the uniform distribution since this is the distribution that maximizes the entropy function of the information.

We will mainly consider the event $A$ defined as : "At time $T$, no spare shortage has occured for this subsystem". This will mean that, at time $T$, the number of breakdowns of this subsystem (since the beginning) is no greater than $N_{S}$.

The purpose of this paper is to propose a method for determining the value $N_{S}$ such that the probability of event $A$ is greater than $\left(1-\epsilon_{0}\right)$ under the assumption that MUT is uniformly distributed on the time interval $[a, b]$.

\section{SPARE SHORTAGE PROBABILITY}

Given the above expression of the inequality 1, it is more convenient to consider the inverse of the MUT, i.e., the pseudo-failure rate $\Lambda$ (that is also a random variable).

\subsection{Distribution of the pseudo failure rate}

If MUT $\sim U[a, b], 0<a<b<+\infty$, then the $r v \Lambda=\frac{1}{\text { MUT }}$ has the following density function : 


$$
f_{\Lambda}(y)=\frac{1}{(b-a) y^{2}}, \quad y \in[1 / b, 1 / a]
$$

and also the cumulative probability function :

$$
F_{\Lambda}(y)= \begin{cases}0 & \text { if } y \leq 1 / b \\ \frac{b-1 / y}{(b-a)} & \text { if } 1 / b \leq y \leq 1 / a \\ 1 & \text { if } y \geq 1 / a\end{cases}
$$

Figures 1 and 2 give an illustration of these results. The expectation of $\Lambda$ is equal to :

$$
\mathbb{E}[\Lambda]=\int_{1 / b}^{1 / a} \frac{d x}{(b-a) x}=\frac{1}{(b-a)}[\ln (x)]_{a}^{b}
$$

or, if we introduce the notation $\beta=\frac{b}{a}: \quad \mathbb{E}[\Lambda]=\frac{1}{a(\beta-1)} \ln (\beta)$,

where $\beta$ can be seen as a index of uncertainty $(\beta>1)$.

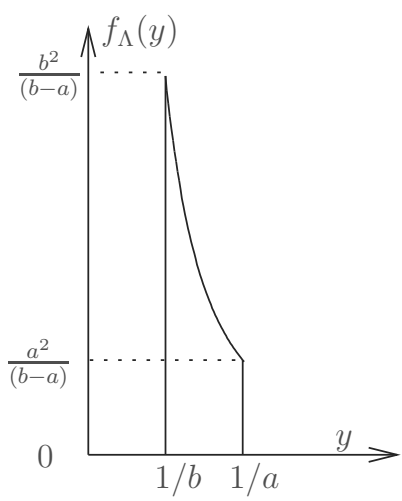

Figure 1: Density function of $\Lambda$

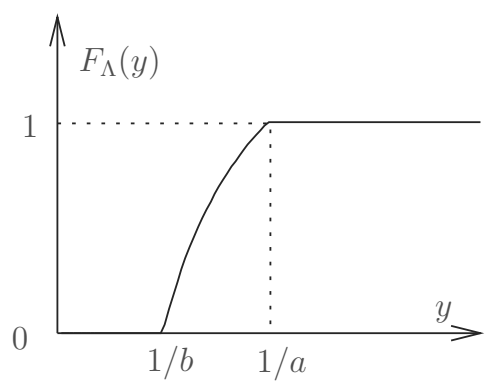

Figure 2: Cumulative function of $\Lambda$

\subsection{Probability of event $A$}

Knowing the value of $\Lambda$, we can express the conditional probability of the event $A$ :

$$
\mathbb{P}(A \mid \Lambda=y)=\sum_{k=0}^{N_{S}} e^{-n T y} \frac{(n T y)^{k}}{k !}
$$


Then, assuming we know the density function of $\Lambda$, we get formaly the unconditional probability of the event $A$.

$$
\mathbb{P}(A)=\sum_{k=0}^{N_{S}} \int_{1 / b}^{1 / a} e^{-n T y} \frac{(n T y)^{k}}{k !} \frac{d y}{(b-a) y^{2}}
$$

Before developing the determination of probability $\mathbb{P}(A)$, let us recall the following formulaes:

For a positive real $\alpha$ and for a non-negative integer $m$ :

$$
\int x^{m} e^{-\alpha x} d x=\frac{e^{-\alpha x}}{-\alpha}\left[\sum_{k=0}^{m}\left(\frac{1}{\alpha}\right)^{k} \frac{m !}{(m-k) !} x^{(m-k)}\right]
$$

For the first two negative values of $m$, we also have:

$$
\int \frac{e^{-\alpha x}}{x} d x=+E i(-\alpha x) \quad \text { and } \quad \int \frac{e^{-\alpha x}}{x^{2}} d x=-\frac{e^{-\alpha x}}{x}-\alpha E i(-\alpha x)
$$

where $\operatorname{Ei}(y)$ is the logarithmic integral function : $\operatorname{Ei}(y)=\ln |y|+\sum_{k=0}^{\infty} \frac{y^{k}}{k . k !}$

Let us also introduce the following notations : $\quad \alpha=n T, \quad c=\frac{1}{b} \quad$ and $\quad d=\frac{1}{a}$;

We will assume in general that $N_{S}$ is greater than one. Thus we have

$$
\begin{aligned}
\mathbb{P}(A) & =\sum_{k=0}^{N_{S}} \int_{c}^{d} e^{-\alpha y} \frac{(\alpha y)^{k}}{k !} \frac{d y}{(b-a) y^{2}} \\
& =\frac{1}{(b-a)}\left\{\int_{c}^{d} \frac{e^{-\alpha y}}{y^{2}} d y+\alpha \int_{c}^{d} \frac{e^{-\alpha y}}{y} d y+\sum_{k=2}^{N_{S}} \frac{\alpha^{k}}{k !} \int_{c}^{d} e^{-\alpha y} y^{k-2} d y\right\}, \\
& =\frac{1}{(b-a)}\left\{\int_{c}^{d} \frac{e^{-\alpha y}}{y^{2}} d y+\alpha \int_{c}^{d} \frac{e^{-\alpha y}}{y} d y+\sum_{m=0}^{N_{S}-2} \frac{\alpha^{m+2}}{(m+2) !} \int_{c}^{d} e^{-\alpha y} y^{m} d y\right\},
\end{aligned}
$$

Fortunately enough, we can see the following reduction of the sum of the first two integrals

$$
\int_{c}^{d} \frac{e^{-\alpha y}}{y^{2}} d y+\alpha \int_{c}^{d} \frac{e^{-\alpha y}}{y} d y=\frac{e^{-\alpha c}}{c}-\frac{e^{-\alpha d}}{d}
$$


Considering now one element of the discrete sum of the second part of the expression of $\mathbb{P}(A)$, we have :

$$
\begin{aligned}
& \frac{\alpha^{m+2}}{(m+2) !} \int_{c}^{d} e^{-\alpha y} y^{m} d y \\
= & \frac{\alpha^{m+2}}{(m+2) !}\left\{\frac{e^{-\alpha c}}{\alpha}\left[\sum_{k=0}^{m}\left(\frac{1}{\alpha}\right)^{k} \frac{m !}{(m-k) !} c^{(m-k)}\right]-\frac{e^{-\alpha d}}{\alpha}\left[\sum_{k=0}^{m}\left(\frac{1}{\alpha}\right)^{k} \frac{m !}{(m-k) !} d^{(m-k)}\right]\right\}, \\
= & \frac{\alpha^{m+1}}{(m+2) !}\left\{e^{-\alpha c}\left[\sum_{k=0}^{m}\left(\frac{1}{\alpha}\right)^{k} \frac{m !}{(m-k) !}\left(c^{(m-k)}-e^{-\alpha(d-c)} d^{(m-k)}\right)\right]\right\} \\
= & \frac{\alpha}{(m+1)(m+2)}\left\{e^{-\alpha c}\left[\sum_{k=0}^{m} \frac{1}{(m-k) !}\left((\alpha c)^{(m-k)}-e^{-\alpha(d-c)}(\alpha d)^{(m-k)}\right)\right]\right\} \\
= & \frac{\alpha}{(m+1)(m+2)}\left\{e^{-\alpha c}\left[\sum_{k=0}^{m} \frac{1}{k !}\left((\alpha c)^{k}-e^{-\alpha(d-c)}(\alpha d)^{k}\right)\right]\right\}
\end{aligned}
$$

Taking now the discrete sum into consideration

$$
\begin{aligned}
& \sum_{m=0}^{N_{S}-2} \frac{\alpha}{(m+1)(m+2)}\left\{e^{-\alpha c}\left[\sum_{k=0}^{m} \frac{1}{k !}\left((\alpha c)^{k}-e^{-\alpha(d-c)}(\alpha d)^{k}\right)\right]\right\} \\
= & \alpha e^{-\alpha c} \sum_{k=0}^{N_{S}-2}\left[\frac{1}{k !}\left((\alpha c)^{k}-e^{-\alpha(d-c)}(\alpha d)^{k}\right)\right] \sum_{m=k}^{N_{S}-2}\left(\frac{1}{(m+1)}-\frac{1}{(m+2)}\right) \\
= & \alpha e^{-\alpha c} \sum_{k=0}^{N_{S}-2}\left[\frac{1}{k !}\left((\alpha c)^{k}-e^{-\alpha(d-c)}(\alpha d)^{k}\right)\right]\left(\frac{1}{(k+1)}-\frac{1}{N_{S}}\right) \\
= & \frac{1}{c} \sum_{k=0}^{N_{S}-2} \frac{(\alpha c)^{k+1}}{(k+1) !} e^{-\alpha c}-\frac{\alpha}{N_{S}} \sum_{k=0}^{N_{S}-2} \frac{(\alpha c)^{k}}{k !} e^{-\alpha c} \\
= & \frac{1}{c} \sum_{k=1}^{N_{S}-1} \frac{(\alpha c)^{k}}{k !} e^{-\alpha c}-\frac{\alpha}{N_{S}} \sum_{k=0}^{N_{S}-2} \frac{(\alpha d)^{k+1}}{(k+1) !} e^{-\alpha d}+\frac{\alpha}{N_{S}} \sum_{k=0}^{N_{S}-2} \frac{(\alpha c)^{k}}{k !} e^{-\alpha c} e^{-\alpha d}, \\
& -\frac{1}{d} \sum_{k=1}^{N_{S}-1} \frac{(\alpha d)^{k}}{k !} e^{-\alpha d}+\frac{\alpha}{N_{S}} \sum_{k=0}^{N_{S}-2} \frac{(\alpha d)^{k}}{k !} e^{-\alpha d},
\end{aligned}
$$




$$
\begin{aligned}
=\frac{1}{c} \sum_{k=0}^{N_{S}-1} & \frac{(\alpha c)^{k}}{k !} e^{-\alpha c}-\frac{e^{-\alpha c}}{c}-\frac{\alpha}{N_{S}} \sum_{k=0}^{N_{S}-2} \frac{(\alpha c)^{k}}{k !} e^{-\alpha c} \\
& -\frac{1}{d} \sum_{k=0}^{N_{S}-1} \frac{(\alpha d)^{k}}{k !} e^{-\alpha d}+\frac{e^{-\alpha d}}{d}+\frac{\alpha}{N_{S}} \sum_{k=0}^{N_{S}-2} \frac{(\alpha d)^{k}}{k !} e^{-\alpha d},
\end{aligned}
$$

Merging the partial expressions, we get for $\mathbb{P}(A)$

$$
\begin{aligned}
\mathbb{P}(A)= & \frac{1}{(b-a)}\left\{\frac{1}{c} \sum_{k=0}^{N_{S}-1} \frac{(\alpha c)^{k}}{k !} e^{-\alpha c}-\frac{\alpha}{N_{S}} \sum_{k=0}^{N_{S}-2} \frac{(\alpha c)^{k}}{k !} e^{-\alpha c}\right. \\
& \left.-\frac{1}{d} \sum_{k=0}^{N_{S}-1} \frac{(\alpha d)^{k}}{k !} e^{-\alpha d}+\frac{\alpha}{N_{S}} \sum_{k=0}^{N_{S}-2} \frac{(\alpha d)^{k}}{k !} e^{-\alpha d}\right\},
\end{aligned}
$$

This result can be presented as

$$
\begin{aligned}
\mathbb{P}(A)=\frac{\beta}{(\beta-1)} \sum_{k=0}^{N_{S}-1} \frac{(\alpha c)^{k}}{k !} e^{-\alpha c}-\frac{1}{(\beta-1)} \sum_{k=0}^{N_{S}-1} \frac{(\alpha d)^{k}}{k !} e^{-\alpha d} \\
\quad-\frac{\alpha}{(b-a) N_{S}}\left\{\sum_{k=0}^{N_{S}-2} \frac{(\alpha c)^{k}}{k !} e^{-\alpha c}-\sum_{k=0}^{N_{S}-2} \frac{(\alpha d)^{k}}{k !} e^{-\alpha d}\right\},
\end{aligned}
$$

Note that $c$ and $d$ are respectively equal to the minimal and the maximal values of the pseudo failure rate $\Lambda$.

The case where $N_{S}$ equals one corresponds to the special expression

$$
\mathbb{P}(A)=\frac{\beta}{(\beta-1)} e^{-\alpha c}-\frac{1}{(\beta-1)} e^{-\alpha d}
$$

\section{NUMERICAL EXAMPLE}

We consider in this example the situation where $n=5$ and $T=30$ years, therefore $\alpha=150$. In addition either MUT follows the uniform distribution [10,20] or MUT has the constant value 15 , corresponding to the expectation of the considered uniform distribution. 


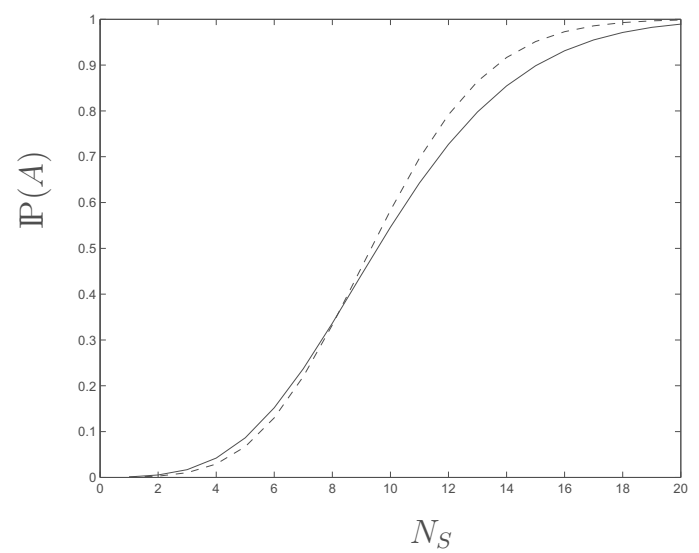

Figure 3: Probability $\mathbb{P}(A)$. Random MUT : solid line. Constant MUT: dotted line.

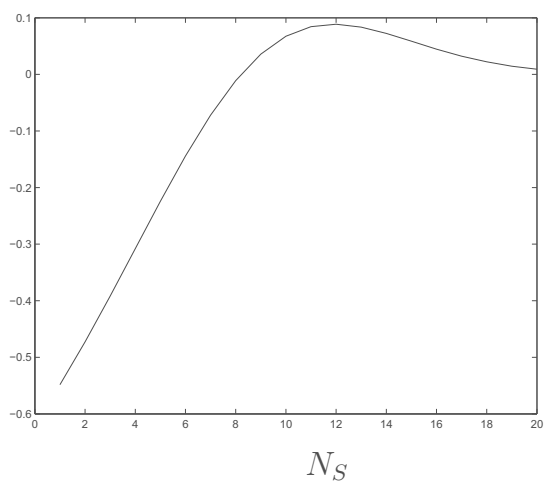

Figure 4: Relative error.

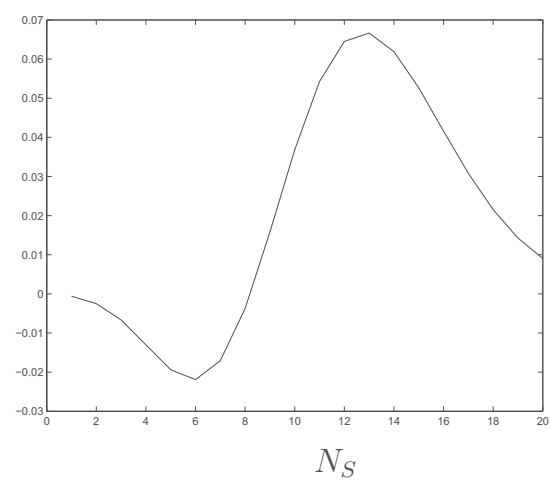

Figure 5: Absolute error.

Figure 3 shows the probability of event $A$ as a function of $N_{S}$, for the two cases. The solid line corresponds to the case where MUT follows the uniform distribution $[10,20]$ and the dotted line corresponds to the case where MUT takes the constant value 15 . We see that the approximation done by assuming wrongly a perfect knowledge of MUT under-estimates the probability $\mathbb{P}(A)$ for small values of $N_{S}$ but over-estimates it for large values of $N_{S}$. Figures 4 and 5 respectively give the relative and absolute errors. The main point of interest is that for large values of $N_{S}$, such that $\mathbb{P}(A)$ is not too far from one, the difference between the two answers is significant as it is shown on figure 6. For example, assuming $\epsilon_{0}=0.05$ and constant MUT will involve the choice $N_{S}=15$, while assuming a random MUT will involve the choice $N_{S}=17$. 


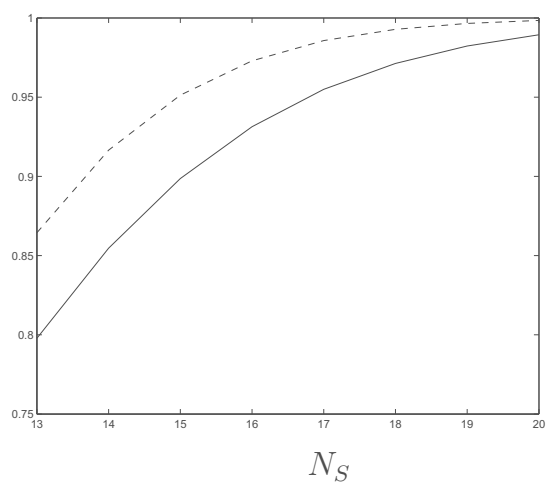

Figure 6: The two $\mathbb{P}(A)$ cases for large values of $N_{S}$.

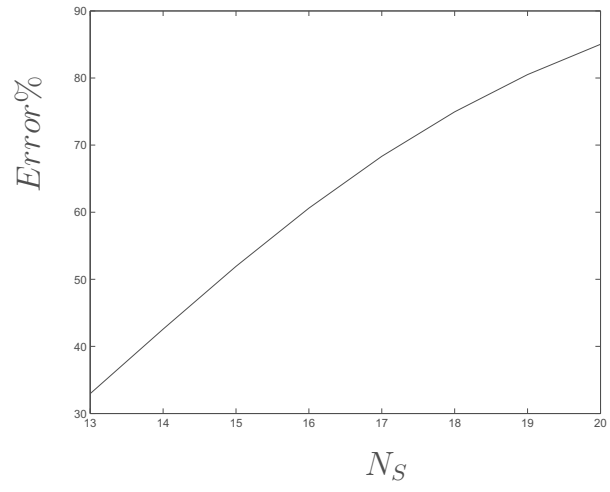

Figure 7: Corresponding relative error on $\epsilon$, in pourcentage.

\section{CONCLUSIONS}

In this study, we have pointed out a way to determine the number of spares $N_{S}$ to initially produce for life-time maintenance purposes when, due to a lack of knowledge, the mean up time is considered as a random variable. A closed form expression has been obtained for the case where it is assumed to follow a uniform distribution.

We conducted this research with the aim of helping the engineer to understand the consequences of such uncertainties on the mean up time.

\section{References}

[1] R.E. Barlow And F. Proschan, Statistical Theory of Reliability and Life Testing, Holt, Rinehart and Winston, NY, 1975.

[2] A. Papoulis, Probability, Random Variables and Stochastic Processes, Third ed., McGraw-Hill, 1991. 


\title{
IMPLEMENTATION OF DATA-WAREHOUSES IN CUSTOMER RELATIONSHIP MANAGEMENT SYSTEMS
}

\author{
${ }^{1}$ A. Micu and ${ }^{2}$ A. E. Micu \\ ${ }^{1}$ Department of Management-Marketing, \\ ${ }^{2}$ Department of Finance \\ « Dunarea de Jos »University of Galati
}

\begin{abstract}
In the actual business environment, forward-looking companies are structuring their activities toward the goal of understanding each customer individually in view to gain a competitive advantage. These companies are learning to evaluate the value of each customer, using the information gathered with every contact and stored in data-warehouses, which contribute to an efficient targeting of customers' portfolio and creation of efficient marketing campaigns. Building a business in the information era based on customer data-warehouses is in the same time a real "challenge" and a revolutionary change for all the companies.
\end{abstract}

\section{INTRODUCTION}

Customer Relationship Management (CRM) appoints the establishment, development and optimization of relationships between an organization and its customers and focuses on the understanding and satisfaction of customers' needs and expectations that are placed in the center of an efficient business strategy.

The customer-focused companies regard every interaction with a client or a prospect (point-of-sale transaction, calls to Customer Care Centers, visit and register to a website, marketing survey, etc.) as a business opportunity that can be exploited.

\section{THE ROLE OF DATA WAREHOUSES IN CRM}

There are many companies that gather an important amount of data concerning their customers but they use it for operational purposes as inventory control or billing. The companies that are looking for leader position in their markets track hundreds of gigabytes or even terabytes of data from and about their clients in view to learn everything about them, 
starting with their behaviors and arriving to determine their loyalty and reduce the churn rate. This is the key for a successfully CRM strategy.

One of the most important aspects of the data-warehouses is the capability to track customer behavior over the time. Data warehousing allows to a company specialists to manage the information about their customers and create links that can offer answers to different questions like: What is the average expense of each customer in a period of time?, How frequently does the customer return?, Which distribution channels does the customer prefer?, Which promotions does the customer respond to?, etc.

CRM data-warehouses provide great opportunities for marketers to realize multidimensional analyses, by taking into account OLAP functions (On-Line Analytical Processing), which is a capability of a data-warehouse to manipulate a great amount of data from multiple perspectives; it focuses on providing a set of data attributes from a datawarehouse organized around certain dimensions, such as time, locations and products. For example, a marketing specialist access a data-warehouse which contains information referring to company's sales, displayed by geographical regions, types of products and distribution channels. Using an OLAP session, he can extract the sales from each region and for each type of product. Requesting a new OLAP session, he can obtain the sales volume from each distribution channel, in correlation with the other two dimensions: region and product type; in this way, he can choose the most efficient strategy to sell the company's products.

CRM is not considered a data ware-housing best practice, but the inverse is true: data ware-housing availing rich customer information across the enterprise is definitely a Customer Relationship Management best practice. [1]

A well-designed CRM data-warehouse, as a result of the collaboration between marketing and IT specialists, provides access to information about customers in a much friendly format than the way that is stored by transaction processing systems, located on the base of information systems pyramid. Ideally, data in warehouses has been gathered from many sources, cleaned, merged, tied to particular customers and summarized in various useful ways. The corporate data-warehouses are the most important source of data for analytical CRM. [2]

Data gathered in a CRM data-warehouse can be used in a lot of tasks, as customer profiling, customer satisfaction analysis, prospect qualification, promotion campaigns measurement, distribution channel analysis, customer value measurement, churn analysis and 
prediction, etc. Customer-focused companies can launch different types of marketing campaigns, like: reward most profitable customers with personalized discounts, offer products and services that fit to customers' needs, based on what they have already purchased, increase purchase rates especially on websites, personalizing visitors' profiles, prevent customer churn by offering them incentives based on individual preferences.

In a data-warehouse, information is organized around subjects, such as sales and once placed in the warehouse, it is not changed in short periods of time; one of the most important challenges in building a warehouse is data integration, particularly where there are many types of technology in use. A warehouse must add time dimension to the data, as it's almost impossible to predict what will happen in the future without observing what happened in the past (for example, we can't predict the future expenses of a customer without taking into account its past acquisitions). [3]

In the process of designing a data-warehouse for Customer Relationship Management, the problems experienced by most organizations when they attempt to build it concerns what technology should be use and how will be populated with information about customers.

The main components of a data-warehouse are: data extraction and integration capabilities, relational warehouse database, data mining and client query tools. Some are concerned with getting the information out of the source systems and into the warehouse, while others are concerned with getting the information out of the ware-house and presenting it to the users. [4]

In view to insert details about the information that will be stored in the warehouse, we must create a mechanism for identifying the links between the components. This problem can be solved by constructing a state transition diagram. Data integration consists of series of rules that can ensure the fact that data is standardized. After the information has been extracted and integrated, it can be inserted in the relational databases of the warehouse.

\section{CASE STUDY: BUILDING A DATA WAREHOUSE FOR A CRM SYSTEM}

This section of the article refers to the technologies and methodologies that are actually involved in the construction and use of a data warehouse regarding customer relationship management. 
We face the follow situation: an organization wants to use a technological solution in order to keep track of all the purchases made by its clients. Associated with every purchase, each client will receive a number of points.

First we can think that a normal database structure will be enough to work with this kind of data. This is not completely inaccurate but if we want to stock data for a long time, normal structures will fail to provide information we seek in a reasonable amount of time. The solution lies in the theory of multidimensional structures (cubes or hypercubes) described in the previous sections.

Fig. 1: Design of tables from the CRM database

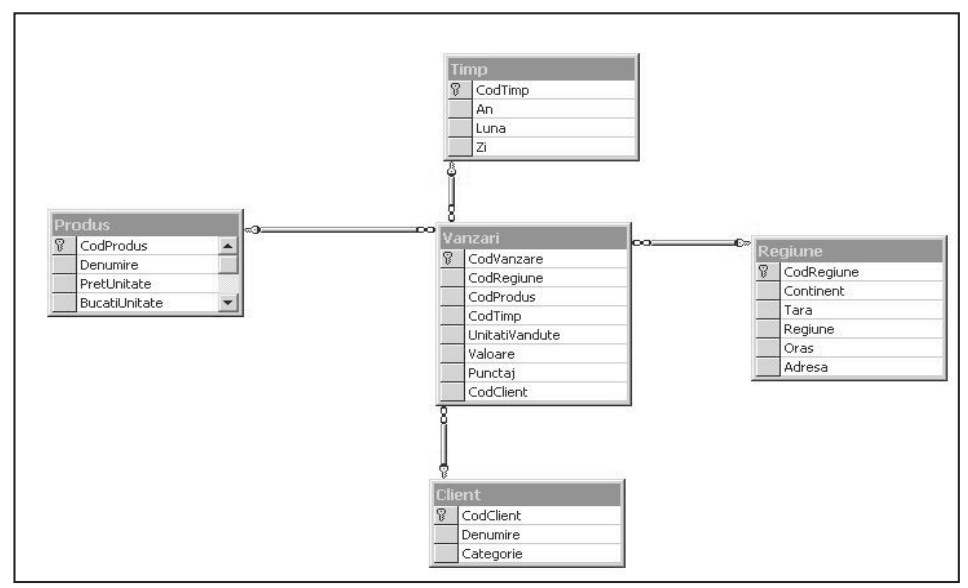

First step will be to create a database suitable to sustain a cube. There are two approaches: by using a star or snowflake schema. In our case we choose a star schema that we present in the figure no.1.

We have five tables in our database that express the relevant entities which interact in the real life situation: Product, Time, Region, Client and Sales.

Every multidimensional structure is defined by two components: dimensions and facts. We'll define as a dimension the following tables: Produs, Timp, Regiune, Client and as facts table: Vanzari. We notice that there are four dimensions and still the structure will use it's called: cube - that allow to represent the aspect of multidimensional and not to restrict at three dimensions. When the stage concerning the creation of the database is complete, we'll move forward to define the multidimensional structure. If in the first case we need a database management system, now the technology that will assist us to define the cube is called: OLAP 
(On-Line Analytical Processing) Services. For this example, we used Microsoft SQL Server as DBMS and OLAP services from Microsoft.

Using a cube means to extract data from it which will become information after adding some context to it and in the final stage of its evolution will be transformed into actionable knowledge. We can solve questions like this: What is the score (sum of all points that it gain) for all the medium-size institutions in a specific region on a certain date: month/day/year. We can also query for the effective value of sales to a specific client, or to a specific region, for a product or a category of products. Dimensions are those elements that make these queries possible. We define values (parameters) for dimensions and important numerical data (facts) will shown up. The definition of dimensions and fact we can say that we have a cube structure. Unfortunately it can't be represented due to its 4-th dimension. If we presume that we have only three dimensions, we can represent the structure like this:

\section{Fig. 2: Partial representation of multidimensional structure}

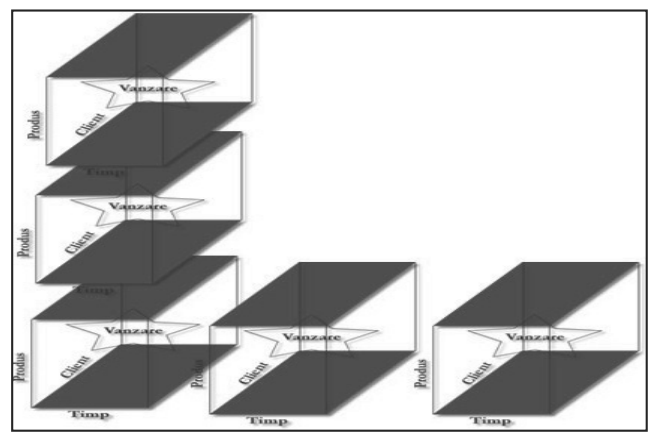

Using a cube means to extract data from it which will become information after adding some context to it and in the final stage of its evolution will be transformed into actionable knowledge. We can solve questions like this: What is the score (sum of all points earned) for all the medium-size institutions in a specific region on a certain date: month/day/year. We can also query for the effective value of sales to a specific client, or to a specific region, for a product or a category of products. Dimensions are those elements that make these queries possible. We define values (parameters) for dimensions and important numerical data (facts) will shown up. 
The cube we defined can be used by using its browse option which will generate a common form which we'll be populated with data, drop downlists and drilling features. The following picture presents the results of the query: Which is the number of units sold and how many points have achieved so far those clients in case of a product named "Fanta", bought by European clients in year 2005. The results can be detailed in order to see the size of client (small, medium, large):

Fig. 3: Sales analysis using Cube Browser of SQL Server

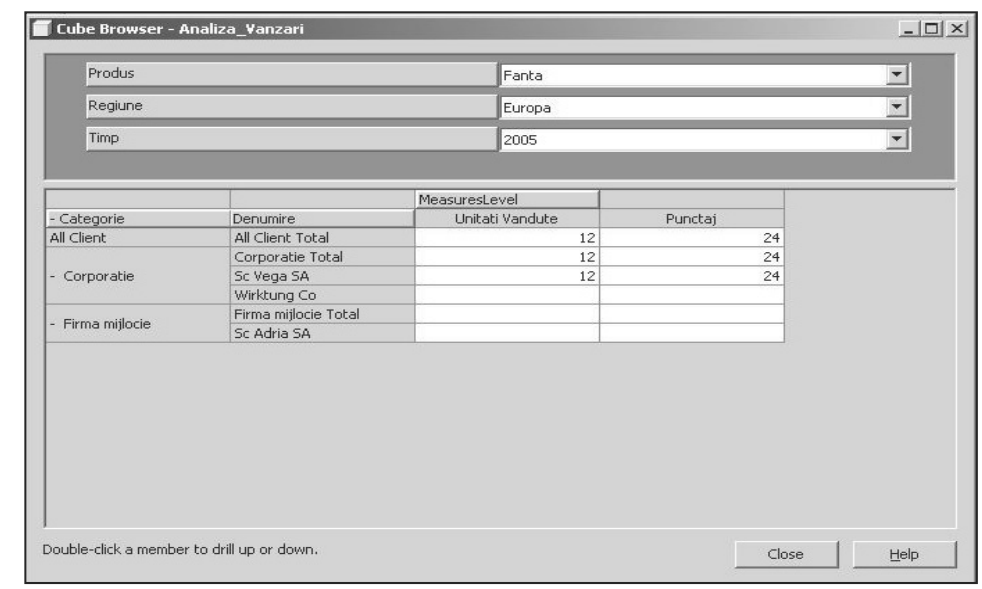

Usually all data-warehouses and especially multidimensional models and structures are used in case of situations where we deal with hundreds of thousands, even over one million records. In our case, the result is based on a sample, just as an example. It's not difficult to imagine about the volume of data should be in our case if we have hundreds of clients, plenty of products, and each client buy at least half of the products we have on regular schedule each week, or even each month.

\section{CONCLUSIONS}

There is no doubt that, in most organizations with large portfolio of customers, the development of a data-warehouse in support of a CRM strategy can almost always provide 
positive and profitable benefits. Data warehousing represents a major investment and, in this way, companies must be able to show how and when it will become an opportune investment. The main thing to remember is that the development of the warehouse should be focused on assisting customers in the achievement of their individual goals, as each goal usually has an associated value. If the CRM data warehouse helps an organization to achieve the goal, then it also can be assigned a value that prove its planning and building processes.

\section{REFERENCES}

1. J. Dyché - "The CRM Handbook - A Business Guide to Customer Relationship Management", Addison-Wesley, 2002

2. M. Berry, G. Linoff - "Data Mining Techniques for Marketing, Sales and Customer Relationship Management”, Wiley Publishing, 2004

3. C. Todman - "Designing a Data Warehouse: Supporting Customer Relationship Management", Prentice Hall, 2000

4. Allard C. - "Le Management de la Valeur Client", Ed. Dunod, Paris, 2002

5. www.datawarehousing.com

6. www.intelligententerprise.com 


\title{
AN EFFICIENT ANT COLONY SYSTEM FOR VEHICLE ROUTING PROBLEMS WITH TIME WINDOWS
}

\author{
O. S. Silva Junior and J. E. Leal \\ Department of Industrial Engineering - Pontific University Catholic of Rio de Janeiro \\ Rua Marquês de São Vicente, 225, Gávea, Rio de Janeiro, RJ - Brasil - 22453-900
}

\begin{abstract}
This paper presents an efficient algorithm based on metaheuristic Multiple Ant Colony System for solving Vehicle Routing Problems with Time Windows. This problem aims to determine the minimum cost routes for a fleet of vehicles of same capacity to meet the demand of a set of customers within a specified time interval called time window. The methodology, called MACS-VRPTW, uses two ant colonies to reduce the number of vehicles and total distance traveled. The implementation of the algorithm in the Java environment was performed and tested in 6 standard problems used as benchmarking in literature.
\end{abstract}

\section{INTRODUCTION}

The vehicle routing problem with time windows (VRPTW) has been widely studied in recent decades. There are two major reasons for this fact. First, the costs related to transporting people and goods are generally high, with a tendency to growth, driven by the current expansion of trade borders of all kinds of business.

The second major motivation for the study of VRPTW is related to the great challenge that the solution of this problem represents. VRPTW is in NP-hard class, i.e., there are no algorithms that solve it in polynomial time and the use of exact methods is quite limited. It is also one of the most difficult problems in combinatorial optimization, representing a major challenge for researchers.

VRPTW is defined as follows: $n$ customers must be supplied by a single storehouse. Each customer $i$ orders a demand $d i$ of products, service time $s i$ and time window $\left[b_{i}, e_{i}\right]$, where $b i$ represents the start time of service and $e_{i}$ the time limit that the vehicle reaches the customer to be supplied. A fleet of vehicles $V$, each with capacity cap is available to supply the customers. The final solution of the problem is a set of routes. 
This problem can be modeled mathematically by a complete graph $G(N, A)$, where $N=(0,1, \ldots n)$ is a set containing all nodes with the storehouse being represented by node $(0)$ and customers $(1, \ldots, n)$, and $\mathrm{A}$ is a set containing all the edges, each containing the associated travel time Tij Basically, VRPTW consists of finding a set of minimum cost routes for vehicles from a storehouse (0), ensuring that every client is supplied by one and only one vehicle, respecting the restrictions of vehicle capacity and time windows returning to the storehouse (0). Furthermore, finding the minimum number of vehicles needed to perform the task is also desired.

We propose a solution based on the paradigm of Ant Colonies Systems (ACS), which are mathematical models based on the behavior of ants when immersed in colonies of similar individuals. These algorithms are very useful in solving large combinatorial optimization problems, usually too complex to be solved by exact optimization techniques.

This technique was initially proposed by Dorigo et al. [1], who proposed a model called Ant System (AS) to solve the Traveling Salesman Problem (TSP). In 1997, Dorigo and Gambardella [2] created the Ant Colony System (ACS) from the AS, which represented a new breakthrough in the performance of algorithms. In 1999, Bullnheimer et al. [3] applied the vehicle routing problem (VRP) for the first time. In 1999, Gambardella et al. [4] proposed a technique called Multiple Ant Colony System applied to the vehicle routing problem with time windows (MACS-VRPTW), which was used as the basis for this work.

\section{ANT SYSTEM (AS)}

This algorithm does not perform simulations of the life cycle of each ant, which is the performance of a path from their nest up to a food source. Each step of an ant is defined by a probabilistic decision rule, since an arc between all other existing ones should be chosen from its current position. This rule is based on the values of the amount of pheromone accumulated by the passage of previous ants and the cost (distance) in each arc. For each of these values, a different weight for parameters alpha and beta can be given, respectively. The calculation of the attractiveness of each arc can be mathematically described by:

$$
a_{i j}(t)=\frac{\left[\tau_{i j}(t)\right]^{\alpha}\left[\eta_{i j}\right]^{\beta}}{\sum_{l \in N_{i}}\left[\tau_{i l}(t)\right]^{\alpha}\left[\eta_{i l}\right]^{\beta}}
$$


From expression 1, the attractiveness $a_{i j}(t)$ is obtained for an ant that is in any node $i$, and for every node $j$ belonging to $N i$, where $N i$ is the set of nodes adjacent to node $i$. The variable $\tau_{i j}$ represents the amount of pheromone accumulated on arc $(i, j)$, and variable $\eta i j$ is equal to the inverse of the length of arc $(i, j)$. The parameter $t$ indicates that the values are varying at each iteration $t$. After calculating the values of $a$ for all arcs that come across $i$, the probability of an ant $k$ choose to go through arc $i j$ is defined as:

$$
p_{i j}^{k}(t)=\frac{a_{i j}(t)}{\sum_{l \in N_{i}^{k}} a_{i l}(t)}
$$

In expression $2, N_{i}{ }^{k}$ is the subset of $N i$ containing only the nodes that have not been visited by ant $k$, that is, nodes that are not included in the memory of the ant.

For an ant to select an arc among all possible alternatives, the probability accumulated from the probabilities of each arc pij is calculated, and a random number between 0 and 1 is selected. The arch chosen will be the one in which the selected number has value greater than or equal to $p_{i j-1(\text { accumulated) }}$ and lower than $p_{i j(\text { (accumulated). }}$.

After all ants $k$ complete their paths, the amount of pheromones of all the arches is updated. This update consists of the evaporation of pheromones and deposition of new pheromones, which is represented by the following equation:

$$
\tau_{i j}(t) \leftarrow(1-\rho) \tau_{i j}(t)+\sum_{k=1}^{m} \Delta \tau_{i j}^{k}(t)
$$

In expression 3, the parameter $\rho$ represents the level of evaporation of pheromones. The sum represents all the individual contributions of each ant $k$ which has passed the $\operatorname{arc}(i, j)$ in the iteration in question; $\Delta \tau_{i j}{ }^{k}$ is the amount of pheromone that ant $k$ deposits on $\operatorname{arc}(i, j)$, which is defined as the inverse of the total length of route $L_{k}$ that the ant $k$ traveled. The more ants travel by an arch, more pheromones will be deposited in the arc, and the size of these depositions is proportional to the quality of solutions found. Mathematically, we have:

$$
\Delta \tau_{i j}^{k}(t)=\left\{\begin{array}{c}
\frac{1}{L_{k}(t)}, \text { if }(i, j) \in \text { route traveled by ant } k \text { in iteration } t \\
0, \text { otherwise }
\end{array}\right.
$$

This is the basic idea of AS applied to the traveling salesman problem. Below, another metaheuristic that was developed based on the AS is presented, known as Ant Colony System. 


\section{ANT COLONY SYSTEM (ACS)}

The Ant Colony System is an improvement of the Ant System. An important difference between AS and ACS is that ACS uses update of pheromones. In the case of AS, it is done in a comprehensive and unified way after the end of each iteration. In ACS, the update of pheromones takes place both locally after the action of each ant, and globally, after the end of each iteration, increasing only the best path found by the ants.

The ACS also performs the change in the treatment of the deposition of the initial amount of pheromone on each arc $(\tau 0)$, which is defined as the inverse of the length of the solution found by the Nearest Neighbor method (1/Lnn)[5]. Additionally, this length $\operatorname{lnn}(L=$ length) can be multiplied by the number of nodes of the problem, decreasing even more the initial pheromones (1/n.Lnn). Therefore, the oldest information will gradually assume an increasing smaller weight in the current decision of each ant so that better solutions arise.

However, the main difference between algorithms is the decision rule of ants. In ACS, this decision rule works simultaneously with the probabilistic rule (breaking) of AS and with the deterministic rule (exploratory). There is a new parameter called $q 0$, which ranges from 0 to 1 and defines the exploring power of new paths. A random number $q$ is then selected, and if this number is greater than $q 0$, the decision rule of the ant is probabilistic, using expressions (1) and (2), but with exponent $\alpha$ of variable $\tau i j$ equal to 1 . On the other hand, if $q$ is less than $q 0$, the decision rule of the ant is deterministic, based on knowledge available in the form of deposits of pheromones and distances. Thus, the decision rule of the ant is, for all $j$ belonging to $N_{i}{ }^{k}$. Expression 5 defines that the ant will choose node $j$ that maximizes the value of $a_{i j}$.

$$
p_{i j}^{k}(t)=\left\{\begin{array}{c}
1, \text { se } j=\arg \max a_{i j}, \quad \text { where }_{i j}=\frac{\left[\tau_{i j}(t)\right]\left[\eta_{i j}\right]^{\beta}}{\sum_{l \in N_{i}}\left[\tau_{i l}(t)\right]\left[\eta_{i l}\right]^{\beta}} \\
0, \text { otherwise }
\end{array}\right.
$$

The ACS was the basis for the development of MACS-VRPTW, which will be seen in the next section and is applied to the vehicle routing problem with time windows.

\section{MULTIPLE ANT COLONY SYSTEM (MACS)}

Proposed by Gambardella et al. [4], MACS-VRPTW is an extension of the ACS for the vehicle routing problem with time windows. Its distinguishing feature is the treatment of multiple objectives, which are to minimize the amount of vehicles and total distance traveled. 
In this case, the first objective has priority over the second. This model uses two ant colonies, where each one seeks to optimize one of the objectives of the problem.

As proposed by Gambardella et al. [4], the algorithm should use parallel computing, where both colonies would be active and searching for better solutions at the same time. In order to simplify this process, as proposal of [5], the following MACS-VRPTW routine algorithm is presented, working with cycles (Fig. 1).

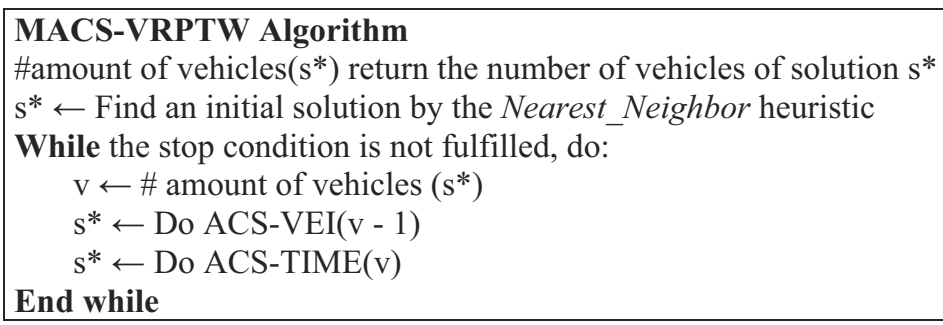

Fig. 1: MACS-VRPTW Algorithm

Initially, a feasible solution to the VRPTW is obtained by the heuristic nearest neighbor, which is used as initial reference to reduce the search time by MACS-VRPTW. So, the solution is improved by both colonies. Within an iterative process, the initial solution is firstly improved by the ACS-VEI algorithm (Fig. 3), in the attempt of finding a feasible solution that has fewer vehicles than the current solution. Soon after, the solution found is used by the ACS-TIME algorithm (Fig. 2), which seeks to find a feasible solution that minimizes the total time spent by a given number of vehicles found by the first colony. After the execution of the second algorithm, the cycle is restarted and continues until some end criterion is met. For example, this criterion may be the number of iterations.

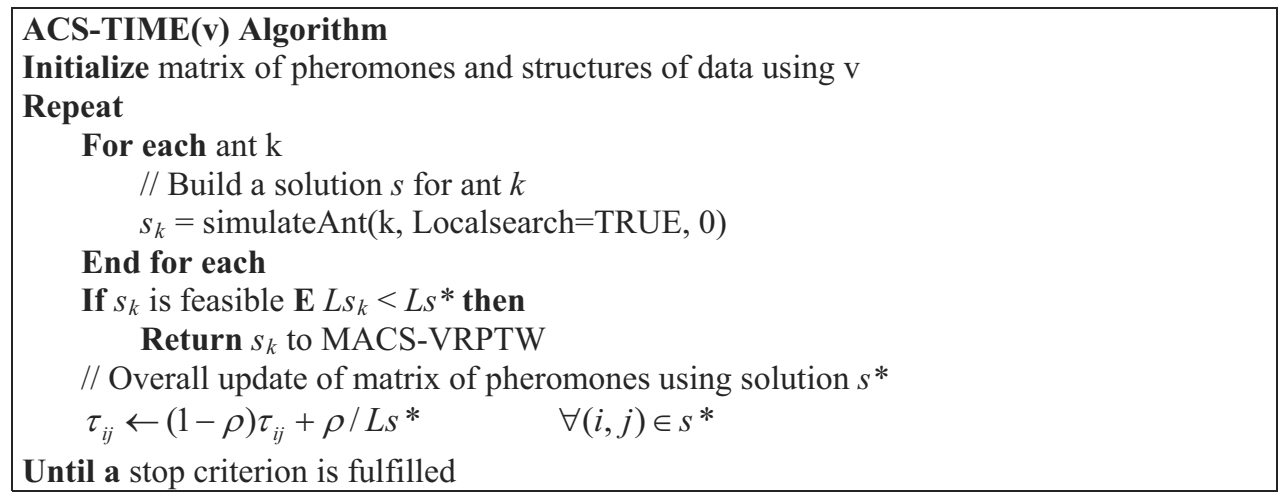

Fig. 2: ACS-TIME algorithm 


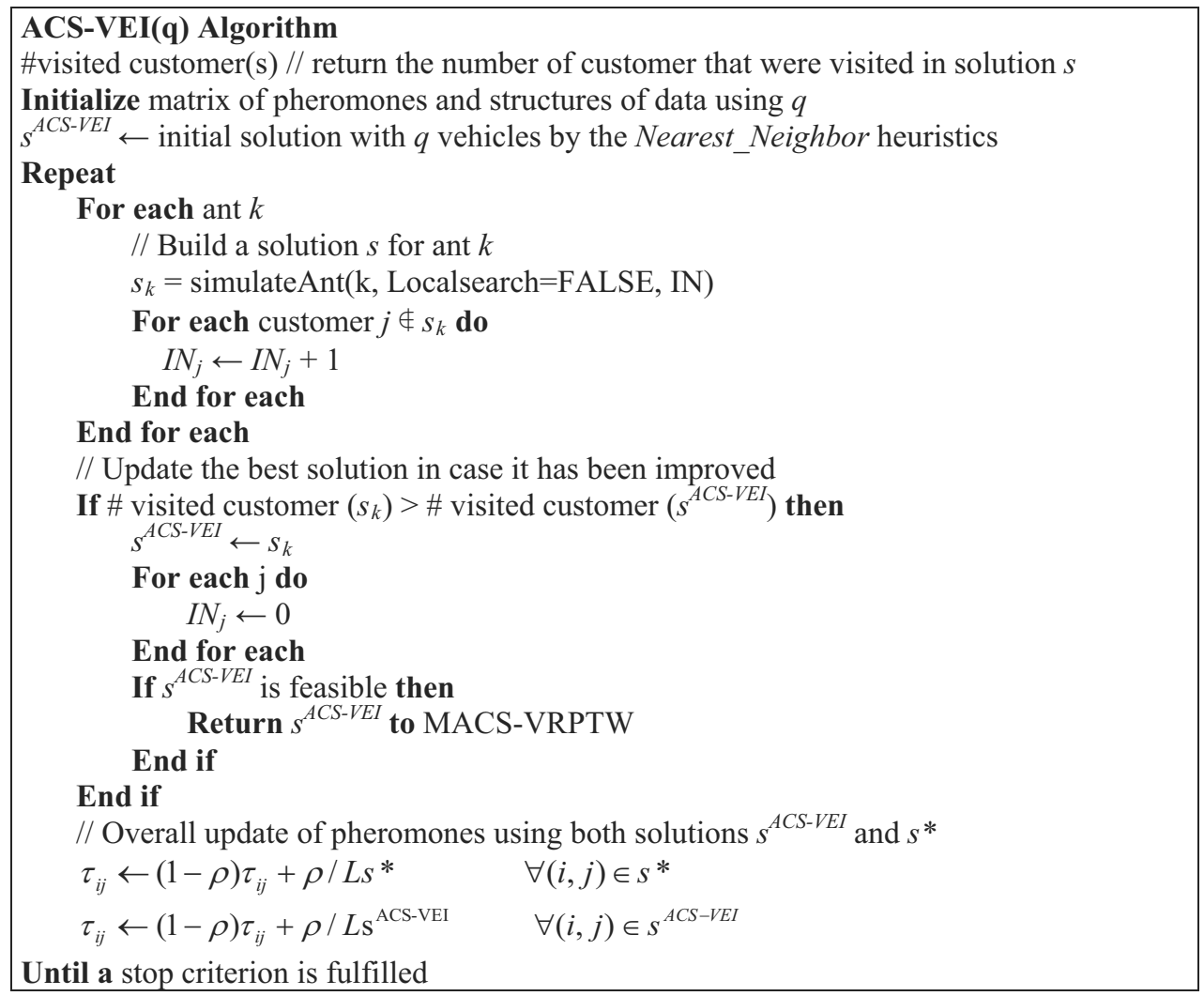

Fig. 3: ACS-VEI algorithm

Both colonies use independent pheromone deposits, but they communicate through the sharing of the best solution found up to the moment, which operation is managed by the MACS-VRPTW.

For the generation of the paths traveled by each of the ants, the simulate ant algorithm is used, which is similar to ACS for TSP. However, since the VRP involves multiple routes, and no longer a single path through all nodes, and adaptation for this problem needs to be done. This is done by including a virtual deposit for each vehicle used in the problem, which are identical copies of the actual deposit. Thus, the operation of ACS in VRP can be equivalent to TSP, resulting in a unique path.

The basic idea of the MACS-VRPTW algorithm was described above, but its implementation has many peculiarities that need to be seen in more details, which can be attained in works of Gambardella et al. [4] and [5], which were used as basis for the implementation of this algorithm. 


\subsection{Implementation of MACS-VRPTW}

In the work of [5], the MACS-VRPTW algorithm was implemented with a high-level programming language: Matlab. The authors reported that the algorithm demanded very long computational time to solve relatively small problems. For example, a problem with 50 nodes demanded about 20 to 22 minutes. To reduce this time, the authors suggest the use of some lower-level programming language, when compared to Matlab. Following this suggestion, the Java programming language was used to efficiently implement this algorithm.

\section{COMPUTATIONAL RESULTS}

The purpose of this section is to show the performance of MACS-VRPTW as for the quality of the solution. A set of problems was used to test this model. The algorithms were run on a computer with Intel Core Duo 1.66GHz processor and $1 \mathrm{~GB}$ of RAM, under WinXP.

The problems adopted for the validation of the algorithms are the 6 instances presented by Solomon [6]. These instances are divided into 3 groups: C, where customers are clustered, in other words, they are geographically distributed into groups of customers close to each other, $\mathrm{R}$, where customers are randomly distributed without forming groups and far from each other and $\mathrm{RC}$, where there is a mixture of the previous groups. All instances involve 25 and 50 customers and were executed thirty times each.

For the application of the MACS-VRPTW algorithm to problems, the parameters rho = 0.1 , beta $=1, q 0=0.9$ were defined, and the parameters $\mathrm{a}, \mathrm{b}$ and $\mathrm{c}$ of the Nearest Neighbor were set equal to 0.6, 0.2 and 0,2 respectively. Each simulation of ACS-TIME and ACS-VEI functions was made up to 20 iterations with $\mathrm{k}=10$ ants each.

A set of problems obtained in [5] was used to test the model. These problems are instances developed by Solomon, which were tested by [5]. Table 1 shows the results for the performance of the algorithm applied to instances involving 25 and 50 clients.

Table 1: Results of instances and average execution time

\begin{tabular}{|l|r|r|r|l|r|r|r|r|r|r|}
\hline \multirow{2}{*}{ Name } & \multirow{2}{*}{ Customers } & \multicolumn{2}{|c|}{ Best Solution } & \multicolumn{3}{|c|}{ Matlab } & \multicolumn{3}{|c|}{ Java } & \multirow{2}{*}{ NT } \\
\cline { 3 - 12 } & & DT & NV & DT & NV & TM (s) & D & NV & TM (s) & \\
\hline R101 & 25 & 617.1 & 8 & 616.38 & 8 & $\mathbf{1 5 8 . 1 4}$ & 616.34 & 8 & $\mathbf{2 . 3 6 5}$ & 66 \\
\hline R201 & 25 & 463.3 & 4 & 550.88 & 2 & $\mathbf{7 6 . 1 2 7}$ & 549.77 & 2 & $\mathbf{1 . 2 6 5}$ & 60 \\
\hline C101 & 25 & 191.3 & 3 & 191.42 & 3 & $\mathbf{1 9 4 . 2 6 1}$ & 191.42 & 3 & $\mathbf{2 . 4 2 1}$ & 80 \\
\hline RC101 & 25 & 461.1 & 4 & 461.85 & 4 & $\mathbf{1 0 4 . 4 9 6}$ & 458.28 & 4 & $\mathbf{1 . 6 4 5}$ & 63 \\
\hline R111 & 25 & 428.5 & 5 & 475.30 & 4 & $\mathbf{6 4 . 4 0 8}$ & 458.44 & 4 & $\mathbf{1 . 0 4 7}$ & 61 \\
\hline R103 & 50 & 772.9 & 9 & 896.34 & 8 & $\mathbf{1 . 3 6 6 . 2 0 9}$ & 896.34 & 8 & $\mathbf{1 1 . 3 5 1}$ & 120 \\
\hline
\end{tabular}

$\mathrm{DT}=$ distance, $\mathrm{NV}=$ number of vehicles used, $\mathrm{AT}=$ average processing time, $\mathrm{NT}=\mathrm{TM}_{\text {(Matlab) }} / \mathrm{TM}_{\text {(Java) }}$ 
As can be seen in Table 1, the best solutions generated by MACS-VRPTW developed in Matlab and Java have values very close to the best results found in literature and in some cases, the optimal solution was found. Thus, considering that the best solutions from literature were obtained by different algorithms, each exploring the specificities of a particular instance or set of instances, the algorithm developed was able to produce fairly good final solutions.

It is also observed that the program developed in Java solved the instances with 25 nodes with computational time between 61 and 80 times shorter than the program developed in Matlab. For instances with 50 nodes, this number nearly doubled, obtaining solutions with computational time 120 times shorter.

\section{CONCLUSIONS}

This paper proposed an efficient algorithm based on the metaheuristic multiple ant colony system (MACS) to solve the vehicle routing problem with time windows (VRPTW). A solution algorithm was proposed as a way to understand the metaheuristic functioning more deeply. Through the application of the algorithms to 6 instances in literature, it was possible concluding that the models are really able to find a solution close to optimal, or even to itself and that the algorithm proved to be very efficient to obtain solutions in reduced time.

\section{REFERENCES}

1. Dorigo, M.; Maniezzo, V.; Colorni (1991) A. Positive feedback as a search strategy. Milão: Dip. di Elettronica e Informatica, Politecnico di Milano, Itália, Relatório Técnico.

2. Dorigo, M.; Gambardella, L. M. (1997) Ant Colonies for the Travelling Salesman Problem. Biosystems, Vol. 43, No. 2. pp. 73-81.

3. Bullnheimer, B.; Hartl, R. F.; Strauss, C. (1999) An improved Ant System algorithm for the Vehicle Routing Problem. Annals of Operations Research, Vol 89, No. 0. pp. 319-328.

4. Gambardella, L. M.; Taillard, É.; Agazzi, G. (1999) MACS-VRPTW: A Multiple Ant Colony System for vehicle routing problems with time windows. In: New Ideas in Optimization. Londres: McGraw-Hill, pp. 63-76.

5. Santos, R. L. (2006) Uma Aplicação de Algoritmos de Colônias de Formigas em Problemas de Roteirização de Veículos com Janelas de Tempo. Rio de Janeiro, 86p. Dissertação de Mestrado - Departamento de Engenharia Industrial, PUC-Rio.

6. Solomon, M. M. (1987) Algorithms for the Vehicle Routing and Scheduling Problems with Time Windows Constraints. Operations Research, 35, 2, 254-2. 


\title{
THE NEED FOR INTERNET-BASED, LIGHT-WEIGHT TRACKING AND ERP SYSTEMS FOR SCM IN SME -INTENSIVE MULTI- COMPANY NETWORKS - THE CASE OF THE FINNISH FURNITURE INDUSTRY
}

\author{
M. Ehrs and M. Suorsa \\ Department of Production \\ Faculty of Technology \\ University of Vaasa \\ P.O.Box 700, Vaasa 65101, Finland
}

\begin{abstract}
The purpose of this paper is to illustrate the tracking and Supply Chain management (SCM) needs of Small and Medium-sized Enterprise (SME) -intensive multi-company networks, and investigate the solutions available to the same. The case supply chains studied are two major Finnish furniture retail store chains, including a multitude of SME suppliers ranging from micro-production units to medium size enterprises. The findings from these chains are viewed in light of a project aimed at identifying and piloting the next generation of SME-oriented ERP systems.

The conclusion of the work is that while current SCM and tracking system are cumbersome for the average SME to implement and upkeep, a new generation of internetbased, light-weight, easy-to-use-and-edit tracking and ERP systems could become the answer for such companies.
\end{abstract}

\section{INTRODUCTION}

In all supply chains, there are gains to be made from the better flow of information, up and down the stream of the flow of products. The internet has brought forth numerous possibilities to increase this flow of information, and encouraged companies to closer integration of their information services (IS). However, in the midst of all this development, one group of 
businesses still struggle to attain the benefits of closer IS integration - the SME:s and the SME-intensive supply chains or multi-company networks.

The research questions to be answered in this paper are: what kinds of tracking and SCM data solutions (e.g. product tracking, shared ERP data or other SCM software) could be implemented to benefit SME-intensive multi-company networks, such as those in the Finnish furniture industry? And how to make such solutions work specifically in the SME-intensive environment?

The method used to collect and assess the need for SME-focused tracking and SCM software involved interviews and discussions with key managers and operatives in two significant supply chains of the Finnish furniture industry. Both suppliers and retailers are represented in these supply chains. The findings from these interviews are discussed in the light of knowledge from a current Network Resource Planning (NRP) -project, which in turn derives its data from surveys done in co-operations with local Finnish businesses, on the expectations and options for future ERP solutions. [1]

\section{THE CASE SUPPLY CHAINS - CURRENT SITUATION, AMBITIONS}

The two case networks consist of the retailer chains - two major Finnish furniture store chains - plus their domestic first- and second-tier suppliers. The supply systems (at least for larger items) are similar: in both cases, the retail stores receive the end customers' orders and payment, and then the products are made to order by the chains' first tier suppliers. The second tier suppliers, in turn, make components or custom products for the first tier supplier. The retail chain companies are big - both have a significant market share in the Finnish furniture industry, albeit in somewhat different price segments - but their first tier suppliers are most often small (10-50 workers), and the second tier suppliers mostly micro production units with only a few employees.

While the these networks in fact do consitute supply chains, there is quite a low degree of common planning and integration of information flow: the order situation of the retail chains is totally unknown to the second tier suppliers, and the first tier suppliers do not consider themselves to be an integral part of the logistical decision making process of the retail chains. Also, the degree of interfirm IS integration is also very low. There are some systems in place to arbitrate the end customers' orders to the first tier suppliers, but they are not generally advanced enough to input information directly into the ERP systems of the suppliers, and the 
information is not passed on direcly to the second-tier suppliers. Much of the supply chains' information is passed by fax, e-mail and phone - including order tracking.

The ERP situation, finally, is succinctly varied. The members of the supply chain use many different ERP solutions, and in the cases of most of the second-tier suppliers - none at all. The small size of the second-tier suppliers make ERP system usage unnecessary, costly and even impossible. Total SCM integration by enforcing a common ERP solution is currently - impossible, because of this fact, and unwanted, because of unwillingness at all levels of the supply chain to tie themselves "irrevocably" to a specific supplier.

However, a greater degree of interfirm IS nevertheless seems necessary, considering the improvement paths of both supply chains. There is investigation in one of the retail chains into implementing a Merge-in-Transit system for some product/order combinations; both retain chains express wishes to gain a greater degree of delivery reliability and the same is in fact even more true for the first-tier suppliers. But what kinds of solutions could satisfy such an ambition, given the current state of the IS situation in the supply chains? A situation that furthermore is extremely common in the SME-intensive supply chains of Finland, and why not the rest of the world?

\section{IS SOLUTIONS FOR SME-INTENSIVE MULTI-COMPANY NETWORKS}

\subsection{Internet based product tracking systems}

One of the basic levels of IS integration - that nevertheless consitutes a great step forward in supply chain integration - is the efficient tracking of products through the chain. This feature is essentail to the improvement of delivery reliability, and especially so when considering Merge-in-Transit - examples of M-I-T implementations that have hinged on the tracking system are given in [2] [3] and [4]. This tracking should not, either, only be based upon intermediary forwarder companies' tracking data - the downstream companies may need more specific knowledge than when a product has has left the supplier's building. Furthermore, the forwarder companies' data is often only available to manual access - no automatic and pro-active supply chain tracking is possible [5].

The automatic and pro-active kind of tracking can generally be achived from two perspectives: the point-to-point system approach (explained further in the next section), and the product centric approach [6]. The Point-to point system, working on the basis of connecting existing ERP systems, has a clear drawback in the multi-company SME-intensive 
network: if all parties are not using ERP:s, the full chain span is not accessible. The transition to linked ERP systems usage in a supply chain should not be a prerequisite to efficient tracking, but rather the next step up.

Product centric tracking systems on the other hand, have proven successful when concerning multi-company networks. Kärkkäinen, Ala-Risku and Främling [5] suggest a solution of forwarder independent tracking systems, based on distributed programming and peer-to-peer information sharing - for instance using java programming to achieve a lightweight system which is easy to install, across the span of the supply chain. This system assigns every product a unique identity - barcode, RFID, or free of choice - and tracks the progress of a product whenever it passes through checkpoints.

A case study of the DIALOG system (a program version incorporating the suggested principles) [7] found the system to be lean, simple to use and capable of handling quite heavy data streams, even at the usage of modest server hardware.

\subsection{Light-weight, Internet based ERP and SCM solutions}

For the continuation of the supply chain integration development, there is the much varied field of SCM data solutions to choose form. A SCM software solution can have many purposes, but commonly it aims to coordinate separate firms' processes - such as purchase order processing, inventory management, sourcing, goods receipts and warehouse management - for the greater efficiency of the supply chain [8]. There are two basic groups of solutions: connected ERP-systems, by the means of Electronic Data interchange (EDI) and stand-alone supply chain spanning solutions that are Intenet-based, but vary in function an purpose [1].

The ERP solution is common, and has the benefit of being automatically incorporated in the bigger ERP solutions: the three most well-known players in the ERP software market (Microsoft, Oracle and SAP AG) all have integrated SCM functions in their software. If software is used that does not include this option, it can be implemented by additional auxiliary programs The oldest method of EDI is the use of Point-to-Point interface modules, that translates the output of one type of ERP to the input of another. The somewhat newer, more flexible method, using Enterprise Application Integration (EAI) instead translates the output into a "central" format, from which other ERP's in turn can retranslate to their own input language. [1] According to Izza, Vincent \& Burlat [9] however, the EAI solution can be 
problematic to implement because of the heteogenity and semantic differences of the member ERP:s.

As for the suitability of this solution to the Multi-company, SME-intensive network? There are freeware, open source ERP solutions available, such as Open ERP. The NRP project tested the connecting of two ERP:s - Microsoft Dynamics Nav (for SME:s) and Open ERP - by means of the Microsoft BizTalk Server -program. The conclusion was that this kind of information interchange is possible for a SME to implement, but ardous and fairly timeconsuming, at least in the initial configutration stages [1]. The mini-SME:s of the second tier would not be able to, nor willing to go through such a process, despite the programs being freeware. On the other hand, Jacobs and Weston [10] predict a greater focus on SME:s in the development path of the ERP developers, something that may bring simpler and lighter commercial versions to the market and end up making this kind of solution more attractive.

The other possibility is stand-alone solutions. SCM software comes in many forms, such as (but not limited to) buziness portals, e-Procurement systems, service registries and XMLbased data exchange webapplications (such as ebXML, RosettaNet, HL7, and cXML) [1][11]. The range is very wide, but this proposes a problem in itself - to effectievly integrate the information stored in different systems can be very difficult. For a more gathered, ERP-like SCM solution, e-SCM/ERP solutions similar in vision to that of the DIALOG system are beginning to pop up [12] (see for instance WebERP and OpenBravo). Panetto and Molina [13] posit that the future of SCM software lie in malleable, and intuitively user friendly software tools that can become an integrating factor, rather than a barrier to development.

The NPR project has striven to chart the identifying factors present in such a new system. The following features were proposed as critical to such a program: 1) the system should be easy to change: when the business changes, the system should follow, not hinder, 2) a normal employee should be able to change the fundamentals of the program, without aid of an ITprofessional (point-and-click interface, drag-and-drop functionality), 3) supply chain information sharing should lie at the very base of the program (accessible through the Internet), 4) the system should be based on open source code for legal sharing of modules and solutions, 5) the system's user interface should be the Internet, 6) the system should be made from scratch, without old remnants of source code as in today's ERP:s, 7) the software should always be up-to-date; if the system is light and Internet based - it will be, 8) the system should support flexible and lean production options, 9) the information database should 
contain highly detailed data, 10) the electronic accountancy and inventory should be closely tied to the physical dimension (by efficient tracking systems) [1].

The NRP project is set to develop a pilot program embodying these principles. If succesfully implemented, such a software solution could prove very benefitial to the mulicompany SME-intensive networks. This because it would encompass many of the factors that are necessary for them, such as as being easy to use, resource light, easy to adapt, based on open source technology and accessible simply through the Internet.

\section{CONCLUSIONS}

Within the furniture supply chain assessment project, the need for a common solution encompassing the requirements of both the supplier SME's and the greater retailer chains was evaluated, and established to be of significant importance to the development path of the two supply chains. The retail chains as well as the SME suppliers have an outspoken need of keeping their incoming and outgoing deliveries Just-it-Time, which is not addressed by their current systems. At the moment, the companies in question utilize a variety of different data solutions, ranging from large-scale to almost non-existent.

Considering this situation, today's standard product tracking and ERP solutions seem illfitted to supply their needs. A first step towards greater supply chain integration seems to be product centric, light-weight product tracking systems, aimed at securing a greater degree of delivery reliability and automatic delivery failure detection.

For further informational supply chain integration (developing the aspects of material and production planning from the point of view of the supply chain) two options seem open to the SME-intensive multi-company networks: supporting the SME:s in adopting freeware, open source ERP solution already existant, or investigating the coming e-SCM/ERP solutions. The NRP project identified ten characteristics of vital to such a solution: e.g. internet-based, lightweight, open source, easy-to-use, etc, for use in a future pilot implementation. For a summary of each software solution cathegory's compliance to these features, see figure 1 . 
TRACKING

\begin{tabular}{|c|c|c|}
\hline Product type & Point-to-Point & Product centric \\
\hline Possible product examples & ERP-EDI & DIALOG \\
\hline Purpose & $\begin{array}{l}\text { Product information } \\
\text { sharing between } \\
\text { companies }\end{array}$ & $\begin{array}{l}\text { Company } \\
\text { independent product } \\
\text { tracking }\end{array}$ \\
\hline \multicolumn{3}{|l|}{ Features: } \\
\hline 1) easy to change & 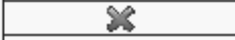 & $\sqrt{2}$ \\
\hline 2) easy to edit & 28 & $?$ \\
\hline 3) Supply Chain focus & 8 & 2 \\
\hline 4) Open source software & 8 & ? \\
\hline 5) Internet user interface & $\$$ & 7 \\
\hline 6) modern core & 8 & 7 \\
\hline 7) easy to update & 2 & $?$ \\
\hline exible and lean production & ? & ? \\
\hline 9) contain detailed data & 3 & 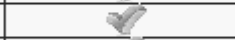 \\
\hline tomatic inventory systems & $\%$ & $\sqrt{7}$ \\
\hline
\end{tabular}

SCM

\begin{tabular}{|c|c|c|c|c|}
\hline Product type & Commercial ERP & XML-based data excha & Free ERP & "future" ERP \\
\hline Possible product examples & $\begin{array}{l}\text { SAP Biz suite, } \\
\text { Microsoft Dynamics, } \\
\text { Oracle e-Business }\end{array}$ & $\begin{array}{l}\text { ebXML, RosettaNet, } \\
\text { HL7, and CXML }\end{array}$ & $\begin{array}{l}\text { OpenERP, Compiere, } \\
\text { GNU Enterprise }\end{array}$ & $\begin{array}{l}\text { WebERP, Openbravo, } \\
\text { Opentaps, Jfire }\end{array}$ \\
\hline Purpose & \begin{tabular}{|l|} 
Coordinate \\
resources, \\
information, and \\
functions within a \\
business \\
\end{tabular} & $\begin{array}{l}\text { Sharing of business } \\
\text { information }\end{array}$ & $\begin{array}{l}\text { Coordinate resources, } \\
\text { information, and } \\
\text { functions within a } \\
\text { business }\end{array}$ & $\begin{array}{l}\text { Coordinate resources, } \\
\text { information, and } \\
\text { functions within a } \\
\text { supply chain }\end{array}$ \\
\hline \multicolumn{5}{|c|}{ Features: } \\
\hline 1) easy to change & $\$ 8$ & 4 & 28 & $\sqrt{7}$ \\
\hline 2) easy to edit & 88 & $\sqrt{2}$ & 23 & $\sqrt{2}$ \\
\hline 3) Supply Chain focus & 8 & P? & $\sqrt{2}$ & 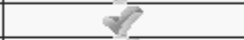 \\
\hline 4) Open source software & 8 & 8 & 8 & 8 \\
\hline 5) Internet user interface & 8 & 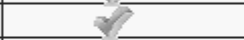 & 25 & 2 \\
\hline 6) modern core & 8 & 2 & 9 & 8 \\
\hline 7) easy to update & 2 & $\sqrt{2}$ & 電 & 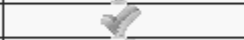 \\
\hline exible and lean production & 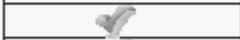 & $\sqrt{2}$ & $\sqrt{l}$ & 9 \\
\hline 9) contain detailed data & $\sqrt{?}$ & 88 & $\sqrt{2}$ & $\sqrt{2}$ \\
\hline tomatic inventory systems & 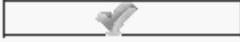 & 30 & $\sqrt{2}$ & $\sqrt{1}$ \\
\hline
\end{tabular}

Figure 1. Summary of evaluation. 


\section{REFERENCES}

1. NRP - Netwok Resource Planning, project plan, unpublished [quoted 12.09.2009], 2009.

2. M. Kärkkäinen, T. Ala-Risku and K. Främling, Efficient tracking for short-term multicompany networks, International Journal of Physical Distribution \& Logistics Management 34, pp. 545-564, 2004.

3. G. Stefansson and B. Tilanus, (2001), "Tracking and tracing: principles and practice", International Journal of Services Technology and Management 2, pp. 187-206, 2001.

4. K.J. van Dorp, Tracking and tracing: a structure for development and contemporary practices, Logistics Information Management 15, pp. 24-33, 2002.

5. M. Kärkkäinen, T. Ala-Risku and J. Holmström, Increasing customer value and decreasing distribution costs with merge-in-transit, International Journal of Physical Distribution \& Logistics Management 33, pp. 132-148, 2003.

6. E. Gattolin, Merge in Transit, A Distribution Method in the Industrial Environment, Thesis work 2008, [online], [cited 12 Sep. 2009]. Available from Internet: <URL:http:/hj.diva-portal.org/smash/get/diva2:3794/FULLTEXT01>, 2003..

7. M. Kärkkäinen, T. Ala-Risku, K. Främling, The product centric approach: a solution to supply network information management problems?, Computers in Industry 52, 147-159, 2003.

8. S. de Burca, B. Fynes and D. Marshall, Strategic technology adoption: extending ERP across the supply chain. The Journal of Enterprise Information Management 18, pp. 427-440, 2005.

9. S. Izza, L. Vincent and P. Burlat. Exploiting semantic web services in achieving flexible application integration in the microelectronics field. Computers in industry 59, pp. $722-$ 740, 2008.

10. J.Robert and T. Weston, Enterprise resource planning (ERP) - A brief history, Journal of Operations Management 25, pp. 357-363, 2006.

11. R. Malhotra, and C. Temponi, Critical decisions for ERP integration: Small business issues, International Journal of Information Management, 2009.

12. C. Tarantilis, C. Kirandoudis and Theodorakopoulos, A Web-Based ERP System for Business Services and Supply Chain Management: Application to Real-World Process Scheduling, European Journal of Operational Research 187, pp. 1310-1326, 2006.

13. H. Panetto, and A. Molina, Enterprise integration and interoperability in manufacturing systems: Trends and issues, Computers Industry 59, pp. 641-646, 2008. 


\title{
STRATEGIC INTERMODAL DECISION MAKING IN BRAZIL
}

\author{
B. Gonçalves, M. B. Costa and M. D’Agosto \\ Transport Engineering Program \\ Federal University of Rio de Janeiro
}

\begin{abstract}
This article presents a stated choice experiment developed to model logistic decision making on a strategic level to select road or intermodal alternatives for general cargo transport in Brazil. It starts from the premise that this kind of decision making involves a tradeoff between logistic cost and service level attributes and a subjective attribute related to the "Brazilian road transport culture", in other words, the natural tendency of cargo owners to use truck transportation. From the modal split model calibrated, it was possible to evaluate the relative importance of the logistic cost, reliability and modal tendency attributes, verifying their possible impacts on the utilization levels of road and intermodal transport.
\end{abstract}

\section{INTRODUCTION}

In Brazil, the use of intermodal transport for general cargo is still incipient. Studies conducted by the National Land Transportation Agency (ANTT) [1], the federal land transportation regulator, indicate that approximately $87 \%$ of general cargo is carried by trucks and trains. Since railway, coastal and river-borne transportation have lower unitary costs than truck transportation, changes in the Brazilian transportation matrix would allow goods to reach end consumers at lower costs.

This article presents a procedure developed through a stated choice experiment (SCE) to propose based on scientific literature, criteria used for decision-making at the strategicplanning level for the choice between road and intermodal transport for general cargo in Brazil. This procedure enables evaluation, in the opinion of cargo owners, logistics planners and experts, of the relative importance of selected attributes for the choice among different logistic alternatives for general cargo transportation. 
The study investigates the hypothesis that there is an unexploited intermodal potential for general cargo transportation in Brazil. To evaluate this hypothesis, we start from the premise that the attributes for analyzing logistics alternatives for the flow of general cargo in Brazil involve a tradeoff between the logistic cost and service level attributes and another attribute related to the "Brazilian road transport culture", which is the natural tendency of cargo owners to use trucking in detriment to other transport modes.

Topic 2 explains the procedure chosen to study the problem, emphasizing the advantages of SCE and the development of the procedure. Topic 3 provides the results of a pilot study, highlighting the utility function calibrated and the sensitivity analysis of selected attributes. Topic 4 presents the final conclusions and recommendations.

\section{PROCEDURE}

According to Schmitz [6], a SCE can be defined as a set of methods to obtain information about the behavior of subjects or possible alterations in their preferences in the face of some hypothetical scenarios. For the author, one of the main characteristics of a SCE is the possibility to deal with the behavior expectation of those interviewed instead of their real behavior, which occurs due to the fact that those interviewed are stimulated to show their preferences facing real and/or hypothetical scenarios pre-defined by the researcher. These scenarios inform those interviewed about the most relevant implications of the proposed options, not only with the intention of creating realistic environments, but also of exploring the tradeoffs associated with the choices made as much as possible. According to Schmitz [6], the main advantages of a SCE are:

- The perception of value attributed by the user to different factors or attributes under analysis;

- The possibility of evaluating qualitative variables, such as reliability and security; and

- The possibility of evaluating still non-existent alternatives, scenarios or situations.

The first stage of a SCE involves the choice of attributes to be evaluated. This is a fundamental step in the modeling, since the attributes must incorporate the main aspects to be evaluated in the problem to be modeled, which in this study is strategic intermodal decisionmaking in Brazil.

The two attributes selected were based on studies of intermodal decision-making by Baumol and Vinod [2], Tsamboulas and Kapros [7] and Novaes et al. [5]. 
Baumol and Vinod [2] demonstrated that the optimum transportation choice involves a tradeoff among freight rates, speed, reliability (expressed by the variations in operational speed) and risks of damage along the way, and that all these attributes can be encompassed in a single attribute: the total logistic cost.

By questioning 92 decision makers of large European companies, Tsamboulas and Kapros [7] concluded that transportation costs and reliability are the key attributes that affect the process of modal choice for intermodal freight transport.

Novaes et al. [5] elaborated from a SCE a method to verify in the opinion of cargo owners and logistic experts, what the relative importance is of freight rates, reliability, time, shipment frequency and security when they have to choose among road, railway or coastal shipping. The results show that freight rates and reliability are the main attributes considered in this choice.

However, in Brazil, a country where general cargo is hauled mostly by trucks, cargo owners naturally tend to opt for road carriage as the first choice. This fact that makes it relevant to consider in this modeling an attribute not considered in any of the researched articles, which we call the modal tendency attribute. Therefore, we designed the experiment with the following attributes:

- Logistic cost: sum of the transportation and inventory costs from the origin to the final destination of the cargo;

- Reliability: measures the mutual confidence level between the cargo owner and trucking company concerning the agreements and deadlines contracted;

- Modal tendency: accounts for the tendency of cargo owners to choose trucking in Brazil.

The second stage of the SCE involves the design scenarios to be analyzed in the interviews. To do this it is necessary to establish varying levels of selected attributes and then to group the alternatives generated. For the attribute logistic cost, we chose two variation levels, since for each existing transportation means (road or intermodal), there already are variations relating to logistic cost. For the reliability attribute, assuming that the same levels of reliability can occur both for road or intermodal transport, we established three levels of variation. The selected attributes and their respective variation levels are presented in Table 1. 
Table 1: Selection and variation level of attributes

\begin{tabular}{|c|c|c|}
\hline \multirow{2}{*}{ Attribute } & \multicolumn{2}{|c|}{ Logistic Alternative } \\
\hline & Road & Intermodal \\
\hline Modal Tendency & 1. Choice for road based alternative & 2. Choice for intermodal alternative \\
\hline Logistic Cost & $\begin{array}{ll}\text { 1. } & 270.00 \text { US } \$ / t \\
\text { 2. } & 260.00 \text { US } \$ / t \\
\end{array}$ & $\begin{array}{ll}1 . & 260.00 \text { US } \$ / t \\
\text { 2. } & 230.00 \text { US } \$ / t\end{array}$ \\
\hline Reliability & $\begin{array}{l}\text { 1. } 5 \% \text { of load delayed } \\
\text { 2. } 10 \% \text { of load delayed } \\
\text { 3. } 30 \% \text { of load delayed }\end{array}$ & $\begin{array}{lr}\text { 1. } & 5 \% \text { of load delayed } \\
\text { 2. } & 10 \% \text { of load delayed } \\
\text { 3. } & 30 \% \text { of load delayed }\end{array}$ \\
\hline
\end{tabular}

The logistic costs presented in Table 1 refer to a hypothetical logistic operation of coffee transportation from the southern region of Minas Gerais state to the Port of Rio de Janeiro. The reliability values are those indicated for logistic operators.

The combination of the level of the attributes for each of the logistic alternatives resulted in 12 different logistic alternatives (Table 2), which we grouped 3 by 3 to generate 4 blocks with 3 alternatives each (Table 3). We group the alternatives so as to guarantee the tradeoff among the analyzed attributes in the comparison of each block's alternatives.

Table 2: Possible Alternatives

\begin{tabular}{cccc}
\hline Alternatives & $\begin{array}{c}\text { Transportation } \\
\text { Means }\end{array}$ & $\begin{array}{c}\text { Logistics Costs } \\
\text { (US } \mathbf{\$} / \mathbf{t})\end{array}$ & Reliabilities \\
\hline \hline 1 & Road & 270.00 & $5 \%$ of load delayed \\
2 & Road & 270.00 & $10 \%$ of load delayed \\
3 & Road & 270.00 & $30 \%$ of load delayed \\
4 & Road & 260.00 & $5 \%$ of load delayed \\
5 & Road & 260.00 & $10 \%$ of load delayed \\
6 & Road & 260.00 & $30 \%$ of load delayed \\
7 & Intermodal & 260.00 & $5 \%$ of load delayed \\
8 & Intermodal & 260.00 & $10 \%$ of load delayed \\
9 & Intermodal & 260.00 & $30 \%$ of load delayed \\
10 & Intermodal & 230.00 & $5 \%$ of load delayed \\
11 & Intermodal & 230.00 & $10 \%$ of load delayed \\
12 & Intermodal & 230.00 & $30 \%$ of load delayed \\
\hline
\end{tabular}

Table 3: Alternative Blocks

\begin{tabular}{cccc}
\hline Blocks & \multicolumn{1}{c}{ Alternatives } \\
\hline \hline $\mathrm{A}$ & 1 & 5 & 12 \\
$\mathrm{~B}$ & 2 & 6 & 9 \\
$\mathrm{C}$ & 4 & 7 & 11 \\
$\mathrm{D}$ & 3 & 8 & 10 \\
\hline
\end{tabular}

We chose a best-worst question (BWQ) type of experiment, whereby a scenario is presented to the interview respondents with three different logistic alternatives, and the respondents indicate the best and worst alternatives in their own opinions. According to Louviere [4], people tend to give their opinions more precisely when they have to choose 
between extreme alternatives - the best and worst alternatives - rather than when asked to place preferential alternatives in order.

\section{RESULTS}

We conducted nine interviews, five with logistic analysts, two with general cargo owners and two with transportation and logistics experts. Those interviews generated 72 choices, which were enough to obtain satisfactory statistical results and to calibrate the utility function.

\subsection{Calibration of the utility function}

We used the LMPC software to calibrate the utility function. The results are presented in Table 4.

Table 4: Pilot study results

\begin{tabular}{|c|c|c|c|}
\hline Attribute & Coeficient & $\begin{array}{l}\text { Student's } \\
\text { t-statistic }\end{array}$ & $\mathrm{R}^{2}$ \\
\hline "Modal Tendency (MT i) & 1.844 & 3.179 & \\
\hline Logistic Cost (LCi) & -14.607 & -5.744 & 0.3506 \\
\hline Reliability $(\mathrm{R} i)$ & 6.658 & 3.784 & \\
\hline
\end{tabular}

In a first analysis, the signs of the coefficient were as expected. The modal tendency and reliability attributes, which are directly proportional to utility, were calibrated with positive signs and the logistic cost attribute, which is inversely proportional to utility, was calibrated with a negative sign.

The Student's t-test showed that all the attributes were significant at $98 \%$, considering a double-tailed test with (n-2) equals 70. Another important statistic is the $\mathrm{R}^{2}$, which was 0.3994. According to Louviere [3], an acceptable $\mathrm{R}^{2}$ interval in a SCE should be between 0.2 and 0.4. This way, we calibrated the utility function shown in equation 1.

$$
U_{i}=5,0644 \cdot M T_{i}-46,228 \cdot L C_{i}+4,2343 \cdot R_{\mathrm{i}_{\mathrm{i}}}
$$

Where: $U_{i}$ - Utility of the logistic alternative ' $\mathrm{i}$ ';

$M T_{i}$-Modal tendency of logistic alternative ' $i$ ';

$L C_{i}$ - Logistic cost of logistic alternative ' $i$ ';

$R_{i}$-Reliability of logistic alternative ' $\mathrm{i}$ '. 


\subsection{Sensitivity Analysis}

The sensitivity analysis of the utility function calibrated aims to verify the impact of changes in the analyzed attributes on the modal split between road and intermodal means. To carry out this procedure, we constructed a reference scenario considering the following hypothetical conditions for the analyzed attributes:

- Modal tendency: cargo owners have the perception that road transportation is more efficient than intermodal transportation and when pure trucking and intermodal service with the same logistic costs and reliabilities are offered, the tendency is that cargo owners will choose trucking;

- Logistic cost: intermodal cost in a determined operation is 5\% smaller than road cost of the same operation;

- Reliability: road transport is more reliable than intermodal transport, which incurs $25 \%$ more delays than road transport.

Assigning the values of the hypothetical conditions of these reference scenarios in the utility function (Equation 1) and applying a binomial logit model, we obtained a reference modal split of $98 \%$ for road and $2 \%$ for intermodal.

With changes in the attributes considered, in comparison with the other attributes analyzed, logistic cost proved to have the biggest impact on the modal split. As can be seen Figure 1, an intermodal operation with a $25 \%$ lower logistic cost than trucking has the potential to capture $100 \%$ of demand.

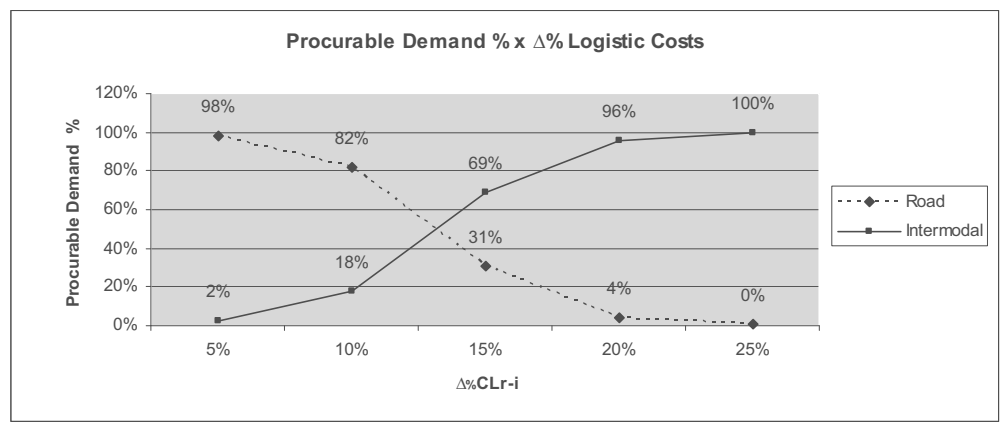

Figure 1: Sensitivity analysis of the logistic cost attribute

Modal tendency also proved to be a highly useful attribute in the choice of a logistic service. The increase in usage of intermodality in Brazil, and the improvement in quality of 
services may influence the perception of general cargo owners of the viability of opting for intermodal service.

The gradual improvement in the intermodal option viability perception rate, to the point where decision-makers become indifferent to the characteristics intrinsic to the intermodal or road services, opting only in function cost and reliability, would increase the market share of intemodality to $78 \%$ against $22 \%$ of the trucking alternative, as can be seen in Figure 2 .

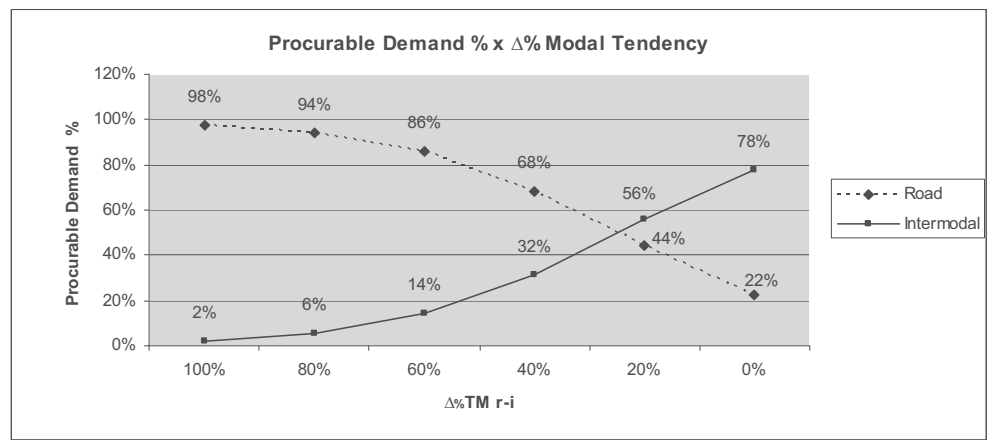

Figure 2: Sensitivity analysis of the modal tendency attribute

Increases in the reliability rates of the intermodal services offered did not have a great impact on the market share of intermodal transportation. Figure 3 shows that if the reliability levels of the intermodal alternative reached those of trucking, the latter would be able to capture only $6 \%$ of the general cargo analyzed.

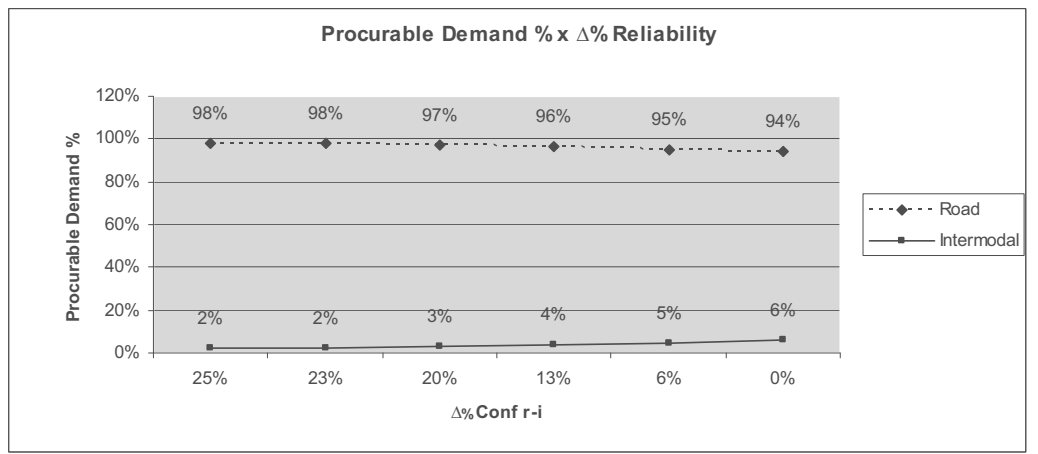

Figure 3: Sensitivity analysis of the reliability attribute 


\section{CONCLUSIONS}

We believe that the initial goal of the article, to present a procedure developed through SCE to identify criteria for decision-making at the strategic-planning level for the choice between road and intermodal transportation of general cargo in Brazil was reached.

The sensitivity analysis of the logistic cost, reliability and modal tendency attributes showed that logistic cost is the main attribute in the strategic-level choice of the method of general cargo transportation.

The modal tendency attribute, although it is subjective, could be measured and had less importance in the kind of modal choice analyzed.

The reliability attribute demonstrated small significance in the calibrated model, because according to the respondents, the lack of reliability caused by delays can be equated with higher security costs, which raise the logistic costs.

We hope this study has contributed to reinforce the importance of logistic cost analysis in the planning of new intermodal services for general cargo transportation in Brazil, which once implemented can help gradually change the "Brazilian road transport culture", thus making it possible to build a more balanced and efficient transportation matrix.

\section{REFERENCES}

1. ANTT, Logística e Transporte para Produtos de Alto Valor Agregado no Contexto Brasileiro. Unpublished study, 2004.

2. W.J. Baumol,., H.D.Vinod, An Inventrory Theoretic Model of Freight Transport Demand, Management Science, n.16, pp. 413-421, 1970.

3. J.J. Louviere, Stated Choice Methods - Analysis and Applications, Cambridge University Press, 2000.

4. J.J Louviere, D.A. Hensher, What you don't know might hurt you: Some unresolved issues in the design analysis of discrete choice experiments. Envirionmental \& Resource Economics, 34, pp. 173-188, 2006.

5. A. G. Novaes, B. Gonçalves; M. B. Costa; S.Santos, Rodoviário, Ferroviário ou Marítimo de Cabotagem: O Uso da Técnica de Preferência Declarada para Avaliar a Intermodalidade no Brasil. Transportes (Rio de Janeiro), v. XIV, pp. 11-17, 2006.

6. R. Schmitz, Uma contribuição Metodológica para a Avaliação da Tarifa de Pedágio em Rodovias. Doctoral Thesis, UFSC, Florianópolis, 2001. 
Gonçalves, Costa \& D’Agosto

7. D. A Tsamboulas, S Kapros, Decision-Making Process in Intermodal Transportation, Transportation Research Record, n. 1707, pp. 86 -93, 2000. 


\title{
GREENER WAREHOUSES THROUGH INCREASED EFFICIENCY
}

\author{
G. Dukic ${ }^{1}$, T. Opetuk ${ }^{2}$, V. Cesnik ${ }^{3}$ \\ ${ }^{1}$ University of Zagreb, FSB, Industrial Engineering Department, Zagreb, Croatia \\ ${ }^{2}$ Koncar D\&ST d.d., Zagreb, Croatia \\ ${ }^{3}$ P.Z. Auto d.o.o., Zagreb, Croatia
}

\begin{abstract}
As a way to demonstrate a commitment to sustainability, green supply chain management is gaining popularity all over the world. Warehouses, as an imortant part of supply chains, are not excluded. However, wider adoption of green warehousing depends also on it's contribution to better economic performances and competitiveness. Hopefully, increasing warehousing efficiency could be in correlation with decreasing energy consumption, therefore simultaneously greening warehouses too. In order to improve warehousing efficiency there are many methods, models and technologies developed and used. Since in most warehouses the biggest potencial lies in orderpicking, this paper presents an overview of order-picking methods and technologies and their potentials in improving order-picking efficiency, based mainly on reducing traveling distances.
\end{abstract}

\section{INTRODUCTION}

Nowadays there is more and more ecological awareness among people and every day there are more people who think and act green. Apart from end consumers, green thinking emerged also in the various initiatives adopted by companies, driven by environmental regulations (legislation), environmental concerns of their customers (marketing) and environmental impact of their production activities (ecological awareness). The concept that encompasses environmental initiatives in all stages of supply chain is called Green Supply Chain Management (GSCM), defined in [1] as integrating environment thinking into supply chain management, including product design, material sourcing and selection, manufacturing processes, delivery of the final product to consumers, and end-of-life management of the product after its useful life. Despite GSCM is evidently gaining popularity all over the world, 
to be fully adopted by organizations, the greening of supply chains should contribute to better economic performances and competitiveness (economy). Therefore it is necessary to understand the elements and roots of the concept, with positive linkage between environmental impact and economical performances and competitiveness.

Green warehousing is definitely a part of the broader picture of green supply chain management, and lately many distribution centers and warehouses around the world are aiming green, "faced with a lot of tough choices between economy or eco-friendliness, discovering that much of good logistics engineering is not only compatible with greener business practices, it's actually synonymous with it [2]". Improving warehouse efficiency by various methods and technologies confirms this quoted sentence, at least in the case of orderpicking presented in this paper.

\section{GREEN WAREHOUSING}

Environmental awareness and ecology are not so new in industrial systems and supply chains. Taking a look into field of Industrial ecology, one could conclude that Industrial ecology and green supply chain management are practically the same thing with a difference in scope. While Industrial ecology is mainly a field of study and research for a cleaner manufacturing processes, GSCM is a field of implementation of green thinking in all the segments of companies' supply chain activities.

To highlight the segments of GSCM as they often appear in literature as methods or approaches to sustainability in supply chains, definition of Supply Chain Management (SCM) - "supply chain management encompasses the planning and management of all activities involved in sourcing and procurement, conversion, and all logistics management activities", as well as definition of logistisc - "that part of Supply Chain Management that plans, implements, and controls the efficient, effective, forward, and reverse flow and storage of goods, services, and related information between the point of origin and the point of consumption in order to meet customers' requirements" are used. Making SCM green is simply implementing environmental thinking into its activities. Focusing on the three basic groups of activities from the definitions - sourcing and procurement, conversion (operations) and logistics activities, green supply chain management could be illustrated as in Figure 1.

Green warehousing is a relatively new approach which implements the greening into warehouses and distribution centers. There are many elements that you can implement in a 
warehouse, like using an energy efficient lightening, using doors with sensor, using wind turbines or/and solar energy, using a sensors for the lightening so the light is turned on only in the passage/area where needed, using ventilators to push hot air from the top to the bottom of a warehouse, using building materials which are better insulator and/or recyclable, using equipment with less carbon emission and less energy consumption, using returnable/recyclable containers and packaging materials, implementation of paperless warehouse management system (WMS) etc. In short, each element which reduces energy consumptions, carbon emmission, material usage and waste is a greening element.

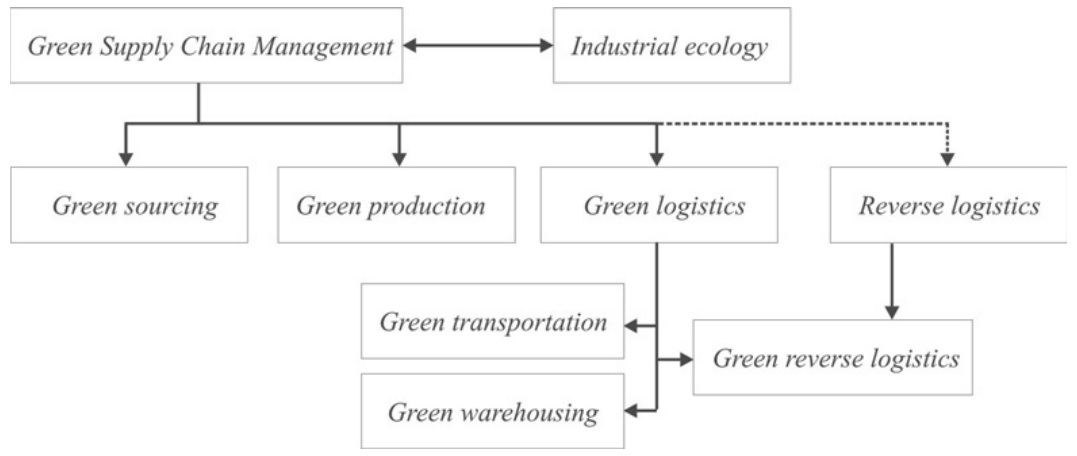

Fig. 1: The segments of Green Supply Chain Management

\section{ORDER-PICKING EFFICIENCY FOR GREENER WAREHOUSING}

\subsection{Order-picking process}

Order-picking process, defined as the process of retrieving items from storage locations in response to a specific customer request, is the most laborious and the most costly activity in a typical warehouse, with up to $55 \%$ of warehouse total operating costs [3]. With a direct link with speed of delivery, it influences service level too. Therefore, it is very important to put some efforts to improve efficiency, which is hopefully possible using appropriate operating policies. The research in this area has grown rapidly and considerable literature exists on various methods of picking an order as efficiently as possible [4]. The time to pick an order can be divided on three components: time for traveling between items, time for picking the items and time for remaining activities. The fact that about $50 \%$ of total order-picking time is spent on travelling [3] gives a potential to improve order-picking efficiency by reducing travelling distances. Most methods of improving operational efficiency of order-picking focuses on reducing travel times, and can be categorized into one of three groups of operating 
policies: routing, storage and batching. The performances of those methods depend greatly on various parameters. Therefore it is important to have deeper insight into performances, as well to understand mutual interactions of various methods in combination.

There are also technology achievements that significally aid the order-picking process. Using Warehouse Management System with RF, voice or pick-to-light system makes possible further improvements in efficiency - raising productivity and improving accuracy of picking.

The short overview of order-picking methods and technologies given further is aimed to present the possibilities and potentials in reducing routes for order-pickers, simultaneously making warehouses greener and more sustainable.

\subsection{Order-picking methods, layouts and technologies}

Routing methods determine the sequences and routes of traveling, trying to minimize total travel distances. Various methods (policies) are developed and used in practice, ranging from the very simple to the slightly more complex heuristics, as well as optimal algorithm. The performance of heuristics depends on the particular operating conditions of the system under study due to their definitions. According to one case study [5], with routing order-pickers efficiently using routing methods it is possible to obtain a reduction between 17 and $34 \%$ in traveling distance. The amount of reduction depends naturally on method used in partucular situation. All heuristics by their definitions have some restrictions of creating a route. An optimal algorithm results in a shortest possible, thus optimal route. However, in practice heuristics are predominantly used to route order-pickers. The reason that particular heuristic policy in some situations may provide near optimal solutions and avoid the confusion inherent in optimal solutions is true, but in the other hand in some other situations it could perform badly. Therefore, it is important to know in what situations some heuristics are good or bad. Even more, which are, and how much, better than another. For more detailed overview of routing methods and some results of performance analyses readers are directed to various references listed in [4].

Storage methods, assigning items to storage locations based on some rule, could also reduce travel distances compared to random assignment (where items are stored in any available location by randomized rule). Items could be assigned to warehouse storage locations based on popularity, demand, size, hazard etc. In order-picking systems, storage methods are usually based on rule of assigning the frequently accessed items to the locations 
near depot (like volume-based storage policy or Cube-per-order index based storage policy). There are several different types (patterns) of storage used in practice in order-picking systems. The performance of a particular storage type could greatly depends on the routing method implemented. The question is which type of storage suites the best particular routing method. More details of the evaluation of storage methods and performance analyses of routing methods in combination with different types of storage are given in [6], as well as in various references listed in [4]. Large savings are possible using particular storage method, achieving in some cases $45-55 \%$ of travel distance reduction compared to a random storage.

Methods of organization of order-picking (pick strategies) determine how orders are picked in warehouses. Most basic method is single order-picking. Pickers pick one customer order at a time (in one route). This method can work well in operations with a small total number of orders and a high number of picks per order. Operations with low picks per order will find the travel time excessive. In batch picking, multiple customer orders are grouped into batches - picking orders. Therefore, the items from several customer orders are picked in one route, which generally reduces the travel distances per order. There are several orderbatching methods (algorithms) developed and used in practice, from very simple where algorithm adds orders to a group in a sequence they have arrived, to more complex algorithms intended to combine received orders in groups in such way that overall travel distance is reduced. For an good overview of many different order-batching algorithms readers are referred to [7], while the performance analyses of order-batching in combination with routing methods and storage methods are presented in [8] and [9]. The potential savings using orderbatching in comparison with single order-picking (picking by order) depend mostly on the number of customer orders per group, and ranged from cca. 40 to $70 \%$ in conducted simulations for random storage. The analysis of orderbatching algorithms with volume-based storage showed that savings are cumulative, with potential savings in travel distances up to and even over $80 \%$ compared to random storage and single order-picking.

Evaluation of order-picking methods showed that layouts of order-picking area have significant influence on resulting traveling distances. Traditional warehouse/order-picking area layouts are layouts we could find today in majority of warehouses. The basic form is with parallel aisles, a centralized depot (pick up/delivery point), and two possibilities for changing aisles, at the front and at the rear of warehouse. For a given storage capacity, one can find optimal layout regarding number and length of aisles [10]. Results of previous 
researches showed also that adding one or more cross aisles (in this case we refer to a layout with multiple cross-aisles) could benefit the total traveling distances, and that is also possible to find optimal number of cross aisles which generally decreases the picking travel distance by $20-30 \%$ of associated route in layout with no cross aisles [11]. Additionally to traditional layouts of order-picking systems, some radically new, innovative warehouse layouts that could reduce retrieval times in pallet picking were also proposed and investigated. In Gue and Meller [12] authors showed that some traditional design assumptions, neither of which is necessary from a construction point of view, limit efficiency and productivity because they require workers to travel longer distances and less-direct routes to retrieve products from racks and deliver them to designated pickup-and-deposit points. So they proposed some new layouts. One was named Flying-V layout, with the expected distance to retrieve a single pallet $8-12 \%$ less than in an equivalent traditional design, depending on the dimensions of the warehouse. In the other one, named fishbone layout, the expected travel distance can be more then $20 \%$ less than in a traditional warehouse. Unfortunatelly, despite the great potential of this new innovative layout designs in reducing traveling distance in pallet picking (single command), it seems that this not hold for case and item picking from multiple locations per route. According to analysis of routing presented in [13], traditional layout with straight, right angled cross aisle performed better then fishbone layout.

The technology that is obviously necessary to be able to implement mentioned methods is Warehouse Management System (WMS) with built-in algorithms for routing, storage and orderbatching. Although we mentioned paperless WMS as an element of greening warehousing, paper-based WMS would be satisfactory. One could imply that paperless WMS encourages greening of warehousing mainly by reducing paper usage in warehouses. However, technologies enabling paperless WMS have also additional capability of greening through increased efficiency, explained hereafter. The three technologies that are used in order-picking systems inherent with paper-less directing order-pickers are RF scanning, Voice Technology and Pick-to-light systems. All three systems can offer increased speed and accuracy compared to paper-based WMS, but choice depends on the nature of the business and products being handled [14]. Increased speed directly improves productivity. For instance, using $R F$ orders are issued on terminal eliminating need to physically take the picklist, while improved accuracy will reduce number of returns in order to correct picking errors. Voice provides significant benefits over $R F$ scanning because it is "hands- and eyes-free". 
Voice operators visually focus on assigned tasks, so errors due to keying in RF hand held terminal are eliminated. RF scanning device limits freedom of hands and makes picking heavy and awkward items more difficult, thus slowing down picking. Pick-to-Light can provide even better productivity than Voice, because picker can see simultaneously all the items to be picked, rather then being given sequential instructions (however, please note that tpick-to-light systems are more likely used for picking small fast-moving items from a relatively small areas, while RF and Voice being more suitable for case picking). Figure 6 shows characteristics of those tree technologies in terms of accuracy and productivity gains over paper-based picking (data from [14]), which are also interesting from the "greening your warehouse" point of view.

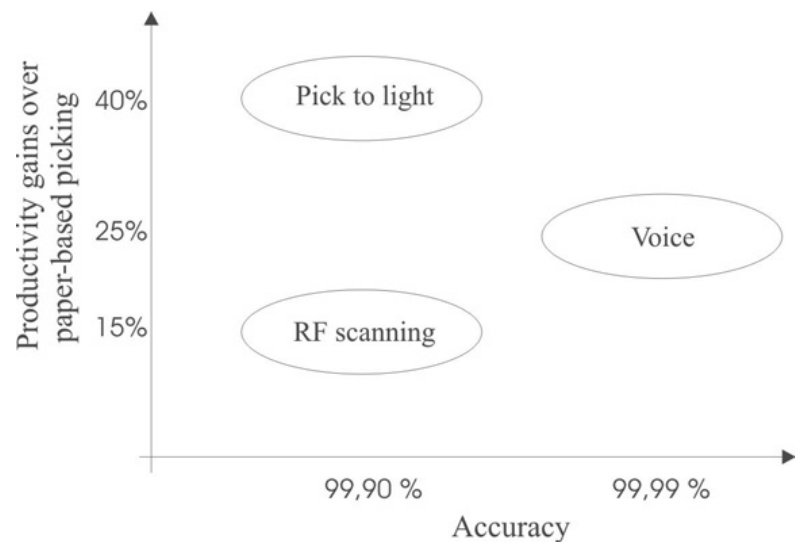

Fig. 6: Comparison of order-picking technologies

\section{CONCLUSIONS}

Making warehouses more green definitely is worth effort from the ecological point of view. But for warehouse managers and company owners can't be viewed without implications on operational and economic performances and competitiveness. In this paper we showed that improving efficiency of order-picking process in warehouses using operational methods and advanced technologies is not in confrontation with greening. Since gains in productivity are mostly achieved by reduction of travelling distances, large energy savings are possible by setting a suitable routing method, storing and picking strategy, choosing the right picking technology and most suitable layout, simultaneously making warehouse efficient and greener. The influence of reduced traveling distances for order-picking on green level depends naturally on type of forklifts used, and could be expressed in saved energy or reduced $\mathrm{CO}_{2}$ 
emission. No matter if new energy efficient electric order-picking trucks are used, reduced operating hours of forklifts due to reduced traveling is still significant contribution to total saved energy and lowered $\mathrm{CO}_{2}$ emission.

\section{References}

1. S.K. Srivastara, Green Supply-Chain Management: A State-of-The-Art Literature Review, International Journal of Management Reviews 9 (1), pp. 53-80, 2007

2. R. Underwood, Green Ware(house) Effect, Area Development Online, Aug/Sep 2008

3. J.A. Tompkins et al., Facilities Planning $2^{\text {nd }}$ ed., John Wiley \& Sons, New York, 1996

4. R. De Koster, T. Le-Duc, K.J. Roodberge, Design and control of warehouse orderpicking: A literature review, European Journal of Operational Research 182, pp. 481501,2007

5. R. De Koster, K.J. Roodbergen, R. Van Voorden, Reduction of walking time in distribution center of De Bijenkorf, in: New Trends in distribution logistics, Springer, Berlin, pp. 215-234, 1999

6. G. Dukic, C. Oluic, Order-picking Routing Policies: Simple Heuristics, Advanced Heuristics and Optimal Algorithm, Strojniški vestnik - Journal of Mechanical Engineering 50 (11), pp.530-535, 2004

7. M.B.M. De Koster, E.S. Van Der Poort, M. Wolters, Efficient orderbatching methods in warehouses, International Journal of Production Research 37 (7), pp. 1479-1504, 1999

8. C.G. Petersen, G.Aase, A comparison of picking, storage and routing policies in manual order picking, International Journal of Production Economics 92 (1), pp. 11-19, 2004

9. G. Dukic, C.Oluic, Order-picking methods: improving order-picking efficiency, International Journal of Logistics Systems and Management 3 (4), pp. 451-460, 2007

10. K.J. Roodbergen, I.F.A. Vis, A model for warehouse layout, IIE Transactions 38 (10), p.p. $799-811,2006$

11. T.S. Vaughan, C.G. Petersen, The effect of warehouse cross aisles on order picking efficiency, International Journal of Production Research 37 (4), pp. 881-897, 1999

12. K.R. Gue, R.D: Meller, Aisle Configurations for Unit-Load Warehouses, IIE Transactions 41 (3), pp. 171-182, 2009

13. G. Dukic, T. Opetuk, Analysis of order-picking in warehouses with fishbone layout, Proceedings of ICIL'08, Tel Aviv, Israel, pp. 197-205, 2008

14. T. Beales, Making an informal choice, Manufacturing \& Logistics IT, February 2008 


\title{
BACK TO BASICS \\ Is Logistics Again About Cutting Costs?
}

\author{
K.Spens ${ }^{1}$ and G.Kovács ${ }^{1}$ \\ ${ }^{1}$ Hanken School of Economics \\ Supply Chain Management and Corporate Geography \\ POBox 479, FI-00101 Helsinki, Finland
}

\begin{abstract}
Logistics underwent different eras throughout the past decades. Each of these eras had their own focal factors, from cost efficiencies from total cost analysis to a shift towards customer orientation, to the rise of globalisation, and recently, green values. This paper presents a study of these factors over the past 15 years and with a glimpse to the future. Of special interest is the focus of logistics during times of recession. The study shows that the focus of logistics follows economic cycles.
\end{abstract}

\section{INTRODUCTION}

Eras [10] and trends [18] have been identified in logistics along with factors [20] or characteristics [10] underlying the development of the field. As in any evolutionary process, events in the macro-environment involving dimensions of business and society drive changes. Influential to the evolutionary process are also technology, shifting business needs, crossfertilization of disciplines, and new research findings [10]. But at any period in the history of logistics, Kent and Flint [10] state that only a few frameworks seem to have guided research. Some examples of dominant themes are the functional perspective that lasted into the 1960s, the integrating and systems view of the 1970s, the customer service focus during that same decade, and the integrated supply-chain management framework of the 1980s. Skjøtt-Larsen [18] puts forward the perspective that there are different trends or as Törnroos et al. [20] label them, factors, that drive theory and practice.

Yet the eras and trends identified so far in literature seemingly focus very much on a linear development of the field and the evolution of logistics thought appears continuous [10]. Nevertheless, one factor or characteristic that is seemingly noted in different time periods is 
the effect of times of recession. Interest in logistics raises in times of recession due to logistics' cost cutting notion. Such times also instigate new approaches and ideas [16]. Based on these notions, this paper aims to explore trends and eras in logistics with a focus on recent developments in the field. After investigating trends in literature, a survey was conducted on the focus of logistics in different time periods.

\section{THE EVOLUTION OF LOGISTICS THOUGHT}

Early logistics literature is predominantly US focused, only in the 1980s did Martin Christopher enter the stage with a book on the development of logistics from a European perspective. From 2000 onwards globalization brings an even more international perspective to logistics. This overview is therefore not comprehensive but rather highlights the development of logistics in an increasingly international environment.

At the turn to the $20^{\text {th }}$ century, attention centred on transporting products from the farm to the point of sale and agricultural economics had a great deal of influence, thus logistics focused on the issue of transportation [10]. The American Marketing Association defined logistics in 1948 as "the movement and handling of goods from the point of production to the point of consumption or use" [9]. The interest in logistical capabilities for moving products more efficiently from production to consumption points did not occur until the mid-1950s as part of the era of "modern marketing" [16]. The first time managers took notice of the benefits of a well-managed logistics operation was after WW II inspired by the logistics success of the military [16]. Nonetheless, from 1945 until the late 1950s, business saw physical distribution as a subset of marketing and viewed it from a functional perspective [16].

In 1956, Lewis et al. [12] introduced the concept of total cost analysis that provided a significant integrative concept to the field of logistics. The study presented total cost as all expenditures required to accomplish a specified logistical mission [19]. The development of this concept provided the framework for the definition of the field and the basis for its decision-making methodology [1]. Other reasons for the awakening of logistics were the recession of 1958 as well as increasing competition during the late 1950s and the 1960s [16]. These reasons caused managers to look for new ways to improve their firms cost positions.

Beginning in the early 1960s, a systems approach was sought, and the term "integrated logistics" appeared in business [19]. There was a shift from physical distribution as the main focus of logistics to an entire system of activities working with and relying on one another. 
This view consolidated the management of both in-bound and outbound transportation, warehousing, inventory control, and materials handling, with logistics spanning over the management of raw materials to the delivery of the final product, thinking about the entire system rather than just one part of it. Logistics management then is the means whereby customer needs are satisfied through the co-ordination of the materials and information flows that extend from the market place, through the firm and its operations and beyond that to suppliers [4]. 1963 also saw the foundation of the first organisation for logistics professionals, the National Council of Physical Distribution (NCPDM).

In the early 1970s, the customer became the primary focus of the firm [10]. As one scholar quoted in the interviews carried out by Kent and Flint [10, p.25] said, his generation "started talking about the function as being not to minimize cost but to maximize profits and start looking at logistics as a way to satisfy the customer." Other significant factors of the 1970s and 1980s were the development of techniques such as MRP, DRP and JIT. Their implementation was largely facilitated by the use of computers and led to a further integration of logistics activities. Cost trade-off decisions could now be made quickly and optimally which improved logistics efficiency and productivity [11].

In the early 1980 s, logistics started to be considered a key means of differentiation for the firm. Graham Sharman's 1984 "rediscovery of logistics" provided evidence of the increasing role of logistics in business strategy [17]. Emerging concepts were integrated supply-chain management, logistics channel management, interorganizational efficiency, environmental logistics, reverse logistics, and a heightened awareness of globalization. Information technology as well as strategy concepts also had a significant influence. A historical milstone in logistics management was Porter's (1985) introduction of the "value-chain" concept, creating awareness that logistics can help firms create competitive advantage [11]. In 1985 the NCPDM even changed its name to The Council of Logistics Management (CLM) to acknowledge the expanding scope of logistics management. In the 1990s, the focus changed from internal efficiency in the logistics function to external relations between the parties in the total supply chain [18], leading to the development of supply chain management (SCM).

Beyond 2000, Kent and Flint [10] called for a deeper understanding of behavioral issues, specifically, customer perceptions of a firm's logistics systems and their related behaviors. Further predictions for this era was for integrated supply chain management and service response logistics. According to Skjøtt-Larsen [18], European companies supplying 
components or systems to multinational companies would be required to participate in global sourcing by their customers. Other trends are a reduction in the supplier base, differentiated supplier co-operation, as well as a virtualization of companies and an increasing requirement of companies on environmental certification [18]. "Greening" comprises all links from the manufacturer of raw materials to the end user and include products, processes, packaging, transport and disposal $[3,18]$. At the same time, a shift in focus from functional areas to cross-business processes including inter-organisational teams, joint product development and shared assets was seen as future enablers of a "frictionless" transition between the links in the total supply chain $[18,7]$. In the end, it is employees and not systems and processes that ensure solutions to logistics tasks and grant competitiveness. Therefore, it is crucial not to underestimate the human and cultural aspects in the implementation of change projects. [18]. Further trends evident for the future are the emerging emphasis on risk management [13]. At the same time, the current economic crisis leads to a rethinking of outsourcing due to high total landed costs [6]. With the current recession and its increasing magnitude, seemingly a new era of heightened interest in cutting costs is emerging [5]. In such a situation it is worth looking back for some clues for the future [22].

\section{RESEARCH METHODS}

This paper builds upon these thoughts and investigates the views of academics and practitioners through exploring logistics trends in different time periods. The focus on this investigation is on the last 15 year period, due to the scarcity of research in the area from this time period. A survey instrument was developed that included the key factors listed in literature for different eras of logistics thought. Respondents were asked to rate the importance of these factors for specific time periods (15/10/5 years ago, now, and in the future). The survey was sent out to Finnish logistics professionals, as Finland has undergone two recessions within these periods, one in the early 1990s (ca. 15 years ago) and another currently in the late 2000s. This setting provides an opportunity for exploring the nature of the evolution of logistics thought.

Finland is one of the most developed countries in the fields of electronic data transmission and automatic recognition [15]. It is to be noted, however, that logistics thought in Finland developed with a time lag to US dominant literature. Interestingly, Haapanen [8] argues that the logistics boom in Finland started as late as in the 1990's with the depression as a driving 
force, even though the concept of logistics had been introduced many decades earlier. To date Finland it can be argued that the state of logistics in Finland has caught up with global developments. Some geographical issues are worth noting, however: the location of Finland as an "island" related to its main supplier bases and customer markets, and the low density of its population spread out over a vast area. Both impact on the importance of transportation costs in the country, which indeed lie over the OECD average [20].

A cross-sectional web-based e-mail survey was sent out to delegates of the 2009 Finnish logistics day. The survey was sent out in March 2009 to 627 of 1000 participants, eliminating students, translators, and guests of participants from the sample. The effective sample size was much lower (520) due to failure messages and a vast number of vacation messages and changes in jobs, in fact the loss of jobs in the economic downturn. Whilst the resulting demographics of respondents is biased towards experienced logisticians, the otherwise problematic issue of "mature respondents" (with 30.7\% of respondents having over 25 years of experience) is not seen as impacting negatively on the survey as experience is at its core. 75 responses were received, accounting for $14.42 \%$ of responses in terms of the effective sample size, though in terms of responses / views of the survey (cf. [14]) it is up to $51.02 \%$.

\section{DISCUSSION OF FINDINGS}

Considering the Finnish environment, it is not surprising that respondents devoted much attention to transportation costs. This factor was indeed the only one rated as important for the time period of 15 years ago. Interestingly, all factors could be confirmed in a principal component analysis. When it comes to trends, the general finding was that more areas were deemed significant with time, and the significance levels (in absolute ratings) increased over time as well. Nonetheless, trends do become evident when looking at the relative ratings of different factors (see Table 1 for the top five factors in each period). Topics such as energy efficiency, corporate social responsibility and green logistics were at the bottom of the lists 15 years ago, whilst energy efficiency ranks second on the list of focal areas in the future. This group of topics undergoes a steady increase in focus, indicating its increase in importance. A service orientation becomes significant already in the 10 years ago period, and similarly climbs up steadily to becoming focal area number one for the future. 
Table 1: Top rated focal areas across the years

\begin{tabular}{|l|lllll|}
\hline Focal area & 15 years ago & 10 years ago & 5 years ago & Now & In the future \\
\hline 1. & $\begin{array}{l}\text { Transportation } \\
\text { costs }\end{array}$ & Cost efficiency & $\begin{array}{l}\text { Transportation } \\
\text { costs }\end{array}$ & Cost efficiency & $\begin{array}{l}\text { Service } \\
\text { orientation }\end{array}$ \\
2. & - & Quality & Customer focus & $\begin{array}{l}\text { Transportation } \\
\text { costs }\end{array}$ & $\begin{array}{l}\text { Energy } \\
\text { efficiency }\end{array}$ \\
3. & - & Time efficiency & Cost efficiency & Time efficiency & $\begin{array}{l}\text { Customer } \\
\text { relations }\end{array}$ \\
4. & - & Flexibility & Time efficiency & Customer & Customer focus \\
5. & - & Transportation & Customer & Customer focus & Quality \\
& & costs & relations & & \\
\hline
\end{tabular}

An interesting drop in focus is to be observed in a customer focus. During both economic downturns (15 years ago and now) cost efficiency indicators take over as primary focal areas. This indicates not just a trend, but a circular development in the focus of logistics that follows the economic cycle and confirms the prediction of a refocus on costs in times of recession (cf. [22]. However, transportation costs sink again to rank 12 for the future. In fact all cost measures (labour costs, transportation costs, cost efficiency) decrease not only in relative but also in absolute ratings as a focus in the future.

Other interesting areas are that of outsourcing and globalisation. Whilst globalisation enters the focus 10 years ago, the trend 5 years ago is a mixed one of globalisation, outsourcing, and a focus on labour costs combined with a closeness to markets and localisation while centralising decision-making. The current trend confirms the focus on centralised decision-making, though both globalisation and outsourcing drop in importance (also in absolute rates) for the future, again confirming a reorientation away from outsourcing [6]. This may be explained by the raise of energy efficiency as a focal area, impacting on the location of production units and the subsequent need for transportation. A subsequent correlation analysis revealed that CSR, green logistics and energy efficiency strongly correlated with risk management (CSR / risk management $t=0.527^{* *}$, significant at 0.01 ). This supports the risk view in literature on CSR in the supply chain.

Interestingly, internal organisational issues such as talent retainment and employee empowerment gain absolute but no relative significance. However, a further correlation analysis showed a strong correlation between talent retainment and service orientation $\left(t=0.370^{* *}\right)$, indicating the importance of talent retainment nonetheless. 
Topics related to supply chain integration are evident already 10 years ago, where IT integration comes up strongly along with supplier relations, though still with a focus on the control of assets while reducing the supplier base. The focus on IT integration is lost over the years but comes up again strongly for the future. Control of assets, however, decreases in importance and is replaced by questions of risk sharing and for the future, financial supply chain management. Interestingly, flexibility correlated with supplier relations $(t=0.397 * *)$ as well as customer relations $\left(t=0.345^{* *}\right)$, supporting a supply chain view in logistics. Moreover, customer perceptions correlated with supplier relations $\left(t=0.337^{* *}\right)$, indicating that customers show an interest in the supply chain beyond their own direct suppliers.

\section{CONCLUSIONS}

The study confirmed the general trends found in literature. However, an interesting conclusion from the refocus on cost factors during times of recession contradicts the view of a linear development of logistics thinking. Rather, the focus of logistics is cyclical and follows economic cycles.

New factors rise with time. For the future, a service orientation is predicted even more, which is facilitated by the human factor of talent retainment as already indicated by SkjøttLarsen [18]. Green issues, as predicted, are also on the rise, particularly energy efficiency entering the scene. Less importance is attributed to globalisation in the future. These two trends may be interrelated as a focus on energy efficiency prescribes a closeness to suppliers as well as markets to eliminate transportation costs.

\section{REFERENCES}

1. R.Ballou, Business Logistics Management. Englewood Cliffs: Prentice-Hall Inc., 1992.

2. D.Bowersox, Logistical Management. New York: MacMillan Publ. Co., 1978.

3. C.Brickman and D.Ungerman, Climate change and supply chain management, McKinsey Quarterly, Jul 2008.

4. M.Christopher, Logistics and Supply Chain Management. Strategies for reducing costs and improving services. London: Pitman Publishing, 1992.

5. D.Court, The downturn's new rules for marketers, McKinsey Quarterly, 2009 (1), pp.6675, 2009. 
6. AK.Goel, N.Moussavi and VN.Srivatsan, Time to rethink offshoring? McKinsey on Business Technology, Winter 2008, pp.32-35.

7. G.Grover, E.Lau and V.Sharma, Building better links in high-tech supply chains, McKinsey on Business Technology, Winter 2008, pp.14-19.

8. M.Haapanen, Yritysjohdon logistiikka. Espoo: Karisto Oy., 1993.

9. J.Heskett, RM.Ivie and NA.Glaskowsky, Business Logistics-Management of Physical Supply and Distribution. New York: The Ronald Press Company, 1964.

10. JL.Kent and DJ.Flint, Perspectives on the evolution of logistics thought, Journal of Business Logistics, 18(2), pp.287-299, 1997.

11. DM.Lambert and JR.Stock, Strategic Logistics Management. 3rd ed. Homewood, Illinois: Richard D. Irwin Inc., 1993.

12. HT.Lewis, JW.Culliton and JD.Steele, The Role of Air Freight in Physical Distribution, Harvard University, 1956.

13. McKinsey Quarterly, Managing global supply chains, Survey on Global Supply Chains, Jul 2008.

14. D.Menachof, BJ.Gibson, JB.Hanna and AE.Whiteing, An analysis of the value of supply chain management periodicals. International Journal of Physical Distribution and Logistics Management, 39 (2), pp.145-166, 2009.

15. S.Nieminen, Editorial, Materiaalitalous 5(3), 1993.

16. RD.Shapiro and JL.Heskett, Logistics Strategy: Cases and Concepts. St. Paul, Minn., West Pub. Co., 1985.

17. G.Sharman, The rediscovery of logistics, Harvard Business Review, 62 (5), pp.71-79, 1984

18. T.Skjøtt-Larsen, European logistics beyond 2000, International Journal of Physical Distribution and Logistics Management, 30(5), pp.377-387, 2000.

19. J.Stock and D.Lambert, Strategic Logistics Management, McGraw Hill, 1993

20. J-Å.Törnroos, K.Haime and V.Ekholm, Geography and logistics - The missing link, Working Paper No. 301, Swedish School of Economics and Business Administration, Helsinki, Finland, 1995.

21. World Bank, Logistics Performance Index, at web.worldbank.org, 2007.

22. RE.Wright, Financial crisis and reform: looking back for clues for the future. McKinsey Quarterly, 2009 (1), pp.98-101, 2009 


\title{
INVENTORY LOCATION PROBLEM WITH STOCHASTIC CAPACITY CONSTRAINTS UNDER PERIODIC REVIEW $(R, s, S)$
}

\author{
Pablo A. Miranda ${ }^{1}$ and Guillermo Cabrera G. ${ }^{2}$ \\ ${ }^{1}$ Industrial Engineering School, ${ }^{2}$ Informatic Engineering School, \\ Network Configuration Research Group \\ Pontificia Universidad Catolica de Valparaiso \\ Av. Brasil 2241, Valparaiso, CHILE
}

\begin{abstract}
In this paper we propose a novel inventory location model with stochastic capacity constraints, based on a periodic inventory control policy. This model allows designing the distribution network for a two level supply chain, addressing warehouse location and customer assignment decisions, taking into consideration several aspects of inventory planning, and particularly for evaluating impacts of inventory control review period into network configuration and system costs. Solution approach to the proposed model is based on an exhaustive algorithm, which found an optimal solution for small instances.
\end{abstract}

\section{INTRODUCTION AND LITERATURE REVIEW}

Distribution Networks Design (DND) is one of the most important problems for companies with the aim of distributing products to their customers. The problem consists of selecting sites to install plants, warehouses, and distribution centers, assigning customers to serving facilities, and interconnecting facilities by flow assignment decisions. This paper considers a two-level supply chain, where a single plant serves a set of warehouses, which serve a set of end customers or retailers. This paper presents a model that, unlike traditional approaches and according to recent inventory location literature, incorporates inventory control policy as a relevant factor which affects directly the DND, according to a periodic inventory control policy (R, s, S) for each Distribution Center (DC), in a single product scenario. This model can be regarded as a variant of the models presented in the literature (e.g. Miranda and Garrido [1] and [2] and Daskin et al. [3]) that considers a continuous inventory review $(\mathrm{Q}, \mathrm{R})$ policy. 
The DND is typically solved as part of a sequential approach that simplifies related tactical and operational issues. Then, omitted decisions are tackled only once DND is already solved. Simchi-Levi[4], Mourits and Evers[5], Bradley and Arntzen[6], Miranda[7], and Miranda and Garrido [8], analyze levels of the decision making related to DND and SCM. Daskin[9], Simchi-Levi et al.[10], and Drezner and Hamacher[11], present detailed FLP reviews and analysis. However, traditional structure of FLP is not useful for considering interactions between facility location and inventory decisions, as well as the impacts of the latter into network configuration. For example, the Risk Pooling effect states that total system safety stock is reduced when customers are served by a smaller amount of warehouses.

Daskin et al. [3] and Shen et al.[14] incorporate a (Q, RP) inventory control policy into the widely studied Uncapacitated Facility Location Problem, while establishing a safety stock at each site. Daskin et al. [3] employ Lagrangian Relaxation to solve the model, while Shen et al [14] reformulate the model as a Set-Covering problem and solve it through a column generation method. Based on the same inventory control policy, Miranda and Garrido[15] consider order quantity for each warehouse as decision variable, and the Capacitated Facility Location Problem (CFLP) as a base framework. Finally, Miranda and Garrido[16],[17] and Ozsen et al [18] handle capacity constraints based on previous inventory-location models.

This paper is organized as follows: section 2 presents and analyzes stochastic capacity constraint under periodic review (R, s, S). In section 3, we propose a model formulation for the problem. Section 4 shows the solution approach and a numerical application. Finally, section 5 presents conclusions and a future research discussion.

\section{INVENTORY CONTROL AND STOCHASTIC CAPACITY CONSTRAINTS}

The model presented by Miranda and Garrido [16] and [17] optimizes warehouse location and customer assignment decisions, taking into account fixed installation, transportation, inventory, and fixed ordering costs. The authors assume each warehouse $i$ considers a continuous inventory review policy, based on a $\left(Q_{i}, R P_{i}\right)$ policy to meet a stochastic demand, with mean $D_{i}$ (units of product per time unit) and variance $V_{i}$. It is also considered that plant takes a lead time of $L T_{i}$ to fill incomings orders from warehouse $i$. A stochastic constraint of inventory capacity is proposed, assuming a maximum inventory level for each warehouse ICap (homogenous). This constraint is based on chance constrained programming and it fixes a maximum probability $\beta$, to violate inventory capacity at peak instants, which occur only when orders arrive to warehouses. This inventory level corresponds to the reorder point $R P_{i}$, 
which is stated for satisfying demand during lead-time at least with a probability of 1- $\alpha$, minus stochastic demand during lead time, plus order quantity, $R P_{i}-S D\left(L T_{i}\right)+Q_{i}$. Thus, inventory capacity constraint can be written as a deterministic nonlinear constraint as follows:

$$
Q_{i}+\left(Z_{1-\alpha}+Z_{1-\beta}\right) \cdot \sqrt{L T_{i}} \cdot \sqrt{V_{i}} \leq I \text { Cap } \quad \forall i=1, \ldots, N
$$

It can be noted that a related more conservative capacity constraint is proposed in Ozsen, et al (2006), which assures in $100 \%$ of cases, that inventory capacity is observed.

However, when a periodic review is considered, particularly assuming an $(s, S, R)$ inventory control policy (Axsäter[19]), capacity constraint cannot be stated at any moment and does not takes the same fashion of equation (1). In an $(s, S, R)$ inventory control policy, inventory levels are reviewed only each $R$ periods (parameter), and if the inventory level is lower than $s$, then an order is submitted in order to reach the objective level $S$. Consequently, order size must consider the well known Under-Shoot magnitude (US), which is the amount of items required in addition to $S-s$, to reach $S$ units of inventory. As in Kiesmüller and Kok [20] and [21], the average Under-Shoot magnitude, as a function of Demand Mean and Variance of a warehouse $i, D_{i}$ and $V_{i}$, and for a review period $R_{i}$, can be computed as:

$$
U_{i}\left(D_{i}, V_{i}\right)=V_{i} / 2 \cdot D_{i}+D_{i} \cdot R_{i} / 2
$$

In terms of inventory capacity constraints, peak inventory levels are not controlled at any moment, but only in specific moments for each review period. The peak inventory level is reached only when orders arrives to the warehouse, $L T_{i}$ time units after the last order, and naturally only if an order was submitted to the central warehouse or plant. Consequently, each time an order arrives to a warehouse the inventory level is:

$$
\underbrace{\left(s-U S_{i}\right)}_{\begin{array}{c}
\text { Inventory level when } \\
\text { an order is submited }
\end{array}}+\underbrace{\left(S-s+U S_{i}\right)}_{\begin{array}{c}
\text { Submited } \\
\text { Order size }
\end{array}}-\underbrace{S D_{i}\left(L T_{i}\right)}_{\begin{array}{c}
\text { Stochastic demand } \\
\text { during Lead-Time }
\end{array}}=\underbrace{S_{i}-S D_{i}\left(L T_{i}\right)}_{\begin{array}{c}
\text { Maximum inventory level } \\
\text { when an order arrives }
\end{array}}
$$

This expression is not surprising, due to when an order is submitted to plant, it is required that total inventory position (on hand plus on order inventory) reaches the level $S_{i}$, and $L T_{i}$ time units later, inventory level is reduced by lead-time demand, $S D_{i}\left(L T_{i}\right)$. Similar to Miranda and Garrido [16] and [17], in this paper we propose that this constraint must be observed for each peak inventory instant (i.e. for each order period) with a fixed and known probability of $1-\beta$, but now assuming a periodic review, as follows:

$$
S \leq I C a p+D_{i} \cdot L T_{i}-Z_{1-\beta} \cdot \sqrt{V_{i} \cdot L T_{i}}
$$

Forehand we define $Q$ as the minimum order size as: 
$S_{i}=s_{i}+Q_{i}$

Consequently, constraint (4) can be written as:

$Q+s \leq I C a p+D_{i} \cdot L T_{i}-Z_{1-\beta} \cdot \sqrt{V_{i} \cdot L T_{i}}$

Finally, the reorder point $s$, is set in order to assure that for each time an order is not submitted (inventory level is larger than s), inventory level is enough to fill demand until the next order is arrived $R_{i}+L T_{i}$ time units, with a probability or service level 1- $\alpha$ :

$s_{i}=D_{i} \cdot\left(L T_{i}+R_{i}\right)+Z_{1-\alpha} \cdot \sqrt{L T_{i}+R_{i}} \cdot \sqrt{V_{i}} \sqrt{ }$

Finally, replacing (7) in (6) inventory capacity constraint can be finally written as:

$Q_{i}+D_{i} \cdot R_{i}+\left(Z_{1-\alpha} \cdot \sqrt{L T_{i}+R_{i}}+Z_{1-\beta} \cdot \sqrt{L T_{i}}\right) \cdot \sqrt{V_{i}} \leq$ ICap

From this equation w estate an alternative order capacity constraint as follows:

$$
Q \leq Q \operatorname{CapAux}=I \operatorname{Cap}-D_{i} \cdot R_{i}-\sqrt{V_{i}} \cdot\left(Z_{1-\alpha} \cdot \sqrt{L T_{i}+R_{i}}+Z_{1-\beta} \cdot \sqrt{L T_{i}}\right)
$$

\section{MODEL FORMULATION}

In this section, and according to previous inventory control assumption, we describe the proposed Inventory Location Model with Stochastic Constraints of Inventory Capacity under Periodic Review (ILM-SCC-PR), as a stochastic non-linear mixed inter programming model. Based on a periodic $(s, S, R)$ inventory control policy, the safety stock to be included in the objective function is the average inventory level just before an order arrive to the warehouse:

$$
\underbrace{\left(s-U S_{i}\right)}_{\begin{array}{c}
\text { Inventory level when } \\
\text { orders are submited }
\end{array}}-\underbrace{D_{i} \cdot L T_{i}}_{\begin{array}{c}
\text { Expected demand } \\
\text { during Lead-Time }
\end{array}}=D_{i} \cdot R_{i}+Z_{1-\alpha} \cdot \sqrt{L T_{i}+R_{i}} \cdot \sqrt{V_{i}}-\left(\frac{V_{i}}{2 \cdot D_{i}}+\frac{D_{i} \cdot R_{i}}{2}\right)
$$

Additionally, inventory and ordering costs related to order size or cycle inventory, is evaluated in terms of the minimum order size $Q$ as a decision variable, as in EOQ model:

$$
\frac{O C_{i} \cdot D_{i}}{\left(Q_{i}+U S_{i}\left(D_{i}, V_{i}\right)\right)}+\frac{H C_{i} \cdot\left(Q_{i}+U S_{i}\left(D_{i}, V_{i}\right)\right)}{2}
$$

Consequently, the SNL-MIP model to solve the analyzed problem is:

$$
\begin{aligned}
P \backslash \operatorname{Min} & \sum_{i=1}^{N} F_{i} \cdot X_{i}+\sum_{i=1}^{N} \sum_{j=1}^{M} C_{i j} \cdot Y_{i j}+\sum_{i=1}^{N}\left(O C_{i} \cdot \frac{D_{i}}{\left(Q_{i}+U S_{i}\left(D_{i}, V_{i}\right)\right)}+H C_{i} \cdot \frac{\left(Q_{i}+U S_{i}\left(D_{i}, V_{i}\right)\right)}{2}\right) \\
& +\sum_{i=1}^{N} H C_{i} \cdot\left(D_{i} \cdot R_{i}+Z_{1-\alpha} \cdot \sqrt{L T_{i}+R_{i}} \cdot \sqrt{V_{i}}-U S_{i}\left(D_{i}, V_{i}\right)\right)
\end{aligned}
$$

s.t.: 


$$
\begin{array}{lc}
\sum_{i=1}^{N} Y_{i j}=1 & \forall j=1, \ldots, M \\
Y_{i j} \leq X_{i} & \forall i=1, \ldots, N, \forall j=1, \ldots, M \\
Q_{i}+D_{i} \cdot R_{i}+\left(Z_{1-\alpha} \cdot \sqrt{L T_{i}+R_{i}}+Z_{1-\beta} \cdot \sqrt{L T_{i}}\right) \cdot \sqrt{V_{i}} \leq I \operatorname{Cap} \cdot X_{i} & \forall i=1, \ldots, N \\
Q_{i}+U S\left(D_{i}, V_{i}\right) \leq Q C a p & \forall i=1, \ldots, N \\
D_{i}=\sum_{j=1}^{M} \mu_{j} \cdot Y_{i j} & \forall i=1, \ldots, N \\
V_{i}=\sum_{j=1}^{M} \sigma_{j}^{2} \cdot Y_{i j} & \forall i=1, \ldots, N \\
U S_{i}\left(D_{i}, V_{i}\right)=\frac{V_{i}}{2 \cdot D_{i}}+\frac{D_{i} \cdot R_{i}}{2} & \forall i=1, \ldots, N \\
X_{i}, Y_{i j} \in\{0,1\} & \forall i=1, \ldots, N, \forall j=1, \ldots, M
\end{array}
$$

Equation (12) is the total system cost. The first term is the fixed setup and operating cost when opening warehouses. The second term is the daily transport cost between warehouse and customers. The third term contains fixed order and inventory costs related to warehouse order size. The fourth term represents the storage cost associated to safety stock at each warehouse. Equation (13) assures that retailers are served exactly by one warehouse. Equation (14) assures that customers are assigned to installed warehouses $\left(X_{i}=1\right)$. Equation (15) assures that inventory capacity for each warehouse is respected at least with a probability $1-\beta$. Equation (17) and (18) computes mean and variance of the served demand by each warehouse $i$. Finally, equation (20) states integrality (0-1) for the variables $Y_{i j}$ and $X_{i}$. This model is NPHard, because it is clearly an extension of the UFLP, which is already NP-hard (UFLP can be obtained from $\mathrm{P}$ doing $H C_{i}=0$ and $\left.O C_{i}=0, \forall i=1, \ldots, N\right)$. In addition, objective function and one constraint are nonlinear, resulting in an model that is very hard to solve.

\section{COMPUTATIONAL RESULTS}

In order to solve the proposed ILM-SCC-PR problem, but only small instances, we implement an exhaustive algorithm. This algorithm was used to obtain the optimal solution for small instances in both ILM-SCC-PR and Inventory Location Model with Stochastic Capacity Constraint under Continuous Review (ILM-SCC-CR), presented previously in Miranda and Garrido [16] and [17]. The goal of this numerical application is to compare the network configurations obtained with both models. We use 16 small instances which consider 15 clients and 4 locations. We also include variations in several parameters such as Holding 
Cost $\left(H C_{i}\right)$, Order Cost $\left(O C_{i}\right)$, Allocation Cost $\left(C_{i j}\right)$, variance of customer demand $\left(v_{j}\right)$, Maximum Order Quantity $\left(Q_{i}^{C A P}\right)$ and maximum capacity of the DC $\left(I_{i}^{C A P}\right)$.

TABLE 1. Optimal DND obtained for both ILM-SCC-PR and ILM-SCC-CR model

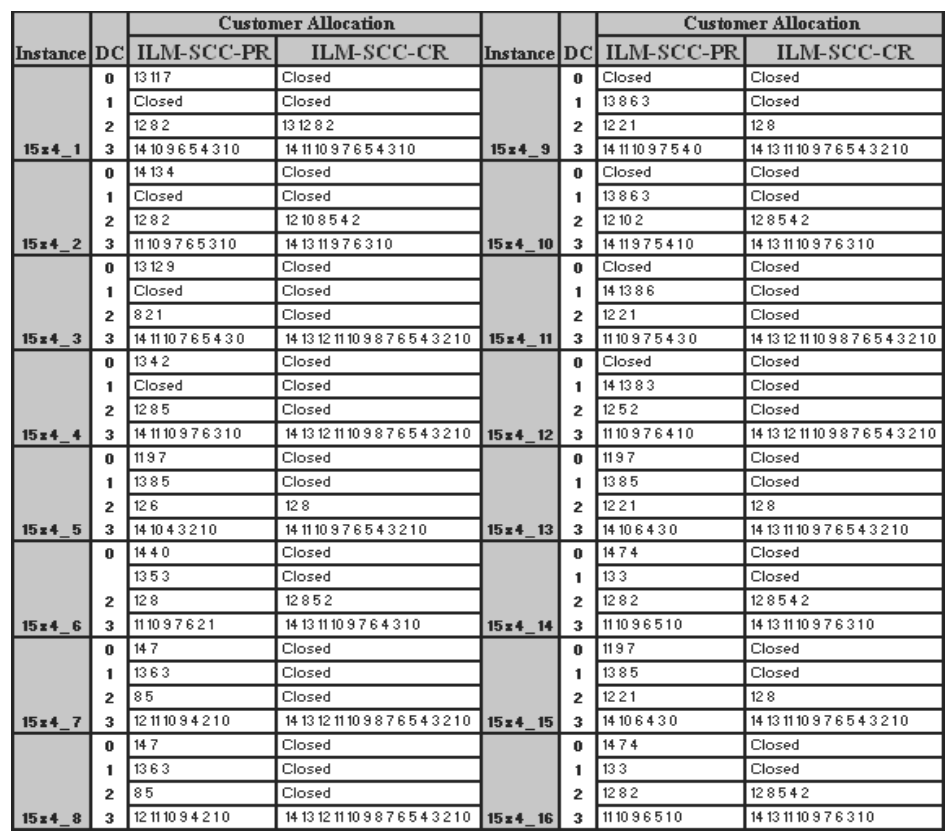

The results obtained in table 1 show, for each instance, that the inventory policy adopted affects the optimal configuration. In this sense, is possible to see that for all instances the ILM-SCC-PR model open more DC comparing to ILM-SCC-CR model, independent to the variations in input parameters. This fact is due to the ILM-SCC-PR model is more restrictive in terms of inventory for each DC, forcing them to serve a smaller set of customers comparing to the ILM-SCC-CR model. Consequently, the ILM-SCC-PR model is forced to open more centers than ILM-SCC-CR. In other worlds, is possible to see that for the first 4 instances $\left(15 \times 4\right.$ _ 1 to $\left.15 \times 4 \_4\right)$ less open DC's. For example, for the first 4 instances $\left(15 \times 4 \_1\right.$ to $\left.15 \times 4 \_4\right)$, the $I_{i}^{C A P}$ as well as the $Q_{i}^{C A P}$ are between $10 \%$ and $20 \%$ larger, which allows to allocate more customers for each DC, and consequently not requiring more DC's. Finally, both models have the same unselected locations for each instance, i.e., the unselected locations that are determined by the ILM-SCC-PR model are a subset of the unselected locations that is determined by the ILM-SCC-CR model. Above is due that the models 
consider the same cost for installation, transportation and customers allocation, and the expressions that be related with these issues are too similar (or equals) in both models.

For the last 8 instances, where $v_{j}$ are increased in 33\%, the results do not show big differences in comparison with the obtained ones in previous instances.

\section{CONCLUSIONS AND FUTURE RESEARCH}

This paper presents an inventory-location model that integrates inventory decisions at the strategic level. This model considers a periodic review inventory policy (R, s, S) unlike previous models assuming continuous review inventory policies. Based on the proposed model, a comparison to continuous review models was made in order to show that changing the inventory control policy may cause a change in network configuration. The results validate this hypothesis and allow understanding how inventory effects, such as risk pooling, lead to the models to select different sets of DC's.

As a conclusion, we can say that the inventory policy considered when designing a distribution network is extremely important, both in the allocation of customers and in the decision to open or close a specific DC.

As for future work is to test whether a policy change from $(R, s, S)$ to $(R, s)$ periodic review policy has an effect on the obtained DND. On the other hand is still possible to further integrate other tactical elements to the models presented in this article, so that even more representative of reality and therefore improve the quality of the solutions. Examples of these elements are the transportation decisions or the DC layout decisions. Furthermore, resolution techniques that can be applied on these models are varied and open a new research line.

\section{REFERENCES}

1. Miranda P., Garrido R., “A Simultaneous Inventory Control and Facility Location Model with Stochastic Capacity Constraints", Netw Spat Econ, 2006, Springer Science.

2. Miranda P. Garrido R. "Incorporating inventory control decisions into a strategic distribution network design model with stochastic demand". Transportation Research Part E, May 2004, 40, 3, 183-207.

3. M.S. Daskin, C.R. Coullard, Z.-J.M. Shen, "An inventory-location model: Formulation, solution algorithm and computational results", Annals of Operations Research 110 (2002) 83-106.

4. Simchi-Levi, D. and Y. Zhao, (2003), The Value of Information Sharing in a Two-stage Supply Chain with Production Capacity Constraints. Naval Research Logistics, 50, pp. 888-916. 
5. Mourits and Evers, Distribution network design: An integrated planning support framework. International Journal of Physical Distribution \& Logistics Management.1995. v25. 43-57.

6. James R. Bradley, Bruce C. Arntzen, The Simultaneous Planning of Production, Capacity, and Inventory in Seasonal Demand Environments, Operations Research, v.47 n.6, p.795-806, June 1999

7. Miranda, P. A. (2004). "Un Enfoque Integrado para el Diseño Estrategico de Redes de Distribucion de Carga". Doctoral Thesis, Escuela de Ingenieria, Pontificia Universidad Catolica de Chile.

8. Miranda, P. A. and Garrido, R. A. (2004a). "Diseño de la red de distribución y gestión de la cadena de abastecimientos: Antecedentes generales y enfoques de modelación". Documento de Trabajo N 86, Departamento de Ingeniería de Transporte, Pontificia Universidad Católica de Chile.

9. Daskin, M. Network and discrete location: Models, algorithms, and applications. WileyInterscience, New York.

10. Simchi-Levi, D., Chen, X. and Bramel, J. The logic of logistic. Springer-Verlag, New York.

11. Drezner, Z. and Hamacher, H.W. (eds.) (2002) Facility Location: Applications and Theory. Springer-Verlag, New York, NY.

12. L. Dupont, Branch and bound algorithm for a facility location problem with concave site dependent costs, International Journal of Production Economics 112 (1) (2008), pp. 245254

13. M.A.J. Arostegui, S.N. Kadipasaoglu and B.M. Khumawala, An empirical comparison of tabu search, simulated annealing, and genetic algorithms for facilities location problems, International Journal of Production Economics 103 (2006), pp. 742-754

14. Z.-J.M. Shen, C. Coullard and M.S. Daskin, A joint location-inventory model, Transportation Science 37 (1) (2003), pp. 40-55

15. P.A. Miranda and R.A. Garrido, Incorporating inventory control decisions into a strategic distribution network design model with stochastic demand, Transportation Research, Part E 40 (3) (2004), pp. 183-207

16. P.A. Miranda and R.A. Garrido, A simultaneous inventory control and facility location model with stochastic capacity constraints, Networks and Spatial Economics 6 (1) (2006), pp. 39-53

17. P.A. Miranda and R.A. Garrido, Valid inequalities for Lagrangian relaxation in an inventory location problem with stochastic capacity, Transportation Research Part E, Logistics \& Transportations Review 44 (1) (2008), pp. 47-65

18. L. Ozsen, M.S. Daskin and C. Coullard, Capacitated facility location model with risk pooling, Naval Research Logistics 55 (4) (2008), pp. 295-312

19. S. Axsäter, Approximate optimization of a two-level distribution inventory system, International Journal of Production Economics 81-82 (2003), pp. 545-553

20. Kiesmuller G., Kok A. "A multi-item multi-echelon inventory system with quantitybased order consolidation”. Beta Working Paper, Rep. No. 147, 2005, 28 pp.

21. G.P. Kiesmüller, A.G. de Kok, "Safety stok allocation in a multi-item multi-echelon inventory system with quantity-based order consolidation". 


\title{
A COMPARISON OF MATHEMATICAL MODELLING APPROACHES FOR STABILITY ANALYSIS OF SUPPLY CHAINS
}

\author{
Bernd Scholz-Reiter $^{1}$, Michael Schönlein ${ }^{2}$, Michael Kosmykov ${ }^{3}$, Thomas Makuschewitz ${ }^{1}$ \\ ${ }^{1}$ BIBA - Bremer Institut für Produktion und Logistik GmbH at the University of Bremen \\ ${ }^{2}$ Institute of Mathematics, University of Würzburg, Würzburg, Germany \\ ${ }^{3}$ ZeTeM - Centre of Industrial Mathematics, University of Bremen, Bremen, Germany
}

\begin{abstract}
Production and transportation processes along a supply chain are dynamic.

In particular they are subject to perturbations (e.g. breakdown of a resource) that can destabilise the network. Stability is a major property of a supply chain that is essential for a sustainable relationship to its customers. In order to verify the stability of a given supply chain different criteria have been developed. This paper addresses the problem of choosing a proper mathematical modelling approach for a real world network in order to investigate stability. For this reason we discuss four different modelling approaches. Each of these approaches can model different characteristics of a supply chain and features a specific stability criterion. By comparing these approaches the paper supports choosing a proper modelling approach for a real world supply chain.
\end{abstract}

\section{INTRODUCTION}

Supply chains often consist of production facilities around the world and serve local markets on different continents. Dynamic production and transportation processes along these chains have to be aligned in order to create a sustainable network and to materialise its competitiveness [1]. Stability is a major property of a given supply chain. In the case that a given network is stable it is able to meet the expectations of the customers in time, quantity and quality. Hence, the work in progress is bounded. This means for instance that a seasonable changing demand can be handled by the given resource capacities. Internal or external perturbations of production and transportation processes may lead to instability. For instance, a breakdown of a machine or transportation vehicle can be regarded as an internal perturbation. Traffic jams are examples of external perturbations that increase the travel time 
between locations or customers. In the case of instability the work in progress grows unboundedly with time, high inventory cost for intermediate products occur and throughput times become large. Hence, the supply chain is not able to meet the customers' demand.

Stability criteria allow to verify the mode of operation of a given supply chain. These criteria can be applied to a single location or the whole network. Since the stability of all individual processes or locations is not sufficient for the stability of the network, the supply chain has to be considered as one large dynamical system. In the case of stability, robustness describes the kind and size of manageable perturbations before the system becomes unstable. Feature characteristics and dynamics of a supply chain can be modelled either by simulation models [2] or by mathematical modelling approaches. For instance mathematical modelling approaches can model discrete, continuous or hybrid material flows. These approaches feature stability criteria or methods to investigate robustness. In the literature several modelling approaches have been developed.

In Section 2 we introduce four different mathematical modelling approaches. Each approach features a specific stability criterion and a method to investigate robustness of a real world supply chain. Section 3 compares the modelling approaches in regard to their capability to capture the properties of the real world network and applicable stability criteria. Some conclusions and suggestions for future research are presented in section 4.

\section{MODELLING APPROACHES FOR STABILITY ANALYSIS}

A supply chain consists usually of several locations, e.g. production facilities, warehouses and retailers. Each location can be considered as a single dynamical system that has to be modelled and analysed. An embedded location within the supply chain is connected to other locations by material, information and monetary flows. These links create an overall dynamical system. Hence, the dynamics of the supply chain are described by the dynamics of all single locations and their interconnections.

\subsection{Continuous dynamical systems}

In the framework of continuous dynamical systems the dynamics of a single location $i \in\{1, \ldots, N\}$ are modelled by a differential equation

$$
\dot{x}_{i}=f_{i}\left(x_{1}, \ldots, x_{N}, u_{i}\right) .
$$


The state $x_{i}$ of location $i$ describes for instance the work in progress of the considered location. The state is subject to an external input $u_{i}$. This input might be caused by new orders from customers of the supply chain. Furthermore the state also depends on the state of other locations $j \neq i$. This allows to model the dependence and interconnections between the locations. In particular the supply of components and intermediate products can be modelled. The state of the whole supply chain is obtained by combining the states of all locations in one vector, i.e. $x=\left(x_{1}, \ldots, x_{N}\right)^{T}$. The dynamics of the supply chain is given by

$$
\dot{x}=f(x, u)=\left(\begin{array}{c}
f_{1}\left(x_{1}, \ldots, x_{N}, u_{1}\right) \\
\vdots \\
f_{N}\left(x_{1}, \ldots, x_{N}, u_{N}\right)
\end{array}\right) .
$$

If the supply chain is stable it is able to fulfil the customers demand in time. As a consequence the work in progress, represented by state $x$, stays within certain bounds. These bounds depend naturally on the demand which is given by $u$. This property is the basic idea for the input-to-state stability (ISS) concept that is used in mathematical systems theory to analyse stability. In general a system (2) with initial value $x(0)$ is input-to-state stable, if the state $x(t)$ is bounded by the initial value $x(0)$ and the input $u$ over time. A precise definition is given by [3]. The following Figures 1 and 2 illustrate two equivalent ways to define ISS.

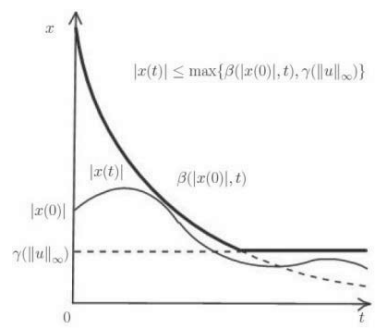

Figure 1.

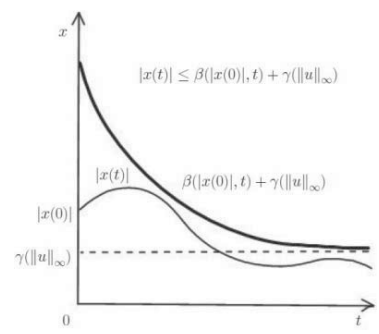

Figure 2.

In both figures the bold line represents the bounds of the state $x(t)$, e.g. the work in progress of a supply chain. Here it is shown that in the beginning the state $x(t)$ is bounded by some comparison function $\beta(x(0), t)$ of the initial value $x(0)$ of the dynamical system. In the long time the influence of the initial value decreases and the state is bounded by some comparison function $\gamma\left(\|u\|_{\infty}\right)$ that depends on the input, e.g. new orders from the customers. 
The concept of ISS comprises a small gain condition for interconnected systems. The obtained gains are functions that relate the magnitude of input with the expected maximal work in progress. This allows to analyse the robustness of such systems. [4].

\subsection{Hybrid dynamical systems}

Similar to the previous approach the locations within a supply chain are modelled with differential equations. But in the framework of hybrid dynamical system the state of a supply chain is additionally allowed to be discontinuous in some time instants. Roughly speaking such discontinuities are states where the supply chain jumps to another state. This enables the description of transportation processes. For instance, if the state represents the stock level then modelling of the shipping of material, products etc. is possible. Moreover according to the state and the demand, that is denoted by $u$, a distinction of the kind of shipping's can be drawn, e.g. shipping's by train, ship or airplane.

The cases where the state, respectively the stock level, changes continuously are determined by a set $C$, i.e. the dynamics of location $i$ is then given by

$$
\dot{x}_{i}=f_{i}\left(x_{1}, \ldots, x_{N}, u_{i}\right), \quad(x, u) \in C .
$$

The discontinuities are described by the set $D$. The jumps in the state follow the equation

$$
x_{i}^{+}=g_{i}\left(x_{1}, \ldots, x_{N}, u_{i}\right), \quad(x, u) \in D .
$$

For a detailed description see [5]. Analogous the dynamics of the supply chain is given by

$$
\begin{array}{rlrl}
\dot{x} & =f(x, u), & (x, u) \in C \\
x^{+}=g(x, u), & (x, u) \in D .
\end{array}
$$

The concept of input-to-state stability can be applied as well to analyse stability. The state is bounded by the some functions of initial value $x(0)$ and the input $u$. For a precise definition see [5]. In the following figures the behaviour of a hybrid system that is ISS is shown. 


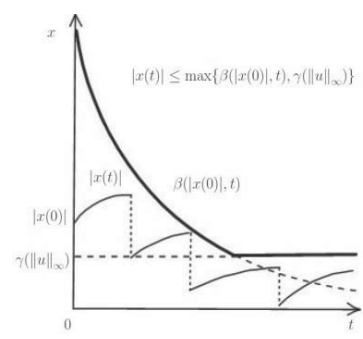

Figure 3.

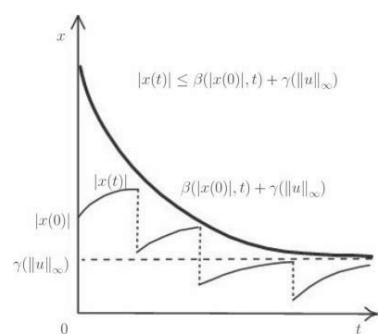

Figure 4.

The bold lines bound the state $x(t)$ of the supply chain, e.g. the stock level within the supply chain. The ISS concept for hybrid dynamical system also comprises a small gain condition that guarantees the ISS property of the supply chain, if all single locations are ISS.

\subsection{Multiclass queueing networks and fluid approximation}

Multiclass queueing networks are a well-established modelling approach to capture stochastic events that influence the discrete material flow of a supply chain. Here only a brief description of a multiclass queueing network is given, for details see [6]. The network consists of $N$ locations that process $K$ different types of products. The dynamics of the network can be described by the following stochastic processes. The arrival process $A_{k}(t)$ describes the number of external arrivals in the time period $[0, t]$. The production process $S_{k}(t)$ reflects the number of finished products of type $k$ during the first $t$ time units. For convenience we assume that each type of product is produced exclusively at one location. The mapping $s:\{1, \ldots, K\} \rightarrow\{1, \ldots, J\}$ determines which type is produced at which location and generates the constituency matrix $C$, where $c_{j k}=1$ if $s(k)=j$ and $c_{j k}=0$ otherwise. After being processed products either change their type according to a given probability or leave the network. The routing process $R_{k}^{l}(n)$ denotes the number of type $l$ products among the first $n$ type $l$ products that become products of type $k$. As each location can produce various product types a policy is needed that determines in which order the products are processed. Typical examples of such service disciplines are FIFO, priority or processor sharing. The allocation process $T_{k}(t)$ denotes the total amount of time that location $s(k)$ has devoted on producing type $k$ products. The initial amount of type $k$ products is $Q_{k}(0)$ and the number of type $k$ products at time $t$ is given by the flow-balance equation 


$$
Q_{k}(t)=Q_{k}(0)+A_{k}(t)+\sum_{l=1}^{K} R_{k}^{l}\left(S_{l}\left(T_{l}(t)\right)\right)-S_{k}\left(T_{k}(t)\right) .
$$

To obtain a complete description of the network dynamics further conditions on $Q$ and $T$ that depend on the service discipline have to be taken into account (see [7,8]). Roughly speaking a queueing network is said to be stable if the total number of products in the network remains bounded over all time. An approach to analyse the stability of multiclass queueing networks is to rescale the stochastic processes and take the limits [6]. The so called fluid limit model is obtained through replacing the stochastic processes by their rates, i.e.

$$
\frac{1}{t} A_{k}(t) \rightarrow \alpha_{k}, \quad \frac{1}{t} S_{k}(t) \rightarrow \mu_{k}, \quad \frac{1}{t} R_{k}^{l}(n) \rightarrow p_{l k} .
$$

The flow-balance equation in the continuous deterministic fluid model takes the form

$$
Q_{k}(t)=Q_{k}(0)+\alpha_{k}(t)+\sum_{l=1}^{K} p_{l k} \mu_{l} T_{l}(t)-\mu_{k} T_{k}(t) .
$$

Again there are additional conditions on $Q$ and $T$ that are specific to the service discipline, see e.g. [7, 8]. A fluid model is stable, if for all $k \in\{1, . ., K\}$ there is a time $\tau>0$

such that for any $Q_{k}(\cdot)$ with $\sum_{k=1}^{K} Q_{k}(0)=1$ it holds that $Q_{k}(\tau+\cdot) \equiv 0$. In [6] it is shown that the stability of the fluid limit model is sufficient for the stability of the multiclass queueing network.

Up to now a comprehensive approach to analyse the robustness of a fluid model and its implications on the robustness of the corresponding queueing network does not exist. In [9] a first step is presented that allows to quantify the size of admissible perturbations of the external arrival rate such that the network remains stable.

\section{COMPARISON OF THE CAPABILITIES OF THE APPROCHAES}

The presented modelling approaches vary in their capabilities. In regard to the dynamics continuous dynamical systems and hybrid dynamical systems are able to capture linear and nonlinear processes. Queueing networks and fluid models are only able to describe linear dynamics. Furthermore continuous dynamical systems and hybrid dynamical systems can be used to describe the dynamics of a single location as well as the dynamics of the whole supply chain. In contrast to this queueing networks describe the dynamics of the whole network. One 
major difference is that only queueing networks can deal with stochastic processes. The other presented approaches are completely deterministic. All modelling approaches have the ability to cover different types of products and to handle re-enterings. Material and information flows between the locations determine the structure of a supply chain. Different intermediate and finished products circulate between the locations and form a comprehensive material flow. In order to model the structure of this flow all modelling approaches can be used to capture linear, convergent or divergent flows. Despite these basic properties the approaches differ in regard to their capabilities to model feature characteristics of a supply chain.

Continuous and hybrid dynamical systems are able to consider a time-varying inflow of orders and production. In comparison to this, queueing networks assume a given distribution for the inter-arrival times between consecutive orders and production times. Fluid models are based on the mean values of the distribution of these variables. Production processes are carried out at various locations of a supply chain. Continuous and hybrid dynamical systems as well as fluid models are based on a continuous production. In the case of fluid models the production rate for each type of product is fixed. An adaptive production rate can be considered by continuous and hybrid dynamical systems [10]. By contrast queueing networks are based on the flow of discrete products. In the case that one location produces different kinds of products it needs to allocate its capacity to the production of the individual products $[11,9]$. Service disciplines like FIFO, priority and processor sharing discipline are embedded in the modelling concept of queueing networks and fluid models. It is also possible to incorporate these in continuous and hybrid dynamical systems. If a product needs to repeat a production step this can be modelled by all considered modelling approaches, since the approaches have the capability to model re-entrant systems.

The transportation of products is basically modelled by the connections between the locations. Hybrid dynamical systems and queueing networks can model a discrete flow of intermediate and finished products. If for instance a truck with new intermediate products arrives, this leads to a jump of the work in progress of the considered location. In comparison to this continuous dynamical systems and fluid models capture the transportation by continuous material flows. In order to model transportation times only continuous and hybrid dynamical systems can be used [12].

The stability of a queueing network can be considered by analysing the corresponding fluid model. An advantage of fluid models is that their analysis can be interpreted directly in 
the context of the stochastic system. In the literature some methods exist to optimize the networks processes [13]. However, only a few methods exist to design the network. In [14] this question has been addressed.

\section{CONCLUSIONS}

In this paper we discussed four different mathematical modelling approaches that allow to analyse the stability of a given supply chain. These approaches differ in their capabilities to model feature characteristics of the real world network. Our comparison shows that no dominant modelling approach exists and that the choice strongly depends on the characteristics of the supply chain. Since, we focused on the modelling approaches that are suitable for the concept of input to state stability and analysis of the stability of fluid networks future research should be devoted to other modelling approaches.

\section{REFERENCES}

1. Christopher, M. (1992): Logistics \& Supply Chain Management. Pitmans, London.

2. Scholz-Reiter, B.; Freitag, M.; de Beer, C.; Jagalski, T. (2005): Modelling Dynamics of Autonomous Logistic Processes: Discrete-event versus Continuous Approaches. Annals of the CIRP, 55(2005)1, 413-417.

3. Khalil, H. (2002): Nonlinear Systems. 3rd ed. Upper Saddle River, NJ: Prentice Hall.

4. Dashkovskiy, S.; Rüffer, B.; Wirth, F. (2007): An ISS small-gain theorem for general networks. Math. Control Signals Systems, 19, pp. 93-122.

5. Cai, C.; Teel, A. R. (2009): Characterisations of input-to-state stability for hybrid systems. Systems \& Control letters 58,pp. 47-53.

6. Dai, J. (1995): On positive recurrence of multiclass queueing networks: a unified approach via fluid limit models. Ann. Appl. Prob. 5, 49-77.

7. Chen, H.; Kella, O; Weiss, G. (1997): Fluid approximations for a processor-sharing queue. Queueing Systems. 27, 99-125.

8. Chen, H.; Zhang, H. (2000): Stabilty of multiclass queueing networks: under priority service disciplines. Oper. Res. 48, 26-37.

9. Scholz-Reiter, B.; Wirth, F.; Dashkovskiy, S.; Schönlein, M.; Makuschewitz, T.; Kosmykov, M. (2009): Some remarks on stability and robustness of production networks based on fluid models. Proceedings of $2^{\text {nd }}$ International Conference on Dynamics in Logistics, LDIC 2009, Bremen, Germany.

10. Dashkovskiy, S.; Görges, M.; Naujok, L. (2009): Local input to state stability of production networks. Proceedings of $2^{\text {nd }}$ International Conference on Dynamics in Logistics, LDIC 2009, Bremen, Germany. 
11. Dashkovskiy, S.; Wirth, F.; Jagalski, T. (2004): Autonomous control of shop floor logistics: analytic models. Proceedings of the IFAC-MIM Conference on Manufacturing, Modelling, Management and Control.

12. Polushin, I.; Marquez, H. J.; Tayebi, A. ; Liu, P.X. (2009): A multichannel IOS small gain theorem for systems with multiple time-varying communication delays. IEEE Trans. Automat. Control, 54(2), pp. 404-409.

13. Nazarathy, Y. ; Weiss, G. (2009): Near optimal control of queueing networks over a finite time horizon. Ann. Op. Res., 170, pp. 233-249.

14. Lefeber, E. ; Rooda, J.E. (2008): Controller design for flow networks of switched servers with setup times: the Kumar-Seidman case as an illustrative example. Asian Journal of Control, 10(1), pp. 55-66

\section{ACKNOWLEDGMENTS}

This research is funded by Volkswagen Foundation within the research project: Stability,

Robustness and Approximation of Dynamic Large-Scale Networks - Theory and Applications in Logistics Networks. 


\title{
SUSTAINABLE LOGISTICS - CASE STUDY OF AN AUTOMOBILE MANUFACTURER
}

\author{
S. Schmidt \\ University of Applied Science Munich and VWI \\ Fritzstrasse 41, D-82140 Olching, Germany
}

\begin{abstract}
In its capacity as a company operating across the world with a global production network, the automobile manufacturer under consideration in this paper, hereafter referred to as the Company', naturally moves large quantities of materials and products. To keep the transportation-related environmental stress at a minimum, all commodity flows are constantly being analysed and optimised from procurement to delivery. Here, intelligent transportation logistics achieves the optimum transportation services with a minimum of environmental stress, Quariguasi Frota Neto et al. [1], Wolff [2], Zadek [3].

Company environmental protection can only be "holistic" if it really covers all the links in a production chain. For this reason, the Company aims to establish high environmental standards both for itself and for its approx. 3,000 suppliers and service providers.
\end{abstract}

\section{INTRODUCTION}

The Company's logistics planning and transport logistics regulate the supply of production locations with production materials and components as well as the delivery of spare parts and accessories to the dealerships and, of course, the distribution of new vehicles. That corresponds overall to a transportation capacity of about 14 billion ton-kilometres per year.

Around 2,700 supplier locations and all service workshops worldwide, are integrated into the Company's goods flow management. Approximately two million transport containers made of steel and plastics are used to deliver parts and components to the individual locations. Logistics planning and transport logistics ensure that efficient logistics structures are developed and utilized. The elaborate environment-friendly transport solutions of the logistics experts are in accordance with the logistics and environmental guidelines. The reason: circa one-third of the emissions of noxious substances that occur during vehicle production, are generated along the transport chain that extends from the suppliers, through deliveries between locations to the delivery of the vehicle to the 
customer. In order to reduce environmental impacts, the logistics experts are working on specific projects to

- shift transport to a more ecologically compatible means of transport, for example from road to rail, and minimise air cargo,

- cut the volume of freight by optimising packaging, container filling and the capacity utilisation of the means of transport and traffic networks,

- and reduce the materials used to protect the surfaces of the new vehicles during transport.

- $\quad$ set high standards for suppliers and logistics

The logistics strategy results in exactly defined environmental objectives as well as process descriptions for the operative implementation in planning and purchasing. Using an environmental management system that has been certified to DIN EN ISO 14001 since 2003, the Company records key figures such as the share of vehicles delivered by rail or the share of air cargo in deliveries from Europe to overseas plants. The $\mathrm{CO} 2$ emissions in relation to the transport performance in ton-kilometres serve as an indicator for progress in the field of environmental management. Key figures are used to find out how much its logistics solutions contribute to environmental protection

\section{EFFICIENT AND ECOLOGICAL TRANSPORTATION LOGISTICS}

For the transport of goods, the Company prefers the mode of transportation with the lowest emissions. Accordingly, the shipping of goods via air freight is avoided as far it is possible. Road traffic is eased by choosing ports near the plants as the point of origin for ocean transports. For the vehicle transportation from the plants to the ports and sales operations, the manufacturer prefers to use railways.

\subsection{Shifting from Road to Rail}

The companies logistics experts cannot directly influence the transport performance from the supply market to the various locations of the production network. However, since they are involved in the selection of suppliers, they ensure that ecological aspects are also taken into account during transport from the suppliers to the plants. The logistics experts also have no direct influence on the transport of the finished automobiles to the sales market. After all, the 
development of the sales markets and plant allocation, i.e. the plant at which a particular vehicle is produced, determine the transport performance. However, the logistics experts are working on the development of ecological transport structures for the transport of automobiles from the plants to the sales markets.

Thus, infrastructure projects at individual plants promote the increased use of rail transport. For example, all new cars destined for the UK market are now loaded directly onto railway wagons in the plant in southern Germany. Deliveries to Germany's Rhine-Ruhr conurbation as well as to Belgium, Italy and Spain, have also been shifted from road to rail. With the introduction of the new compact model, around 60 percent of the new cars from the plant in southern Germany are delivered directly by rail. This means 15,000 fewer truck journeys a year and, as a consequence, a significant reduction of the burden of heavy traffic in this area. This shift to rail transport for deliveries from the German plants to Italy and Spain alone, reduces emissions of CO2 by 12,200 tons a year.

In South Africa and the USA, around 70 percent of new vehicles now leave the plants by rail. From 2003 to 2004, the Company increased the share of rail transport for its new vehicles worldwide by around eight percentage points to 60 percent. In 2004, further adjustments were made at the three German plants so that more materials could be supplied and more vehicles dispatched by rail. In order to supply the German plants with materials, the Company currently uses five rail links for freight trains.

The use of trucks for the worldwide supply of spare parts, which is organised by the centralized spare parts distribution centre in southern Germany, has also been reduced. Trucks based at this centre used to travel 190,000 kilometres a year in order to supply the distribution centre with spare parts from the external warehouses. In June 2005, the Company opened a new store and logistics centre, which is located near the plants. This centre replaces almost all the external warehouses and thus significantly reduces the transport performance each year.

\subsection{Combining Rail and Sea}

The Company also chooses ecologically favourable routes to ports for its overseas transport. For example, it changed the port of departure for vehicles produced in Germany for the UK market from Belgium to Cuxhaven/Northern Germany, thus relieving road traffic of 4,300 truck journeys each year. This shift also reduced transport time. Rail links to 
the respective ports are also used for the global supply of spare parts from the plant in southern Germany and for the supply of the plants in USA and South Africa. For example, a new rail link has been specially opened between the vehicle distribution centre in South Africa and the port of Durban. Each day it is used to transport two hundred new vehicles that are either leaving the plant or being imported for the South African market.

The efforts to shift traffic within the plants to ecologically equitable means of transport, such as rail and sea, have already been successful. In 2004, 15 percent of transport was by road and six percent by rail, while sea transport accounted for the lion's share of around 79 percent of the total.

\subsection{Avoiding Transport Packaging}

One of the objectives of environmental management in the field of logistics is to reduce the environmental impact of the materials used to protect vehicle surfaces during transport to the customer. Up to now, vehicles were protected from the elements and transit-related damage during transport by adhesive film, protective covers or wax. After an environmental performance evaluation concluded that a closed transport or an open transport with subsequent cleaning of the vehicles is much more environmentally friendly, the Company is in the process of successively phasing out its surface protection for automobiles.

In $2006,53.4 \%$ of the vehicles from the plants were delivered without surface protection; in the year before, it was $42.5 \%$. Since the start of the project in 2004, this has dramatically reduced the use of solvents and chemicals. Furthermore, about 5,000 tons of $\mathrm{CO} 2$ emissions, which occurred during the manufacture, application and de-waxing processes, were prevented. Without this surface protection and with the subsequent cleaning following transport, there were $80 \%$ fewer $\mathrm{CO} 2$ emissions.

\section{SUSTAINABILITY IN THE SUPPLY CHAIN}

\subsection{High Standards for Suppliers and Logistics}

As of spring 2003, the domestic and international purchasing conditions of the Company contain exact guidelines on environmental responsibility. They obligate suppliers to design the related components as per the state-of-the-art technology so that emissions are reduced during the production, usage and recycling stages. When manufacturing each component, energy and raw materials are to be used efficiently. For this reason, each partner 
is urged to draw up a certified environmental management system according to the established standards ISO 14001 or EMAS II. Alternatively, smaller suppliers may furnish proof of individual management systems and confirmation that they have systematised environmental protection

in their production.

Aside from environmental responsibility, the Company also requires from its suppliers and service providers that they assume social responsibility. For this reason, the purchasing conditions also include the prohibition of child labor and forced labor, discrimination and bribery as well as the implementation of a suitable management system for occupational health and safety. Here, the Company is guided by the globally recognised standards of the International Labour Organisation (ILO) and the principles of the Global Compact.

The purchasing conditions are binding for all existing and new suppliers to the Company. The selection of the suppliers is tasked to a multi-disciplinary team, which is located in the central office in Germany. Experts from the purchasing, logistic, development and quality management areas evaluate the concepts suggested by the suppliers, not only in terms of the cost and quality aspects but also in view of the social and environmental risks. The selection of suppliers also includes an evaluation of the concepts suggested against the backdrop of the protection of resources. Criteria for this include the weight of the components or the resulting mechanical frictional losses with drive components.

\subsection{Suppliers Selection According to Sustainability Criteria}

New suppliers are tested using a "Questionnaire for supplier selection", which also poses questions on the social and ecological performance of the supplier. Attendant to the product design process, environmental questions on the planned production process of the new parts are taken into account in conjunction with a risk management assessment of purchased parts from the existing suppliers. Aside from checking environmental management certificates, the Company requires its suppliers to provide extensive data on resource consumption, the contents used and their risk potential. Using this data, it is possible to create environmental performance evaluations for specific parts and processes, identify situations where there is any room for improvement, and to obligate suppliers to implement an environmentally optimized design and production for new components. 
Should any infringements against the criteria that have been agreed upon, be detected, then the experts responsible for environmental protection, recycling and purchasing from the Company will, together with the supplier, first attempt to find the reasons for these irregularities. Should the supplier fail to implement satisfactory measures, an escalation process is triggered, which may lead to a change of supplier

In this manner, the manufacturer commits its direct suppliers (first-tier suppliers) to conform to reliable and uniform environmental protection and social standards. At the same time, the Company expects from its suppliers, a corresponding examination of those suppliers with whom the manufacturer has no direct business relationship (sub-contractors). When submitting an offer, each new supplier must therefore confirm that subcontractors are checked regularly for compliance with quality, environmental and social standards and, as a result, that the risks of its own supply chain can be reliably controlled.

Especially in the emerging markets, where environmental protection efforts trickle down only slowly to medium and small suppliers, the Company supports its suppliers in establishing environmentally friendly production methods. Since 2000, the South African plant has, by means of a coaching programme, informed it suppliers on the environmental protection standards in force and the economic advantages, which arise from environmentally responsible production. The result: the percentage of suppliers with a certified environmental management system increased from about $10 \%$ in 2000 to $93 \%$ at the end of 2006.

To maintain this status at the suppliers, the product and process auditors from the South African plant regularly inspect the environmental management systems and facilities of all suppliers of major components. The objective is to ensure a constantly high environmental standard at the suppliers in the face of continually emerging new suppliers and expiring certificates.

When embarking upon new projects, the Company also examines the social and environmental standards of possible partners in order to ensure that the standards are observed throughout the value added chain. An example: the engine plant in Austria, which produces around 750,000 engines a year, conducted a competitive enquiry among suppliers worldwide as part of the development of a new four-cylinder diesel engine. Forty-seven potential suppliers returned their completed "Sustainability questionnaire". Unlike the national and international survey of suppliers, this broader survey also included companies that had 
not worked for the Company before. The suppliers provided information on their economic data and on whether they supported international initiatives to protect human rights and safeguard labor and social standards, such as the Global Compact. The Company also enquired about the status of environmental management in each company. Not only the application of an internationally valid environmental management system was decisive, but also the use of environmentally compatible production methods, such as design for recycling, or of life cycle assessment case studies.

The results showed that all the companies surveyed have an environmental management system. And nearly all the potential suppliers take account of standards for environment-oriented product development. Three-quarters of the suppliers who took part are governed by fixed social standards, such as a code of conduct or a corporate ethics charter. The potential suppliers also claim adherence to environmental and social standards along their value added chain. Thus, around 85 percent of the companies demand that their subsuppliers meet corresponding environmental and social standards. Together with other criteria, the Company used all these facts and figures to select suitable partners.

\section{CONCLUSIONS}

Companies assume responsibility for their economic success as well as for the environment and society, because long-term economic success can only be achieved by those companies that take both the interests of people and the needs of the environment into account, i.e. companies that operate sustainably. For the Company, sustainability management means using resources efficiently and sparingly, recognizing and minimizing risks, acting in a socially responsible manner and thus enhancing the Company's reputation. In doing so, both the management and employees constantly strive to improve on their achievements.

Here, it is evident that the Company equates an increased transportation capacity with a continually decreasing ecological impact. This reduction is made possible by numerous individual coordinated measures. One important measure is the minimization of the material transports. The sustainability in the supply chain is achieved by the careful selection of the suppliers and the maintenance of high standards for suppliers and logistics. This selection of the suppliers is evaluated by the Company's interdisciplinary team, which evaluates the concepts suggested by the suppliers and considers the cost and quality aspects as well as the 
social and environmental criteria and risks. Economy and ecology are inseparable, i.e. they are intrinsically tied together, Dahm [4]

Sustainable logistics plays an important part in the corporate sustainability strategy. The Company and Toyota are the industrial leaders by a considerable margin. Both companies consistently create positive Sustainable Value over the entire period under review, and use their economic, environmental and social resources in a value-creating way. In other words, they use these resources more efficiently than their industry peers, Hahn et al. 5]. Now is the time to act - towards creating Sustainable Business Cultures, Dahm [4].

\section{REFERENCES}

1. Quariguasi Frota Neto, J., Bloemhof-Ruwaard, Jacqueline M., Van Nunen, J.A.E.E. and Van Heck, E., Designing and Evaluating Sustainable Logistics Networks, ERIM Report Series Reference No. ERS-2006-003-LIS., 02. January 2006.

2. S. Wolff, Situation und Entwicklungen in der Automobilindustrie, Kühne+Nagel Automotive Day, Bremen, 23. June 2005.

3. H. Zadek, Logistics - a key sector of the 21st century, Skills for the European Logistics Sektor, Brussels, 24th September 2008.

4. D. Dahm., Declaration towards sustainable business cultures (SBC), BMW Stiftung Herbert Quandt, Berlin, 2009

5. T. Hahn, F. Figge and R. Barkemeyer, Sustainable Value in Automobile Manufacturing, Belfast and Berlin, 2008. 


\title{
THE EFFECT OF HIGH BRAZILIAN INTEREST RATES ON A LOGISTICAL OPTIMIZATION STRATEGY
}

\author{
Arnaldo Rabello de Aguiar Vallim Filho \\ Computer Science Department \\ Universidade Presbiteriana Mackenzie \\ R. da Consolação 896 - Prédio 13 - São Paulo, SP - Brazil.
}

\begin{abstract}
Logistics is today one of the most important areas in global economy, and facility location is considered the most important logistic decision. This paper used optimization models to analyze the effect of a high Brazilian interest rate on this logistical strategic decision. A mixed integer linear programming model was combined to a non linear cost model in order to support a facility location decision. An experiment with real data was conducted, and the research showed how optimal solutions may change significantly as the capital cost, which is a key model parameter, varies from very low values to extremely high ones. The models, the experiment and a set of interesting results are discussed in this paper.
\end{abstract}

\section{INTRODUCTION}

Logistics is today one of the most important areas in the global economy. Some logistics aspects, such as transportation mode, inventories and plant locations, may affect considerably the results of large industrial operations. Regarding the relative importance of such decisions, logisticians usually consider a facility location as the most important logistic decision, since it affects strongly the whole operation performance.

A classical logistic problem, the so called location problem, deals with this type of decision. This problem is most times solved with a mixed integer liner programming (MILP) model or through some metaheuristics, once this is a NP-hard problem.

The majority of these models try to minimize logistic costs, and the main components considered are: transportation, inventories and location cost. Among these elements, the inventory cost is the most sensitive to capital cost. In fact, according to some authors, as Ballou $\{1\}$, it may represents more than eighty percent of the total inventory cost. 
Regarding this location problem, the literature presents a significant number of papers, as Brandeau and Chiu [2], Geoffrion and Powers [3] or Vidal and GoetschalcKx [4]. These articles discuss topics as models characteristics, databases development, algorithms, and others. Another class of papers treats some particular type of problem or some specific type of model. Examples of these works are: Geoffrion and Graves [5], Erlenkotter [6] Nozick and Turnquist [7]. Concerning the optimization techniques, Crainic and Laporte [8]; Owen and Daskin [9]; Geoffrion and Graves [5] are examples of papers discussing the main models applied to location decisions. In general, these papers do not approach the impact of specific parameters over the model optimal solution, and most of them consider the logistic cost component with a linear behavior. These two aspects will be treated in this paper.

Another important aspect related to logistics decisions is the capital cost, and this is a very sensitive factor in Brazil. In fact, Brazil attracts capital from all over the world due to its superior interest rates. Most companies earn considerable amounts of money in its financial market. To illustrate this situation, table 1 shows the ten greatest annual interest rates in the world, and as it can be seen, Brazil is on the top of the list.

\begin{tabular}{cccc} 
Table 1 - Reference Rate (prime rate) $^{(1)}$ \\
\hline \multicolumn{3}{c}{ Last 12 Months } & Next 12 Months \\
\hline 1. Australia & $5,6 \%$ & 1. Brazil & $7,9 \%$ \\
2. Brazil & $5,3 \%$ & 2. Hungary & $5,5 \%$ \\
3. Turkey & $4,6 \%$ & 3. Turkey & $5,1 \%$ \\
4. China & $2,8 \%$ & 4. Australia & $4,7 \%$ \\
5. Hungary & $2,6 \%$ & 5. Mexico & $2,7 \%$ \\
6. Mexico & $2,4 \%$ & 6. China & $2.2 \%$ \\
7. Colombia & $1.9 \%$ & 7. Colombia & $2,0 \%$ \\
8. German & $1,2 \%$ & 8. Poland & $1,4 \%$ \\
9. Poland & $1,1 \%$ & 9. German & $0,8 \%$ \\
10. France & $1,1 \%$ & 10. France & $0,7 \%$ \\
\hline
\end{tabular}

Source: UpTrend Consulting - Real Interest Rates Trends

http://www.uptrend.com.br/acesso/uptrend_rankingdejiuros281008.pdf

(1) Inflation is not considered

Even though Brazil presents such a high reference rate, this is still low, once, in general, this is the rate at which banks lend to favored customers. Usually, this is the rate employed when banks lend money to each other. The real rates practiced in the market for the majority of the companies are much superior to this prime rate. The average interest rate for the last twelve months in the Brazilian market has been compiled by ANEFAC, which is a Brazilian association of financial executives. These rates are showed in table 2, and as it can be seen, the average annual rate is around $65 \%$, what would be considered extremely high in the vast majority of countries. 
Table 2 - Real Annual Brazilian Rate (i\%)

\begin{tabular}{|c|c|c|c|c|c|c|c|c|c|c|c|c|c|}
\hline Year & \multicolumn{10}{|c|}{$\mathbf{2 0 0 8}$} & \multicolumn{1}{|c|}{$\mathbf{2 0 0 9}$} \\
\hline Month & 04 & 05 & 06 & 07 & 08 & 09 & 10 & 11 & 12 & 01 & 02 & 03 & 04 \\
\hline $\mathbf{i} \%$ & $62,5 \%$ & $63,3 \%$ & $64,0 \%$ & $64,4 \%$ & $65,2 \%$ & $66,9 \%$ & $68,2 \%$ & $69,0 \%$ & $66,7 \%$ & $68,4 \%$ & $66,7 \%$ & $65,2 \%$ & $64,0 \%$ \\
\hline
\end{tabular}

These high rates produce an additional cost to companies operating in the country, generating a much higher capital cost. From a logistic point of view, the main consequence that can be foreseen is a more elevated inventory cost. So, considering these circumstances it is expected the logistics decisions will be affected in some way by such high rates.

What this work tried to do is to quantify, in terms of additional costs, the effect of these rates in a logistic optimization process. The research tries to analyze the specific effects of such conditions in a particular type of decision. Taking into account, the facility location is according to Ballou[1], the most important logistic decision, an experiment was designed to estimate the influence of the interest rates in this type of decision, particularly, the location of a number of distribution centers (DC).

The study considers first a MILP model taking into consideration transportation cost and a fixed location cost. This model provides the optimal locations for a given number of DC's. On a second stage a non linear model considers a third cost component, corresponding to inventories costs. Using these models, the experiment was conducted to analyze the effect of different capital costs in optimal costs.

The MILP model is presented in section 2, and the cost model in section 3. Next, section 4 presents the experiment employing these models on a practical application and evaluates the effect of the interest rate on the location decision. In section 5 the conclusions and recommendations are presented.

\section{LOCATION MODEL}

This section presents a location model which is well suited to this type of study, according to Vallim $\mathrm{F}^{\mathrm{O}}[10]$. The model searches for a solution of minimum logistic cost, considering three cost components: supply transportation, distribution transportation and a fixed location cost.

The model uses the following indexes:

$\mathrm{i}=$ index to represent production sources; $\mathrm{i}=1,2, \ldots . \mathrm{I} ; \mathrm{I}=$ number of origins

$\mathrm{j}=$ index to represent demand regions; $j=1,2, \ldots . . \mathrm{J} ; \mathrm{J}=$ number of regions

$\mathrm{k}=$ index to represent DC's; $\mathrm{k}=1,2, \ldots . . \mathrm{K} ; \mathrm{K}=$ number of candidates DC's locations. 
The decision variables are:

$$
\begin{aligned}
& \mathrm{x}_{\mathrm{ik}}=\text { material flow from production region } \underline{\mathrm{i}} \text { to } \mathrm{DC} \underline{\mathrm{k}}\left(\mathrm{x}_{\mathrm{ik}} \geq 0\right) \\
& \mathrm{y}_{\mathrm{kj}}=\text { binary decision variable } \\
& \quad \mathrm{y}_{\mathrm{kj}}=1, \text { if CD } \underline{\mathrm{k}} \text { serves cluster } \mathrm{j} ; \mathrm{y}_{\mathrm{kj}}=0 \text {, otherwise; } \\
& \mathrm{Y}_{\mathrm{k}}=\quad \text { binary decision variable } \\
& \quad \mathrm{Y}_{\mathrm{k}}=1 \text {, if DC } \underline{\mathrm{k}} \text { is activated; } \mathrm{Y}_{\mathrm{k}}=0 \text {, otherwise. }
\end{aligned}
$$

The model parameters are:

$$
\begin{aligned}
& \mathrm{c}_{\mathrm{ik}}=\quad \text { transportation cost per unit from production region } \underline{\mathrm{i}} \text { to } \mathrm{DC} \underline{\mathrm{k}} ; \\
& \mathrm{c}_{\mathrm{kj}}=\quad \text { distribution cost per unit from DC } \underline{\mathrm{k}} \text { to demand region } \mathrm{j} ; \\
& \mathrm{f}_{\mathrm{k}}=\mathrm{DC} \underline{\mathrm{k}} \text { fixed location cost; } \\
& \mathrm{O}_{\mathrm{i}}=\text { corresponds to region } \underline{\mathrm{i}} \text { production capacity; } \\
& \mathrm{D}_{\mathrm{j}}=\quad \text { demand of region } \mathrm{i} .
\end{aligned}
$$

The complete model is presented next:

$$
\operatorname{Min} \sum_{i, k} c_{i k} \cdot x_{i k}+\sum_{k, j} c_{k j} D_{j} \cdot y_{k j}+\sum_{k} f_{k} \cdot Y_{k}
$$

Subject to:

$$
\begin{aligned}
& \sum_{k} y_{k j}=1 \quad(j=1,2, \ldots \ldots J) \\
& \sum_{k}^{k} Y_{k}=p \\
& y_{k j}-Y_{k} \leq 0 \quad(k=1,2, \ldots . K ; j=1,2, \ldots \ldots J) \\
& \sum_{j} y_{k j}-Y_{k} \geq 0 \quad(k=1,2, \ldots \ldots . . K) \\
& \sum_{k} x_{i k} \leq O_{i} \quad(i=1,2, \ldots \ldots . . .) \\
& \sum_{i} x_{i k}=\sum_{j} D_{j} \cdot y_{k j} \quad(k=1,2 \ldots \ldots . . K) \\
& y_{k j}=0,1 \quad(k=1,2, \ldots . K ; j=1,2, \ldots . J) \\
& Y_{k}=0,1 \quad(k=1,2, \ldots . . K)
\end{aligned}
$$

The objective function (2.1) aims to minimize the transportation and facilities costs. Constraints (2.2) establish that just one $\mathrm{y}_{\mathrm{kj}}$ for a given value of $\mathrm{j}$ (one region) may be equal to 1 (if $y_{k j}=1$, then DC K serves region $\mathrm{j}$ ). So, each region is served by just one DC, what does not mean that one DC may serve more than one region. Constraint (2.3) defines the number $\mathrm{p}$ of DC's. Constraints (2.4) establish that each region may be served only by active DC's $\left(\mathrm{y}_{\mathrm{kj}} \leq \mathrm{Y}_{\mathrm{k}}\right)$. Constraints (2.5) were included in the model to guarantee that an active DC will serve some region. The model does not allow one active DC does not have any region to 
serve. Constraints 2.6 and 2.7 are supply and demand constraints, which are typical transportation models constraints. Constraints 2.7, also, guarantee DC's balances. Finally, constraints 2.8 and 2.9 assure $y_{k j}$ and $Y_{k}$ will be binary variables. This model can be applied to any value of $\mathrm{p}$. For each $\mathrm{p}$ value the model will provide the $\mathrm{p}$ optimal DC's locations.

\section{INVENTORY COSTS MODEL}

The main types of stocks to be considered in the inventory cost model, as Vallim $\mathrm{F}^{\mathrm{o}}[10]$, are: warehouse inventory, in transit inventory and safety stock. The warehouse inventory is the regular or cyclical inventory, which is necessary to meet the average demand during intervals between successive replenishments. The in transit inventory is the stock in movement in a supply chain, traveling between two stages in the chain. The safety stock is a means of protection against a financial loss that would occur if a stock out took place. It is a hedge against variability in demand and in lead time for replenishment. All of these types of stock generate a capital cost to the inventory owner.

The inventory cost models considered the capital costs, plus services and risk costs. The capital cost refers to cost of money tied up in stocks. This is the opportunity cost of unproductive assets, as well, the expenses incurred by the ownership of a stock. Regarding the service costs, its main components are costs of insurance and taxes. The risk costs are related to losses or pilferage, damages, deterioration and obsolescence.

The model to represent these costs is presented in equation 3.1 .

$$
C_{e s t}=D \cdot V_{u} \cdot\left\{\left[(1+i)\left(a \cdot V^{b}+\frac{d_{C D}}{S \cdot T_{\max }}+\frac{Z \alpha \cdot s_{d} \sqrt{L T}}{d} \sqrt{p}\right)-1\right]+S_{s t}+R_{s t}\right\}
$$

where: $\mathrm{C}_{\text {st }}=$ total monthly stock cost;

$\mathrm{D}=$ average monthly demand;

$\mathrm{V}_{\mathrm{u}}=$ unit value stock;

$\mathrm{i}=$ daily interest rate;

$a$ e $b=$ inventory-throughput model parameters;

$\mathrm{V}=$ average monthly throughput per DC;

$\mathrm{d}_{\mathrm{CD}}=$ distance from production to demand region, through a DC;

$\mathrm{S}=$ average speed;

$\mathrm{T}_{\max }=$ maximum operation time per day;

$\mathrm{Z}_{\alpha}=$ normal distribution critical value at $1-\alpha$ confidence level;

$\mathrm{s}_{\mathrm{d}}=$ demand standard deviation

$\mathrm{LT}=$ lead time

$\mathrm{d}=$ demand per day $=\left(\mathrm{D} / \mathrm{W}_{\mathrm{d}}\right)$

$\mathrm{p}=$ number of DC's;

$\mathrm{W}_{\mathrm{d}}=$ working days per month; 
$\mathrm{S}_{\mathrm{st}}=$ inventories service costs;

$\mathrm{R}_{\mathrm{st}}=$ inventories risk costs;

This model is a power equation, where each of the exponents three terms represents one of the inventory components. The term $a . V^{b}$ represents warehouse inventories. The coefficients $a$ and $b$ should be obtained through a regression analysis with data extracted from the real operation. The second term $\mathrm{d}_{\mathrm{CD}} /\left(\mathrm{S} . \mathrm{T}_{\max }\right)$ corresponds to in transit inventory, and the parameter $\mathrm{d}_{\mathrm{CD}}$, must also be estimated through data obtained in the operation. Finally, the third term represents the safety stock. The sum of these three components constitutes the time covered by the total amount in stock. It is this total time that generates a capital cost. Additionally, the model includes the two other inventory costs, service $\left(\mathrm{S}_{\mathrm{st}}\right)$ and risk $\left(\mathrm{R}_{\mathrm{st}}\right)$ costs.

\section{PRACTICAL APPLICATION AND RESULTS}

An experiment was designed to estimate the effect of the interest rates in the location decision. The experiment was conducted with real data from a set of demand points spread out over three states of the Brazilian southern region. The models presented in sections 2 and 3 were applied to these data and a set of results was drawn. Initially, the MILP model presented in section 2 was applied to the data in order to define the best locations to DC's. The model was tested under seven different $p$ values, the number of DC's. Next, the cost models were applied to analyze the effect of the interest rate on the best DC quantity. For this process the parameters $a$ and $b$, were estimate, as well, $d_{C D}$ (equation 3.1).

In the experiment, the annual interest rates (i\%) were ranged from zero to $100 \%$, and costs were computed for each rate value. This rates variation showed a significant effect on the results. Table 3 presents $i \%$ against the $p$ value which furnished the lowest total cost. What can be observed is that as $i \%$ increases, elevating the inventory cost, the total cost forces the best DC number to decline. This means that becomes more interesting to companies to concentrate their operations in a small number of locations. This concentration, meanwhile, has an opposite effect in transportation costs, once, the MILP model showed that transportation costs decline as the number of DC's increase. Consequently, concentration generates higher transportation cost. Therefore, what happens is an augment on both costs: inventory and transportation. 
Table 3 - Interest Rate vs. Number of DC's Best Solution

\begin{tabular}{ccccccc}
\hline i $\%$ & $7,0 \%$ & $8,0 \%$ & $15,0 \%$ & $19,0 \%$ & $44,0 \%$ & $54,0 \%$ \\
\# of DC's & 7 & 6 & 5 & 3 & 2 & 1 \\
\hline
\end{tabular}

Table 4 presents the effect of such conditions, showing the increase in the operation transportation costs of more than US\$1.6 million a year, and a total increase above US\$12 million a year, representing more than $375 \%$ in the logistic cost.

Table 4 -Interest Rates vs. Logistic Costs

\begin{tabular}{ccrrr}
\hline $\begin{array}{c}\text { Interest } \\
\text { Rate }\end{array}$ & \# of DC's & $\begin{array}{c}\text { Transportation } \\
\text { (US\$/month) }\end{array}$ & $\begin{array}{c}\text { Inventory } \\
(\mathrm{US} \$ / \text { month) }\end{array}$ & \multicolumn{1}{c}{$\begin{array}{c}\text { Total } \\
\text { (US\$/month) }\end{array}$} \\
\hline $5 \%$ & 7 & $79,389.86$ & $140,032.79$ & $219,422.65$ \\
$65 \%$ & 1 & $215,265.25$ & $1,046,894.83$ & $1,262,160.08$ \\
\hline \multicolumn{2}{l}{ Montly Adittional Costs } & $135,875.39$ & $906,862.04$ & $1,042,737.43$ \\
\hline AnnualAdittional Cost & (US\$/year) & $\mathbf{1 , 6 3 0 , 5 0 4 . 6 3}$ & $\mathbf{1 0 , 8 8 2 , 3 4 4 . 5 3}$ & $\mathbf{1 2 , 5 1 2 , 8 4 9 . 1 6}$
\end{tabular}

Therefore, the results obtained seems to be significant, showing important increments in logistics costs due to the high Brazilian interest rates. But an important result is the fact that not only inventory costs increases, but also transportation costs, which are influenced by the number of locations.

\section{CONCLUSIONS AND RECOMMENDATIONS}

This paper used optimization models to evaluate the effect of high Brazilian interest rates on facility location decisions. A MILP model and a non linear cost model were combined to modeling the problem and support the location decision. Variations applied to the interest rate considered in the cost model have showed the strong impact of this parameter on the whole logistic strategy. An experiment has been developed, and the models applied to real data supported the analysis demonstrating they are well suited to this type of problem. The results showed how deeply an operation can be affected by an economic policy. The number of locations change significantly as the interest rates increases, generating a strong impact in transportation costs, and not only in inventory costs, as it may be expected. The losses therefore, showed to be significant. 
New research could be developed in this area, expanding the limits of the paper that deals with one specific operation and with one specific decision. Models considering other logistic decisions and its relations with economic parameters could be a good research field.

\section{REFERENCES}

1 Ballou, R.H.. "Business logistics / supply chain management"; Pearson Ed., $5^{\text {th }}$ Ed. 616 p. 2004

2 Brandeau, M. L., Chiu, S.S.. "An overview of representative problems in location research“; Management Science, vol. 35 , n.6, p.645-674. 1989

3 Geoffrion,A.M., Powers, R.F.. "Twenty years of strategic distribution system design: an evolutionary perspective“; Interfaces, - Vol. 25, N. 5, p.103-127. 1995

4 Vidal, C.J., GoetschalcKx, M.. "Strategic production- distribution models: a critical review with emphasis on global supply chain models“; European Journal of Operational Research, - Vol. 98, 1-18. 1997

5 Geoffrion,A.M., Graves, G.W.. "Multicommodity distribution system design by Benders decomposition“; Management Science, - Vol. 20, No. 5, p.822-844. 1974

6 Erlenkotter,D.. "A dual-based procedure for uncapacited facility location"; Operations Research,-Vol. 26, No. 6, Nov-Dec, p. 992-1009. 1978

7 Nozick, L.K., Turnquist, M.A.. "Integrating inventory impacts into a fixed-charge model for locating distribution centers“. Transportation Research E, Vol. 34, No.3, 173-186. 1998

8 Crainic, T.G. e Laporte, G. . "Planning models for freight transportation". European Journal of Operational Research 97, p. 409-438. 1997

9 Owen, S.H. e Daskin, M. S.. Strategic facility location: a review. European Journal of Operational Research. No. 111, 423-447. 1998

10 Vallim $\mathrm{F}^{\circ}$, A. R. A., Localização de centros de distribuição de carga: contribuições à modelagem matemática. Doctoral Thesis, Escola Politécnica / USP. São Paulo, 286p.. 2004 


\title{
SOME ASPECTS OF PROCESS
}

\section{PLANNING IMPROVEMENT}

\author{
P. Cosic and N. Volarevic \\ Department od Industrial Engineering \\ Faculty of Mechanical Engineering and Naval Architecture \\ University of Zagreb \\ Ivana Lucica 5, Croatia
}

\begin{abstract}
The intention of this paper is to give some methodological approach in process planning.

Within this intention it covers the issues of primary process selection, defining of the sequence of operations, etc. Matrix method for defining the sequence of operations will be very useful in development of IT application, but the development will be continued by AI methods.

Selection of the primary process is useful in optimization process planning. The level of product quality, production time and production costs are results of developed procedures and their factors for sequence of operations, primary process selection, shape commplexity, variants of process plans, etc. The purpose is to analyse the influences of sequence of operations, primary process selection on process planning and how to apply them in decision making.
\end{abstract}

\section{INTRODUCTION}

Good interpretation of the part drawing includes mainly dimensions and tolerances, geometric tolerances, surface roughness, material type, blank size, number of parts in a batch, etc. The following factors would be the basis for decision support selection of the manufacturing process as the primary process selection, shape complexity, selection of machine tools and tools, sequencing the operation, variants of process planning and estimation of production times/costs [1]: a) quantity, b) complexity of form, c) nature of material, d) size of part, e) section thickness, f) dimensional and geometrical accuracy, g) surface roughness, etc [2].

\section{PRIMARY PROCESS SELECTION}

The following factors would be the basis for decision support selection of the manufacturing process as the primary process (for example, forming by deformation): a) 
quantity, b) complexity of form, c) nature of material, d) size of part, e) section thickness, f) dimensional accuracy, g) cost of raw material, h) possibility of defects and crap rate, etc.

\subsection{Methods for Manufacturing process selection}

Initially when product is in the concept stage great number of processes and materials are considered. As product starts to get its shape and more details number of processes and materials reduces. Applying these criterions results in optimal process selection and design that is adapted to process and material avoiding review of the part design in the advanced process planning stage.

All methods included in research have few things in common. They all give some general capability range for each process (tolerances, surface roughness, shape). Each method has its own shape classification but one thing is mutual, shapes are generally divided into round shapes, prismatic shapes and shapes that belong to neither of these two. Within this classification shapes are further divided into subclasses weather they contain features such as holes, change of section thickness. Economical batch is given by some of them $[2,3]$ although some give this in a very wide range which is not very useful for making quality decisions. Material and process combinations are included into every method giving plain sight which combinations are out of question [4]. In order to gain final decision on process selection some authors $[2,4]$ developed manufacturing cost estimation procedures.

Intention is to test some methods through case study and to compare the results. Figure 1. displays a part for which process selection will be carried out. Valve material is stainless steel (X45CrNi18-9; yield strength - 400MPa). The likely annual requirement is 50.000 units. Valve weight is $0,07 \mathrm{~kg}$. Other properties of the part can be found on the drawing (Figure 1.).

\subsection{Selection strategies using Primas (Process Information Maps) [2]}

Starting point is a data that provides information which processes are economically viable for certain combination of material and quantity. For stainless steel and batch quantity of 50.000 peaces combination a list of economically viable process is created. Process candidates are compared with product requirements and ones that don't match them are excluded from list. Figure 2. is example of process information data for shell molding. After analysis process candidates eliminated from further consideration are:

- Centrifugal casting (shape doesn't match - circular bore remains in the finished part), 


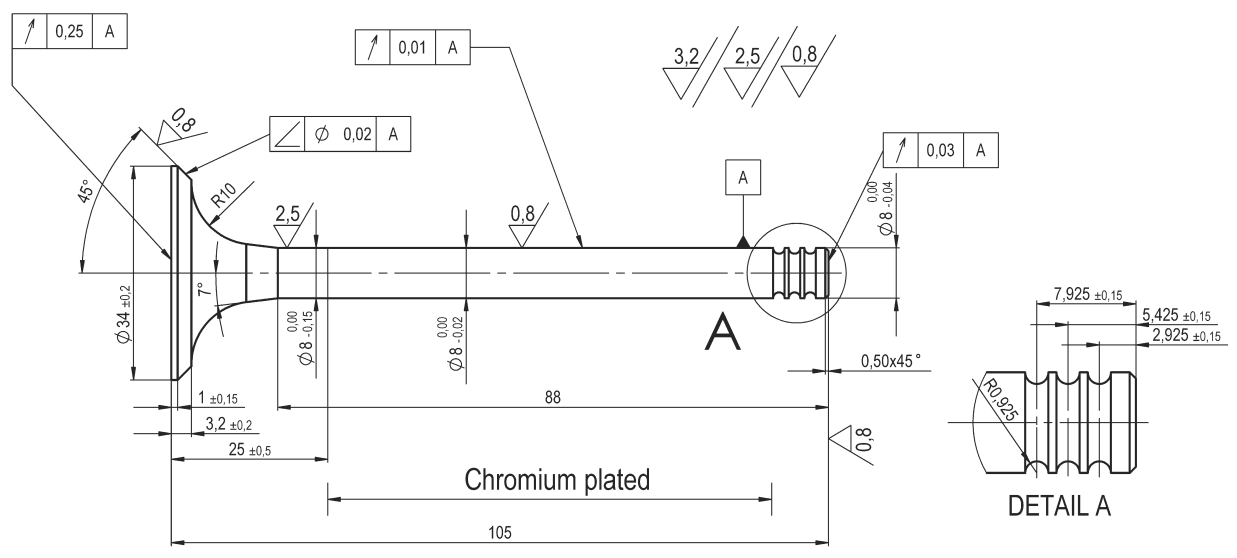

Fig. 1. Air throttle valve example.

- Shell molding, ceramic mold casting, drawing, swaging, powder metallurgy,

- Electro-chemical machining, electro-beam machining, laser beam machining ),

- Chemical, machining (primary.weight reduction by producing shallow cavities)

- Remaining processes are: investment casting, forging, automatic machining, should be able to produce part (valve) according to requirement. It is obvious that further elimination need to be done in order to choose the optimal process. Relative component processing cost analysis for each candidate process can be done according to equation

$$
M_{i}=V_{f} \cdot W_{C} \cdot C_{m t}+\sum\left[\left(C_{m p} \cdot C_{C} \cdot C_{S} \cdot C_{f t}\right) \cdot P_{C}\right] \text {. }
$$

Where Vf is volume of finished component, WC is waste coefficient, Cmt is cost of material per unit volume, $\mathrm{Cmp}$ is relative cost associated with material-process suitability, $\mathrm{CC}$ is relative cost associated with component geometrical complexity, CS is relative cost associated with size and component cross section, $\mathrm{Cft}$ is relative cost associated with tolerance or surface finish, $\mathrm{PC}$ is basic processing cost.

Table 1. represents processing cost estimates of the part presented in Figure 1. which can help process planner select the optimal process and to minimize project and product costs. It is important to mention that relative cost associated with tolerance or surface finish coefficient $(\mathrm{Cft})$ takes into account the need of additional machining since most primary 


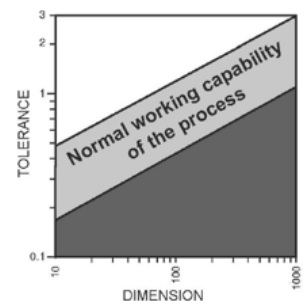

Fig. 2. Shell molding process information [2].

processes are not capable to achieve final tolerances and surface finishes. In this case forging turns out to be most suitable primary process due to material, design, batch quantity and other process limitations.

Table 1. Component processing costs

\begin{tabular}{|c|c|c|c|c|c|c|c|c|c|c|c|c|c|c|c|c|c|}
\hline $\begin{array}{c}\text { Primary } \\
\text { process }\end{array}$ & $\begin{array}{c}\text { Shape } \\
\text { complexity }\end{array}$ & $\begin{array}{c}\text { Volume } \\
{\left[\mathrm{mm}^{3}\right]}\end{array}$ & $\mathrm{C}_{\mathrm{mt}}$ & $\mathrm{W}_{\mathrm{c}}$ & $\mathrm{M}_{\mathrm{c}}$ & $\mathrm{P}_{\mathrm{c}}$ & $\mathrm{C}_{\mathrm{c}}$ & $\mathrm{C}_{\mathrm{mp}}$ & $\begin{array}{c}\text { Section } \\
{[\mathrm{mm}]}\end{array}$ & $\mathrm{C}_{\mathrm{s}}$ & $\begin{array}{c}\text { Toleranc } \\
\mathrm{e}[\mathrm{mm}]\end{array}$ & $\mathrm{C}_{\mathrm{t}}$ & $\begin{array}{c}\text { Surface finish, } \\
\mathrm{Ra}[\mu \mathrm{m}]\end{array}$ & $\mathrm{C}_{\mathrm{f}}$ & $\mathrm{C}_{\mathrm{ft}}$ & $\begin{array}{c}\mathrm{P}_{\mathrm{c}} \mathrm{x} \\
\mathrm{R}_{\mathrm{c}}\end{array}$ & $\begin{array}{c}\mathrm{Mi} \\
\text { (euro-cent) }\end{array}$ \\
\hline $\begin{array}{c}\text { Investmen } \\
\text { t casting }\end{array}$ & $\mathrm{Al}$ & 8760 & 0,00377 & 1,0 & 33,03 & 29,2 & 1 & 1 & 6,1 & 1 & 0,01 & 4,3 & 0,8 & 1,3 & 4,3 & 125,35 & 158,37 \\
\hline Forging & $\mathrm{A} 1$ & 8760 & 0,00377 & 1,1 & 36,33 & 1,9 & 1 & 2 & 6,1 & 1,3 & 0,01 & 4,2 & 0,8 & 2,4 & 4,2 & 20,75 & $\underline{\mathbf{5 7 , 0 8}}$ \\
\hline $\begin{array}{l}\text { Automatic } \\
\text { machining }\end{array}$ & $\mathrm{A} 1$ & 8760 & 0,00377 & 1,6 & 52,84 & 2,9 & 1 & 4 & 6,1 & 1,0 & 0,01 & 3,5 & 0,8 & 1,3 & 3,5 & 40,60 & 93,44 \\
\hline
\end{tabular}

This cost estimation could be inaccurate since at this level it is not possible to determine sequence of operations positioning and work-holding, queuing due to failures or facility occupation, number of machines. It was shown that variants of process planning can have significant influence on production time and therefore cost of production.

\section{SEQUENCING THE OPERATION}

Operations sequencing depends on many influences like [5]: nature of the material, general shape of the part, required level of accuracy, size of the raw material, number of parts in the batch, possible choice of machine tools, etc. One of the possible approaches is to classify different categories in the following way: a) dimensional precedence - dimensions with a datum as anteriority, b) geometric precedence - geometric tolerances with data references as anteriorities, c) datum precedence - case to the choice of a datum, d) 
technological precedence - case of a technological constraint, e) economic precedence economic constraints that reduce production costs and wear or breakage of costly tools.

To achieve the nominated goal for definition of sequencing the operations is very complicated, multi-level, particular problem. Therefore, the expected difficulties in the process of solving this problem can be: pattern recognition, selection of datum, connection between machining surfaces and type of operations, machining tools, tools and positioning and work holding, etc. So, as the first step in process sequencing is selection of the simplified approach. It includes definition of: a) codes for machining surfaces, b) number of passes, c) type of fine $(\mathrm{F})$ / rough $(\mathrm{R})$ machining, d) definition the relevant anteriorities different types (dimensional, geometric, technological, economic).

As it is obviously, this approach expects the experienced process planner. One of the well-known methods of finding the order of precedence of the operations is based on the use of a matrix. Having defined all the anteriorities, it is now possible to find the right sequence of operations for machining. The consistency of the anteriorities depends heavily on the experience of the process planner. Solution is result of weighted category of anteriorities, minimal number of precedence operations and finishing of precedence operations. The chosen order of anteriorities implementation is result of higher priority associated to dimensional and geometrical features then economical aspects. The difficulty can come from the assessment of the anteriorities, which can result in contradictory conditions. In this case the process planners have to introduce additional criterion in order to solve this contradictions. At the same time process planer defines anteriorities needed to establish a matrix, he makes a table that contains possible machining processes, machines, fixture devices and tools for every feature. To solve contradictory situation the feature that precedes according to matrix is compared with the momentarily possible features in the matrix. "Values" in the table that belong to features are compared. The feature whose "values" from table are the most similar to "values" of preceding feature has advantage. The logic in this approach is that as much as possible number operations in a sequence should be done by same process on the same machine in the same fixture and using same tool.

\section{MATHRIX METHOD - BOLT EXAMPLE}

The first step is to analyze the part drawing and "divide" the part into features/surfaces(112). (Fig. 1). Features are made by different machining operations. According to geometric 
shape, tolerances, surface quality and other information a drawing contains we can select possible machines and tools by which a specific feature could be produced.

For the example in Figure 1 a selection was made and is presented below in Table 2. Taking into account geometry of the product the primary shape would be a bar $\Phi 20$. The problem that appears next is which feature should be machined first and more important in which order should features be done. Certainly there are restrictions regarding technology, geometric and dimensional tolerances, datum, economy (reduce production costs and wear or breakage of costly tools). Taking into account all this restrictions another table (Table 2) is

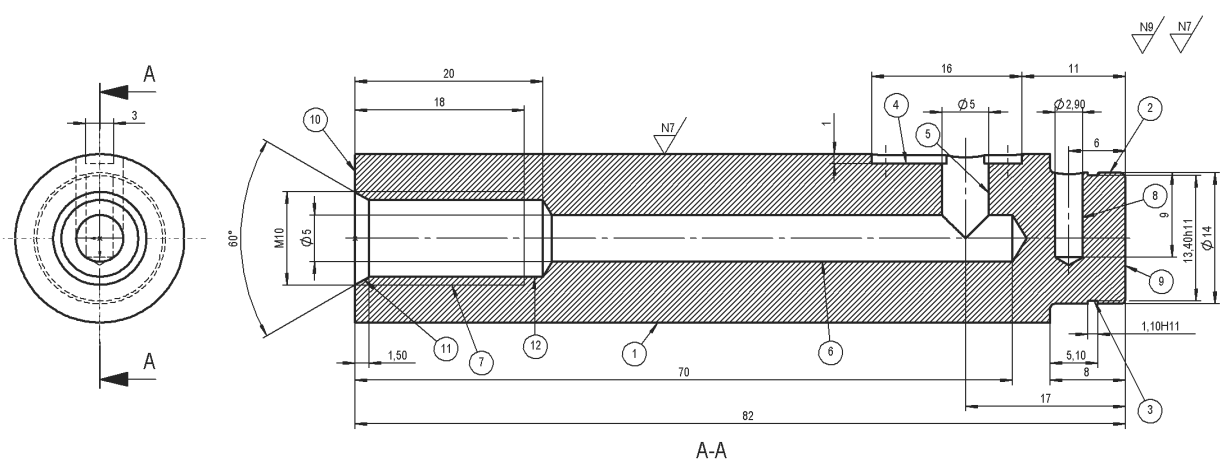

FIGURE 1. Bolt drawing

Quantity: 14000 pcs., Material: St60-2; Quantity: 14000 pcs., Material: St60-2

made in which it is clear which features must precede before other features. If Table 3 is presented in matrix (Table 4), advantages from this approach are now clear. It is easy to see that the first feature to be machined is $10 \mathrm{R}$. When 10R is removed from table it sets free other features that were "blocked" by it. [3]. It would be interesting to look at the situation when two or more features are not preceded by any other feature that needs to be done before. This means that all of them can be done at the same time. But this is not possible because only one feature can be machined in time. One of them must go first and then the other. In this example this situation occurs in the third step.

This situation is shown in Table 4. The feature that was done before is $1 \mathrm{R}$ (Table 4a). In this step we have to decide which feature is going to be machined first $2 \mathrm{R}$ or $4 \mathrm{R}$ (Table $4 \mathrm{~b}$ ). To make this decision we need more data. Therefore another table was made, shown in Table 5. In Table 5. a few additional criteria were brought out. In order of significance they are: same machine (if we change the machine we change all other factors: process, fixture and 
tool), same process (if we change the process we change fixture type, tool and sometimes machine), same fixture (changing fixture needs more time than changing tool and it is recommended to do as much operations as possible in one fixture because it is more precise), same tool (the least significant factor in this list).

If we look at the Table 5. we can see that feature $1 \mathrm{R}$ that proceeded was done by turning process on lathe. Since feature $2 \mathrm{R}$ is also done by turning on lathe which means by the same machining process as feature $1 R$ it has advantage before feature $4 R$. Feature $4 R$ requires milling and therefore different tool and fixture.

TABLE 2. Table of anteriorities

\begin{tabular}{|r|r|c|}
\hline \multicolumn{2}{|c|}{$\begin{array}{c}\text { Surface } \\
\text { (Feature) }\end{array}$} & Anteriorities \\
\hline $1 \mathrm{R}^{1}$ & $\Phi 18 \mathrm{k} 6\left(\begin{array}{c}+15 \mu M \\
+2 \mu M\end{array}\right)$ & $10 \mathrm{R}$ \\
\hline $2 \mathrm{R}$ & $\Phi 14$ & $1 \mathrm{R}, 10 \mathrm{R}$ \\
\hline $3 \mathrm{R}$ & $\Phi 13,40 \mathrm{~h} 11$ & \multicolumn{1}{c|}{$2 \mathrm{R}$} \\
\hline $4 \mathrm{R}$ & Counter bore $2 \mathrm{~mm}$ & $1 \mathrm{R}, 10 \mathrm{R}$ \\
\hline $5 \mathrm{R}$ & $\Phi 5$ & $1 \mathrm{R}, 4 \mathrm{R}, 6 \mathrm{R}$ \\
\hline $6 \mathrm{R}$ & $\Phi 5$ dpth.70 & $10 \mathrm{R}, 1 \mathrm{R}, 3 \mathrm{R}, 2 \mathrm{R}$ \\
\hline $7 \mathrm{R}$ & $\mathrm{M} 10$ dpth.18 & $6 \mathrm{R}, 12 \mathrm{R}, 10 \mathrm{R}, 11 \mathrm{R}$ \\
\hline $8 \mathrm{R}$ & $\Phi 2.90$ dpth.9 & \multicolumn{1}{c|}{$2 \mathrm{R}$} \\
\hline $9 \mathrm{R}$ & 82 (right side) & $1 \mathrm{R}, 2 \mathrm{R}, 3 \mathrm{R}$ \\
\hline $10 \mathrm{R}$ & 82 (left side) & \\
\hline $11 \mathrm{R}$ & $1.5 \times 60^{\circ}$ & $6 \mathrm{R}, 10 \mathrm{R}, 12 \mathrm{R}$ \\
\hline $12 \mathrm{R}$ & $\Phi 8.4$ dpth.20 & $6 \mathrm{R}, 10 \mathrm{R}, 1 \mathrm{R}$ \\
\hline
\end{tabular}

TABLE 3. Matrix of anteriorities

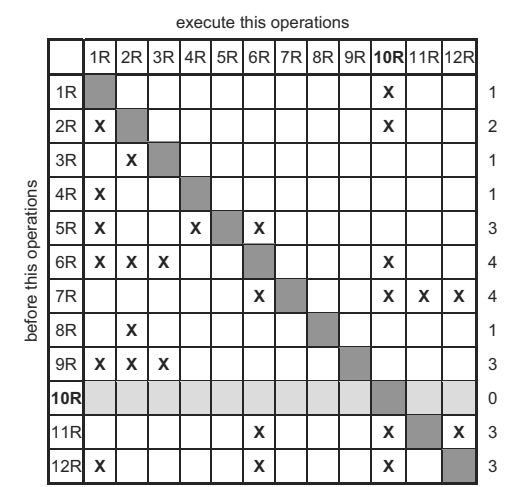

\section{CONCLUSION}

The first process selection strategy is capable to give unique answer which process is optimal regarding its costs and capability, although elimination of processes in 2 nd step could be a bit inaccurate regarding limited information about particular process. Second strategy of candidate process "screening" is more precise but it usually provides more than one process and further reduction is often not possible in the early stage due to lack of information. Experience and knowledge of process planer has lot of influence on decision which features precede other features. The shape of part is usually very complex so process planer can miss or not see some relations. Knowledge and experience are limited. This example shows logical approach that can be used to solve conflict situations in decision making regarding sequencing of operations.

\footnotetext{
${ }^{1} \mathrm{R}$-rough surface in machining process. See Figure 1
} 
TABLE 4. Matrixes of anteriorities for second step and third step

a)

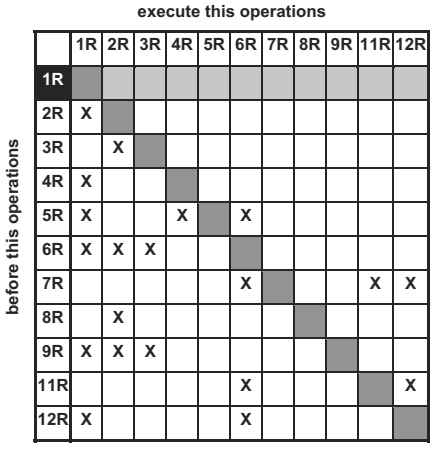

b)

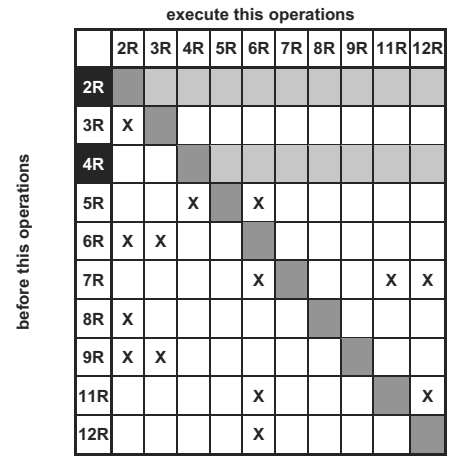

TABLE 5. Additional criterions for solving conflict situations

\begin{tabular}{|c|c|c|c|c|c|}
\hline \multicolumn{2}{|r|}{$\begin{array}{c}\text { Surface } \\
\text { (Feature) }\end{array}$} & Process & Machine & Fixture & Tool \\
\hline $1 \mathrm{R}$ & $\Phi 18 \mathrm{k} 6\left(\begin{array}{c}+15 \mu M \\
+2 \mu M\end{array}\right)$ & Turning & Lathe & $\nabla_{10} \nabla_{9}$ & \\
\hline $2 \mathrm{R}$ & $\Phi 14$ & Turning & Lathe & $\nabla_{10} \nabla_{9}$ & \\
\hline $3 \mathrm{R}$ & $\Phi 13,40 \mathrm{~h} 11$ & Turning & Lathe & $\nabla_{10} \nabla_{9}$ & \\
\hline $4 \mathrm{R}$ & Counter bore $2 \mathrm{~mm}$ & Milling & Mill & $\nabla_{1}$ & $\Rightarrow$ \\
\hline $5 \mathrm{R}$ & $\Phi 5$ & Drilling & $\begin{array}{l}\text { Drilling machine } \\
\text { Mill }\end{array}$ & $\nabla_{1}$ & tis \\
\hline $6 \mathrm{R}$ & $\Phi 5$ dpth.70 & Drilling & $\begin{array}{l}\text { Drilling machine } \\
\text { Lathe }\end{array}$ & $\nabla_{1}$ & i. \\
\hline $7 \mathrm{R}$ & M10 dpth.18 & Threading & $\begin{array}{l}\text { Drilling machine } \\
\text { Mill }\end{array}$ & $\nabla_{1}$ & 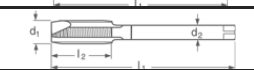 \\
\hline $8 \mathrm{R}$ & Ф2.90 dpth.9 & Drilling & $\begin{array}{c}\text { Drilling machine } \\
\text { Mill } \\
\end{array}$ & $\nabla_{1}$ & 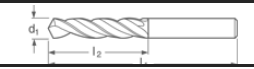 \\
\hline $9 \mathrm{R}$ & 82 (right side) & Turning & Lathe & $\nabla_{1} \nabla_{10}$ & \\
\hline $10 \mathrm{R}$ & 82 (left side) & Turning & Lathe & $\nabla_{1} \nabla_{9}$ & \\
\hline $11 \mathrm{R}$ & $1.5 \times 60^{\circ}$ & Countersinking & $\begin{array}{c}\text { Mill } \\
\text { Drilling machine }\end{array}$ & $\nabla_{1}$ & \\
\hline $12 \mathrm{R}$ & $\Phi 8.4$ dpth. 20 & Drilling & $\begin{array}{l}\text { Drilling machine } \\
\text { Lathe }\end{array}$ & $\nabla_{1}$ & व \\
\hline
\end{tabular}

\section{REFERENCES}

1. Kalpakjian S., Schmid S.: Manufacturing, Engineering \& Technology, Prentice Hall, Upper Saddle River, NJ, 2006.,

2. Swift, K.G., Booker, J.D. Process Selection, from Design to Manufacture, ButterwortHeinemann, Linacre House, Jordan Hill, Oxford, 2003.,

3. Halevi, G., Process of Operation Planning, Kluwer Academic Publishers, Dordrecht, 2003.

4. Boothroyd G., Dewhurst P., Knight W.: Product Design for Manufacture and Assembly, CRC Press, 2nd edition, 2002. 


\title{
STOCHASTIC MODELING OF FUEL PROCUREMENT FOR ELECTRICITY GENERATION
}

\author{
C. Testuri ${ }^{1}$ and B. Zimberg ${ }^{2}$ \\ ${ }^{1}$ Instituto de Computación, Universidad de la República, J. Herrera y Reissig 565, \\ 11300 Montevideo, Uruguay \\ ${ }^{2}$ Administración Nacional de Combustibles, Alcohol y Portland ANCAP, Humboldt 3900, \\ 11900 Montevideo, Uruguay
}

\begin{abstract}
Electricity generation in Uruguay is based mainly on hydro power resources. Increase in demand of electricity and lack of water in dams, due to climate variations, are the main factors behind the requirement of fuel for thermal generation in order to satisfy demand. Most of this uncertain demand of fuel must be purchased as a set of cargoes for a given period and the decision is typically taken two months before the arrival of the product. In the meantime, demand or production of fuel could change and the possibility of extra costs arises such as demurrages or cancellations due to capacity constraints.

This paper presents a simplified multi-stage stochastic model that represents the problem of fuel procurement; whose decisions are based on a minimum expected cost criteria for a given set of scenarios.
\end{abstract}

\section{INTRODUCTION}

Thermal generation contribution in Uruguay has shown an increase in the last years and consequently the demand for fuel to power it. Part of the fuel demand is supplied with production, but most of it must be imported. Due to the higher cost of thermal generation compared to hydroelectric generation, the requirement of fuel decreases as soon as hydroelectric power dams reach their security levels or electricity demand decreases.

At the procurement of fuel, there is a time delay between the moment of purchasing decision and cargo arrival. Different kinds of contracts with fixed and optional volumes are considered in order to satisfy fuel requirements. Due to capacity constraints and adjustments in demand, demurrages and cancellations can increase the final cost of cargoes. Additionally, 
the volume, within discrete sizes, of the cargo is part of the decision, usually taken two months before its arrival.

Uncertainty of demand is modeled as a set of scenarios of fuel consumption and statistical measures of occurrence can be obtained from an electric generation model (unit commitment model) for a given time period.

Usually, decisions on purchasing, cancellation and demurrage assumptions or a combination of them are the result of a scenario analysis (expected, worst and best cases). It combines demand, fuel imports, exports, production and capacity constraints.

We propose an additional procedure for decision support, a multi-stage stochastic model with recourse that represents the problem of fuel purchasing, consumption, production and storage. The decision is based on a minimum expected cost optimization that covers the complete set of scenarios and is taken in the first or deterministic stage of the process.

This article refers to the problem of fuel acquisition. With relation to fuel consumption, other references of stochastic models on the subject of electric power generation are focused on the analysis of which generating units are in use for some period of time [1], or the acquisition of new technologies for power generation [2].

\section{MODELING METHODOLOGY}

The problem requires taking decisions on sequence, over time, interleaved with uncertain events. The successive pairs of decisions and uncertain events over time are denoted stages. For it's modeling, a multistage stochastic programming approach was considered appropriated (Dantzig [3], Beale [4]).

The multistage stochastic programming is an optimization schema that selects the best sequence of decisions over stages with regards to a given objective. At each stage, the methodology models decisions prior to unknown events, by including data parameters that are known within certain probability distribution at the time decisions should be made. Therefore, the decisions are hedged against future events uncertainty by considering its parameters distributions. For a given stage decisions, its successive stage decisions act like corrective or recourse actions, after the transitional unknown event is unveil. While the sequence's first stage decisions are considered deterministic, the following ones are considered stochastic, since them depend of random parameters. The aim is to find a sequence of decisions, subject to problem constraints, that optimizes certain expectation of some objective function of the 
decisions (Prékopa [5], Birge and Louveaux [6], Ruszczynski and Shapiro [7], Ziemba and Wallace [8]).

An approach to model uncertainty at each stage is to represent random parameters with a set of finite instances denoted scenarios, together with a probabilistic measure of its occurrence. Therefore, due to the time ordered sequence of stages a tree-graph of scenarios and their relationships is generated, where the edges of the tree represent the scenarios and the vertices encapsulates the decisions with its constraints (Rockafellar and Wets [9]).

Some of the decisions are discrete on its domains, this implies that the model is harder to solve since it requires to incorporate integer programming resolution methods (Benders [10], Schultz [11], Laporte and Louveaux [12], Sen [13]).

\section{MODEL DESCRIPTION}

The model represents decisions on acquisition, devolution and demurrage of cargoes at minimum expected cost, subject to demand and production, inventory constraints for different scenarios over a time horizon of stages.

\subsection{Index Sets}

$T$ : time horizon period, with periods $t=1, \ldots, T$.

$S$ : set of final scenarios $s \in S$, that models uncertainty at the horizon period, $t=T$.

$S_{t}$ : subset of scenarios $s_{t} \in S_{t}$, that models uncertainty at period $t \in T$. For the initial period, $t=1$, there exists an unique scenario, denoted by $\sigma_{t}=1$, for subsequent periods the scenarios are established as $S_{t}:=\left\{\sigma_{t-1}+1, \ldots, \sigma_{t}\right\}$, where $S_{T}=S$.

$I$ : set of import cargoes to decide on, $i \in I$.

$J$ : set of assigned import cargoes, $j \in J$.

$E$ : set of export cargoes to decide on, $e \in E$.

$D_{i}$ : set of import cargoes $i$ sizes (discrete), with $d_{i} \in D_{i}$.

$D_{e}$ : set of export cargoes $e$ sizes (discrete), with $d_{e} \in D_{e}$.

\subsection{Parameters}

For each period $t=1, \ldots, T$, scenarios $s_{t} \in S_{t}$ and cargoes $i \in I$ or $e \in E$ :

Inputs and Outputs 
StkIni : initial stock level

$D T^{s t}$ : thermal demand

$D O^{s t}$ : non-thermal demand

$P^{s t}:$ production

$\operatorname{StkMin}^{\text {st }}$ : minimum stock level

$\mathrm{DStkMin}^{\text {st }}$ : maximum change (absolute) bellow the minimum stock level for which corresponds a penalization cost

StkMax ${ }^{s t}$ : maximum stock level

DStkMax ${ }^{\text {st }}$ : maximum change (absolute) above the maximum stock level for which corresponds a penalization cost

TEfect $(i)$ : number of periods after $t=1$, when the cargo is received.

$\operatorname{Imp} A_{j}{ }^{t}$ : import cargo volume, previously assigned, $j \in J$, effective on period $t=\operatorname{TEfect}(i)$; such that $\operatorname{Imp} A_{j}^{t^{\prime}}=0, \forall t^{\prime} \neq t$

$\operatorname{DimImp}_{i d}$ : volume size for each $d_{i} \in D_{i}$, for import cargoes $i \in I$

$\operatorname{DimExp}_{e d}$ : volume size for each $d_{e} \in D_{e}$, for export cargoes $e \in E$

WUMax: upper adjustment on production (maximum)

WLMax: lower adjustment on production (maximum)

\section{$\underline{\text { Costs and Prices }}$}

$C I_{i}$ : unitary import cost

$C D_{i}$ : unitary cancellation cost

$C I_{j}$ : unitary import cost

$C D_{j}$ : unitary cancellation cost

$C M^{t}$ : unitary demurrage cost

$C P^{t}$ : unitary penalization cost for minimum stock violation

$C W^{s t}$ : cost associated with production reduction

$B W^{s t}$ : benefit associated with production increase

$P E_{e}$ : unitary export price

\section{$\underline{\text { Probabilities }}$}

For all $s_{t} \in S_{t}$, let $p_{s_{t}}$ be the path probabilities of the corresponding subsequences of scenario realizations, such that $p_{s_{t}}>0$ and $\sum_{s_{t}=\sigma_{t-1}+1}^{\sigma_{t}} p_{s_{t}}=1$. 


\subsection{Variables}

For each period $t=1, \ldots, T$, scenarios $s_{t} \in S_{t}$ and cargoes $i \in I$ or $e \in E$ :

$S t k^{s t}:$ stock level

$W^{s t}$ : adjustment on production parameter, $P^{s t}$,

$W U^{s t}$ : upper adjustment on production,

$W L^{s t}$ : lower adjustment on production,

$\operatorname{Exp}_{e}{ }^{s t}$ : export volume cargo to be decided $e \in E$, for scenario $s_{t=1}$, initial period $(t=1)$; such that $\operatorname{Exp}_{e}{ }^{t^{\prime}}=0, \forall t^{\prime} \neq 1$.

$X \operatorname{Exp}_{e d e}{ }^{\text {st }}: 1$ if volume size $d_{e}$ is selected for export cargo $e \in E$, for scenario $s_{t=1}, 0$ otherwise.

$\operatorname{Imp}{ }_{i}{ }^{t}$ : import volume cargo to be decided $i \in I$, e for scenario $s_{t=1}$, initial period $(t=1)$; such that $\operatorname{Exp}_{e}{ }^{t^{\prime}}=0, \forall t^{\prime} \neq 1$.

$\operatorname{XImp}_{\text {idi }}{ }^{\text {st }}: 1$ if volume size $d_{i}$ is selected for import cargo $i \in I$, for scenario $s_{t=1}, 0$ otherwise.

$D e v_{i}^{s t}: \quad 1$ if import cargo $i \in I$ is cancelled, scenario $s_{t}$, effective on period $t=\operatorname{TEfect}(i)$.

$\operatorname{Dev}_{j}{ }^{s t}: 1$ if previously assigned import cargo $j \in J$ is cancelled, scenario $s_{t}$, effective on period $t=T E f e c t(j)$.

$V_{S t k M i n}{ }^{s t}$ : change (absolute) bellow the minimum stock level

$V S t k M a x^{s t}$ : change (absolute) above the maximum stock level

\subsection{Constraints}

\section{Balance constraints}

$$
\begin{aligned}
S t k^{s t+1}= & S t k^{s t}+P^{s t}+W U^{s t}-W L^{s t}-D T^{s t}-D O^{s t}+ \\
& +\sum_{j \in J} \operatorname{Imp}_{j}{ }^{t} \times\left(1-D e v A_{j}^{s t}\right)+\sum_{i \in I} \operatorname{Imp}_{i}{ }^{t} \times\left(1-\operatorname{Dev}_{i}{ }^{s t}\right)-\sum_{e \in E} \operatorname{Exp}_{e}{ }^{s t}, \\
& \forall s_{t} \in S_{t}, \quad t=1, \ldots, T-1 .
\end{aligned}
$$

where Stk $^{s, t=1}=$ StkIni.

\section{Capacity constraints}

$$
S t k M i n^{s t}-D S t k M i n^{s t} \leq S t k^{s t} \leq S t k M a x x^{s t}+D S t k M a x x^{s t}, \forall s_{t} \in S_{t}, t=1, \ldots, T .
$$


Activation of stock level changes and bounds

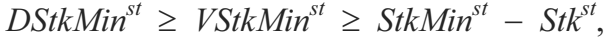

$$
\begin{aligned}
& \text { DStkMax }^{s t} \geq \text { VStkMax }^{s t} \geq S t k^{s t}-S t k M a x \text {, } \\
& \text { VStkMin }^{\text {st }} \geq 0, \quad \text { VStkMax }^{\text {st }} \geq 0, \forall s_{t} \in S_{t,}, t=1, \ldots, T \text {. }
\end{aligned}
$$

\section{Import and export cargo size selection}

Only one size of volume for each cargo is selected

$$
\begin{aligned}
& \operatorname{Imp}_{i}{ }^{s t}=\sum_{d i \in D i} \operatorname{DimImp}_{i, d i} X \operatorname{Imp}_{i, d i}{ }^{s t}, t=1 \\
& \sum_{d i \in D i} X \operatorname{Imp}_{i, d i}{ }^{s t}=1, \\
& \operatorname{Exp}_{e}{ }^{s t}=\sum_{d e \in D e} \operatorname{DimExp}_{e, d e} X \operatorname{Exp}_{e, d e}{ }^{s t}, \\
& \sum_{d e \in D e} X \operatorname{Exp}_{e, d e}{ }^{s t}=1,, \forall s_{t} \in S_{t}, t=1, \ldots, T .
\end{aligned}
$$

Upper and lower adjustments on production and bounds

$$
\begin{aligned}
& \text { WUMax } \geq W U^{s t} \geq W^{s t}-P^{s t}, \\
& W L M a x \geq W L^{s t} \geq P^{s t}-W^{s t}, \forall s_{t} \in S_{t}, t=1, \ldots, T .
\end{aligned}
$$

General non-negative constraints of continuous variables

All continuous (real) variables are non-negative.

\subsection{Objective function}

The goal is to minimize total expected cost:

$$
\begin{aligned}
& \text { Minimize } \sum_{t=1}^{T} \sum_{s_{t}=\sigma_{t-1}+1}^{\sigma_{t}} p_{s_{t}}\left[\Sigma_{j \in J} C I_{j} \times \operatorname{Imp} A_{j}{ }^{t} \times\left(1-\operatorname{Dev} A_{j}{ }^{s t}\right)\right. \\
& +\sum_{i \in I} C I_{i} \times \operatorname{Imp}_{i}{ }^{t} \times\left(1-\operatorname{Dev}_{i}{ }^{s t}\right) \\
& +\sum_{j \in J} C D_{j}^{s t} \times \operatorname{Dev}_{j}^{s t}+\sum_{i \in I} C D_{i}^{s t} \times \operatorname{Dev}_{i}{ }^{s t} \\
& +\sum_{e \in E} P E^{s t} \times \operatorname{Exp}_{e}{ }^{s t} \\
& \left.+C W^{s t} \times W U^{s t}-B W^{s t} \times W L^{s t}+C P^{t} \times V S t k M i n^{s t}+C M^{t} \times V S t k M a x{ }^{s t}\right]
\end{aligned}
$$

\section{CONCLUSIONS}

The model comprises the effect of production, demand and purchase of discrete volumes of fuel for a set of scenarios and probabilities taking into account the impact of the market and inventories through parameters such as import, cancellation and demurrage costs. 
Model's results would provide the user with the scope of corrective actions for each scenario, one of the main capabilities of the stochastic programming technique.

This paper is part of a project that aims to develop a tool for decision support in stochastic processes. Once defined the problem and model the work will follow with the process of implementation.

\section{REFERENCES}

[1] Takriti, S., Birge, J. and Long, E., A Stochastic Model for the Unit Commitment Problem. IEEE Transactions on Power Systems, 11, ํo3 (1996).

[2] Bienstock, D. and Shapiro, F.e, Optimizing Resource Acquisition Decisions by Stochastic Programming, Management Science 34, N², 215-229. (1988).

[3] Dantzig, G.B., Linear programming under uncertainty, Management Science, 1, 197206 (1955).

[4] Beale, E.M.L., On minimizing a convex function subject to linear inequalities, Journal of the Royal Statistical Society, Series B, 17, 173-184 (1955).

[5] Prékopa, A., Stochastic Programming, Kluwer, Dordrecht, Boston, 1995.

[6] Birge, J.R. and Louveaux, F., Introduction to Stochastic Programming, Springer, 1997.

[7] Ruszczynski, A. and Shapiro, A., (Eds.), Stochastic Programming, Handbook in OR \& MS, Vol. 10, North-Holland Publishing Company, Amsterdam, 2003.

[8] Ziemba, W.T. and Wallace, S.W., Applications of Stochastic Programming, SIAM, 2006.

[9] Rockafellar, R.T. and Wets, R.J-B., Scenarios and policy aggregation in optimization under uncertainty, Mathematics of Operations Research, 16, 119-147 (1991).

[10] Benders, J.F., Partitioning procedures for solving mixed-variable programming problems, Numerische Mathematic, 4, pp. 238-252 (1962).

[11] Schultz, R, Continuity properties of expectation functions in stochastic integer programming, Mathematics of Operations Research, 18, pp. 578-589 (1993).

[12] Laporte, G. and F.V. Louveaux, The integer L-shaped methods for stochastic integer programs with complete recouse, Operations Research Letters, 13, pp. 133-142 (1993).

[13] Sen, S., Algorithms for stochastic mixed-integer programming models', in Aardal, K., Nemhauser, G.L. and Weismantel, R. (Eds.): Handbooks in OR \& MS, Vol. 12, Dordrecht, North-Holland, Chapter 9, pp.515-558 (2005). 


\title{
HOW RADIO FREQUENCY SIGNALS CAN ASSIST IN PROVIDING SECURITY TO INDUSTRIAL LOGISTICS
}

\author{
G. R. DeJean and D. Kirovski \\ Microsoft Research \\ One Microsoft Way \\ Redmond, WA 98052, U.S.A.
}

\begin{abstract}
RF-DNA is a new anti-counterfeiting technology that uses randomly arranged objects that exhibit highly distinctive RF electromagnetic properties. The responses

of these objects are cryptographically signed with the private key of the issuer.

This signature, "fingerprint," and data, associated with the tag, are then stored on a low-cost storage such as an RFID and attached to the object. Verification of the resulting RF-DNA instance is done using an inexpensive off-line device that verifies the stored signature using the widely-proliferated public key of the issuer, and then compares the in-field scanned "fingerprint" with the "fingerprint" signed during issuing to confirm the authenticity of the RF-DNA instance. Researchers at Microsoft Research explore the feasibility of RF "fingerprints" constructed based on the reflection, refraction, and reradiation of energy impinging upon a constellation of metal wires in the RF domain. In addition, the potential benefits of RF-DNA are explored with respect to security in industrial logistics. Furthermore, the process of issuing and verifying RF-DNA certificates are explained. Finally, some ways that RF-

DNA can be applied to products are discussed.
\end{abstract}

\section{INTRODUCTION}

Counterfeiting is as old as the human desire to create objects of value. For example, historians have identified counterfeit coins just as old as the corresponding originals. There are examples of counterfeit coins netting a $600 \%$ instant profit to the counterfeiter [1]. It is hard to assess and quantify the market for counterfeit objects of value today. With the ease of marketing products on-line, it seems that selling counterfeit objects has never been easier. National economies and industries that are under attack include the software and hardware, 
the pharmaceutical, the entertainment, and the fashion industry. RF-DNA attempts to tackle this on-going problem.

RF-DNA certificates are actually certificates of authenticity (COA) in the RF domain. A certificate of authenticity (COA) is a digitally signed physical object of fixed dimensions that has a random unique structure which satisfies the following requirements:

R1: the cost of creating and signing original COAs is small, relative to a desired level of security,

R2: the cost of manufacturing a COA instance is several orders of magnitude lower than the cost of exact or near-exact replication of the unique and random physical structure of this instance,

R3: the cost of verifying the authenticity of a signed COA is small, again relative to a desired level of security, and

R4: it should be computationally difficult to construct an object of fixed dimensions with a "fingerprint" $\mathrm{y}$ such that $\|\mathrm{x}-\mathrm{y}\|<\delta$, where $\mathrm{x}$ is a given "fingerprint" of an unknown COA instance and $\delta$ bounds the proximity of $\mathrm{x}$ and $\mathrm{y}$ with respect to a standardized distance metric $\|\cdot\|$.

An additional requirement, mainly impacted by a desired level of usability, is that a COA must be robust to ordinary wear and tear. COA instances can be created in numerous ways. To the best of our knowledge, we are the first to develop RF-DNA technology based on COAs with the aim of addressing counterfeiting. It is noted that traditional RFIDs with encoded digital information could be easily replicated and thus, are not capable of resolving the problem of tag authenticity.

\section{RF-DNA CERTIFICATE AND SCANNER PROTOTYPES FOR TESTING}

We investigate which objects behave as COAs in the electromagnetic field and the kind of properties they offer as counterfeit deterrents. RF-DNA certificates are built based upon several near-field phenomena that electromagnetic waves exhibit when interacting with complex, random, and dense objects. An object created as a random constellation of small (diameter $>1 \mathrm{~mm}$ ) randomly-shaped conductive and/or dielectric objects should have distinct behavior in its near-field when exposed to electromagnetic waves coming from a specific point and with frequencies across the RF spectrum (from UHF to EHF bands). The key to system efficiency is to produce a reader capable of reliably extracting an RF fingerprint" from 
a certificate in the high, but still inexpensive range of frequencies (e.g., 5-6GHz). For example, in order to disturb the near-field of the certificate, we build it as a collection of randomly bent, thin conductive wires with lengths randomly set within $3-7 \mathrm{~cm}$. The wires are integrated into a single object using a transparent dielectric sealant and their position in the sealant is fixed.

An RF-DNA reader is constructed as a matrix of antennas with an analog/digital backend. Each antenna can behave as a transmitter or receiver of RF waves in a specific frequency band supported by the back-end processing. For different constellations of dielectric or conductive objects between a particular transmitter-receiver coupling, the scattering parameters for this coupling are expected to be distinct. Hence, in order to compute the RF "fingerprint", the reader collects the scattering parameters for each transmitter-receiver coupling in the group of antennas. In other words, the unique response "fingerprint" of an RFDNA certificate is measured as a collection of transmission (e.g., $s_{21}$ parameter) responses in the $5-6 \mathrm{GHz}$ frequency range for each transmitter-receiver coupling on the reader. Certificates were placed about $0.5 \mathrm{~mm}$ from the antenna matrix ( in the near-field of the scanner). While the analog/digital back-end in our testbed was resolved using an expensive off-the-shelf network analyzer, it is speculated that a custom reader could cost less than US\$100 if manufactured en masse. An RF-DNA certificate test prototype and a proposed RF-DNA scanner prototype are illustrated in Fig. 1.
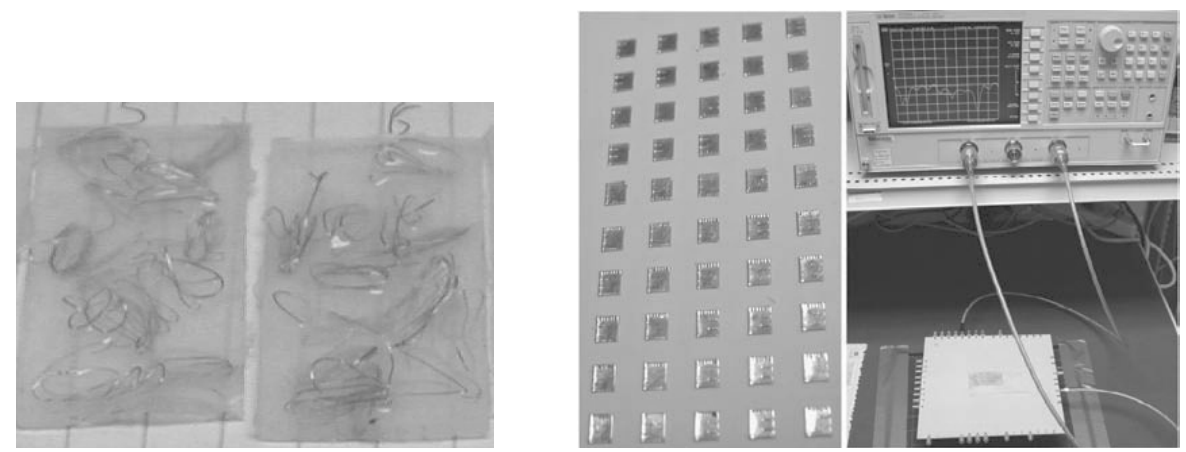

Fig. 1 (Left) Examples of RF-DNA certificates built from copper wire and Dragon Skin ${ }^{\mathrm{TM}}$. The instances were created using standard 22gauge copper wire as a conductive resonator and Dragon Skin ${ }^{\mathrm{TM}}$ silicone rubber as sealant. (Right) Prototype of an RFDNA scanner: a custom built antenna matrix and a network analyzer. 


\section{RF-DNA AND SECURITY SIGNIFICANCE ON LOGISTICS}

The significance of security to logistics can be directly tied to the importance and value of the product one tries to protect. Although the world of logistics typically focuses on areas of warehouse storage, the transportation of goods, the packaging of materials, and inventory control, it is important to include how better methods of security can be integrated into the overall equation. In a study by International Planning \& Research, it is noted that between 5$8 \%$ of world trade, $10 \%$ of the pharmaceuticals market, and $36 \%$ of the software market is counterfeited. In the United States, a 1994 study showed that out of the $\$ 380$ billion in U. S. currency circulated abroad, around \$207 billion of it was counterfeit. In addition, a study completed in 1998 showed that the piracy rate for Western Europe was 34\%. Counterfeiting dates back many years ago with the idea of inscribing small cuts into coins to trick consumers and manufacturers into believing the coin was authentic. Since security procedures have well been implemented as a means of protecting goods, it is obvious that these measures are not enough to circumvent the amount of piracy and counterfeiting that continues to destroy the world economy. Therefore, is there a better means of providing security to goods that does not add complexity or significant time to the process?

Most security methods that have been utilized to this point are implemented in a twodimensional manner. The idea of barcodes dates back 60 years and was mainly constructed as a fast and simple way to track inventory. In terms of security, barcodes have been extensively used in the airline industry for boarding passes and baggage tags. This level of security presents a potential threat due to its $2 \mathrm{D}$ landscape. In a threat scenario, a person $\mathrm{X}$ is scheduled to fly to another city and prints his boarding pass from his computer the day before his scheduled flight. An attacker Y remotely accesses X's computer from an unknown location and gains access to a printer image file of $X$ 's electronic boarding pass, for example, and effectively assumes X's identity at the airport. The 2D image of the barcode makes this scenario an unlikely but true possibility. In libraries, books are often loaded with a barcode and an accompanying magnetic strip that is demagnetized at checkout. This strip can be easily removed from the book and the book stolen from the library. Watermarking is another way of adding security to the goods and services industry. One can commonly see digital watermarking security on passports, currency, and a person's state, province, or country identification. Since watermarks on licenses are typically verified optically through the human eye, a potential threat to watermarking is the ability to produce a copy of the $2 \mathrm{D}$ image (with 
the appropriate software) and alter it in a way that makes a security agent falsely believe the license is authentic. Holograms can be distorted in a similar manner.

What makes RF-DNA an attractive option for a security application is its threedimensional (3D) physical landscape. Each RF-DNA certificate is a random constellation of materials that can be composed of metal wires and/or small dielectric shapes. RF-DNA has the same uniqueness as barcodes and watermarks, but the additional dimension of verticality provides more bits of entropy (randomness). Although the hottest technology on the market for inventory control is RFIDs, a major drawback is that RFIDs provide little security. RFIDs (when used for security purposes) utilize a different method of placing the secure information on the chip of the circuit. Unfortunately, any RFID reader that sends out the appropriate RF signal can gain access to the tag, and effectively, read its contents. The near-field communication mechanism of RF-DNA certificates circumvents the problem of an unintended interrogator intercepting a signal. To that extent, RF-DNA can be used in conjunction with RFID technology to create a"super-tag" that can store information about a product and authenticate or secure its contents.

\section{PROCESS OF ISSUING AND VERIFYING RF-DNA CERTIFICATES}

The process of issuing and verifying an RF-DNA certificate is displayed in Fig. 2. When creating a certificate, the issuer digitally signs instance's electromagnetic response using traditional public-key cryptography. First, the "fingerprint" is scanned, digitized, and compressed into a fixed-length bit string $f$. Next, $f$ is concatenated to the information $t$ associated with the tag (e.g., product ID, expiration date, assigned value) to form a combined bit string $w=f \| t$. One way to sign the resulting message $w$ is to use the Bellare-Rogaway recipe, PSS-R [2], for signing messages using RSA [3] with message recovery. The resulting signature $s$ as well as $w$ are encoded directly onto the certificate using existing technologies such as an RFID. Each certificate is associated with an object whose authenticity the issuer wants to vouch. Once issued, an RF-DNA certificate can be verified off-line by anyone using a reader that contains the corresponding public key of the issuer. In case the integrity test is successful, the original response "fingerprint" $f$ and associated data $g$ are extracted from $w$. The verifier proceeds to scan in-field the actual RF "fingerprint" $f$ ' of the attached instance (obtain a new reading of the instance's electromagnetic properties) and compares them with $f$. 


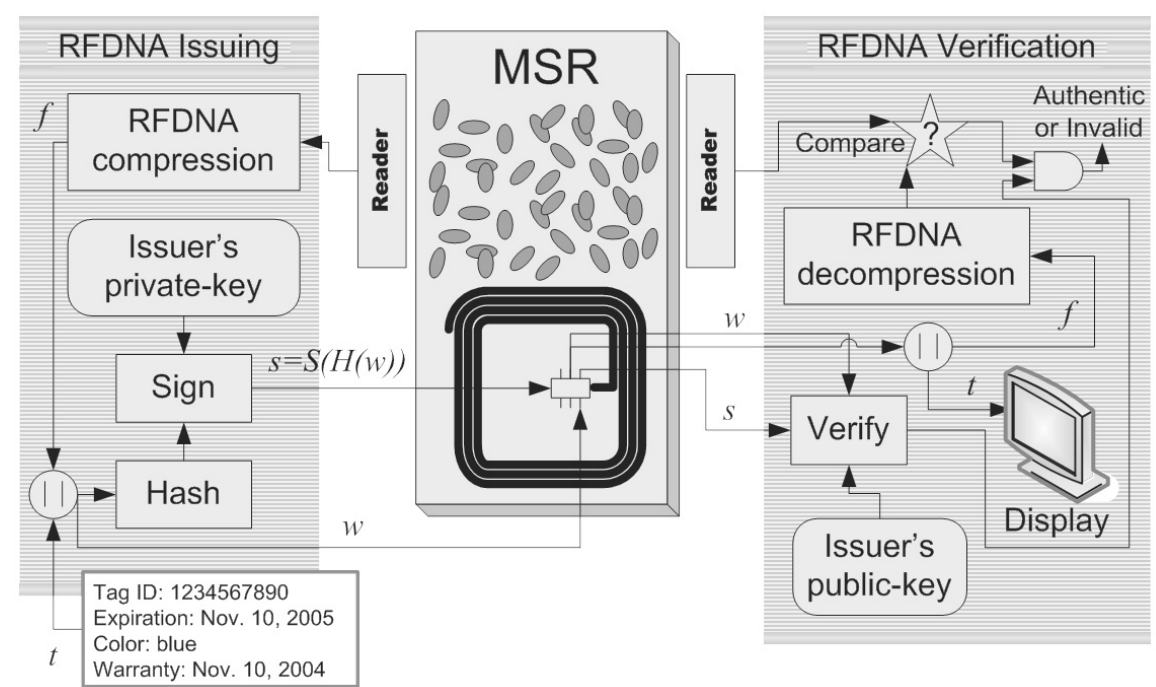

Fig. 2 Process of Issuing and Verifying RF-DNA certificates.

If the level of similarity between $f$ and $f$ ' exceeds a pre-defined and statistically validated threshold $\delta$, the verifier declares the instance to be authentic and displays $t$. In all other cases, the reader concludes that the instance is not authentic. In order to counterfeit protected objects, the adversary needs to:

(i) compute the private key of the issuer - a task which can be made arbitrarily difficult by adjusting the key length of the used public-key crypto-system [3, 4, 5],

(ii) devise a manufacturing process that can exactly replicate an already signed certificate, a task which is not infeasible but requires certain expense by the malicious party - the forging cost dictates the value that a single certificate can protect [6], or

(iii) misappropriate signed RF-DNA certificates - a responsibility of the organization that issues certificate.

\section{APPLICATIONS}

The value of one RF-DNA certificate is approximately equal to the cost of forging the certificate. There are certainly many applications in which this technology can be applied. This section focuses specifically on a couple of applications that have been researched extensively over the past 40 years. 


\subsection{Credit Cards, Checks}

Credit cards and checks can be signed by the issuing bank. In addition, some of these documents can be signed by other parties signifying ownership, timestamp, and/or endorsement. Banks, account holders, and document recipients can all verify that the document has been issued by a specific bank. The framework can enable all features required to transfer, share, merge, expire, or vouch checks. One of the key features of RF-DNA certificates are that their "fingerprints" do not reveal their physical structure in a straightforward fashion. Practically, one can assume the application where credit cards are protected using RF-DNA. Then, by accessing full credit card information from a merchant database (holder's name, card's number and expiration date, PIN code, and RF-DNA "fingerprint"), it would be still difficult for the adversary to create a physical copy of the original credit card produced by the issuing bank. To complete the operation, the enemy would have to gain physical access to the original credit card and accurately scan its $3 \mathrm{D}$ structure (e.g., using X-rays or other 3D imaging systems). Finally, the enemy still faces the task of actually building the 3D object, a task that, we speculate, requires significant costs.

\subsection{Personal Identification Cards}

RF-DNA can make personal visas, passports, and identity cards (both paper and smart card based) hard to copy. In addition, they can protect and/or associate additional information to signed paper documents or artwork. The technology can be used preventively against identity theft; illegally obtained identity information could not be used to materialize a valid identity card unless the original is physically accessible.

\section{CONCLUSIONS}

A system for manufacturing and verifying RF-DNA certificates of authenticity which exhibit their random behavior in the electromagnetic near-field has been proposed. The potential benefits of RF-DNA have been investigated with respect to security for everyday use in industrial logistics. The 3D physical landscape of RF-DNA makes it an attractive option for security applications. In addition, a cryptographic protocol of issuing and verifying RF-DNA certificates has been presented that discusses how RF-DNA can be implemented to RFID technology. Finally, a couple of commercial applications have been explored that show the potentially wide range of use that RF-DNA certificates can provide. 


\section{REFERENCES}

1. K. Barry, "Counterfeits and Counterfeiters: The Ancient World," Available on-line at: http://www.ancient-times.com/newsletters/n13/n13.html. July 2003.

2. M. Bellare and P. Rogaway. The exact security of digital signatures how to sign with RSA and Rabin. EUROCRYPT, pp.399-414, 1996.

3. R.L. Rivest, et al. A method for obtaining digital signatures and public-key cryptosystems. Communications of the ACM, vol.21, no.2, pp.120-126, 1978.

4. ANSI X9.62-1998. Public Key Cryptography for the Financial Services Industry: The Elliptic Curve Digital Signature Algorithm (ECDSA), 1998.

5. IEEE 1363-2000: Standard Specifications For Public Key Cryptography, 2000.

6. D. Kirovski. Toward An Automated Verification of Certificates of Authenticity. ACM Electronic Commerce, pp.160-169, 2004. 


\title{
MANAGEMENT OF LOADING SEMI-TRAILERS WITH VIRTUAL BALANCE SOFTWARE \\ Cezar Augusto M Souza, Jardel Inácio M Vieira e Carlos Alberto Faria \\ Faculty of Civil Engeneering \\ Federal University of Uberlândia \\ Campus Sta Mônica, Av João Naves de Avial 2121
}

38.400-902 Uberlândia, MG

\begin{abstract}
Some companies of road freight transport use truck load skills in the distribution of products based on the total weight. In the axle weighting scales was observed the axle load exceed the maximum weight of the rear axle in tractor unit. These companies have had a serious problem, in addition to fines that had received even the inconvenience of moving another vehicle to make the transhipment the excess of cargo. This problem came to the idea of developing a program written in spreadsheet to guide the load to not incur in overweight. Based on weight, lots of cargo volumes and the vehicle, the program standardize the height of the load and returns the density of the cargo and the weight of the load in the axles. With these parameters may be held rearrangements in the shipment not to exceed the weight per axle and consideringthe reverse order of deliveries.
\end{abstract}

\section{INTRODUCTION}

The condition of the pavement is directly related to the overloading of trucks. If the trucks do not have excess weight, the pavement would be maintained in good condition according to the service life of the project. Only $28 \%$ of the network is in good conditions of the maintenance and despite of the country had invested about $3 \%$ of gross domestic product (GDP) in infrastructure of transportation in 1977, actually the investment fell down to $0.5 \%$ of GDP in 2000.

The control of truck shipments are not effectives in the carriers and the scales and inspection along the highways, as provided for in the Brazilian Transyt Code, are inadequates. Excess weight can be for loading greater than the total gross weight (PBT) or the improper distribution of cargo, causing serious damage to the suspension systems, brakes and steering, despite of wearing the tires. It is also largely responsible for the high number of accidents, as well as causing the rapid deterioration of pavement deformations such as wrinkles, cracks and breaks that compromise the operational performance substantially reducing the average speed. 
Therefore, this paper presents a software called virtual scale, which guides the semi-trailers loading for not incur in overweight on axle or unit tractor and making lots of storage considering the reverse order of deliveries to different destinations.

\section{STRATEGIES OF DELIVERIES}

As a general rule, the deliveries up to $300 \mathrm{~km}$ from the warehouse, the trucks are loaded directly and go out of the Distribution Center (DC), making deliveries directly to the customers. This operation is performed by trucks up to $6,000 \mathrm{~kg}$ of grow weight. Deliveries in distances greater than $300 \mathrm{~km}$, the shipments are consolidated into semi-trailer trucks of 14.40 meters in length and net capacity of 27 tons. When they arrive at destinations, the lots of cargo are transfered to smaller trucks to make the final stretch of the route.

The difference in these strategies allows the carriers to obtain substantial financial gains by performing loads on larger semi-trailer trucks (BALLOU [1]) and providing better customer service because the driver who will make the final stretch normally is resident in that region, which ensures greater understanding and ease delivery to the customers.

Although the developer to know the amount of charge that can be loaded on trucks for practical issues and historical information contained in the worksheet, it is proposed to use a microcomputer software to perform the loading based on:

1. to group the requests depending on the type and model of truck which attend a given region and

2. the maximum number of deliveries for each trip.

After the separation, it is done the conference of the products and quantities of the cargo lot. If all items are corrects it is done the load and then loading the truck observed the following points:

1. put at the bottom, the products with better carrying capacity;

2. separate lots of load by placing canvas

3. accommodate lots of cargo according to the reverse order of deliveries;

4. observe constrains on the weight and volume of loading the truck.

If there is any change in the sequence of lots of load it is necessary to note the change in the document which came from Routing Sector. This document must be attached to the package of bills, with the number of lots that will be in the truck. This information must be 
transmitted to the warehouse management system (WMS) to be made other procedures, such as, separation, conferencing, and truck loading. In the same time, the loading sector get a document which contain the following data: numbers of consignments of cargo, weights and volumes and the vehicle to be loaded. Then, the invoices are issued in the same order of delivery to customers.

According to Lambert [4], the routing software is specially beneficial to companies that deal with a large number of supplies or when the deliveries occur in cities of medium and large sized, because these software provide the reduction of costs and delivery times. As the main objectives the routing is intended to provide a high level of service to customers, but at the same time, keeping operating costs as low as possible (NOVAES [5]).

\section{THE TRUCK LOADING PROBLEM}

Concern about the weight loaded on trucks which does not exceed the maximum load of 27 tons as the difference between the Total Gross Weight (PBT) of 41.5 tons and the tare of 14,5 tons permitted in Resolution No. 210/06 (CONTRAN [2]), Nevertheless, shipments continued to present overloads in some axle scaling, mainly in the state of Sao Paulo. According to Resolution 001 of 24/10/04 of the National Road Infrastructure Department (DNIT [3]), vehicles with single rear axle in tractor unit may show that axis, the maximum of 10.0 tons of cargo.

Some trucks loaded with less than 27 tons of net cargo, while weighing by axle, still had excess weight on the rear of the tractor unit. In addition to the fines for overloading, it was necessary to move other trucks or hire third parties to make transshipments. To avoid such problems, some companies began to limit the load up to 17 tons that means around $60 \%$ of load capacity of the trucks, becoming the operation more inefficacy.

To solve this problem and find an optimal solution, distributing the load better and without incurring excessive weight on the rear of the tractor unit, on the basis of volume and weight of loads, that means the factor stowage of cargo and vehicle was developed a software called virtual scale that would guide the balance of vertical forces and moments to load.

\section{THE VIRTUAL SCALE}

The software performs two procedures of controls loading, firstly strikes a balance of vertical forces and moments to obtain the resultant on the axles and the secondly, to rearrange 
the loads lots of standardizing the maximum height of cargo in the truck. The typical vehicle that was considered in this study is the semi-trailer truck (2S3) brand Facchini with 14.40 meters long, 2.60 meters height and 2.48 meters wide, which amounts to the gross volume of $92.85 \mathrm{~m} 3$ and the net capacity of 27 tons of cargo.

The weight of the semi-trailer is unloaded on fifthwheel (point Q) of tractor unit at a distance of $0.30 \mathrm{~m}$ of the rear axle, as shown in Figure 1 (a). The distance between the front and rear axle is 3.53 meters, therefore, it was considered the factor of $91.5 \%$ for the rear axle and $8.5 \%$ for the front axle in the equilibrium of forces in the tractor unit. The software calculates the reaction force (RF) applied to the rear axle of the tractor unit as shown in Equation 1, below:

$$
\mathrm{FR}=0,915 \times \mathrm{F}
$$

Based on data from the lots of load previously chosen for a given route, the software begins by standardizing the heights of the lots of cargo to prevent damage in transit. The scheme of loading is shown in Figure 1 (b), ie., "n" lots of load Pi is the weight of lot, respectively

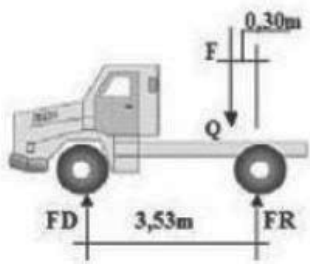

(a)

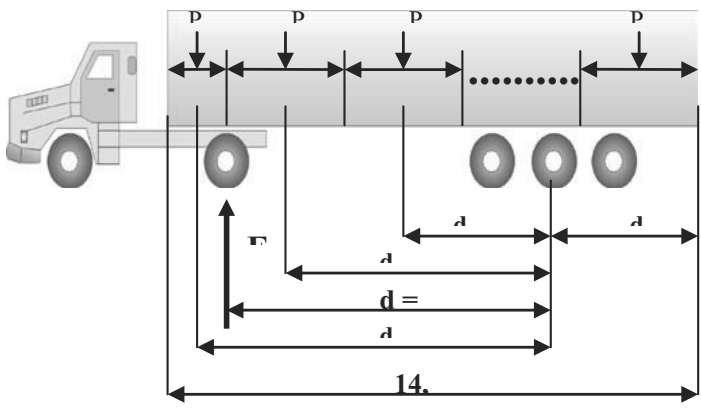

(b)

Figure 1: Scheme of forces and distances

The software considers the center of the triple tandem axle on semi-trailer as a reference point around which the sum of the moments must be zero. Then, the parameter to be calculated is the reaction force of the rear axle of the tractor unit. As the structural system of the truck is not rigid one because of damping and suspension springs, it was used to correct these effects and increase the safety in the calculations the relief of the load at the end of the 
semi-trailer, after the center of the tandem axle triple should be about $60 \%$. Therefore, the damping system of the vehicle would absorb $40 \%$. The reaction forces were made in the rear of the tractor unit. The software compares the result with the maximum net load in that axle, as shown in Equation 2:

$$
\sum_{i=1}^{n} M^{O}=P_{1} \times d_{1}+P_{2} \times d_{2}+\ldots+P_{n} \times d_{n}+F R \times d=0
$$

If the resultant force (FR) is less than or equal to the maximum net weight allowed on the rear axle, the software returns the information that the load complies with the maximum allowed value. Otherwise, the software returns to the loading should not be done in the initial way planned. In this case, must be clicked again in optimize key for the software to to reorganize new loading until it meets the limitations of axle weight

The software also has the length, width and height of the semi-trailer truck, so when redistribute the useful area in the trailer, says the length and height of the lots because the width is bounded by the dimension of the truck.

\section{STUDY OF CASE}

The loading in Figure 2 shows the total net weight of 24,594.00 kilograms, overweight on the rear axle of the tractor unit of 1455.03 kilograms and clearance of 2987.51 kilograms in tandem triple axle. If the truck loading respect the procedure done by the sector routing and travel with the indicated sequence of cargo lots, would be fined and have to perform the transfer of excess load to another vehicle. By having two different destinations, the software must comply with this condition during the processing load without mixing lots of loads. To generate new load must be clicked in Optimize key. Figure 3 show the new sequence of loading produced by the virtual balance software.

\begin{tabular}{|l|r|}
\hline Wide and height & 2,60 \\
\hline length & 14,40 \\
\hline $\begin{array}{l}\text { Net weight on rear axle of tractor } \\
\text { unit }\end{array}$ & $6.290,00$ \\
\hline Net weight on triple tanden axle & $19.117,00$ \\
\hline Weight on fifthwheel & $8.464,51$ \\
\hline Weight on rear axle of tractor unit & $7.745,03$ \\
\hline
\end{tabular}

\section{OPTIMIZE}

\begin{tabular}{|c|c|}
\hline Load height & 2,30 \\
\hline$\%$ & 0,88 \\
\hline Vsemi-trailer volume & 76,00 \\
\hline Total weight & $24.594,00$ \\
\hline
\end{tabular}




\begin{tabular}{|l|r|}
\hline Relief on rear axle of tractor unit & $1.455,03$ \\
\hline Relief on triple tanden axle & $-2.987,51$ \\
\hline
\end{tabular}

\begin{tabular}{|l|r|}
\hline Volume & 67,22 \\
\hline Semi-trailer & 14,40 \\
\hline
\end{tabular}

\begin{tabular}{|c|c|c|c|c|c|c|c|c|c|}
\hline item & $\begin{array}{l}\text { No. of } \\
\text { load }\end{array}$ & Destination & $\begin{array}{c}\text { Weight } \\
\text { (kg) }\end{array}$ & $\begin{array}{c}\text { Load } \\
\text { volume } \\
\left(\mathrm{m}^{3}\right)\end{array}$ & $\begin{array}{l}\text { Lot of load } \\
\text { length } \\
\text { (m) }\end{array}$ & $\begin{array}{c}\text { Density } \\
\left(t / m^{3}\right)\end{array}$ & $\begin{array}{c}\text { Total } \\
\text { legth } \\
(\mathbf{m}) \\
\end{array}$ & Moment & \begin{tabular}{|c}
$\begin{array}{c}\text { Reaction } \\
\text { force } \\
\text { (kg) }\end{array}$ \\
\end{tabular} \\
\hline $1^{a}$ & 100.619 & 1 & $1.808,00$ & 4,93 & 1,06 & 0,37 & 1,06 & $16.763,67$ & $1.972,20$ \\
\hline $2^{a}$ & 100.620 & 1 & $2.516,00$ & 5,88 & 1,26 & 0,43 & 2,32 & $20.415,01$ & $2.401,77$ \\
\hline $3^{a}$ & 100.621 & 1 & $3.474,00$ & 8,91 & 1,91 & 0,39 & 4,22 & $22.684,88$ & $2.668,81$ \\
\hline $4^{a}$ & 100.622 & 1 & $3.191,00$ & 7,19 & 1,54 & 0,44 & 5,76 & $15.334,08$ & $1.804,01$ \\
\hline $5^{a}$ & 100.623 & 1 & $3.153,00$ & 14,00 & 3,00 & 0,23 & 8,76 & $7.995,17$ & 940,61 \\
\hline $6^{a}$ & 100.624 & 1 & $2.107,00$ & 6,01 & 1,29 & 0,35 & 10,05 & 826,88 & 97,28 \\
\hline $7^{a}$ & 100.625 & 1 & $2.664,00$ & 6,26 & 1,34 & 0,43 & 11,39 & $-1.473,42$ & $-173,34$ \\
\hline $8^{a}$ & 100.400 & 2 & 924,00 & 2,75 & 0,59 & 0,34 & 11,98 & $-1.046,09$ & $-123,07$ \\
\hline $9^{a}$ & 100.401 & 2 & $3.182,00$ & 7,14 & 1,53 & 0,45 & 13,51 & $-5.624,90$ & $-661,75$ \\
\hline $10^{a}$ & 100.402 & 2 & $1.575,00$ & 4,15 & 0,89 & 0,38 & 14,40 & $-3.926,94$ & $-461,99$ \\
\hline
\end{tabular}

Figur 2: Initial sequence of loading

\begin{tabular}{|l|r|}
\hline Wide and height & 2,60 \\
\hline length & 14,40 \\
\hline $\begin{array}{l}\text { Net weight on rear axle of tractor } \\
\text { unit }\end{array}$ & $6.290,00$ \\
\hline Net weight on triple tanden axle & $19.117,00$ \\
\hline Weight on fifthwheel & $6.395,29$ \\
\hline Weight on rear axle of tractor unit & $5.851,69$ \\
\hline Relief on rear axle of tractor unit & $-438,31$ \\
\hline Relief on triple tanden axle & $-918,29$ \\
\hline
\end{tabular}

\begin{tabular}{|l|r|}
\hline \multicolumn{1}{|c|}{ Load height } & 2,30 \\
\hline \multirow{2}{|c|}{ Vsemi-trailer volume } & 0,88 \\
\hline \multicolumn{2}{|c|}{} \\
\hline \multicolumn{2}{|c|}{} \\
\hline Total weight & 24,00 \\
\hline Volume & 67,22 \\
\hline Semi-trailer & 14,40 \\
\hline
\end{tabular}

\begin{tabular}{|c|c|c|c|c|c|c|c|c|c|}
\hline item & $\begin{array}{l}\text { No. of } \\
\text { load }\end{array}$ & Destination & $\begin{array}{c}\text { Weight } \\
\text { (kg) }\end{array}$ & $\begin{array}{c}\text { Load } \\
\text { volume } \\
\left(\mathrm{m}^{3}\right)\end{array}$ & $\begin{array}{l}\text { Lot of } \\
\text { load } \\
\text { length } \\
\text { (m) }\end{array}$ & $\begin{array}{l}\text { Density } \\
\left(t / m^{3}\right)\end{array}$ & $\begin{array}{c}\text { Total } \\
\text { legth } \\
\text { (m) }\end{array}$ & Moment & $\begin{array}{c}\text { Reaction } \\
\text { force } \\
\text { (kg) }\end{array}$ \\
\hline $1^{a}$ & 100.623 & 1 & $3.153,00$ & 14,00 & 3,00 & 0,23 & 8,30 & $26.171,31$ & $3.078,98$ \\
\hline $2^{a}$ & 100.624 & 1 & $2.107,00$ & 6,01 & 1,29 & 0,35 & 6,16 & $12.973,13$ & $1.526,25$ \\
\hline $3^{a}$ & 100.619 & 1 & $1.808,00$ & 4,93 & 1,06 & 0,37 & 4,99 & $9.013,53$ & $1.060,42$ \\
\hline $4^{a}$ & 100.621 & 1 & $3.474,00$ & 8,91 & 1,91 & 0,39 & 3,50 & $12.169,23$ & $1.431,67$ \\
\hline $5^{a}$ & 100.625 & 1 & $2.664,00$ & 6,26 & 1,34 & 0,43 & 1,88 & $5.003,18$ & 588,61 \\
\hline $6^{a}$ & 100.620 & 1 & $2.516,00$ & 5,88 & 1,26 & 0,43 & 0,58 & $1.453,61$ & 171,01 \\
\hline $7^{a}$ & 100.622 & 1 & $3.191,00$ & 7,19 & 1,54 & 0,44 & $-0,82$ & $-1.574,18$ & $-185,20$ \\
\hline $8^{a}$ & 100.400 & 2 & 924,00 & 2,75 & 0,59 & 0,34 & $-1,89$ & $-1.046,09$ & $-123,07$ \\
\hline $9^{a}$ & 100.402 & 2 & $1.575,00$ & 4,15 & 0,89 & 0,38 & $-2,63$ & $-2.481,52$ & $-291,94$ \\
\hline $10^{\mathrm{a}}$ & 100.401 & 2 & $3.182,00$ & 7,14 & 1,53 & 0,45 & $-3,84$ & $-7.322,22$ & $-861,44$ \\
\hline
\end{tabular}




\section{Figure 3: Sequence performed by Virtual scale software}

Optimization procedure applied in this loading by virtual scale software provides a new load that maintains the target sequence and removes the overweight observed on the rear axle of the tractor unit and also does not cause any excess weight on tandem triple axle. The clearance in this situation were of 438.31 kilograms and 918.29 kilograms, respectively.

\section{RESULTS}

The software shows up to be confident with the truck loading and the weight of the cargoes was limited to approximately 17 tons per truck (63\% of net charge), could be increased to 23.5 tons ( $87 \%$ of net maximum load) and carried out without overweight on the rear of the tractor unit. The benefits of this procedure of loading were very productive for the carriers, which also optimizes the delivery, was a saving in logistics costs, therefore, had improvements in productivity and profits.

\section{ACKNOWLEDGMENTS}

The writer thanks to Civil Engineering Faculty and Foundation for Research Support in state of Minas Gerais (FAPEMIG) by the financial support to this research.

\section{REFERÊNCES}

1. BALlOU, Ronald H. Logística Empresarial: Transportes Administração de Materiais, Distribuição Física. São Paulo: Atlas, 1995. 388p.

2. CONSELHO NACIONAL DE TRÂNSITO (CONTRAN). Resolução $\mathbf{N}^{\mathbf{2}}$ 210/06 de 13/11/2006. Estabelece os limites de peso e dimensões para veículos que transitem por vias terrestres e dá outras providências. Brasília(DF). 2006.

3. DNIT. Resolução No 001 de 24/010/04. Brasília (DF). 2004.

4. LAMBERT, D M..; STOCK, J.R. Strategic Logistics Management. 4. ed. Boston: MacGraw-Hill/Irwin, c2001. 872 p.

5. NOVAES, Antônio Galvão. Logística e gerenciamento da cadeia de distribuição: estratégia, operação e avaliação. Rio de Janeiro: Campus, 2001. 


\title{
EVALUATING THE IMPACT OF ACCIDENTS RISK ON HYDROGEN ROAD TRANSPORTATION COST
}

\author{
A.C. Caputo, P. M. Pelagagge and P. Salini \\ Department of Mechanical, Energy and Management Engineering \\ University of L'Aquila, Italy \\ Coppito, L'Aquila, 67100
}

\begin{abstract}
A model to estimate the expected cost of accidents for road transport of hydrogen is developed in this paper. The model allows to determine whether, in a given context, the risk of accidents is an influencing variable in the selection of the hydrogen transport mode. A parametric analysis is also carried out and representative values of both safey-related and overall specific transportation costs are presented and discussed in scenarios characterized by varying values of hydrogen demand, delivery distance and route type.
\end{abstract}

\section{INTRODUCTION}

Hydrogen would represent the energy carrier of the so called future "sustainable hydrogen economy" [1]. Nevertheless, hydrogen, which is not freely available in nature, has to be produced and subsequently transported to the point of use. Road transport of hydrogen within a supply chain is a critical task owing to technical problems and safety concerns. In order to assess the potential economic viability of alternative production and transport modes and to determine the lowest cost modes, several hydrogen pathways cost estimation models have been developed in the literature. However, available hydrogen transportation cost models [24] neglect any safety issue, while hydrogen transportation risk analyses focus only on the accidents consequences neglecting the transportation cost. In order to fill this gap, in this paper an economic model is developed to estimate the cost of delivering hydrogen from a central production facility to a single demand point (point-to-point transmission) including the expected cost of possible transportation accidents based on consequences modeling and frequency estimation. The model allows the comparison of two major road transport modes, namely compressed hydrogen $\left(\mathrm{CH}_{2}\right)$ or liquified hydrogen $\left(\mathrm{LH}_{2}\right)$ transport, in function of the 
key variables: transport distance, flow rate, and route characteristics. This allows to make risk-based informed decision about the most cost effective alternative in different economic and geographical scenarios.

\section{TRANSPORTATION RISK MODEL}

Hydrogen safety issues have been already discussed in the literature [5]. In transportation accidents involving truck-mounted tanks, the relevant loss of containment events are catastrophic hydrogen release, release through a large hole or through a small hole. In this work the standard amount of hydrogen transported by a single truck is assumed to be about $300 \mathrm{~kg}$ of $\mathrm{CH}_{2}$ or $4000 \mathrm{~kg}$ of $\mathrm{LH}_{2}$. In case of compressed gas transport and a catastrophic failure, the cloud is predicted to dilute horizontally and vertically upwards, reaching the maximum extent after only about 1 second and disappearing within a few seconds. In case of release through large or small holes a steady state cloud is produced having a length in the order of 20 meters within the Low Flammability Limit of 4\%. If a large cloud were to ignite in the open a flash fire rather than an explosion would be likely to occur. Early ignition of a sudden release of hydrogen would be expected to give rise to a fireball. Early ignition of a continuous release of hydrogen from a small or large hole would give rise to a jet fire rather than a fireball, continuing until the release is over. The above considerations lead to the event tree depicted in Figure 1. Effect distances shown in Table 1 have been adapted from values provided by numerical simulations reported in literature studies referring to scenarios similar to the one examined in this work [6-8], and refer to a 50\% fatality probability. The effect area is assumed to be circular except in the case of jet fires where it is considered to be elliptical with values of major and minor semi-axis reported in the Table. Note that release from a small hole has not been included in Table 1 since the effect range would be limited to a few meters, thus being irrelevant with respect to societal risk. In case of liquid gas transport, hydrogen is stored at cryogenic conditions $\left(-253{ }^{\circ} \mathrm{C}\right)$ and a rapid phase transition is expected as the spilled liquid will boil and evaporate outside the tank. In case of catastrophic release and immediate ignition the evaporating cloud will give rise to a fireball, otherwise a liquid pool will form. According to literature data [9] in case of a $4000 \mathrm{~kg}$ release the pool is expected to have a maximum diameter of about $15-20 \mathrm{~m}$ to be reached in $10-15 \mathrm{~s}$. A subsequent pool ignition would give rise to a pool fire. Otherwise the evaporated hydrogen cloud could ignite determining a VCE. In case of release from holes, instead, a jet fire would 
happen if immediate ignition occurs. Otherwise a pool will form leading to effects similar to the ones previously cited. Overall, the event tree can be depicted as shown in Figure 2. $\mathrm{LH}_{2}$ release effect ranges are also shown in Table 1.

Table 1: Effect ranges $\mathrm{R}_{\mathrm{i}}(\mathrm{m})$ for $\mathrm{CH}_{2}$ and $\mathrm{LH}_{2}$ hydrogen release (50\% death probability).

\begin{tabular}{|c|c|c|c|c|c|c|c|c|c|c|}
\hline Release & \multicolumn{2}{|c|}{ Fireball } & \multicolumn{2}{c|}{ Flash Fire } & \multicolumn{2}{c|}{ Jet fire } & \multicolumn{2}{c|}{ VCE } & \multicolumn{2}{c|}{ Pool fire } \\
\hline & $\mathrm{CH}_{2}$ & $\mathrm{LH}_{2}$ & $\mathrm{CH}_{2}$ & $\mathrm{LH}_{2}$ & $\mathrm{CH}_{2}$ & $\mathrm{LH}_{2}$ & $\mathrm{CH}_{2}$ & $\mathrm{LH}_{2}$ & $\mathrm{CH}_{2}$ & $\mathrm{LH}_{2}$ \\
\hline Catastrophic & 27 & 80 & 38 & 1520 & $\mathrm{No}$ & - & 23 & 55 & No & 10 \\
\hline Large hole & - & - & 8 & 26 & $20 / 7$ & $67 / 18$ & 15 & 15 & No & 6 \\
\hline
\end{tabular}

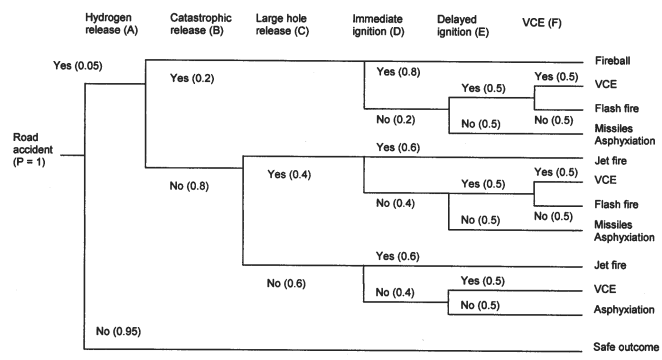

Figure 1: Possible outcomes of $\mathrm{CH}_{2}$ tube trailer accident (numbers in brackets indicate expected probability of the event).

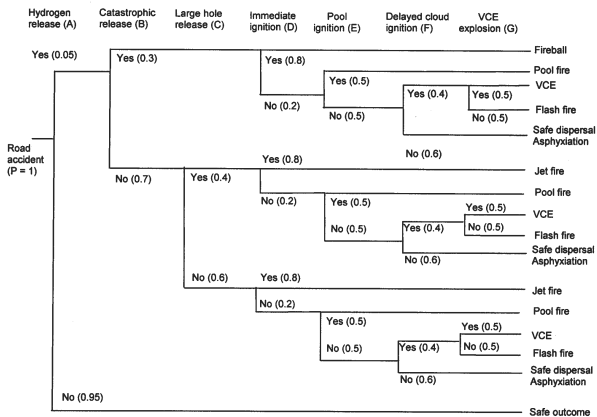

Figure 2. Possible outcomes of $\mathrm{LH}_{2}$ tube trailer accident (numbers in brackets indicate expected probability of the event).

In this paper a simplified approach has been taken to risk assessment given that only an order of magnitude estimate of expected economic loss per shipment is required. In order to compute the risk involved in a single truck trip, we at first assume that the route is segmented into $\mathrm{N}$ trunks. The generic $j$-th trunk is characterized by a length $L_{j}$, a population density in the surroundings $D_{j}$ (people $/ \mathrm{km}^{2}$ ), and an accident rate $A R_{j}$ (accidents/vehicle $\mathrm{km}$ ). Typical values for $A R_{j}$ and $D_{j}$ are given in Table 2 according to Bubbico et al. [10].

Table 2: Reference values for road trunks characteristics.

\begin{tabular}{|c|c|c|c|c|c|}
\hline Road type & $\begin{array}{c}A R_{j} \\
\text { accidents/vehicle km) }\end{array}$ & Area type & $\begin{array}{c}D_{j} \\
\left(\text { people } / \mathrm{km}^{2}\right)\end{array}$ & $\begin{array}{c}S P V_{j} \\
\left(\$ / \mathrm{m}^{2}\right)\end{array}$ & $\begin{array}{c}P B_{j} \\
(\%)\end{array}$ \\
\hline Highway & $8.1 \times 10^{-7}$ & Remote & 100 & 500 & 0.08 \\
\hline State road & $1.6 \times 10^{-6}$ & Rural & 200 & 750 & 1.00 \\
\hline Provincial road & $1.0 \times 10^{-7}$ & Suburban & 1500 & 1000 & 7.00 \\
\hline Urban street & $1.2 \times 10^{-6}$ & Urban & 10000 & 1500 & 30.00 \\
\hline
\end{tabular}


The probability of a hydrogen transport truck to have an accident while crossing a generic trunk $j$ is $p_{j}^{\prime}=\mathrm{AR}_{\mathrm{j}} \mathrm{L}_{\mathrm{j}}$. However, to occur an accident in trunk $j$ requires that an accident has not occurred in any of the previous trunks, given that a single truck can have at most one accident during a trip. Therefore, the actual accident probability is [11]

$$
p_{j}=\prod_{k=1}^{j-1}\left(1-p_{k}\right) p_{j}^{\prime}
$$

Assuming that an accident has occurred, $M$ different consequences scenarios can be generated as shown in the event trees of Figures 1 and 2, each one having a probability of occurrence $F C_{i}$ (with $\mathrm{i}=1$ to $\mathrm{M}$ ), and a corresponding fatality range $R_{i}$ from Table 1 . Values of $F C_{i}$ can be readily computed from the events probabilities assumed in Figures 1 and 2. The $i$-th consequence scenario extends its physical effects within a circular zone of radius $R_{i}$, having a surface area $A_{i}=\pi R_{i}^{2}$. In case of jet fire the effect area is elliptic with surface area $\mathrm{A}_{\mathrm{i}}=\pi a b$ being $a$ and $b$ the length of the major and minor semi-axis. In this work physical effects are assumed omnidirectional, exception made for the jet fire, and the occurrence of different weather conditions is neglected. The expected number of fatalities occurring in trunk $j$ from the $i$-th consequence scenario is $\mathrm{EF}_{\mathrm{ji}}=\mathrm{p}_{\mathrm{j}} \mathrm{FC}_{\mathrm{i}} \mathrm{A}_{\mathrm{i}} \mathrm{D}_{\mathrm{j}}$. This implies that the entire population within the effect area is deceased, i.e. like the fatality probability were 1 . However, given that we conventionally bound the effect area by a radius correponding to a $50 \%$ fatality probability, an overestimation of the number of fatalities within the effect area results. Nevertheless, this is made to account for the fatalities occurring outside the conventional effect area, and the resultimng fatalities can be considered as a lower bound for the actual overall number of fatalities. An upper bound of the overall expected number of fatalities can be instead obtained by doubling the effect radius given in Table 1. With this position made, the overall expected number of fatalities in trunk $j$ and per trip are respectively

$$
E F_{j}=\sum_{i=1}^{M} E F_{j i}=p_{j} \sum_{i=1}^{M} F C_{i} A_{i} D_{j} \quad \text { and } \quad E F=\sum_{j=1}^{N} \sum_{i=1}^{M} p_{j} F C_{i} A_{i} D_{j}
$$

The expected human loss per trip EHTL (\$/trip) follows as EHTL = EF FL where FL is the fatality loss ( $\$$ /fatality), i.e. an overall economic loss associated to each fatality $(\mathrm{FL}=0.7 \mathrm{x}$ $10^{6} \$$ /fatality was assumed here). However, to account even for property loss, a prescribed percentage $\mathrm{PB}_{\mathrm{j}}$ of the overall affected area $\mathrm{A}_{\mathrm{i}}$ can be assumed to be occupied by buildings 
and other infrastructures. If a specific average property value $\mathrm{SPV}_{\mathrm{j}}\left(\$ / \mathrm{m}^{2}\right)$ is assumed for each trunk, then the expected property loss per trip is computed as

$$
E P T L=\sum_{j=1}^{N} \sum_{i=1}^{M} p_{j} F C_{i} A_{i} P B_{j} S P V_{j}
$$

Adopted parameter values to compute EPTL are shown in Table 2. Overall expected loss per trip (\$/trip) is then ETL $=$ EHTL + EPTL and the Expected specific loss ESL $\left(\$ / \mathrm{kg} \mathrm{H}_{2}\right)$ is finally computed as the ratio of the expected loss per trip to the truck capacity per trip $\mathrm{C}_{\mathrm{TR}}$ ( $\mathrm{t} /$ truck trip): $\mathrm{ESL}=\mathrm{ETL} / \mathrm{C}_{\mathrm{TR}}$. The transport cost of hydrogen can be, instead, computed according to a previously developed model [3] including capital expenses and operating cost of the required truck fleet and the ground infrastructure at the production site comprising storage systems and compressor station or liquefaction plant. This allows to compute the specific transport cost LC $(\$ / \mathrm{kg})$ so that an expected transport cost of hydrogen ETC $=\mathrm{LC}+$ ESL $\left(\$ / \mathrm{kg} \mathrm{H}_{2}\right)$ results for any given flow rate, transmission distance and type of route.

\section{ANALYSIS RESULTS}

A parametric analysis, based on flow rate, transportation distance, and type of routes, was carried out in order to evaluate the ESL and its contribution to the overall transportation cost. Owing to space limitations only a few representative results are shown here. Figures 3 and 4 compare the upper and lower bounds of ESL (in the following simply referred to as "safety cost") for $\mathrm{CH}_{2}$ and $\mathrm{LH}_{2}$ transport respectively. Computations refer to routes composed by $50 \%$ highway - $40 \%$ provincial road - $10 \%$ state road. For each kind of road, instead, $50 \%$ of its length is in a remote area, 30\% in rural area, 20\% in suburban area. Urban centres are distributed along the routes at distances of $100 \mathrm{~km}$ and are $3 \mathrm{~km}$ long. It appears that the safety cost in case of $\mathrm{LH}_{2}$ is much lower than $\mathrm{CH}_{2}$ because the reduced number of trips required fully offset the higher effect radius and the higher economic loss per accident. Please note that the specific safety cost is not related to the overall supplied hydrogen flow rate as an increase of this latter parameter only determines a proportional increase on the number of truck tips while the hydrogen amount transported per trip remains fixed. However, the transport cost is influenced by both the trip length and the flow rate. This appears in Figs. 5 and 6, computed also resorting to the transportation cost model [3], which show the total transport cost for two flow rates values of $100 \mathrm{~kg} / \mathrm{h}$ and $10000 \mathrm{~kg} / \mathrm{h}$ respectively. 


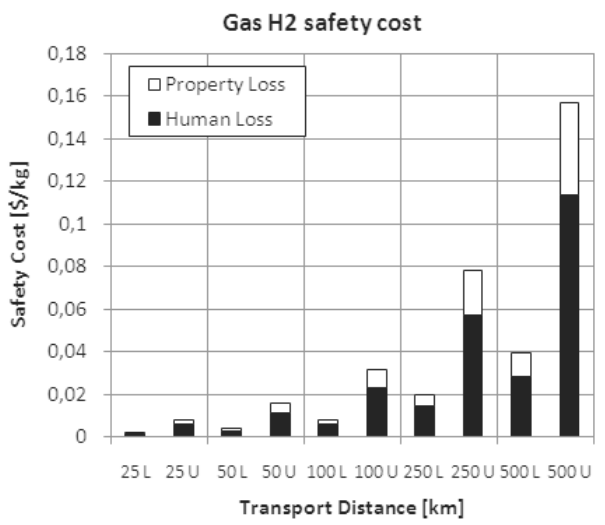

Figure 3: Safety costs for $\mathrm{CH}_{2}$ transport (low urbanization route; $\mathrm{L}=$ lower bound, $\mathrm{U}=$ upper bound).

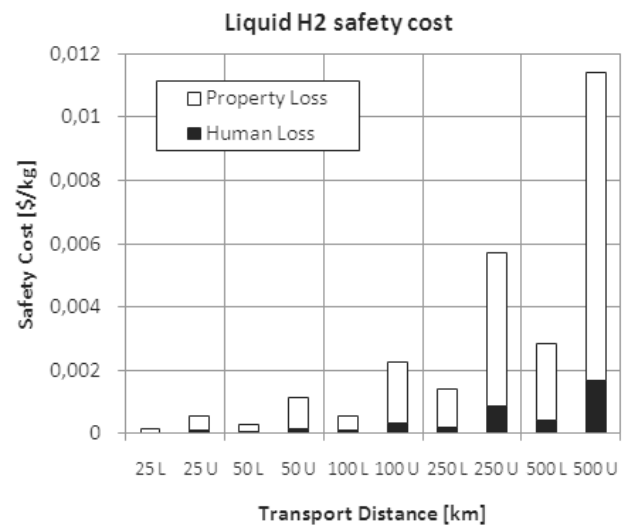

Figure 4: Safety costs for $\mathrm{LH}_{2}$ transport (low urbanization route; $\mathrm{L}=$ lower bound, $\mathrm{U}=$ upper bound).

The $\mathrm{LH}_{2}$ transport cost is scarcely sensitive to the transport distance given the high weight of the capital investment for the fixed infrastructure respect the $\mathrm{CH}_{2}$ case. By comparison with Figs. 3 and 4, Figures 5 and 6 also show that, for the selected road scenario representative of a trip through scarcely urbanized areas, the safety cost is practically irrelevant respect the transport cost. However, the presence of break even values of distance and flow rate between the two competing transport modes is also evident. Figure 7, instead, compares the overall transport costs for a route through more urbanized areas composed by $82 \%$ highway (having a length $12 \%$ through urban areas, $75 \%$ through remote areas, and $13 \%$ through rural areas) and 18\% state road (of which $45 \%$ in suburban areas, $33 \%$ urban zones and $22 \%$ rural areas). The increase of the safety cost is remarkable even if its total contribution to the overall transport cost is still scarcely relevant. Figure 8 shows the effect of passing to a still more urbanized route composed by $92 \%$ state road (of wich $11 \%$ in urban area, $36 \%$ in suburban areas and $43 \%$ in remote areas) and $8 \%$ of urban road. In this case the safety cost becomes significant reaching roughly the same order of magnitude of the transport cost. Given the great influence on the safety cost of the population density of the land crossed by the transport route, an extreme case has been finally considered assuming an entirely urban route (Fig. 9). This case is representative of the trips of trucks feeding refuelling stations within a city area. Considering that a vehicle needs about $4 \mathrm{~kg} \mathrm{H}_{2}$ to refill and hypothesizing that about 200 vehicles during a $10 \mathrm{~h}$ work day will be refuelled by a station, this means feeding a network of about 10 refuelling stations. 


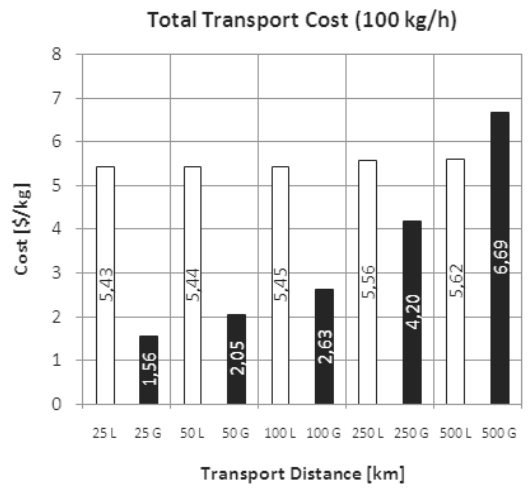

Figure 5: Comparison of total transport costs (low urbanization route - Flowrate $100 \mathrm{~kg} / \mathrm{h}$; L $=\mathrm{LH}_{2}, \mathrm{G}=\mathrm{CH}_{2}$ ).

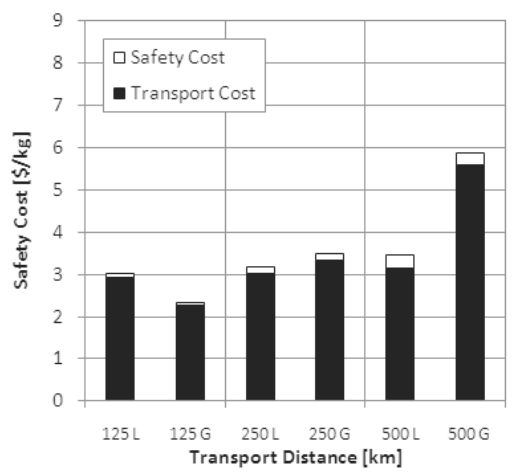

Figure 7: Comparison of total transport costs (mild urbanization route - Flowrate $1000 \mathrm{~kg} / \mathrm{h}$; $\left.\mathrm{L}=\mathrm{LH}_{2}, \mathrm{G}=\mathrm{CH}_{2}\right)$.

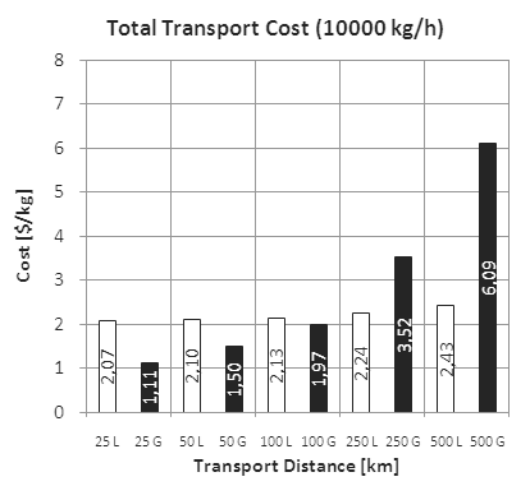

Figure 6: Comparison of total transport costs (low urbanization route - Flowrate 10000 $\mathrm{kg} / \mathrm{h} ; \mathrm{L}=\mathrm{LH}_{2}, \mathrm{G}=\mathrm{CH}_{2}$ ).

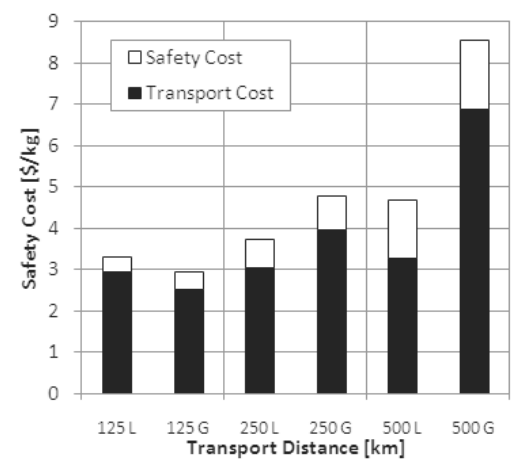

Figure 8: Comparison of total transport costs (heavy urbanization route - Flowrate 1000 $\mathrm{kg} / \mathrm{h} ; \mathrm{L}=\mathrm{LH}_{2}, \mathrm{G}=\mathrm{CH}_{2}$ ).

In this case the safety cost not only becomes relevant but can even surpass the sole transport cost. Therefore, while in some scenarios, i.e. 75 or $100 \mathrm{~km}$ range, the liquid transport cost is the same or lower than the compressed gas transport, when one includes the safety cost, the overall cheapest option may become delivery of compressed gas. From the analysis results the following general conclusions can be made. While safety cost in many cases can be considered negligible as far as road transport of hydrogen is concerned, there are cases (high flow rate, long distance) where accident cost is relevant, especially in case of routes passing through densely populated areas. $\mathrm{LH}_{2}$ transport has higher consequences per single accident, owing to the higher mass per trip, but the much lower number of trips makes the safety cost contribution usually lower than the corresponding cost for $\mathrm{CH}_{2}$. This is not 
true for transport routes through densely populated city areas where the higher consequences of liquid hydrogen release outweight the advantage of a lower number of expected accidents. In cases where safety cost is appreciable, factoring in accidents cost may significantly modify the break even point between $\mathrm{CH}_{2}$ and $\mathrm{LH}_{2}$ transport respect the value estimated resorting to traditional transport cost models which neglect sefety concerns.

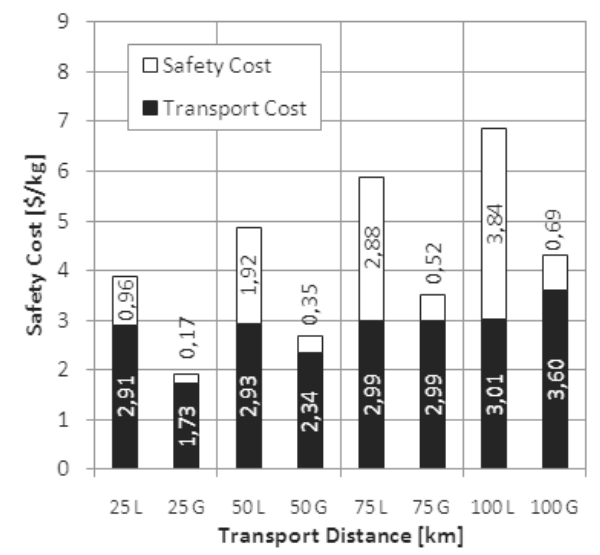

Figure 9: Comparison of total transport costs (city route- Flowrate $1000 \mathrm{~kg} / \mathrm{h}$ ).

\section{CONCLUSIONS}

In this paper a simplified risk assessment model is developed to estimate the expected loss involved in hydrogen road transport and the impact it has on the delivery cost of hydrogen according to user-specified routes. This allows to assess whether this contribution is relevant or not, in a specific scenario, so that the choice between alternative routes or transport options can be made in a more informed manner.

\section{REFERENCES}

1. National Research Council \& National Academy of Engineering, The Hydrogen Economy: Opportunities, Costs, Barriers, and R\&D Needs. National Academy Press, ISBN 0-309-09163-2, 2004.

2. Simbeck, D. R., Chang, E. Hydrogen supply: Cost Estimate for Hydrogen Pathways - Scoping Analysis. NREL/SR-540-32525, July 2002.

3. Caputo, A.C., Pelagagge, P.M., Salini, P., Economic Analysis of Pipeline Hydrogen Transport Respect Alternative Refuelling Infrastructures, Proc. Rio Pipeline Conference, 2-4 October, Rio de Janeiro, 2007.

4. Yang, C., Ogden, J. Determining the Lowest-cost Hydrogen Delivery Mode. Int. J. of Hydrogen Energy 32, n. 2, p. 268-286, 2007. 
5. Cadwallader, L.C., Herring, J.S., Safety Issues with Hydrogen as a Vehicle Fuel, Idaho National Engineering and Environmental Laboratory, INEEL/EXT-99-00522, September 1999.

6. Moonis, M., Wilday, J., Wardman, M., Balmforth, H., Assessing the Safety of Delivery and Storage of Hydrogen, Healt \& Safety Laboratory, Report PS/08/01, Derbyshire, United Kingdom, 2008.

7. O.A. Rosyid, System-Analytic Safety Evaluation of the Hydrogen Cycle for Energetic Utilization, Dissertation, Otto von Guericke Universität, Magdeburg, Germany, 2006.

8. O.A. Rosyid, D. Jablonski, U. Hauptmanns, Risk Analysis for the Infrastructure of a Hydrogen Economy, International Journal of Hydrogen Energy 32, pp. 3194 - 3200, 2007.

9. K. Verfondern, B. Dienhart, Pool Spreading and Vaporization of Liquid Hydrogen, International Journal of Hydrogen Energy 32, pp. 256 - 267, 2007.

10. Bubbico, R., Di Cave, S., Mazzarotta, B., Risk Analysis for Road and Rail Transport of Hazardous Materials: A Simplified Approach, Journal of Loss Prevention in the Process Industries 17, pp. 477-482, 2004.

11. Erkut, E., Verter, V., Modeling of Transport Risk for Hazardous Materials, Operations Research 46, pp. 625-642, 1998. 


\title{
AN EXACT METHOD TO EVALUATE THE SOURCE-TO-TERMINAL DIAMETER CONSTRAINED RELIABILITY OF A COMMUNICATION NETWORK
}

\author{
H. Cancela ${ }^{1}$, M. El Khadiri ${ }^{2}$, L. Petingi ${ }^{3}$ \\ ${ }^{1}$ Depto. de Investigación Operativa \\ Instituto de Computación \\ Facultad de Ingeniería \\ Universidad de la República \\ J. Herrera y Reissig 565 \\ Montevideo, URUGUAY \\ ${ }^{2}$ Département Gestion Logistique et Transport \\ Institut universitaire de technologie de Saint-Nazaire \\ Université de Nantes \\ 58 rue Michel Ange, \\ 44606 Saint-Nazaire Cedex, FRANCE \\ ${ }^{3}$ Computer Science Department \\ College of Staten Island \\ City University of New York \\ 2800 Victory Boulevard \\ Staten Island, N.Y. 10314, USA
}

\begin{abstract}
In this paper we consider a new technique to evaluate the Source-to-terminal Diameter Constrained Network reliability of a communication network. This reliability model is a generalization of the classical reliability and it was defined in order to reflect performance objectives of a network in which the quality of the communication depends on the existence of short-enough paths connecting a set of distinguished set of terminal vertices.

Although the general problem is NP-hard, we propose an exact evaluation recursive method based on the inclusion-exclusion principle and topological reductions of a network and we show numerical illustrations to reflect the computational gain offered in comparison to other predominantly used evaluation techniques.
\end{abstract}

\section{INTRODUCTION}

The system under study is a communication network modeled by an undirected graph $G=(V, E)$ consisting of a set of nodes (vertices) $V$, a set of edges $E$ and a distinguished set 
$K=\{s, t\}$ of two nodes called terminal nodes (also called participating nodes). Nodes do not fail, but each edge $l$ of $G$ is assigned an independent probability of failure $q_{l}$ (called the edge unreliability). In the classical reliability measure, the network is supposed to work if after the removal of the failed edges the terminal nodes can be connected by at least an operational path between $s$ and $t$. This is a random event, which has probability $R_{s t}(G)$. The problem of evaluating $R_{s t}(G)$ is called the Source-to-terminal network reliability problem (see [1] for further information regarding this reliability model).

There are many situations where it is not enough that the terminal nodes are connected after the removal of the failed edges, but the quality of the communication depends on the existence of a path, connecting them, whose length (measured as the number of edges) is bounded by a given integer $D$. The Source-to-terminal Diameter Constrained Network reliability measure, denoted by $R_{s t}(G, D)$, is the probability of this event and it was originally introduced by Petingi and Rodríguez in 2001 (see [2]) for any arbitrary subset of terminal vertices $K$ of $V$. As $R_{s t}(G,|V|-1)=R_{s t}(G)$ (since any path in a network is composed of at most $|V|-1$ edges), and since the evaluation of $R_{s t}(G)$ is a NP-hard problem (see Provan and Ball [1]), the evaluation of $R_{s t}(G, D)$ is also a computationally expensive problem [3].

The aim of our work is to propose an exact algorithm to evaluate $R_{s t}(G, D)$ and compare its computational performance with a backtracking evaluation technique presented in [2].

The proposed technique is based on a recursive procedure. On each recursive step a given network goes possibly first through a series of topological reductions which allow to consider the reliability of a smaller network, followed then by an application of a partitioning approach which transforms the evaluation of the resulting reduced network into the evaluation of smaller ones. Partitioning is based on the edges of a $D$-cut of a network (i.e., a set of edges whose removal destroys all paths from $s$ to $t$ composed of $D$ or less number of edges) and the inclusion-exlusion principle applied to probability theory. This recursive process terminates when trivial networks are reached.

The paper is organized as follows. In next section, we give a notation and definitions pertaining the Diameter Constrained reliability. In Section 3 we review the widely used backtracking approach for the exact evaluation of $R_{s t}(G, D)$. In Section 4 we present topological reductions and partitioning procedures yielding the proposed recursive method for evaluating $R_{s t}(G, D)$. In Section 5 we illustrate experimental results comparing the proposed evaluation approach with the backtracking technique discussed in Section 3, by evaluating the 
reliability of different families of graphs and for different values of the diameter bound $D$, in order to highlight the contributions and ideas suggested in this paper. Finally, in Section 6, we present conclusions and future work.

\section{MODEL DEFINITION AND NOTATION}

This section presents definitions and some notation pertaining to the Source-to-terminal Diameter Constrained Reliability that will be employed in the remaining of the paper:

- $G=(V, E)$ : an undirected graph modeling a communication network;

- $V$ : the node-set of $G$;

- $E$ : the edge-set of $G$;

- $s, t$ : two terminal nodes;

- $\quad r_{l}=\left(1-q_{l}\right)$ : the probability that edge $l$ is operational (reliability of $l$ );

- a $D$-path of $G$ is a path between $s$ an $t$ with at most $D$ edges;

- $G$ is $D$-connected if it contains at least one $D$-path;

- $G$ is $D$-coherent if each edge of $G$ is in at least one $D$-path;

- A subgraph of $G$ is an operating state if it is $D$-connected;

- A subgraph of $G$ is a failure state if it is not $D$-connected;

- A subset $C$ of $E$ is a $D$-cut of $G$ if removal of the edges of $C$ from $G$ results in a graph that is not $D$-connected (possibly disconnecting $s$ from $t$ );

- $R_{s t}(G, D)=\operatorname{Pr}\{G$ is $D$-connected $\}$ : the Source-to-terminal Diameter Constrained Network Reliability.

In the next section we present a widely used technique called Backtracking (see [2]) that evaluates the reliability of a network by generating all possibles operating states of $G$.

\section{BACKTRACKING ALGORITHM FOR THE EVALUATION OF THE RELIABILITY}

The simplest way to exactly evaluate $R_{s t}(G, D)$ for a graph $G=(V, E)$ with diameter bound $D$ is to enumerate all possible states (i.e., subgraphs) of $G$, and determine the ones where the terminals are connected by a path of length smaller or equal to $D$ (i.e., operating states), and then sum the probabilities of being operative. Indeed, under the assumption of independent edge failures, an operating state $H=\left(V_{H}, E_{H}\right)$ has occurence probability $P(H)=\prod_{e \in E_{H}} r_{e} \prod_{e \notin E_{H}} q_{e}$.

Let $O p$ represent the set of operating states $H$ of $G$; we can then write the Source-toterminal Diameter Constrained as $R_{s t}(G, D)=\sum_{H \in O P} P(H)$. 
Starting with the original graph $G$, at a particular state we determine if a state (subgraph) is an operating state by application of Dijkstra's shortest path algorithm [4] (of $O\left(n^{2}\right)$ complexity). We then make recursive calls of states with one edge less.

Once we have reached a state whose $s, t$-diameter is larger than $D$, it is not necessary to consider any of its subgraphs since they will also be failure states. We can also model this recursive backtracking approach as a decision tree whose root is the original graph $G$ and a state (i.e., node of the decision tree) has children corresponding to its subgraphs with an edge less. Thus the decision tree internal nodes are the operating states of $G$ and its leaves are some of the failure states of $G$.

Even tough the complexity of this algorithm is $O\left(|O p| n^{2}\right)$ and $|O p|$ is likely to be of exponential cardinality, this approach is an excellent reference point for comparison with other exact evaluation algorithms of the Source-to-terminal Diameter Constrained reliability since it enumerates all the operating states of $G$.

\section{RECURSIVE FORMULA TO CALCULATE THE DIAMETER CONSTRAINED RELIABILITY}

In this section we introduce a new evaluation approach for $R_{s t}(G, D)$ (see Section 4.2). As we previously discussed, this technique exploits topological reductions (or transformations) which at each step reduce, in polinomial time, the size of a network under consideration. In the next subsection we present such reductions.

\subsection{Reduction Procedures}

Let $G$ be a network with terminal set $\{s, t\}$ and diameter bound $D$. We proposed the following polinomial topological reductions:

R.1) Irrelevant edge deletion: if an edge $e$ does not belong to a D-path, we have $R_{s t}(G, D)=$ $R_{s t}(G-e, D)$, consequently the edge $e$ can be deleted without altering the reliability. There are two types of irrelevant edges detected; the first type are edges that do not belong to any $s, t$ path and they are identified by application of an algorithm based on the biconnectivity of a graph (see [5] and [6]). The other type of irrelevant edges are edges that belong to some $s, t$ paths but none of those are $D$-paths and these edges are spotted by application of Dijkstra's shortest-path algorithm [4]. 
R.2) Path-terminal reduction: if a terminal node (say $t$ for instance) has degree 1 and it is connected to a node $g$ by a path $P=\left\{\left(g, n_{1}\right),\left(n_{1}, n_{2}\right), \ldots,\left(n_{p}, t\right)\right\}$ with $(p+1)$ edges and each internal node $n_{k}$ is of degree two, we have $R_{s t}(G, D)=R_{s g}\left(G^{\prime}, D-p-1\right) \prod_{k \in P} r_{k}$, where $G^{\prime}=$ $\left(V-\left\{t, n_{1}, \ldots, n_{p}\right\}, E-P\right)$.

R.3) Parallel reduction: if two edges $l$ and $l$ ' have the same end-nodes, these two edges can be replaced by a single edge with reliability $r_{l}+r_{l},-r_{l} r_{l}$, without altering the reliability.

R.4) Disjoint paths reduction: if the edge set of a network $G$ can be partitioned into edgedisjoint $D$-paths $P_{1}, P_{2}, \ldots, P_{m}$, we have: $R_{s t}(G, D)=1-\prod_{k=1, \ldots, m}\left(1-\prod_{l \in P_{k}} r_{l}\right)$.

R.5) All edges incident at a terminal nodes are operational: in this case, if we contract the terminal and all its adjacent nodes into a single node, and delete all looping edges, we obtain an smaller network $G^{\prime}$ which verifies $R_{s t}(G, D)=R_{s t}\left(G^{\prime}, D-1\right)$.

\subsection{A partitioning procedure based on a D-cut and the related recursive algorithm}

In this section we introduce notation and definitions in which $G$ ' represents a network obtained from an original network $G$ after applications of the topological transformations discussed in Section 4.1. Moreover let $C=\left\{l_{1}, l_{2}, \ldots, l_{|C|}\right\}$ represent a $D$-cut of $G$ ':

- $E_{0}(C)$ is the event "all edges of $C$ failed" and

- $p_{0}(C)=\operatorname{Pr}\left\{E_{0}(C)\right\}=q_{0} q_{1} \ldots q_{|C|}$;

- $G_{0}{ }^{\prime}(C)$ is the network obtained from $G$ ' by deleting the edges $l_{1}, l_{2}, \ldots, l_{|C|}$;

- $E_{l}(C)$ is the event "edge $l_{l}$ is operational";

- $p_{l}(C)=\operatorname{Pr}\left\{E_{l}(C)\right\}=r_{l}$;

- $G^{\prime}{ }_{l}(C)$ is the network from $G$ ' by fixing $l_{l}$ operational (reliability of $l_{l}$ is fixed to $1)$;

- for each $i, 2 \leq i \leq|C|$,

- $E_{i}(C)$ is the event "all edges $l_{1}, l_{2}, \ldots, l_{i-1}$ are failed and $l_{i}$ is operational";

- $p_{i}(C)=\operatorname{Pr}\left\{E_{i}(C)\right\}=\left(q_{0} q_{1} \ldots q_{i-1}\right) r_{i}$;

- $G^{\prime}{ }_{i}(C)$ is the network obtained from $G$ ' by deleting edges $l_{1}, l_{2}, \ldots, l_{i-1}$ and fixing edge $l_{i}$ operational (reliability of the edge $l_{i}$ is fixed to 1);

By the inclusion-exclusion principle, the $|C|+1$ events $E_{i}(C), \quad 0 \leq i \leq|C|$, are disjoint and mutually exhaustive. By using the total probability theorem and the fact that $R_{s t}\left(G_{0}{ }^{\prime}, D\right)=0$, we obtain: $R_{s t}\left(G^{\prime}, D\right)=\sum_{i=0,1,2, \ldots .,|C|} p_{i}(C) R_{s t}\left(G_{i}^{\prime}, D\right)=\sum_{i=1,2, \ldots ., C \mid} p_{i}(C) R_{s t}\left(G_{i}^{\prime}, D\right)$. 
Thus the Source-to-terminal Diameter constrained reliability of a network $G$ ' can be written as a function of the reliabilities of $|C|$ smaller networks. Then, we propose to use the following recursive formula for computing $R_{s t}\left(G^{\prime}\right)$ (see Fig. 1 for an illustration):

$$
R_{s t}(G, D)=\left\{\begin{array}{l}
0 \text { if } G \text { is not } D-\text { connected } \\
1 \text { if } G \text { contains a } D-\text { path with operational links } \\
R_{s t}\left(G^{\prime}, D\right) \text { if } G^{\prime} \text { can be computed by reduction procedures } \\
\sum_{i=1, \ldots,|C|} p_{i}(C) \cdot R_{s t}\left(G_{i}^{\prime}, D\right) \text { otherwise }
\end{array}\right.
$$

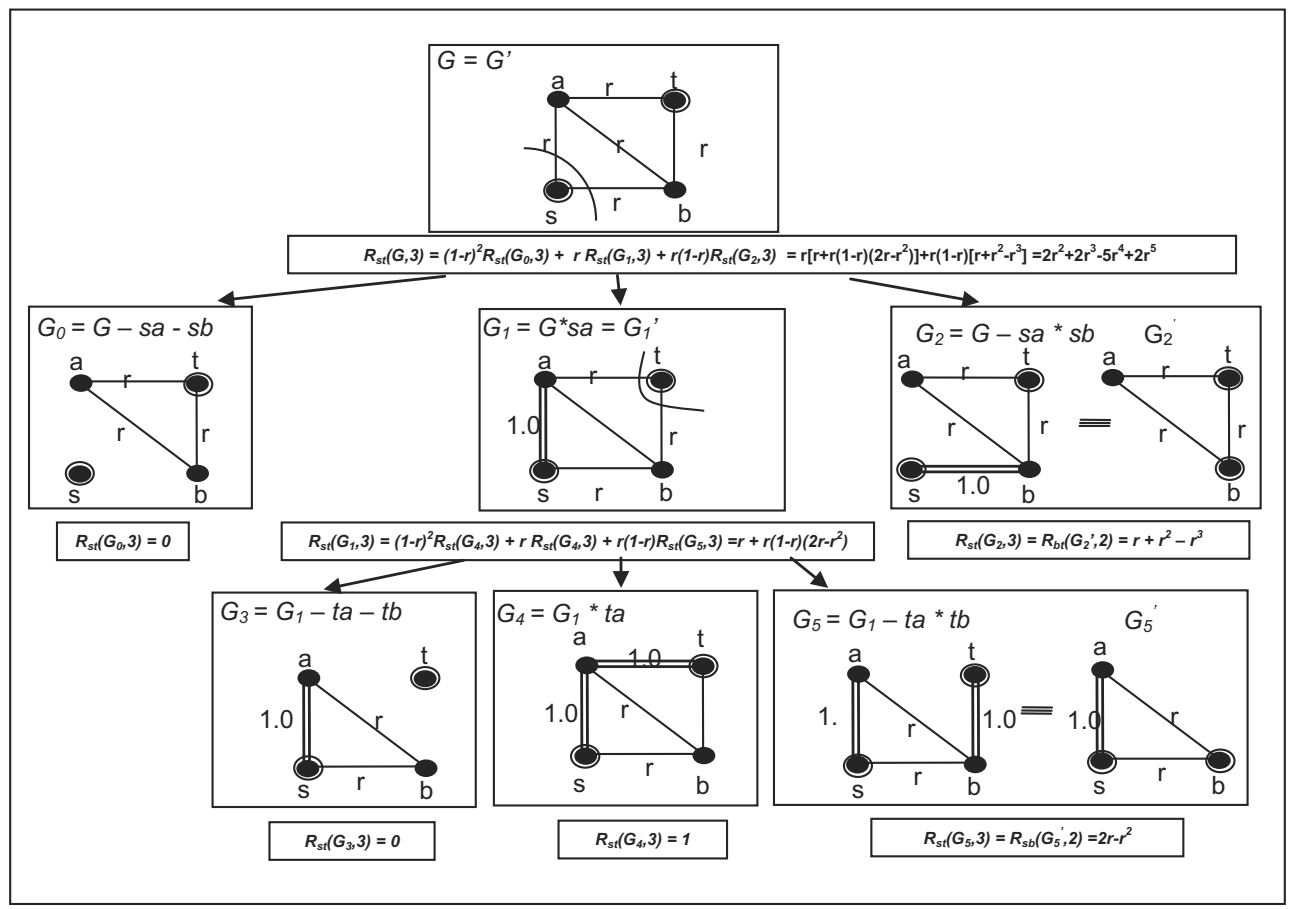

Fig 1. Example of reductions and partitioning algorithm applied for computing $R_{s t}(G, 3)$.

In Fig. 1, $G-u v$ and $G^{*} u v$ denote the networks which are obtained from $G$ by fixing edge uv failed and operational respectively. Failed edges are deleted and the operational ones are represented by double lines in Fig. 1.

\section{EXPERIMENTAL RESULTS OF THE PROPOSED ALGORITHM}

We present now experimental results comparing the performance of the algorithm presented in Section 4 to the commonly used backtracking technique discussed in Section 3. 
Table 1 corresponds to experimental results obtained, for different values of the diameter bound $D$, on the dodecahedron (shown in Fig. 2) topology, while Table 2 corresponds to a complete topology on 8 vertices (i.e., $K_{8}$ ). Moreover to show the contribution independently made by the topological reductions presented in Section 4.1, we also present results of the new exact evaluation technique with and without these transformations.

The tables include information about the diameter bound $D$, the method used, the computed unreliability (i.e., $Q_{s t}(G, D)=1-R_{s t}(G, D)$ ), the tree size (i.e., number of nodes of the decision tree, each representing a recursive call), and in last column the execution time (tests were performed using a 2.66 Ghz. Celeron's processor machine). All the edges of these topologies were assigned the same reliability value of 0.5 .

The experimental results are eloquent, in that they show the good behavior of the proposed method, in comparison with the widely used Backtracking approach. Moreover we can observe a substantial computational gain attained by the new exact evaluation approach particularly when this technique is complemented with the topological reductions. The impact of the reductions decreases with $\mathrm{D}$, and it is not significant when $\mathrm{D}=|\mathrm{V}|-1$ (the classical source-to-terminal network reliability problem, which can be evaluated by specific methods).

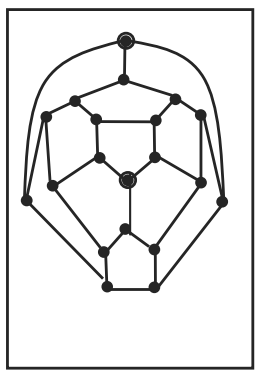

\begin{tabular}{|c|l|l|l|l|}
\hline D & \multicolumn{1}{|c|}{ Method } & \multicolumn{1}{|c|}{$\boldsymbol{Q}_{\text {st }}(\mathbf{G}, \mathbf{D})$} & \multicolumn{1}{c|}{ Tree's size } & \multicolumn{1}{c|}{ T(s) } \\
\hline 2 & Cut\&Reductions & $8.89892580 \mathrm{E}-02$ & $1.00000000 \mathrm{E}+00$ & 0 \\
\hline 2 & Cut & $8.89892580 \mathrm{E}-02$ & $5.04867700 \mathrm{E}+06$ & 112 \\
\hline 2 & Backtrack & $8.89892578 \mathrm{E}-02$ & $2.55645217 \mathrm{E}+08$ & 135 \\
\hline 4 & Cut\&Reductions & $1.80738570 \mathrm{E}-02$ & $2.29630000 \mathrm{E}+04$ & 1 \\
\hline 4 & Cut & $1.80738570 \mathrm{E}-02$ & $3.20530000 \mathrm{E}+05$ & 6 \\
\hline 4 & Backtrack & $1.80738568 \mathrm{E}-02$ & $2.66059838 \mathrm{E}+08$ & 182 \\
\hline 7 & Cut\&Reductions & $1.74265500 \mathrm{E}-02$ & $2.97510000 \mathrm{E}+04$ & 1 \\
\hline 7 & Cut & $1.74265500 \mathrm{E}-02$ & $3.67320000 \mathrm{E}+04$ & 1 \\
\hline 7 & Backtrack & $1.74265504 \mathrm{E}-02$ & $2.66104868 \mathrm{E}+08$ & 180 \\
\hline
\end{tabular}

Fig. 2: Dodecahedron

Table 1: Experimental results on the dodecahedron

\begin{tabular}{|l|l|l|l|l|}
\hline D & \multicolumn{1}{|c|}{ Method } & \multicolumn{1}{|c|}{$\boldsymbol{Q}_{s t}(\mathbf{G}, \boldsymbol{D})$} & \multicolumn{1}{c|}{ Tree's size } & T(s) \\
\hline 5 & Cut\&Reductions & $8.31559241 \mathrm{E}-01$ & $4.19000000 \mathrm{E}+02$ & 0 \\
\hline 5 & Cut & $8.31559241 \mathrm{E}-01$ & $6.86748200 \mathrm{E}+06$ & 430 \\
\hline 5 & Backtracking & $8.31559241 \mathrm{E}-01$ & $2.82836936 \mathrm{E}+08$ & 641 \\
\hline 10 & Cut\&Reductions & $7.12143730 \mathrm{E}-01$ & $2.71634000 \mathrm{E}+05$ & 17 \\
\hline 10 & Cut & $7.12143730 \mathrm{E}-01$ & $1.79663600 \mathrm{E}+06$ & 111 \\
\hline 10 & Backtracking & $7.12143730 \mathrm{E}-01$ & $4.36401353 \mathrm{E}+08$ & 1099 \\
\hline 19 & Cut\&Reductions & $7.09744986 \mathrm{E}-01$ & $5.43438000 \mathrm{E}+05$ & 37 \\
\hline 19 & Cut & $7.09744986 \mathrm{E}-01$ & $7.98318000 \mathrm{E}+05$ & 56 \\
\hline 19 & Backtracking & $7.09744986 \mathrm{E}-01$ & $4.38373496 \mathrm{E}+08$ & 1091 \\
\hline
\end{tabular}


Table 2: Performance of algorithms on the complete graph on 8 nodes.

\section{CONCLUSIONS}

In this paper, we have presented and discussed exact methods for computing the Diameter Donstrained network reliability measure for a set $K=\{s, t\}$ of terminal nodes. While computing this measure is an NP-hard problem, and as such intractable for large networks, we have shown experimentally that the method based in recursive partitioning of the state space on the basis of cuts of the network and applying topological reductions can compute the reliability for networks with some tens of edges very efficiently.

As future work, we plan on complete the study of the applicable reductions, and to further improve exact methodology, as well as to develop approximate methods, based on the same ideas, but suitable for estimating the reliability measure for large topologies, and which can be used to tackle network design problems such as the one discussed in [7] .

\section{REFERENCES}

1. J. Provan and M. Ball, The complexity of counting cuts and of computing the probability that graph is connected, SIAM Journal on Computing 12, pp. 777-788, (1983).

2. L. Petingi and J. Rodriguez, Reliability of networks with delay constraints, Congressus Numerantium 152, pp. 117-123, (2001).

3. H. Cancela and L. Petingi, Properties of a generalized Source-to-All-terminal network reliability model with diameter constraints. Omega (The International Journal of Management Science) 35(6), pp. 659-670, (2007).

4. E. W. Dijkstra, A note on Two Problems in Connexion with Graphs, Numerische Math. 1, pp. 269-271, (1959).

5. R.E. Tarjan, Depth-first search and linear graph algorithms. SIAM J. Comput. 1(2), pp. 144-160, (1972).

6. M. El Khadiri, Evaluation directe et par simulation d'indices de fiabilité de réseaux de communication: algorithmes séquentiels et dédiés à des architectures à mémoire distribuée. Ph.D. thesis (in French). Université de Rennes I, Rennes, France (1992).

7. P. Burgos, H. Cancela, A. Godoy and L. Petingi, Source-terminal reliability maximization with path length constraints. International Conference on Industrial Logistics (ICIL'03), pp. 76-83, Vaasa, Finland (2003). 


\title{
EFFECT OF A BRIDGE INFRASTRUCTURE IN THE ECONOMIC GROWTH OF AN INDUSTRIAL REGION
}

\author{
K. O Ferreira and M. I. Faé \\ Geography Department \\ Federal University of Espírito Santo \\ Campus Universitário Goiabeiras, Vitoria, ES
}

\begin{abstract}
This study aims to identify the effect that a bridge may have on the economic growth of an industrial region. The methodology includes the exploratory analysis of data and information, the application of location measures, and econometric analysis. The methodology applied to a case study provided partial results of the analysis that has been carried on. The results so far obtained gave clear trends that the bridge has played an important role in the growth of the industrial region considered.
\end{abstract}

\section{INTRODUCTION}

The traditional approach of urban economy relates transport infrastructure to regional growth. However, the literature shows cases that such a relation does not apply, as reported by Magalhães (2006) [1] at the XXVI National Meeting on Production Engineering (ENEGEP). His work considers the interrelation among transport, space and economic growth as a result of the opening of the Bridge between the cities of Rio de Janeiro and Niteroi, in 1974.

Magalhães (2006) used the structural-differential method and the combination of two indicators of regional analysis. The traditional deterministic view of the relationship between transport and economic growth was argued, and he concluded that although the bridge has contributed to a significant increase in population (above the average for the rest of the region studied), one may not associate the bridge as a factor that induced development for this subspace.

According to Haddad (1989) [2], economic growth is a key parameter for the assessment of regional development. In this context, regional analysis methods are used such as measures of location and specialization. Such a method gives information about behavioral patterns related to the productive sectors of the economy as well as highlight possible differences in 
the regional context for each sector. The authors Rippel and Lee (1999) analyze the locational behavior of the branches of productive activities of the Southeast Region of Brazil, seeking to identify the most dynamic sectors that give grants to public policies for economic growth.

In this paper measures of specialization and location were used in the data analysis. These measures are useful for understanding patterns of economic growth, and are particularly appropriate because they allow comparison of regions with different sizes (Costa, 2002) [3]. Pumain and Saint-Julien (1997) [4] call attention to the fact the size differences in regions may cause disturbances in the analysis. To prevent this problem, measures of the relative importance of an event or category in a region are used.

Ruiz (2003) [5] reviews several approaches to urban and regional economics, from the traditional themes such as the isolated town of von Thünen, the urban hierarchies handled by Lösch and Christaller, the inter-regional relations through input-product and the modern views of authors such as Paul Krugman, Masahisa Fujita and Anthony Venables [6].

Location measures compares the location of activities between regions and aim to identify patterns of dispersal and concentration of a given variable in a given timeline. Among the measures of location used in regional analysis one may pinpoint the location quotient and the location coefficient. The location quotient compares a particular economic sector with the whole sector, in terms of percentage. When the ratio value is greater than 1 , the region is more important than the whole, considering all sectors. This location measure was applied by the Center for Metropolitan Studies - Cebrap, the study of Economic Development Strategies for the Central Area of São Paulo, in 2002.

Location Coefficient aims to relate the percentage distribution of a variable in a given industry with the percentage of total variable between regions. This coefficient varies between 0 and 1 values, 0 is the value that indicates a specific sector are distributed regionally in line with other sectors, the value of 1 means that this same industry has a pattern of regional concentration more intense than the set of all sectors.

Other methods of analysis of economic development are called regional measures, whose purpose is to evaluate the productive structure of each region (Haddad, 1989). The basic idea is to investigate the degree of specialization of regional economies in a given period. These measures are usualy determined by the coefficient of specialization and restructuring. The coefficient of specialization compares the productive structure of a region with the global production structure. The resulting values are between 0 and 1 . The zero value indicates a 
sectoral composition identical to the whole, while the value 1 indicates a high degree of specialization of the sector in a particular activity. The coefficient of restructuring aims to assess the degree of specialization in a particular region in relation to an activity through the analysis of this activity between two distinct periods. Values are between 0 and 1 , zero means no indicator of sectoral variation in the region, and 1 indicator of restructuring, as it demonstrates a greater specialization in the industry for a particular activity.

\section{METHODOLOGY}

This paper proposes an analysis of regional growth based on an exploratory approach that includes measures of location and specialization, location quotient, location specialization and restructuring, as well as statistical analysis and application of descriptive methods econometrics. As a step in a near future, besides the application of measures of location, we we suggest statistical and econometric analysis of data, which together provide support to the understanding of the phenomenon studied. The data analysed comprised the Gross Domestic Product - GDP, number of jobs, and retail shops available in different sectors, that were obtained in the Annual Social Information - RAIS, of the Ministry of Labor and Employment. The analysis comprised the period before and after the construction of a given bridge.

\section{CASE STUDY}

The study was undertaken in the metropolitan area of Victoria, composed by 5 counties: Victoria, Vila Velha, Serra, Viana and Cariacica, as shown in figure 1. The industrial district is located in the North part of the region (Serra), while most of the labour residences are in Vitoria and Vila Velha. 


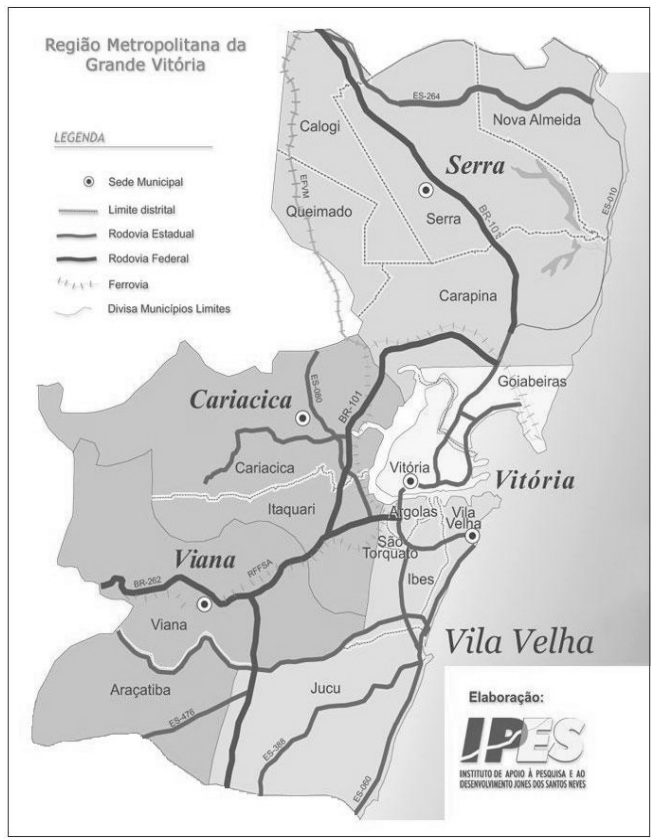

Figure 1- Metropolitan area of Vitoria. [7]

An important Bridge links the counties of Victoria to Vila Velha. It was open in 1989, and the number of vehicles crossing the bridge has increased from a daily average of 13,808 in January 1990 to 51,433 in January 2005. In 15 years, an increase of more than $270 \%$ was observed.

The comparison of the local economy shows the difference in the development of Vila Velha at the expense of other neighboring counties. The labor force employed in industry in Vila Velha showed a growth of $90 \%$ over the period 1985 to 1995 while the city of Victoria presented a decrease of $-3 \%$ in the same period. The other counties in the metropolitan area also showed negative growth. This substantial increase in manufacturing employment was due to significant industrial growth of $245 \%$. The Gross Domestic Product growth in the county of Vila Velha (74\%) was also the greatest among the others, and the sum of wages paid for services presented an increase of $665 \%$.

The statistical analysis of the variables GDP, number of establishments and employment in 1985 and 1996, shows that Vila Velha had the greatest variation in the three factors 
compared. From a comparative analysis, there is considerable positive growth of Vila Velha at the expense of others, including Victoria, along the years the bridge has been used.

Unfortunatelly, this economical growth has not been accompanied by improovements in the social area. For example, the growth of households served by piped water increased by $5 \%$ in Vila Velha, while $25 \%$ in Viana. The number of poor people decreased by only $17 \%$ in Vila Velha while $30 \%$ in Viana.

The location quocient considering the number of jobs in each county, between 1985 and 1995 , is given in table 1 .

Table 1: Locacional Quotient - Number of jobs

\begin{tabular}{c|cccccccccc}
\hline \multicolumn{10}{c}{ jobs } \\
\hline Economic Sector / & Cariacica & \multicolumn{1}{c}{ Serra } & \multicolumn{1}{c}{ Viana } & \multicolumn{1}{c}{ Vila Velha } & \multicolumn{2}{c}{ Vitória } \\
\cline { 2 - 11 } County & $\mathbf{1 9 8 5}$ & $\mathbf{1 9 9 5}$ & $\mathbf{1 9 8 5}$ & $\mathbf{1 9 9 5}$ & $\mathbf{1 9 8 5}$ & $\mathbf{1 9 9 5}$ & $\mathbf{1 9 8 5}$ & $\mathbf{1 9 9 5}$ & $\mathbf{1 9 8 5}$ & $\mathbf{1 9 9 5}$ \\
\hline Retail Shopping & 1,15 & 1,40 & 0,66 & 1,06 & 0,48 & 0,99 & 1,26 & 1,12 & 1,00 & 0,84 \\
Industry & 1,19 & 1,14 & 2,65 & 1,97 & 2,94 & 2,86 & 1,10 & 1,33 & 0,45 & 0,47 \\
Service & 0,76 & 0,43 & 0,39 & 0,56 & 0,40 & 0,32 & 0,72 & 0,72 & 1,30 & 1,41 \\
\hline
\end{tabular}

In relation to location quotient related to persons employed in retail shops, there was a slight decrease in the city of Vila Velha. It was 1.26 in 1985 and rose to 1.12 in 1995 , but remained higher than the figures showed by Victoria. In the sector of Commerce / Services, the location quotient of Vila Velha decreased from 0.97 in 1985 to 0.95 in 1995, an amount of only $2 \%$ in the period of ten years. For the same period, Victoria felt from 1.16, in 1985, to 1.09 , in 1995. As concerns the industrial sector, Vitoria had a slight increase from 0.45 to 0.47, while Vila Velha presented the significant figures of 1.10, in 1985, and 1,33, in 1995.

This growth in formal employment also was accompanied by improvements in wages. There was an increase in the wages paid in the industrial sector in Vila Velha of 204.0\% while the average change in the metropolitan area that includes the 5 counties was $49.2 \%$. Figure 2 highlights the variations observed in the number of jobs for each county of Cariacica, Serra, Viana, Vila Velha e Vitória, as well for the average of the metropolitan area that comprises the 5 counties (RM). Table 2 shows the percentual increases in jobs also for the ES, which stands for the whole state of Espírito Santo, as well as the increases in wages in the industrial sector. 


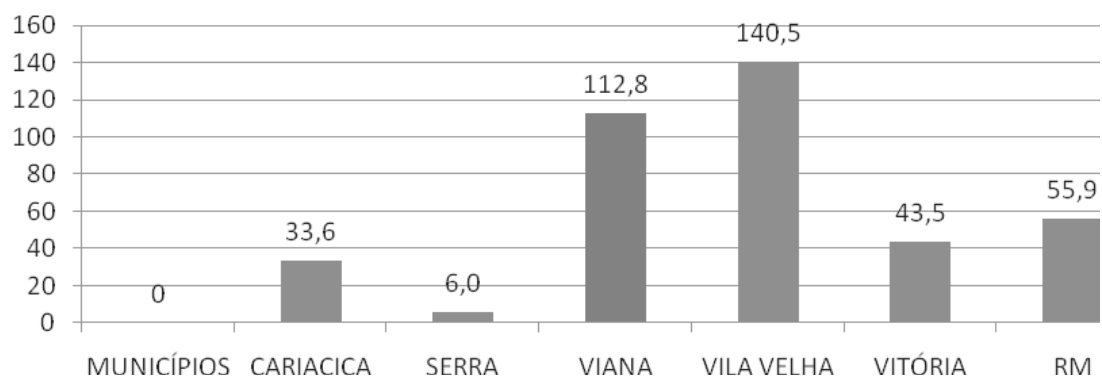

Figure 2- Variations in jobs (1985-1995)

Table 2- Increases (\%) from 1985 to 1995

\begin{tabular}{|l|l|l|}
\hline Counties & Jobs & Wages in industry \\
\hline Cariacica & 33,6 & 20,0 \\
\hline Serra & 6,0 & 87,0 \\
\hline Viana & 112,8 & $-8,0$ \\
\hline Vila Velha & 140,5 & 204,0 \\
\hline Vitória & 43,5 & 7,0 \\
\hline RM & 55,9 & 49,2 \\
\hline ES & 63,3 & 86,0 \\
\hline
\end{tabular}

\section{CONCLUSIONS}

The data analysis indicated that the County of Vila Velha showed a significant growth after the opening of the Bridge. By itself, this fact is not sufficient to relate this growth to the bridge infra-structure. The continuation of the analysis, using the techniques suggested in the methodology, might shed some light in this problem.

The proposed method performed satisfactorily, and the results suggest that in the period 1985-1996 the urban accessibility provided by the bridge affected the socio-economic growth of Vila Velha in some sectors of the economy. Taking into account that the study is exploratory, there is need for continuing this research into aspects identified in the study, for example, using the Gross Domestic Product in the engineering construction and jobs in the industry. 
Considering the short time of activity of the bridge, it is important to consider the positive impact of locational quotients of employment in the county of Vila Velha. This was in line with changes that the new structure began to bring in those early years for the city.

The county of Vitoria, which had always been strong in sectors related to business and services, has accumulated decreases in the Gross Domestic Product concerning the Industry and Manufacturing sectors, and minor increases in the service sector given by the quocient of location. The county of Vila Velha, in turn, showed rates of growth in almost all relevant sectors.

\section{REFERENCES}

1. Magalhães, L. R. L. Condicionantes conceituais e metodológicos para a percepção da relação entre infra-estrutura de transporte rodoviário e desenvolvimento econômico regional: o caso do eixo Leste metropolitano do Rio de Janeiro. XXVI ENEGEP Fortaleza, CE, 2006.

2. Haddad, J. H. (Org.). Economia regional: teoria e métodos de análise. Fortaleza. BNB/ETIENE, 1989.

3. Costa, J. S. (Coord). Compêndio de Economia Regional. APDR. Coimbra: Gráfica Coimbra. Lisboa, APDR, 2002.

4. Pumain, D.; Saint-Julien, T. Lanalyse spatiale: localizations dans lespace. Paris: Armand Colin, 1997.

5. Ruiz, R. A nova geografia econômica: um barco com a lanterna na popa?, Cedeplar, 2003 Belo Horizonte, Brasil.

6. Krugman, P.; Fujita, M.; Venables, A. Economia Espacial. Cidade, Região e Comércio Internacional. Gráfica de Cambridge. Massachutes.

7. http://www.ijsn.es.gov.br/mapas/esmapas/1.CARACTERIZACAO_TERRITORIAL/L imites_e_Regionalizacoes/1.2_Regiao_Metropolitana_da_Grande_Vitoria.

8. Ferrera de Lima, J. ; Piacenti, C. A.; Alves, L. R. e Piffer, M. A Localização e as mudanças da distribuição setorial do PIB nos estados da região Sul (1970-1998). In: Congresso Brasileiro de Economia e Sociologia Rural (SOBER), Cuiabá, Anais... Cuiabá: SOBER, 1 CD-ROM, 2004.

9. North, D. C. Location Theory and Regional Economic Growth. Journal of Political Economic, 1956, 63(3): 243-258 


\title{
THE INDUSTRY OF STANDARDIZATION PROCESS: A COMPARISON BETWEEN TWO INTERNATIONAL ORGANIZATIONS
}

\author{
Lemuel Brasil Aguiar \\ Fernando Ferrari Av., Vitória \\ Department of Administration \\ Federal University of Espírito Santo
}

\begin{abstract}
The efforts for making technology a global success are increasing highly with the power of Internet for people and for organizations. That's why some standardization organizations are dueling to reach objectives that weren't their priority until few years ago. This is the case of ITU-T, that doesn't produce Recommendations only for telephone techs, but has a great participation in computer networks' studies and today has many specifications being researched in the same field of IETF, an organism highly turned to develop standards in Internet and its protocols, to assure the well operation of it. With different structures and policies, they now are facing each other in a market conquer.
\end{abstract}

\section{INTRODUCTION}

The information is something that needs to be available all the time and up to date for everyone. This requires a harmony, which is based in one unique concept: standardization. To show how organizations develop these standards, this paper will talk about the International Telecommunication Union - Standardization Sector (ITU-T) and Internet Engineering Task Force (IETF). These two different organizations work to standardize technologies, like protocols and networks' architectures to assure the success of telecommunications around the world. The structure of each organization will be shown, as well as how standards are developed and the stages to reach the 'mature state' to be implanted in computer networks. 


\section{ABOUT ITU}

International Telecommunication Union is one of the oldest organizations in world today. It was founded in 1865 with the name International Telegraph Union, in France. Many years later, in 1947, ITU became the official agency from United Nations (UN). In 1956, the state members of ITU realized that ITU's role had become more important and with a broad scope. Therefore, they decided to change the name for International Telegraph and Telephone Consultative Committee (CCITT, from the French "Comité Consultatif International Téléphonique et Télégraphique"). Finally, in 1993 the name International Telecommunication Union (ITU) was defined and all telecommunication's subjects would be treated since then [1]. The ITU is headquartered in Geneva, Switzerland, and is divided in three sectors: the Radiocommunication Sector (ITU-R), Development Sector (ITU-D) and Telecommunication Standardization Sector (ITU-T). This last one is the focus of the paper.

\subsection{ITU's Structure}

With more than 900 members and associates, the mission of ITU is to guarantee worldwide high quality telecommunication standards and define tariff bases of international services. The main event of ITU is the Plenipotentiary Conference, which elects the presidents and directors of the organization and establishes policies, strategies and financial plans for four years, the period for having another Conference. During this time, there is a Council to ensure that Union's activities, policies and strategies fully respond for today's dynamic, rapidly changing telecommunication environment [2]. All these decisions affect directly ITU-T's plans and strategies for working programs. The Conference elects the director of the Telecommunication Standardization Bureau (TSB), who is responsible for the approving of standards, who gives the 'last word'. The TSB is responsible for maintain ITUT's website and its database with all standards published since ITU's foundation. TSB determines the telephony international area codes (e.g. in U.S. is +1 , in Brazil is +55 , Japan's is +81); TSB collaborates with ITU-D and ITU-R in developing countries providing technical information; provides administrative and operational information through the ITU Operational Bulletin [2]; and still is responsible for edit and publish the Recommendations (the name given for standards). Another group is the Telecommunication Standardization Advisory Group (TSAG), which reviews the financial programs, priorities and strategic subjects of ITU-T. They advice TSB's director and restructure and establish the Study Groups 
(SGs). There is an event, the World Telecommunication Standardization Assembly (WTSA), which, with TSAG's action, establishes the SGs, their work for next four years and their chairpersons. In WTSA the policies from the Sector are defined.

\subsection{Study Groups (SGs)}

To participate in a SG is necessary to be: a state member - the national governments that are members of ITU. Today they are 191; a sector member - primarily companies from the private sector and other regional and international organizations, who participate in the work of all ITU-T SGs; and an associate - who comes from the private sector and are entitled to work in only one ITU-T SG [2]. Standards are implemented after develop, discuss and test that technology in simulations of the real world. The TSB determines meetings of each SG, location, draft agenda and deadline for submitting contributions. All work programs from SGs are based on market demand, so one important point is to ensure that SG's priorities must be close to those requested by the membership (companies and private sector members) [3]. Inside a SG, we find subdivisions called Working Parties (WPs), divisions in themes related with that field of study. Each WP has many study Questions, for example, the SG13 - Future networks including mobile and NGN (Next Generation Networks) has the WP4/13 - QoS and Security, and inside this WP there is one division, from three, called Q16/13 - Security and identity management (Q- study Question; 16- number of Question; 13- number of SG).

ITU-T created an instrument to make an effort in specific questions: the Focus Groups. They are responsible for discuss some emergent subjects, that need to be solved quickly. A Focus Group works during a period of a SG, since any SG is permanent, but they all have a temporary character. A SG has the structure below:

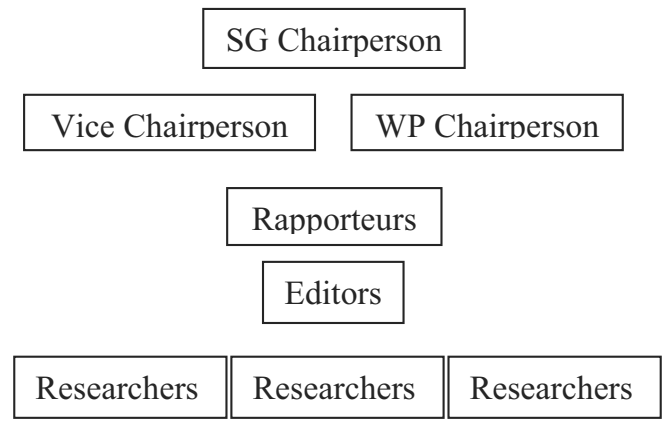

Fig. 1: SG structure 
The SG's Chairperson and Vice Chairperson are responsible for the efficient running of the SG. Generally, the Vice Chairperson is the Working Parties Chairperson. The researchers make the studies and develop technologies about what the SG is doing. During the process of development, drafts are made and published in ways that all members can see what is being doing. The drafts are edited and published by the editors. The rapporteurs are responsible for leading discussions and coordinating the progress on the works.

\subsection{Approving Recommendations}

When a standard is approved, it receives the name of Recommendation. But there are two types of approval: the Traditional Approval Process and the Alternative Approval Process.

\subsubsection{The Traditional Approval Process - TAP}

The Traditional Approval Process (TAP) is used when a Recommendation has a regulatory or policy implication. It starts with a SG meeting and the consensus that a draft is already mature to become a Recommendation. The Chairman will make a request for TSB's Director to announce the period for voting. The edited text will be available for the Director, so he can make the announcement. It must be announced at least 3 months before the next SG meeting. The text of the possible Recommendation is distributed to all members and so there is a period for voting [4]. When deadline comes, the votes are counted and if $70 \%$ or more approves the draft, so there is one new Recommendation.

\subsubsection{The Alternative Approval Process - AAP}

This newer process is the most used today. It can be done by electronic means and is more quickly than the TAP. This process was approved in 2000, by WTSA.

When a draft is considered mature enough to become a Recommendation, the text is edited for Last Call (LC). The TSB Director announces the LC and, in a period of 4 weeks, the members can vote and decide to approve or not that Recommendation. If there is no suggestion in the text, the Recommendation is approved. In other way, the members can decide that one more SG meeting is sufficiently close to consider the comments received, in case of comments in the text. The third way, if more reviews are necessary, the Director announces the Additional Review (AR) that encompasses a three-week time period. In a new 
SG meeting, the approval is decided if there's no more reviews to be done. So, the Director makes the notification and publication of the new Recommendation [5].

\section{ABOUT IETF}

The Internet Engineering Task Force is an open international standardization body of network designers, operators, vendors and researchers focused on the development of Internet standard protocols to use on the Internet and intranets [6]. This standardization provides the success of Internet and its global connectivity.

\subsection{IETF'S Environment}

In general way, the IETF is in an environment of other standardization's organizations. In the bigger sphere, we find the Internet Society (ISOC) concerned with the evolution and growth of the Internet globally and the political, social and technical consequences. In the same context of IETF, there is the Internet Assigned Numbers Authority (IANA) who determines numbers of protocols, port numbers and controls DNS (Domain Name System). IANA still coordinates global IPs. Another organization is the Internet Architecture Board (IAB), who oversights architecture and protocols of the Internet, appoints IETF's chair and approve and review the Working Groups (WGs) of IETF. At last, there is the Internet Engineering Steering Group (IESG), which is responsible for the progression of the WGs and their advances on technical specifications along standards track.

Fig. 2: IETF and other organizations wrapped up in standardization process.

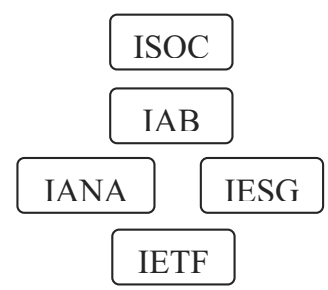

All these organizations form a smooth society where information and technical issues are always shared among them. 


\subsection{Inside IETF}

IETF has no corporate membership. Is an open organization of individuals [7]. Anyone can join this open group and suggest his or her idea to become a standard. But there is a small structure to administrate the standardization process. There are the Working Groups (WGs) who develop studies and researches to reach a Request For Comments (RFC), an approved standard. These WGs are composed by network operators, researchers, students, network designers and so on. They are within 8 different areas: general, application, Internet, operations and management, routing, security, transport and user services. Each WG and quoted area has a Director. To have a determined issue in the WGs, the members must do the "Birds of Feather", that means, a discussion to establish objectives for the WG and communicate the decisions to the area director.

The WGs have a mailing list with information of all members from that group and where they have some "meetings". Three meetings a year are held and two of them are in U.S., at least. The decisions and discussions are made face-to-face or through the mailing list. The votes are not computed one by one to decide an approval of a RFC, because there is no formal vote. The votes are on "rough consensus". Generally, the dominant view of the WG shall prevail [6].

\subsection{Approving RFCs}

The RFCs are formal documents identified with a series number that standardize many technologies developed by IETF (e.g. RFC 2328 - standardizes OSPFv2).

Any person can send a suggestion to IETF. It is important that the suggestion be compatible with all technologies already developed and in operation. After that, it becomes an "Internet Draft". By this moment the draft is open to everyone who wants to participate in that RFC, reviewing and adding technical data and information. If a period of six months is passed and nobody has contributed in the draft, it will be discarded. Continuing the standard track, the IESG is requested to move the specification onto the standards track at the "Proposed Standard" level. It means that the specification had some tests resolved, is well-understood and the community thinks that is a good specification, that need just more experiences. The IESG will require some operational implementation to prove that that "Proposed Standard" is functionally acceptable and relevant for Internet [8]. A specification, from which at least two independent and interoperable implementations from different code bases have been 
developed with successful experience, may be elevated to the "Draft Standard" level [6]. To prove that, the specification shall remains at least 6 months in "Proposed Standard" level. The "Draft Standard" is the last mature level from the standard track. For minimum of 4 months, the specification must be considered well-understood and be quite stable. If the specification fails through this process, it becomes a Historic RFC. But if everything gives right, so it goes to the "Internet Standard" level [8], becoming a RFC, plus its serial number (e.g. RFC xxxx).

\section{ITU-T AND IETF DUELING FOR MARKETS}

The IETF has proved till now its capability on standardizes specifications, in a very simple way, open to everyone who wants to share his/her idea. Otherwise, ITU-T has the power of being a huge organization, with support of almost countries in world, including UN's strength. Despite these two organizations didn't have the same focus in the beginning, today they act in similar technologies researches. ITU-T doesn't provide only specifications for physical components of telecommunication, but is increasing its scope by investing in Internet standards researches, with participation of many companies which have their own interest on global market. In this context, a new competition is emerging to standardize specifications for the same use. An example of this competition is the ASON (Automatically Switched Optical Network), from ITU-T that promises to enable new transport services such as bandwidth on demand, rapid service restoration for disaster recovery, switched connections, support for client signals such as IP, Ethernet, ATM, Audio/Video, and so on. In IETF's side we find the GMPLS (Generalized Multiprotocol Label Switching), that satisfy all the requirements of ASON and wants to prove that GMPLS routing protocols are provided in other documents.

\section{CONCLUSION}

The example given shows how there is a competition for conquer a space in a unique market niche. Of course some values, like patents and technologies rights, are included in this competition that involves companies from private sector, organizations around the world, research centers and States Governments. The difference on structures and management is not the major factor in this competition that can define this game. Some political questions and domains of market are also included in this case. 
With all sure we can say that independently of being ASON or GMPLS the winner of this competition, any technology developed by ITU-T or IETF can guarantee a better service offered from Internet and all the protocols that allows the global communication in real time.

\section{REFERENCES}

1. http://www.itu.int/net/about/history.aspx

2. T. Johnson, P. Rosa, The Working Methods and Basic Rules of Standardization in the Standardization Sector of the International Telecommunication Union: ITU-T, IEEE Communications Magazine, October 2008.

3. T. Irmer, Shaping Future Telecommunications: The Challenge of Global Standardization, IEEE Communications Magazine, January 1994.

4. ITU-T - Telecommunication Standardization Sector of ITU, Resolution 1 - Rules of procedures of the ITU Telecommunication Standardization Sector (ITU-T), World Telecommunication Standardization Assembly, Florianópolis, October 2004.

5. Telecommunication Standardization Advisory Group, Recommendation ITU-T A.8, World Telecommunication Standardization Assembly, Johannesburg, October 2008.

6. M. Ohta, IETF and Internet Standards, IEEE Communications Magazine, September 1998.

7. H. Alvestrand, The Role of the Standards Process in Shaping the Internet, Proceedings of the IEEE, vol. 92, no.9, September 2004.

8. S. Bradner, The Internet Standards Process - Revision 3, Request For Comments: 2026, October 1996.

\section{ACKNOWLEDGMENTS}

The author is grateful to Maria Inês Faé, professor from Federal University of Espírito Santo and great friend, who encouraged him to write about the subject and deepen in researching about new technologies and their impact on industrial logistics and on the market. 


\title{
STEEL SUPPLY CHAIN MANAGEMENT BY SIMULATION MODELLING
}

\author{
M. Sandhu ${ }^{1}$, P. Helo ${ }^{2}$ and J. Kristianto ${ }^{3}$ \\ ${ }^{1}$ United Arab Emirates University,CBE, P.O. Box 17555, Al Ain, U.A.E. \\ ${ }^{2 \& 3}$ University of Vaasa, P.O.Box 700, FIN-65101 Vaasa, FINLAND
}

\begin{abstract}
This paper presents a simulation modelling of the "Steel Supply Chains" to demonstrate the effect of information sharing in the inventory level reduction. A framework is presented for a better understanding of the importance of the order information in the chains. The choice of concepts and final construction of the framework is informed by an empirical research where data was collected from two steel manufacturing case companies and simulated by using discrete event simulation. Design of experiment showed that information sharing mitigates the bullwhip effect by reducing buffer stock level in steel supply chains. Production and delivery sequencing is also important in terms of buffer stock level reduction. Simulation gives benefit to managers by showing the dynamic behaviour of inventory level in steel supply chain. Finally, a simulation model contributes to the steel supply chain in the development of task scheduling and order prioritization rule.
\end{abstract}

\section{INTRODUCTION}

The pace of change and growing uncertainty about how markets will evolve has made it increasingly important for companies to be aware of supply chain management (SCM). In general, SCM can be defined as a process of integrating a chain of entities (such as suppliers, manufacturers, warehouses, and retailers) in a manner that ensures the production and delivery of goods in the right quantities and at the right time, while minimising costs and satisfying customers.

The supply chain itself can be understood as a network of autonomous (or semiautonomous) business entities involved in various business activities that produce and deliver, through upstream and downstream links, goods and/or services to customers. Lin and Shaw (1998) emphasised the notion of value in seeing a supply chain as a series of activities that 
delivers value to its customers, in the form of a product or a service (or a combination of both), whereas Moon et al. (2005) emphasised the notion of core flows in describing a supply chain in terms of flows (of information, cash, and materials) through a series of processes, beginning with suppliers of raw materials and finishing with the end customers.

If a supply chain is understood in the second sense (that is, in terms of information and material flows), a so-called 'bullwhip effect' can occur over time as the dynamics of the flows change. The 'bullwhip effect' is a phenomenon whereby a small change in demand among end customers is amplified as it progresses upstream along the supply chain. This has the potential to causes cycles of excess inventory, severe backlogs, inadequate product forecasts, unbalanced capacities, poor customer service, uncertain production plans, high backlog costs, and lost sales (Lee et al., 1997). In the case of the steel industry, information sharing is used to coordinate lead time and inventory level by coordinating of activities of various entities in the supply chains (Chandra and Kumar, 2000). There are a number of studies stating problems when using both the traditional perspective. However, there is a need for development of new ideas, which integrate the peculiar information sharing events of the supply chains.

There are three specific characteristics that differentiate the theoretical view of this study from the earlier studies on steel supply chain simulation modelling. First, it reflects the interaction between involved parties, i.e. upstream and downstream. The next, it discusses the effect of information sharing in steel supply chains and finally, the activities and order scheduling in use between the partners engaged. The elevation of these three aspects permits the authors to examine other theoretical construction than the traditional steel supply chain simulation modelling views. When comparing the views on simulation, the strength is gained from case companies. Therefore, our research question is: 'How can information sharing reduce inventory level in the entire steel supply chain?'

\section{SUPPLY CHAIN MANAGEMENT}

As noted above, a supply chain consists of several entities (including customers, distributors, manufacturers, and suppliers), each of which contributes materials, resources, and activities to the chain. Managing a supply chain thus requires integration of the entities at the structural level and integration of their individual systems to produce an optimal result. The benefits of effective SCM include:

* Throughput improvements: better coordination of materials and capacity prevents loss 
of utilisation while waiting for parts;

* Cycle time reduction: consideration of constraints and alternatives in the supply chain helps to reduce cycle time;

* Inventory cost reductions: knowledge of when to buy materials (based on accurate assessment of customer demand, logistics, and capacity) decreases the need for high inventory levels to guard against uncertainty;

* Optimised transportation: effective SCM optimises logistics and vehicle loads;

* Increased order fill rate: real-time visibility across the supply chain (alternate routings, alternate capacity) enables order fill rates to be increased; and

* Enhanced responsiveness to customers: improved capability to deliver (based on availability of materials, capacity, and logistics) enhances responsiveness to customer needs.

Computer simulation has become a useful form of modelling in many systems, including economics, social sciences, manufacturing, and engineering. Simulation typically uses a mathematical model to predict the behaviour of the system from a set of parameters and initial conditions. The technique is often used for modelling systems in which simple closed-form analytical solutions are not possible. Although there are different types of computer simulation, the common feature of all is the generation of a sample of representative scenarios for a model in which a complete enumeration of all possible states of the model would be prohibitive or impossible.

The application of simulation in supply chains has tended to emphasise a multi-agent approach that takes account of the fact that supply chains are composed of autonomous or semi-autonomous agents (Swaminathan et al., 1998). However, the main issue in such multiagent simulation is uncertainty regarding the distribution of supply-chain activities among the various agents (Fox et al., 2000). Nevertheless, Fu et al. (2000) has used such a multi-agent simulation to enhance collaborative inventory management and Towill, 2003) applied a similar technique with a view to eliminating the 'bullwhip effect'. These studies suggest that multi-agent simulation promises significant improvement in SCM.

According to Chang et al. (2003), the benefits of supply-chain simulation include:

improved understanding of the overall supply-chain processes and characteristics by the provision of graphics/animation.

capturing of system dynamics through probability distribution (including modelling of 
unexpected events in certain areas and their impact on the supply chain); and

minimisation of the risk of changes in the planning process through the utilisation of so-called 'what-if' simulation, which enables the user to test various alternatives before changing a plan.

\section{STEEL SUPPLY CHAIN}

All supply chains are different and a lot of companies struggle to understand the dynamics of their supply chain (Özbayrak et al, 2007; Wadhwa et al, 2008). Furthermore, in considering steel industry, the dynamics of the supply chain could possibly create what is called "the bullwhip effect". Figure 1 illustrates a typical steel supply chain from iron mining to finished product. The present paper concentrates on the 'make-to-order' steps shown in Figure 1 because the steps from iron mining to slab-casting production ('make-to-stock') produce homogeneous bulk product in a continuous production process (rather than as discrete processes). The difference is significant. A continuous process ensures smooth production whereas discrete processes are characterised by numerous setups and stock points, with an increased likelihood of overstocking or stock-outs.

The 'bullwhip effect' has long been a significant problem in steel supply chains. Possible solutions for reducing the effect were originally proposed by Forrester (1961) (based on a 'DYNAMO' simulation model) and more recently by Burbidge (1984) (based on his shop-floor observations, supplemented by industrial engineering analysis). According to Forrester (1961), 'bullwhip effects' can broadly be identified as continuous changes in the echelon time-series with respect to demand, orders, shipments, production, and inventory. These 'Forrester effects' generally exhibit long-wavelength periodicity, which can sometimes be related to the time delays in the feedback paths used to correct inventory discrepancies. According to Burbidge (1984), 'bullwhip effects' arise from the batching of demand and production, and can therefore be identified by discontinuous (or sharp-edged) changes in the time series. These 'Burbidge effects' are generally of shorter wavelength, although infrequent re-ordering or large batch sizes can be expected to produce longer wavelength fluctuations.

In the years since Forrester (1961) and Burbidge (1984) proposed their ideas, research into the 'bullwhip effect' have been greatly extended and further refined. McCullen and Towill (2002) have claimed that variations in the steel supply chain can be minimised, but that it is important to identify the particular causes of 'bullwhip' in each instance. Metters (1997) has built up a sophisticated model for estimating the cost of 'bullwhip' using a form of dynamic programming that models the optimum supply chain response to a number of demand patterns. Towil's (2002) result is an interesting one. He shows that Forrester effect which causes supply chain demand amplification or Bullwhip effect. The 
interesting result is that this factor is dependent of the information confidence level of both of supplier and buyer.

\section{STEEL SUPPLY CHAIN SIMULATION}

Simulation has been applied to multi-agent supply chains to investigate the dynamics of the systems against sudden deviations in parameters, with a view to optimising lead times and minimising total costs (Swaminathan et al., 1998). Similarly, Towill (1996) studied the 'bullwhip effect' by applying control theory to inventory and lead-time minimisation, and Wilkner et al. (2007) and Pesonen et al (2008) used simulation to investigate order-book effectiveness against demand uncertainty and product development process. Supply-chain simulation to reduce the 'bullwhip effect' has been undertaken in the automotive steel industry by Holweg and Bicheno (2002), who used a lean processing program applied to three tiers of the supply chain (slab casting, hot rolling mills, and finishing coils) prior to component manufacture. The authors investigated an information-distortion effect to demand magnification in two rounds of simulation. This differed from the well-known 'beer game' simulation in using a 'lean leap' logistics game - because the 'beer game' is not appropriate for application to a manufacturing process that consists of multiple stages and significant capacity constraints. Holweg and Bicheno (2002) concluded that synchronisation within the supply chain is influenced by three factors: (i) demand visibility; (ii) process visibility; and (iii) appropriate time buffer.

Steel supply chain simulation has also been undertaken in the context of business strategy development by Hafeez et al. (1996), who analysed and modelled two echelons of a steel supply chain for the construction industry. The authors adopted a system-dynamics approach similar to that of Holweg and Bicheno (2002) to minimise lead times and inventory level. Two kinds of model were utilised: (i) a conceptual model (to determine dominant factors that influence system performance); and (ii) a quantitative model (representing a close-loop system). The study, which utilised supply lead times as disturbance for the modelled system, produced a steel industry competitiveness index according to various competitive criteria. The authors concluded that this tool can be as a management information system to measure competitiveness in the industry.

\section{SIMULATION MODEL FOR STEEL INDUSTRY}

The following features of the steel supply chain were simulated in the model:

- orders;

- inventory level; 
- steel-shaping process.

- Asset utilization

We exclude slab casting scheduling and sequencing due to the scope of our present study which lie on information sharing benefit on steel supply chains. Order and inventory level are used as simulation variables by considering that order information and inventory level are two sources of supply chain dynamic (Forrester, 1960). When implementing the strategies of prioritisation, there is potential for decreased asset utilisation because batch sizes might not be achieved. With low-priority products, production is directly linked to orders, with no extra percentage to achieve a full batch size. In planning make-to-stock production, stock levels determine decision making, which therefore introduces variability in production. By inducing these variations in production, there is potential for the 'bullwhip effect' to spread along the supply chain. However, with a prioritisation strategy, it should be possible to reduce the impact of this effect.

\section{Details of simulation model}

The specific problem areas in steel-production planning (as described above) were simulated in a socalled 'Simulsteel' model using EXTEND simulation software (see Figure 1). The objectives of this simulation were: (i) to identify relationships between external factors (such as variety of customer demand) and internal factors (such as inventory levels); (ii) to note the effects of these relationships on system performance indicators (such as final inventory level, order completion rate, and production rate) and (iii) to investigate information sharing effect to bullwhip effect reduction.

In pursuit of these objectives, the simulated system took orders from the order database, and then prioritised them. Scheduled production was then simulated and outputs were analysed. These outputs included inventory levels, production throughput-time, and customer satisfaction (proportion of orders produced on time). Order batching was used to represent economic production quantity, and the simulation model was run under three replications.

The model was able to generate production slips to the steel factory based on orders. These orders were placed in a queue, and orders were fulfilled according to priority. The priority order was as follows:

1. stock of finished coils: if steel type and size matched from shipment queue;

2. stock of coils: if steel type and thickness and width matched or if it were possible to cut ordered width size from coils of finished department queue;

3. stock of raw slabs: if steel type and order weight size matched or if it were possible to cut ordered weight size from slabs of Furnace \& HSM queue; and

4. from raw material: if steel type did not match any stocks of smelting queue. 
The model was able to generate orders to raw material suppliers, if:

- the actual inventory level of raw material was below the safety stock limit of raw material orders; and

- There are backorders, where after orders were matched against available stocks, the unfilled orders still remain in the orders queue

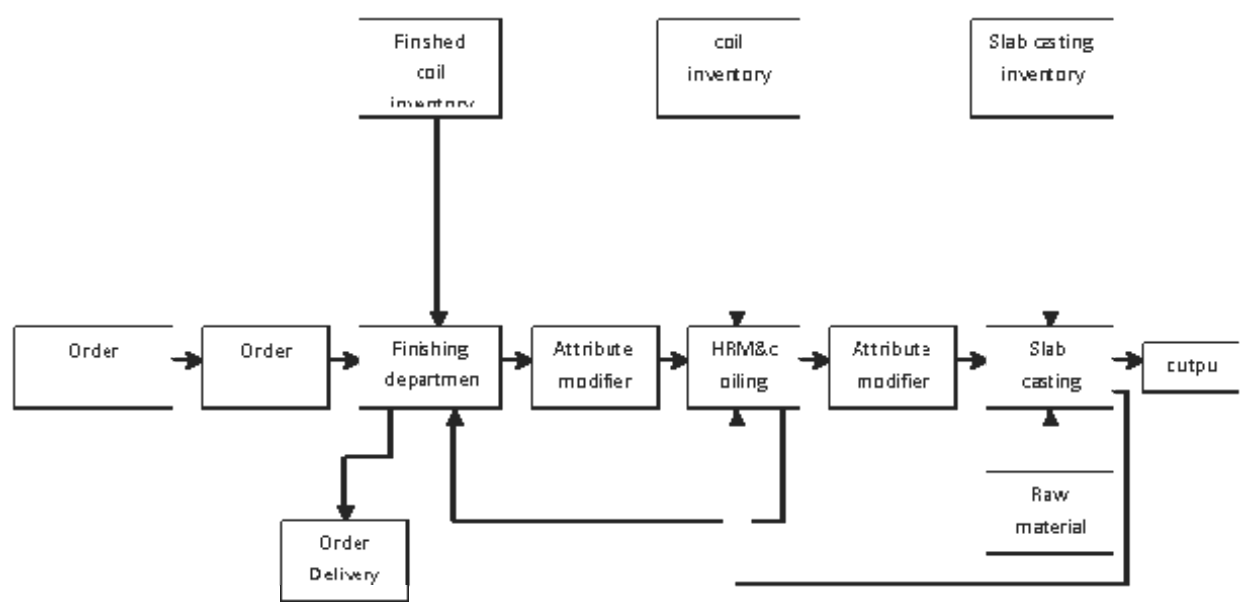

Figure 1: Steel shaping process model

The detailed steps of the simulation is introduced as follows

1. Demands arrive according to $\mathrm{M} / \mathrm{M} / 1$ distribution and the sales department prioritize them according to their priority and stock availability. Order scheduling by prioritization is used by considering the process commonality in the entire factories. It is assumed that among product varieties have different processing time and the highest priority is given to the least processing time. Prioritization is done manually by using Microsoft EXCEL.

2. In a simulation model without information sharing, production slip is then issued every 24 hours, where the finishing department selects their processing according to stock availability. If the stocks are ready, then, finishing department will schedule the finishing operation by scheduling the manufacturing process. Otherwise, finishing department will issue production slips to Hot Rolling Mills (HRM) department. Finishing department directly order the unfilled orders to HRM department. This decision is taken in order to make quick response to the orders. If HRM must wait until batch size is achieved, then production will stagnant in the finishing department. Until this stage, production scheduling should be optimized against customized orders because we cannot depend fully to inventory.

3. In a simulation model with information sharing, customer order is transmitted directly to Hot Rolling Mills (HRM) department. This decision is taken in order to short cut information flow 
from finishing department to HRM department and to reduce inventory level in finishing department.

4. To investigate effect of information sharing, then, simulation model is modified by changing the order information path from finished coil manufacturer directly to hot rolling mill factory.

The above steps are then simulated by giving some inputs and outputs to investigate the performance of the supply chains. The choice of input and output parameters are taken carefully to focus on the objective of this simulation, that is to investigate the effect of inventory level to service level and the effort of bullwhip effect mitigation.

\section{Conclusion and discussion}

This experiment is intended to answer research question of how can information sharing reduce inventory level in the entire level of steel supply chain?. From this point on this simulation is subjected to incorporate inventory level as dependent variables to investigate the effect according to simulation model. Multivariate analysis of variance is used in order to observe the effect of demand variety and beginning inventory level. Thus, output rate, final inventory level and completion rate are used as performance measures. Our results Informs us that solely or jointly both of inventory level and demand variety have significance effect to steel supply chain performance (output rate, final inventory level and completion rate). Furthermore, beginning inventory level gives significance effect to inventory variance. Conclusion for those results is low level of beginning inventory gives advantage to the whole system because it can reduce inventory variance and as a consequence is bullwhip effect elimination. Furthermore, this reduction also gives advantage to holding and penalty cost reduction. Higher variance forces manufacturer invests more in inventory and in this case s,S policy can be used. Unfortunately s,S policy can creates bullwhip effect. (Towill, 1996).

Argument for lower level inventory application is also supported by our results where beginning inventory level has no any effects to system output (output and completion rate) but final inventory level. This situation is not in effect to demand which has significant impact to completion rate. In conclusion, low inventory level is recommended to be applied rather than high level in order to avoid high inventory variance that can create bullwhip effect. In conclusion, this simulation gives information to readers that high demand variety should not cause bullwhip effect as long as such an order is handed individually by continuous replenishment policy and information sharing as a consequence then flexible production line should be represented.

\section{References}

Burbidge, J.L. (1984), "Automated production control with a simulation capability", IFIP Working Paper, WG5(7), Copenhagen.

Chang, Y. And Makatsoris, H. (2003). Supply chain modeling using simulation", International Journal of Simulation, Vol. 2, No 1, pp 24-30 
Forrester, J. (1961), Industrial Dynamics, MIT Press, Cambridge, MA.

Fox, M, Barbuceanu, M and Teigen R, (2000),"Agent oriented supply chain management", The International Journal of Flexible Manufacturing System”, 12, pp 165-188.

Hafeez K, Griffiths M, Griffiths J and Naim M.M, (1996), "System Design of Two Echelon Steel Industry Supply Chain”, International Journal of Production Economics, Vol 45, pp 121-130.

Hlupic, V. and Vreede, GJ. (2005)."Business process modelling using discrete-event simulation: current opportunities and future challenges”. International Journal of Simulation and Process Modeling, Vol. 1, No 1-2, pp 72-81.

Holweg M and Bicheno J (2002), "Supply Chain Simulation-a tool for education, enhancement and endeavour", International Journal of Production Economics, Vol 78, pp 163-175.

McCullen P., Towill D. (2002), "Diagnosis and reduction of bullwhip in supply chains", International Journal of Supply Chain Management, Vol. 7 No. 3, pp.164-179

Moon et al (2005)," Systems thinking ability for supply chain management", Supply Chain Management: An International Journal. Vol. 10 Issue 5, pp 394-401

Özbayrak. M, Papadopoulou. T. C., and Akgun. M., (2007), “System dynamics modelling of a manufacturing supply chains system”. Simulation Modelling Practice and Theory, 15(1), pp 1338-1355.

Pesonen. L.T.T., Salminen. S. J., and Riihimäaki. P., (2008), “Dynmaic simulation of product process".Simulation Modelling Practice and Theory, 16(1), pp 1091-1102.

Swaminathan J.R, Smith S.F and Sadeh N.M, (1998),'Modeling supply chain dynamics: a multi agent approach.”, Decision Sciences, 29(3), 607-632

Towill D.R , (1996). Industrial dynamics modeling of supply chains, International Journal of Physical Distribution and Logistics, 26(2), $23-42$

Wadhwa. S, Saxena. A., and Chan. F.T.S., (2008), "Framework for flexibility in dynamic supply chain management", International Journal of Production Research, 46(6), 1373-1404

Wilkner J , Mohamed M. Naim and Martin Rudberg .(2007). Exploiting the Order Book for Mass Customized Manufacturing Control Systems With Capacity Limitation. IEEE Transactions on Engineering Management. 54(1). $145-155$ 


\title{
IDENTIFICATION OF STRATEGIC LOGISTICS NODES IN THE CENTRAL REGION OF MEXICO
}

\author{
J.P. Antún, A. Lozano, R. Alarcón, F. Granados y L. Guarneros \\ Laboratorio de Transporte y Sistemas Territoriales \\ Instituto de Ingeniería, Universidad Nacional Autónoma de México (UNAM) \\ Torre de Ingeniería, Nivel 2 Ala Norte, Ciudad Universitaria, México DF (04510)
}

\begin{abstract}
This paper presents the process carried out for the identification of strategic logistics nodes (SLN) in the Central Region of Mexico. The analysis is based on the identification of logistics activities zones, the trucks traffic on the main road and the connectivity to the road infrastructure, and an analysis of the decision factors for location from logistics managers, 3PL leaders and real estate companies. Additionally, a set of Reserve Area for Logistics Activities (RALA) was identified for each SLN.
\end{abstract}

\section{INTRODUCTION}

This paper is based on a research carried out by the Transport and Territorial Systems Group of the Engineering Institute of the Universidad Nacional Autónoma de México (UNAM), under request from the Ministry of Economy of the Federal Mexican Government and the Committee for the Central Region Development (FIDCENTRO) (Antún et al. [1]).

The study provides strategies for the competitive logistical territorial management of the Central Region of Mexico, which includes: i) the identification of a Strategic Logistics Nodes (SLN) and ii) the determination of adequate sites for locating Reserves Areas for Logistical Activities (RALA), in order to facilitate physical distribution of goods to a market of over 30 millions inhabitants in the megalopolis of Central Region of Mexico.

The main background of this research is the following: i) a general review and classification of Logistics Centers, based on Mexican and international experience, particularly considering the European situation (Antún et al., [2]); ii) a previous study 
confined to the MZMC and the first ring of urban expansion (Lozano et al., [3] y Lozano et al., [4]); and iii) the analysis of new trends on metropolitan physical distribution of goods (Antún et al., [5]).

\section{GEOGRAPHIC INFORMATION SYSTEM FOR LOGISTICS FACILITIES AND LOGISTICS ACTIVITIES ZONES}

The location of logistics facilities and logistics activities zones were identified. Their geographical and attributes information was included in a Geographic Information System (GIS) in order to facilitate a territorial analysis.

2.1 Logistics centers, logistics parks and others facilities dedicated to logistical activities, which are currently in operation

Based on information from the Mexican Industrial Parks Promotion System (SIMPPI, in Spanish) and the Mexican Association of Industrial Parks (AMPIP, in Spanish), the major 62 industrial parks and logistics parks (I\&LP) within the Central Region of Mexico were identified. Information of each facility was included in a GIS.

The majority of I\&LP are located in a few areas or corridors (see Figure 1):

- In Mexico State, three corridors were identified: the México-Querétaro highway corridor, where the Tultitlán-Cuautitlán-Tepotzotlán, and Tlalnepantla-Huehuetoca areas are located; the Toluca-Lerma corridor, to the south of Toluca City; and the Toluca-Ixtlahuaca-Atlacomulco-Jilotepec corridor.

- In Hidalgo State, three corridors were identified: the México-Pachuca highway corridor, the Pachuca-Sahagún corridor, and the segment of the Mexico-Queretaro highway corridor within Hidalgo, mainly in the Tepeji del Río and TulaAtitalaquia areas.

- In Puebla State, industrial parks are concentrated between the San Martín Texmelucan and Puebla-Amozoc areas.

- In Morelos State, the main industrial parks are located on the AlpuyecaCuernavaca and Cuautla corridors.

- Tlaxcala State has a quite homogeneous industrial parks distribution.

- Finally, in the Federal District, industrial parks are mainly in the Vallejo industrial area, in the municipality of Azcapotzalco. 


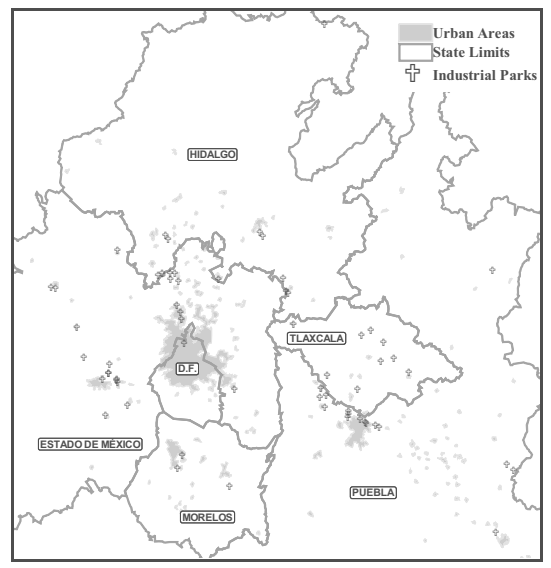

Figure 1. Industrial \& Logistics Parks within the Central Region of Mexico.

Detailed information was obtained for each area and corridor. For example, the I\&LP in the metropolitan area of Toluca form the following nine clusters: 1) the Toluca-Lerma Industrial corridor, 2) the Cerrillo Industrial Park I, 3) the Cerrillo Industrial Park II, 4) the Santiago Tianguistenco Industrial Park, 5) the Exportec Industrial Park I, 6) the Exportec Industrial Park II, 7) the San Antonio Buenavista Industrial Park, 8) the Tenango Industrial Park and 9) the Toluca 2000 Industrial Park.

\subsection{Territorial clusters with logistics activities}

Several distribution centers and clusters of facilities dedicated to logistics activities were identified within the Central Region of Mexico. This identification was based on: a detailed review of information of the main real estate developers and industrial and commercial leaders, and field work undertaken for some case studies. Then, information of each facility was included in a GIS.

The information search was focused on the major real estate developers of logistics infrastructure: 1) Corporate Properties of the Americas (CPA), 2) FINSA, 3) Friso, 4) GICSA, 5) Grupo Acción (now AMB Property Corporation), 6) Grupo O'Donnell, 7) Prologis, 8) Tlanepark and 9) Vesta.

Fifty real estate logistics developments were found; 44 of them in Mexico State, two in the Hidalgo State, and one in Puebla, Tlaxcala, Morelos and Federal District each. 
Many of the logistics real estate developments are located in the northern part of the Metropolitan Zone of Mexico City (MZMC), mainly in the San Martín Obispo, CuautitlánTultitlán-Tepotzotlán and Tlalnepantla areas and on the Toluca-Lerma corridor.

\subsection{Main Distribution Centers within the metropolitan zone of Mexico City, recently} developed by leading companies

The Central Region of Mexico has the largest number of Distribution Centers (DC) in the country. In particular, the Teoloyucan-Huehetoca-Tepeji_del_Río area has achieved importance due to its saturation with suitable sites for DC inside the southern zone of the toll gate (Tepotzotlán) and the new mobility options generated by two new highways: Vialidad Mexiquense and Libramiento Arco Norte. The most important DC in this area, are the following:

- The new MABE`s DC, in the Huehuetoca Logistics Center developed on 2008 by CPA in the municipality of Tepeji del Río in Hidalgo.

- The new LIVERPOOL's DC, developed on 2007, located within the Huehuetoca municipality in Mexico State.

- The new COTSCO DC, developed on 2009, in the Tepeji Industrial Park in Hidalgo.

- The new Chedrahui`s DC, developed on 2008, in the Teoloyucan Logistics Center (property of CPA), within the Teoloyucan municipality in Mexico State.

Some interviews with logistics managers of these companies where carried out in order to discover and discuss the reasons for their choice of that location.

\section{CONNECTIVITY TO ROAD INFRASTRUCTURE}

An important factor for determining the location of a logistics facility is the road infrastructure. Hence the connection to road infrastructure and the congestion problems (bottle necks) on it must be consider.

Also, the analysis of trucks traffic on the roads provides an idea about the goods flow within the Central Region, which is very important for determining the location of logistic facilities.

\subsection{Road Infrastructure}


The most important roads in the Central Region are seven national corridors. They have at least a segment within Mexico City. Another important road is the new Arco Norte toll highway, which is located on the northern part of the Central Region and connects the seven corridors without crossing Mexico City (see Figure 2).

The majority of the logistics facilities are located close to the mentioned corridors, as shown in Figure 2.

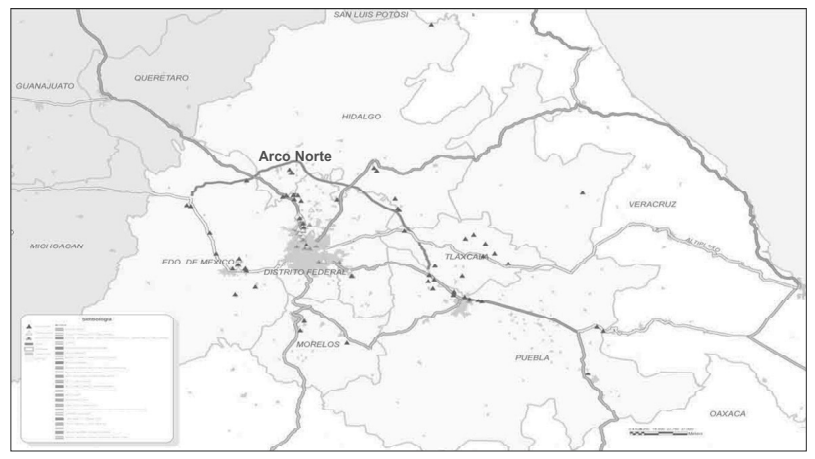

Figure 2. Road infrastructure (including the new Arco Norte highway) and logistics facilities in the Central Region.

\subsection{Road segments which are preferred by trucks}

The average daily traffic for each vehicle type, on some roads within the Central Region, was obtained from the Datos Viales 2008 (SCT DGST [6]). This information was useful for the identification of the road segments which are preferred by trucks (trucks and trailers). The average daily truck traffic (ADTT) is approximately $5 \%$ of the total average daily traffic.

The ADTT and the road characteristics allowed identify the bottle necks for trucks flow.

The ADTT on the main road of the Central Region is shown in Figure 3. The traffic volume is represented by the road width.

The road segments with the highest ADTT are located around the Federal District, especially on: San Pedro Barrientos-Ecatepec, México-Toluca, Naucalpan-Toluca, MéxicoQuerétaro, Tlalnepantla-San Gabriel y Los Reyes-Zacatepec.

The road average daily traffic, for each vehicle type, was also included in the GIS. 


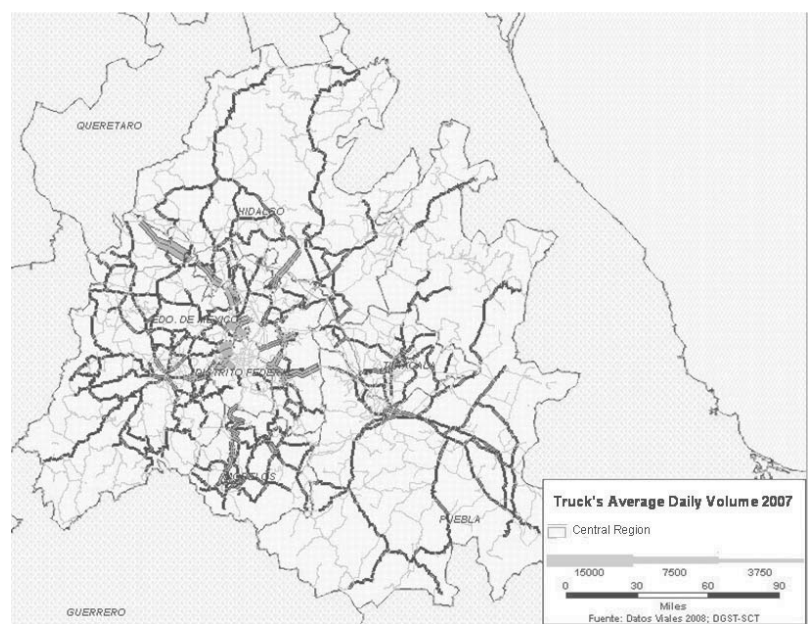

Figure 3. Average daily truck traffic of on the main road of the Central Region for year 2007.

\section{IDENTIFICATION OF STRATEGIC LOGISTICS NODES}

The decisions making process for determining the possible locations for logistical facilities, at inbound and distribution centers levels, takes into account the following: i) stakeholders in the supply chain (including the relative power of the goods producers, the dominant role of large commercial distributors and the 3PL "maneuver" margin), ii) interviews with managers of real estate companies and land use management public authority, and iii) trucks flow on the highways and main roads.

A set of high-priority strategic logistics nodes were identified; then, based on the processing of multispectral and panchromatic SPOT satellite images and field work, Reserves Areas for Logistical Activities (RALA), related to the hinterland of connections to new toll highways - Libramiento Arco Norte, Vialidad Mexiquense and Libramiento de Toluca-, were proposed.

The strategic logistics nodes are the following (as shown in Figure 4).

- Four nodes inside the Metropolitan Zone of Toluca (MZT).

- Four nodes inside the Western Zone of the Arco Norte highway.

- Three nodes inside the Northern Zone of the Arco Norte highway.

- Two nodes inside the Metropolitan Zone of Puebla-Tlaxcala.

- Two nodes inside the Metropolitan Zone of Cuernavaca-Cuautla 
- Four nodes inside the Metropolitan Zone of Mexico City (MZMC).

In order to identify suitable plots for RALAs, empty polygons in each node were explored on field studies and their real connectivity was analyzed. An example is shown in Figure 5, for Node 3 of the Metropolitan Zone of Mexico City (MZMC3).

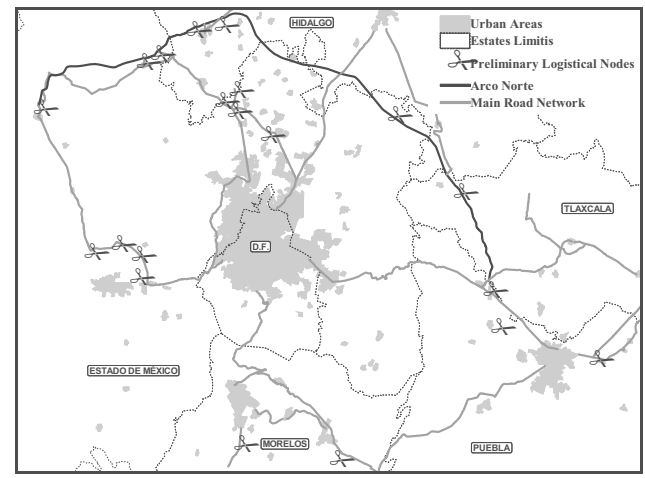

Figure 4. Identification of logistics nodes within the Central Region.

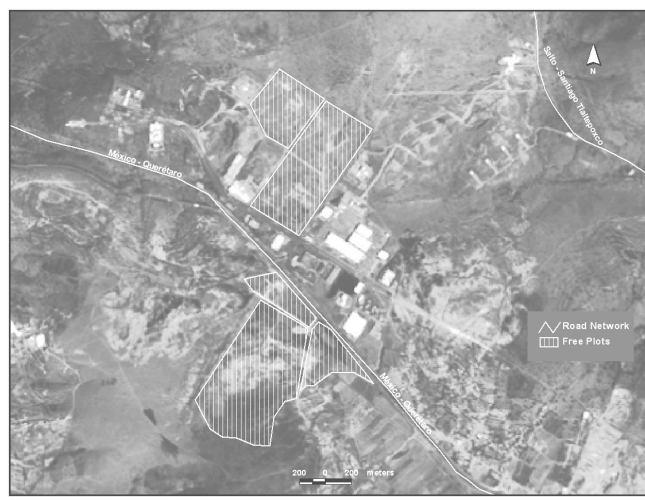

Figure 5. Two explored areas at Node $3 \mathrm{MZMC} 3$ on a satellite image.

\section{CONCLUSIONS}

The use of recent satellite images, Google Earth images, GPS and GIS, let us useful information about the territory and its relation with the existent road infrastructure and the new toll highways. Field works was required in order to update territorial information. The knowledge of the expertise and new projects of the main real estate developers was very useful for the determination of the Strategic Logistics Nodes (SNL) and the type of facility to be built. Location practice indicates that companies are trying to save money by means of 
closing distribution centers and setup a new one in a SLN. Research results provide a guide for designing public policies for promoting a wide portfolio of logistical facilities projects.

\section{REFERENCES}

1. Antún, JP; Lozano, A; Alarcón, R; Granados F, Guarneros, L. et al (2008) Estrategias para el Ordenamiento Territorial Logístico competitivo de la Región Centro, Convenio de investigación con la Secretaría de Economía del Gobierno Federal de México, Fondo PROLOGYCA y Fideicomiso para el Desarrollo de la Región Centro País (FIDCENTRO), Instituto de Ingeniería, Universidad Nacional Autónoma de México, México DF.

2. Antún, JP; Lozano, A; Hernández, R; Alarcón, R; Muñoz, MA (2008) Centros Logísticos, SD-50, Series del Instituto de Ingeniería, April, México DF, 185 pages.

3. Lozano A., Antún JP., Granados F., \& Santos C. (2007) Reserve areas for logistics activities in the metropolitan zone of Mexico City, Proceedings of the Fifth International Conference on City Logistics, Crete (Greece), July 11-13, 2007.

4. Lozano A., Antún JP., Santos C., Alarcón R., Guzmán A. \& Hernández, R (2008) Propuestas de Centros Logísticos para el Valle de México, SD-51, Series del Instituto de Ingeniería, July, México DF, 119 pages.

5. Antún, JP., Lozano A., Hernández R., \& Alarcón R. (2007) New trends on physical distribution logistics in Mexico City metropolitan area, Proceedings of the Fifth International Conference on City Logistics, Crete (Greece), July 11-13, 2007.

6. SCT, DGST, 2008. Libro de Datos Viales 2008. Dirección General de Servicios Técnicos, Subsecretaría de Infraestructura, Secretaría de Comunicaciones y Transportes (SCT), Mexico.

\section{ACKNOWLEDGMENT}

This paper presents some results of the project "Strategies for a competitive logistics territorial management of the Central Region of Mexico", performed during 2007-2008, under an agreement with FIDCENTRO \& PROLOGYCA, a Fund of the Ministry of Economy for the innovation in logistics and supply chain processes and operations; they appreciate diffusion of this work in the International Conference on Industrial Logistics ICIL Rio 2010. 


\section{Author Index}

\begin{tabular}{ll} 
L. B. Aguiar & 381 \\
\hline
\end{tabular}

\begin{tabular}{ll} 
R. Alarcón & 399 \\
\hline
\end{tabular}

$\begin{array}{ll}\text { J. P. Antún } & 399\end{array}$

\begin{tabular}{lr} 
M. Aragão & 153 \\
\hline
\end{tabular}

$\begin{array}{lc}\text { D. Banic } & 103\end{array}$

\begin{tabular}{ll} 
A. Bargelis & 13,79 \\
\hline
\end{tabular}

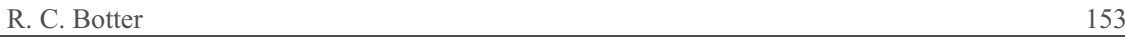

T. Brito 153

$\begin{array}{ll}\text { A. Burinskiene } & 29\end{array}$

$\begin{array}{ll}\text { G. Cabrera G. } & 289\end{array}$

$\begin{array}{ll}\text { H. Cancela } & 365\end{array}$

A. G. Canen 45

\begin{tabular}{ll} 
A. Capatina & 71 \\
\hline
\end{tabular}

\begin{tabular}{ll} 
A. C. Caputo & 355 \\
\hline
\end{tabular}

\begin{tabular}{ll} 
V. Cesnik 273 \\
\hline
\end{tabular}

$\begin{array}{ll}\text { P. Cosic } & 323\end{array}$

M. B. Costa 263

M. D'Agosto 263

$\begin{array}{ll}\text { D. de La Fuente } & 215,223\end{array}$

$\begin{array}{ll}\text { G. R. DeJean } & 339\end{array}$

$\begin{array}{ll}\text { D. Donevski } & 103\end{array}$

\begin{tabular}{ll} 
G. Dukic & 273 \\
\hline
\end{tabular}

M. Ehrs 255

M. El Khadiri $\quad 365$

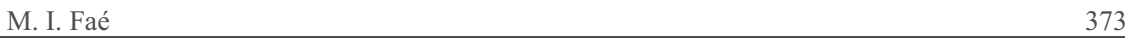

$\begin{array}{ll}\text { C. A. Faria } & 347\end{array}$

$\begin{array}{ll}\text { I. Fernandez } & 215,223\end{array}$

\begin{tabular}{ll} 
K. O. Ferreira 373 \\
\hline
\end{tabular}

$\begin{array}{lr}\text { E. M. Frazzon } & 21,163\end{array}$

\begin{tabular}{lr} 
M. J. Garcia 133,215 \\
\hline
\end{tabular}

M. Gerschberger 111,141

$\begin{array}{ll}\text { B. Gonçalves } & 263\end{array}$

$\begin{array}{ll}\text { C. Görg } & 37\end{array}$

F. Granados 399

$\begin{array}{ll}\text { L. Guarneros } & 399\end{array}$

$\begin{array}{ll}\text { P. Helo } & 173,389\end{array}$ 
L. Ivanovic 95

Z. Ivanovic 95

$\begin{array}{ll}\text { T. Kekale } & 181\end{array}$

\begin{tabular}{ll} 
D. Kirovski & 339 \\
\hline
\end{tabular}

$\begin{array}{ll}\text { G. M. Kopanos } & 125\end{array}$

$\begin{array}{ll}\text { M. Kosmykov } & 297\end{array}$

$\begin{array}{ll}\text { G. Kovács } & 281\end{array}$

Y. Kristianto 173

$\begin{array}{ll}\text { J. Kristianto } & 389\end{array}$

\begin{tabular}{lr} 
E. Leal & 247 \\
\hline
\end{tabular}

\begin{tabular}{ll} 
A. Lozano & 399 \\
\hline
\end{tabular}

$\begin{array}{lr}\text { T. Makuschewitz } & 163,297\end{array}$

$\begin{array}{ll}\text { R. Manketu } & 79\end{array}$

\begin{tabular}{ll} 
R. Marie & 231 \\
\hline
\end{tabular}

$\begin{array}{ll}\text { R. M. Melo } & 207\end{array}$

C. A. Méndez 125

\begin{tabular}{ll} 
A. Micu & 239 \\
\hline
\end{tabular}

\begin{tabular}{ll} 
A. E. Micu & 239 \\
\hline
\end{tabular}

\begin{tabular}{ll} 
S. Mihic & 191 \\
\hline
\end{tabular}

\begin{tabular}{ll} 
D. Milcic & 103 \\
\hline
\end{tabular}

\begin{tabular}{ll} 
M. T. Mine & 199 \\
\hline
\end{tabular}

$\begin{array}{ll}\text { P. A. Miranda } & 289\end{array}$

M. Monterrey 223

\begin{tabular}{ll} 
A. G. N. Novaes & 21,163 \\
\hline
\end{tabular}

$\begin{array}{ll}\text { L. S. Ochi } & 199\end{array}$

\begin{tabular}{ll} 
A. Olaru & 71 \\
\hline
\end{tabular}

\begin{tabular}{ll} 
T. Opetuk 273 \\
\hline J. Panteno
\end{tabular}

\begin{tabular}{ll} 
J. Parreño 223 \\
\hline
\end{tabular}

$\begin{array}{ll}\text { P. M. Pelagagge } & 355\end{array}$

\begin{tabular}{ll} 
L. Petingi & 365 \\
\hline
\end{tabular}

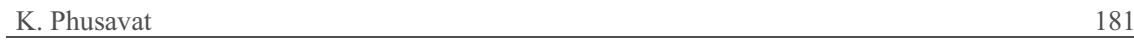

\begin{tabular}{ll} 
R. Pino & 215 \\
\hline
\end{tabular}

\begin{tabular}{ll} 
A. C. B. R. F. Pinto & 207 \\
\hline
\end{tabular}

\begin{tabular}{ll} 
L. Puigjaner & 125 \\
\hline
\end{tabular}

$\begin{array}{ll}\text { S. Raletic } & 191\end{array}$

$\begin{array}{ll}\text { F. Roithmayr } & 141\end{array}$

$\begin{array}{ll}\text { H. Rosa } & 21\end{array}$ 


\begin{tabular}{ll} 
P. Salini & 355 \\
M. Sandhu & 389 \\
\hline S. Schmidt & 307 \\
\hline B. Scholz-Reiter & 163,297 \\
\hline M. Schönlein & 297 \\
\hline V. Senkus & 63 \\
\hline I. Senkuviene & 63 \\
\hline V. M. D. Silva & 21 \\
\hline M. S. A. Silva & 199 \\
\hline M. M. Silva & 207 \\
\hline O. S. Silva Junior & 247 \\
\hline G. Singh & 37 \\
\hline C. Söser & 111,141 \\
\hline M. J. F. Souza & 199 \\
\hline C. A. M. Souza & 347 \\
\hline K. Spens & 181,281 \\
\hline F. Staberhofer & 111 \\
\hline A. Subramanian & 199 \\
\hline M. Suorsa & 255 \\
\hline I. Tammela & 45 \\
\hline M. M. Tentzeris & 55 \\
\hline C. Testuri & 331 \\
\hline A. M. T. Thomé & 87 \\
\hline A. Timm-Giel & 37 \\
\hline O. Ungureanu & 71 \\
\hline A. R. A. V. Vallim Filho & 315 \\
\hline A. F. C. Vieira & 87 \\
\hline N. I. M. Vieira & 347 \\
\hline B. Zimberg & 323 \\
\hline & 331 \\
\hline
\end{tabular}

